\title{
DITTY-A Computer Program for Calculating Population Dose Integrated Over Ten Thousand Years
}
B. A. Napier
R. A. Peloquin
D. L. Strenge

March 1986:

Prepared for the U.S. Department of Energy under Contract DE-AC06-76RLO 1830

Pacific Northwest Laboratory Operated for the U.S. Department of Energy by Battelle Memorial Institute 


\title{
DISCLAIMER
}

This report was prepared as an account of work sponsored by an agency of the United States Government. Neither the United States Government nor any agency thereof, nor any of their employees, makes any warranty, express or implied, or assumes any legal liability or responsibility for the accuracy, completeness, or usefulness of any information, apparatus, product, or process disclosed, or represents that its use would not infringe privately owned rights. Reference herein to any specific commercial product, process, or service by trade name, trademark, manufacturer, or otherwise, does not necessarily constitute or imply its endorsement, recommendation, or favoring by the United States Government or any agency thereof. The views and opinions of authors expressed herein do not necessarily state or reflect those of the United States Government or any agency thereof.

\author{
PACIFIC NORTHWEST LABORATORY \\ operated by \\ BATTELLE \\ for the \\ UNITED STATES DEPARTMENT OF ENERGY \\ under Contract DE-AC06-76RLO 1830
}

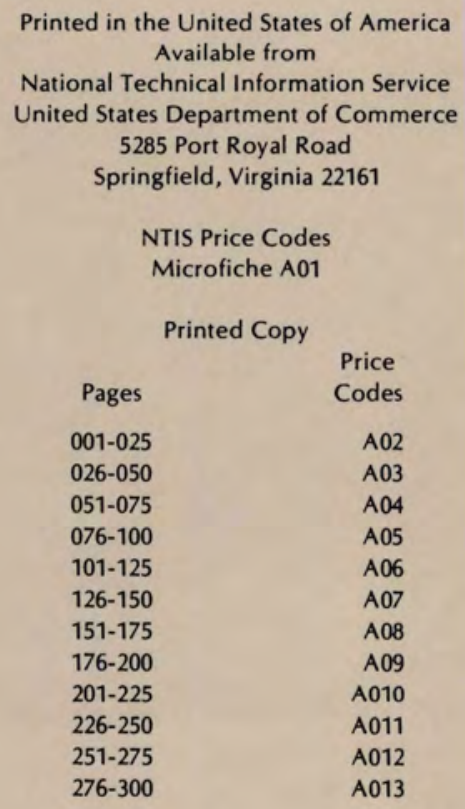




\section{BA Napier \\ RA Peloquin \\ DL Strenge}

March 1986

Prepared for the U.S. Department of Energy under Contract DE-AC06-76RLO 1830

Pacific Northwest Laboratory Richland, Washington 99352 
, 


\section{ABSTRACT}

The computer program DITTY (Dose Integrated Over Ten Thousand Years) was developed by Pacific Northwest Laboratory for the U.S. Department of Energy to determine the collective dose from long term nuclear waste disposal sites resulting from the ground-water pathways. DITTY estimates the time integral of collective dose over a ten-thousand-year period for time-variant radionuclide releases to surface waters, wells, or the atmosphere.

This document includes the following information on DITTY: a description of the mathematical models, program designs, data file requirements, input preparation, output interpretations, sample problems, and program-generated diagnostic messages. 


\section{ACKNOWLEDGMENTS}

The authors would like to thank those who have contributed support for the development of the DITTY computer program. Supporters include E. C. Watson, I. C. Nelson, and J. B. Burnhain of Pacific Northwest Laboratory, and the POSECS program of Rockwell Hanford Operations. We are especially thankful to

W. E. Kennedy, Jr., for the original formulation of the integrated dose calculation. 


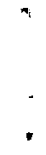




\begin{tabular}{|c|c|c|c|c|c|c|c|c|c|c|c|c|}
\hline ABST & RACT & • & - & • & - & - & - & - & - & - & & $\mathbf{i} \mathbf{i} \mathbf{i}$ \\
\hline 1.0 & INT & ODUCTION & . & . & . & . & - & - & - & & & \\
\hline 2.0 & MAT & EMAT ICAL & MODELS & . & . & . & . & . & - & - & & \\
\hline & 2.1 & SOURCE & - & • & - & - & - & - & - & 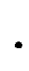 & & \\
\hline & 2.2 & AIRBORN & IE PATHWF & & . & - & - & - & . & & & \\
\hline & 2.3 & WATERBO & ORNE PATH & HWAYS & - & . & . & . & . & & & \\
\hline & 2.4 & POPULAT & IION EXPC & OSURE & PATH & IWAYS & . & . & . & - & & \\
\hline & 2.5 & PATHWAY & $Y$ DOSE CA & ALCUL & ATION & & . & . & . & & & \\
\hline & & 2.5 .1 & Air Subn & mers $i$ & & - & - & - & • & • & & \\
\hline & & 2.5 .2 & Inhalat & & • & . & . & . & . & $\bullet$ & & \\
\hline & & 2.5 .3 & Terrestr & rial & Inges & ition & Pathw & ays & - & & & \\
\hline & & 2.5 .4 & Aquatic & Inge & stion & Path & iways & . & - & & & \\
\hline & & 2.5 .5 & Externa & 1 Exp & osure & & - & - & - & - & & \\
\hline REFE & RENC & $S$ & • & - & . & . & - & . & . & • & & \\
\hline APPE & NDIX & $A-$ COMP & PUTER PRC & OGRAM & DESI & & . & - & - & & & \\
\hline APPE & NDIX & $B-$ COMM & 1ON BLOCK & $K$ DES & ;CRIPT & IONS & - & - & - & . & & B. \\
\hline APPE & NDIX & $C$ - DATA & FILES & - & - & - & - & . & . & & & . \\
\hline APPE & NDIX & $D-P R O G$ & GRAM AND & DATA & FILE & LIST & IINGS & - & - & & & D. 1 \\
\hline APPE & NDIX & $E-I N P U$ & JT PREPAF & RATIO & & - & - & - & - & & & \\
\hline APPE & NDIX & $F$ - SAMP & PLE PROBL & & $\cdot$ & - & - & . & - & & & F. \\
\hline APPE & NDIX & $G-D I A G$ & ENOSTIC & MESSA & IGES & - & - & - & - & & & \\
\hline APPE & NDIX & $H-V A X /$ & $\angle I B M P C$ & CODE & VARIA & TIONS & 5 & . & 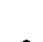 & & & \\
\hline
\end{tabular}





\subsection{INTRODUCTION}

Many computer programs have been developed for environmental consequence analysis of radionuclide releases to air and surface waters. Several reviews of such models have been prepared in the past several years (Hoffman et al. 1977; Strenge et al. 1976; Fields 1982; Mills and Vogt 1983). The majority of these programs only consider the environmental consequences in the near term (0 to 100 years) following release to the environment. Such programs are useful for most nuclear fuel cycle facilities, except nuclear waste disposal sites which may have long-term impacts. The long transport times through waste barriers and groundwater aquifers require that longer time periods be considered. The computer program DITTY (Dose Integrated Over Ten Thousand Years) was, therefore, developed to calculate the total population exposure over long time periods.

Total population exposure is dependent on many parameters that are subject to large variations over thousands of years. Therefore, the user must realize that the calculated results from use of DITTY are only estimates and are limited in accuracy by the validity of the input assumptions. The time variant input parameters include: 1) air and water source terms, 2) atmospheric dispersion patterns, and 3) exposed population.

Source terms of DITTY may be defined for releases to the atmosphere or to water. Releases to water may be to wells or surface water via groundwater. The actual release rates are specified in an input file as the curies per year released for selected years following time zero for the calculation. One such data set is defined for each radionuclide of interest. Sophisticated groundwater transport programs are generally used to determine the time variant release rate following transport from a geologic repository to the environmental access point (well or surface water). A similar definition of release rate as a function of time is needed for atmospheric releases.

For releases to the atmosphere, estinates of dispersion patterns are needed to deternine total exposure of the regional population. The purpose of the dispersion calculation is to provide estimates of ground-level air concentrations of released radioactivity as a function of distance and direction from the release location. The downwind air concentrations are related back 
to the release rate by use of "dispersion factors" which may be either supplied as input to the program or calculated by the program. When the program calculates the dispersion factors, meteorological data must be provided in the form of joint frequency of occurrence of windspeed, wind direction, and atmospheric stability. The dispersion calculation may be performed external to the program with the results entered through input, or joint frequency meteorological data may be supplied and dispersion factors will be calculated as a function of distance and direction. A straight-line crosswind-averaged Gaussian plume model is used for the dispersion calculation.

The regional population is defined for airborne and waterborne pathways as a function of time. For airborne pathways the population is defined as a function of distance and direction corresponding to the locations for which dispersion factors are given or calculated. A population-weighted dispersion factor is calculated as the sum of the product of population and dispersion factor for each location. Alternatively, the population-weighted factor may be calculated external to the program and supplied as input.

The time frame for the calculation is any 10,000-year period. This period is broken into 143 periods of 70 years each. The average release in each of these periods is calculated from source-term data provided, and the total population dose to selected organs is determined for each period. The activity present during any period is the sum of material released during that period (uniformly released over 70 years) and residual material in the environment from releases in previous periods. The dose is calculated for all contributing pathways of exposure, including external exposure, inhalation, and ingestion of contaminated water and foods.

Two versions of DITTY are currently available. One is for a mainframe VAX 780; the other is for an IBM Personal Computer. The models and solutions are identical in both cases. Minor variances between the codes exist. These variances are discussed in Appendix $H$. 


\subsection{MATHEMATICAL MODELS}

This section describes the mathematical models and algorithms used in the DITTY program. The discussion is divided into five sections as follows:

- Source Terms - specification and use

- Airborne Release - modes for estimating average air concentrations downwind of the release, and definition of the exposed population

- Waterborne Release - model for definition of exposed populations

- Environmental Concentrations - models to estimate important environmental pathway concentrations

- Pathway Dose Calculations - models to determine total population doses from important pathways.

\subsection{SOURCE TERMS}

The environmental source terms represent the rate at which radionuclides enter the environment through airborne or waterborne routes. The generation of source terms is nomally performed by sophisticated computer programs for groundwater transport. To interface easily with these programs, a general method for source-term specification was chosen: all radionuclide releaserate data are provided as time/rate data pairs. Each data pair gives a time (years after a reference time) and a release rate in curies per year for a given radionuclide. The data for each radionuclide are provided in a set of data pairs with up to 450 time points. Such a set is provided for each radionuclide of interest. Using this procedure, a different set of time points can be used for each radionuclide. Considering the great variation in transport properties among the radionuclides of interest in high-level waste, it is important to be able to specify releases over a range of time periods.

To use the release rate data within the 70 -year increment calculational scheme, the release rate data are interpolated and integrated to give the total activity released in each 70 -year increment.

A special option is included to describe an acute release to the environment at the beginning of the time period. This acute release can be selected 
for either dirborne or waterborne pathways. No more than one acute release per computer simulation is allowed.

\subsection{AIRBORNE RELEASE}

To estimate the radiation dose received from releases to the atmosphere, it is necessary to consider atmospheric transport of radionuclides. The atmospheric processes transport the radionuclides throughout the region surrounding the release point. The resulting distribution of material is important in determining the radiation exposure received by inembers of the regional population through potential exposure pathways. This section describes the methods available for specifying and estimating atmospheric dispersion.

Calculation of population exposure is based on a spatial grid as illustrated in Figure 1. The population data set is specified as the number of people living within each area element of the grid at a given time. Sixteen directions and up to 10 distance intervals are used. The atmospheric dispersion calculation is based on joint frequency of occurrence data for wind speed, wind direction, and atmospheric stability for the site. One set of joint frequency data is given to be used with all population data. The downwind normalized air concentration is estimated for each area element using the long-term average equation provided by slade (1968), as follows:

$$
\left(\bar{x} / Q^{\prime}\right)_{i j}=\left(\frac{2}{\pi}\right)^{1 / 2} \sum_{\ell=1}^{\text {wind }} \sum_{m=1}^{\text {speed }} \text { stabjlity } \frac{0.01 f_{j \ell m} \exp \left[-h^{2} / 2 \sigma_{z m i}^{2}\right]}{\left(2 x_{i} \pi / 16\right) \sigma_{z m i} \bar{u}_{\ell}}
$$

where

$$
\begin{aligned}
\left(\bar{x} / Q^{\prime}\right)_{i j}= & \text { normalized air concentrations at the center of the area } \\
& \text { interval in direction } j \text { at distance } i, \mathrm{sec} / \mathrm{m}^{3} \\
f_{j \ell m}= & \text { joint frequency of occurrence for windspeed } \ell, \text { stability } m \\
& \text { and direction } j, \% \\
h= & \text { height of release, } m \\
\sigma_{z m i}= & \text { vertical standard deviation of air concentration for } \\
& \text { stability } m \text { at distance } i, m
\end{aligned}
$$




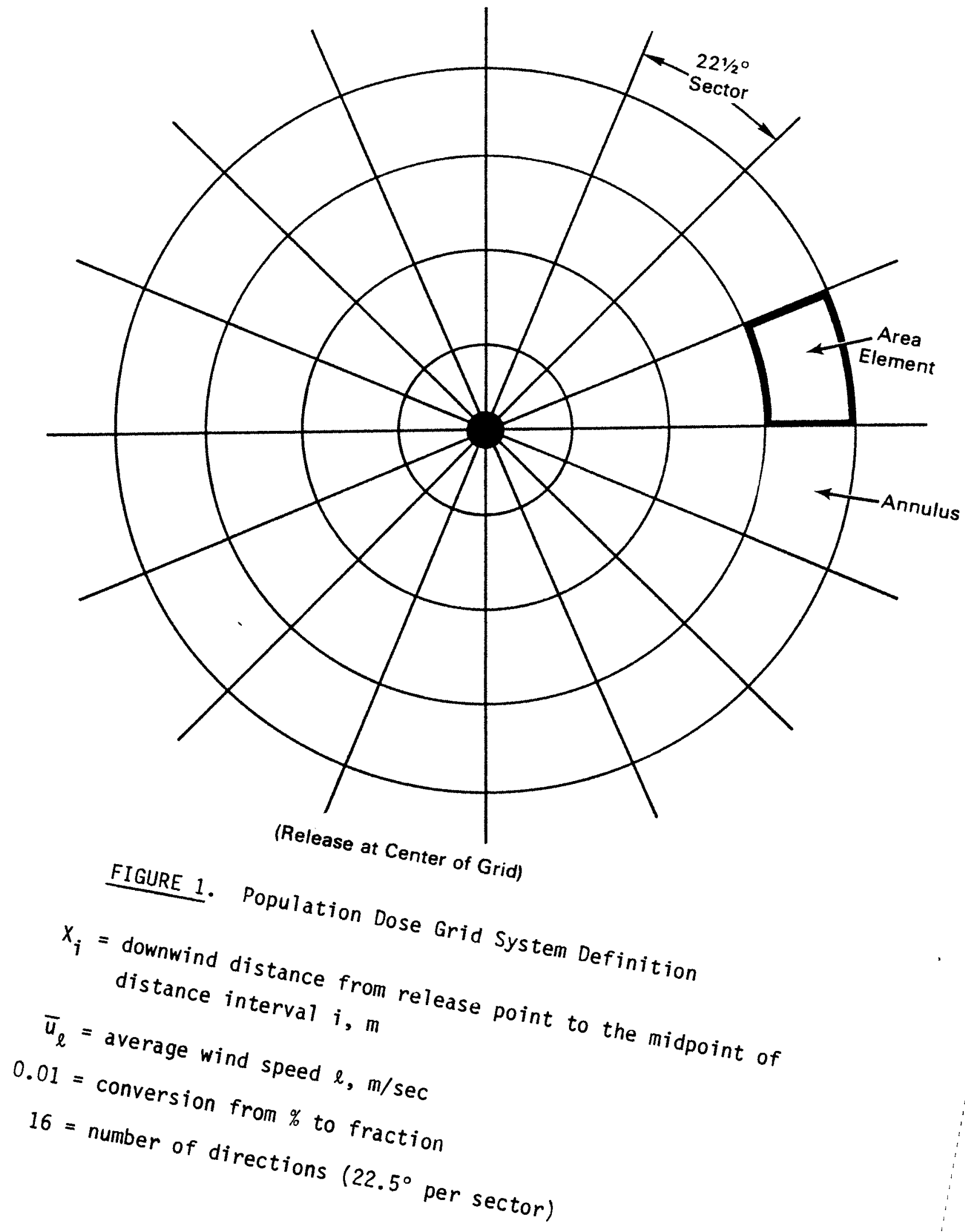


The above equation represents the crosswind-integrated normalized air concentration also referred to as the dispersion factor. It assumes that the annual joint frequency data describe the directional dependence of downwind transport and that transport is uniform across each sector and in a straight line from the release to the location of interest. The vertical standard deviation, $\sigma_{z m i}$, is evaluated based on curves presented by Slade (1968). A somewhat arbritrary maximum value of $2000 \mathrm{~m}$ for $\sigma_{\text {zmi }}$ provides a limit to vertical dispersion (as would be expected due to mixing height limitations). If values of normalized air concentrations are already known, they may be supplied as input rather than being calculated. The dispersion factors are used with the population distribution data to provide a population-weighted dispersion factor. The factor represents a population-weighted estimate of the average normalized air concentration for the region. The factor is calculated as follows:

$$
P M(t)=\sum_{i=1}^{\text {directions }} \sum_{j=1}^{\text {distances }} P_{i j}(t)\left(\bar{x} / Q^{\prime}\right)_{i j}
$$

where $P M(t)=$ population-exposure factor at time $t$, person-sec $/ \mathrm{m}^{3}$

$$
\begin{aligned}
P_{i j}(t)= & \text { number of people living in the area interval in direction } j \\
& \text { at distance } i \text { at time } t \text {, persons }
\end{aligned}
$$

As the equation indicates, the population exposure factor is a function of time. Changes in population over the 10,000-year period will be the primary cause of change in the population-exposure factor. While climate changes may also affect the factor, such changes are difficult to predict and are not considered.

Two options are available for use of normalized air concentration values to determine population-exposed factors. When estimates of the total population change are known, the population exposure factor for the initial time may be calculated, and values for remaining time increments will then be calculated by ratio to population changes with time. If population distribution data are 
known as a function of time, they may be used to calculate population-exposure factors at each of the specified times, which are, in turn, interpoldted for each 70-year increment.

Specification of population exposure factors can be by direct input of factors at defined time points or by calculation from defined meteorological data and population data. When population exposure values are input, interpolations are made to determine the values at the midpoint of each 70-year time increment.

\subsection{WATERBORNE RELEASE}

Pathways associated with waterborne releases include external exposure to contaminated water and sediment; ingestion exposure from drinking water, farm products (via irrigation), and aquatic foods; and inhalation of resuspended material after irrigation. The release of activity to water is described by a release rate in curies per year defined at specific times. The activity released is assumed to result in exposure of a regional population. Specification of the number of people exposed to waterborne pathways is performed similarly to definition of population for airborne pathways. The major difference is that only the total population is specified (spatial distribution is not needed).

Two methods are available for defining population data for waterborne release. The first method is to define the population exposed during each of the 14370 -year periods. The second method is to give the population present at specified times for interpolation at the midpoint of each 70-year period.

\subsection{ENVIRONMENTAL CONCENTRATIONS}

In estimating exposure of the regional population from airborne as well as waterborne releases, it is necessary to determine radionuclide concentrations in several environmental media and exposure-pathway media. This section describes models used to estimated air, water, soil, sediment and food concentrations for the important pathways. All concentrations (except soil and sediment) are expressed as time integrals over a 70-year period. This is done to facilitate dose calculations that use the concentration data. 
Input to the pathway analysis is the total curies released in each 70-year time period. The total release is combined with population and dispersion parameters to estimate an environmental parameter for use in the exposure analysis. For airborne releases the value is calculated as:

$$
A_{c}(i, t)=P M(t) \frac{3.16 \times 10^{-8}}{\lambda_{r i}} \int_{t_{0}}^{t_{0}}+\frac{70}{a_{i}(t) d t}
$$

where $A_{C}(i, t)=$ population-weighted airborne release for radionuclide $i$ over 70 years, person- $\mathrm{C} i-\mathrm{yr} \mathrm{r}^{2} / \mathrm{m}^{3}$

$$
\begin{aligned}
P M(t)= & \text { population exposure factor for time period } t \text {, person- } \\
& \text { sec/ } \mathrm{m}^{3} \\
\lambda_{r i}= & \text { radiological decay constant for radionuclide } i, \mathrm{yr}^{-1} \\
a_{j}(t)= & \text { release rate of radionuclide } i \text { at time } t, C i / y r
\end{aligned}
$$

$3.169 \times 10^{-8}=$ conversion factor, $\mathrm{yr} / \mathrm{sec}$

For waterborne releases, the water concentration parameter is calculated as:

$$
W_{c}(i, t)=\frac{P(t) N M 1.119 \times 10^{-9}}{F_{r}{ }^{\lambda}{ }_{r i}} \int_{t_{0}}^{t_{0}}+70
$$

where $W_{c}(i, t)=$ population-weighted water concentration for radionuclide $i$ and time period $t$, person-Ci-yr $r^{2} / L$

$$
\begin{aligned}
P(t) & =\text { population exposed to water for time period } t \text {, persons } \\
N & =\text { reconcentration factor, dimensionless } \\
M & =\text { mixing ratio, dimensionless } \\
F_{r} & =\text { flow rate of receiving water, } \mathrm{ft}^{3} / \mathrm{sec} \\
C(t) & =\text { release rate to the receiving water, } \mathrm{Ci} / \mathrm{yr}, \text { at time } t
\end{aligned}
$$

$1.119 \times 10^{-8}=$ conversion factor, $\frac{1}{28.31 \frac{\mathrm{L}}{\mathrm{ft}^{3}} \times 3.156 \times 10^{7} \frac{\mathrm{sec}}{\mathrm{yr}}}, \frac{\mathrm{ft}^{3} \mathrm{yr}}{\mathrm{Lsec}}$ 
The airborne pathway analysis uses the dir concentration paralneter, $A_{C}(i, t)$, to deternine several environmental concentrations:

- $S_{\mathrm{ca}}(i, t)$, soil concentration parameter for radionuclide $i$ at the end of the current period, person-Ci-yr/kg

- $L_{c a}(i, p, t)$, time integral of leaf concentration for radionuclide $i$ and pathway $p$, from air deposition and resuspension over the current period $t$, person-Ci-yr ${ }^{2} / \mathrm{kg}$

- $P_{c a}(i, p, t)$, time integral of plant concentration for radionuclide $i$ and pathway $p$, from air-deposited contaminants on plants and root uptake over the current period $t$, person-Ci-yr ${ }^{2} / \mathrm{kg}$.

The soil concentration parameter is calculated from the air concentration parameter assuming deposition to be at a uniform rate over the 70 -year period:

$$
S_{c a}(i, t)=\frac{A_{c}(i, t) V_{d i}}{T 7.069 \times 10^{9}}\left(\frac{1-e^{-\lambda} t}{\lambda_{b}}\right)
$$

where $\quad V_{d i}=$ deposition velocity for radionuclide $i, \mathrm{~m} / \mathrm{sec}$

$$
T=\text { length of period, years (taken as 70) }
$$

$\lambda_{b}=$ environmental decay constant, $\mathrm{yr}^{-1}$

$7.069 \times 10^{9}=$ constant, $224 \mathrm{~kg} / \mathrm{m}^{2} \times 3.156 \times 10^{7} \mathrm{sec} / \mathrm{yr}$

The environmental decay constant, $\lambda_{b}$, is calculated as the sum of a radiological decay constant, $\lambda_{r i}$, and a soil removal constant for weathering, $\lambda_{w i}$. The soil removal constant is read from the Food Transfer Coefficient Library, FTRANSLIB, described in Appendix C. It is a correction for long-term leaching of deposited radionuclides out of the soil rooting and resuspension zones. The values given in FTRANSLIB for $\lambda_{w i}$ are calculated using the formula of Baes and Sharp (1981);

$$
\lambda_{w i}=\frac{P+I-E}{d\left(1+\frac{\rho}{\theta} k_{d i}\right)}
$$


where $P=$ total precipitation, $\mathrm{cm} / \mathrm{yr}$

$I=$ total irrigation, $\mathrm{cm} / \mathrm{yr}$

$E=$ total evapotranspiration, $\mathrm{cm} / \mathrm{yr}$

$\mathrm{d}=$ depth of the roofing zone, $\mathrm{cm}$

$\rho=$ soil bulk density, $\mathrm{g} / \mathrm{cm}^{3}$

$\Theta=$ soil volumetric water content, $\mathrm{mL} / \mathrm{cm}^{3}$, and

$k_{d i}=$ distribution coefficient for isotope $i, \mathrm{~mL} / \mathrm{g}$.

For simplicity, the term P + I - E was approximated as an overwatering term, implying about 15 centimeters per yedr of percolation. The depth, d, was taken as 15 centimeters. Baes and Sharp (1981) show that the term $\frac{P}{\theta}$ averages about 3 . Thus, the soil removal constant for percolation can be considered to be inversely proportional to the soil distribution coefficient $k_{d i}$. For the values presented in Appendix $C$ in FTRANSLIB, the most conservative (largest) value of $k_{d}$ identified in a wide range of literature was applied. The exponential expression represents the calculation of the amount of a radionuclide remaining after accumulation at a constant rate for $T$ years. The rate of deposition is proportional to $A_{c} / T$. The actual calculation is performed by subroutine BCHAIN, which considers production of daughters in decay chains.

The time integral of leaf concentration is calculated from the air and soil concentration parameters assuming a constant soil concentration equal to the value at the end of the 70 -year period. This is a conservative assumption. The equation is:

$$
\begin{gathered}
L_{c a}(i, p, t)=\frac{0.25 V_{d i}}{Y_{p}}\left[A_{c}(i, t)+1.49 \times 10^{-8} S_{c a}(i, t) 70\right] \\
\frac{1-e^{-\lambda} e^{\top} p / 365}{\lambda_{e i}} 3.156 \times 10^{7}
\end{gathered}
$$

where $Y_{p}=$ crop yield for food pathway $p, \mathrm{~kg} / \mathrm{m}^{2}$

$\lambda_{e j}=$ effective retention rate constant for radionuclide $i, \mathrm{yr}^{-1}$; 


$$
\begin{aligned}
\lambda_{e i} & =\lambda_{r i}+18.0838, y^{-1} \\
18.0838 & =\text { rate constant for a 14-day half time } \\
T_{p} & =\text { growing period for food pathway } p, \text { days } \\
0.25 & =\text { interception fraction, dimensionless }
\end{aligned}
$$

$1.49 \times 10^{-8}=$ conversion factor, $1 \times 10^{-9}\left(\mathrm{~m}^{-1}\right) \times 224 / 15 \frac{\mathrm{kg}}{\mathrm{m}^{2}}$

$$
365=\text { days per year }
$$

$3.156 \times 10^{7}=$ seconds per year

The factor of $1 \times 10^{-9}\left(\mathrm{~m}^{-1}\right)$ represents a resuspension factor assumed constant, characteristic of aged deposited material (Anspaugh 1975). The resuspended activity is assumed to deposit on the plants near the soil from which it was suspended. Downwind transport of resuspended activity is not considered. The factor of 224 is the soil area density to a depth of $15 \mathrm{~cm}$ of $224 \mathrm{~kg} / \mathrm{m}^{2}$, and $15 \mathrm{~cm}$ is the plow depth through which the contamination is distributed. This value is included so that only the top centimeter of material (1/15 of the total) is considered available for resuspension. The leaf concentration as calculated above represents the time integral over a 70-year period.

The concentration in edible parts of the plant includes material from direct deposition plus material from root uptake:

$$
P_{c a}(i, p, t)=L_{c a}(i, p, t) T_{v p}+70 S_{c a}(i, t) B_{i v}
$$

where $P_{c a}(i, p, t)=$ time integral of plant concentrations for plant type $p$ for radionuclide $i$ and time period $t$, person- $\mathrm{C} i-\mathrm{yr} \mathrm{r}^{2} / \mathrm{kg}$

$T_{v p}=$ translocation factor of externally deposited radionuclides to edible parts of the plant, dimensionless

$B_{i v}=$ concentration ratio for plant uptake of radionuclide $i$, $\mathrm{Ci} / \mathrm{kg}$ (wet weight plant) per $\mathrm{Ci} / \mathrm{kg}$ (dry weight soil)

Other terms are as previously defined. 
The concentration used for calculating uptake by the population is the plant concentration for plant pathways. For animal pathways, the uptake is calculated as:

$$
A_{c a}(i, p, t)=P_{c a}(i, p, t) S_{i p} Q_{p}
$$

where $A_{c a}(i, p, t)=$ time integral of animal product concentration for radionuclide $i$, aninal product $p$, and time period $t$, person- $\mathrm{C} i$ $\mathrm{yr}^{2} / \mathrm{kg}$, (person-Ci/yr ${ }^{2} / \mathrm{L}$ for $\mathrm{milk}$ )

$S_{i p}=$ transfer coefficient of radionuclide $i$ from daily intake by animal to edible portion of animal product, $\mathrm{Ci} / \mathrm{L}$ (milk) per $\mathrm{Ci} /$ day or $\mathrm{Ci} / \mathrm{kg}$ (animal product) per $\mathrm{Ci} /$ day

$Q_{p}=$ the consumption rate of contaminated feed or forage by the animal for animal product $\mathrm{p}, \mathrm{kg} / \mathrm{day}$

The waterborne pathway analysis uses the water concentration $W_{c}(i, t)$ to determine the following environmental concentrations:

- $S_{\mathrm{CW}}(i, t)$, soil concentration for radionuclide $i$ at the end of the current period $t$ for irrigation deposition, person-Ci-yr/kg

- $S_{d w}(i, t)$, sediment deposition concentration for radionuclide $i$ at the end of the current period $t$ for shoreline of contaminated water body, person-Ci-yr $/ \mathrm{m}^{2}$

- $L_{c w}(i, p, t)$, leaf concentrations for radionuclide $i$, plant type $p$, and time period $t$ from irrigation deposition and resuspension, person-Ci-yr ${ }^{2} / \mathrm{kg}$

- $P_{C W}(i, p, t)$, plant concentration for radionuclide $i$ and pathway $p$, from irrigation deposition onto plant and root uptake through soil, person-Ci-yr ${ }^{2} / \mathrm{kg}$.

The soil concentration at the end of the period is calculated assuming uniform deposition over the period.

$$
S_{C W}(i, t)=\frac{W_{c}(i, t) I T_{i}}{T 224}\left(\frac{1-e^{-\lambda_{b} T}}{\lambda_{b}}\right)
$$


where $\quad I$ = irrigation rate, $L / \mathrm{m}^{2} \mathrm{mo}$

$T_{\mathbf{i}}=$ irrigation period, $\mathrm{mo} / \mathrm{yr}$

$224=$ soil area density, $\mathrm{kg} / \mathrm{m}^{2}$

The exponential term represents the integral over the 70 year period $T$.

The concentration in the sediment is calculated similarly as:

$$
S_{d W}(i, t)=W_{c}(i, t) 25300
$$

where $25300=$ constant to represent deposition to sediment, $\mathrm{L} / \mathrm{m}^{2} / \mathrm{yr}$. The value of the sediment deposition constant (25300) was derived from radionuclide concentrations measured in water and sediment samples collected over a period of years in the Columbia River between Richland, Washington and the river mouth in Tillamook Bay, Oregon, 75 kilometers south of the river mouth (Nelson 1965; Toombs and Cutler 1968).

The concentration on leaves is calculated for contributions from direct irrigation deposition plus resuspension from soil:

$$
\begin{gathered}
L_{c W}(i, p, t)=\frac{0.25}{Y_{p}}\left[W_{c}(i, t) \cdot I \cdot 12+S_{c W}(i, t) \cdot 70 \cdot 0.47 V_{d i}\right] \\
\left(\frac{1-e^{-\lambda} e^{T} p^{/ 365}}{\lambda_{e}}\right)
\end{gathered}
$$

where $0.25=$ plant retention factor, dimensionless

$Y_{p}=$ plant yield for plant type $p, \mathrm{~kg} / \mathrm{m}^{2}$

12 = unit conversion constant, mo/yr

$0.47=$ conversion factor for resuspension;

$0.47=\left(10^{-9} \mathrm{~m}^{-1}\right)\left(3.156 \times 10^{7} \mathrm{sec} / \mathrm{yr}\right)\left(224 \mathrm{~kg} / \mathrm{m}^{2}\right)(1 / 15)$

$v_{d i}=$ deposition velocity of resuspended activity, $\mathrm{m} / \mathrm{sec}$ 


$$
\begin{aligned}
\lambda_{e i}= & \text { environmental weathering constant for 14-day half time, } \mathrm{yr}^{-1} ; \\
& 24-\text { day half time, } \mathrm{yr}^{-1} ; \\
& \lambda_{e i}=\lambda_{r i}+18.0838 \\
70= & \text { length of period, } y r
\end{aligned}
$$

The concentration in edible parts of the plant is calculated for root uptake plus direct deposition as follows:

$$
P_{c w}(i, p, t)=L_{c w}(i, p, t) T_{v p}+70 \cdot S_{c w}(i, t) B_{i v}
$$

where $T_{v p}=$ translocation factor of externally deposited radionuclides to edible parts of plant, dimensionless

$B_{i v}=$ concentration ratio for plant uptake of radionuclide $\mathrm{i}, \mathrm{Ci} / \mathrm{kg}$ (wet weight plant) per $\mathrm{Ci} / \mathrm{kg}$ (dry weight soil)

The total uptake of plants during the 70 -year period is given by the above plant concentration parameter. For animal products, the uptake is calculated for animal consumption of plants plus animal consumption of water:

$$
A_{c W}(i, p, t)=S_{i p}\left[P_{c W}(i, p, t) Q_{p}+W_{c}(i, t) Q_{p w}\right]
$$

where $A_{C W}(i, p, t)=$ time integral of animal product $p$, concentration in time $t$, for radionuclide $i$ from waterborne pathways, person-Ci$\mathrm{yr}^{2} / \mathrm{kg}$ (person-Ci-yr $\mathrm{r}^{2} / \mathrm{L}$ for $\mathrm{mi} l \mathrm{k}$ ).

$S_{i p}=$ transfer coefficient of radionuclide $i$ from daily intake by animal to edible portion of animal product $\mathrm{p}, \mathrm{Ci} / \mathrm{L}$ (milk) per $\mathrm{Ci} /$ day or $\mathrm{Ci} / \mathrm{kg}$ (animal product) per $\mathrm{Ci} /$ day $Q_{p}=$ the consumption rate of contaminated feed or forage by animal for animal type $\mathrm{p}, \mathrm{kg} / \mathrm{day}$ 


$$
\begin{aligned}
Q_{p w}= & \text { the consumption rate of water by animal for animal type } \\
& p, L / d
\end{aligned}
$$

The time-integrated concentration in aquatic foods is calculated from the water concentrations as follows:

$$
A_{f w}(i, p, t)=W_{c}(i, t) B_{i p}
$$

where $A_{f w}(i, p, t)=$ time-integrated concentration of radionuclide $i$ in aquatic food $p$, person-Ci-yr ${ }^{2} / \mathrm{kg}$

$$
\begin{aligned}
B_{i p}= & \text { bioaccumulation factor for radionuclide } i \text { and aquatic food } \\
& p, C i / k g \text { per } \mathrm{C} i / \mathrm{L}
\end{aligned}
$$

The time-integrated water concentration for the drinking water pathway is calculated as:

$$
A_{d w}(i, t)=W_{c}(i, t) C_{i}
$$

where $A_{d w}(i, t)=$ time-integrated of concentration in drinking water for radionuclide $i$ and time period $t$, person-Ci-yr ${ }^{2} / L$

$c_{i}=$ water purification plant cleanup factor, dimensionless

The radionuclides tritium and carbon-14 are handled in a special manner. The concentrations of tritium or carbon-14 in environmental media (soil, plants, and animal products) are assumed to have the same specific activity (picocuries of radionuclide per kilogram of soluble element) as the contaminating medium (air or water). The fractional content of hydrogen or carbon in a plant or animal product is then used to compute the concentration of tritium or carbon-14 in the food product under consideration. Hydrogen contents in both the water and the nonwater (dry) portion of the food product are used when calculating the tritium concentration. It is assumed that plants obtain all their carbon from airborne carbon dioxide and that animals obtain all their carbon through ingestion of plants. 
When carbon-14 is present only in the water used for irrigation, it is difficult to model its transfer to vegetation because plants acquire most of their carbon from the air. At this time, the transfer of carbon from the water to the air or soil has not yet been determined. Currently available models for carbon-14 uptake by plants from water use specific-activity models relating the activity in the plants directly to the activity in irrigation water. This is extremely conservative in that it assumes that plants receive all of their carbon from water. An interim model has been implemented in DITTY with the basis being the ratio of grams of carbon-14 to grams of total carbon in soil and a correction for the amount of carbon plants obtain from soil.

The concentration of tritium in vegetation, $\mathrm{C}_{\mathrm{Hv}}$, is calculated as:

$$
C_{H v}=9 C_{H w} F_{h v}
$$

where $C_{H W}=$ the concentration of tritium in the environmental water ( $\left.p C i / L\right)$; for a water release $C_{H W}$ represents concentration in irrigation water; for an airborne release $C_{H w}$ represents concentration in airborne moisture; hence $\mathrm{C}_{\mathrm{HW}}=$ air concentration in $\mathrm{pCi}\left({ }^{3} \mathrm{H}\right) / \mathrm{m}^{3} \div$ absolute humidity in $\mathrm{L} \cdot \mathrm{m}^{-3}$,

$F_{h v}=$ the fraction of hydrogen in total vegetation (see Table 1); the coefficient 9 converts tritium concentration in environmental water to concentration in hydrogen

The concentration of tritium in the animal product, $\mathrm{C}_{\mathrm{Ha}}$, is:

$$
C_{H a}=\left[\frac{C_{H F} Q_{F}+C_{H a w} Q_{a w}}{F_{h f^{Q} Q_{F}}+Q_{a w} / 9} F_{h a}\right]
$$

where $C_{H F}=$ the concentration of tritium in feed or forage calculated in the equation above where now $\mathrm{C}_{\mathrm{HF}}=\mathrm{C}_{\mathrm{Hv}}, \mathrm{pCi} / \mathrm{kg}$

$F_{h f}=$ the fraction of hydrogen in animal feed, where now $F_{h f}=F_{h v}$ (grain)

$F_{\text {ha }}=$ the fraction of hydrogen in animal product (see Table 1) 
$\mathrm{C}_{\text {Haw }}=$ the concentration of tritium in animal drinking water (set to 0 unless there is a release of water)

Similarly, the concentration of carbon-14 in vegetation from irrigation, $c_{14 C v}$, is:

$$
c_{14 C V}=C_{C W} \text { I } T_{i} \frac{0.1}{224(0.01)}\left(\frac{1-e^{-\lambda_{b}{ }^{T}}}{\lambda_{b}}\right)
$$

where $C_{14 C_{v}}=$ the concentration of carbon-14 in the plant, $\mathrm{pCi} / \mathrm{kg}$

0.1 = the assumed uptake of $10 \%$ of plant carbon from soil

0.01 = the average fraction of soil that is carbon

The concentration of carbon-14 in vegetation from atmospheric contamination is

$$
C_{14 C v}=C_{14 C a} F_{c v}
$$

where $c_{14 \mathrm{Ca}}=$ the air concentration of carbon $-14\left(\mathrm{pCi} / \mathrm{m}^{3}\right) \div$ the carbon concentration in air $\left(\mathrm{kg} / \mathrm{m}^{3}\right)$

$$
\mathrm{F}_{\mathrm{CV}}=\text { the fraction of carbon in total vegetation }
$$

The concentration of carbon-14 in the animal product is:

$$
C_{14 C a}=\left[\frac{C_{14 C F} Q_{F}+C_{14 C a w} Q_{a w}}{F_{c f} Q_{F}+F_{C w} A_{a w}}\right] F_{c a}
$$

For an air release, $C_{14 C a w}$ is equal to zero, and since $F_{C W}$ is very small compared with $F_{c f}$, this equation reduces to:

$$
C_{14 \mathrm{Ca}}=C_{14 \mathrm{CF}} \frac{F_{C a}}{F_{c F}}
$$

Table 1 contains the various parameters and fractions needed for these calculations. 
TABLE 1. Generic Fractions and Concentrations of Hydrogen and Carbon in Vegetation, Animal Products, and Environmental Media

\begin{tabular}{|c|c|c|c|c|c|}
\hline Food or Fodder & Water & $\begin{array}{l}\text { Carbon } \\
\text { (dry) }\end{array}$ & $\begin{array}{l}\text { Hydrogen } \\
\text { (dry) }\end{array}$ & $\begin{array}{c}\text { Carbon (a) } \\
\text { (wet) }\end{array}$ & $\begin{array}{r}\text { Hydrogen } \\
\text { (wet) }\end{array}$ \\
\hline $\begin{array}{l}\text { Fresh fruits, vegetables, } \\
\text { grass }\end{array}$ & 0.80 & 0.45 & 0.062 & 0.090 & 0.10 \\
\hline Grain, stored animal feed & 0.12 & 0.45 & 0.062 & 0.40 & 0.068 \\
\hline Eggs & 0.75 & 0.60 & 0.092 & 0.15 & 0.11 \\
\hline Milk & 0.88 & 0.58 & 0.083 & 0.070 & 0.11 \\
\hline Beef & 0.60 & 0.60 & 0.094 & 0.24 & 0.10 \\
\hline Pork & 0.50 & 0.66 & 0.10 & 0.33 & 0.11 \\
\hline Poultry & 0.70 & 0.67 & 0.087 & 0.20 & 0.10 \\
\hline
\end{tabular}

Media

Absolute Humidity

Concentrations of carbon in water

Concentrations of carbon in air

Fraction of soil

that is carbon 0.03

Soil moisture $0.1 \mathrm{~L} / \mathrm{kg}$

\section{Concentration}

$0.008 \mathrm{~L} / \mathrm{m}^{3}$

$2.0 \times 10^{-5} \mathrm{~kg} / \mathrm{L}(\mathrm{c})$

$1.6 \times 10^{-4} \mathrm{~kg} / \mathrm{m}^{3(\mathrm{~d})}$

(a) $F_{c v}$ or $F_{c a}=f_{c}\left(1-f_{w}\right)$.

(b) $F_{h v}$ or $F_{h a}=f_{w} / 9+9+f_{h}\left(1-f_{w}\right)$.

(c) Assumes a typical bicarbonate concentration of $100 \mathrm{mg} / \mathrm{L}$.

(d) Assumes a typical atmospheric $\mathrm{CO}_{2}$ concentration of $320 \mathrm{ppm}_{\mathrm{v}}$.

The environmental parameters defined above are used to estimate doses during each 70-year period, as defined in the next section. 


\subsection{PATHWAY DOSE CALCULATIONS}

The total dose received by the regional population is estimated as the sum of contributions from all pathways. The doses are calculated as the population dose received in each 70-year time period from material released to the environment during that period plus all previous periods. Precalculated dose conversion factors are used to estimate dose from uptake and environmental concentration. The exposure pathways are described in the following sections.

Doses can be calculated for up to six body "organs": total body, kidney, liver, bone, lungs, thyroid, and lower large intestine. Other organs may be included (up to a total of 10) through additions to File 10, DSFCT (see Appendix C).

\subsubsection{Air Submersion}

Contributions for external exposure from air submersion are included for: 1) submersion in the release plume, 2) submersion in resuspended activity from an initial airborne release, and 3) submersion in suspended activity from an initial irrigation water deposition. The dose is calculated as:

$$
D_{\text {oei }}=D_{e i} \lambda_{r i} 3.156 \times 10^{7}\left[A_{c}(i, t)+1.49 \times 10^{-8} \cdot 70\left(S_{c a}(i, t)+S_{c w}(i, t)\right)\right]
$$

where $D_{\text {oej }}=$ population dose from air submersion to organ o from radionuclide $i$, person-rem

$D_{\text {ei }}=$ external exposure dose conversion factor for air submersion, rem per $\mathrm{C} i-\mathrm{sec} / \mathrm{m}^{3}$

$\lambda_{r i}=$ radiological decay constant for radionuclide $i, \mathrm{yr}^{-1}$

$3.156 \times 10^{7}=$ conversion factor, sec/yr

$A_{c}(i, t)=$ time-integrated air concentration of radionuclide $i$ in time period $t$, person-Ci-yr ${ }^{2} / \mathrm{m}^{3}$

$1.49 \times 10^{-8}=$ resuspension factor constant, $\mathrm{kg} / \mathrm{m}^{3}$;

$$
1.49 \times 10^{-8}=\left(1 \times 10^{-9} \mathrm{~m}^{-1}\right)\left(224 \frac{\mathrm{kg} \mathrm{soil}}{\mathrm{m}^{2}}\right)
$$




$$
\begin{aligned}
70= & \text { time of exposure to resuspended activity, } y r \\
S_{c a}(i, t)= & \text { soil concentration from airborne release of radionuclide } \\
& i \text { at the end of time period } t \text {, person-Ci-yr } / \mathrm{kg} \\
\mathrm{S}_{\mathrm{cw}}(i, t)= & \text { soil concentration from waterborne release of radio- } \\
& \text { nuclide } i \text { at the end of time period } t \text {, person-Ci-yr } / \mathrm{kg}
\end{aligned}
$$

The contribution from deposited material is based on the concentration at the end of the current period. This concentration is assumed to occur throughout the period, which is a conservative assumption by no more than a factor of two. Resuspension is based on a constant resuspension factor of $10^{-9} \mathrm{~m}^{-1}$, representing resuspension of aged deposited material (Anspaugh 1975). The resuspended activity is assumed to expose individuals in the vicinity of the soil from which it was suspended. Downwind transport of resuspended activity is not considered. The decay constant, $\lambda_{r i}$, is included to convert the units of radionuclide concentration from mass to activity. The calculations are perforined in units proportional to mass to meet requirements of the chain decay processor, BCHAIN.

\subsubsection{Inhalation}

Inhalation exposure includes contributions from the released airborne activity plus the resuspended activity from airborne and irrigation water deposition. The dose is calculated as:

$D_{\text {ohi }}=D_{h i o} 3.156 \times 10^{7} \lambda_{r i}\left[A_{c}(i, t)+1.49 \times 10^{-8} \cdot 70\left(S_{C d}(i, t)+S_{C w}(i, t)\right)\right]$ where $D_{\text {ohi }}=$ dose from inhalation exposure from organ o from radionuclide $i$, person-rem

$D_{\text {hio }}=$ inhalation dose conversion factor for radionuclide $i$ and organ 0 , rem per $\mathrm{Ci-sec} / \mathrm{m}^{3}$

and other terms are as previously defined.

\subsubsection{Terrestrial Ingestion Pathways}

Terrestrial pathways include ingestion of crops and animal products. The seven terrestrial ingestion pathways available are vegetables, grain, eggs, 
milk, beef, pork, and poultry. The dose for each pathway is calculated from the time-integrated food-product concentration. For plants the dose is calculated as:

$$
D_{\text {oti }}=D_{g i 0} \lambda_{r i} U_{p}\left[P_{c a}(i, p, t)+P_{C W}(i, p, t)\right]
$$

and for animal products, the dose is calculated as:

$$
D_{\text {oti }}=D_{g i o} \lambda_{r i} U_{p}\left[A_{c a}(i, p, t)+A_{c w}(i, p, t)\right]
$$

where $D_{o t i}=$ dose from terrestrial ingestion pathways for organ 0 , person-rem

$\mathrm{D}_{\text {gio }}=$ ingestion dose conversion factor for radionuclide $i$ and organ 0 , $\mathrm{rem} / \mathrm{Ci}$

$U_{p}=$ the usage rate by humans of food product $p, \mathrm{~kg} / \mathrm{yr}$ (or L/yr for Ini1k)

$P_{c a}(i, p, t)=$ time integral of plant concentration from dirborne pathways for radionuclide $i$, plant type $p$, and time period $t$, person-Ci-yr ${ }^{2} / \mathrm{kg}$

$P_{C W}(i, p, t)=$ time integral of plant concentration from waterborne pathways for radionuclide $i$, plant type $p$, and time period $t$, person-Ci-yr ${ }^{2} / \mathrm{kg}$

$A_{c a}(i, p, t)=$ time integral of animal product concentration from airborne pathways for radionuclide $i$, animal product $p$, and time period $t$, person-Ci-yr ${ }^{2} / \mathrm{kg}$, (person-Ci-yr $r^{2} / \mathrm{L}$ for milk)

$A_{C W}(i, p, t)=$ time integral of animal product concentration from waterborne pathways for radionuclide $i$, animal product $p$, and time period $t$, person-Ci-yr ${ }^{2} / k g$, (person-Ci-yr $/ L$ for milk)

The total dose from terrestrial ingestion pathways is calculated by summing contributions from all plant and animal product food types.

\subsubsection{Aquatic Ingestion Pathways}

Ingestion pathways resulting from release of radionuclide to surface or groundwater include ingestion of drinking water and aquatic foods. The five 
pathways available are fish, crustacea, molluscs, water plants, and drinking water. The dose for each pathway is calculated from the time-integrated aquatic media concentration as follows for aquatic foods:

$$
D_{\text {oai }}=D_{g i o} \lambda_{r i} U_{d} A_{f w}(i, p, t)
$$

and for drinking water:

$$
D_{\text {oa }}=D_{\text {gio }} \lambda_{r i} U_{a} A_{d w}(i, t)
$$

where $D_{\text {oa }}=$ dose from ingestion of aquatic food or water for organ 0 , person-rem

$U_{a}=$ the usage rate by humans of aquatic-food pathway a, $\mathrm{kg} / \mathrm{yr}$ (L/yr for drinking water)

$A_{f W}(i, p, t)=$ time integral of aquatic food $p$, concentration for radionuclide $i$, in time period $t$, person-Ci-yr ${ }^{2} / \mathrm{kg}$,

$A_{d W}(i, t)=$ time integral of drinking water concentration for radionuclide $i$ in time period $t$, person-Ci-yr ${ }^{2} / L$

\subsubsection{External Exposures}

External exposures result from proximity to contaminated ground, shoreline, and water. Swimning and shoreline doses are calculated from the timeintegrated sediment concentration and water concentration:

$$
D_{\text {oew }}=\lambda_{r i}\left[70 S_{d w}(i, t) D_{o s} U_{s h} w+w_{c}(i, t) D_{o w} U_{s w}\right]
$$

where $D_{\text {oew }}=$ dose from external exposure to shoreline and water for organ 0 , person-rem

$D_{\text {os }}=$ external dose factor for organ o for exposure to concontaminated soil or shoreline, $\mathrm{rem} / \mathrm{hr}$ per $\mathrm{Ci} / \mathrm{m}^{2}$

$D_{\text {ow }}=$ external dose factor for organ o for submersion in contaminated water, $\mathrm{rem} / \mathrm{hr}$ per $\mathrm{Ci} / \mathrm{L}$ 


$$
\begin{aligned}
& U_{s h}=\text { time of exposure to contaminated shoreline, } \mathrm{hr} / \mathrm{yr} \\
& U_{S W}=\text { time of exposure to contaminated water, } \mathrm{hr} / \mathrm{yr} \\
& S_{d w}(i, t)=\text { sediment concentration for radionuclide } i \text { at the end of the } \\
& \text { current time period } t \text {, person-Ci-yr/m}{ }^{2} \\
& W_{c}(i, t)=\text { time integral of water concentration for radionuclide } i \text { and } \\
& \text { time period } t \text {, person-Ci-yr } r^{2} / L \\
& W=\text { shore-width factor for shoreline exposure, dimensionless } \\
& 70 \text { = duration of exposure, } y r
\end{aligned}
$$

The shore-width factor is an approximate correction to the infinite-plane geometry of the external exposure factors. To correct for the actual geometry of a river bank or beach, a shore-width factor is applied corresponding to the particular exposure situation. Suggested shore-width factors are given in Table 2. Contamination of soil can result from deposition of airborne material or from irrigation with contaminated water. The dose from external exposure to contaminated soil is calculated as:

$$
D_{\text {oes }}=\lambda_{r i} E_{t} D_{\text {ow }} 22470\left[S_{C d}(i, t)+S_{c w}(i t)\right]
$$

where $D_{\text {oes }}=$ dose from external exposure to soil for organ 0 , person-rem

$$
\begin{aligned}
E_{t}= & \text { time of exposure to contaminated ground, hr/yr } \\
S_{C a}(i, t)= & \text { soil concentration due to airborne deposition of radionuclide } i \\
& \text { at the end of time period } t \text {, person-Ci-yr/kg } \\
S_{C W}(i, t)= & \text { soil concentration due to waterborne deposition of radionuclide } \\
& i \text { at the end of time period } t, \text { person- } \mathrm{C} i-y r / \mathrm{kg} \\
224= & \text { soil areal density, } \mathrm{kg} / \mathrm{m}^{2} \\
70= & \text { time of exposure period, } y r
\end{aligned}
$$

Other terms are as previously defined. Note that the external exposure is based on the soil concentration at the end of the current 70-year period. 
This results in an over-estimation of dose when the deposition is uniform over the 70-year period.

\section{TABLE 2. Shore-Width Factors}

\begin{tabular}{lc} 
Exposure Situation & Shore-Width Factor $(W)$ \\
\cline { 2 - 2 } Discharge canal bank & 0.1 \\
River shoreline & 0.2 \\
Lake shore & 0.3 \\
Nominal ocean site & 0.5 \\
Tidal basin & 1.0
\end{tabular}




\section{REFERENCES}

Anspaugh, L. R., J. H. Shinn, P. L. Phelps and N. C. Kennedy. 1975. "Resuspension and Redistribution of Plutonium in Soils." Health Physics. 29:571-582.

Baes, C. F., and R. D. Sharp. 1981. Predicting Radionuclide Leaching From Root Zone Soil from Assessment Applications (Draft). CONF-810606, Oak Ridge National Laboratory, Oak Ridge, Tennessee.

Fields, D. E. 1982. EPA Liquid Release Health Impact Code: Feasibility Study. ORNL-5867, Oak Ridge National Laboratory, Oak Ridge, Tennessee.

Hoffman, F. 0., C. W. Miller, D. L. Shaeffer and C. T. Garten, Jr. 1977. "Computer Codes for the Assessment of Radionuclides Released to the Environment." Nuclear Safety. 18(3):343-354.

Mills, M. and D. Vogt. 1983. A Summary of Computer Codes for Radiological Assessment. NUREG/CR-3209, U.S. Nuclear Regulatory Commission, Washington, D.C.

Napier, B. A., W. E. Kennedy, Jr., and J. K. Soldat. 1980. PABLM--A Computer Program to Calculate Accumulated Radiation Dose from Radionuclides in the Environment. PNL-3209, Pacific Northwest Laboratory, Richland, Washington.

Nelson, J. L. 1965. "Distribution of Sediments and Associated Radionuclides in the Columbia River Before Hanford," p. 3.80. In Hanford Radiological Sciences Research and Development Annual Report for 1964, D. W. Pearce and J. K. Green, Eds. BNWL-36, Pacific Northwest Laboratory, Richland, Washington.

Slade, D. H. (editor). 1968. Meteorology and Atomic Energy. U.S. Atomic Energy Commission, Washington, D.C.

Strenge, D. L., E. C. Watson and J. G. Droppo. 1976. Review of Calculational Models and Computer Codes for Environmental Dose Asses Sillent of Radioactive Releases. BNWL-B-454, Pacific Northwest Laboratory, Richland, Washington.

Toombs, G. L., and P. B. Cutler (compilers). 1968. Comprehensive Final Report for the Lower Columbia River Environmental Survey in Oregon June 5, 1961 - Juty 31, 1967. Oregon State Board of HeaTth, Division of Sanitdtion and Engineering, Portland, Oregon. 
APPENDIX A

COMPUTER CODE DESIGN 
This appendix provides information on the computer code design useful to programmers desiring to make modifications to the program. The average user of the code will not need the information provided here. The following sections provide:

- code hierarchy diagrams (Section A.1)

- module specifications (Section A.2).

The computer program was developed for execution on the UNIVAC 1100/44 system operated by Boeing Computer Services for the Department of Energy at Richland, Washington. The programming language is ASCII FORTRAN as implemented by the UNIVAC FTN compiler. A listing of the FORTRAN source code is given in Appendix $D$.

A version of the code also exists in FORTRAN 77 for an IBM personal computer. The listing is essentially identical to that for the UNIVAC, and so is not also reproduced.

\section{A.1 CODE HIERARCHY}

The computer program DITTY is composed of 40 modules, including the main program. The calling sequence for the program is indicated in the hierarchy diagrams of Figure A.1. This diagram only indicates module calling sequences; module logic diagrams are given in Section A.3.

\section{A.2 MODULE SPECIFICATIONS}

This section provides summary information on each of the 40 modules of the computer program DITTY. The information presented on each module includes:

- module name

- calling module(s)

- primary function

- common block usage

- argument list

- subordinate modules

- detailed specifications 


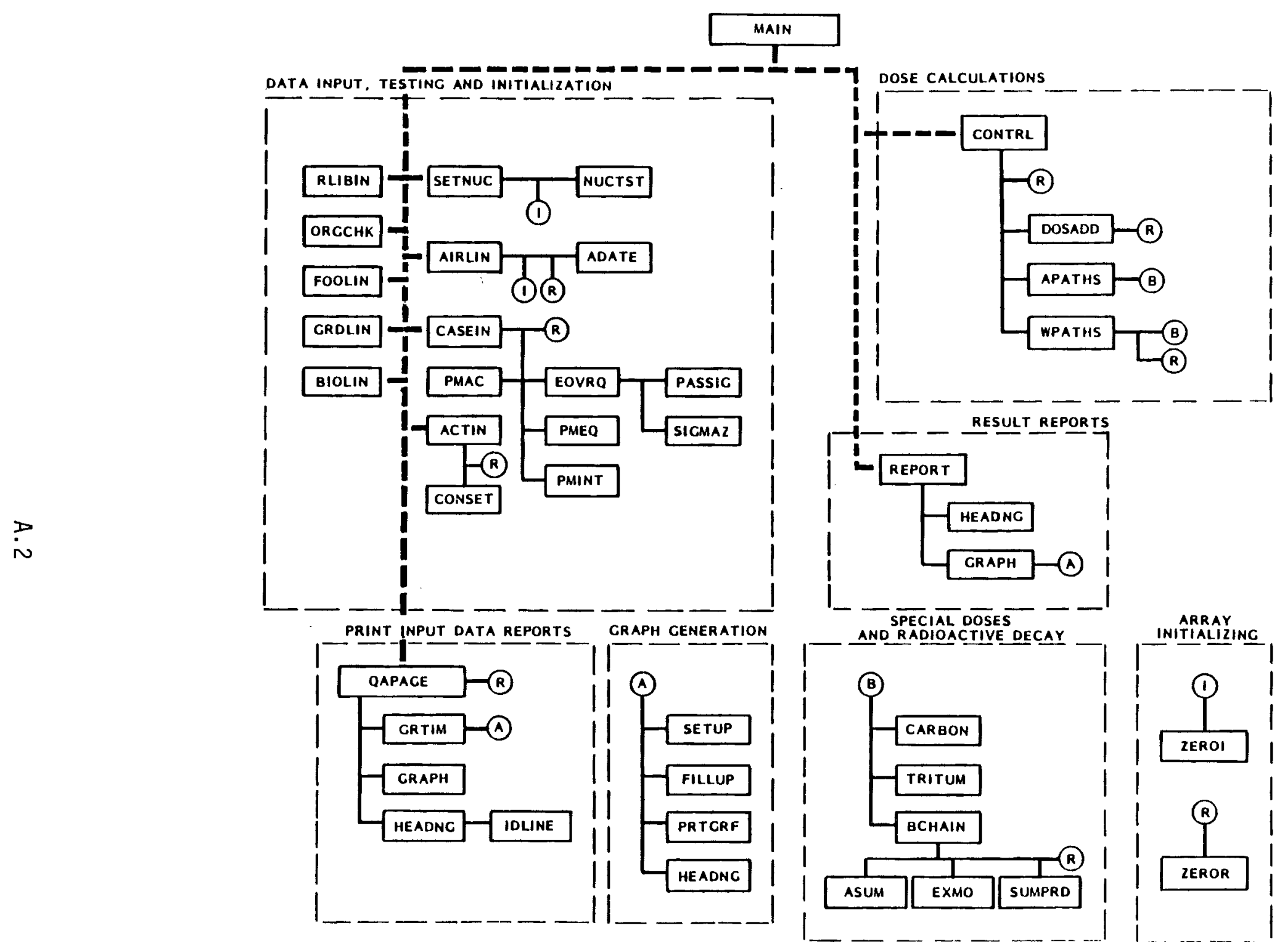

FIGURE A.1. DITTY Hierarchy Diagram--Module Calling Sequence from MAIN 
The main program (module MAIN) is described first followed by the other modules in alphabetical order. All modules are included except for the special function IDLINE which is called from RQAPAGE to print a descriptive line defining the version and preparation date of the program being executed.

\section{A.2.1 Specifications for MAIN Program}

Primary Function: This module controls input of data and case iterations. Common Blocks Used: BIODAT, DECAY, DISPSN, DKAY, FODATA, NAMLST, OPTION, ORGID, PATHIN, SOURCE, TIMES, TITLES, VARYBL

Argument List: None

Subordinate Modules: RLIBIN, SETNUC, ORGCHK, AIRLIN, BIOLIN, FOOLIN, GRDLIN, CASEIN, ACTIN, QAPAGE, CONTRL, REPORT, ZEROI.

This module controls input of data and case iteration through calls to subroutines. The master data library RMDLIB is called first to provide radionuclide decay information. Next, the list of radionuclides and organs to be considered for the run are read. The subroutine SETNUC is called to select decay data for the input radionuclides and establish the master radionuclide list for the run (including necessary daughters of selected radionuclides). Three additional data libraries are read next to provide necessary data as follows:

\begin{tabular}{|c|c|}
\hline Module & Data File Read \\
\hline ARLIN & DSFCT, internal dose factors \\
\hline FOOLIN & FTRANSLIB, food transfer coefficient data \\
\hline GRDLIN & GRDFLIB, external dose factors \\
\hline
\end{tabular}

For each case to be run, the program calls subroutine CASEIN to read input from cards. Subroutine BIOLIN is called to read bioaccumulation factors for fresh or salt water. The subroutine ACTIN is called (if necessary) to establish release rate data arrays. A quality assurance report of input data is generated by subroutine QAPAGE. Then dose calculations are performed (subroutine CONTROL) and result reports are printed (subroutine REPORT).

An attempt is made to read a title card for the next case. An end-of-file on input at this point is the normal mode for termination of execution. 


\section{A.2.2 Specifications for Subroutine ACTIN \\ Called by MAIN}

Primary Function: This subroutine reads release activity data for specified times for airborne or waterborne releases

Common Blocks Used: NUCNAM, TITLES

Argument List: IP, IAW, ITX, ITM, IBEG, IEND, CON

Subordinate Modules: CONSET, ZEROR

This subroutine reads release activity data from the appropriate input unit and then calls subroutine CONSET to set radionuclide release activities for each of the 143, 70-yr periods. Radionuclide names are compared with the master list names of common block NUCNAM.

The argument list parameters have the following uses:

Parameter

IP

IAW

ITX

ITM

$\operatorname{IBEG}(100)$

$\operatorname{IEND}(100)$

$\operatorname{CON}(143,100)$

\section{Description}

Pathway section index

IP $=1$ for airborne releases

$I P=2$ for waterborne releases

Control integer for input file specification IAW $=1$ for card input

IAW $>1$ for permanent file input on unit 24 (waterborne) or unit 26 (airborne)

Maximum time increment index during which any releases are made for this mode (air or water). $1 \leq$ ITX $\leq 143$ and ITX $\geq$ ITM

Minimum time increment index during which any releases are made for this mode (air or water) $1 \leq$ ITM $\leq 143$

The first time increment during which each radionuclide is released, $1 \leq \operatorname{IBEG}(i) \leq 143$

The last time increment during which each radionuclide is released, $1 \leq \operatorname{IEND}(i) \leq 143$ and $\operatorname{IBEG}(i) \leq \operatorname{IEND}(i)$

Total activity released during each $70-y$ r period for 100 radionuclides, $\mathrm{C}$. 


\section{A.2.3 Specifications for Subroutine AIRLIN \\ Called by MAIN}

Primary Function: This subroutine reads internal (inhalation and ingestion) dose conversion factors

Common Blocks Used: DAY, DECAY DOSFAC, FLAGS, NUCNAM, ORGID, TITLES

Argument List: None

Subordinate Modules: ADATE (special system routine), ZEROI, ZEROR

This subroutine reads inhalation and ingestion dose conversion factors from the data file DSFCT on logical unit 18. The first three records provide descriptive information on the information to follow including a title that is printed in the input summary report (subroutine QAPAGE). Data for each radionuclide are then read sequentially. The flag array [INFLG(i)] is set to 1 if data are supplied for master list radionuclide $i$.

Each radionuclide read from DSFCT is compared to those in the master radionuclide list. If a radionuclide cannot be identified, an error message is printed and execution is stopped.

Index values for organs considered in the library are given at the beginning of the data file. These index values are compared to the master organ list read at the beginning of the main program. All master list organs must be included in the library list or execution will be terminated.

\section{A.2.4 Specifications for Subroutine APATHS}

Called by CONTROL

Primary Function: This module calculates environmental concentrations from atmospheric deposition

Common Blocks Used: DKAY, EDCN, FODATA, PATHIN, NUCNAM, VARYBL

Argument List: ITAX, ITIM

Subordinate Modules: BCHAIN, CARBON, TRITUM 
This routine calculates the concentration of each radionuclide in the media of the following pathways from atmospheric deposition:

1. leafy vegetables

2. other vegetables

3. eggs

4. milk

5. beef

6. pork

7. poultry

Soil concentrations are also calculated. Separate subroutines are called to calculate the concentration of tritium and carbon 14. Radioactive decay is calculated by calls to subroutine BCHAIN.

The argument list parameters give the minimum (ITIM) and maximum (ITAX) time period during which any radionuclides are released to the atmosphere.

\section{A.2.5 Specifications for Function ASUM}

Called by BCHAIN

Primary Function: This function sums terms of an array

Common Blocks Used: None

Argument List: $A, J$

Subroutine Routines: None

This function calculates the sum of $\mathrm{J}$ terms of array $A$, as follows:

$$
\text { ASUM }=\sum_{i=1}^{J} A(i)
$$

\section{A.2.6 Specifications for Subroutine BCHAIN}

Called by APATHS, WPATHS

Primary Function: Calculate either radioactive decay and buildup for a chain of radionuclides for a given time period, 
allowing for nonradiological removal to a sink, or the time integral of the activity.

Common Blocks Used: None

Argument List: NUC, T, KD, IFRM, AL, AB, AM, A0. INTGRL

Subordinate Routines: ZEROR, EXMO, ASIMM, SUMPRD

This subroutine calculates amounts of radionuclides following radioactive decay, allowing for daughter buildup for a time period $(T)$ for a chain of NUC radionuclides, or the time integral of the activity. The argument list parameters have the following uses:

Parameter

NUC

T

$\operatorname{DK}(2,9)$

$\operatorname{IFRM}(2,9)$

$\operatorname{AL}(9)$

$A B(9)$

AM(9)

$\mathrm{AO}(9)$

INTGRL
Description

Number of radionuclides in the decay chain. $1 \leq$ NUC $\leq 9$

Time over which decay is to be considered. Units of $T$ must be compatible with the units of the decay constants, AL.

Branching ratios:

$$
\begin{aligned}
\operatorname{DK}(1, i)= & \text { fraction of first parent decays resulting in } \\
& \text { production of chain member } i \\
\operatorname{DK}(2, i)= & \text { fraction of second parent (if any) decays resulting } \\
& \text { in production of chain member } i
\end{aligned}
$$

Position in chain of parents for each chain member $\operatorname{IFRM}(1, i)=$ index of first parent for chain member $i$ $\operatorname{IFRM}(2, i)=$ index of second parent for chain member $i$

Radiological decay constants for each chain member in units compatible with $T$

Sum of the radiological and nonradiological removal constants in units compatible with $T$

Initial quantity of each radionuclide in mass units (or Curie-seconds)

Final activity (or time integral) of each radionuclide Control integer to calculate the time integral of activity when INTGRL > 0 


\section{A.2.7 Specifications for Subroutine BIOLIN}

Called by MAIN

Primary Function: This subroutine reads values of the bioaccumulation factor for fish, molluscs, crustaceans, and water plants, as well as drinking water cleanup factors from the data file BIOAC (Unit 14)

Common Blocks Used: BIODAT, NUCNAM, TITLES

Argument List: None

Subordinate Routines: None

This subroutine is used to read (logical unit 14) data on the bioaccumulation of elements in aquatic organisms and the cleanup of drinking water by water treatment plants. The data are then arranged in arrays based on the order of the master list from routine SETNUC.

Data in the file are in the order:

\begin{tabular}{|c|c|c|}
\hline Record & Format & Description \\
\hline E & A2 & Element Name \\
\hline $\mathrm{BF}(1)$ & Fa. 1 & Bioaccumulation factor for fish in salt water \\
\hline $\mathrm{BF}(2)$ & F9.1 & Bioaccumulation factor for crustacea in salt water \\
\hline$B F(3)$ & Fa.1 & Bioaccumulation factor for molluscs in salt water \\
\hline$B F(4)$ & F9.1 & Bioaccumulation factor for water plants in salt water \\
\hline $\mathrm{BF}(5)$ & F9.1 & Bioaccumulation factor for fish in fresh water \\
\hline$B F(6)$ & F9.1 & Bioaccumulation factor for crustacea in fresh water \\
\hline $\mathrm{BF}(7)$ & F9.1 & Bioaccumulation factor for molluscs in fresh water \\
\hline $\mathrm{BF}(8)$ & F9.1 & Bioaccumulation factor for water plants in fresh water \\
\hline DW & F6.1 & $\begin{array}{l}\text { Drinking water cleanup factors (the fraction passing } \\
\text { through a water treatment facility) }\end{array}$ \\
\hline
\end{tabular}

The parameter ISALT determines whether salt or fresh-water factors are used. Default is zero $=$ fresh water. 


\section{A.2.9 Specifications for Subroutine CARBON}

Called by APATHS, WPATHS

Primary Function: This subroutine calculates environmental concentrations of $\mathrm{C}-14$ using a simplified specific-activity mode1. The specific-activity for plants from water uptake is calculated on basis of soil carbon and ten percent plant uptake

Common Blocks Used: BIODAT

Argument List: IST, IAW, WATCN, AIRCN, ANCONS, ANDRNK, CSOIL, EDIBL, AQUA, RIRR, MOYPR

Subordinate Routines: None

This subroutine calculates the concentration of $\mathrm{C}-14$ from atmospheric deposition in leafy vegetables, other vegetables, eggs, milk, beef, pork, and poultry. The concentration of $\mathrm{C}-14$ in environmental media for the following aquatic pathways is also calculated: fish, drinking water, sediment, and water for recreation and irrigation. Irrigation water in turn is assumed to contaminate vegetables, animal feed and drinking water, and the soil.

\section{A.2.10 Specifications for Subroutine CASEIN}

Called by MAIN

Primary Function: This subroutine controls input file reading plus input from population data file 22

Common Blocks Used: AIRCON, BIODAT, DISPSN, NAMLST, OPTION, PATHIN, POPU, TIMES, TITLES, VARYBL, NAMLST, TIMES, OPTION, DISPSN

Argument List: None

Subordinate Routines: EOVRQ, PMAC, PMEQ, PMINT, PMSET, ZEROR

This subroutine controls input of data for one case from the input file. Population data from file 22 are also read for input option IPOP $=3$. 
First, a namelist input record set is read to provide control parameters and small data arrays. When airborne releases are to be considered (IPATH $\neq$ 2) data for $\bar{x} / Q^{\prime}$ calculation are read depending on the value of IEOQ. Also, $\bar{x} / Q^{\prime}$ parameters are read in or calculated if necessary. Airborne population data are read as required (control integer IPOP) and population dispersion factors are calculated for each 70 -yr increment.

If waterborne releases are to be considered (IPATH >1), the total population in each $70-y r$ period is set as necessary (control integer IPL).

\section{A.2.11 Specifications for Subroutine CONSET}

Called by ACTIN

Primary Function: This subroutine establishes release data for one radionuclide for each $70-y r$ increment

Common Blocks Used: TIMES

Argument List: T, C, NT, IBEG, IEND, CONS

Subordinate Routines: None

This subroutine determines the total activity released during each 70-yr increment for one radionuclide. The release activity history datd (times $T_{j}$ and activity release rates $C_{j}$ ) are interpolated and integrated over each period. The beginning and ending time increments for release are also set. The argument 1 ist parameters have the following uses:

Parameter

$T(450)$

$C(450)$

NT

IBEG

IEND

$\operatorname{CONS}(143)$
Description

Time points for specification of activity release rates, years since start of release calculation

Activity released per year at each time point, $\mathrm{Ci} / \mathrm{yr}$

Number of time points data is supplied for in arrays $T$ and $C$, $2 \leq N T \leq 300$

First $70-y r$ increment that has a nonzero release activity for the current radionuclide

Last $70-y r$ increment that has a nonzero release activity for the current radionuclide

Total activity released in each of the $14370-y r$ increnents, $\mathrm{Ci}$ 
The first value of CONS corresponds to the value $\operatorname{CON}(1$, IN) in the calling routine ACTIN.

\section{A.2.12 Specifications for Subroutine CONTRL}

Called by MAIN

Primary Function: This routine controls the calling of the routines calculating environmental accumulation and decay of radionuclides, and calculation and summation of the resulting doses

Common Blocks Used: EDCN, OUTORG

Argument List: IAC, IPATH, ITAM, ITAX, ITWM, ITWX

Subordinate Routines: APATHS, DOSADD, WPATHS, ZEROR

For chronic releases, the incremental increase in the environmental concentration for each $70-y r$ block is calculated, using deposition from either air or water and decay of previously deposited nuclides. Doses for this time increment are calculated and added to the running total. A special preliminary step is taken for acute releases, for year one only, to account for maximized leafy deposition, before reverting back to the standard chronic mode. This routine controls the 143 step time loop.

\section{A.2.13 Specifications for Subroutine DOSADD}

Called by CONTRL

Primary Function: This routine calculates $70-y$ r incremental population doses from exposure to contaminated environmental media

Common Blocks Used: PATHIN, EDCN, RESULT, DOSFAC, GRDDAT, DKAY, ORGID, DOSIN, OUTORG

Argument List: ICUTE, ITT

Subordinate Routines: ZEROR

This routine calculates the $70-y$ r population dose increment for each $70-y r$ period and adds it to the running total. Additionally, running totals are kept for each organ. DOSADD saves the result from the time period of 
highest dose, along with the corresponding time. For acute releases, the dose saved is the 70-yr commitment from the first year of exposure. The doses are saved in common block RESULT. Required input variables are defined as:

1. From Common Block PATHIN:

$\operatorname{CONSUM}(7)$ : leafy vegetables, other vegetables, eggs, milk, beef, pork USAGE(7): fish, crustaceans, molluscs, plants, drinking water, shore line, swimming

EXTIME: hr/yr external exposure, avg.

SH: shore width factor, defautt to 0.2

2. From Common Block EDCN:

Water Pathways

WATCON $(100)$ : water concentration

SCONW(100): soil concentration from irrigation

$\operatorname{SEDCON}(100)$ : sediment concentration

$\operatorname{EDBCNW}(7,100)$ : terrestrial concentrations by pathway (see CONSUM)

AQUATC $(5,100)$ : aquatic concentrations by pathway (see USAGE)

Air Pathways

AIRCON(100): atmospheric concentration from diffusion/disperson

$\operatorname{SLCON}(100)$ : soil concentration from fallout

$\operatorname{EDBCON}(7,100)$ : terrestrial concentrations by pathway (see CONSUM)

**Note: all of these concentrations already contain the population values, as well as a factor of $1 / A R$

3. From Common Block GRDDAT:

$\operatorname{EDS}(100)$ : soil external factors, rem $/ \mathrm{hr}$ per $\mathrm{Ci} / \mathrm{m}^{2}$

EDW(100): water external factors, rem/hr per $\mathrm{Ci} / \mathrm{m}^{3}$

EDA(100): air external factors, rem per $\mathrm{Ci-sec} / \mathrm{m}^{3}$

4. From Common Block DOSFAC:

$\operatorname{DFH}(2,5,100)$ : inhalation dose factors

$\operatorname{DFG}(2,5,100)$ : ingestion dose factors

Other pertinent points: Air concentrations used for the dose calculations include resuspension from the soil at a fraction of $10^{-9} \mathrm{~m}^{-1}$ from the top $1 \mathrm{~cm}$ of soil, as:

$$
C i / \mathrm{kg}\left(10^{-9} \mathrm{~m}^{-1}\right)\left(224 \mathrm{~kg} / \mathrm{m}^{2}\right)(1 \mathrm{~cm} / 15 \mathrm{~cm})=1.49 \times 10^{-8} \text {. }
$$




\section{A.2.14 Specifications for Subroutine EOVRQ \\ Called by CASEIN}

Primary Function: This subroutine calculates an annual average air concentration at each spatial interval midpoint

Common Blocks Used: AIRCON, DISPSN

Argument List: None

Subordinate Routines: PASSIG, SIGMAZ

This subroutine calculates an annual average air concentration at each spatial interval midpoint. The equation used is:

$$
\operatorname{EOQ}(I X, I T)=0.02032 \sum_{i=1}^{\text {NUBAR }} \sum_{j=1}^{\text {NMET }} F(i, j, I T) \frac{\exp \left(-H S^{2} /\left(2 \cdot \sigma_{z}{ }^{2}\right)\right.}{X_{I X}{ }^{\sigma} \bar{u}_{i}}
$$

where $E O O(I X, I T)=$ air concentration at distance IX and in direction IT, $\mathrm{sec} / \mathrm{m}^{3}$

$F(i, j, I T)=$ joint frequency of occurrence for windspeed $i$, stability $j$ and direction IT

HS = effective height of release, $m$

$\sigma_{Z}=$ crosswind vertical standard deviation of air concentration, $m$

$X_{I X}=$ distance to position $I X, m$

$\bar{u}_{i}=$ windspeed $i, \mathrm{~m} / \mathrm{sec}$

$0.02032=0.1 * \frac{8}{\pi} \quad \frac{2}{\pi} \quad 1 / 2$

The dispersion parameter $\sigma_{z}$ is calculated by subroutine PASSIG for Pasquil1 categories and by function SIGMAZ for Hanford stable categories.

\section{A.2.15 Specifications for Function EXMO}

Called by BCHAIN

Primary Function: The function calculates a value for the expression

$$
\left(1-e^{-\lambda t}\right) / \lambda \text {. }
$$


Common Blocks Used: None

Argument List: $A L, A R G$

Subordinate Routines: None

This function calculates a value for the expression:

$$
\frac{1-e^{-\lambda t}}{\lambda}
$$

The argument list is:

$A R G=\lambda t$

$A L=\lambda$

The method used to evaluate the expression is determined by the value of ARG. When ARG is positive, an error message is printed and execution is stopped. When $-A R G>0.001$, then the expression is evaluated as

$$
\operatorname{EXMO}=[1.0-\operatorname{EXP}(A R G)] / A L
$$

When $-A R G \leq 0.001$, the expression is evaluated as

$$
\operatorname{EXMO}=\sum_{n=1}^{I} \frac{(\lambda t)^{n}(-1)^{n-1}}{n ! \lambda}
$$

where $I=$ integer value of $8-\log _{10}(-A R G)$ and $I \geq 2$.

A.2.16 Specifications for Subroutine FILLUP

Called by GRAPH

Primary Function: FILLUP is a graphing subroutine which sets points of the function array in the graphics printing array

Common Blocks Used: NUCNAM, PLOT

Argument List: FOFX, YINC, IN, NOAVE

Subordinate Routines: None 
The subroutine FILLUP looks at each point in one function of the array FOFX. Up to eight functions may be superimposed on one graph. FILLUP selects a plotting symbol for each function. If two or more points are to occupy the same storage location, FILLUP will substitute the digit equal to the number of overlays from the plotting symbols for that location.

The printing array has a time (horizontal) dimension of 72 which corresponds to 144 periods. For most functions the average of two consecutive time points is plotted in one position. Some functions (i.e., population input data) where only a few points are plotted would be distorted if the average algorithm were used. The argument list parameter NOAVE allows the option of not averaging zero values with data points.

Each point is stored in the printing array based on the $y$-axis increment value, which is passed in the argument 1ist. Testing is done to ascertain that no points are plotted outside the graph.

The argument list parameters have the following functions:

$\begin{array}{lll}\frac{\text { Parameter }}{\text { FOFX }(144,8)} & \frac{\text { Type }}{\text { REAL }} & \begin{array}{l}\text { Description } \\ \text { versus time }\end{array} \\ \text { YINC } & \text { REAL } & \begin{array}{l}\text { Y-axis plotting increment } \\ \text { IN }\end{array} \\ \text { INTEGER } & \begin{array}{l}\text { Index of the function in FOFX to be placed in } \\ \text { printing array }\end{array} \\ \text { NOAVE } & \text { INTEGER } & \begin{array}{l}\text { FLAG - if set to } 1 \text {, do not average zeros into } \\ \text { array }\end{array}\end{array}$

\section{A.2.17 Specifications for Subroutine F00LIN} Called by MAIN

Primary Functions: This subroutine reads in crop and animal food concentration ratios, deposition velocities, and soil percolation constants from data file FTRANSLIB

Common Blocks Used: FODATA, NUCNAM, TITLES

Argument List: None

Subordinate Routines: None 
This subroutine reads data on the deposition velocity of radioriuclides onto soil; the concentration ratios between soil and plants, and plants and animal products; and the factors describing the percolation of radionuclides out of the root zone into deeper soil. The data are then arranged into arrays based on the order of the master radionuclide list from routine SETNUC.

Data in the file are in the format:

\begin{tabular}{|c|c|c|}
\hline Record & Format & Description \\
\hline $\mathrm{E}$ & $\mathrm{A} 2$ & Element Name \\
\hline DVL & E9.2 & Deposition velocity, $\mathrm{m} / \mathrm{s}$ \\
\hline $\operatorname{CR}(1)$ & E9.2 & Soil/food CR, dimensionless \\
\hline $\mathrm{CR}(2)$ & E9.2 & Egg $C R$, day $/ \mathrm{kg}$ \\
\hline $\mathrm{CR}(3)$ & E9.2 & Milk CR, day/L \\
\hline $\operatorname{CR}(4)$ & E9.2 & Beef $C R$, day $/ \mathrm{kg}$ \\
\hline $\mathrm{CR}(5)$ & E9.2 & Pork CR, day $/ \mathrm{kg}$ \\
\hline $\operatorname{CR}(6)$ & E9.2 & Poultry CR, day $/ \mathrm{kg}$ \\
\hline PERC & E9.2 & Percolation constant, $\mathrm{yr}^{-1}$ \\
\hline
\end{tabular}

FOOLIN reads from the data file FTRANSLIB assigned to logical unit No. 12.

A.2.18 Specifications for Subroutine GRAPH

Called by QAPAGE, REPORT

Primary Function: This subroutine controls the printing of graphs of functions in relation to time

Common Blocks Used: NUCNAM, ORGID

Argument List: IYL, FOFX, NGRF, IORNUC, IFROM, NOAVE, IGRAW

Subordinate Routines: SETUP, FILLUP, PRTGRF

This subroutine is called by QAPAGE and REPORT to output a graph of a particular function. The function to be plotted versus $144,70-y r$ time increments is passed in the array FOFX. Up to eight plots may be superinposed on one graph, though this feature is not currently being utilized.

Labels for the functions are stored in data statements and in some cases constructed from information passed in the argument list. There are seven 
label options selected by the value of the argument list parameter IYL as follows:

1. "total population"

2. "population dispersion factor"

3. "population for waterborne pathways"

4. "total curies per period"

5. "curies per period of radionuclide name"

6. "total organ dose"

7. "organ dose"

The radionuclide name or organ is determined by the value of the index. parameter IORNUC which indicates the storage position in the appropriate character name array. The subroutine SETUP is called to ready the labels for printing.

The argument list parameters are outlined in the following table:

\begin{tabular}{|c|c|c|}
\hline Parameter & Type & Description \\
\hline IYL & INTEGER & Index of selected label for function \\
\hline FOFX $(144,8)$ & REAL & $\begin{array}{l}\text { Array of Function(s) to be plotted versus time } \\
\text { (14470-yr periods). Up to eight plots may be } \\
\text { superimposed on the graph }\end{array}$ \\
\hline NGRF & INTEGER & $\begin{array}{l}\text { Number of functions to be superimposed on this } \\
\text { graph }\end{array}$ \\
\hline IORNUC & INTEGER & $\begin{array}{l}\text { Index of radionuclide or organ to be graphed. } \\
\text { Used to include appropriate name in } y \text {-axis label }\end{array}$ \\
\hline IFROM & INTEGER & $\begin{array}{l}\text { Indicates calling subroutine: } \emptyset=\text { QAPAGE, } 1= \\
\text { REPORT. Used for page heading }\end{array}$ \\
\hline NOAVE & INTEGER & If set to 1 , do not average in zero values \\
\hline IGRAW & INTEGER & $\begin{array}{l}\text { Release message flag to be printed on graph: } \emptyset= \\
\text { no message, } 1=\text { air message, } 2 \text { = water message }\end{array}$ \\
\hline
\end{tabular}

The maximum value in the FOFX array is determined, the $y$-axis increment is calculated, and the $y$-axis tick mark values are calculated. For each plot the subroutine FILLUP is called to plot the function into the print array. PRTGRF is then called to print the graph. 


\section{A.2.19 Specifications for Subroutine GRDLIN}

Called by MAIN

Primary Function: This subroutine reads in dose factors for external exposure to soil, water and air (data file GRDFLIB)

Common Blocks Used: GRDDAT, NUCNAM, TITLES

Argument List: None

Subordinate Routines: None

This subroutine is used to read in data on the external dose rate factors for exposure to contaminated soil, water, or air. Only the factors for total body dose are read in.

Since some data from the library are omitted, the read format is A2, A6, $9 \mathrm{x}, \mathrm{E} 9.2,9 \mathrm{x}, 2 \mathrm{E} 9.2$ parameters are:

\begin{tabular}{|c|c|c|}
\hline E & $A 2$ & Element Name \\
\hline A & A6 & Atomic weight, $+D$, and/or metastable designations \\
\hline EDS & E9. 2 & $\begin{array}{l}\text { External dose function from soil exposure, mrem/hr per } \\
\mathrm{pCi} / \mathrm{m} 2\end{array}$ \\
\hline EDW & E9. 2 & External dose from swimming, mrem/hr per $\mathrm{pCi} / \mathrm{m}^{2}$ \\
\hline EDA & E9.2 & $\begin{array}{l}\text { External dose factor from air submersion, mrem/hr per } \\
\mathrm{pCi} / \mathrm{m} 3\end{array}$ \\
\hline
\end{tabular}

GRDLIN reads from data file GRDFLIB assigned to logical unit No. 16.

\section{A.2.20 Specifications for Subroutine GRFIL}

Called by QAPAGE

Primary Function: This subroutine transfers values in a 20-position array to be plotted versus time into corresponding positions in a 144-position array

Common Blocks Used: None

Argument List: IT, Y20, FOFX, NT

Subordinate Modules: None 
This subroutine determines the ordinate position for plotting points in the function array $\mathrm{Y20}$. The values are transferred into the 144-position plotting array Fox.

The argument list parameters have the following uses.

\begin{tabular}{|c|c|c|}
\hline Parameter & Type & Description \\
\hline $\mathrm{IT}(20)$ & INTEGER & $\begin{array}{l}\text { Cross-index of subscripts corresponding to a } \\
\text { 144-position array }\end{array}$ \\
\hline Y20(20) & REAL & Input array to be plotted versus time \\
\hline FOFX(144) & REAL & $\begin{array}{l}\text { Output array corresponding to the 144-position } \\
\text { time array }\end{array}$ \\
\hline NT & INTEGER & Number of time periods in arrays IT and $Y 20$ \\
\hline
\end{tabular}

\section{A.2.21 Specifications for Subroutine GRTIM}

Called by QAPAGE

Primary Function: GRTIM is a graphing subroutine which selects the corresponding positions of a 144-position time array for the 20-position input time array

Common Blocks Used: TIMES

Argument List: T20, IT144, NT

Subordinate Modules: ZEROI

The array T20 gives times at which population data are supplied for air or water releases. To graph the population data in the same time configuration as the releases and doses it is necessary to locate the corresponding time position in a 144 element array. GRTIM selects those corresponding positions.

ZEROI initiates the 144-position time array. The testing parameter TT is initialized to the starting time (TZ) and the increment is set to 70 years. 
The argument list parameters have the following uses:

$\frac{\text { Parameter }}{\text { T20(20) }} \quad \frac{\text { Type }}{\text { REAL }}$

IT144(20) INTEGER

INTEGER

Description

20-position time array. Corresponds to times at which population data are supplied

20-position array of indices indicating in which position in a 144 point array, with $70-y r$ increments, the times in T20 should be plotted

No. of times in the array T20

Each time in T20 is tested until its corresponding position is found in the 144-position array. The index of that position is stored in the array IT 144 .

\section{A.2.22 Specifications for Subroutine HEADNG}

Called by QAPAGE, GRAPH, REPORT

Primary function: This subroutine prints page headings for quality assurance pages and result reports

Common Blocks Used: TIMES, TITLES, DAY

Argument List: IFROM

Subordinate Modules: None

HEADNG prints appropriate page headings on output based on the value of the argument list parameter IFROM. When IFROM $=\emptyset$, the quality assurance heading is printed. When IFROM $=1$, the report format is used. IDLINE is an RL UNIVAC-1100/44 subroutine which prints a message indicating the data and time of execution.

\section{A.2.23 Specifications for Subroutine NUCTST}

Called by SETNUC

Primary Function: This subroutine tests the input radionuclides list for unidentified radionuclides

Common Blocks Used: FLAGS, NUCNAM, SOURCE

Argument List: NIN

Subordinate Routines: IDLINE 
NUCTST tests the integer array INFLG for unidentified radionuclides. If $\operatorname{INFLG}(i) \leq 0$, then radionuclide $i$ of the input list was not found in the master data library RMDLIB. The name of each unidentified radionuclide is printed. If any unidentified radionuclides were found execution is stopped.

The total number of radionuclides required for this run is tested. If NUCS > 100 execution is stopped.

\section{A.2.24 Specifications for Subroutine ORGCHK}

Called by MAIN

Primary Function: This subroutine checks the organ selection data for correctness

Common BTocks Used: ORGID

Argument List: None

Subordinate Routines: None

This subroutine checks the organ selection parameter KORG for correctness. Limitations on this parameter are as follows:

$$
\begin{aligned}
1 \leq \operatorname{KORG}(i) & \leq 23 \text { for } 1 \leq i \leq N O R G \\
\operatorname{KORG}(i) & \leq 0 \text { for } i>N O R G
\end{aligned}
$$

The number of correct values given in KORG determines the number of organs to be considered, NORG. $1 \leq$ NORG $\leq 5$.

\section{A.2.25 Specifications for Subroutine PASSIG}

Called by EOVR

Primary Function: This subroutine calculates dispersion parameters for a given distance and Pasquili stability category

Common Blocks Used: None

Argument List: $X X, I P, S Y, S Z$

Subordinate Routines: None 
This subroutine interpolates stored data to determine dispersion parameters $\sigma_{y}$ and $\sigma_{z}$ for a Pasquill atmospheric stability category and a given distance. The argument list parameters have the following uses:

Parameter

$x x$

IP

SY

SZ
Use

Distance from the release point to the location at which dispersion parameters are to be determined, $m$

Index to indicate which Pasquill stability category is to be used: $I P=1$ for $A$, IP $=2$ for $B, I P=3$ for $I P=4$ for $D$, $I P=5$ for $E$ and $I P=6$ for $F$

Crosswind horizontal standard deviation of plume concentration at the location of interest, $m$

Crosswind vertical standard deviation of plume concentration at the location of interest, $m$

Tabulated values are interpolated for the distance $x x$ between 1 and $10^{5}$ meters. In practical applications the distance $X X$ should not be less than 100 meters or greater than $10^{5}$ meters. The vertical dispersion parameter $\sigma_{z}$ is limited to 2000 meters.

Tabulated values are provided for distances given in array DIST(20). Horizontal dispersion parameters are given for 6 stabilities and 20 distances in the array $\operatorname{SIGY}(6,20)$ and vertical dispersion parameters are given for the same stability/distance combinations in the array $\operatorname{SIGZ}(6,20)$.

\section{A.2.26 Specifications for Subroutine PMAC}

Called by CASEIN

Primary Function: This subroutine interpolates population data at one time

Common BTocks Used: None

Argument List: NT, P, T, TZ, P1

Subordinate Routines: None

This subroutine interpolates NT values of population data array $P$ as a function of time (array T) to return the population parameters P1 at time TZ. If $T S$ is less than the first time, $T(1)$, then $P 1$ is set to $P(1)$. If $T Z$ is 
greater than the last time value, $T(N T)$, then $P 1$ is set to $P(N T)$. The times of array $T$ must be in increasing order.

\section{A.2.27 Specifications for Subroutine PMEO}

Called by CASEIN

Primary Function: This subroutine calculates a population dispersion factor from air concentrations and a population distribution

Common Blocks Used: AIRCON, POPU

Argument List: NDIST, PM

Subordinate Routines: None

This subroutine calculates a population dispersion factor based on the annual average air concentration array EOO and the population distribution array POP. The number of distance intervals is supplied as NDIST and the number of directions (sectors) is taken as 16 . The resulting population dispersion (PM) factor is returned through the argument list. PM is calculated as:

$$
P M=\sum_{i=1}^{N D I S T} \sum_{j=1}^{16} \operatorname{EOQ}(i, j) \star \operatorname{POP}(i, j)
$$

\section{A.2.28 Specifications for Subroutine PMINT}

Called by CASEIN

Primary Function: This subroutine interpolates time vs. population dispersion factor arrays to determine population dispersion factors at each 70-yr increment midpoint

Common Blocks Used: None

Argument List: NT, TZ, T, PM1, PM

Subordinate Routines: None 
This subroutine interpolates the population dispersion factor array PM1 (given as a function of time, T array) to determine the values for each $70-y r$ time increment in array PM. The argument list parameters have the following uses:

$\underline{\text { Parameter }}$

NT

$T Z$

$T(20)$

PM1(20)

PM(143)

\section{Description}

Number of time periods for which data are supplied in arrays $T$ and PM1. When NT $\leq 1$ the first value of PM1 is used for a 11 time increments

Time (years $A D$ ) at the start of the 10,000 year integration period

Time points corresponding to definition of data in array PM1, years $A D$

Population dispersion factor array to be interpolated, person-sec $/ \mathrm{m}^{3}$

Population dispersion factor array for each 70-yr period of the $10,000 \mathrm{yr}$ integration period

\section{A.2.29 Specifications for Subroutine PMSET}

Called by CASEIN

Primary Function: This subroutine establishes interpolation values for population dispersion factor options 2 and 5

Common Blocks Used: None

Argument List: NTA, POPT or PMI

Subordinate Routines: None

This subroutine calculates population dispersion values for each time period (NTA) used for interpolation. The values are calculated as:

$$
\operatorname{PMI}(i)=\operatorname{POPT}(i) * \frac{\operatorname{PMI}(1)}{\operatorname{POPT}(1)}
$$




\title{
A.2.30 Specifications for Subroutine PRTGRF
}

Called by GRAPH

Primary Function: PRTGRF is a graphing subroutine which prints the graph on the line printer

Common Blocks Used: Plot, times

Argument List: TY, YINC, IGRAW, IFROM

Subordinate Routines: HEADNG

This subroutine calls the subroutine HEADNG to print a page heading and then prints increment information and a message indicating an air or water release if applicable. The graph array is then printed with labels, borders, tick marks and tick mark values.

The argument list parameters have the following functions:

\begin{tabular}{|c|c|c|}
\hline Parameter & Type & Description \\
\hline $\operatorname{TY}(5)$ & REAL & Array containing $y$-axis tick values \\
\hline YINC & REAL & Y-axis increment \\
\hline IGRAW & INTEGER & $\begin{array}{l}\text { Release message flag: } \\
\emptyset \text { - no message } \\
1 \text { - air } \\
2 \text { - water }\end{array}$ \\
\hline IFROM & INTEGER & $\begin{array}{l}\text { Calling routine: (used by HEADNG) } \\
\emptyset \text { - QAPAGE } \\
1 \text { - REPORT }\end{array}$ \\
\hline
\end{tabular}

\author{
A.2.31 Specifications for Subroutine QAPAGE \\ Called by MAIN \\ Primary Function: QAPAGE prints a report of input parameters \\ Common Blocks Used: BIODAT, DISPSN, NAMLST, NUCNAM, OPTION, ORGID, PATHIN, \\ TITLES, VARYBL
}

Argument List: None

Subordinate Routines: HEADNG, GRAPH, GRFIL, GRTIM, ZEROR 
QAPAGE prints a report of library information, terrestrial and aquatic pathways data, organ data, site grid information, and the selected radionuclides. Additionally, plots of population dispersion, population for each pathway, total activity of selected radionuclides, and the activity of each radionuclide may be printed.

Graph options are input as namelist parameters. Separate graphs are printed for each pathway where applicable. Graph option variables are set if greater than zero and control graph selection as follows:

\begin{tabular}{|c|c|c|}
\hline Option & $\begin{array}{c}\text { Additional } \\
\text { Test } \\
\end{array}$ & Graph \\
\hline IGRPOP & None & Population data \\
\hline IGRPM & IAIR $>\emptyset$ & Population dispersion values \\
\hline IGRPL & IWAT $>\emptyset$ & Population for waterborne pathways \\
\hline IGRTNV & $\begin{array}{l}\text { IAIR }>\emptyset \\
\text { IWAT }>\emptyset\end{array}$ & $\begin{array}{l}\text { Total activity of radionuclides, air pathways } \\
\text { Total activity of radionuclides, water pathways }\end{array}$ \\
\hline I GRNUC & $\begin{array}{l}\text { IAIR }>\emptyset \\
\text { IWAT }>\emptyset\end{array}$ & $\begin{array}{l}\text { Separate graph of activity of each radionuclide's } \\
\text { air releases } \\
\text { Separate graph of activity of each radionuclide's } \\
\text { water releases }\end{array}$ \\
\hline
\end{tabular}

If the graph options IGRPOP, IGRNUC, or IGRPM are not set, a numeric report of that information is printed.

\section{A.2.32 Specifications for Subroutine REPORT \\ Called by MAIN}

Primary Function: This subroutine prints graphic reports of organ doses as a function of time, numerical reports of organ doses and a maximum dose period report

Common Blocks Used: NUCNAM, OPTION, ORGID, OUTORG, RESULT, TIMES

Argument List: None

Subordinate Modules: GRAPH, HEADNG 
REPORT utilizes a group of graphing subroutines to plot organ doses as a function of time. A graph is printed for each organ by moving the doses into the array FOFX and calling the plot-control subroutine GRAPH.

A numeric report of the dose to each organ at each time period is printed followed by a report of each radionuclide's contribution to each organ during the maximum dose time period.

\section{A.2.33 Specifications for Subroutine RLIBIN}

Called by MAIN

Primary Function: This subroutine reads data from the master radionuclide data file

Common Blocks Used: DECAY, NAMES, TITLES

Argument List: None

Subordinate Routines: ZEROR

This subroutine reads from the radionuclide master data library, RMDLIB. Data read include radionuclide identification parameter arrays ELT and AW and radiological half-life and chain decay data.

In reading the data file this subroutine does several functions:

- the number of nuclides are counted, NUC

- decay constants are calculated, AL

- chain branching parameters are set, IFR, DKF

- chain lengths are set, NOFNUC

The radionuclide master data file is read from logical unit 10.

\section{A.2.34 Specifications for Subroutine SETNUC}

Calling by MAIN

Primary Function: This subroutine establishes the master list of radionuclides to be included in this run

Common Blocks Used: DECAY, DKAY, FLAGS, NAMES, NUCNAM, SOURCE

Argument List: None

Subordinate Routines: NUCTST, ZEROI 
This subroutine compares the radionuclides of data file RMDLIB (radionuclide master data) with the input list of radionuclides. A master list of radionuclides is generated (including daughter radionuclides) for use during this run. Decay data are also put into data arrays for the selected radionuclides.

SETNUC calls NUCTST to determine if all master list radionuclides were found in data file RMDLIB.

\section{A.2.35 Specifications for Subroutine SETUP}

Called by GRAPH

Primary Function: SETUP is a graphing subroutine which prepares various arrays for printing

Common Blocks Used: PLOT

Argument List: $Y L, N L$

Subordinate Routines: None

This subroutine stores tick marks in arrays, transfers the $y$-axis label to a single character array and centers it for vertical printing, blanks out the printing array and sets the vertical borders into the print array. The argument list variable $Y L$ is the selected $y$-axis label. NL indicates the number of characters in that label.

\section{A.2.36 Specifications for Function SIGMAZ}

Called by EOVRQ

Primary Function: This function calculates $\sigma_{z}$ at a given location using the Hanford model

Common Blocks Used: None

Argument List: KS, IT

Subordinate Routines: None 
The value of $\sigma_{z}(m)$ is evaluated at the travel time distance, TT (seconds). When $\mathrm{KS} \leq 0$, moderately stable conditions are used, and when KS $>0$ very stable conditions are used, the equation is

$$
\sigma_{z}^{2}=a\left[1-\exp \left(-k^{2} T^{2}\right)\right]+b T
$$

where $T=T T$, travel time, sec, and values for $a, b$ and $k^{2}$ are as follows:

\begin{tabular}{|c|c|c|}
\hline Parameter & $\begin{array}{c}\text { Moderately } \\
\text { Stable }\end{array}$ & $\begin{array}{c}\text { Very } \\
\text { Stable }\end{array}$ \\
\hline$a\left(m^{2}\right)$ & 97 & 34 \\
\hline$b_{2}\left(m^{2} / \mathrm{sec}\right)$ & 0.33 & 0.025 \\
\hline$k^{2}\left(\sec ^{2}\right)$ & $2.5 \times 10^{-4}$ & $8.8 \times 10^{-2}$ \\
\hline
\end{tabular}

\section{A.2.37 Specifications for Function, SUMPRD}

Called by BCHAIN

Primary Function: This function sums the term by term products of two arrays

Common Blocks Used: None

Argument List: J, A, B

Subordinate Routines: None

The function evaluates the expression:

$$
\text { SUMPRD }=\sum_{i=1}^{J} A(i) * B(i)
$$

\section{A.2.38 Specifications for Subroutine TRITUM}

Called by APATHS, WPATHS

Primary Function: This subroutine calculates environmental concentrations of $\mathrm{H}-3$ using a specific-activity model 
Common Blocks Used: BIODAT

Argument List: IST, IAW, WATCN, AIRCN, ANCONS, ANDRNK, CSOIL, EDIBL, AQUA

Subordinate Routines: None

This subroutine calculates the concentration of $\mathrm{H}-3$ from atmospheric deposition in leafy vegetables, other vegetables, eggs, milk, beef, pork, and poultry. The concentration of $\mathrm{H}-3$ in environmental media for the following aquatic pathways is also calculated: fish, drinking water, sediment, and water for recreational use and irrigation. Irrigation water in turn is assumed to contaminate vegetables, animal feed and drinking water, and the soil.

\section{A.2.39 Specifications for Subroutine WPATHS}

Called by CONTRL

Primary Function: This routine calculates environmental concentrations of radionuclides from aquatic pathways

Common Blocks Used: BIODAT, KDAY, EDCN, FODATA, NUCNAM, PATHIN, VARYBL

Argument List: ITIM, ITWX

Subordinate Routines: TRITUM, CARBON, BCHAIN, ZEROR

This routine calculates the concentrations of radionuclides in environmental media for the following aquatic pathways:

1. fish

2. drinking water

3. sediment

4. water for recreational use and irrigation

The irrigation water is in turn assumed to contaminate these pathways:

1. leafy vegetables

2. other vegetables

3. eggs through contaminated feed and water

4. milk through contaminated feed and water

5. beef through contaminated feed and water 
6. pork through contaminated feed and water

7. poultry through contaminated feed and water as well as soil.

Much of this routine is similar to APATHS.

Concentrations for tritium and carbon-14 are caiculated separately by calis to other routines.

A.2.40 Specifications for Subroutine ZEROI

Called by SETNUC and AIRLIN

Primary Function: This subroutine initializes an integer array to zero

Common Blocks Used: None

Argument List: $\mathrm{N}, \mathrm{K}$

Subordinate Routines: None

This subroutine sets the first $\mathrm{N}$ members of integer array $\mathrm{K}$ to zero.

A.2.41 Specifications for Subroutine ZEROR

Called by RLIBIN, AIRLIN, CASEIN, CONTRL, DOSADD, BCHAIN

Primary Function: This subroutine initializes a real value array to zero

Common Blocks Used: None

Argument List: $\mathrm{N}, \mathrm{A}$

Subordinate Routines: None

This subroutine sets the first $N$ values of real array $A$ to zero. 



\section{APPENDIX B}

COMMON BLOCK DESCRIPTIONS 
APPENDIX B

COMMON BLOCK DESCRIPTIONS

The computer program DITTY uses labeled common blocks for the majority of data transfers between modules. Table B.1 gives a summary of each common block and indicates the modules that use each block. A detailed description of the parameters in each common block is given in Tables B. 2 to B. 26 . Table B.27 is an alphabetized list of all variables contained in common blocks and the name of the common block in which each variable resides.

The major difference between the mainframe and PC versions of DITTY is in the array specifications. One-hundred radionuclides may be processed simultaneously on the UNIVAC; the IBM version will only accept 25. A11 array dimensions of 100 have been reduced to 25 for the microcomputer version, as a space-saving measure. In addition, two new common blocks were added to implement the NAMELIST emulator. These are discussed in Appendix H. 


\section{TABLE B.1. DITTY Common Block Usage Summary}

\section{AIRCON}

Description: Normalized air concentration factors

Used by: CASEIN, EOVRQ, PMEQ

BIODAT

Description: Bioaccumulation factors for aquatic pathways

Used by: MAIN, BIOLIN, CARBON, CASEIN, QAPAGE, TRITUM, WPATHS

DAY

Description: Date of the current run and heading information

Used by: AIRLIN, HEADNG

DECAY

Description: Master radionuclide data file input radionuclide decay data Used by: MAIN, AIRLIN, RLIBIN, SETNUC

DISPSN

Description: Atmospheric dispersion data and parameters

Used by: MAIN, CASEIN, EOVRQ, QAPAGE

DKAY

Description: Radionuclide decay information for master list

Used by: MAIN, APATHS, DOSADD, SETNUC, WPATHS

DOSFAC

Description: Dose commitment factors

Used by: AIRLIN, DOSADD

EDCN

Description: Radionuclide concentrations in various media

Used by: APATHS, CONTRL, DOSADD, WPATHS

FLAGS

Description; Radionuclide selection control flags

Used by: AIRLIN, NUCTST, SETNUC

FODATA

Description: Data for terrestrial food pathways

Used by: MAIN, APATHS, FOOLIN, WPATHS

GRDDAT

Description: External dose conversion factors

Used by: DOSADD, GRDLIN

NAMES

Description: Master radionuclide data file input radionuclide names Used by: RLIBIN, SETNUC 


\title{
TABLE B.1. (contd)
}

\author{
NAMLST \\ Description: Input parameters for population definition \\ Used by: MAIN CASEIN, QAPAGE \\ NUCNAM \\ Description: Radionuclide names in master list \\ Used by: ACTIN, AIRLIN, APATHS, BIOLIN, FILLUP, FOOLIN, GRAPH, GRDLIN, \\ QAPAGE, NUCTST, REPORT, SETNUC, WPATHS \\ OPTION \\ Description: Input option parameters \\ Used by: MAIN, CASEIN, QAPAGE, REPORT \\ ORGI0 \\ Description: Organ selection and name information \\ Used by: MAIN, AIRLIN, DOSADD, GRAPH, QAPAGE, ORGCHK, REPORT \\ OUTORG \\ Description: Array of organ doses as function of time used for graphic \\ report \\ Used by: CONTRL, DOSADD, REPORT \\ PATHIN \\ Description: Namelist input data for food pathways \\ Used by: MAIN, APATHS, CASEIN, DOSADD, QAPAGE, WPATHS \\ PLOT \\ Description: Storage arrays for graphics \\ Used by: FILLUP, PRTGRF, SETUP \\ POPU \\ Description: Population distribution data \\ Used by: CASEIN, PMEQ \\ RESULT \\ Description: Calculated population doses \\ Used by: DOSADD, REPORT \\ SOURCE \\ Description: Input parameters for radionuclide master list \\ Used by: MAIN, NUCTST, SETNUC \\ TIMES \\ Description: Time reference points \\ Used by: MAIN, CASEIN, CONSET, HEADNG, PRTGRF, REPORT
}




\section{TABLE B.1. (contd)}

\section{TITLES}

Description: Data file and case titles

Used by: MAIN, ACTIN, AIRLIN, BIOLIN, CASEIN, FOOLIN, GRDLIN, HEADNG, QAPAGE, RLIBIN

VARYBL

Description: Calculated population and release data Used by: MAIN, APATHS, CASEIN, QAPAGE, WPATHS 
TABLE B.2. Common Block AIRCON

Symbol \& Dimension $\quad \frac{\text { Type }}{\text { EOQ }(10,16)} \quad \frac{\text { Definition/Values/Units }}{\text { Real }} \quad \begin{aligned} & \text { Normalized time-integrated air concentration } \\ & \text { for each spatial interval, sec/m (10 } \\ & \text { distances and } 16 \text { sectors). }\end{aligned}$

TABLE B.3. Common Block BIODAT

Symbol \& Dimension

Type

Definition/Values/Units

$\operatorname{BIOACF}(4,100)$

Rea 1

Bioaccumulation factors for each radionuclide for:

1. fish

2. crustacea

3. molluscs

4. water plants.

DWCF (100)

Real

Drinking water cleanup factors for edch radionuclide (the fraction passing through a water treatment $\mathrm{plant}$ ).

ISALT

Integer

Control integer for consideration of fresh or saltwater in bioaccumulation factors, ISALT $=\emptyset$, freshwater ISALT $=1$, sal twa ter.

IOSALT

Integer Value of ISALT for previous case; comparison with ISALT determines if different

bioaccumulation factors need to be read in.

TABLE B.4. Common Block DAY

Symbol \& Dimension Type Definition/Values/Units

DAIT

Char.

Eight characters name for day of year, MMDDYY:

$$
\begin{aligned}
& M M \text { - month } \\
& D D \text { - day } \\
& Y Y \text { - year. }
\end{aligned}
$$

CHIPAT

Char. Descriptive output for parameter IPATH.

CHIAC

Char. Descriptive output for parameter IAC. 


\section{TABLE B.5. Common Block DECAY}

\begin{tabular}{|c|c|c|}
\hline Symbol \& Dimension & Type & Definition/Values/Units \\
\hline NUC & Integer & $\begin{array}{l}\text { Number of radionuclides in the master } \\
\text { library, RMDLIB. } 1 \leq N U C \leq 300\end{array}$ \\
\hline $\mathrm{NCH}$ & Integer & $\begin{array}{l}\text { Number of decay chains in the master } \\
\text { library, RMDLIB. } 1 \leq \mathrm{NCH} \leq 200 \text {. }\end{array}$ \\
\hline NOFNUC (200) & Integer & $\begin{array}{l}\text { Number of radionuclides in each decay chain. } \\
1 \leq \text { NOFNUC }(i) \leq 9 \text {. When NOFNUC }(i)=1 \text {, the } \\
\text { radionuclide has no daughters. }\end{array}$ \\
\hline $\operatorname{NCHST}(200)$ & Integer & $\begin{array}{l}\text { Location in the master radionuclide list of } \\
\text { the first member of a radionuclide chain; } \\
1 \leq N C H S T(i) \leq 300 \text {. }\end{array}$ \\
\hline $\operatorname{IFR}(2,300)$ & Integer & $\begin{array}{l}\text { IFR }(1, i) \text { gives the chain member that is the } \\
\text { first precursor to radionuclide } i \text {. IFR }(2, i) \\
\text { gives the location of the second precursor. } \\
\operatorname{IFR}(1, i) \leq \operatorname{IFR}(2, i) \text {. }\end{array}$ \\
\hline $\operatorname{DKF}(2,300)$ & Integer & $\begin{array}{l}\text { Fraction of first and second precursor that } \\
\text { decay to this radionuclide. }\end{array}$ \\
\hline $\operatorname{AL}(300)$ & Integer & $\begin{array}{l}\text { Radiological decay_constant for each } \\
\text { radionuclide, year }\end{array}$ \\
\hline $\operatorname{NCHN}(300)$ & Integer & $\begin{array}{l}\text { Chain number of which each radionuclide is } \\
\text { d member. }\end{array}$ \\
\hline
\end{tabular}


TABLE B.6. Common Block DISPSN

\begin{tabular}{|c|c|c|}
\hline Symbol \& Dimension & Type & Definition/Values/Units \\
\hline NDIST & Integer & $\begin{array}{l}\text { Number of distances considered for defining } \\
\text { population and } E / Q, 1 \leq \text { NDIST } \leq 10 \text {. }\end{array}$ \\
\hline $\operatorname{DIST}(1 \emptyset)$ & Real & $\begin{array}{l}\text { Distance from the release point to the } \\
\text { center of each population ring, } x_{i}, m \text {. } \\
\text { NDIST values must be given in increasing } \\
\text { order. }\end{array}$ \\
\hline NUBAR & Integer & $\begin{array}{l}\text { Number of windspeed groups used for } \\
\text { definition of joint frequency data, } \\
1 \leq N U B A R \leq 8 \text {. }\end{array}$ \\
\hline $\operatorname{UBAR}(8)$ & Real & $\begin{array}{l}\text { Average wind speed for each energy group, } \\
\mathrm{m} / \mathrm{sec} \text {. }\end{array}$ \\
\hline NMET & Integer & $\begin{array}{l}\text { Number of atmospheric stability categories } \\
\text { for definition of joint frequency data, } \\
1 \leq \mathrm{NMET} \leq 7 \text {. }\end{array}$ \\
\hline \multirow[t]{2}{*}{$\operatorname{MET}(7)$} & Integer & $\begin{array}{l}\text { Atmospheric stability selection index. NMET } \\
\text { values must be given for MET. Valid values } \\
\text { are: }\end{array}$ \\
\hline & & $\begin{array}{l}1 \text { for Hanford very stable } \\
2 \text { for Hanford moderately stable } \\
3 \text { for Pasquill A } \\
4 \text { for Pasquill } \mathrm{B} \\
5 \text { for Pasquill } \mathrm{C} \\
6 \text { for Pasquill } \mathrm{D} \\
7 \text { for Pasquill } \mathrm{E} \\
8 \text { for Pasquill } \mathrm{F} .\end{array}$ \\
\hline$F(8,7,16)$ & Real & $\begin{array}{l}\text { Joint frequency of occurrence of atmospheric } \\
\text { conditions for up to } 8 \text { wind speeds, } 7 \\
\text { stabilities and } 16 \text { sectors, dimensionless. }\end{array}$ \\
\hline HS & Real & Height of the stack, meters. \\
\hline
\end{tabular}


TABLE B.7. Common Block DKAY

\begin{tabular}{|c|c|c|}
\hline Symbol \& Dimension & Type & Definition/Values/Units \\
\hline INUC & Integer & $\begin{array}{l}\text { Number of radionuclides in master list } \\
1 \leq \text { INUC } \leq 100 .\end{array}$ \\
\hline ICHN & Integer & $\begin{array}{l}\text { Number of decay chains in the master } 1 \text { ist } \\
1 \leq \text { ICHN } \leq 100 \text {. }\end{array}$ \\
\hline $\operatorname{NOFN}(100)$ & Integer & $\begin{array}{l}\text { Number of radionuclides in each chain. } \\
1 \leq \text { NOFN }(i) \leq 9 \text {. When NOFN }(i)=1 \text {, the } \\
\text { radionuclide has no daughters. }\end{array}$ \\
\hline $\operatorname{IFRM}(2,100)$ & Integer & $\begin{array}{l}\operatorname{IFRM}(1, i) \text { gives the chain member that is the } \\
\text { first precursor to radionuclide } i \text {. } \\
\operatorname{IFRM}(2, i) \text { gives the location of the second } \\
\text { precursor. IFRM }(1, i)>\operatorname{IFRM}(2, i) \text {. }\end{array}$ \\
\hline $\operatorname{DK}(2,100)$ & Integer & $\begin{array}{l}\text { Fraction of first and second precursor that } \\
\text { decay to this radionuclide; } 0.0 \leq \operatorname{DK}(i, j) \leq \\
1.0 \text {. }\end{array}$ \\
\hline $\operatorname{AR}(100)$ & Integer & $\begin{array}{l}\text { Radiological decay constant for each } \\
\text { radionuclide, years } 1 \text {. }\end{array}$ \\
\hline
\end{tabular}

TABLE B.8. Common Block DOSFAC

Symbol \& Dimension

Type

Definition/Values/Units

$\operatorname{DFH}(2,5,100)$

Real

Dose commitment factors for 2 dose periods for 5 organs for 100 nuclides, from INHALATION.

$\operatorname{DFG}(2,5,100)$

Rea 1

Dose commitment factors for 2 dose periods for 5 organs for 100 nuclides, from INGESTION.

$\star \star$ Both of these are based on continuous exposure at a constant level for 70 years and 1 year. In other words, for intakes of $1 \mathrm{Ci} / 70$ years. 
TABLE B.9. Common Block ECDN

\begin{tabular}{|c|c|c|}
\hline Symbol \& Dimension & Type & Definition/Values/Units \\
\hline $\operatorname{WATCON}(100)$ & Real & $\begin{array}{l}\text { Water concentrations of radionuclides, } \\
\text { weighted with decay constant and population, } \\
\text { person-C } i-y r \text {. }\end{array}$ \\
\hline $\operatorname{SCONW}(100)$ & Rea 1 & $\begin{array}{l}\text { Farm soil concentrations of radionuclides, } \\
\text { weighted with decay constant and population, } \\
\text { person-C } i-y r / k g \text {. }\end{array}$ \\
\hline $\operatorname{SEDCON}(100)$ & Rea 1 & $\begin{array}{l}\text { River sediment concentrations of } \\
\text { radionuclides, weighted with decay constant } \\
\text { and population, person-c } i-y r / m^{2} \text {. }\end{array}$ \\
\hline $\operatorname{EDBCNW}(7,100)$ & Rea 1 & $\begin{array}{l}\text { The concentration of radionuclides in the } \\
\text { edible portion of the terrestrial plants and } \\
\text { animals, weighted with decay constant and } \\
\text { population, person-Ci-yr/kg, from irrigation } \\
\text { deposition. }\end{array}$ \\
\hline AQUATC $(5,100)$ & Rea 1 & $\begin{array}{l}\text { The concentration of radionuclides in the } \\
\text { edible portion of the aquatic plants and } \\
\text { animals, weighted with decay constant and } \\
\text { population, person-Ci-yr/kg (or per liter } \\
\text { for } \mathrm{H}_{2} \mathrm{O} \text { ). }\end{array}$ \\
\hline $\operatorname{AIRCON}(100)$ & Rea 1 & $\begin{array}{l}\text { Atmospheric concentrations of radionuclides } \\
\text { from dispersion/diffusion (no resuspension) } \\
\text { weighted with decay constant and population, } \\
\text { person-Ci-yr/m. }\end{array}$ \\
\hline $\operatorname{SLCON}(100)$ & Rea 1 & $\begin{array}{l}\text { The concentration in farm soil of } \\
\text { radionuclides from atmospheric deposition, } \\
\text { weighted with decay constant and population, } \\
\text { person-Ci-yr } / \mathrm{kg} \text {. }\end{array}$ \\
\hline $\operatorname{EDBCON}(7,100)$ & Rea 1 & $\begin{array}{l}\text { The concentration of radionuclides in the } \\
\text { edible portion of terrestrial animals and } \\
\text { plants from atmospheric deposition, weighted } \\
\text { with decay constant and population, } \\
\text { person-Ci-yr } / \mathrm{kg} \text {. }\end{array}$ \\
\hline
\end{tabular}


TABLE B.10. Common Block FLAGS

Symbol \& Dimension

$\operatorname{INFLG(100)}$
Type

Integer Control integer to indicate which master

list radionuclides have dose factors supplied on input:

$\emptyset$ - no data given

1 - data supplied

TABLE B.11. Common Block FODATA

Symbol \& Dimension

DVEL(100)

CRATIO $(6,100)$

$A B(100)$

TABLE B.12. Common Block GRDDAT

Symbol \& Dimension

$\operatorname{EDS}(100)$

$\operatorname{EDW}(100)$

$\operatorname{EDA}(100)$
Type

Real

Rea 1

Definition/Values/Units

Deposition velocities, $\mathrm{m} / \mathrm{sec}$.

Concentration ratios for

1 - plants

2 - eggs

3 - milk

4 - beef

5 - port

6 - poultry.

Real Soil removal percolation constant, $\mathrm{yr}^{-1}$.
Type

Real

Real

Rea 1
Definition/Values/Units

External dose factor for exposure to contaminated soil, rem $/ \mathrm{hr}$ per $\mathrm{Ci} / \mathrm{m}^{2}$.

External dose factor for exposure tg contaminated water, rem/hr per $\mathrm{Ci} / \mathrm{m}^{3}$.

External dose factor for submersion in contaminated air, rem/sec per $\mathrm{Ci} / \mathrm{m}^{3}$. 
TABLE B.13. Common Block NAMES

\begin{tabular}{|c|c|c|}
\hline Symbol \& Dimension & Type & Definition/Values/Units \\
\hline $\operatorname{ELT}(300)$ & Char. & $\begin{array}{l}\text { Two-character element name for each } \\
\text { radionuclide in the master radionuclide data } \\
\text { library. }\end{array}$ \\
\hline $\operatorname{AW}(300)$ & Char. & $\begin{array}{l}\text { Six-character atomic weight symbol for each } \\
\text { radionuclide in the master radionuclide data } \\
\text { library. Isometric states are indicated by } \\
\text { the letter } M \text { after the atomic weight. } \\
\text { Daughter contributions are indicated by " }+D^{\prime \prime} \\
\text { after the atomic weight and " } M \text { " if present }\end{array}$ \\
\hline
\end{tabular}


TABLE B.14. Common Block NAMLST

\begin{tabular}{|c|c|c|}
\hline Symbol \& Dimension & Type & Definition/Values/Units \\
\hline IEOQ & Integer & $\begin{array}{l}\text { Control reading and calculation of } \\
\text { atmospheric dispersion data. }\end{array}$ \\
\hline IPA & Integer & $\begin{array}{l}\text { Control method of specification of } \\
\text { population dispersion factor. }\end{array}$ \\
\hline IPOPL & Integer & $\begin{array}{l}\text { Selects method for determining populations } \\
\text { for waterborne releases. }\end{array}$ \\
\hline IPL & Integer & $\begin{array}{l}\text { Control method of specification of } \\
\text { population data for acute water release. }\end{array}$ \\
\hline NSECT & Integer & Number of sectors considered. \\
\hline PMA & Rea 1 & $\begin{array}{l}\text { Population dispersion factor for acute } \\
\text { airborne release. }\end{array}$ \\
\hline PPL & Real & $\begin{array}{l}\text { Total population for acute waterborne } \\
\text { release. }\end{array}$ \\
\hline NTA & Integer & $\begin{array}{l}\text { No. of time population data supplied in PMI, } \\
\text { POPT, and T. }\end{array}$ \\
\hline $\mathrm{T}(20)$ & Real & $\begin{array}{l}\text { Times at which population data supplied, } \\
\text { airborne, years A.D. }\end{array}$ \\
\hline $\mathrm{TL}(20)$ & Rea 1 & $\begin{array}{l}\text { Times at which population data supplied, } \\
\text { waterborne, years A.D. }\end{array}$ \\
\hline $\operatorname{PM1}(20)$ & Rea 1 & Population dispersion factor, airborne. \\
\hline POPT (20) & Real & $\begin{array}{l}\text { Total population, airborne release at each } \\
\text { time in } T \text {. }\end{array}$ \\
\hline $\operatorname{PL} 1(20)$ & Rea 1 & $\begin{array}{l}\text { Total population, water release, for each } \\
\text { time in TL. }\end{array}$ \\
\hline NTL & Integer & $\begin{array}{l}\text { Number of times population data supplied } \\
\text { in PLl and TL. }\end{array}$ \\
\hline
\end{tabular}


TABLE B.15. Common BTock NUCNAM

Symbol \& Dimension

NUCS

$\operatorname{AWM}(100)$

$\operatorname{ELTM}(100)$
Type

Integer Number of radionuclides in the master 1 ist.

Char. Six-character atomic weight symbol for each radionuclide in the master list.

Char. Two-character element name for each radionuclide in the master list. 
TABLE B.16. Common Block OPTION

Symbol \& Dimension

IPOP

IPATH

IAC

IWAT

IAIR
Type

Integer

This control integer selects the method for determining population dispersion factors for airborne releases as follows:

IPOP $\leq \emptyset$; use previous values.

IPOP $=1$; supply all 144 values in array PM.

IPOP $=2$; read population data for the first

time, $T(1)$, and calculate PM.

IPOP $=3$; read population data for each time from file 22 and calculate PM for each time.

IPOP $=4$; supply population dispersion factors in array PM1 at times $T$ and interpolate this data to generate PM values for each $70-y$ r increment.

IPOP $=5$; Use previous population distribution data but recalculate the fist time value for PM using new $E / Q$ data.

Default is IPOP $=4$.

Integer This parameter selects pathways to be considered as follows:

IPATH $\leq \emptyset$; airborne and waterborne.

IPATH $=1$; airborne onty.

IPATH $\geq 2$; waterborne only.

Integer If IAC $>\emptyset$, consider an acute release period at the beginning of the first 70-yr period.

Integer Control integer set positive if waterborne release activity data are to be read.

Integer Control integer set positive if airborne release activity data are to be read. 
TABLE B.16. (contd)

Symbol \& Dimension

LUA

LUW

IGRPOP

IGRPM

IGRPL

IGRTNU

IGRNUC
Type

Integer

Integer

Integer

Integer

Integer

Integer

nteger
Definition/Values/Units

Control integer to select logical unit device for reading of airborne release activity data:

LUA $=1$; use card input unit 5

LUA $\neq 1$; use library file unit 26.

Control integer to select logical unit device for reading of waterborne release activity data:

LUW $=1$; use card input unit 5

LUW $\neq 1$; use library file unit 24.

Control integer set to one if graph of population distribution desired in input report. If zero, an abbreviated numeric report is printed. Default: IGRPOP $=\emptyset$.

Control integer set to one to print graph of population dispersion factor, airborne pathways, in input report. Default IGRPM = $\emptyset$.

Control integer set to one if graph of population disperson factor, waterborne pathways, is selected for input report. Default: IGRPL $=\emptyset$.

Control integer to set to one if graph of total release of all radionuclides is desired in input report. Separate graphs will be printed for airborne and waterborne pathways depending on the values of IAIR and IWAT. Default: IGRTNU $=\emptyset$.

Control integer set to one if graph of release of each radionuclide is to be included in the input report. Separate graphs will be printed for airborne and waterborne pathways depending on the values of IAIR and IWAT. If zero, a numeric report is printed. Default: IGRNUC $=\emptyset$. 
TABLE B.16. (contd)

Symbol \& Dimension IGRDOS

ISPEC

IORG(10)

NORG

KORG(5)

$\operatorname{MORG}(5)$

ORGT(6)

ONAME (10)

Symbol \& Dimension

LORG

ONAME (10)

Dinension

ORG(6)

Integer

TABLE B.17. Common Block ORGID

Type

Definition/Values/Units

Integer Number of organs for which data is supplied in the inhalation and ingestion dose factor library DSFCT. $1 \leq$ LORG $\leq 10$.

Integer Organ index values for which data is supplied in the inhalation and ingestion dose factor library DSFCT. $1 \leq \operatorname{IORG}(i) \leq$ 23.

Integer Number of organs for which doses are to be calculated. $1 \leq N O R G \leq 5$.

Integer Organ index values for which doses are to be calculated. The index values must be taken from values in index array IORG from the inhalation and ingestion library DSFCT.

organs. This array is set in subroutine ORGCHK.

Char. Ten-character organ names for output. Extra array position used for specialty option heading.

Char. Ten-character organ names for data in library DSFCT.

TABLE B.18. Common Block OUTORG

Symbol \& Dimension Type

$\operatorname{DTOTAL}(5,144)$
Definition/Values/Units

Rea 1
Total dose to each organ as a function of time. 
TABLE B.19. Common Block PATHIN

\begin{tabular}{|c|c|c|}
\hline Symbol \& Dimension & Type & Definition/Values/Units \\
\hline \multirow[t]{2}{*}{ CONSUM $(7)$} & Real & $\begin{array}{l}\text { Consumption rates, } \mathrm{kg} / \mathrm{yr} \text {, for terrestrial } \\
\text { paths: }\end{array}$ \\
\hline & & $\begin{array}{l}\text { 1. leafy vegetables } \\
\text { 2. other vegetables } \\
\text { 3. eggs } \\
\text { 4. milk } \\
\text { 5. beef } \\
\text { 6. pork } \\
\text { 7. poultry. }\end{array}$ \\
\hline \multirow[t]{2}{*}{ USAGE(7) } & Real & $\begin{array}{l}\text { Consumption of exposure rates for aquatic } \\
\text { paths }\end{array}$ \\
\hline & & $\begin{array}{l}\text { 1. fish, } \mathrm{kg} / \mathrm{yr} \\
\text { 2. crustaceans, } \mathrm{kg} / \mathrm{yr} \\
\text { 3. molluscs, } \mathrm{kg} / \mathrm{yr} \\
\text { 4. plants, } \mathrm{kg} / \mathrm{yr} \\
\text { 5. drinking water, } \mathrm{L} / \mathrm{yr} \\
\text { 6. shoreline exposure, } \mathrm{hr} / \mathrm{yr} \\
\text { 7. swimming, } \mathrm{hr} / \mathrm{yr} \text {. }\end{array}$ \\
\hline EXTIM & Real & $\begin{array}{l}\text { Hours/year exposure time to contaminated } \\
\text { soil. }\end{array}$ \\
\hline SW & Real & $\begin{array}{l}\text { Shore width factor for shoreline } \\
\text { calculations. }\end{array}$ \\
\hline $\operatorname{GRWP}(7)$ & Real & $\begin{array}{l}\text { Growing periods (time above ground) for the } \\
\text { drops or forage for the seven pathways } \\
\text { associated with coNSUM. }\end{array}$ \\
\hline YELD (7) & Real & $\begin{array}{l}\text { The crop yield, } \mathrm{kg} / \mathrm{m}^{2} \text {, for the crops or } \\
\text { forage associated with the seven CONSUM } \\
\text { pathways. }\end{array}$ \\
\hline MOPYR & Integer & $\begin{array}{l}\text { The number of months per year irrigation } \\
\text { occurs. }\end{array}$ \\
\hline RECON & Real & $\begin{array}{l}\text { Reconcentration ratio for water } \\
\text { concentration calculation. }\end{array}$ \\
\hline RM & Real & $\begin{array}{l}\text { Mixing ratio for water concentration } \\
\text { calculation. }\end{array}$ \\
\hline
\end{tabular}


TABLE B.19. (contd)

$\begin{array}{lll}\text { Symbol \& Dimension } & \text { Type } & \frac{\text { Definition/Values/Units }}{\text { CFLO }} \\ \text { Real } & \begin{array}{l}\text { River flow rate, } \mathrm{ft}^{3} / \mathrm{sec}, \text { for water } \\ \text { concentration calculation. }\end{array} \\ \text { RIRR } & \text { Real } & \text { Irrigation rate, } \mathrm{L} / \mathrm{m}^{2} / \mathrm{month} .\end{array}$

TABLE B.20. Common Block PLOT

Symbol \& Dimension Type

Definition/Values/Units

$\operatorname{ARRAY}(40,73)$

Char.

Storage array for graph.

$\operatorname{LABEL} Y(40)$

Char. Storage array for the selected Y-axis label.

LABELX

Char. X-axis label.

$\operatorname{TICKY}(40)$

Char. Array of Y-axis tick marks.

$\operatorname{TICKX}(73)$

Char.

Array of X-axis tick marks.

$\operatorname{LEGEND}(40)$

Char.

Array for radionuclide names for IGRTNU option.

TABLE B.21. Common Block POPU

Symbol \& Dimension Type Definition/Values/Units

$\operatorname{POP}(10,16)$

Rea 1

Population within each spatial interval for 10 distances and 16 direction sections, $P_{i j}$, persons.

TABLE B.22. Common Block RESULT

Symbol \& Dimension Type

Definition/Values/Units

$\operatorname{POPDOS}(5,100)$

Real

The population weighted integrated dose to 5 organs for 100 radionuclides.

MAXTIM

Integer The dose integral period (70-yr period) during which the maximum dose rate occurs.

$\operatorname{HIDOSE}(5,100)$

Real

The 70-yr dose increment larger than any other, for each of five organs; associated with MAXTIM. 
TABLE B.23. Common Block SOURCE

\begin{tabular}{|c|c|c|}
\hline Symbol \& Dimension & Type & Definition/Values/Units \\
\hline NIN & Integer & $\begin{array}{l}\text { Number of radionuclides in the input } \\
\text { inventory, } 1 \leq N I N \leq N U C \text {. }\end{array}$ \\
\hline$E(100)$ & Char. & $\begin{array}{l}\text { Two-character names for input radionuclides; } \\
\text { spelling must be identical to master } \\
\text { radionuclides list. }\end{array}$ \\
\hline$A(100)$ & Char. & $\begin{array}{l}\text { Six-character atomic weight symbol for each } \\
\text { input radionuclide. Spelling must } \\
\text { correspond to the master list spelling. }\end{array}$ \\
\hline
\end{tabular}

TABLE B.24. Common Block TIMES

\begin{tabular}{lll} 
Symbol \& Dimension & \multicolumn{1}{c}{ Type } & \multicolumn{1}{c}{ Definition/Values/Units } \\
TZ & Real & $\begin{array}{l}\text { Time (years A.D.) at beginning of 10,000-yr } \\
\text { integration period. } \\
\text { TZR }\end{array}$ \\
A.Dinning of the release history data, years \\
TABLE B.25. Common Block TITLES
\end{tabular}


TABLE B.26. Common Block VARYBL

\begin{tabular}{|c|c|c|}
\hline Symbol \& Dimension & Type & Definition/Values/Units \\
\hline $\mathrm{PM}(144)$ & Rea 1 & $\begin{array}{l}\text { Population dispersion factor, person-sec/m }{ }^{3} \text {, } \\
\text { for airborne releases for each time period. } \\
\text { This is an effective population-weighted } \\
\text { E/Q'. }\end{array}$ \\
\hline PL (144) & Real & $\begin{array}{l}\text { The total population for each time period, } \\
\text { used in waterborne calculations. }\end{array}$ \\
\hline $\operatorname{ACTA}(144,100)$ & Rea 1 & $\begin{array}{l}\text { Activity released to air for each time } \\
\text { increment for up to } 100 \text { radionuclides. } \\
\text { Units are total curies released in each } \\
\text { period to air. }\end{array}$ \\
\hline ACTW $(144,100)$ & Rea 1 & $\begin{array}{l}\text { Activity released to water for each time } \\
\text { increment for up to } 100 \text { radionuclides. } \\
\text { Units are total curies released in each } \\
\text { period to water. }\end{array}$ \\
\hline
\end{tabular}


TABLE B.27. DITTY Variables Contained in Common Blocks

\begin{tabular}{|c|c|c|c|}
\hline Variable & Common & Variable & Common \\
\hline$A(100)$ & SOURCE & IAC & OPTION \\
\hline$A B(100)$ & FODATA & IAIR & OPTION \\
\hline ACTA $(144,100)$ & VARBYL & IBEGA (100) & BEGEND \\
\hline ACTW $(144,100)$ & VARBYL & IBEGW (100) & BEGEND \\
\hline AIRCON (100) & EDCN & ICHN & DKAY \\
\hline $\mathrm{AL}(300)$ & DECAY & IDFTTL (20) & TITLES \\
\hline AQUATC $(5,100)$ & EDCN & IENDA (100) & BEGEND \\
\hline AR $(100)$ & DKAY & IENDW (100) & BEGEND \\
\hline ARDTTL (20) & TITLES & IEOQ & NAMLST \\
\hline ARRAY $(40,73)$ & PLOT & IFR $(2,300)$ & DECAY \\
\hline AW $(300)$ & NAMES & IFRM $(2,100)$ & DKAY \\
\hline AWM (100) & NUCNAM & IGRDOS & OPTION \\
\hline BIOACF $(4,100)$ & BIODAT & IGRNUC & OPTION \\
\hline BIOTTL $(40)$ & TITLES & IGRPL & OPTION \\
\hline CASTTL (20) & TITLES & IGRPM & OPTION \\
\hline CFLO & PATHIN & IGRPOP & OPTION \\
\hline CHIAC & DAY & IGRTNU & OPTION \\
\hline CHIPAT & DAY & INFLG (100) & EDCN \\
\hline CONSUM (7) & PATHIN & INUC & DKAY \\
\hline CRATIO $(6,100)$ & FODATA & IORG (10) & ORGID \\
\hline DAIT & DAY & IOSALT & BIODAT \\
\hline $\operatorname{DFG}(2,5,100)$ & DOSFAC & IPA & NAMLST \\
\hline DFH $(2,5,100)$ & DOSFAC & IPATH & OPTION \\
\hline DIST (10) & DISPSN & IPL & NAMLST \\
\hline DK $(2,100)$ & DKAY & IPOP & OPTION \\
\hline $\operatorname{DKF}(2,300)$ & DECAY & IPOPL & NAMLST \\
\hline $\operatorname{DOSINC}(5,100)$ & DOSIN & ISALT & BIODAT \\
\hline DTOTAL $(5,144)$ & OUTORG & ISPEC & OPTION \\
\hline DVEL $(100)$ & FODATA & IWAT & OPTION \\
\hline DWCF (100) & BIODAT & KORG (5) & ORGID \\
\hline$E(100)$ & SOURCE & LABELX & PLOT \\
\hline $\operatorname{EDA}(100)$ & GRDDAT & LABELY (40) & PLOT \\
\hline $\operatorname{EDBCON}(7,100)$ & EDCN & LEGEND $(40)$ & PLOT \\
\hline $\operatorname{EDBCNW}(7,100)$ & EDCN & LORG & OPTION \\
\hline EDS $(100)$ & GRDDAT & LUA & OPTION \\
\hline EDW (100) & GRDDAT & LUW & OPTION \\
\hline ELT $(300)$ & NAMES & MAXIM & RESULT \\
\hline ELTM (100) & NUCNAM & MET (7) & DISPSN \\
\hline EOQ $(10,16)$ & AIRCON & MORG (23) & ORGID \\
\hline EXTIM & PATHIN & MOPYR & PATHIN \\
\hline$F(8,7,16)$ & DISPSN & $\mathrm{NCH}$ & DECAY \\
\hline FIRTTL $(60)$ & TITLES & NCHN (300) & DECAY \\
\hline GRDTTL (20) & TITLES & NCHST $(200)$ & DECAY \\
\hline GRWP (7) & PATHIN & NDIST & DISPSN \\
\hline HIDOSE $(5,100)$ & RESULT & NIN & SOURCE \\
\hline HS & DISPSN & NMET & DISPSN \\
\hline
\end{tabular}


TABLE B.27. (contd)

\begin{tabular}{|c|c|}
\hline Variable & Common \\
\hline $\begin{array}{l}\text { NOFN }(100) \\
\text { NOFNUC }(200) \\
\text { NORG } \\
\text { NSECT } \\
\text { NTA } \\
\text { NTL } \\
\text { NUBAR } \\
\text { NUC } \\
\text { NUCS } \\
\text { ORGT (5) } \\
\text { ONAME (10) } \\
\text { PL (144) } \\
\text { PL1 (20) } \\
\text { PM (144) } \\
\text { PM1 (20) } \\
\text { PMA } \\
\text { PODTTL (20) } \\
\text { POP (10,16) } \\
\text { POPDOS (5,100) } \\
\text { POPT }(20) \\
\text { PPL } \\
\text { RECON } \\
\text { RIRR } \\
\text { RM } \\
\text { RMDTTL (20) } \\
\text { SCONW (100) } \\
\text { SEDCON (100) } \\
\text { SLCON }(100) \\
\text { SW } \\
\text { T (20) } \\
\text { TICKX (73) } \\
\text { TICKY (40) } \\
\text { TL (20) } \\
\text { TZ } \\
\text { TZR } \\
\text { UBAR (8) } \\
\text { USAGE (7) } \\
\text { WATCON (100) } \\
\text { WRDTTL (20) } \\
\text { YELD (7) }\end{array}$ & $\begin{array}{l}\text { DKAY } \\
\text { DECAY } \\
\text { ORGID } \\
\text { NAMLST } \\
\text { NAMLST } \\
\text { NAMLST } \\
\text { DISPSN } \\
\text { DECAY } \\
\text { NUCNAM } \\
\text { ORGID } \\
\text { ORGID } \\
\text { VARYYL } \\
\text { NAMLST } \\
\text { VARBYL } \\
\text { NAMLST } \\
\text { NAMLST } \\
\text { TITLES } \\
\text { POPU } \\
\text { RESULT } \\
\text { NAMLST } \\
\text { NAMLST } \\
\text { PATHIN } \\
\text { PATHIN } \\
\text { PATHIN } \\
\text { TITLES } \\
\text { EDCN } \\
\text { EDCN } \\
\text { EDCN } \\
\text { PATHIN } \\
\text { NAMLST } \\
\text { PLOT } \\
\text { PLOT } \\
\text { NAMLST } \\
\text { TIMES } \\
\text { TIMES } \\
\text { DISPSN } \\
\text { PATHIN } \\
\text { EDCN } \\
\text { TITLES } \\
\text { PATHIN }\end{array}$ \\
\hline
\end{tabular}


APPENDIX C

DATA FILES 
Several data files are needed to execute DITTY. Additionally, some site-specific and case-specific data can be accessed from libraries as opposed to being input in the data stream.

Libraries are assigned logical unit numbers by the DITTY code. It is necessary to associate that number with the appropriate file prior to executing the code. Files that must always be attached to the run are:

\begin{tabular}{|c|c|c|c|}
\hline $\begin{array}{l}\text { Logical } \\
\text { Unit No. }\end{array}$ & Library Name & Description & $\begin{array}{l}\text { Reference } \\
\text { Subroutine }\end{array}$ \\
\hline 10 & RMDL IB & Master radionuclide library & RLIBIN \\
\hline 12 & FTRANSL IB & $\begin{array}{l}\text { Food transfer coefficient } \\
\text { library }\end{array}$ & FOOLIN \\
\hline 14 & BIOAC & Bioaccumulation factor library & BIOLIN \\
\hline 16 & GRDFLIB & External exposure factors & GRDL IN \\
\hline 18 & DSFCT & $\begin{array}{l}\text { Internal dose conversions } \\
\text { factors }\end{array}$ & AIRLIN \\
\hline
\end{tabular}

Files which may be utilized based on the value of a namelist input parameter are:

Logical Namelist Variable Unit No.

22

24

26 and Value $I P O P=3$

$\mathrm{LUW}=1$

LUA $=1$
Description

Population data for specified times

Release data for aquatic pathways

Release data for atmospheric pathways
Reference

Subroutine

CASEIN

ACTIN

ACTIN

The data in the files is set up such that additional data or changes to existing data may be made with little difficulty. 
RADIONUCLIDE MASTER DATA FILE - RMDLIB (LOGICAL UNIT NO. 10)

The radionuclide master data file (RMDLIB) contains all radiological decay data used by DITTY. The file is organized into two sections. The first section contains radionuclides which are not members of decay chains, and also radionuclides singled out from chains with the " $D$ " (plus daughters) designation. Radionuclides in the first section are arranged by increasing atomic number. The second section of the file contains radionuclides organized into decay chains, ordered under the radionuclides highest in the chain. RMDLIB contains about 280 entries.

The first record of the file contains 80 characters of descriptive information used as identification in the input data report printed by subroutine QAPAGE. The remainder of the data records have the following information in the listed order:

1. alphabetic element symbol

2. atomic weight, also metastable, "M", and/or daughter, " $+D$ ", designation

3. radiological half-life, days

4. relative position in decay chain

5. precursor in decay chain

6. branching ratio from primary percursor

7. alternate precursor in decay chain

8. branching ratio from alternate precursor.

The RMDLIB FORTRAN format is (A2, A6, E10.2, 2I2, F7.4, I2, F7.4). Parameter No. 4 is also used to signal the end of the data file $(\leq 0)$.

FOOD TRANSFER COEFFICIENT FILE--FTRANSL IB (LOGICAL UNIT NO. 12)

The FTRANSLIB contains factors used by DITTY in relating concentrations of elements in soil to concentrations in farm products produced on that soil, and relating concentrations in animal feed to concentrations in animal products. The file has entries for 63 elements arranged by increasing atomic number compatible with the order of RMDLIB.

The first record of FTRNSLIB is an 80-character title used for identification and printed in the subroutine. QAPAGE. Subsequent records contain information for each element in the following order: 
1. element name

2. deposition velocity, $\mathrm{m} / \mathrm{sec}$

3. soil/food concentration ratio, dimensionless

4. egg concentration radio, day $/ \mathrm{kg}$

5. milk concentration ratio, day/L

6. beef concentration ratio, day $/ \mathrm{kg}$

7. pork concentration ratio, day $/ \mathrm{kg}$

8. poultry concentration ratio, day/kg

9. percolation constant, $\mathrm{yr}^{-1}$.

The FTRANSLIB FORTRAN format is (A2, 8E9.2). Reading of the file is terminated normally when the end-of-file is encountered.

AQUATIC BIOACCUMULATION FACTOR FILE--BIOAC (LOGICAL UNIT NO. 14)

This bioaccumulation factor file contains the aquatic pathway factors used by DITTY relating the concentration of nuclides in aquatic biota to the concentration of the nuclides in the water. There are separate factors for fresh and salt water. Also included is a factor for the clean-up of drinking water in water treatment plants. Units for all bioaccumulation factors and $\mathrm{pCi} / \mathrm{kg}$ per $\mathrm{pCi} / \mathrm{L}$.

The file is organized as:

1. element name

2. bioaccumulation factor for in salt water

3. bioaccumulation factor for crustacea in salt water

4. bioaccumulation factor for molluscs in salt water

5. bioaccumulation factor for water plants in salt water

6. bioaccumulation factor for fish in fresh water

7. bioaccumulation factor for crustacea in fresh water

8. bioaccumulation factor for molluscs in fresh water

9. bioaccumulation factor for water plants in fresh water

10. drinking water cleanup factor (the fraction passing through a water treatment facility).

The BIOAC FORTRAN format is: (A2, 8F9.1, F6.1). The namelist input parameter ISALT determines if the salt- or fresh-water factors are used. Default is zero for fresh water. 
The first record of the file is an 80-character descriptive title used for identification and printed in the input report by the subroutine OAPAGE, the file contains entries for 63 elements. Reading of BIOAC terminates normaliy when the end-of-file is encountered.

EXTERNAL DOSE FACTOR FILE--GRDL IB (LOGICAL UNIT NO. 16)

GRDLIB contains data on the dose rate factors for exposure to soi1, water, and air. Factors for total body dose are read in and used by DITTY as an estimate of the dose to all internal organs. The information in GRDLIB used by DITTY is as follows:

1. element name

2. atomic weight, $+D$, and/or metastable designations

3. external dose factor from soil exposure, $\mathrm{mrem} / \mathrm{hr}$ per $\mathrm{pCi} / \mathrm{m}^{2}$

4. external dose factor from swimming, $\mathrm{mrem} / \mathrm{hr}$ per $\mathrm{pCi} / \mathrm{cm}^{3}$

5. external dose factor from air submersion, $\mathrm{mrem} / \mathrm{hr}$ per $\mathrm{pCi} / \mathrm{m}^{3}$.

The GRDLIB FORTRAN format is: (A2, A6, 9X, E9.2, 9X, 2E9.2).

The first record in the file is an 80-character descriptive title used for identification and printed in the input report. Reading of the file terminates normally when the end-of-file is encountered. The GRDLIB file also contains dose factors for skin, which are not used by current versions of DITTY.

INTERNAL DOSE FACTOR FILE--DSFCT (LOGICAL UNIT NO. 18)

The DSFCT file contains dose commitment factors for inhalation and ingestion of 59 radionuclides for up to 10 organs for dose periods of 1 and 70 years.

The first record of the file contains the number of organs for which data is supplied ( 1 to 10) and the organ index values of those organs ( 1 to 23). Organs for which data are presently available in DSFCT and their indices are:

$\begin{array}{cl}\frac{\text { Organ Index }}{1} & \text { Organ Name } \\ 3 & \text { Total Body } \\ 4 & \text { Kidney } \\ & \text { Liver }\end{array}$




\begin{tabular}{cll} 
Organ Index & & Organ Name \\
\cline { 1 - 1 } 6 & & Bone \\
8 & & Lungs \\
16 & Thyroid \\
23 & LLI
\end{tabular}

The FORTRAN format for the first record is: (5X, I5, 10X, 10I3).

The second record in DSFCT is an 80-character descriptive title used for identification and is printed by the subroutine QAPAGE in the input report.

The third record of the file contains the organ names of the selected organs as listed above. The FORTRAN format for this record is: (10A8).

For each radionuclide there is a header record and a variable number of detail records containing the dose factors.

The header record for each radionuclide contains the following information:

1. element symbol

2. atomic weight symbol including metastable " $M$ " and/or " $D$ " designation

3. the number of organs for which inhalation and ingestion dose commitment factors will be given, parameter $L O$.

The FORTRAN format for this record is: (A2, A6, I2).

There will be LO detail records for each radionuclide. Each record will contain the following data:

1. index of organ for which data is supplied

2. dose commitment factor from inhalation for $1 \mathrm{yr}, \mathrm{Ci} / \mathrm{yr}$

3. dose commitment factor from inhalation for $70 \mathrm{yr}, \mathrm{Ci} / 70 \mathrm{yr}$

4. dose commitment factor from ingestion for $1 \mathrm{yr}, \mathrm{Ci} / \mathrm{yr}$

5. dose commitment factor from ingestion for $70 \mathrm{yr}, \mathrm{Ci} / 70 \mathrm{yr}$

The FORTRAN format for the detail records is: (I2, 8X, 4E10.1).

Reading of the file is terminated when the value read for the parameter LO (header record) equals zero. 
POPULATION DISTRIBUTION DATA FILE (LOGICAL UNIT NO. 22)

When the NAMELIST input parameter IPOP is set equal to three, population distribution data will be read from the file assigned to logical unit no. 22.

The first record in the file is an 80-character descriptive title which is used for identification and is printed in the input report.

Each set of population distribution data contains a header record specifying the date followed by 16 sector records.

The header record contains the date in years A.D. that the following population distribution has been projected for. The FORTRAN format for this record is (E10.2).

Following each header record are 16 detail records. Each record corresponds to a $22-1 / 2^{\circ}$ site-grid sector. Care should be taken to ensure that population site-grid sectors correspond to the sectors used in specifying the meteorological data. Each sector record will have NDIST population values. NDIST is the number of distances considered and is a NAMELIST input parameter. The FORTRAN format is (10E8.1).

When population data is read from logical unit 22 , the NAMELIST input parameter NTA must be set equal to the number of population data sets. Reading of the file will terminate when:

1. 20 population data sets have been read, or

2. the time of the population distribution data is beyond the time period considered in this case, or

3. NTA data sets have been read.

\section{AIRBORNE ACT IVITY RELEASE HISTORY FILE (LOGICAL UNIT NO. 26)}

If the NAMELIST parameter LUA is not equal to one, the airborne release activity will be read from the file assigned to logical unit 26 .

The first record of the file is an 80-character descriptive title, used for identification. 
The second record in the file is the number of radionuclides data are supplied for in the file. This parameter (NNACT) controls reading of the file. The FORTRAN format for this record is: (I5). $1 \leq$ NNACT $\leq 100$.

There are NNACT data sets in the library. Each data set consists of a header record and a series of detail records with times and corresponding concentrations.

The header record contains the following information:

1. element symbol

2. atomic weight, also metastable and/or " $D$ " designator

3. number of times activity release data are supplied for, (NT) $1 \leq N T \leq 450$.

The FORTRAN format for the header record is: (A2, A6, 2X, I5).

There will be NT detail records in each data set. Each record contains the following data:

1. time since the beginning of the release history as number of years since TZR (NAMELIST input parameter)

2. curies of activity released.

The FORTRAN format for the detail record is: (2E10.2).

WATERBORNE ACTIVITY RELEASE HISTORY FILE (LOGICAL UNIT NO. 24)

When the parameter LUW (specified in NAMELIST) is not equal to one, waterborne release activity will be read from the file assigned to logical unit no. 24.

Reading of this file is identical to that of the airborne release file assigned to logical unit no. 26. For information, refer to the preceding section. 



\section{APPENDIX D}

PROGRAM AND DATA FILE LISTINGS 


\section{APPENDIX D \\ PROGRAM AND DATA FILE LISTINGS}

This appendix contains listings of each module for the computer program DITTY plus listings of the five required data files (RMDLIB, FTRANSLIB, BIOAC, GRDFLIB and DSFCT). The program listing (Figure D.1) starts with the main program module (MAIN), followed by the remaining modules in alphabetical order. The comnon blocks are then listed in alphabetical order. Usage of common blocks is indicated in each module by INCLUDE statements. The data file listings are given in Figures D.2 (RMDLIB), D.3 (FTRANSLIB), D.4 (BIOAC), D.5 (GRDFLIB), and D.6 (DSFCT). 


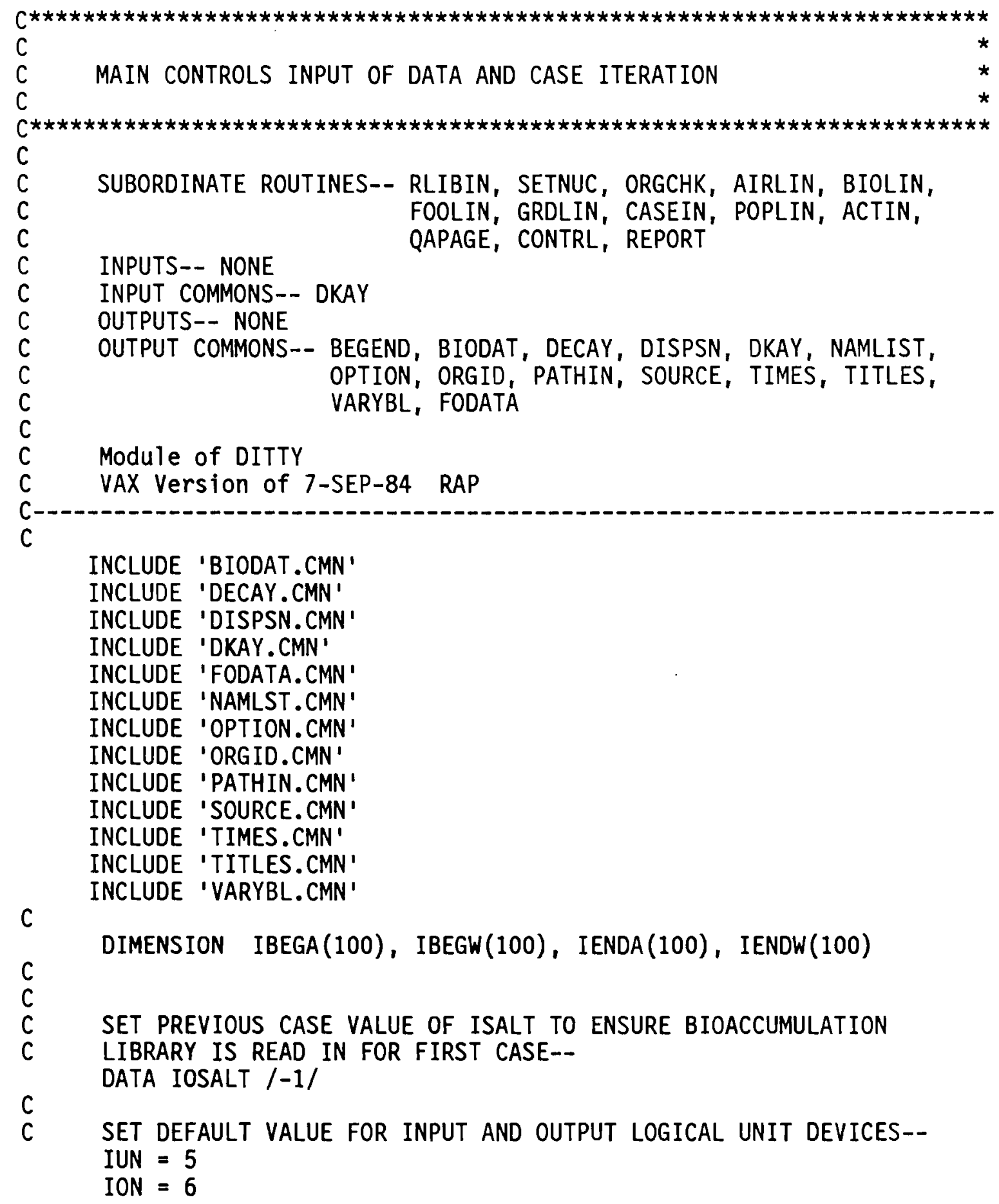

FIGURE D.1. DITTY Program Listing

D.2 
Module Main

C

SET NAMELIST DEFAULT VALUES--

DATA IAC $/ 0 /$

DATA IAIR $/ 0 /$

DATA IWAT $/ 0 /$

DATA LUA /1/

DATA LUW /1/

DATA ISALT $/ 0 /$

C

DATA ISPEC $/ 0 /$

C

DATA TZ /2000./

DATA TZR /2000./

DATA NDIST $/ 0 /$

C

DATA NSECT /16/

DATA IEOQ /0/

DATA HS $/ 0.1$

DATA NMET $/ 0 /$

DATA NUBAR /0/

DATA MET $/ 7 * 0 /$

C

DATA UBAR $/ 8$ * 0.1

DATA IPA /1/

DATA IPL $/ 1 /$

DATA IPOP /4/

DATA IPOPL /2/

DATA NTA $/ 1 /$

DATA NTL $/ 1 /$

DATA PL $/ 144 * 0 . /$

DATA PL1 $/ 20 * 0 . /$

DATA PMA $/ 0.1$

DATA PPL $/ 0.1$

DATA TL $/ 20 * 0.1$

C

DATA POPT $/ 20 * 0 . /$

DATA RECON /1.0/

DATA RM $/ 1.0 /$

C

DATA IGRPOP /O/

DATA IGRPM $/ 0 /$

DATA IGRPL $/ 0 /$

DATA IGRTNU $/ 0 /$

DATA IGRNUC $/ 0 /$

DATA IGRDOS $/ 0 /$

EIGURE 0.1. DITTY Program Listing (continued)

D.3 
Module Main

C

CALL RLIBIN

C TO READ MASTER RADIONUCLIDE DATA LIBRARY RMDLIB.

C

C READ FIRST CASE TITLE RECORD--

READ（IUN, 1000, ERR $=800, E N D=900$ ) CASTTL

C READ MASTER RADIONUCLIDE NAME LIST--

C

C READ NUMBER OF RADIONUCLIDES - RECORD TYPE 2

READ (IUN, 2000, ERR $=800, E N D=900)$ NIN

C

C READ NAMES OF RADIONUCLIDES - RECORD TYPE 3

C

READ (IUN, 3000, ERR $=800, E N D=900)(E(I), A(I), I=1, N I N)$

C READ ORGAN SELECTION DATA--

READ (IUN, 4000, ERR $=800, E N D=900)$ NORG

READ (IUN, 5000, ERR $=800, E N D=900) \quad(K O R G(I), I=1, N O R G)$

C

$\mathrm{C}$

C

C

CALL SETNUC

C TO ESTABLISH MASTER RADIONUCLIDE LIST FOR THIS RUN.

C

C

CALL ORGCHK

C TO TEST INPUT ORGAN SELECTION DATA.

C

C

\section{CALL AIRLIN}

C TO READ AIR SUBMERSION/INHALATION AND INGESTION DOSE FACTORS.

C

CALL FOOLIN

C TO READ FOOD TRANSFER FACTOR DATA.

C

$\mathrm{C}$

\section{CALL GRDLIN}

C TO READ GROUND AND WATER EXTERNAL EXPOSURE FACTORS.

C

C

C SET AB TO SUM OF RADIOLOGICAL AND NON-RAD REMOVAL CONSTANTS DO $456 I=1$, INUC $A B(I)=A B(I)+A R(I)$

EIGURE D.1. DITTY Program Listing (continued) 
Module Main

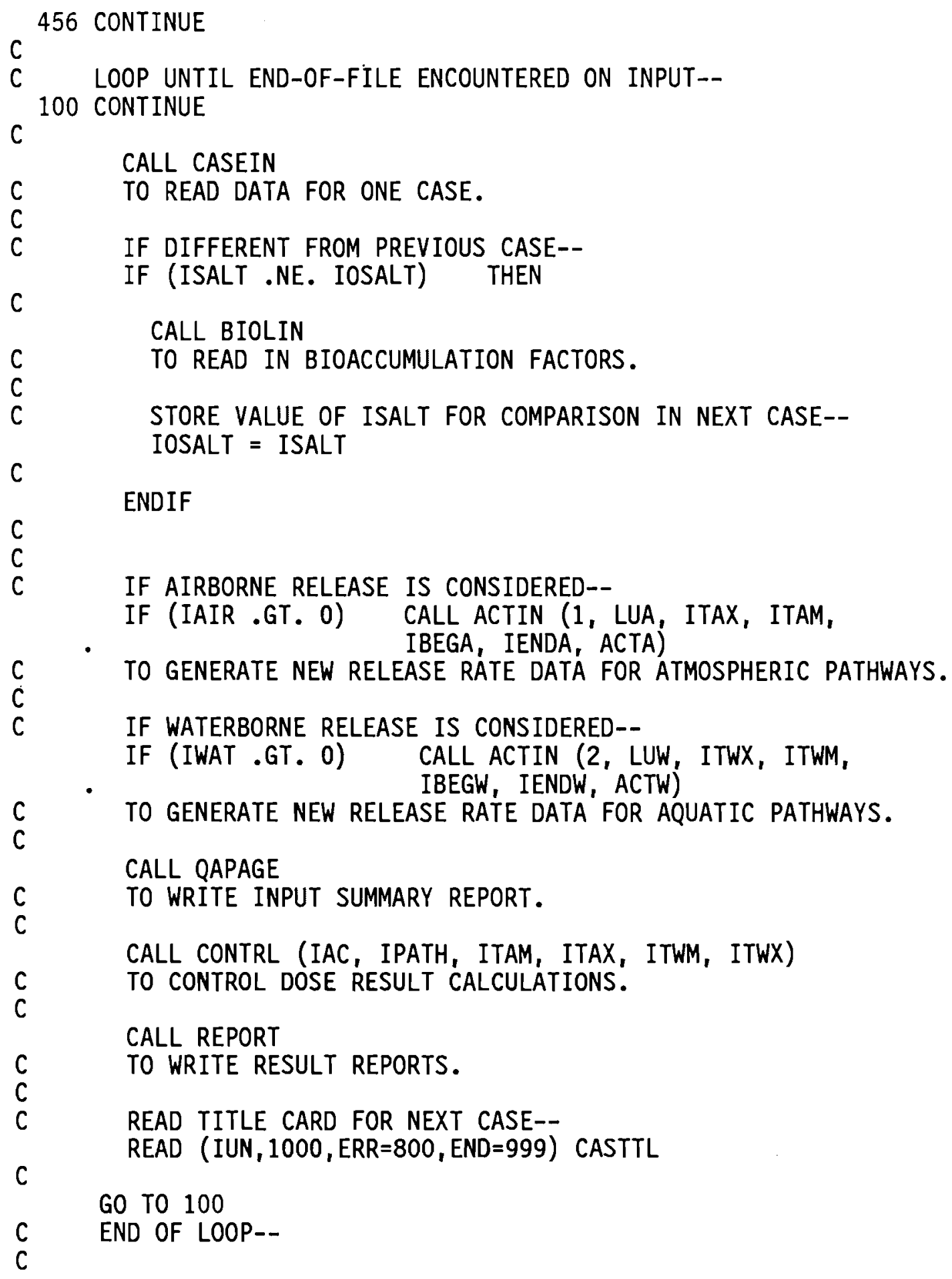

EIGURE 0.1. DITTY Program Listing (continued) 
Module Main

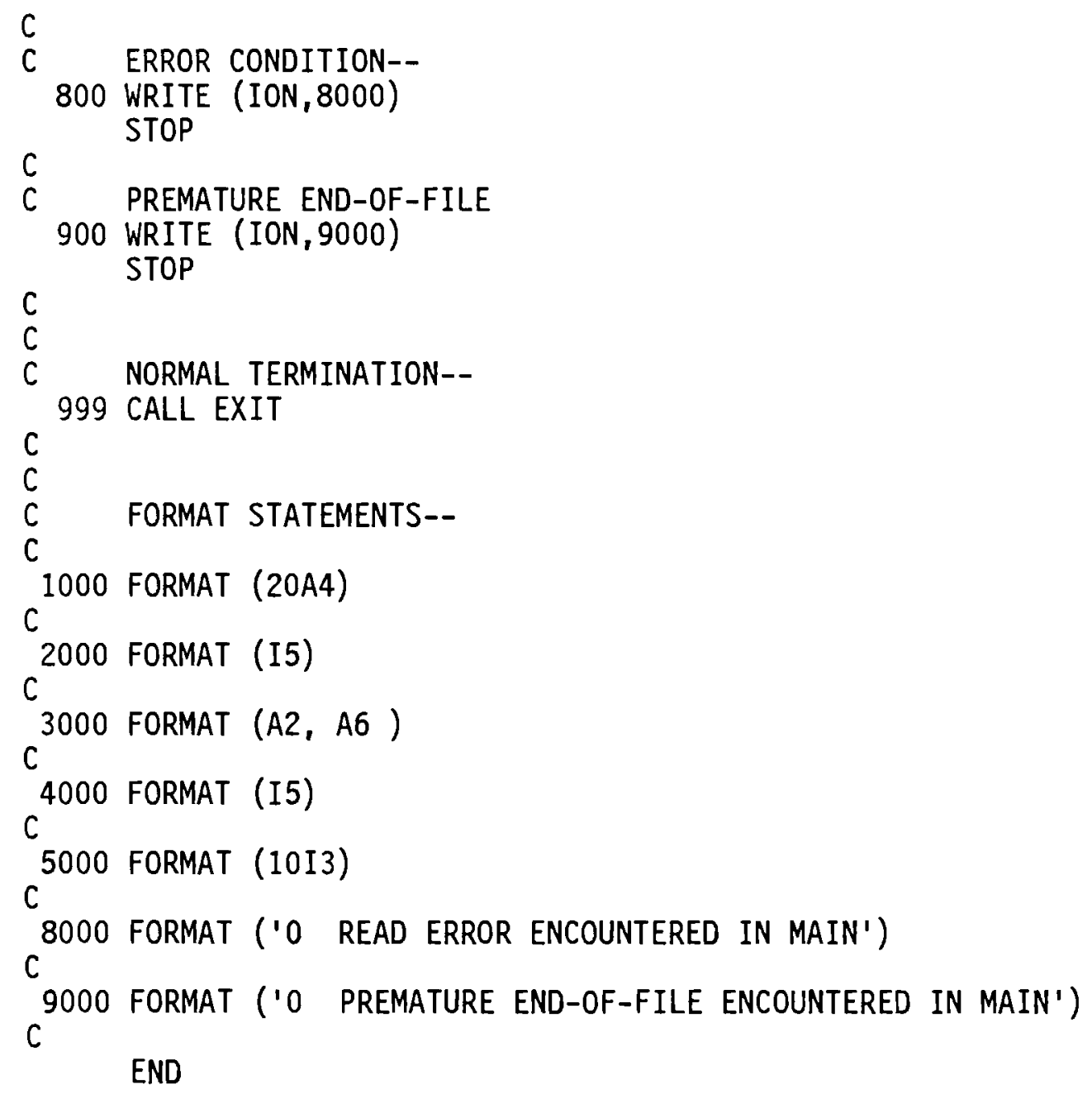

EIGURE D.1. DITTY Program Listing (continued) 
Module ACTIN

SUBROUTINE ACTIN (IP, IAW, ITX, ITM, IBEG, IEND, CON)

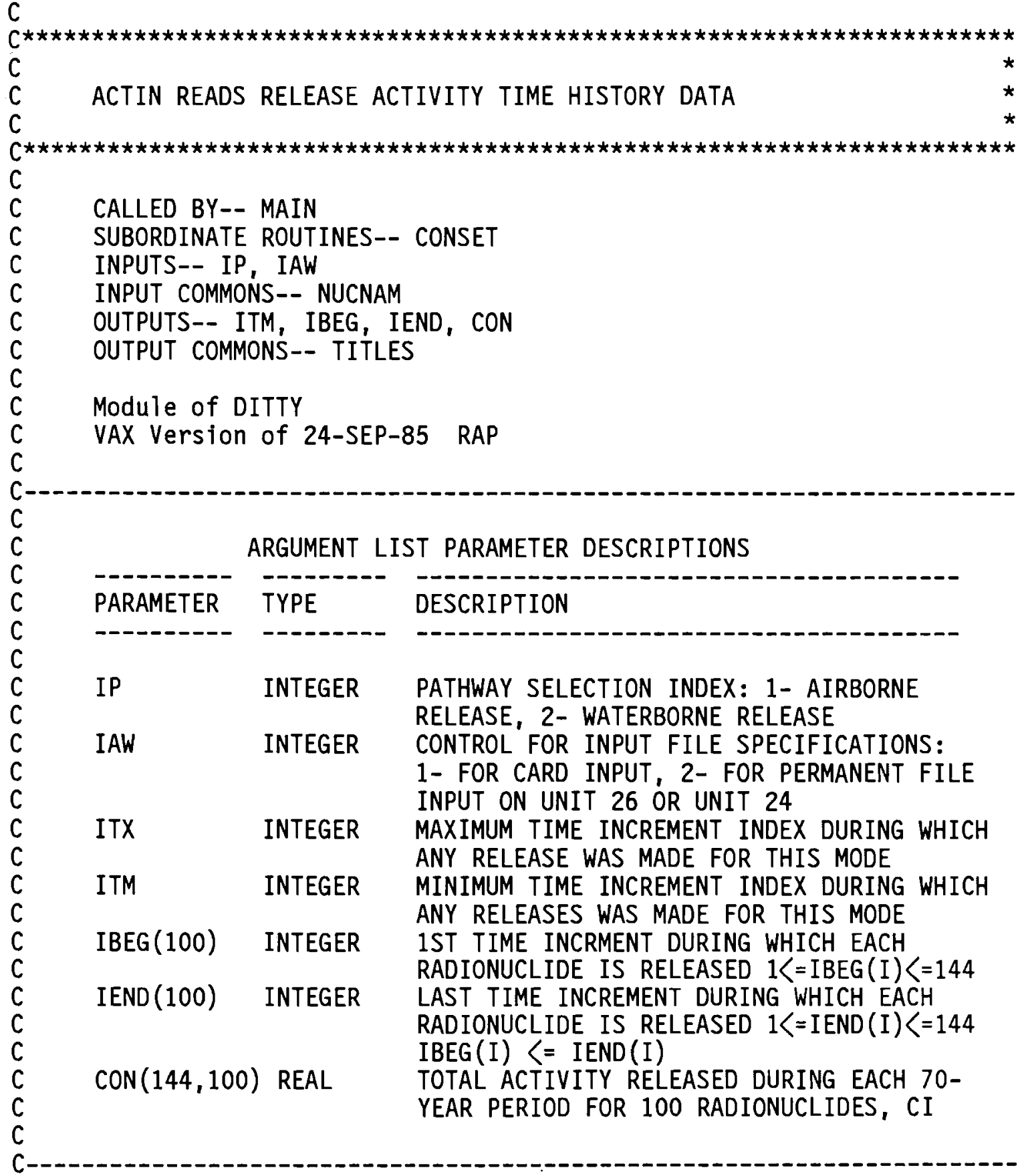

EIGURE D.1. DITTY Program Listing (continued) 


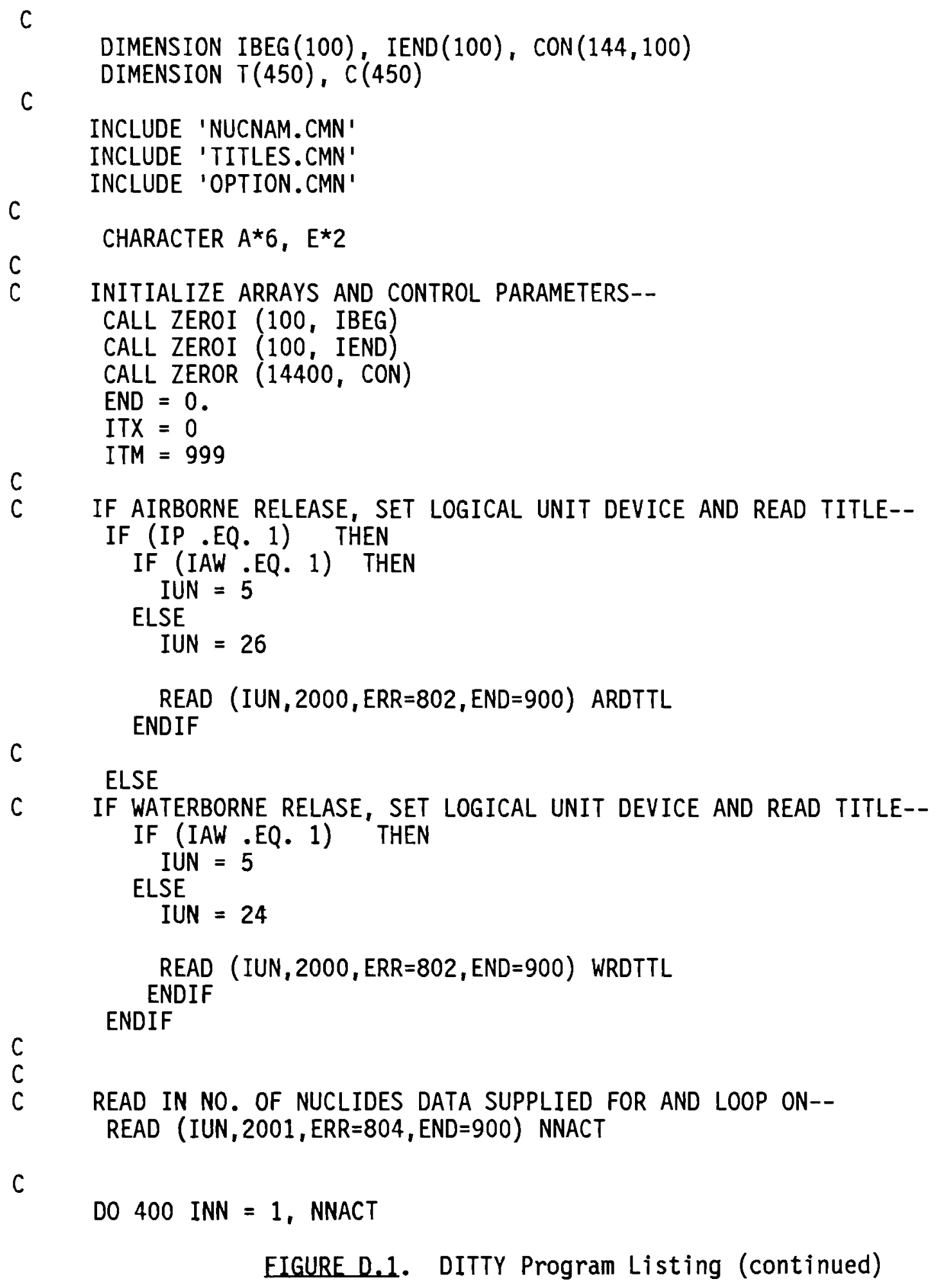

\section{8}




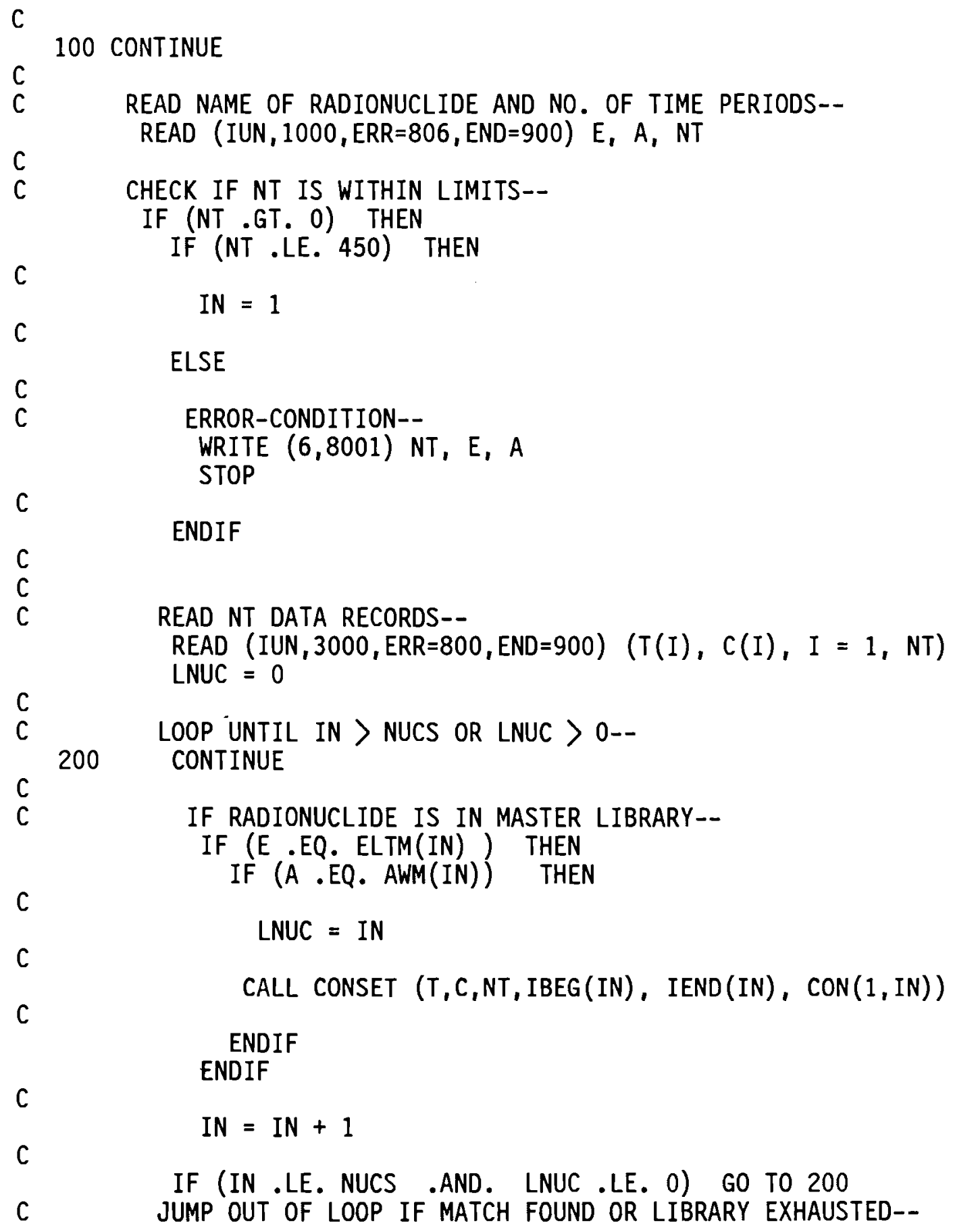

EIGURE D.1. DITTY Program Listing (continued) 
Module ACTIN

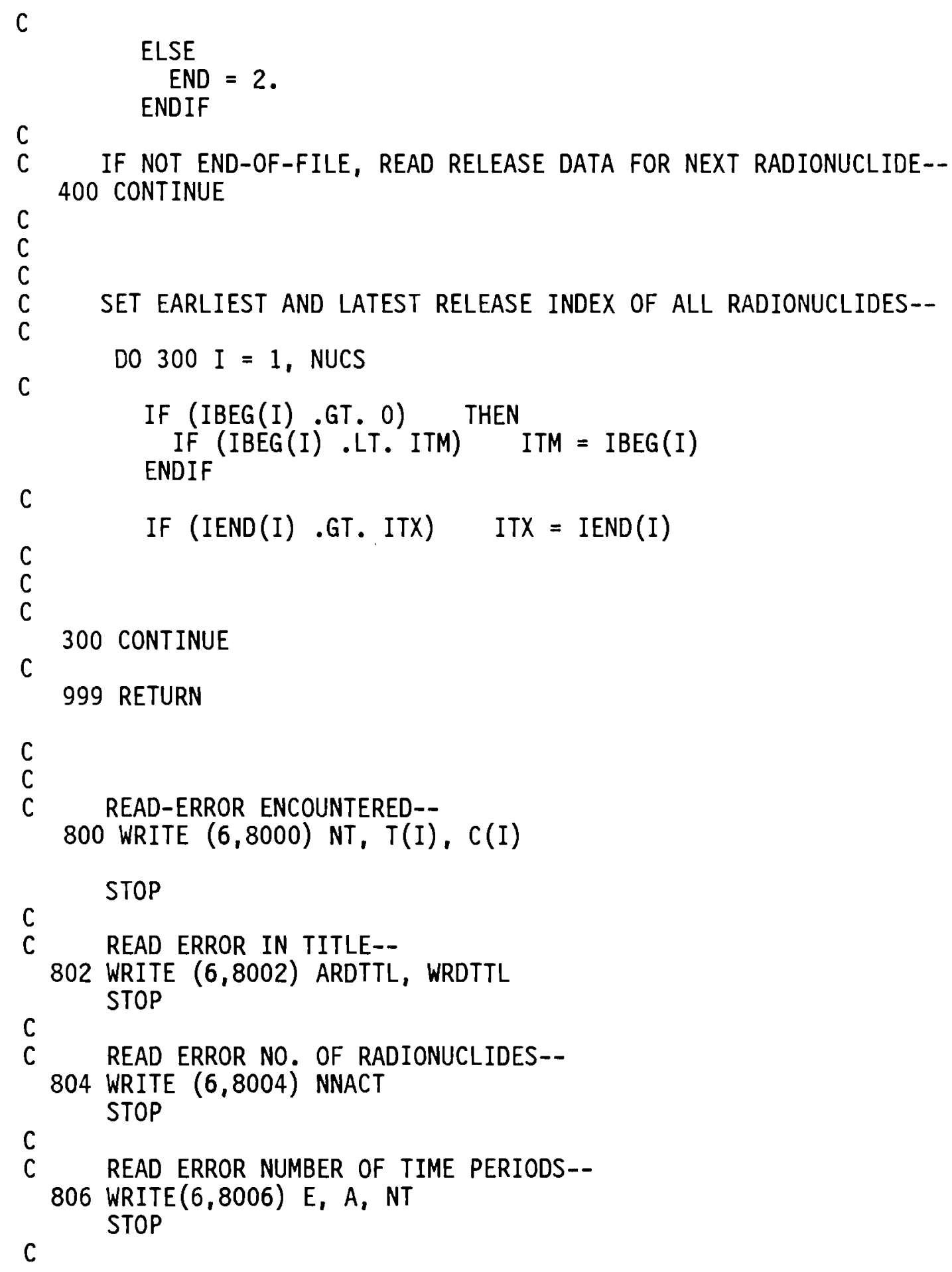

EIGURE D.1. DITTY Program Listing (continued) 


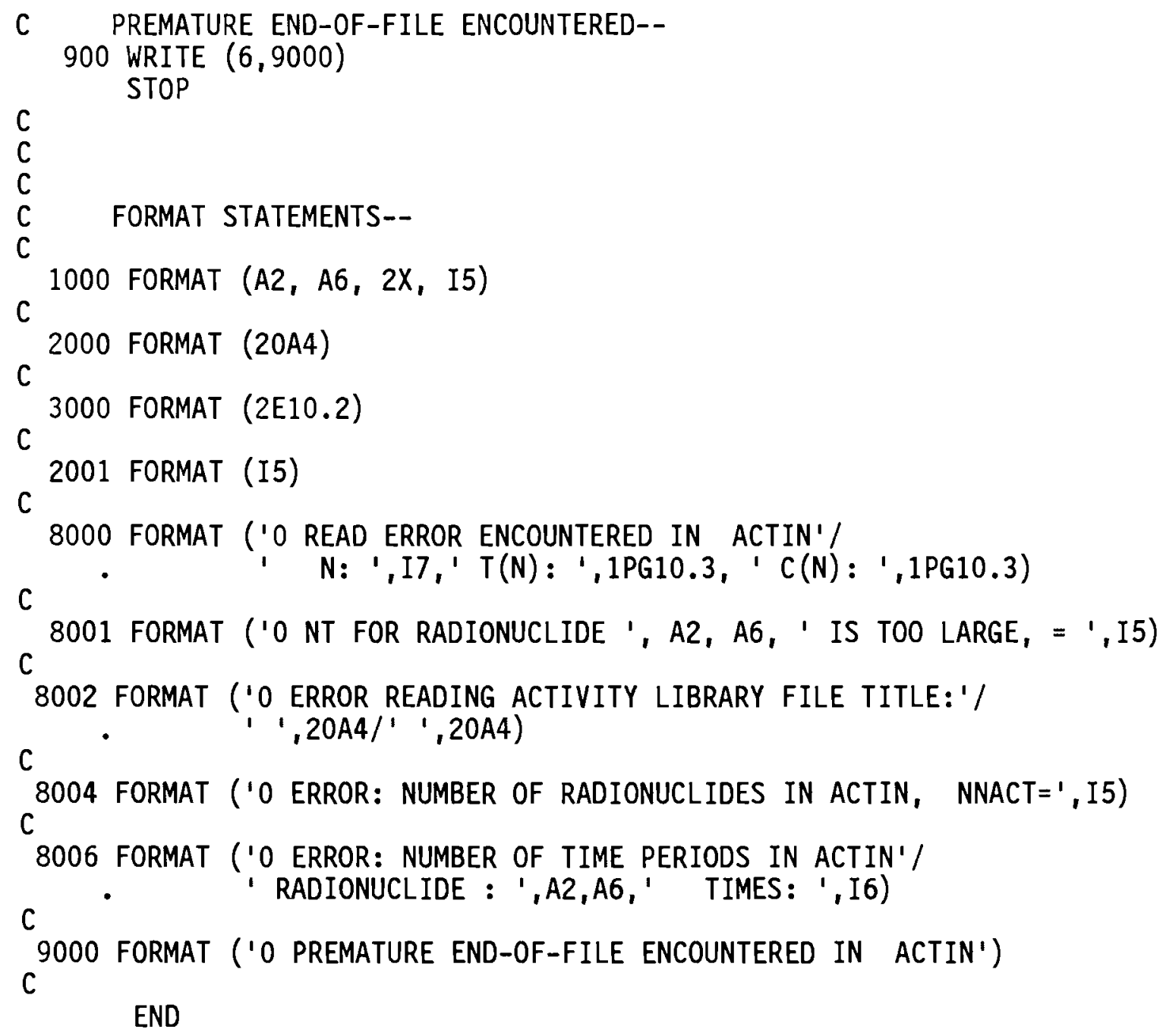

EIGURE D.1. DITTY Program Listing (continued) 
Module AIRLIN

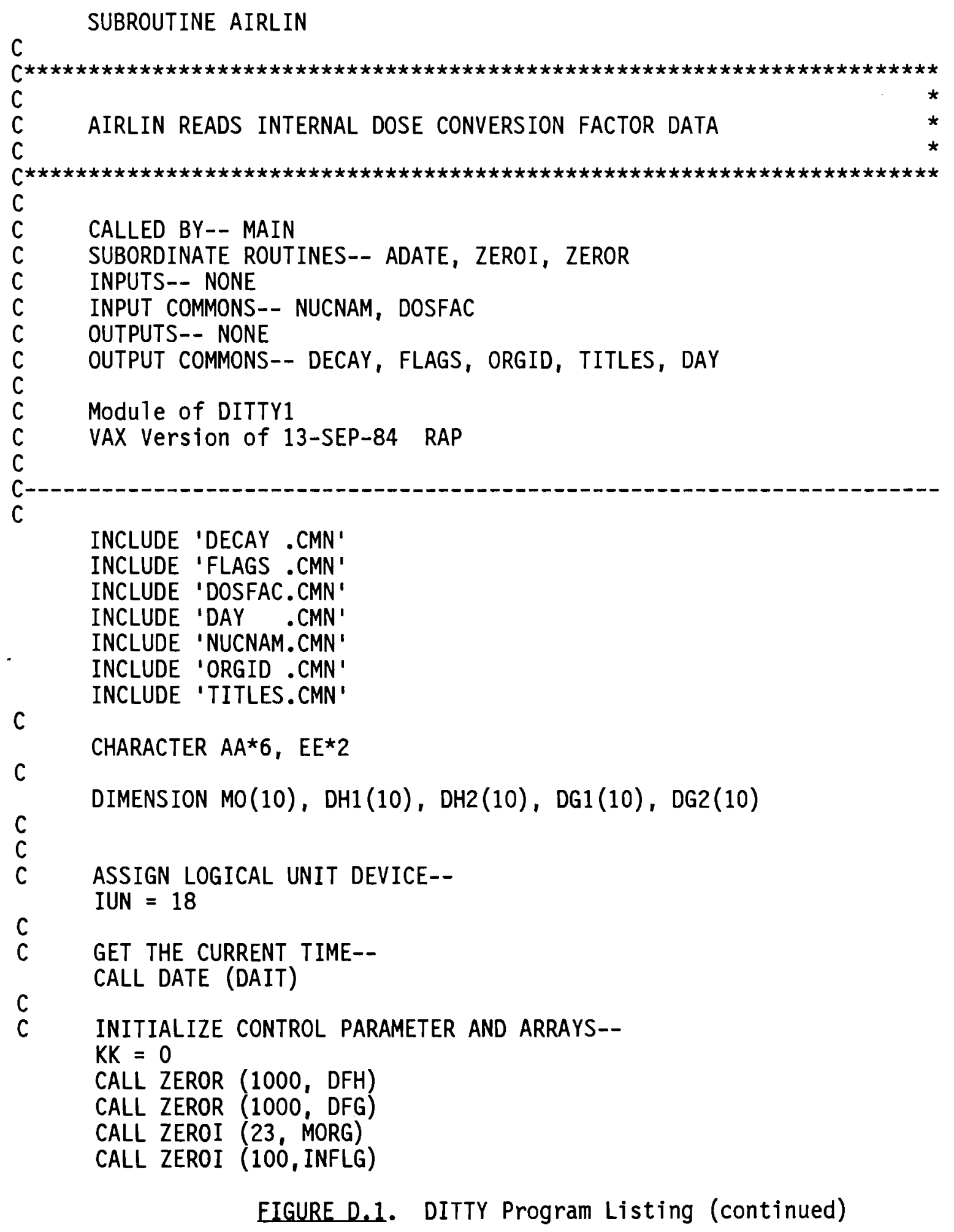

D. 12 


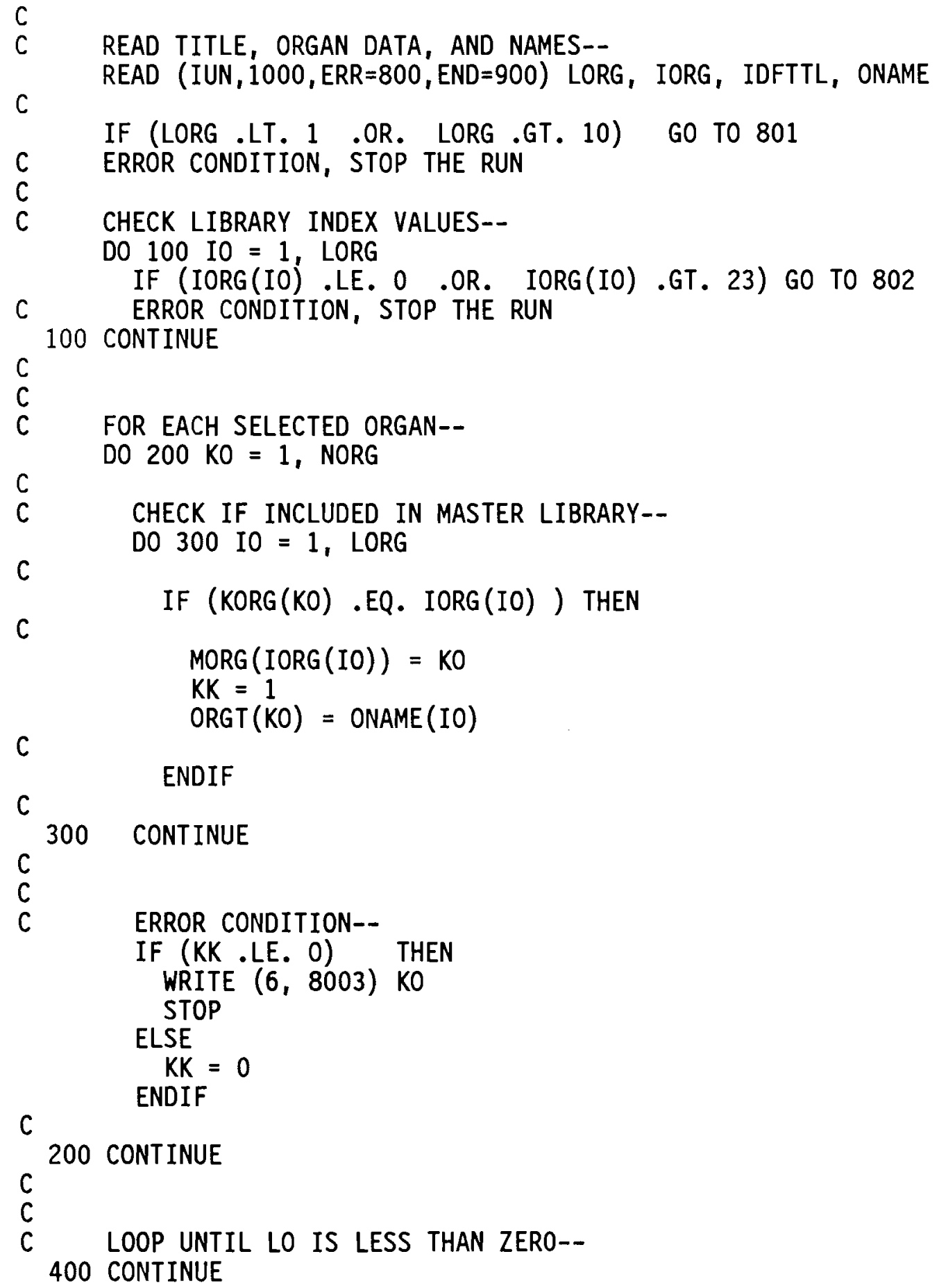

C

ENDIF

C

300 CONTINUE

C

C

EIGURE D.1. DITTY Program Listing (continued) 


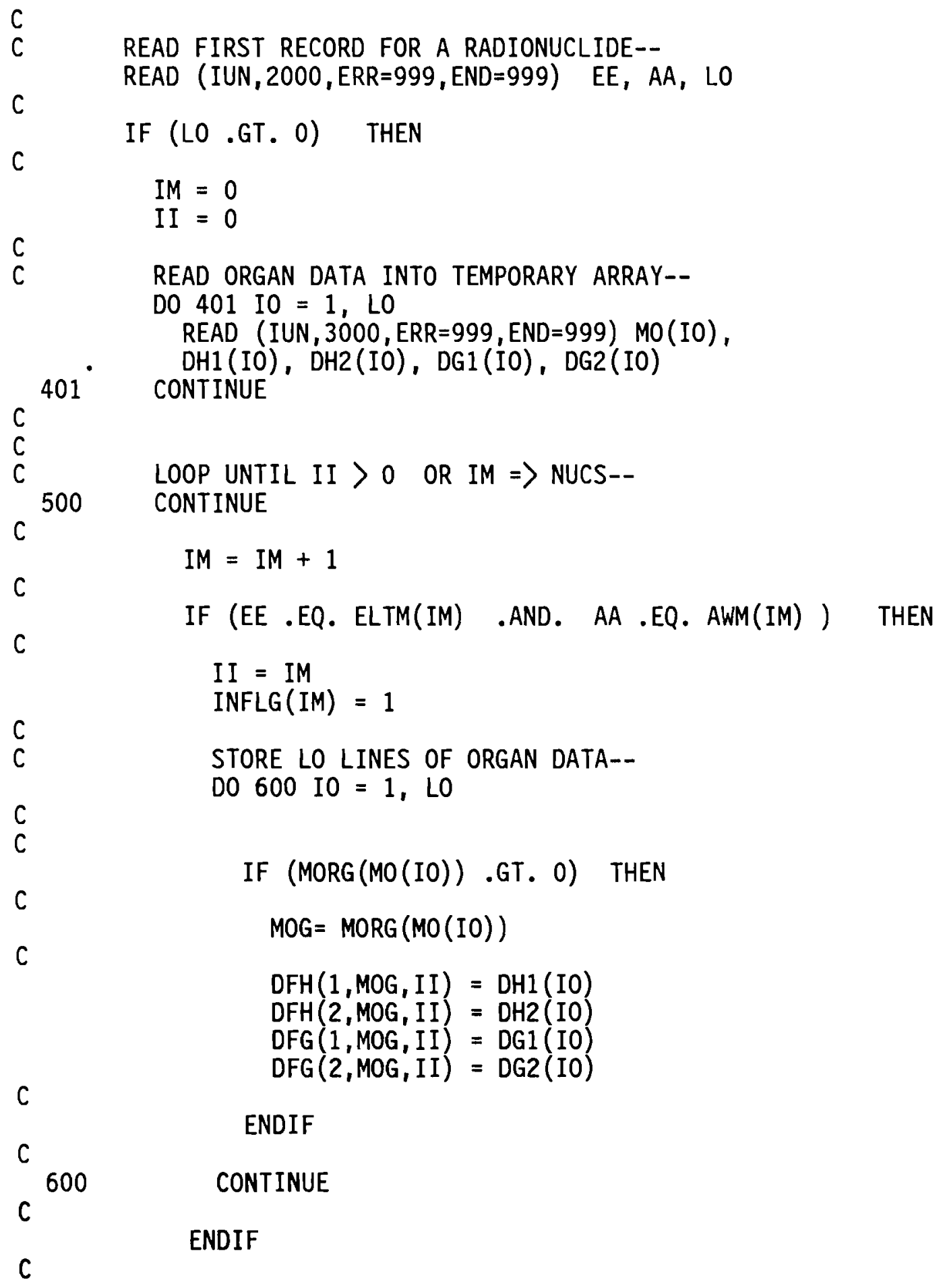

C

C

$600 \quad$ CONTINUE

C

C

\section{ENDIF}

EIGURE D.1. DITTY Program Listing (continued) 


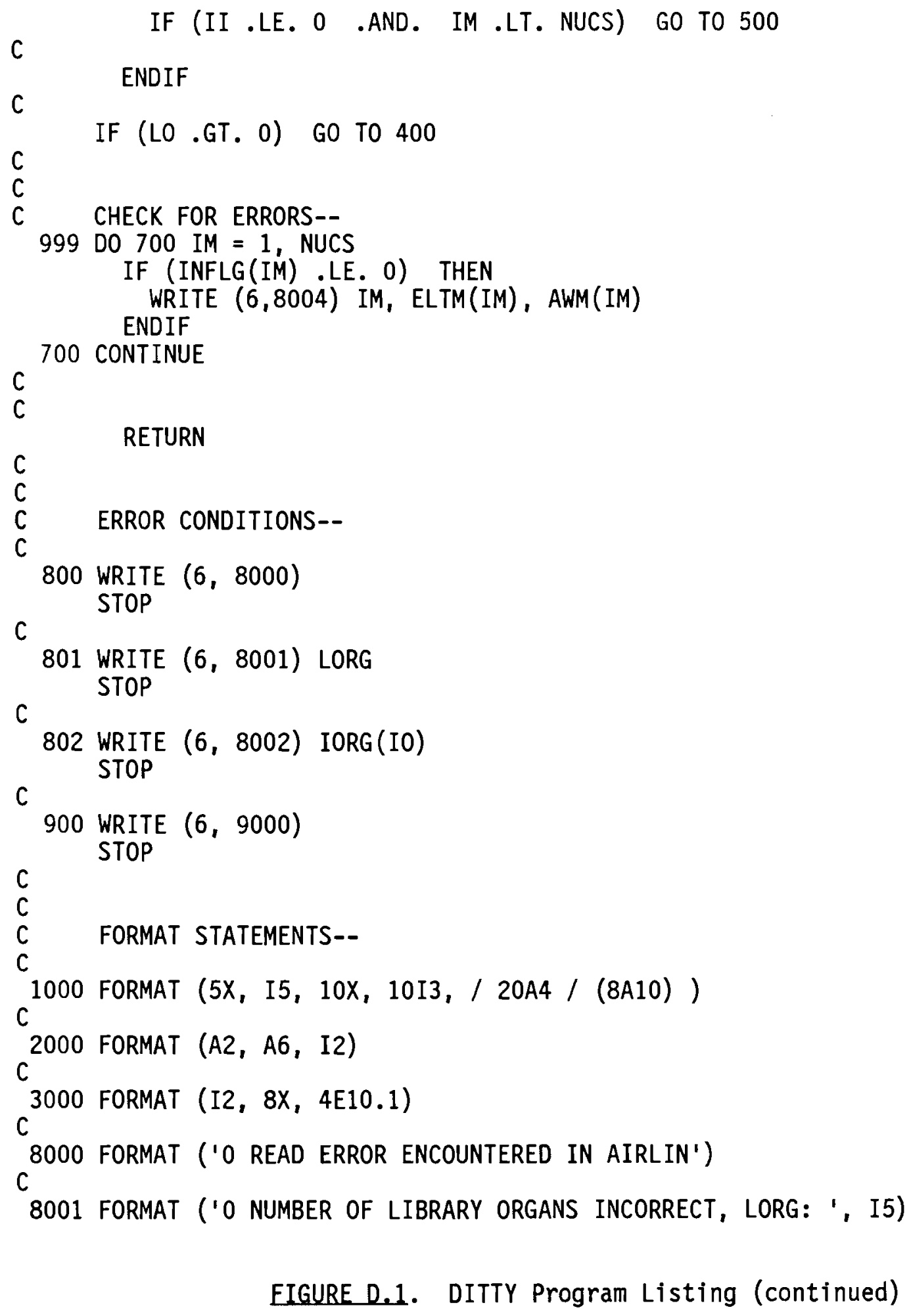


Module AIRLIN

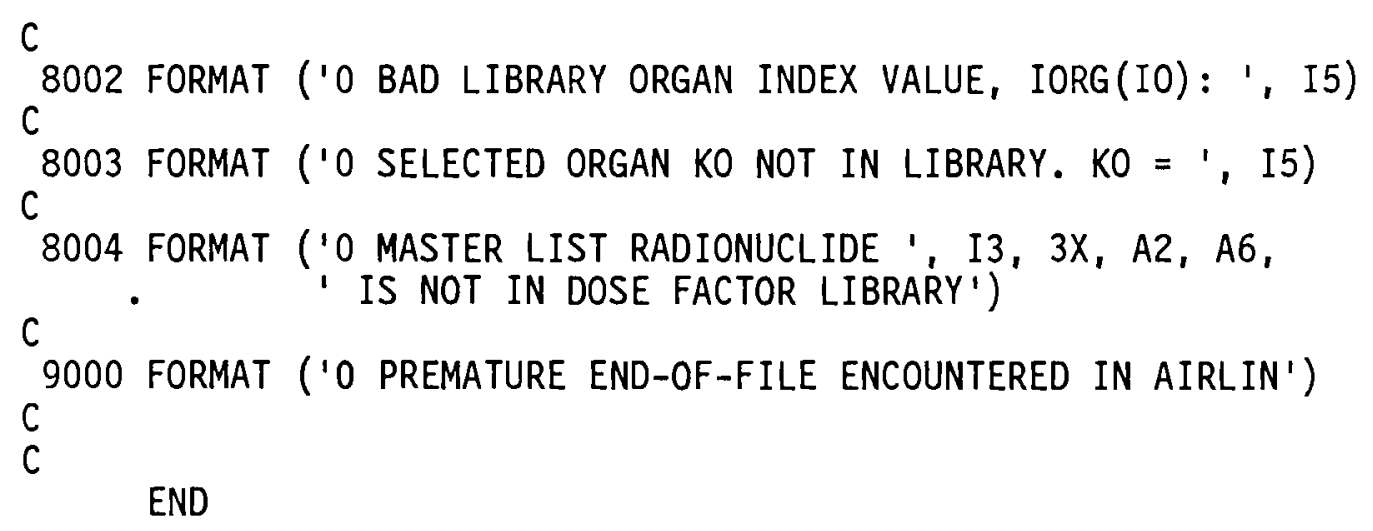

EIGURE D.1. DITTY Program Listing (continued)

\author{
D. 16
}


Module APATHS

SUBROUTINE APATHS (ITIM, ITAX)

C

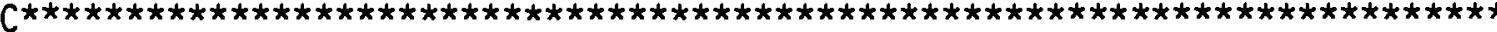

$\mathrm{C}$

APATHS CALCULATES ENVIRONMENTAL CONCENTRATIONS FROM ATMO- * SPHERIC DEPOSITION.

C

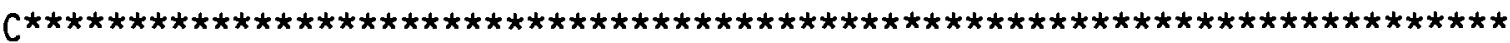

C CALLED BY-- CONTRL

C SUBORDINATE ROUTINES-- TRITIUM, CARBON, BCHAIN

C INPUTS-- ITIM, ITAX

C INPUT COMMONS-- DKAY, FODATA, PATHIN, NUCNAM, VARYBL

C OUTPUTS-- NONE

C OUTPUT COMMONS-- EDCN

C

C Module of DITTY

C VAX Version of 19-NOV-84 RAP

C

C

c

$\mathrm{C}$

C

C

C

C

C

C

C

INCLUDE 'DKAY .CMN'

INCLUDE 'EDCN . CMN'

INCLUDE 'FODATA.CMN'

INCLUDE 'NUCNAM.CMN'

INCLUDE 'PATHIN.CMN'

INCLUDE 'VARYBL.CMN'

C

CHARACTER $* 2$ CONSTC, CONSTH

C

DIMENSION TRNL(7), ANCONS (7), RATE(100), DUMMY (100)

DATA TRNL / 1.0,0.1,0.1, 1.0,0.1,0.1, 0.1/

DATA ANCONS $/ 0 ., 0 ., 0.12,55 ., 68 ., 4.2,0.12 /$

DATA DUMMY $/ 100 * 0.1$

DATA DUMMY1 / $10 . /$

EIGURE 0.1. DITTY Program Listing (continued)

D. 17 
Module APATHS

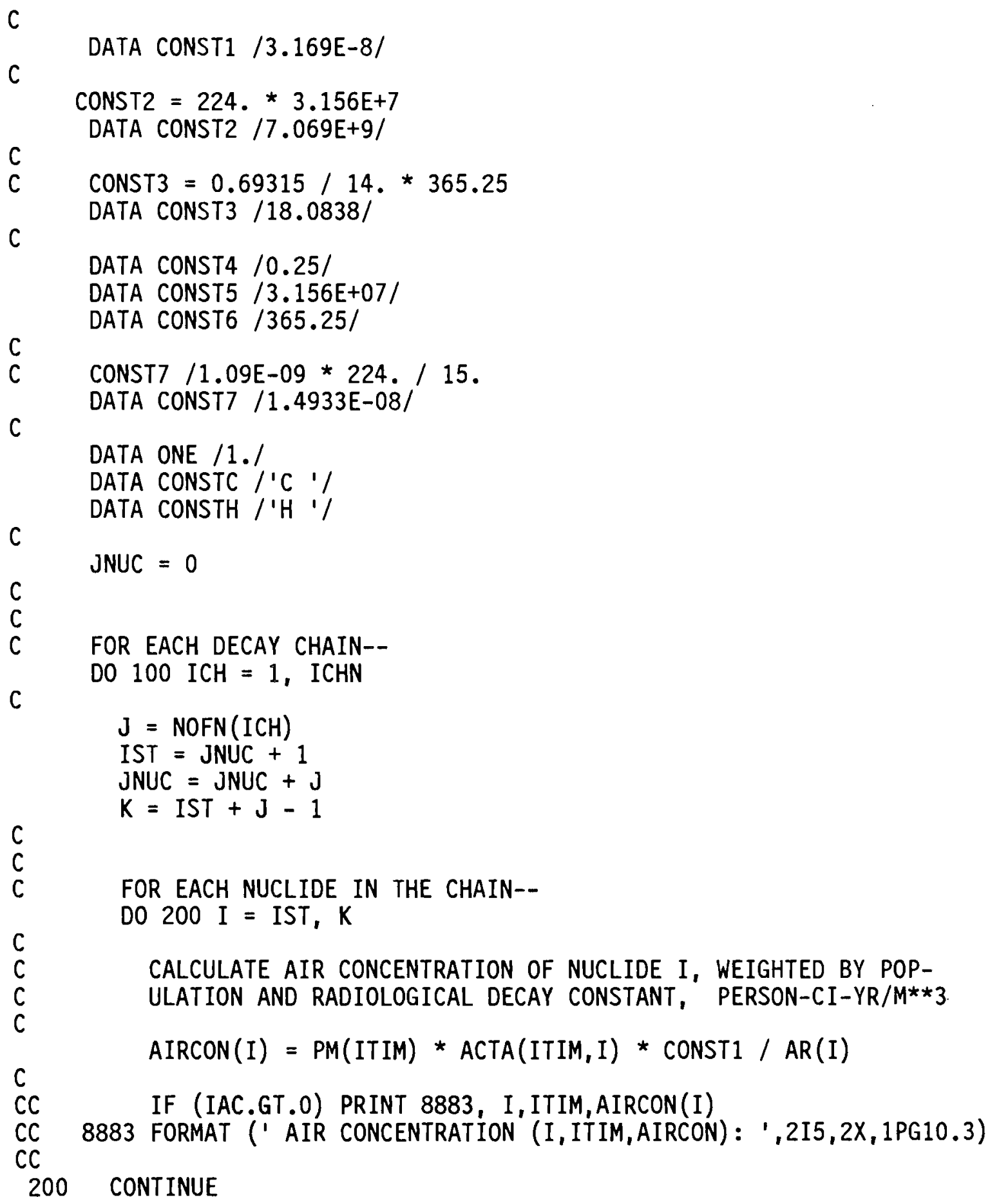

EIGURE 0.1. DITTY Program Listing (continued) 
Module APATHS

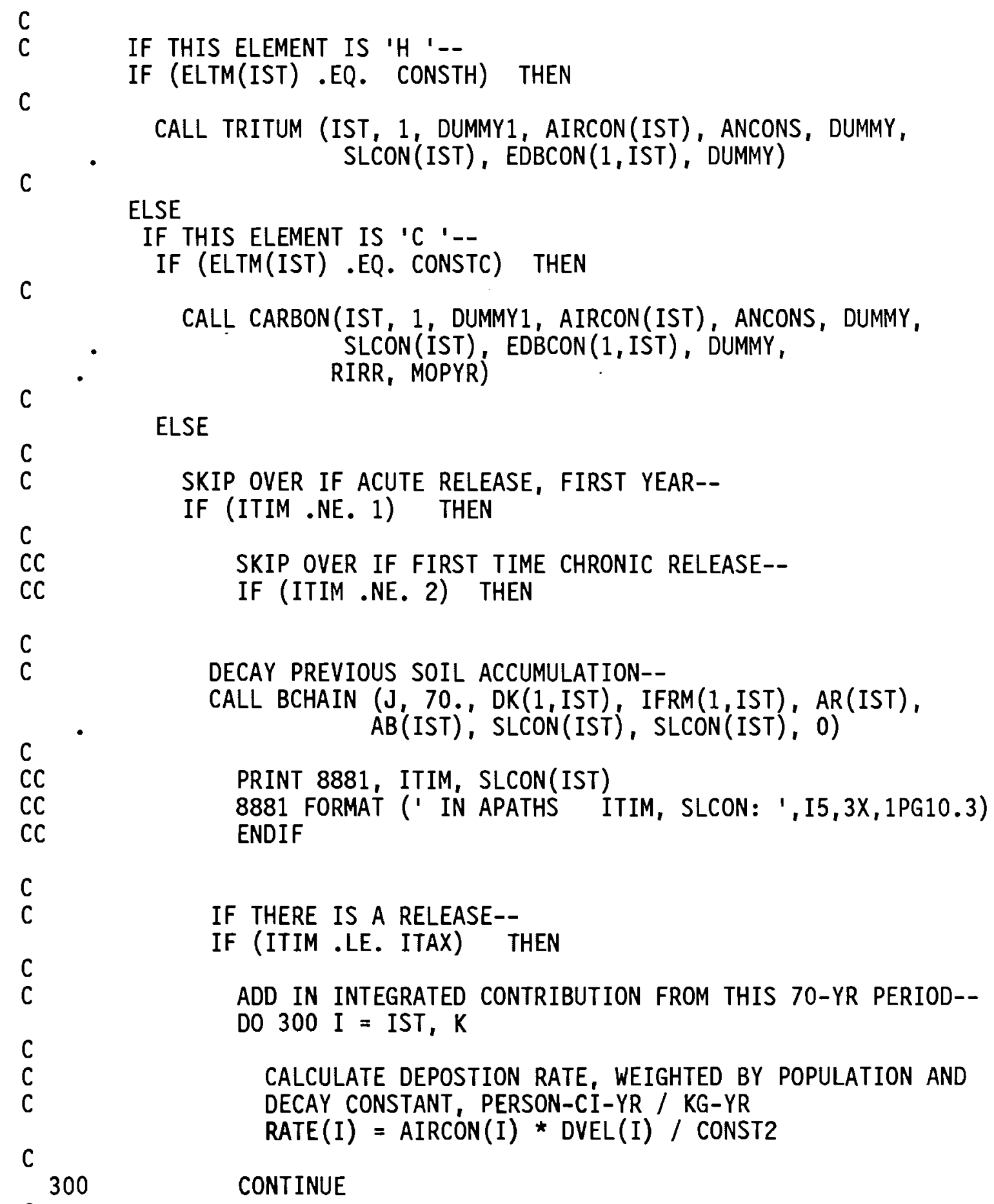

$c$

C

C

$\mathrm{CC}$

$\mathrm{CC}$

ELSE

SKIP OVER IF ACUTE RELEASE, FIRST YEAR-IF (ITIM .NE. 1) THEN

SKIP OVER IF FIRST TIME CHRONIC RELEASE--

IF (ITIM .NE. 2) THEN

C

DECAY PREVIOUS SOIL ACCUMULATION-CALL BCHAIN $(\mathrm{J}, 70 .$, DK( 1, IST), IFRM $(1$, IST), AR(IST), $A B(I S T), \operatorname{SLCON}($ IST), $\operatorname{SLCON}($ IST), 0$)$

C

$\mathrm{CC}$

$\mathrm{CC}$

CC

PRINT 8881, ITIM, SLCON(IST)

8881 FORMAT (' IN APATHS ITIM, SLCON: ', I5, 3X, 1PG10.3) ENDIF

C

C IF THERE IS A RELEASE--

IF (ITIM .LE. ITAX) THEN

C

C

ADD IN INTEGRATED CONTRIBUTION FROM THIS 70-YR PERIOD-DO $300 \mathrm{I}=\mathrm{IST}, \mathrm{K}$

c

c

c

CALCULATE DEPOSTION RATE, WEIGHTED BY POPULATION AND DECAY CONSTANT, PERSON-CI-YR / KG-YR

$\operatorname{RATE}(\mathrm{I})=\operatorname{AIRCON}(\mathrm{I}) * \operatorname{DVEL}(\mathrm{I}) / \mathrm{CONST} 2$

C

300

CONTINUE

EIGURE D.1. DITTY Program Listing (continued) 
Module APATHS

CALL BCHAIN (J, 70,, DK( 1, IST), IFRM $(1$, IST), AR(IST), $A B(I S T), \operatorname{RATE}(I S T), \operatorname{RATE}($ IST), 1$)$

SUM PREVIOUS AND CURRENT DEPOSTIONS--

The following was added to correct population include in SLCON PMT $=1.0$

IF (ITIM .GT. 1) THEN

IF (PM(ITIM-1) .GT. 0. .AND. PM(ITIM) .GT. 0.0) THEN PMT $=$ PM(ITIM) $/$ PM(ITIM-1)

ENDIF

ENDIF

C

DO $400 \mathrm{I}=$ IST, $K$ $S L C O N(I)=S L C O N(I) * P M T+R A T E(I)$

C CONTINUE ELSE

C

C

$\mathrm{CC}$

$\mathrm{CC}$

$\mathrm{CC}$

$\mathrm{CC}$ 500

C

CONTINUE

CALL BCHAIN (J, 1.0, DK(1,IST), IFRM(1,IST), AR(IST), $A B(I S T), S L C O N(I S T), S L C O N(I S T), 0)$

ENDIF

C

C

C

CALCULATE PLANT AND ANIMAL CONCENTRATIONS--

FOR EACH NUCLIDE IN CHAIN-DO 600 I = IST, $K$

CALCULATE ENVIRONMENTAL REMOVAL CONSTANT-ENVLAM $=A R(I)+$ CONST3

FOR EACH TERRESTRIAL PATHWAY-DO 700 IP $=1,7$

EIGURE 0.1. DITTY Program Listing (continued) 


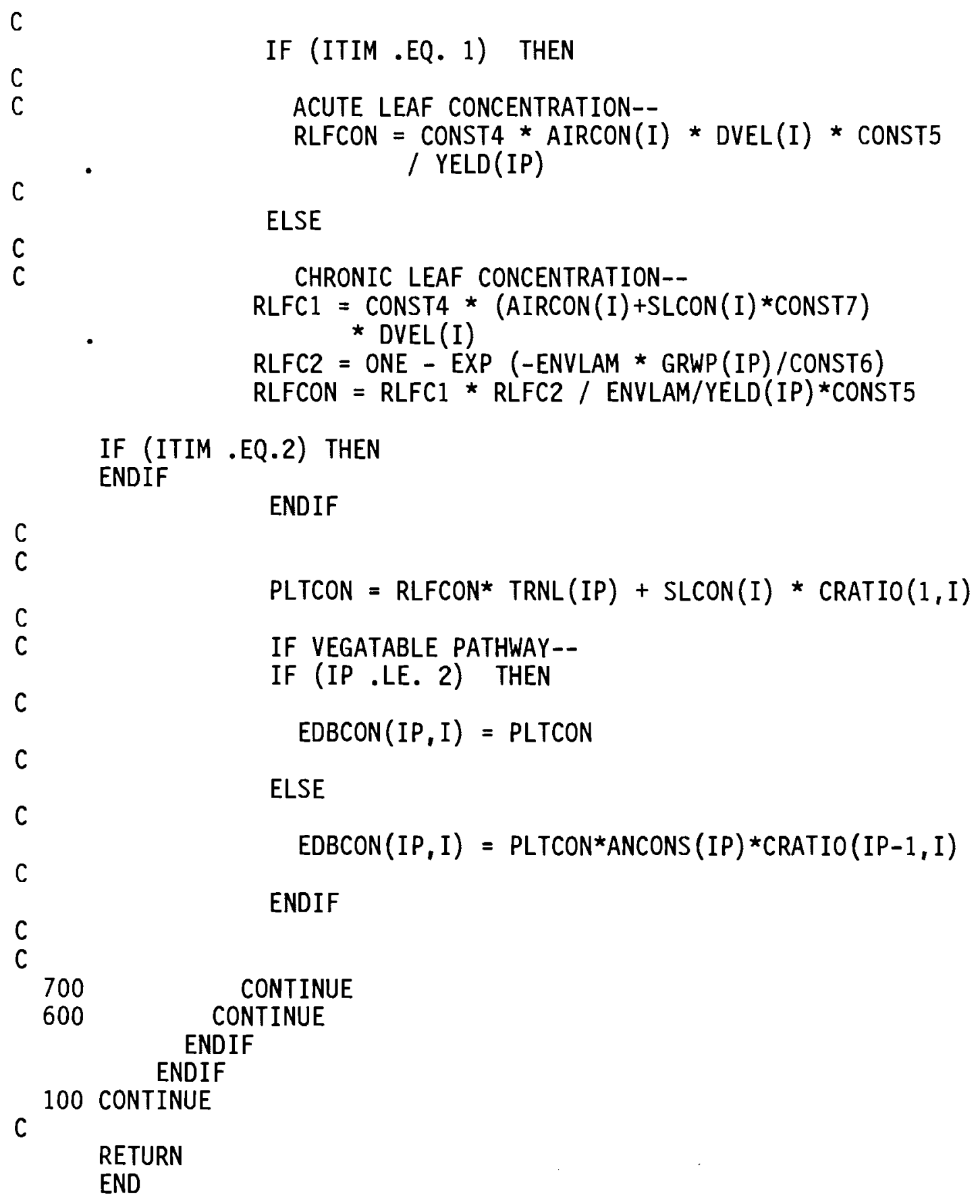

EIGURE D.1. DITTY Program Listing (continued) 
ModuTe BCHAIN

SUBROUTINE BCHAIN (NUC, T, DK, IFRM, $A L, A B, A M, A O$, INTGRL) C

C

C

C BCHAIN CALCULATES DECAY FOR ONE CHAIN

C

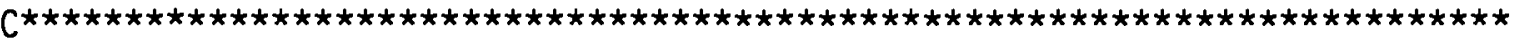

C

C CALLED BY-- APATHS, WPATHS

C SUBORDINATE ROUTINES-- ASUM, SUMPRD, ZEROR, EXMO

C INPUTS-- NUC, T, DK, IFRM, AL, AB, AM, INTGRL

C INPUT COMMONS-- NONE

C OUTPUTS-- AO

c OUTPUT COMMONS-- NONE

C

C

C

c

C

VAX Version of 11-0CT-85 RAP

C

$R E A L * 8 A(45)$, SUMPR, ASUM, AMD, $\operatorname{EXPO}(9), A B D(9)$

REAL*8 ARG, TERM

DIMENSION DK(2,9), $\operatorname{IFRM}(2,9), \operatorname{AL}(9), \operatorname{AM}(9), \operatorname{AO}(9)$,

C

C CHANGE TO QUAD PRECISION

DO 113 IJK $=1,9$

113 CONTINUE

$$
A B(9)
$$

C

C INITIALIZE COEFFICIENT ARRAY TO ZERO--

C N2N $=$ NUC * $(\mathrm{NUC}-1) / 2+\mathrm{NUC}$

C CALL ZEROR (N2N, A)

DO 100 IJK $=1$, N2N

$A(I J K)=0.000$

100 CONTINUE

c

C DO LOOP ON CHAIN MEMBERS, MAX = NUC-DO $5 \mathrm{~J}=1$, NUC

C

CALCULATE EXPONENTIAL FOR CURRENT NUCLIDE-$A R G=-A B D(J) * T$

EIGURE D.1. DITTY Program Listing (continued) 


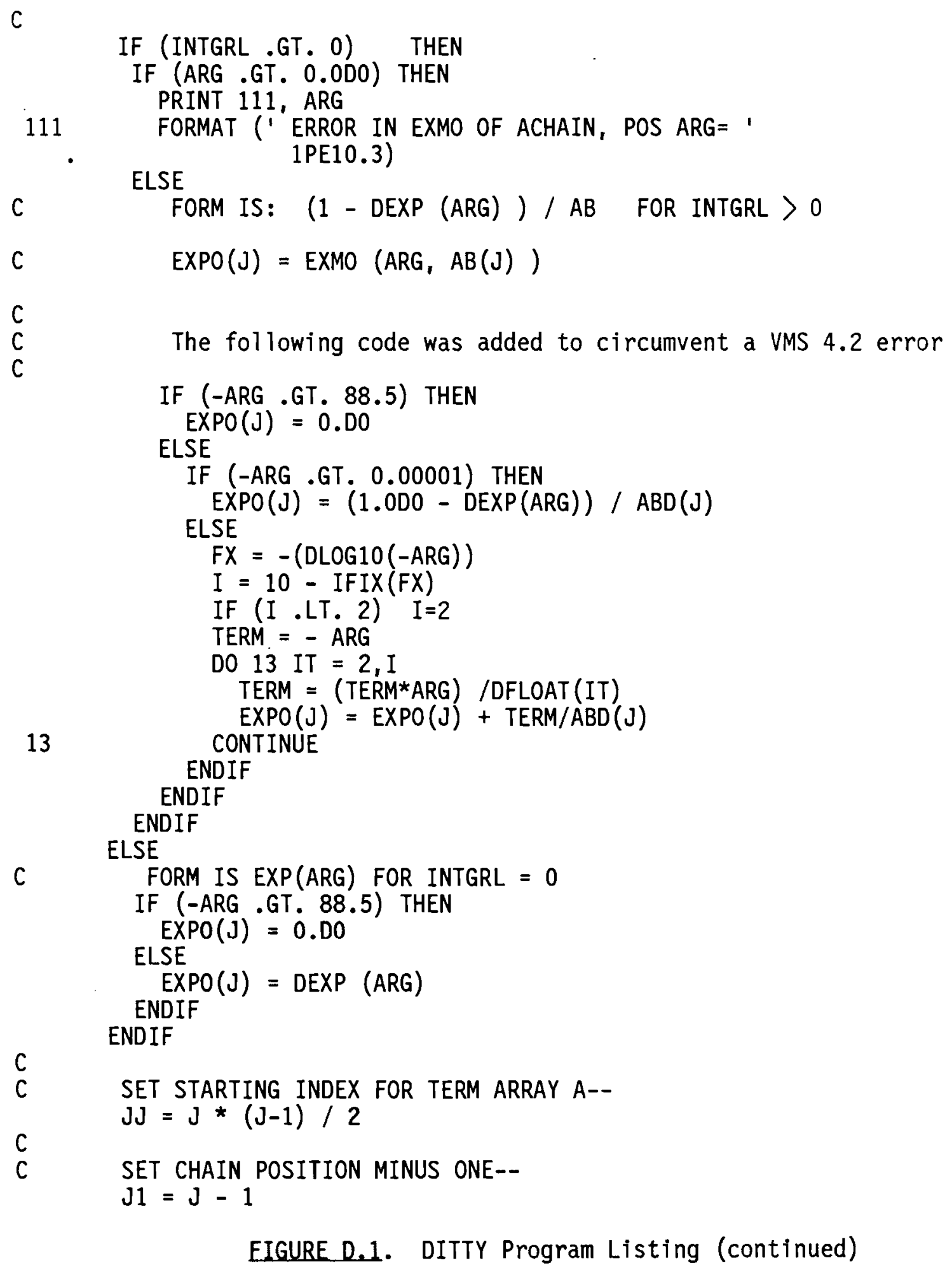

EIGURE 0.1. DITTY Program Listing (continued) 


\section{Module BCHAIN}

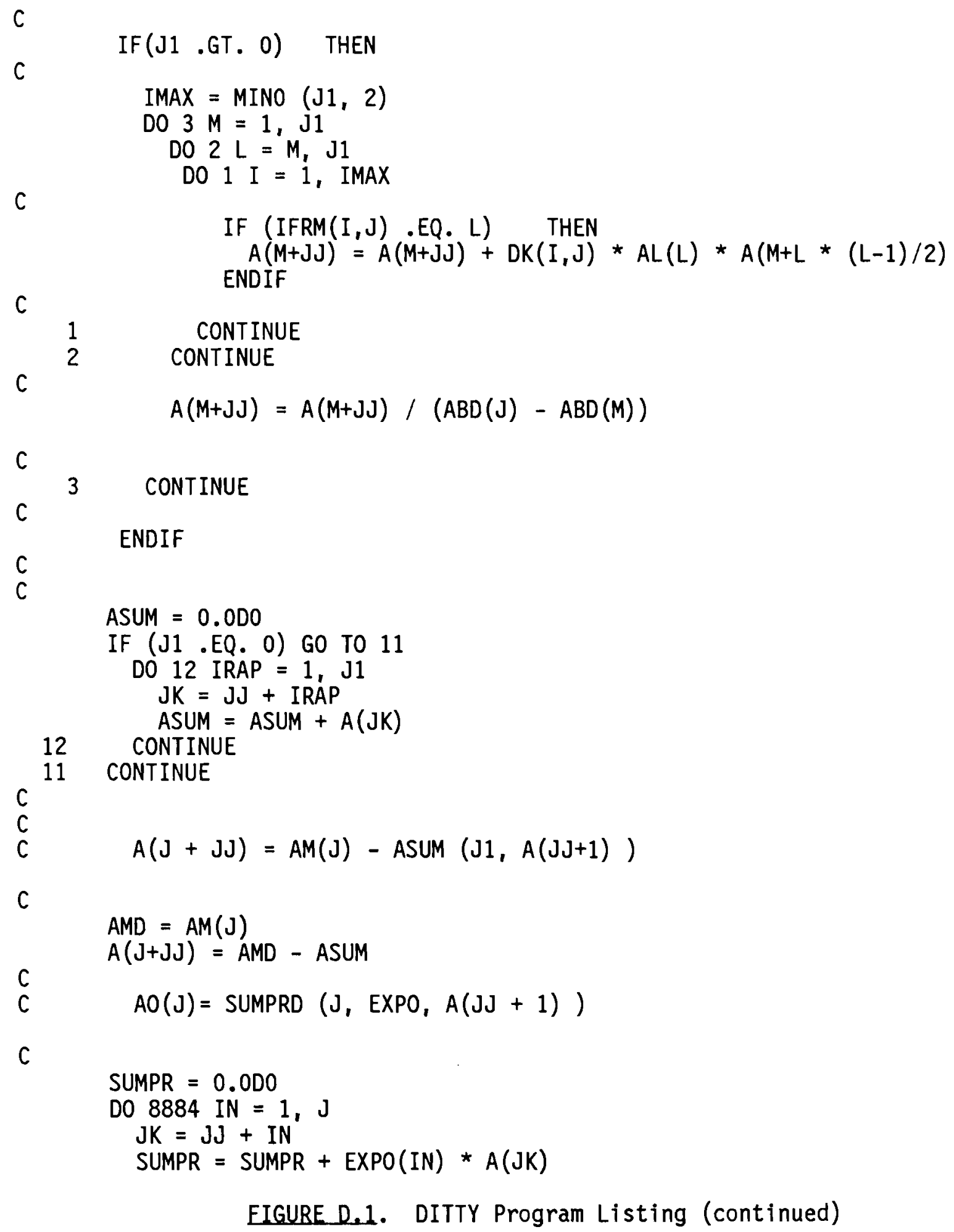

EIGURE D.1. DITTY Program Listing (continued) 
Module BCHAIN

$\begin{array}{ll}8884 & \text { CONTINUE } \\ & \mathrm{AO}(\mathrm{J})=\text { SUMPR } \\ \text { C } & \\ \text { C } & 5 \text { CONTINUE } \\ & \text { RETURN } \\ & \text { END }\end{array}$

EIGURE D.1. DITTY Program Listing (continued)

D. 25 


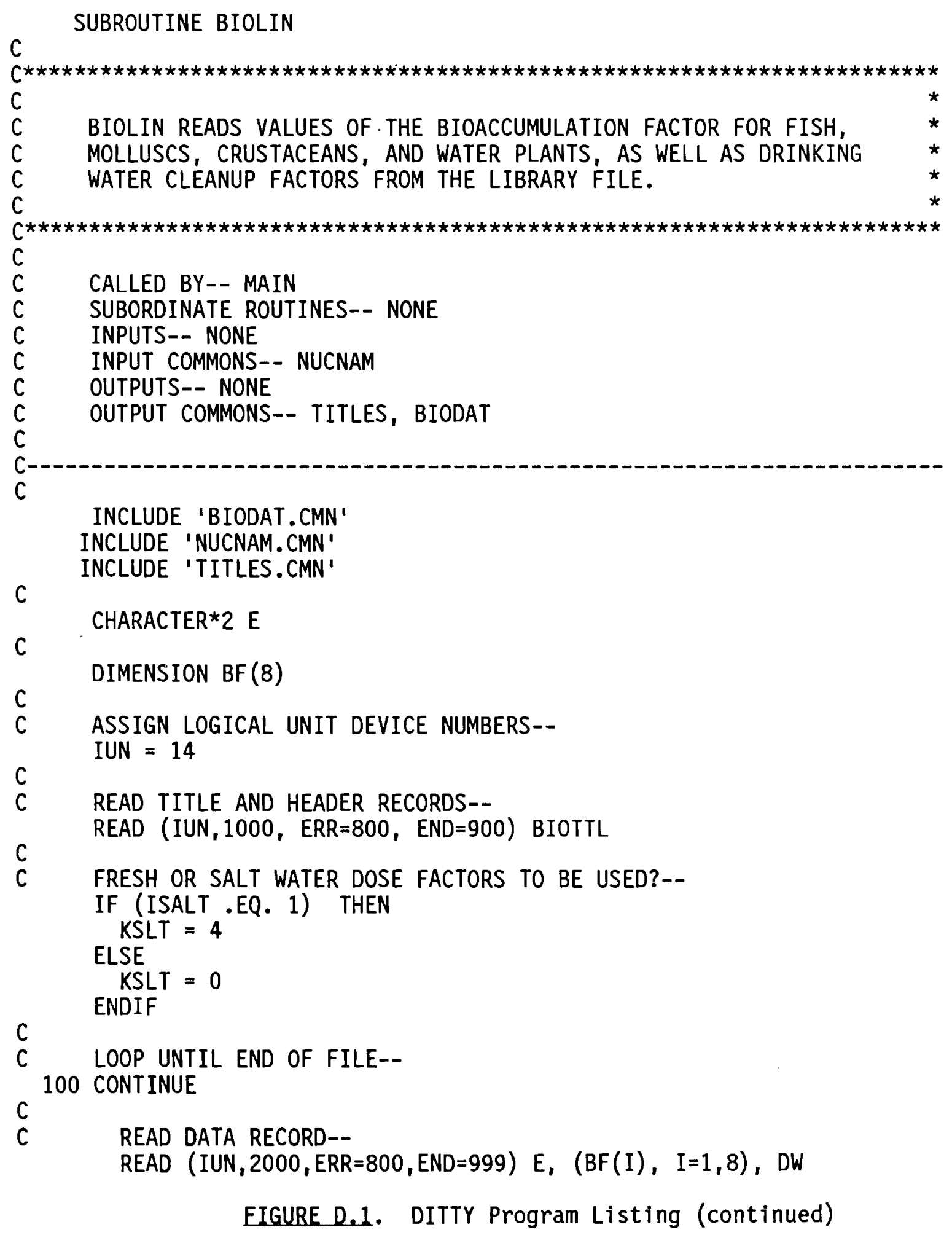


C

C IF RADIONUCLIDE FOUND IN MASTER LIBRARY, SET BIOACCUMULATION FACTORS--

C DO $200 \mathrm{~J}=1$, NUCS

C

$$
\text { IF (E .EQ. } \operatorname{ELTM}(J)) \text { THEN }
$$

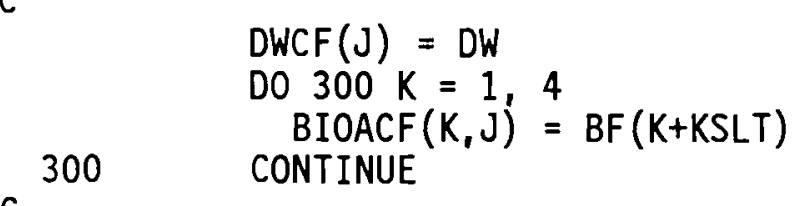

C

200 ENDIF

C

GO TO 100

C IF NOT END-OF-FILE, READ NEXT RECORD--

C

C

C

C

C READ ERROR ENCOUNTERED--

800 WRITE $(6,8000)$

STOP

C

C PREMATURE END-OF-FILE ENCOUNTERED--

900 WRITE $(6,9000)$

C

STOP

C

C NORMAL TERMINATION POINT--

999 REWIND IUN

C RETURN

C FORMAT STATEMENTS--

1000 FORMAT (20A4)

C

2000 FORMAT (A2, 8F9.1, F6.1)

C

8000 FORMAT ('O READ ERROR ENCOUNTERED IN BIOLIN')

C

9000 FORMAT ('O PREMATURE END-OF-FILE ENCOUNTERED IN BIOLIN') C

END

SUBROUTINE CARBON (IST, IAW, WATCN, AIRCN, ANCONS, ANDRNK, CSOIL,

EIGURE D.1. DITTY Program Listing (continued) 
Module CARBON

EDIBL, AQUA, RIRR, MOPYR)

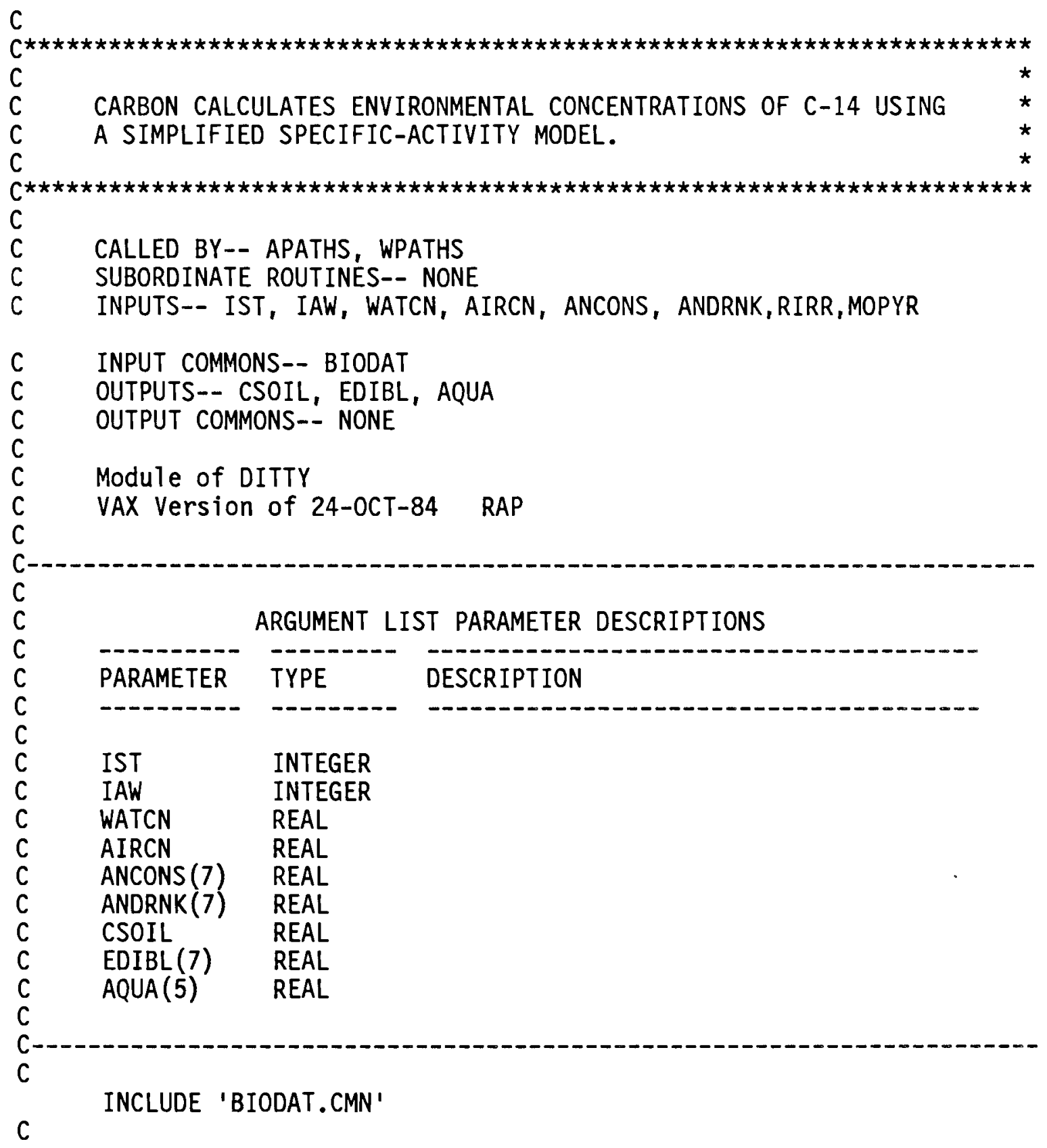

EIGURE 0.1. DITTY Program Listing (continued) 


\section{Module CARBON}

c

C

DiMENSION ANCONS(7), $\operatorname{ANDRNK}(7), \operatorname{EDIBL}(7), \operatorname{AQUA}(5)$

C

REAL MOPYR

DATA CO /2.0E-5/

DATA C1 /1.6E-4/

DATA C2 /0.09/

DATA C3 $/ 0.4 /$

DATA C4 /0.09/

DATA C5 $/ 0.07 /$

DATA C6 /0.24/

DATA C7 / $/ 0.33 /$

DATA C8 $/ 0.20 /$

C

DATA C $/ 0.15 /$

DATA Z1/0.1/

DATA Z2/0.03/

DATA SDEN /224./

DATA SKG $/ 0.01 /$

DATA PKG /0.1/

C

DATA RMV /1.25/

C

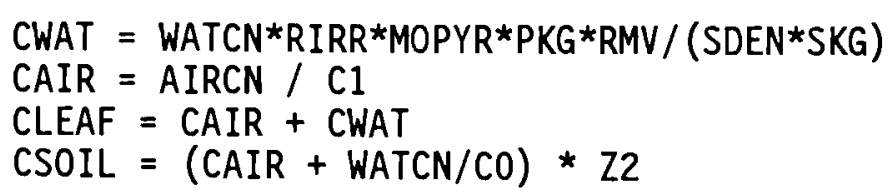

C

$\operatorname{EDIBL}(1)=$ CLEAF * C2

$\operatorname{EDIBL}(2)=\operatorname{EDIBL}(1)$

$\operatorname{EDIBL}(3)=C 9 *$ CLEAF

$\operatorname{EDIBL}(4)=C 5 *$ CLEAF

$\operatorname{EDIBL}(5)=C 6 *$ CLEAF

$\operatorname{EDIBL}(6)=C 7 *$ CLEAF

C

$\operatorname{EDIBL}(7)=\mathrm{C} 8 *$ CLEAF

C

IF (IAW .EQ. 2) THEN

Do $100 I=1,4$ AQUA $(I)=$ BIOACF $(I, I S T) *$ WATCN

C

100 CONTINUE

$$
\text { AQUA (5) }=\text { WATCN * DWCF(IST) }
$$

EIGURE D.1. DITTY Program Listing (continued) 
Module CARBON

\title{
C C ENDIF \\ END
}

EIGURE 0.1. DITTY Program Listing (continued)

\author{
D. 30
}


Module CASEIN

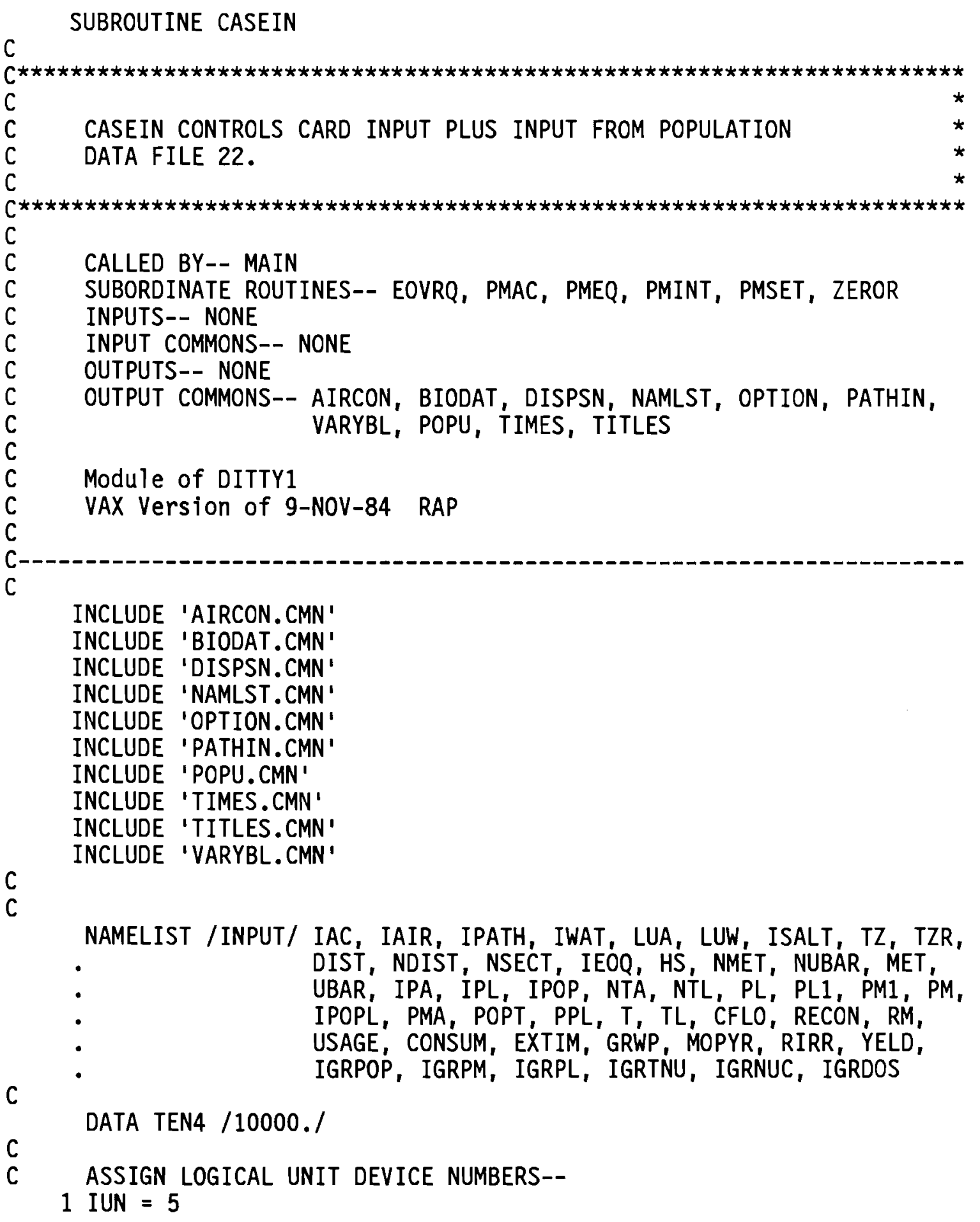

EIGURE D.1. DITTY Program Listing (continued) 
Module CASEIN

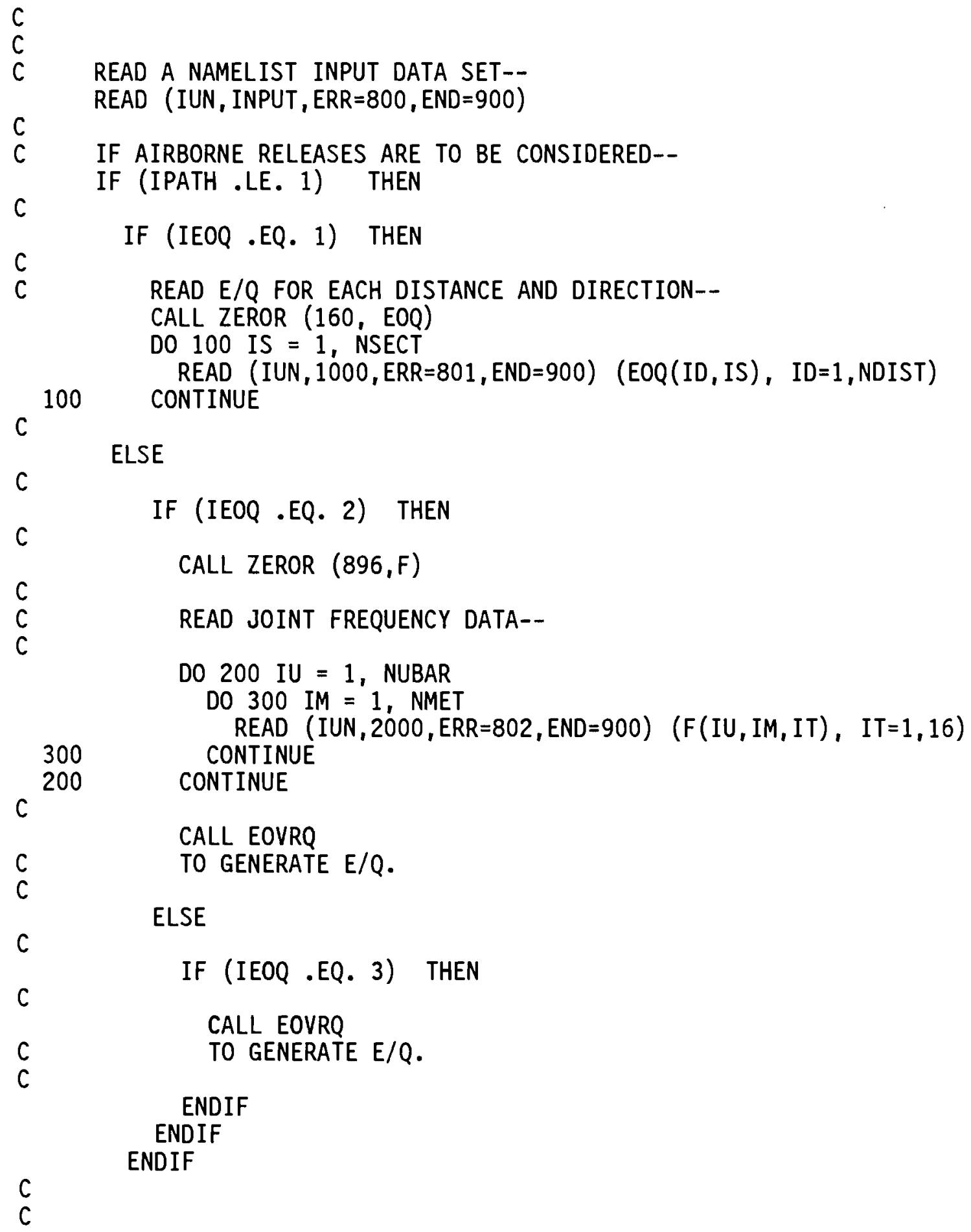

EIGURE D.1. DITTY Program Listing (continued) 


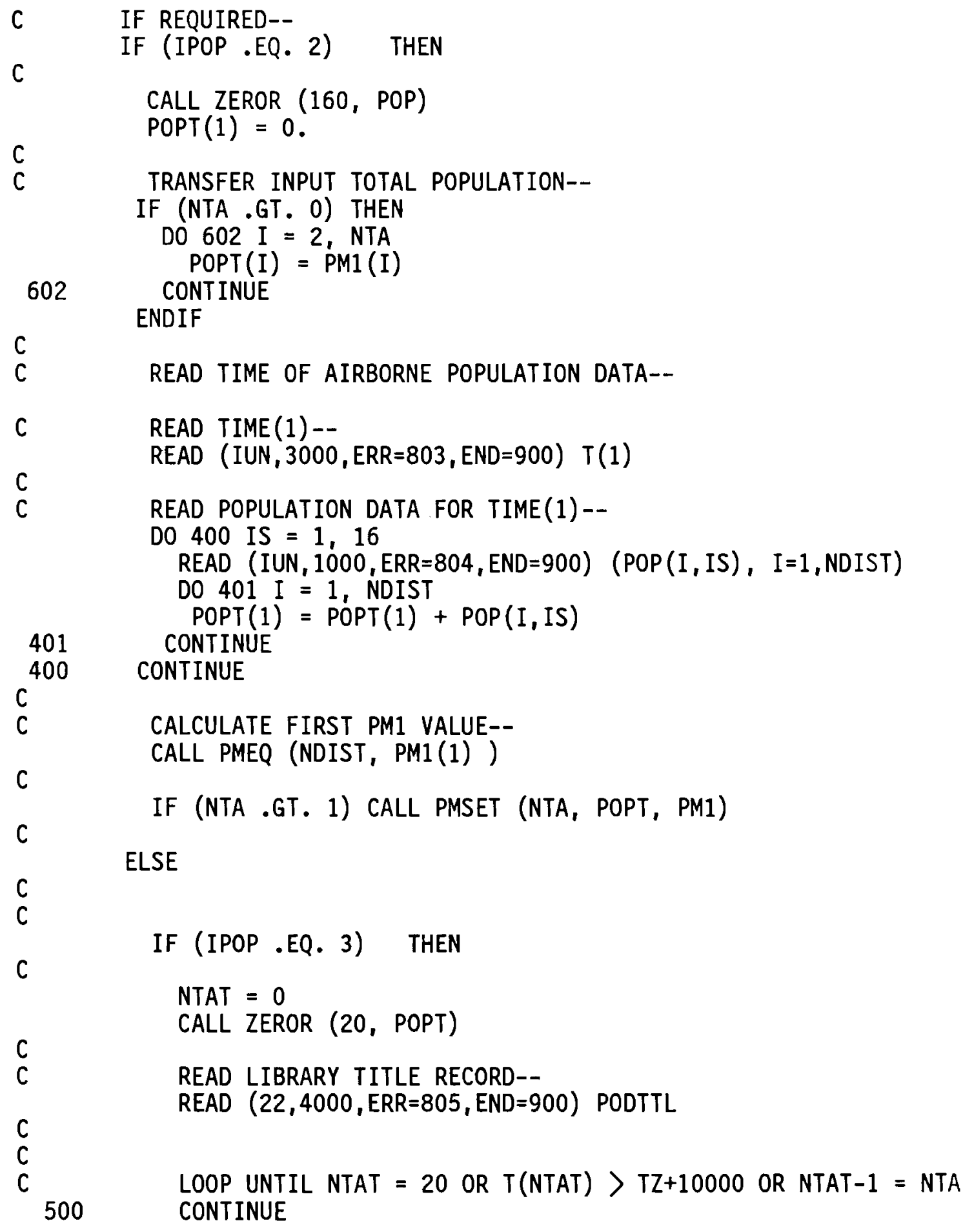




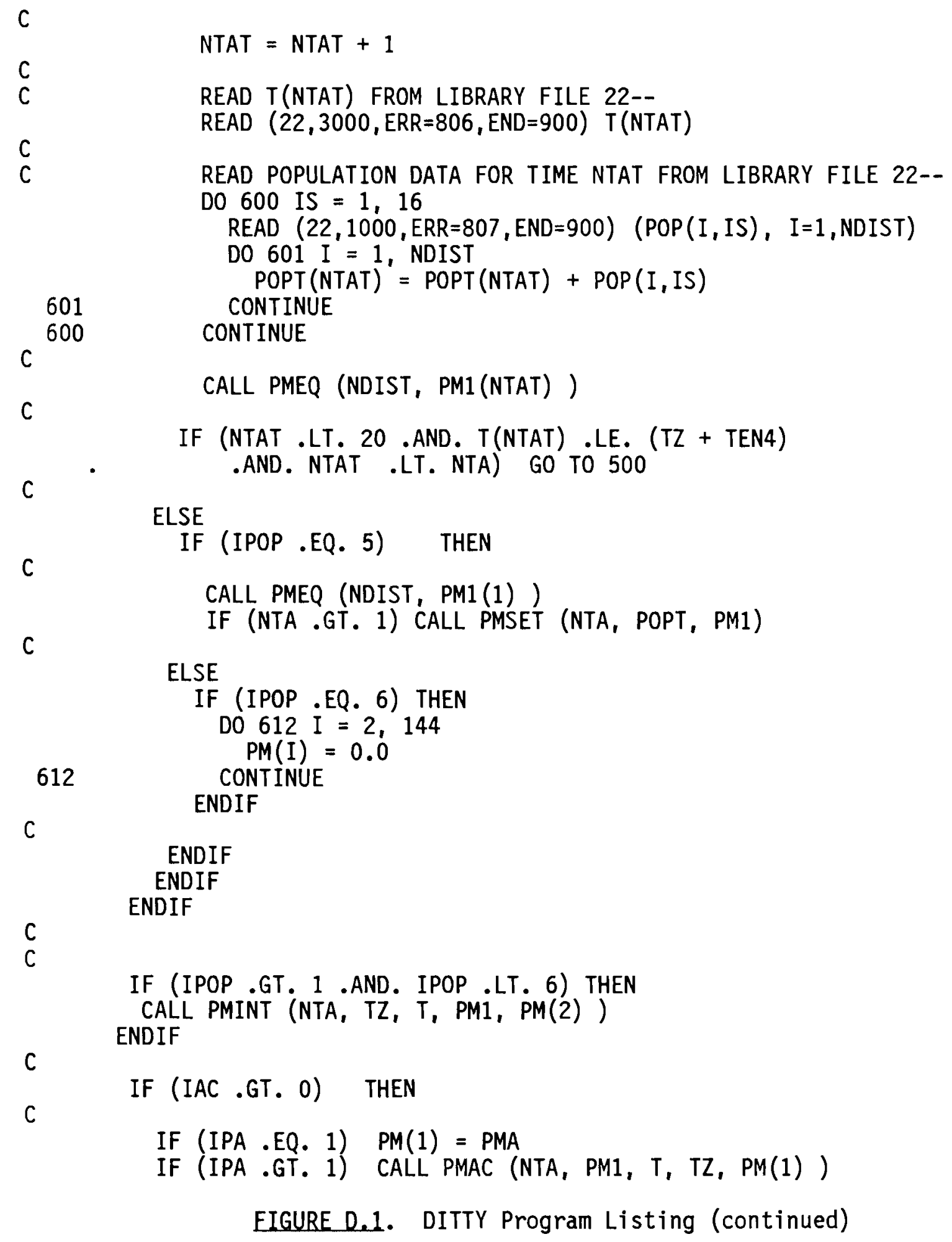

C

ENDIF

ENDIF

ENDIF

C

C

IF (IPOP .GT. 1 .AND. IPOP .LT. 6) THEN ENDIF

CALL PMINT (NTA, TZ, T, PM1, PM(2) )

C

IF (IAC .GT. 0) THEN

C

$$
\begin{aligned}
& \text { IF (IPA .EQ. 1) PM(1) = PMA } \\
& \text { IF (IPA .GT. 1) CALL PMAC (NTA, PM1, T, TZ, PM(1)) }
\end{aligned}
$$

EIGURE D.1. DITTY Program Listing (continued) 


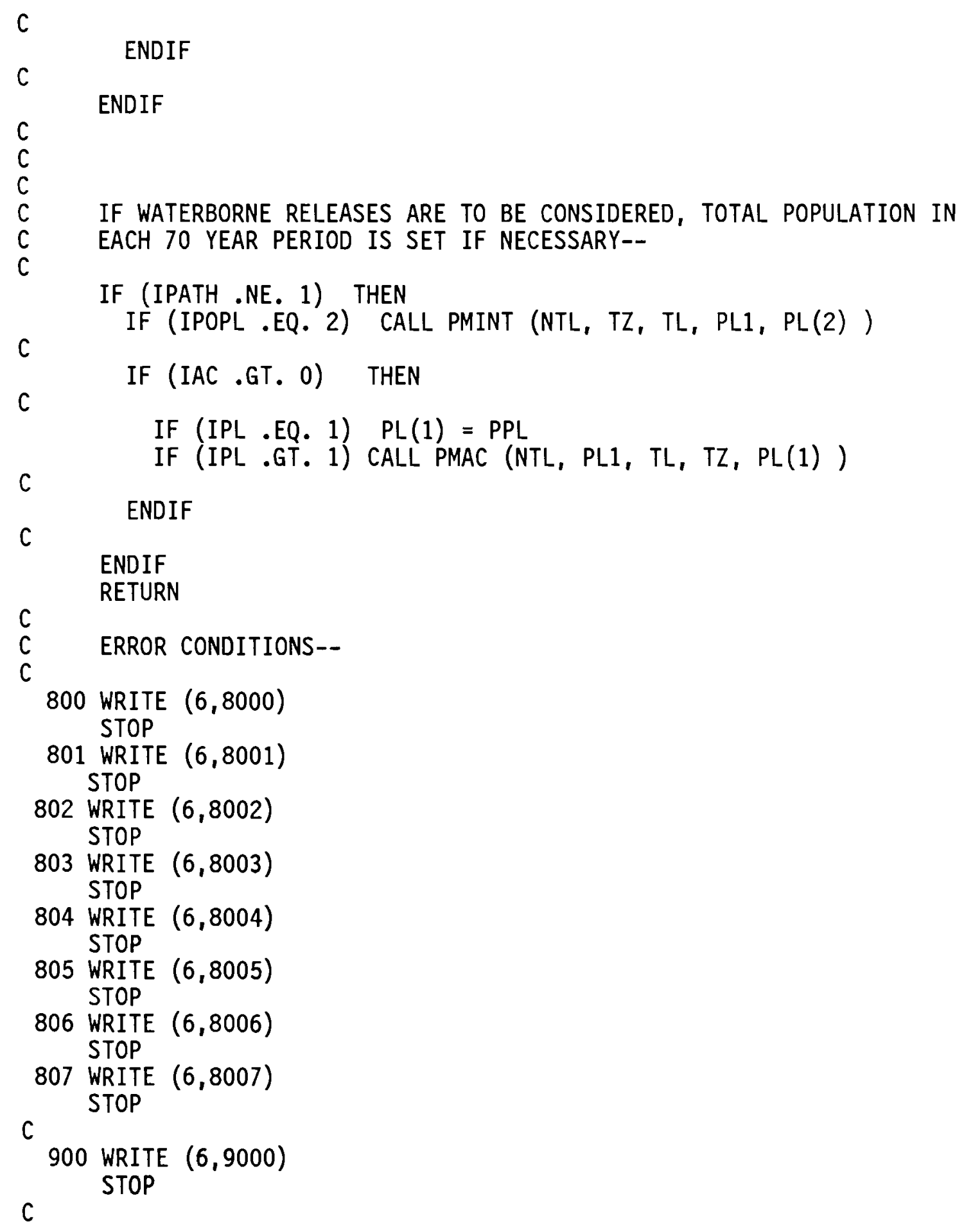

EIGURE D.1. DITTY Program Listing (continued) 
Module CASEIN

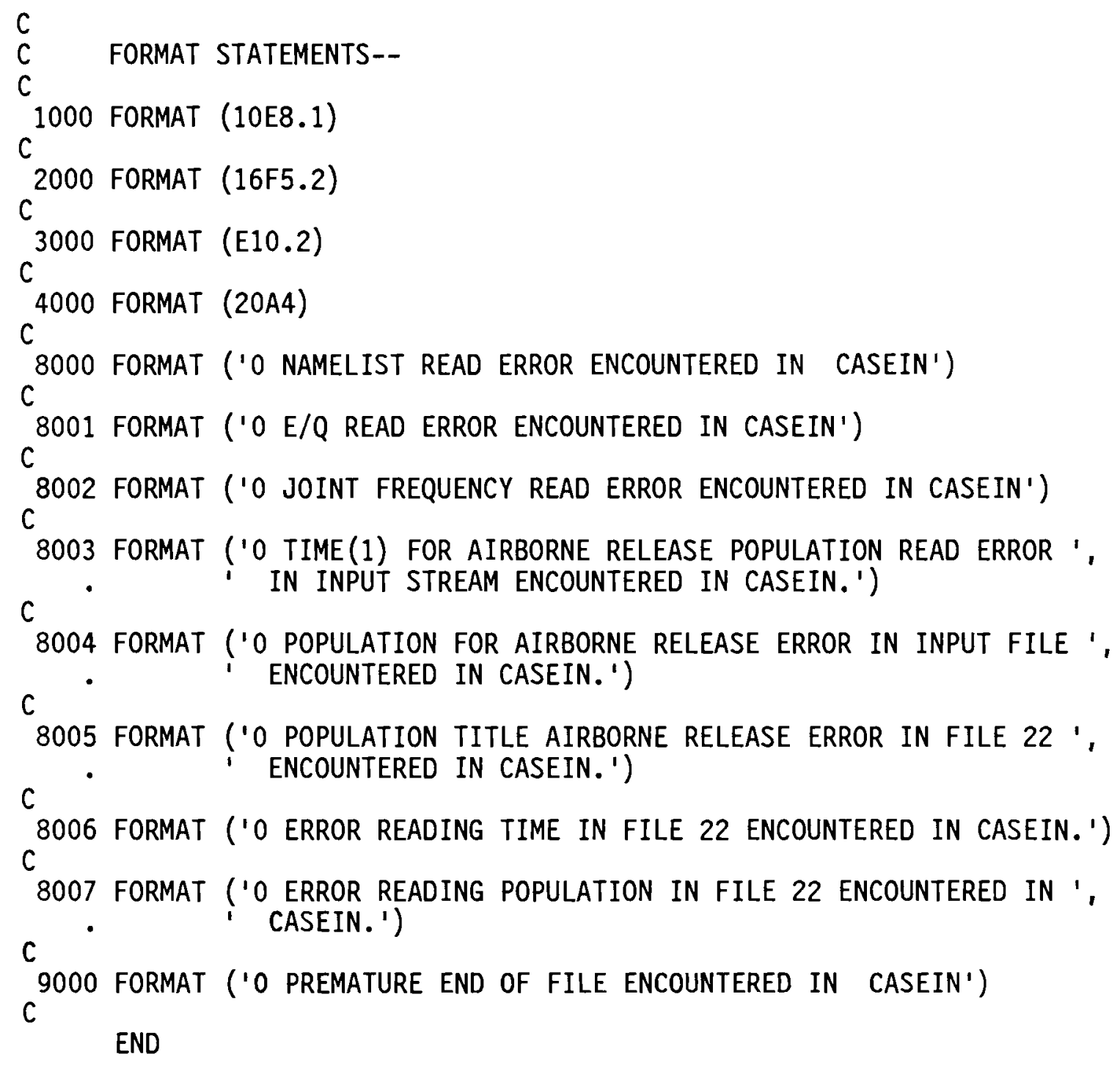

EIGURE D.1. DITTY Program Listing (continued) 
Module CONSET

SUBROUTINE CONSET ( $T, C, N T$, IBEG, IEND, CONS)

C

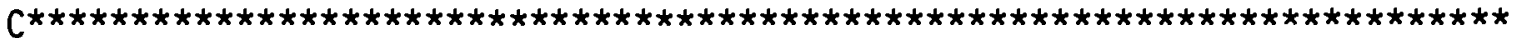

C

C CONSET ESTABLISHES RELEASE DATA FOR ONE RADIONUCLIDE FOR THE

C SEVENTY YEAR INCREMENT.

C

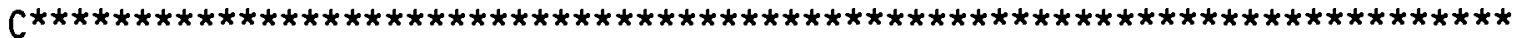

C

CALLED BY-- ACTIN

SUBORDINATE ROUTINES-- NONE

INPUTS-- T, C, NT

INPUT COMMONS -- TIMES

OUTPUTS-- IBEG, IEND, CONS

OUTPUT COMMONS-- NONE

Module of DITTY

VAX Version of 24-SEP-85 RAP

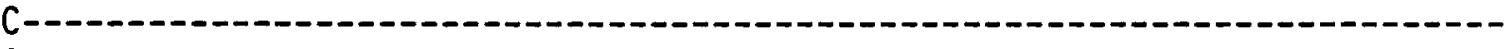

C

C

$-\cdots----1-2$

PARAMETER TYPE

PARAMETER TYPE

DESCRIPTION

$\mathrm{T}(450) \quad$ REAL

TIME POINTS FOR SPECIFYING ACTIVITY RELEASE

C(450) REAL RATES, YEARS SINCE START OF CALCULATION

NT

INTEGER POINT, CI/YR

INTEGER

NO. OF TIME POINTS DATA SUPPLIED FOR IN

IBEG

ARRAYS T \& $C, 2<=N T<=300$

C

C

C

$\mathrm{C}$

C

C

C

IEND

INTEGER

ACTIVITY FOR THE CURRENT RADIONUCLIDE

CONS(143) REAL LAST 70-YR INCREMENT THAT HAS A NON-ZERO RELEASE ACTIVITY FOR THE CURRENT NUCLIDE TOTAL ACTIVITY RELEASED IN EACH OF THE 143 70-YR INCREMENTS, CI

DIMENSION T(450), $C(450)$, CONS(144)

INCLUDE 'TIMES.CMN'

INCLUDE 'OPTION.CMN'

EIGURE 0.1. DITTY Program Listing (continued) 


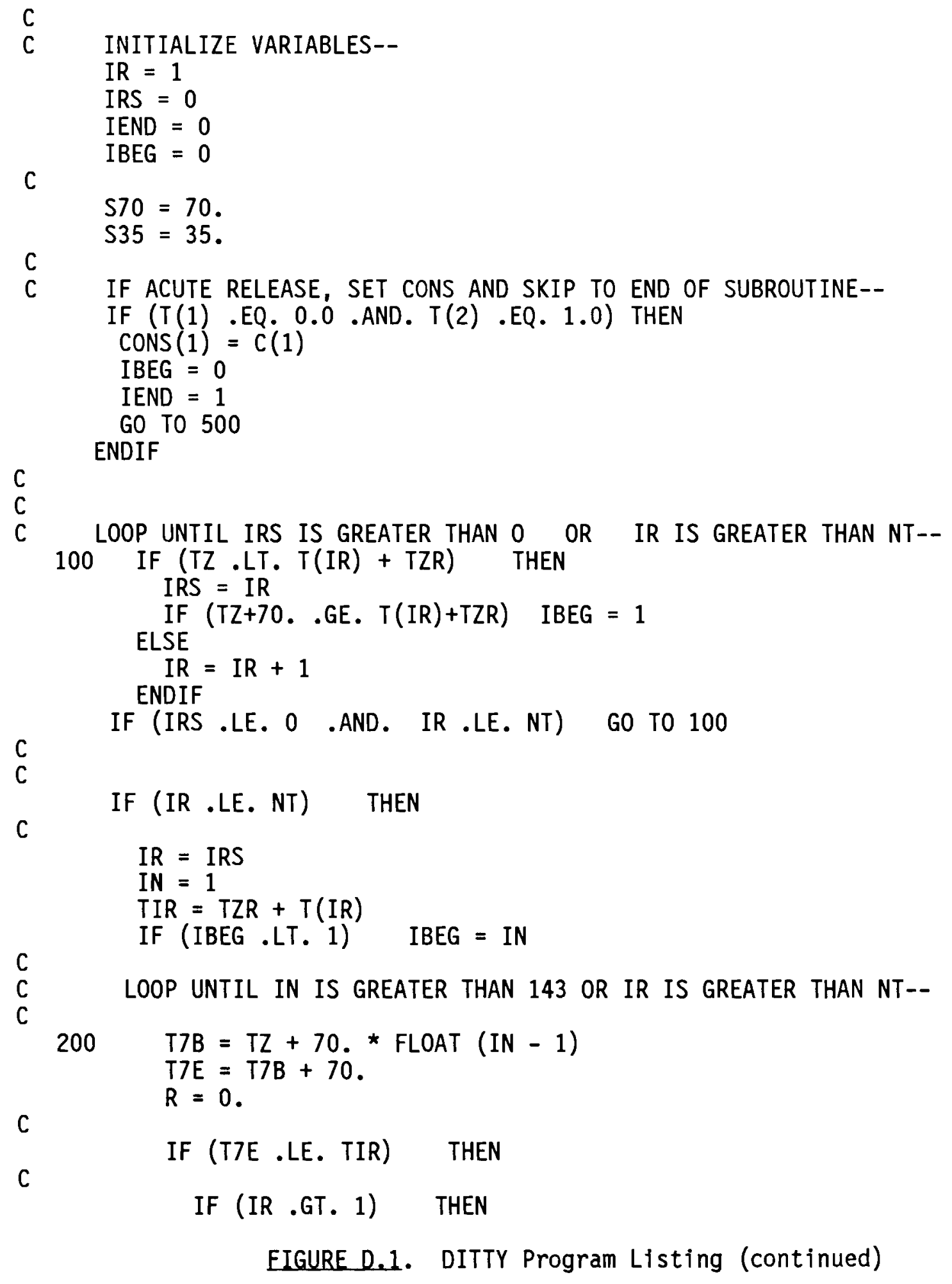


c

C

C

$$
\begin{aligned}
& C I R=C(I R) \\
& T I R=T(I R)+T Z R
\end{aligned}
$$

$$
\text { SLOPE }=(C I R-C(I R-1)) /(T I R-T(I R-1)-T Z R)
$$$$
\text { CONS }(I N+1)=S 35 * S L O P E *(T 7 E+T 7 B)+S 70 * C I R
$$$$
- \text { S70 * SLOPE * TIR }
$$

c

C

ENDIF

C

$I N=I N+1$

C

ELSE

C

$$
\text { IF (IR . GT. 1) THEN }
$$

$$
\begin{aligned}
& T I R=T Z R+T(I R) \\
& C 1=C(I R-1) \\
& C 2=C(I R) \\
& T 1=T Z+T(I R-1) \\
& C 7=(C 2-C 1) *(T 7 B-T 1) /(T I R-T 1)+C 1 \\
& R=(C 2+C 7) *(T I R-T 7 B) / 2 .
\end{aligned}
$$

C

\section{ENDIF}

C

C

C

$I R=I R+1$

IF (IR .LE. NT) THEN

$$
\text { KEND }=0
$$

LOOP UNTIL END IS GREATER THAN $O$ OR IR IS GREATER THAN NT--

$T I R=T Z R+T(I R)$

IF (T7E .LE. TIR) THEN

$$
\begin{aligned}
& \text { KEND }=1 \\
& C 1=C(I R-1) \\
& C 2=C(I R) \\
& T 1=T R+T(I R-1) \\
& C 7=(C 2-C 1) \star(T 7 E-T 1) /(T I R-T 1)+C 1 \\
& R=R+(C 1+C 7) \star(T 7 E-T 1) / 2 .
\end{aligned}
$$

EIGURE D.1. DITTY Program Listing (continued) 
Module CONSET

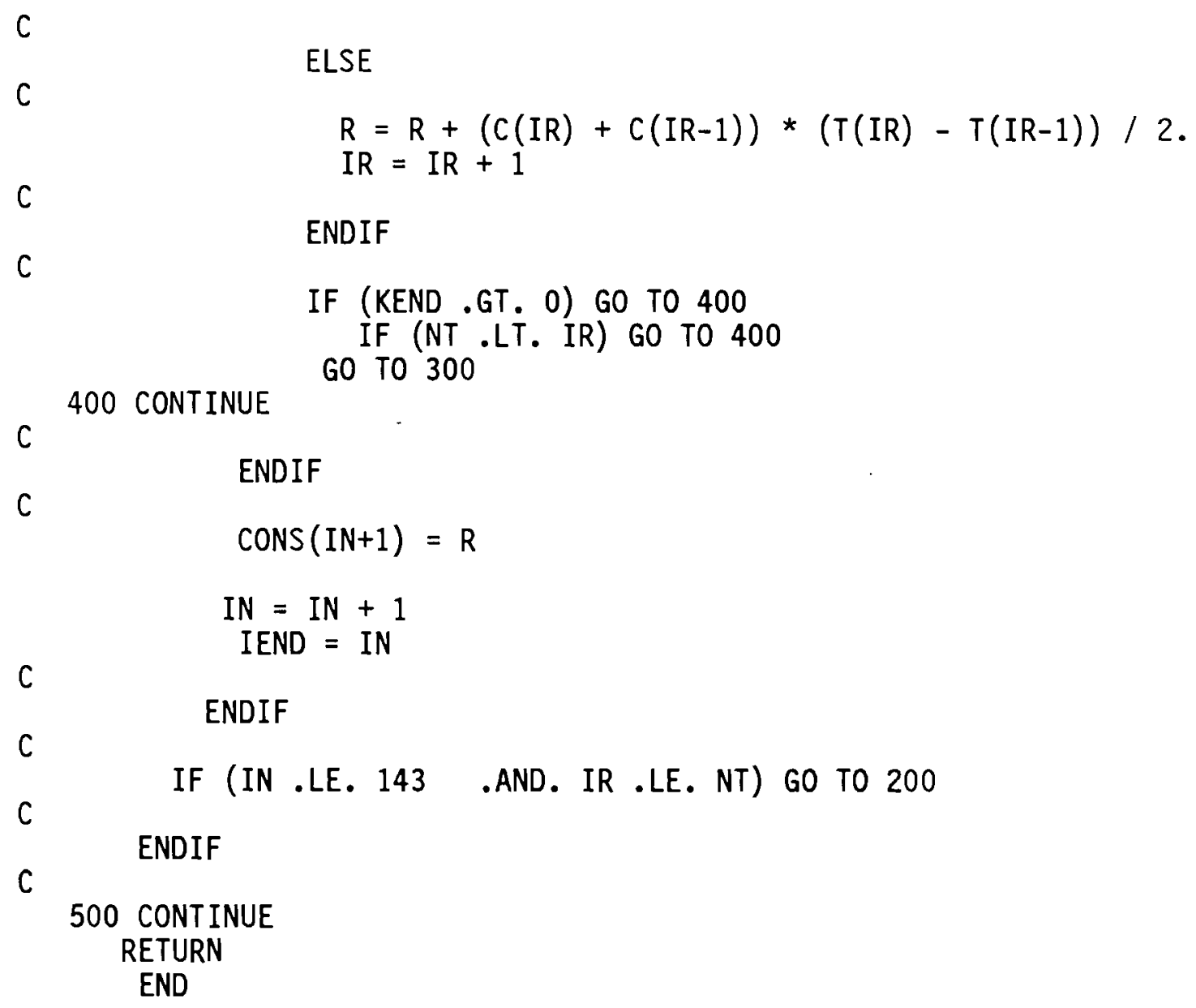

EIGURE D.1. DITTY Program Listing (continued) 
Module CONTRL

SUBROUTINE CONTRL (IAC, IPATH, ITAM, ITAX, ITWM, ITWX)

C

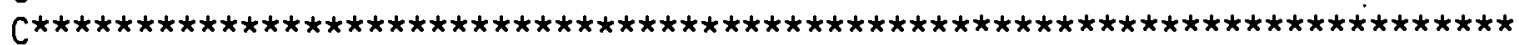

C

C

C

C

THIS ROUTINE CONTROLS THE CALLING OF THE ROUTINES CALCULATING * ENVIRONMENTAL ACCUMULATION AND DECAY OF RADIONUCLIDES AND *

THE CALCULATION AND SUMATION OF RESULTING DOSES *

C

C

C

C

\section{CALLED BY - MAIN}

C

C

C

$\mathrm{C}$

C Module of DITTY

C VAX Version of 12-SEP-84 RAP

C

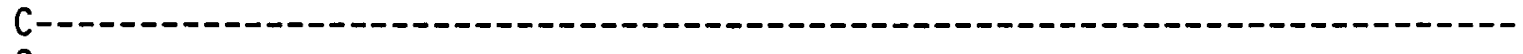

C

C

C

C

C

C

C

C

C

C

$\mathrm{C}$

C

C

INCLUDE 'EDCN.CMN'

INCLUDE 'OUTORG.CMN'

INCLUDE 'RESULT.CMN'

ARGUMENT LIST PARAMETER DESCRIPTIONS

PARAMETER TYPE

DESCRIPTION

IAC

INTEGER

IF >0, CONSIDER AN ACUTE RELEASE PERIOD

IPATH

INTEGER

AT BEGINNING OF 70-YR PERIOD

ITAM

INTEGER

PATHWAY SELECTION: $B O T H=0, A I R=1$, WATER $=2$

C

INITIALIZE CONCENTRATION ARRAYS--

CALL ZEROR (100, SLCON)

CALL ZEROR (100, AIRCON)

EIGURE D.1. DITTY Program Listing (continued) 
Module CONTRL

CALL ZEROR (700, EDBCON)

CALL ZEROR (100, WATCON)

CALL ZEROR (100, SCONW)

CALL ZEROR (100, SEDCON)

CALL ZEROR (700, EDBCNW)

CALL ZEROR (500, AQUATC)

CALL ZEROR (720, DTOTAL)

CALL ZEROR (500, POPDOS)

C

C

IF (IAC . GT. O) THEN

C

IF (IPATH .LE. 1) CALL APATHS (1, ITAX)

C TO CALCULATE CONCENTRATIONS FROM ATMOSPHERIC DEPOSITION.

IF (IPATH .NE. 1) CALL WPATHS (1, ITWX)

C TO CALCULATE CONCENTRATIONS FROM AQAUATIC PATHWAYS.

ENDIF

C

FOR EACH 70-YR TIME STEP FOR 10,000 YEARS--

DO 100 ITT $=2,144$

C

IF (IPATH .LE. 1 .AND. (ITT .GE. ITAM .OR. IAC .GT. 0)) THEN CALL APATHS (ITT, ITAX)

C ENDIF

Third parameter added to call list to indicate acute/chronic case-CALL DOSADD $(1,1$, IAC)

TO ACCUMULATE 70-YR INCREMENTAL DOSES.

IF (IPATH .NE. 1 .AND. (ITT .GE. ITWM .OR. IAC .GT. 0)) THEN CALL WPATHS (ITT, ITWX) ENDIF

C

CALL DOSADD (2, ITT, IAC)

C

100 CONTINUE

C

C

\author{
RETURN \\ END
}

EIGURE D.1. DITTY Program Listing (continued) 
Module CONTRL

SUBROUTINE DOSADD (ICUTE, ITT, IAC)

C

C

$c$

C DOSADDD CALCULATES 70-YEAR INCREMENTAL POPULATION DOSES *

C FROM EXPOSURE TO CONTAMINATED ENVIRONMENTAL MEDIA *

C

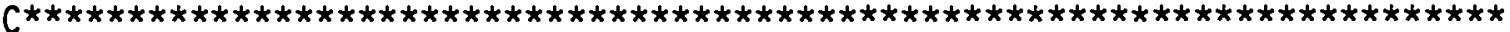

C

C CALLED BY-- CNTRL

C SUBORDINATE ROUTINES-- ZEROR

C INPUTS-- ICUTE, ITT, IAC

c INPUT COMMONS-- PATHIN, EDCN, DOSFAC, GRDDAT, DKAY, ORGID, DOSIN

C OUTPUTS-- NONE

c OUTPUT COMMONS-- RESULT, OUTORG

C Module of DITTY

C Version of 19-NOV-84 RAP

C

$$
\text { C }
$$

C

C

C

C

C

C

C

C

C

C

INCLUDE 'PATHIN.CMN'

INCLUDE 'EDCN.CMN'

INCLUDE 'DKAY.CMN'

INCLUDE 'ORGID.CMN'

INCLUDE 'OUTORG.CMN'

INCLUDE 'DOSFAC.CMN'

INCLUDE 'GRDDAT.CMN'

INCLUDE 'RESULT.CMN'

C

EIGURE D.1. DITTY Program Listing (continued) 
Module DOSADD

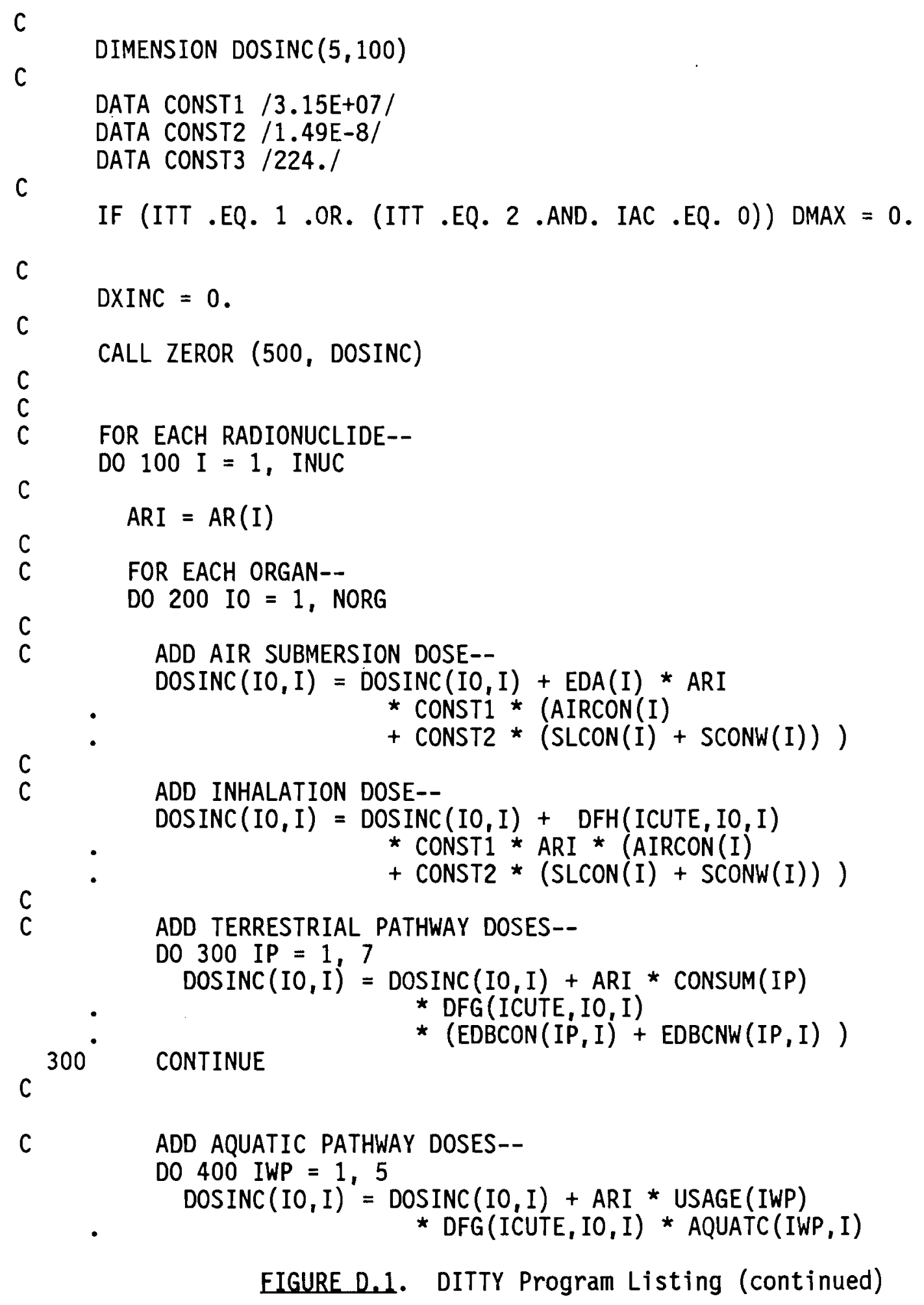

EIGURE D.1. DITTY Program Listing (continued) 
Module DOSADD

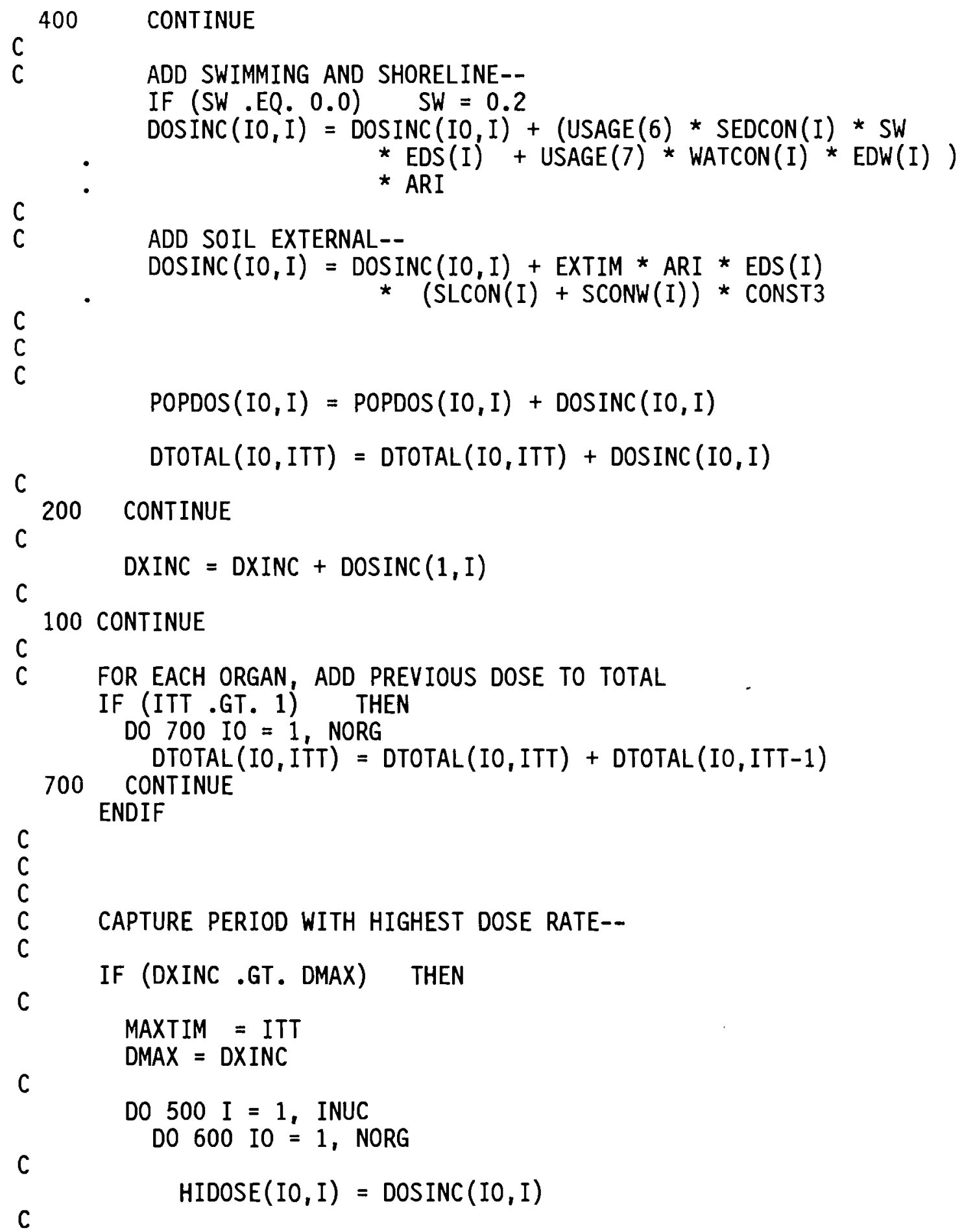

EIGURE D.1. DITTY Program Listing (continued) 
Module DOSADD

\begin{tabular}{|c|c|}
\hline $\begin{array}{l}600 \\
500\end{array}$ & $\begin{array}{l}\text { CONTINUE } \\
\text { CONTINUE }\end{array}$ \\
\hline & ENDIF \\
\hline & $\begin{array}{l}\text { RETURN } \\
\text { END }\end{array}$ \\
\hline
\end{tabular}

EIGURE D.1. DITTY Program Listing (continued)

D. 46 


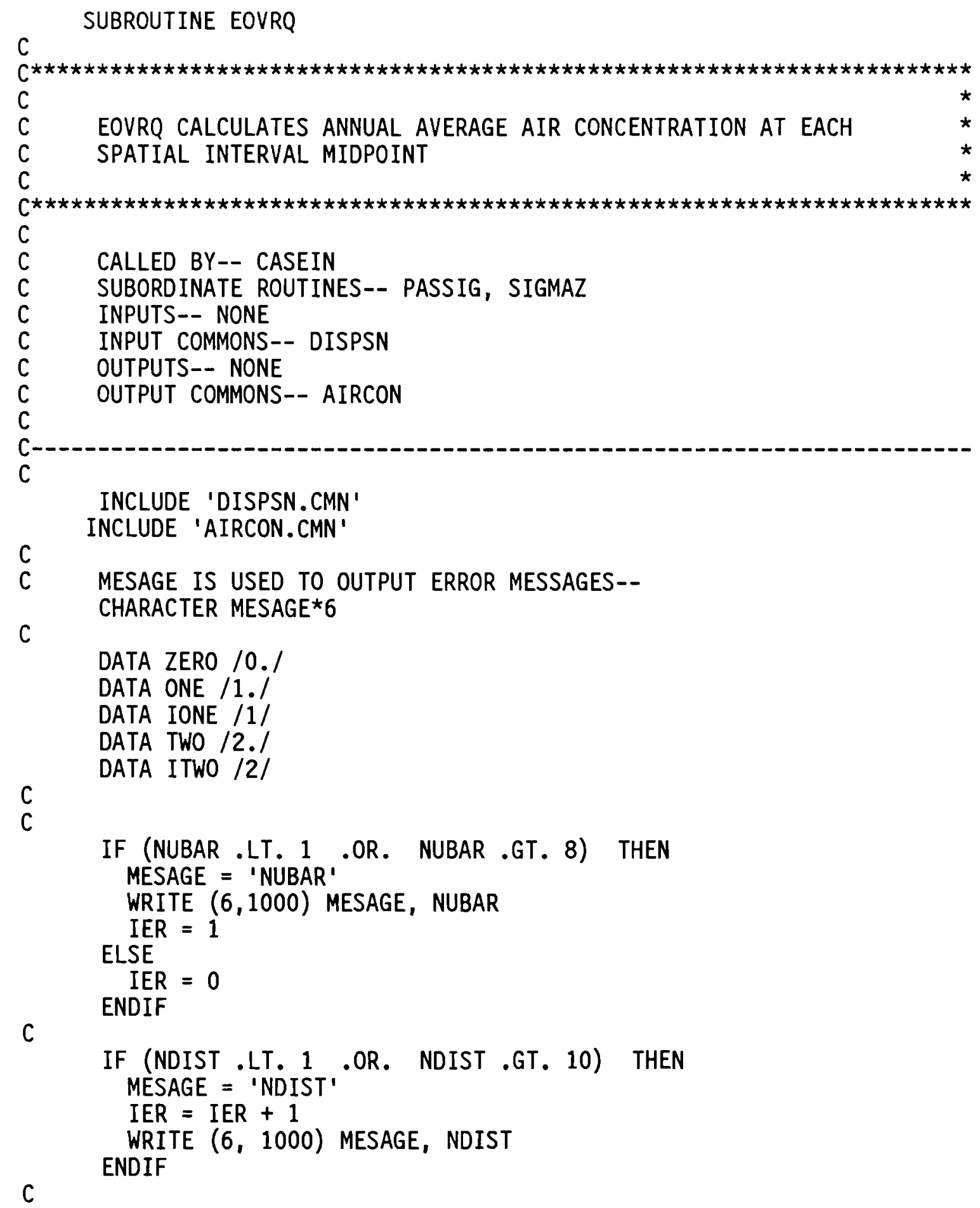

EIGURE D.1. DITTY Program Listing (continued) 


\section{Module EOVRQ}

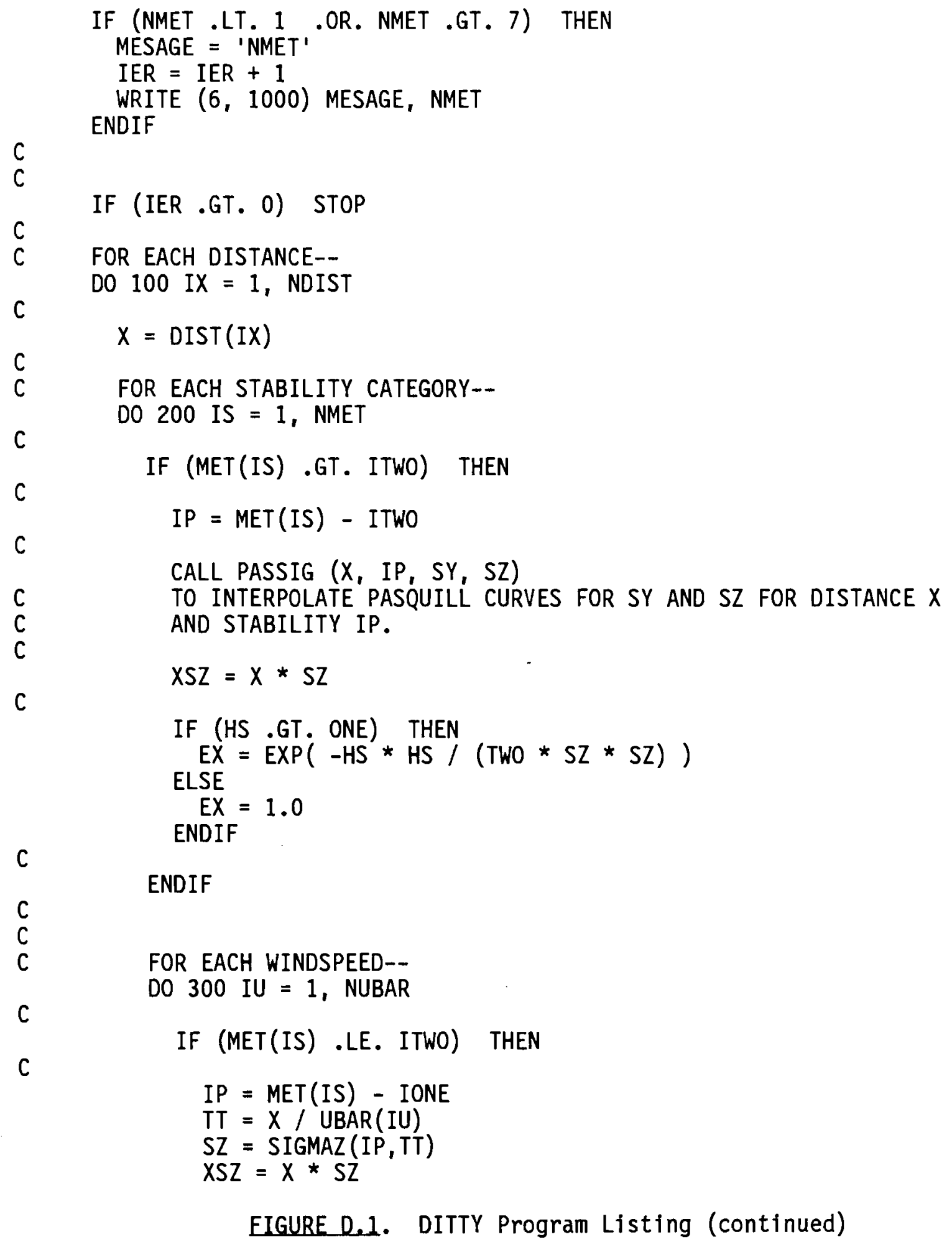

EIGURE D.1. DITTY Program Listing (continued) 


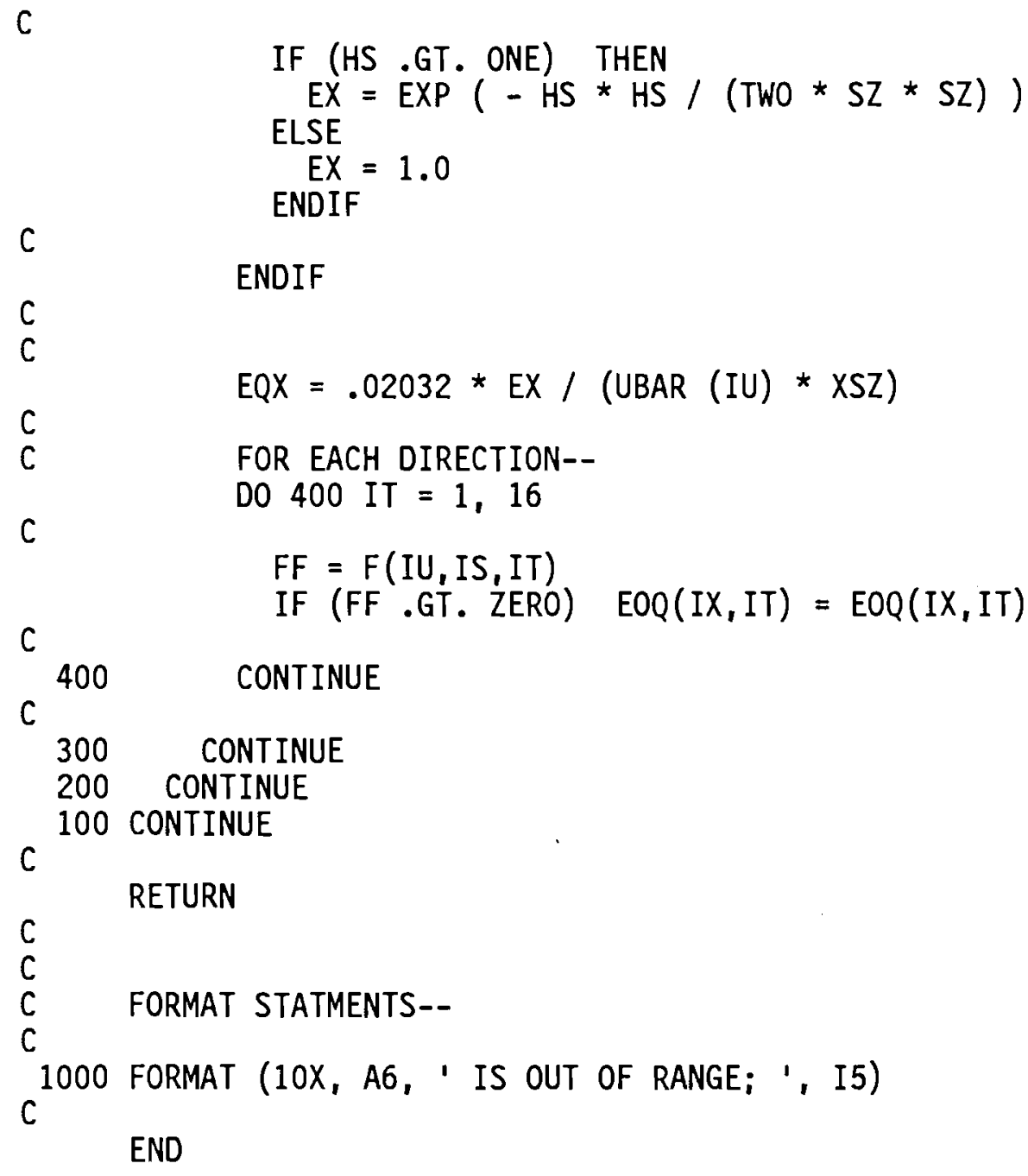

END

EIGURE D.1. DITTY Program Listing (continued) 


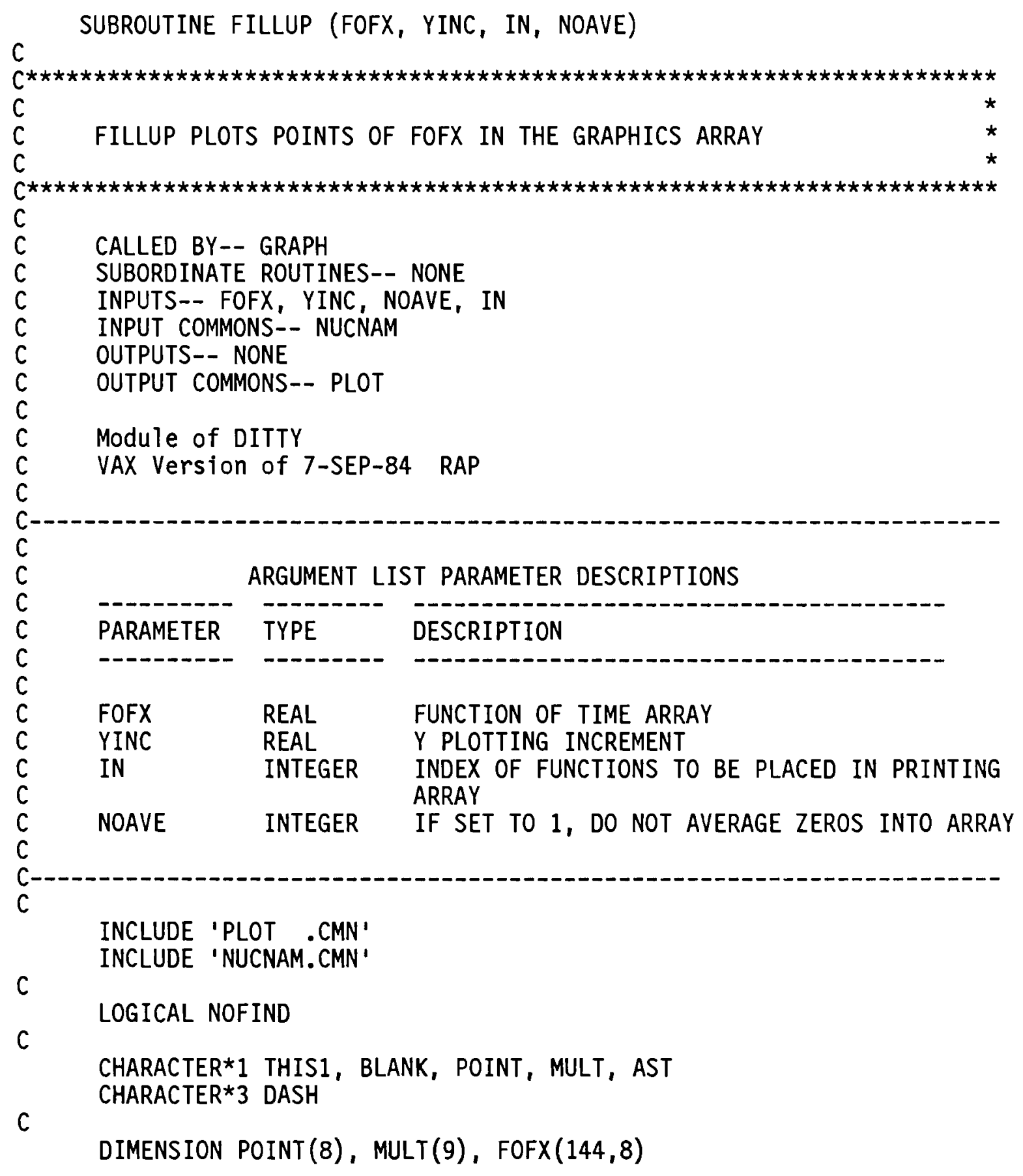

EIGURE 0.1. DITTY Program Listing (continued) 
C

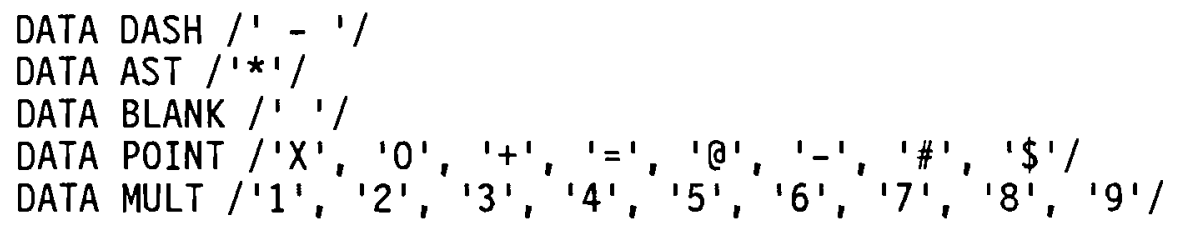

C

DATA IY $/ 40 /$

DATA IX $/ 73 /$

C

C

C

PLOT EACH POINT IN ARRAY--

DO $100 I=1, I X$

C

C

$$
I 2=(I-1) * 2
$$$$
\text { IF ( I .EQ. 1) THEN }
$$

$C$

FIRST VALUE OF ARRAY--

$\mathrm{R} 1=\operatorname{FOFX}(1, \mathrm{IN}) / \mathrm{YINC}$

C

C

ELSE

C

C

C

C

C

C

C

C

IF ( I .EQ. IX) THEN

LAST VALUE OF ARRAY--

$R 1=\operatorname{FOFX}(144, I N) / Y I N C$

ELSE

FOR ALL OTHER POINTS--

$F 1=F O F X(I 2, I N)$

$F 2=F O F X(I 2+1, I N)$

$R 1=(F 1+F 2) / Y I N C$

IF (NOAVE .GT. O) THEN

AVERAGE IF NEITHER POINT IS EQUAL TO ZERO--

IF (F1 .GT. 0. .AND. F2 .GT. 0.) THEN $R 1=R 1 * 0.5$

ENDIF

EIGURE 0.1. DITTY Program Listing (continued) 


\section{Module FILLUP}

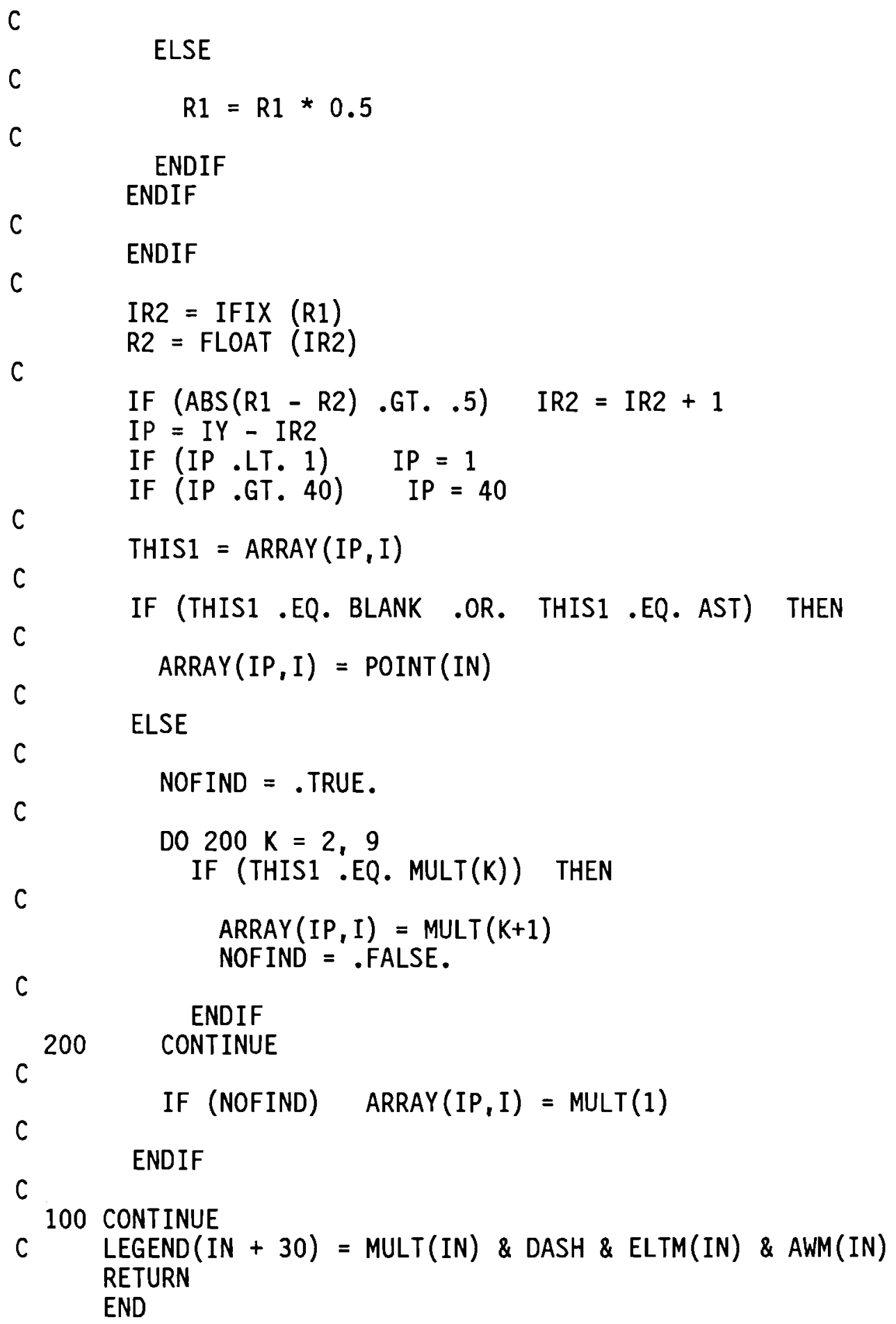

C

EIGURE D.1. DITTY Program Listing (continued) 
Module FOOLIN

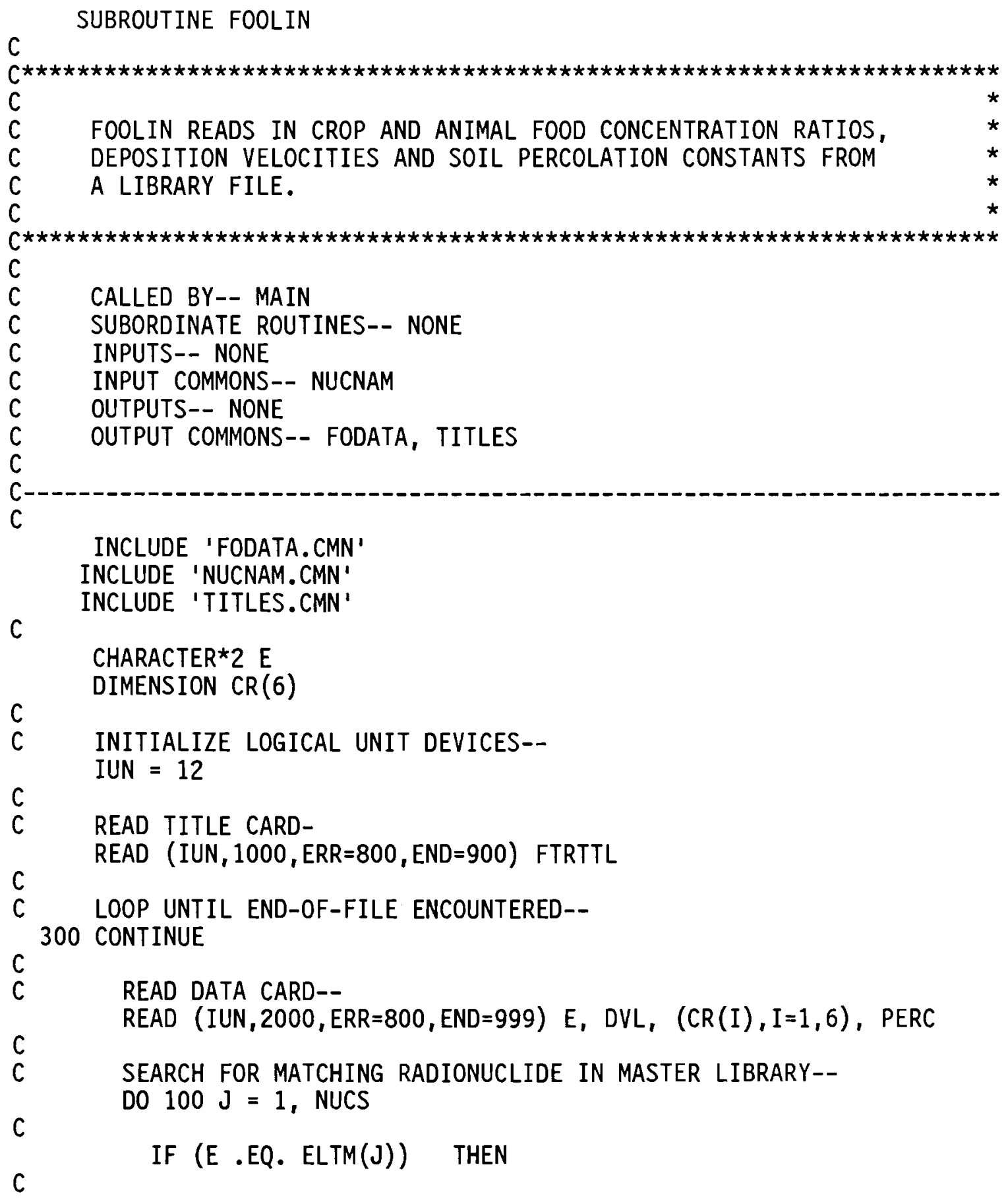

EIGURE D.1. DITTY Program Listing (continued) 
Module FOOLIN

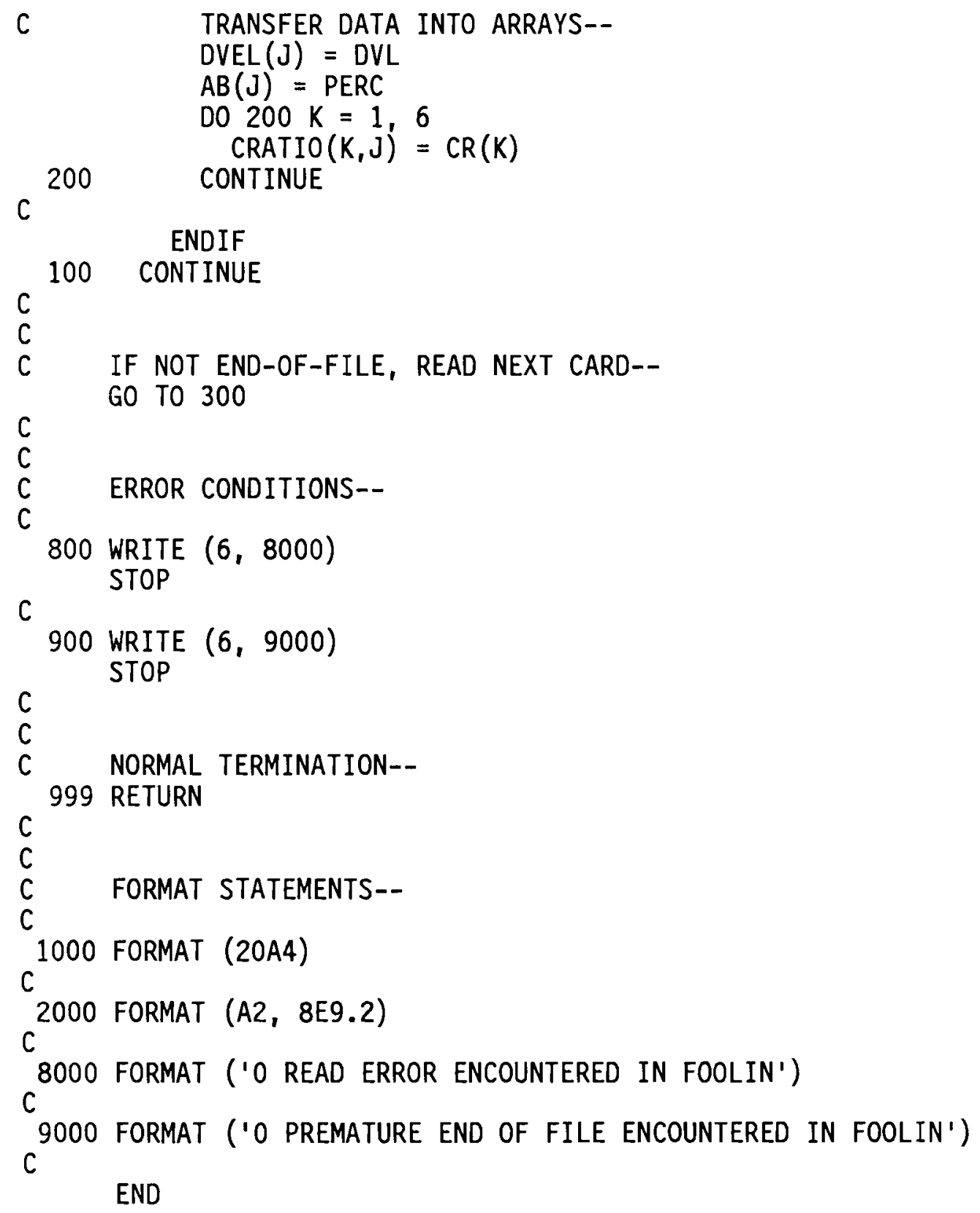

END

EIGURE 0.1. DITTY Program Listing (continued) 
Module FOOLIN

SUBROUTINE GRAPH (IYL, FOFX, NGRF, IORNUC, IFROM, NOAVE, IGRAW)

C

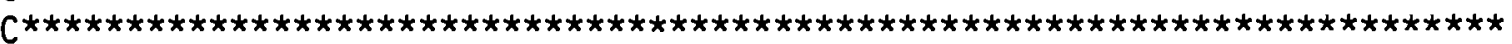

$\mathrm{C}$

$\mathrm{C}$

C

GRAPH CONTROLS THE PRINTING OF GRAPHS OF FUNCTIONS IN *

RELATION TO TIME

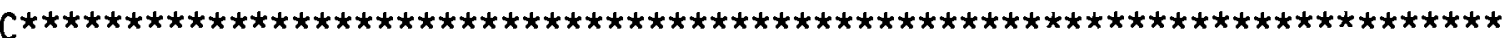

C

C CALLED BY-- QAPAGE, REPORT

C SUBORDINATE ROUTINES-- SETUP, FILLUP, PRTGRF, HEADNG

C INPUTS-- IYL, FOFX, NGRF

C INPUT COMMONS-- ORGID, NUCNAM

C OUTPUTS-- NONE

c OUTPUT COMMONS-- NONE

C Module of DITTY

C VAX Version of 17-OCT-84 RAP

C

C

C

C

C

C

C

C

C

C

C

C

C

C

C

C

C

C

INCLUDE 'ORGID.CMN'

INCLUDE 'NUCNAM.CMN'

c

CHARACTER YLABEL* $1, Y L A B 5 * 1, Y L A B 7 * 1$

C

ARGUMENT LIST PARAMETER DESCRIPTIONS

PARAMETER TYPE DESCRIPTION

IYL

INTEGER

INDEX OF FUNCTION LABEL ARRAY

FOFX

REAL

FUNCTION OF TIME ARRAY

NGRF

INTEGER

IORNUC

INTEGER

ON THIS GRAPH

IFROM

INTEGER

INDEX OF RADIONULIDE OR ORGAN TO BE GRAPHED

NOAVE

INTEGER

CALLED FROM: $0=$ QAPAGE, 1 = REPORT

IGRAW

INTEGER

IF SET TO 1, DO NOT AVERAGE IN ZERO VALUES

RELEASE MESSAGE FLAG; $0=$ NO MESSAGE, $1=$ AIR MESSAGE, 2 = WATER MESSAGE

CHARACTER YLA* 40

DIMENSION YLA(7)

EIGURE D.1. DITTY Program Listing (continued) 
Module GRAPH

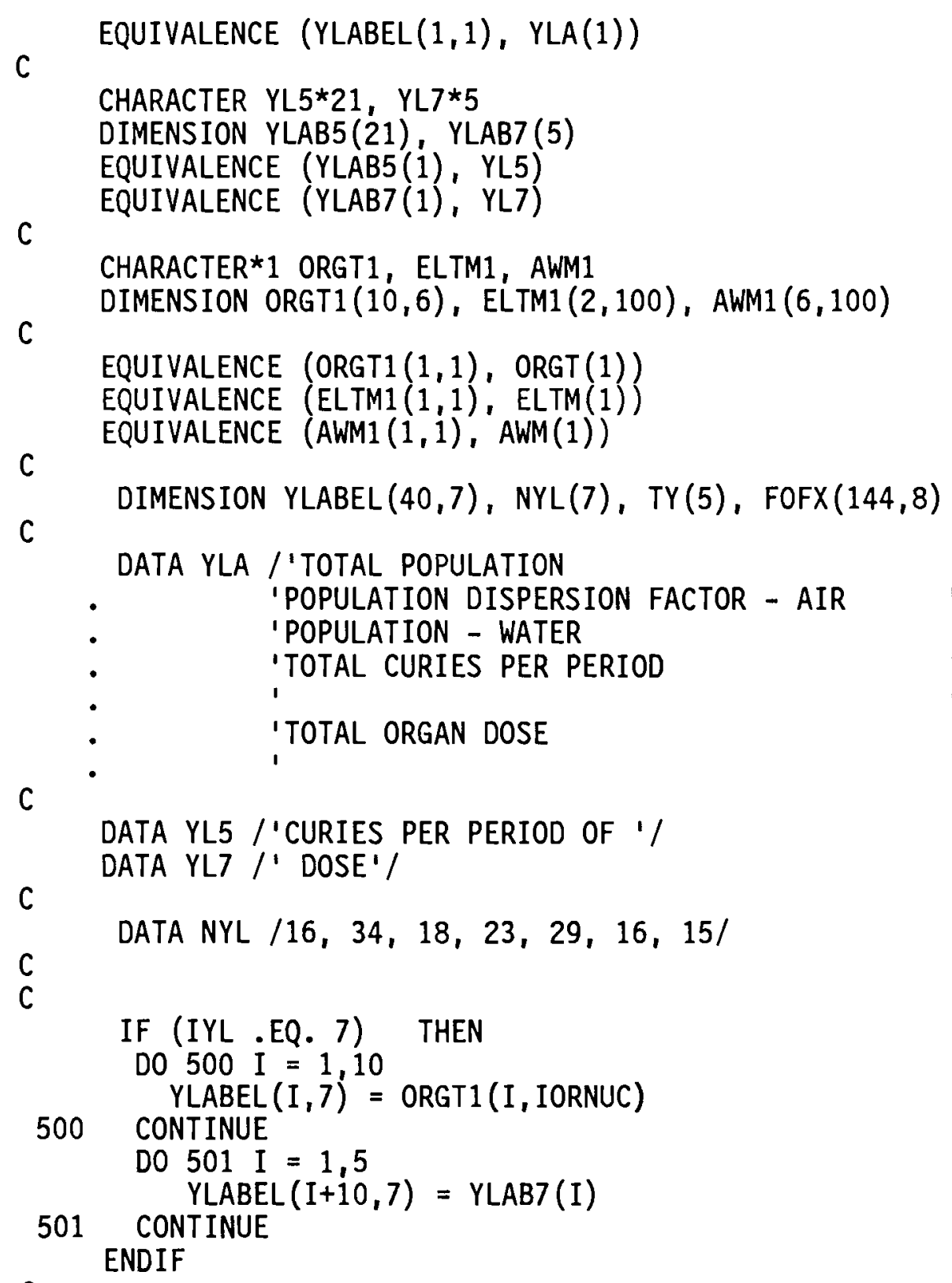

EIGURE D.1. DITTY Program Listing (continued) 


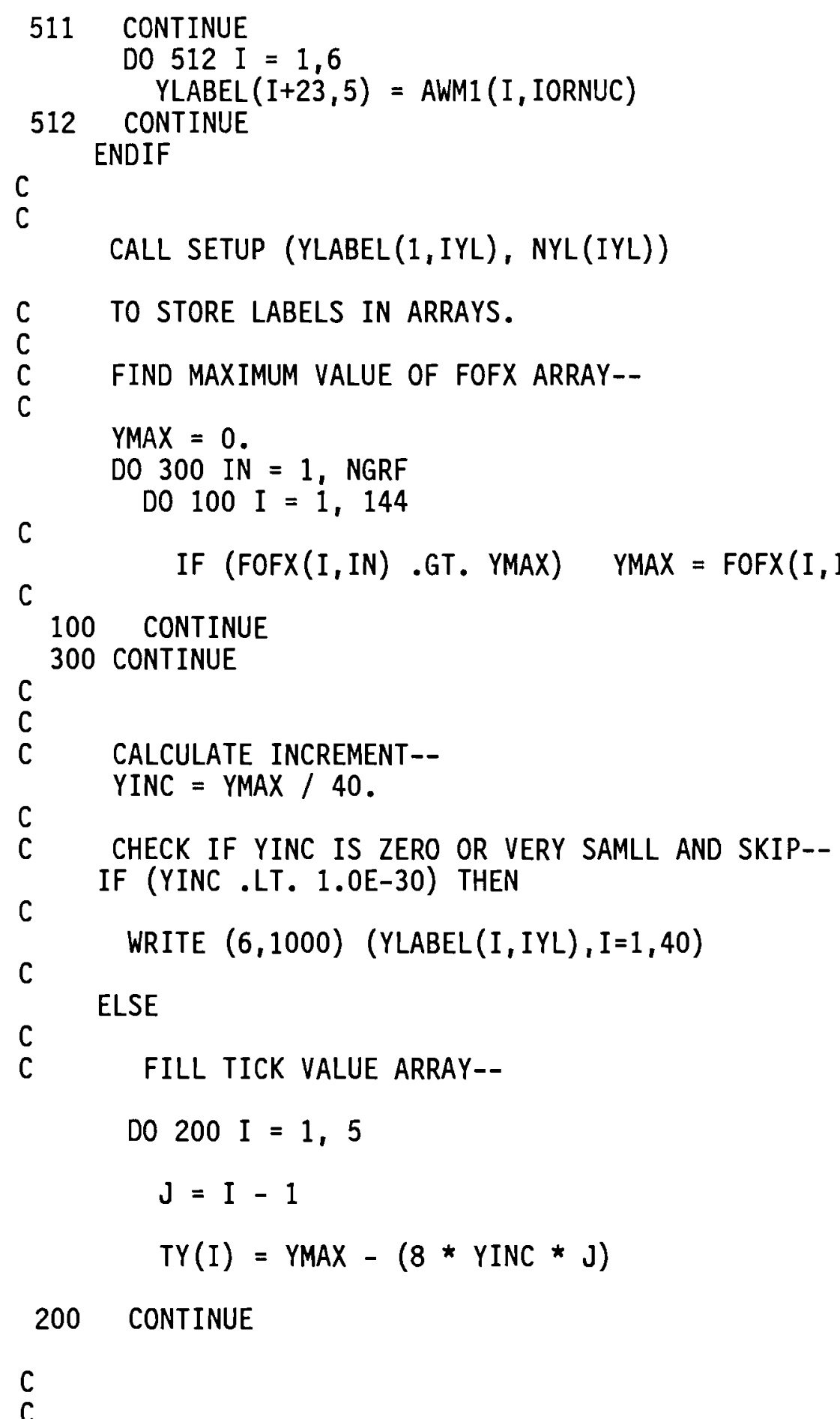

EIGURE 0.1. DITTY Program Listing (continued) 
Module GRAPH

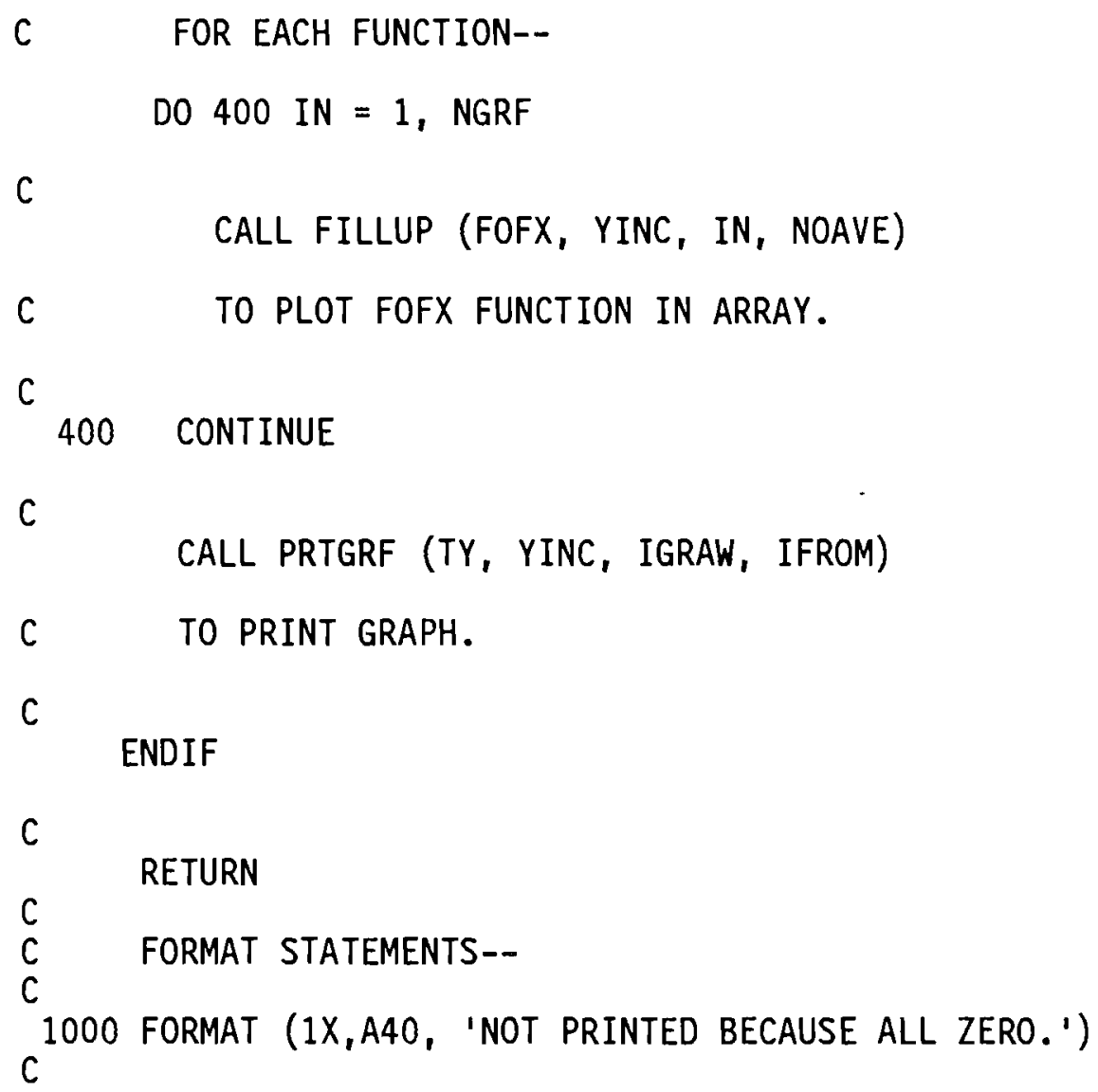

EIGURE D.1. DITTY Program Listing (continued) 


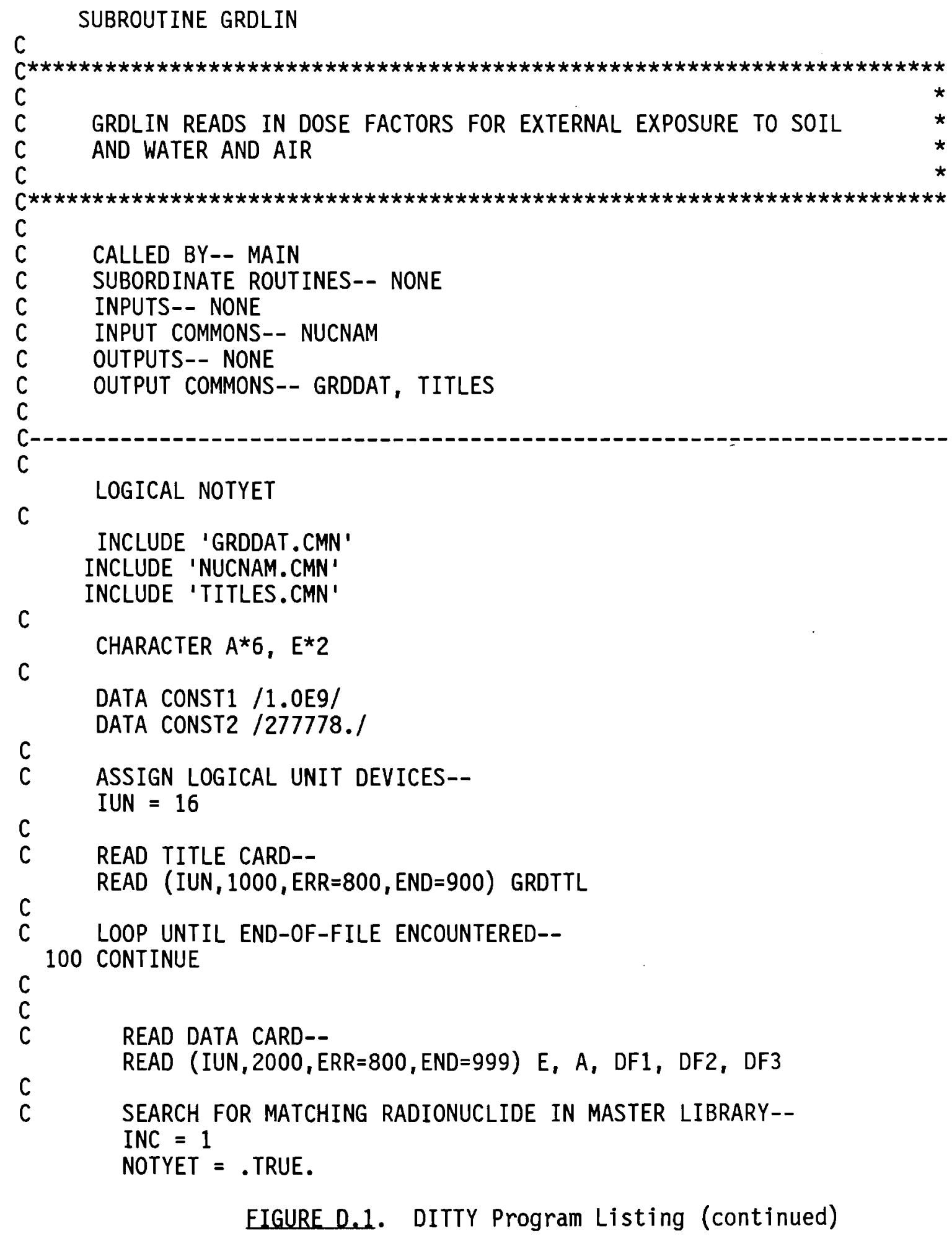


Module GRDLIN

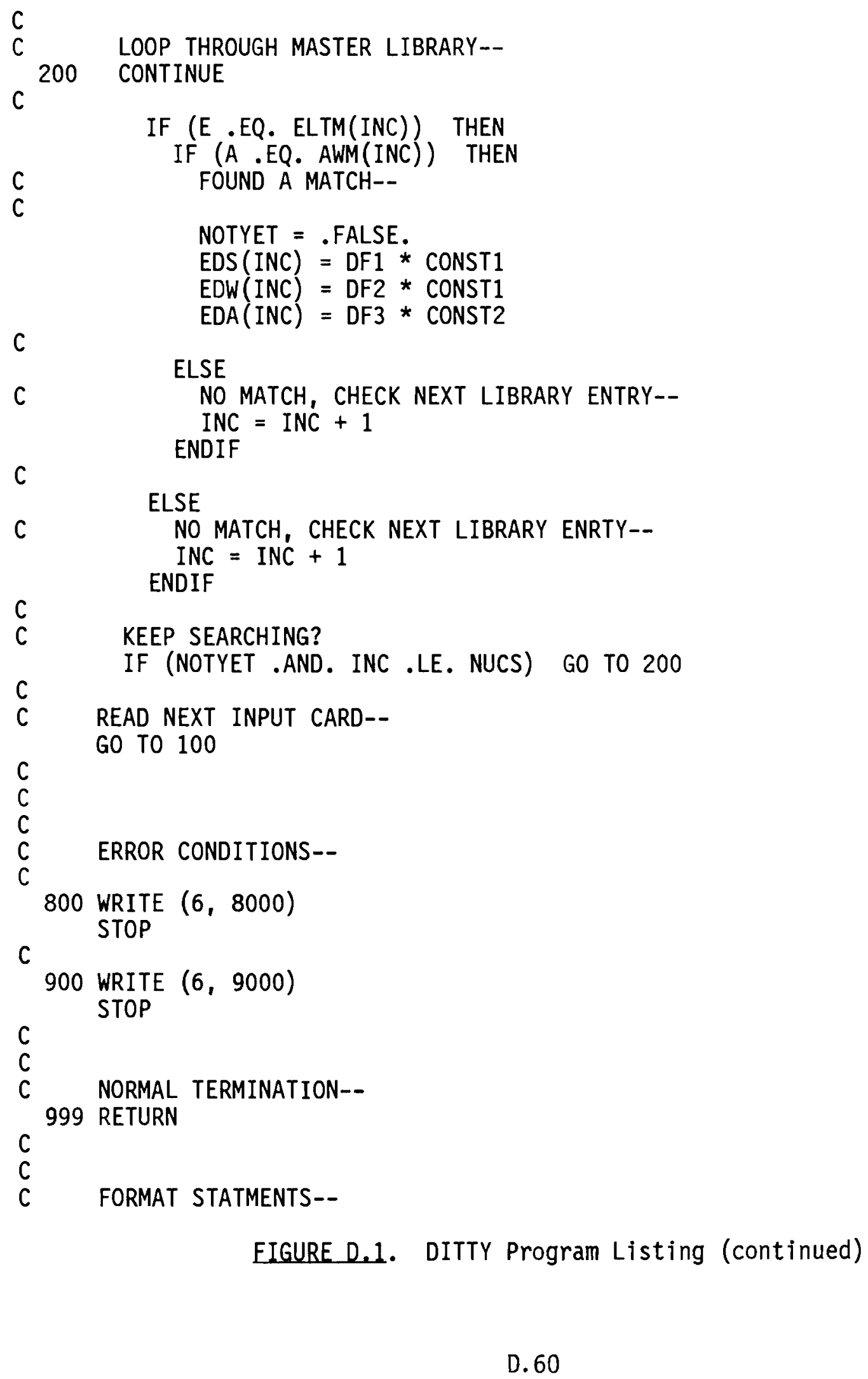

EIGURE D.1. DITTY Program Listing (continued) 
Module GRDLIN

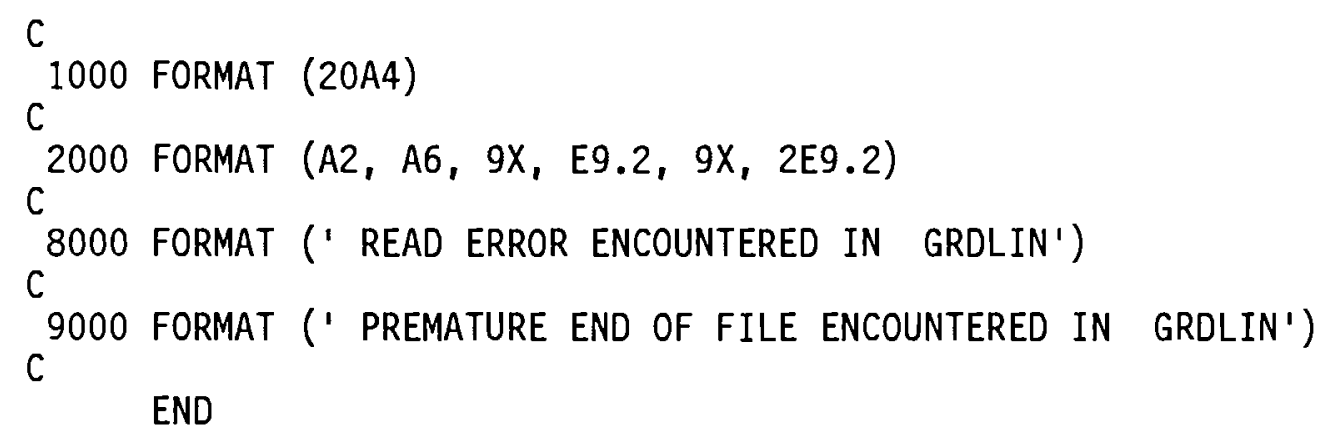

EIGURE D.1. DITTY Program Listing (continued)

$$
\text { D. } 61
$$


Module GRFIL

SUBROUTINE GRFIL (IT, Y20, FOFX, NT)

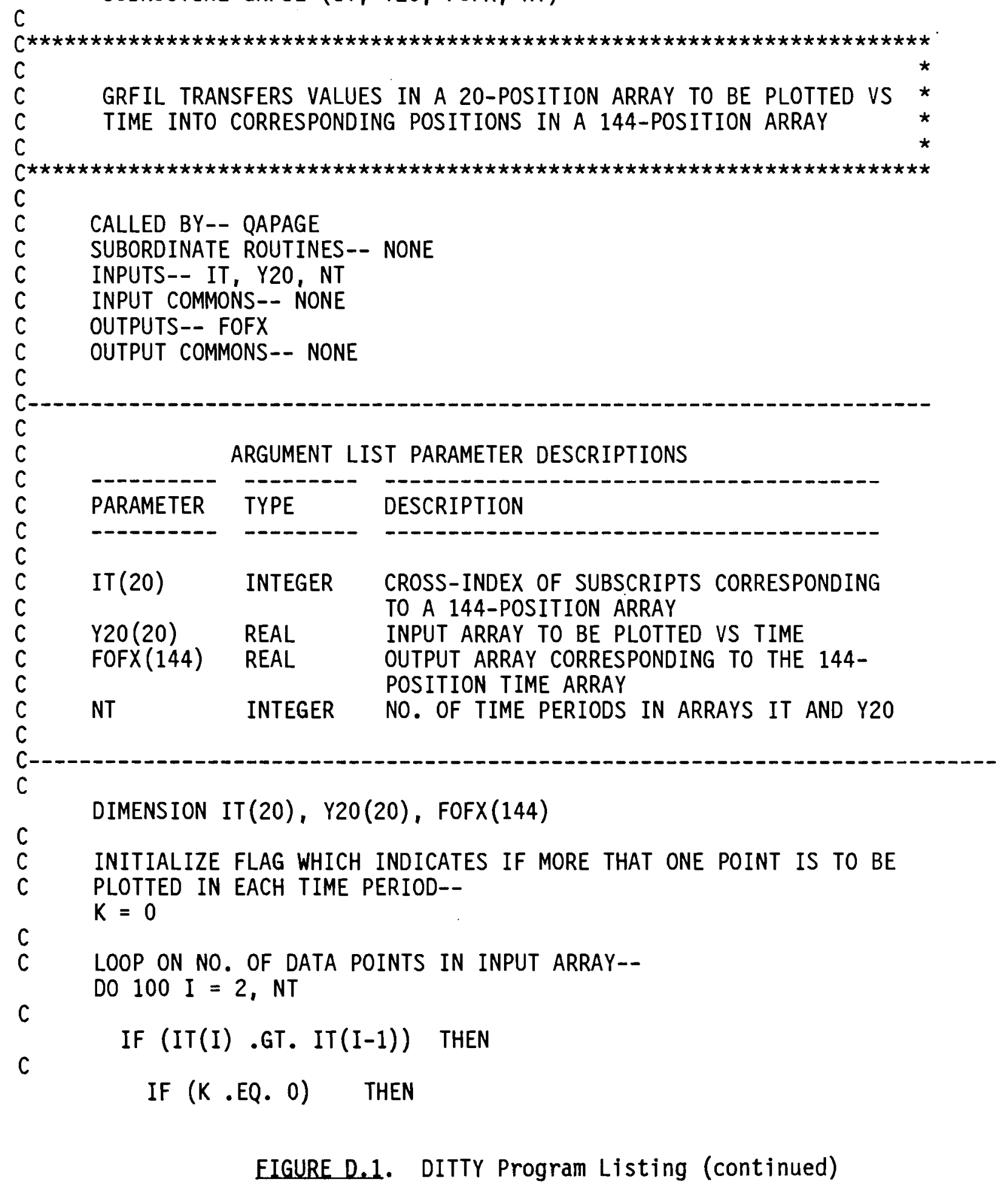

D. 62 
Module GRFIL

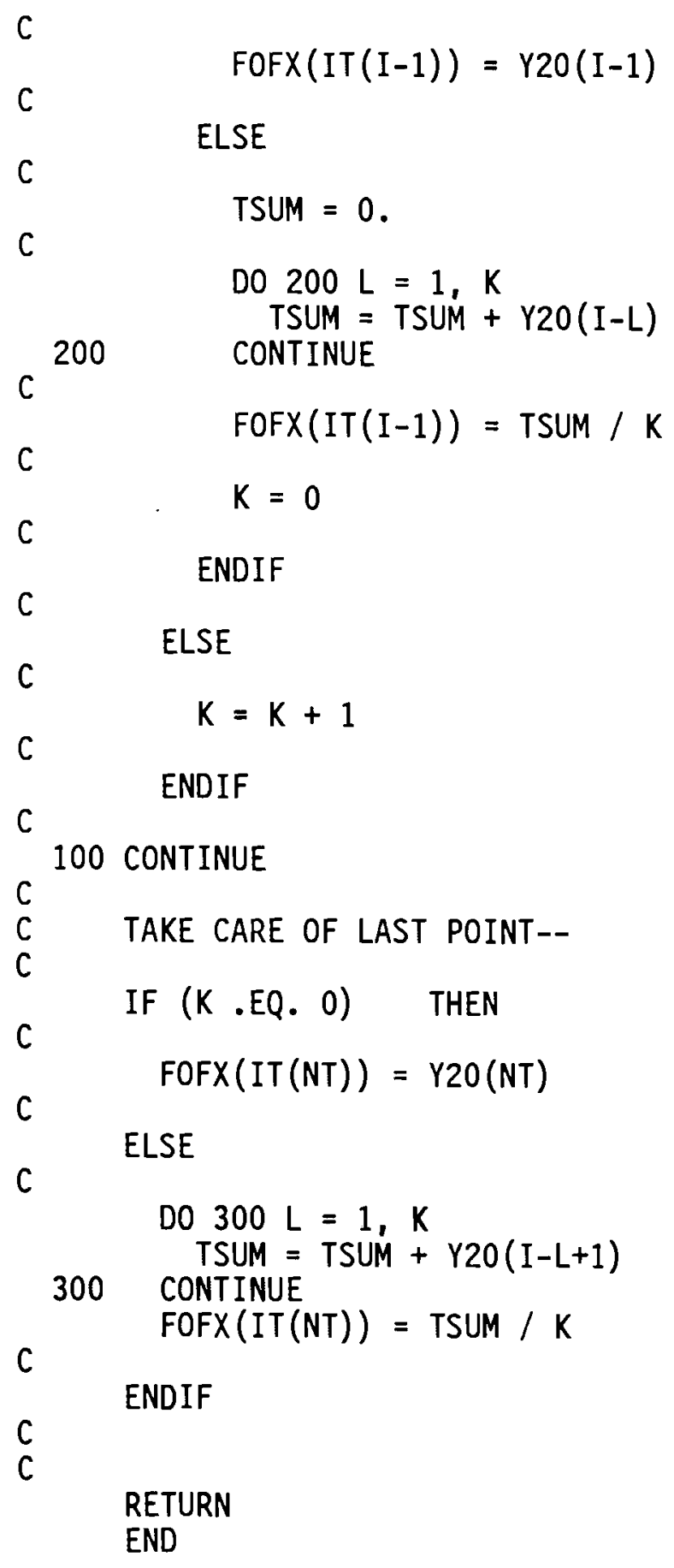

END

EIGURE D.1. DITTY Program Listing (continued) 


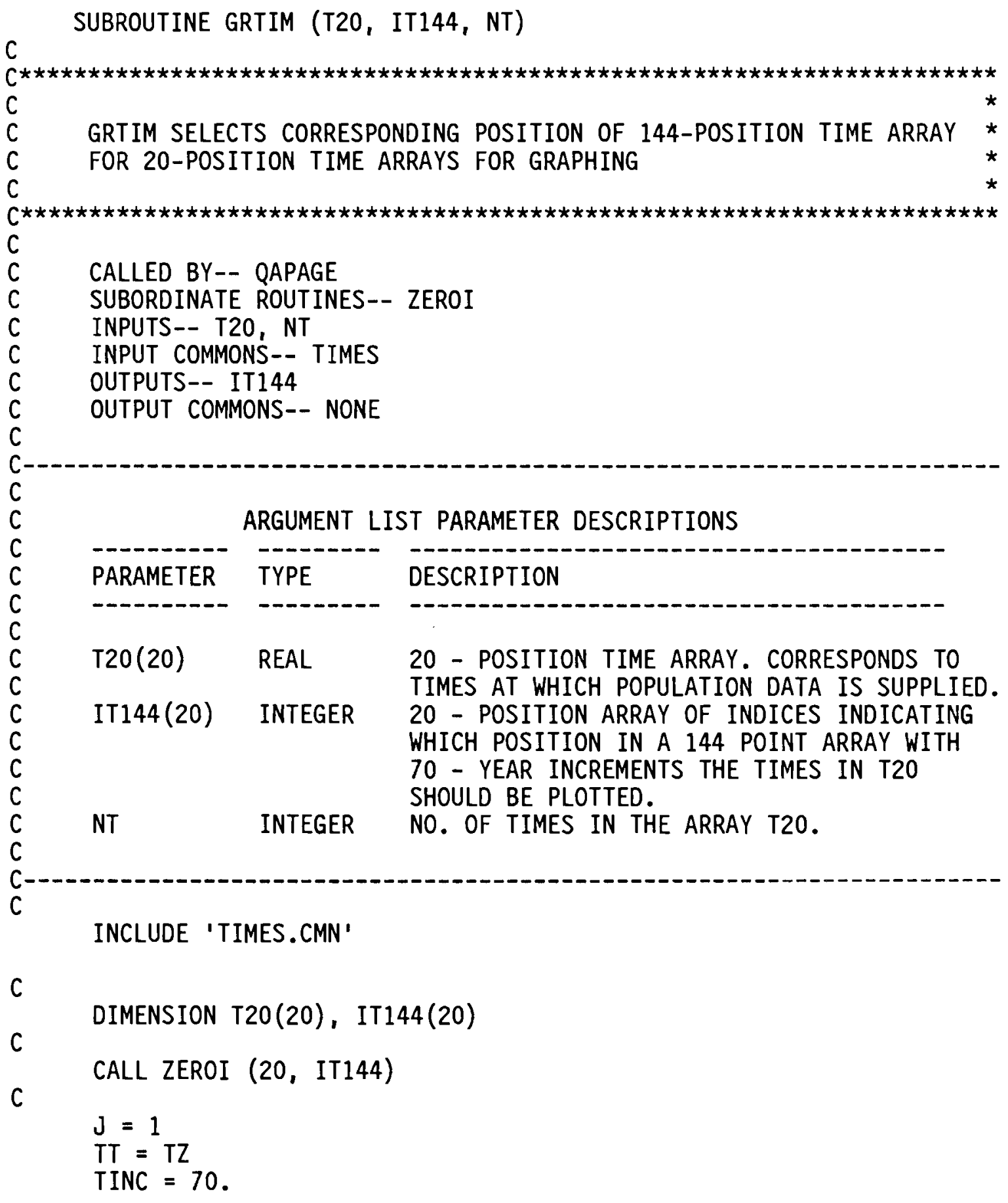

EIGURE D.1. DITTY Program Listing (continued) 
Module GRTIM

C

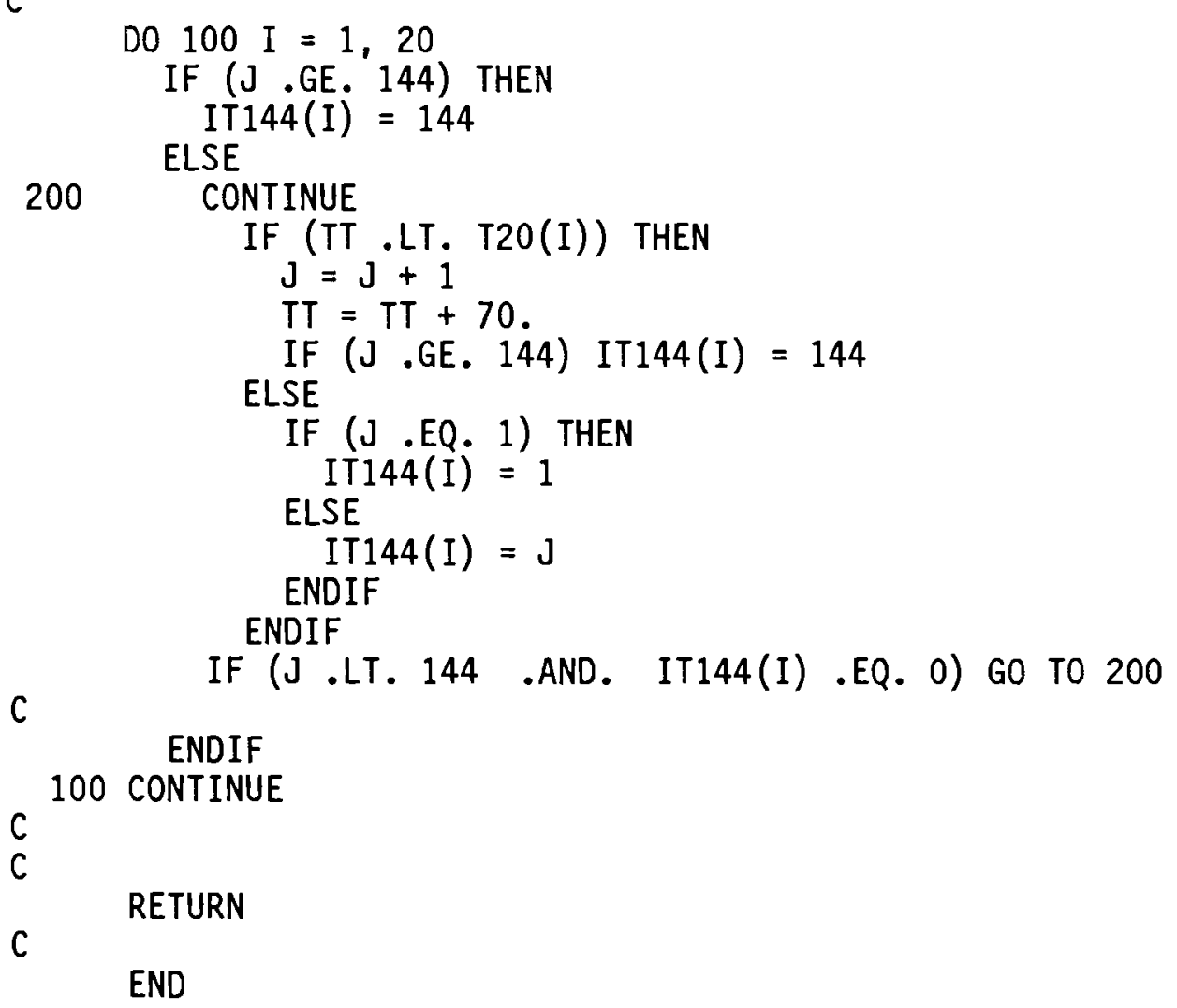

EIGURE D.1. DITTY Program Listing (continued) 
Module HEADNG

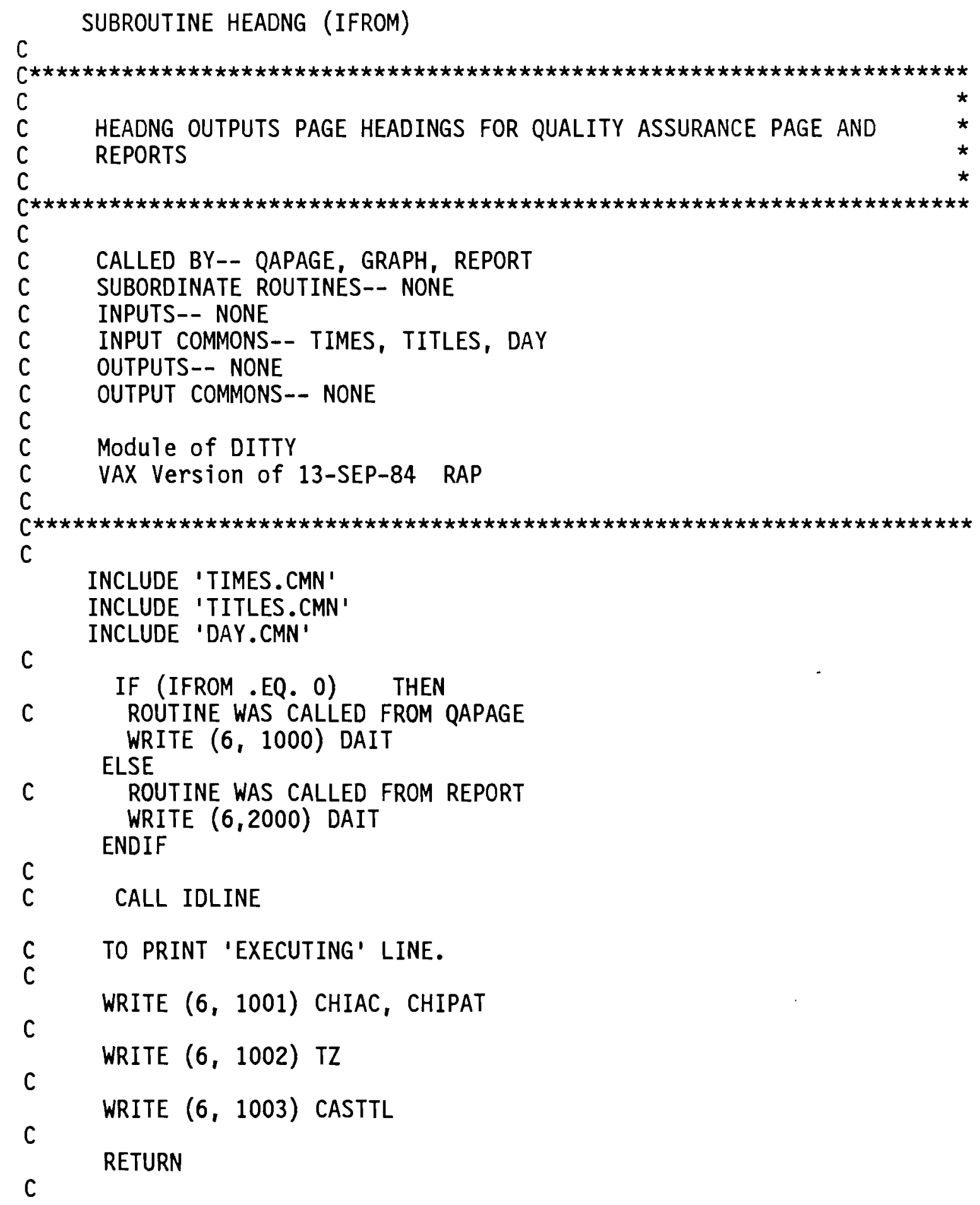

EIGURE D.1. DITTY Program Listing (continued) 


\section{Module HEADNG}

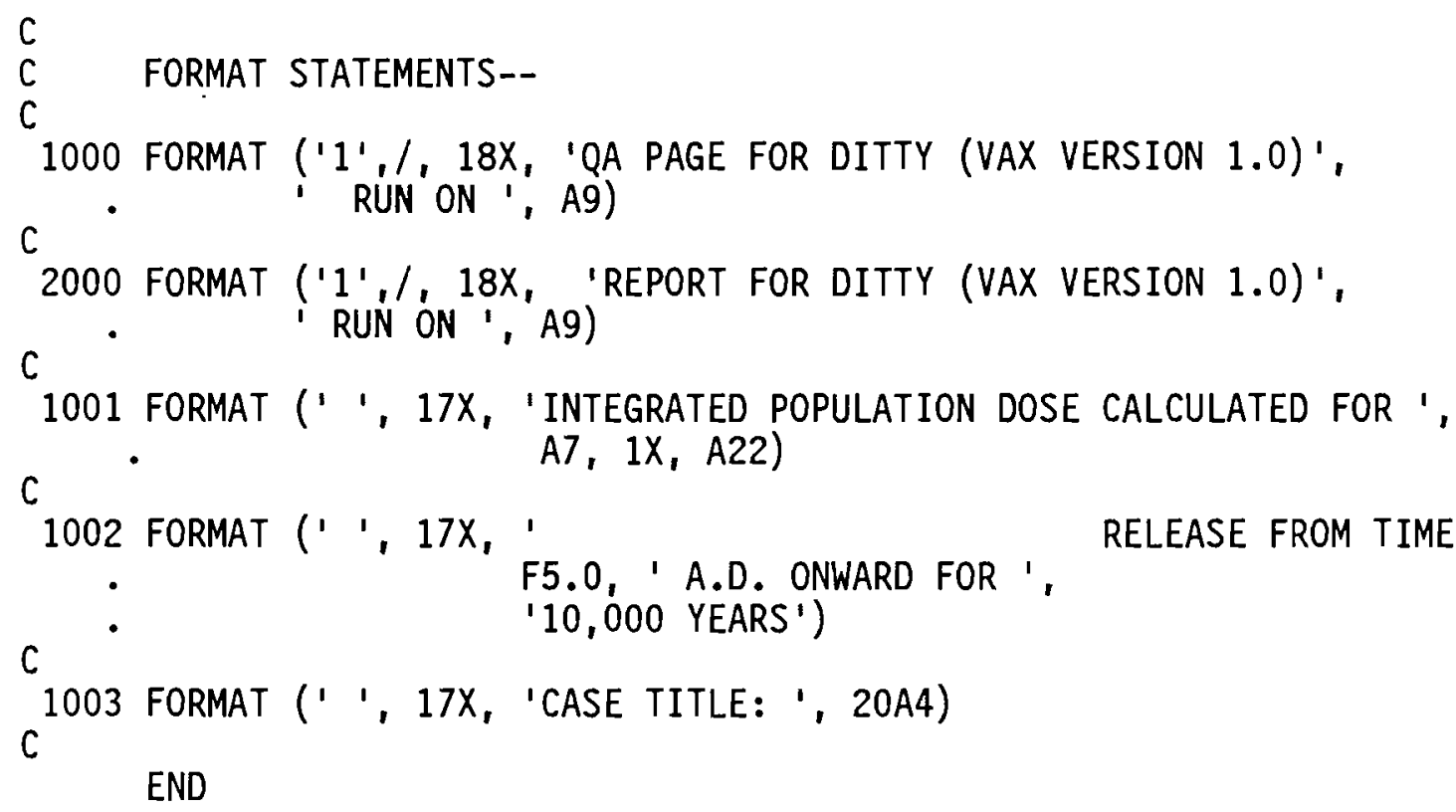

END

EIGURE D.1. DITTY Program Listing (continued) 
Module NUCTST

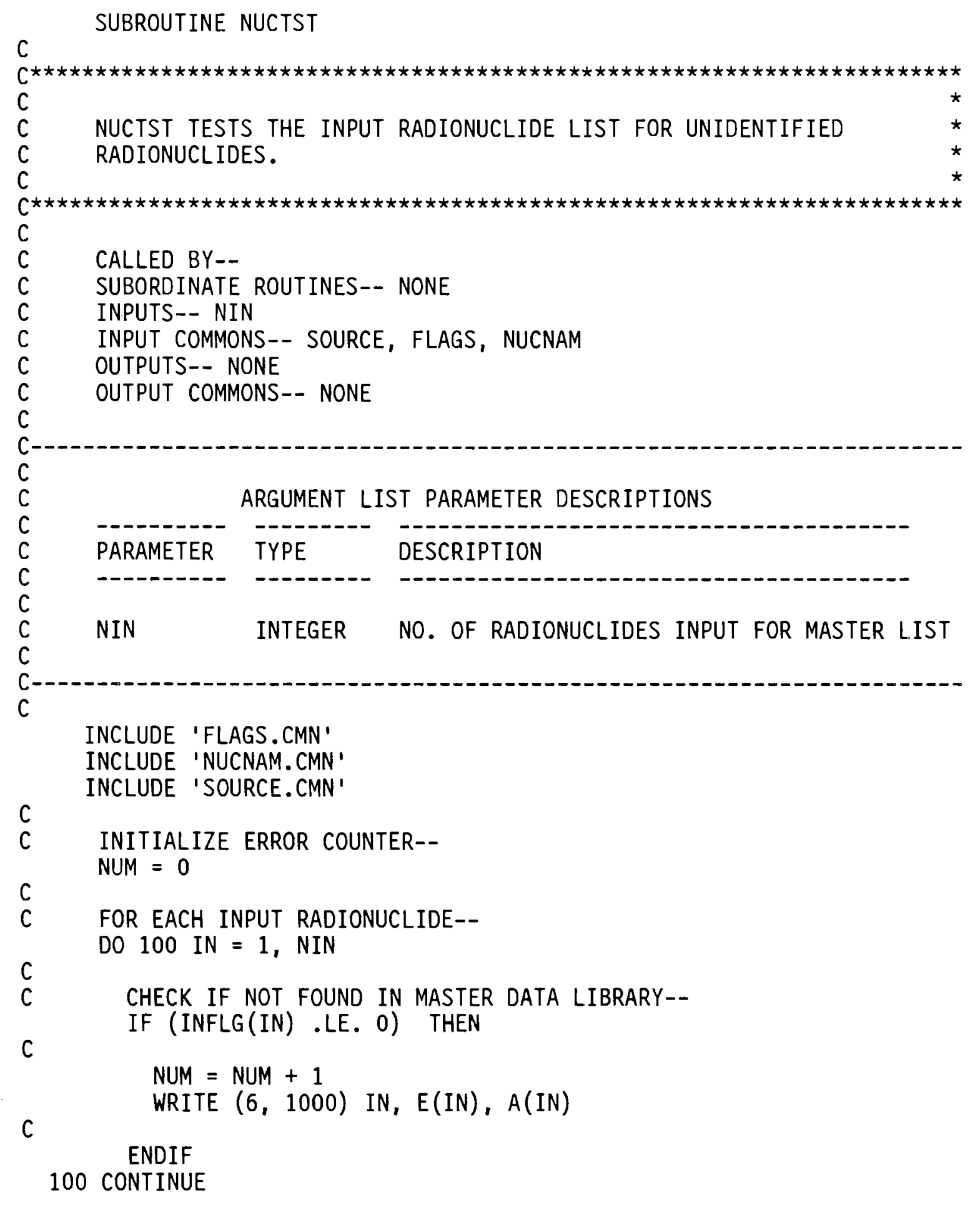

FIGURE 0.1. DITTY Program Listing (continued)

D. 68 


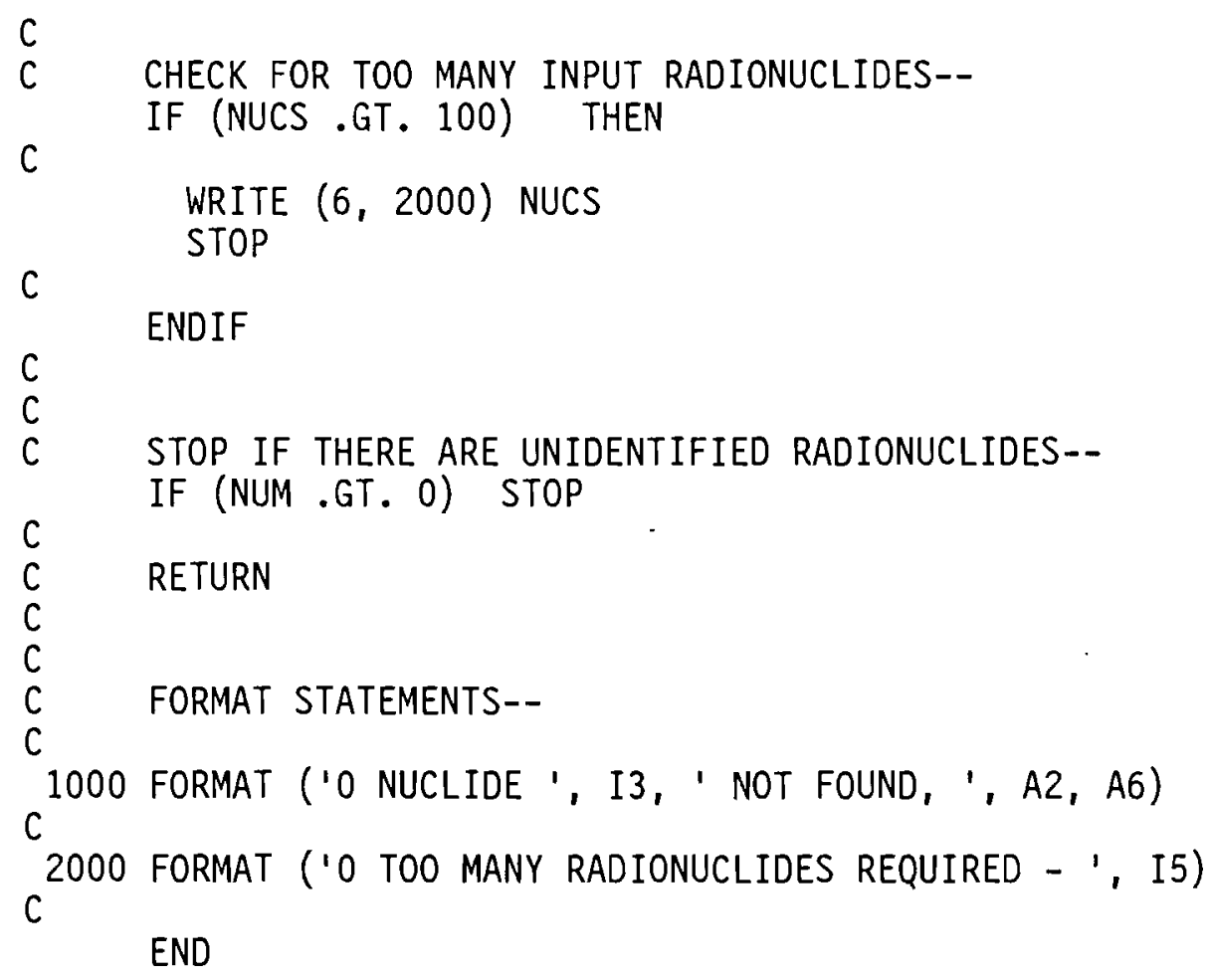

EIGURE D.1. DITTY Program Listing (continued) 
Module ORGCHK

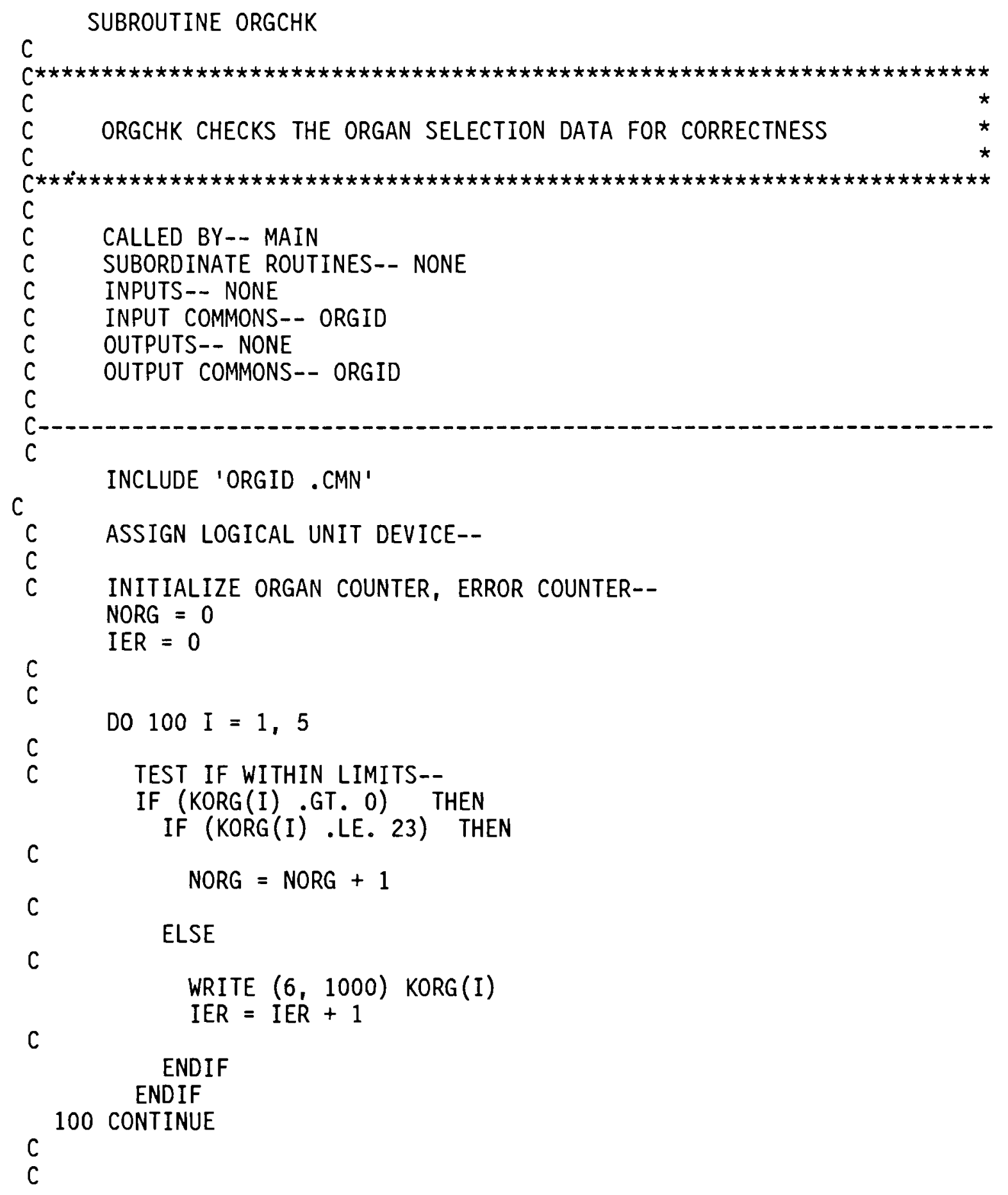

EIGURE D.1. DITTY Program Listing (continued) 
Module ORGCHK

C CHECK IF NO ORGANS ARE SPECIFIED--

IF (NORG . LT. 1) THEN

WRITE $(6,2000)$ NORG

$I E R=I E R+1$

ENDIF

C

C IF THERE ARE NO ERRORS, RETURN; OTHERWISE STOP

IF (IER .LE. O) THEN

RETURN

ELSE

WRITE $(6,3000)$ IER

STOP

ENDIF

C

C FORMAT STATEMENTS--

1000 FORMAT ('O BAD VALUE FOR KORG(I) = ', I5)

2000 FORMAT (' 0 NO ORGANS SPECIFIED, NORG $=$ ', I5)

3000 FORMAT (' $O$ NUMBER OF ERRORS IN ORGCHK $=1$, I3)

C

END

EIGURE 0.1. DITTY Program Listing (continued)

D. 71 


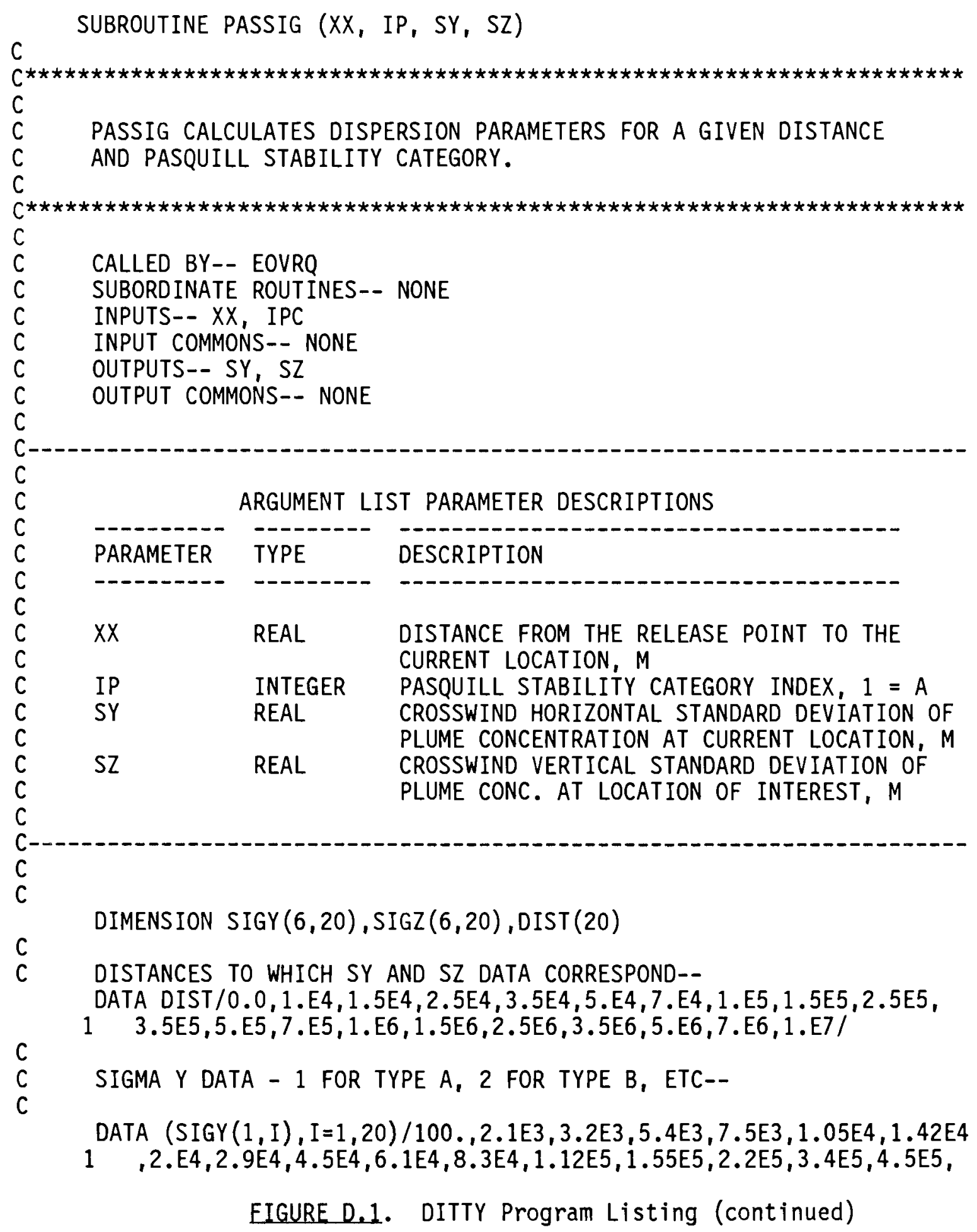

D. 72 
Module PASSIG

C

$2 \quad 6.2 \mathrm{E} 5,8.2 \mathrm{E} 5,1.1 \mathrm{E} 6 /$

$\operatorname{DATA}(\operatorname{SIGY}(2, \mathrm{I}), \mathrm{I}=1,20) / 100,1.6 \mathrm{E} 3,2.4 \mathrm{E} 3,4 . \mathrm{E} 3,5.5 \mathrm{E} 3,7.6 \mathrm{E} 3,1.06 \mathrm{E} 4$,

1 1.48E4,2.15E4,3.4E4,4.6E4,6.3E4,8.4E4, 1.2E5, 1.68E5, 2.6E5, 3.5E5,

2 4.7E5,6.4E5,8.5E5/

C

$\operatorname{DATA}(\operatorname{SIGY}(3, \mathrm{I}), I=1,20) / 100 ., 1.2 \mathrm{E} 3,1.75 \mathrm{E} 3,2.85 \mathrm{E} 3,4 . \mathrm{E} 3,5.5 \mathrm{E} 3,7.6 \mathrm{E} 3$, $1 \quad 1.06 \mathrm{E} 4,1.55 \mathrm{E} 4,2.4 \mathrm{E} 4,3.3 \mathrm{E} 4,4.5 \mathrm{E} 4,6.1 \mathrm{E} 4,8.5 \mathrm{E} 4,1.2 \mathrm{E} 5,1.85 \mathrm{E} 5,2.5 \mathrm{E} 5$,

$23.4 E 5,4.7 E 5,6.3 \mathrm{E} 5 /$

C

$\operatorname{DATA}(\operatorname{SIgY}(4, \mathrm{I}), \mathrm{I}=1,20) / 100,800,1.2 \mathrm{E} 3,1.95 \mathrm{E} 3,2.65 \mathrm{E} 3,3.7 \mathrm{E} 3,5.1 \mathrm{E} 3$,

$17.2 \mathrm{E} 3,1.04 \mathrm{E} 4,1.6 \mathrm{E} 4,2.25 \mathrm{E} 4,3.1 \mathrm{E} 4,4.2 \mathrm{E} 4,5.7 \mathrm{E} 4,7.1 \mathrm{E} 4,1.25 \mathrm{E} 5,1.7 \mathrm{E} 5$,

C

2 2.3E5,3.E5,4.1E5/

$\operatorname{DATA}(\operatorname{SIGY}(5, I), I=1,20) / 100,600,900,1450 \ldots, 2 . E 3,2.8 E 3,3.7 E 3$,

$15.2 \mathrm{E} 3,7.5 \mathrm{E} 3,1.20 \mathrm{E} 4,1.65 \mathrm{E} 4,2.2 \mathrm{E} 4,3 . \mathrm{E} 4,4.1 \mathrm{E} 4,5.7 \mathrm{E} 4,8.8 \mathrm{E} 4,1.18 \mathrm{E} 5$,

$21.6 \mathrm{E} 5,2.1 \mathrm{E} 5,2.8 \mathrm{E} 5 /$

C

$\operatorname{DATA}(\operatorname{SIGY}(6, I), I=1,20) / 100,390,600,980,, 1350,1850,2550 \ldots$ $13600 ., 5200 ., 8100 ., 1.1 \mathrm{E} 4,1.53 \mathrm{E} 4,2.1 \mathrm{E} 4,2.8 \mathrm{E} 4,4 . \mathrm{E} 4,6.1 \mathrm{E} 4,8.2 \mathrm{E} 4,1.12 \mathrm{E} 5$ $2,1.48 \mathrm{E} 5,2 . \mathrm{E5} /$

C

C SIGMA Z DATA - 1 FOR TYPE A, 2 FOR TYPE B, ETC.

$\mathrm{C}$

DATA (SIGZ $(1, I), I=1,20) / 100,, 1500 ., 2250 ., 4300 ., 7 . E 3,1.35 E 4,2.7 E 4$, $16.7 \mathrm{E} 4,2 . \mathrm{E} 5,11 * 2 . \mathrm{E} 5 /$

DATA (SIGZ $(2, I), I=1,20) / 100,1 . E 3,1500,2550,3700,, 5700,8600 \ldots$

C

1 1.35E4,2.4E4,5.8E4,1.2E5,2.E5,8*2.E5/

$\operatorname{DATA}(\operatorname{SIGZ}(3, \mathrm{I}), \mathrm{I}=1,20) / 100,780,1100,1750,, 2400,3400,4600 \ldots$ $16400 ., 9000 ., 1.4 \mathrm{E} 4,1.9 \mathrm{E} 4,2.6 \mathrm{E} 4,3.4 \mathrm{E} 4,4.4 \mathrm{E} 4,6 . \mathrm{E} 4,8.8 \mathrm{E} 4,1.12 \mathrm{E} 5,1.44 \mathrm{E} 5$

C $2,1.78 \mathrm{E} 5,2 . \mathrm{E5} /$

$\operatorname{DATA}(\operatorname{SIGZ}(4, \mathrm{I}), I=1,20) / 100,, 470,680,1050,1400,, 1900,, 2500 \ldots$ $13300.4300,6200,, 7600 ., 9500 ., 1.15 E 4,1.4 E 4,1.7 E 4,2.2 E 4,2.65 E 4$,

C $23.2 \mathrm{E} 4,3.7 \mathrm{E} 4,4.5 \mathrm{E} 4 /$

$\operatorname{DATA}(\operatorname{SIGZ}(5, I), I=1,20) / 100,, 300,430,, 710 \ldots, 940,1300,, 1700,2200$. $1,2900,4100 \ldots, 5000,6100 \ldots, 7200 \ldots, 8400 \ldots, 9900,, 1.17 E 4,1.3 E 4,1.4 E 4$, $21.55 \mathrm{E} 4,1.7 \mathrm{E} 4 /$

C

$\operatorname{DATA}(\operatorname{SIGZ}(6, \mathrm{I}), \mathrm{I}=1,20) / 100,140,1220,400,530,760,1000,1350 .$, $11770 \ldots, 2500 \ldots, 3000 \ldots, 3500,4100 \ldots, 4700,5500,6400 \ldots, 7200 \ldots, 7900 \ldots, 8600 \ldots$, 29400.1

EIGURE D.1. DITTY Program Listing (continued) 
Module PASSIG

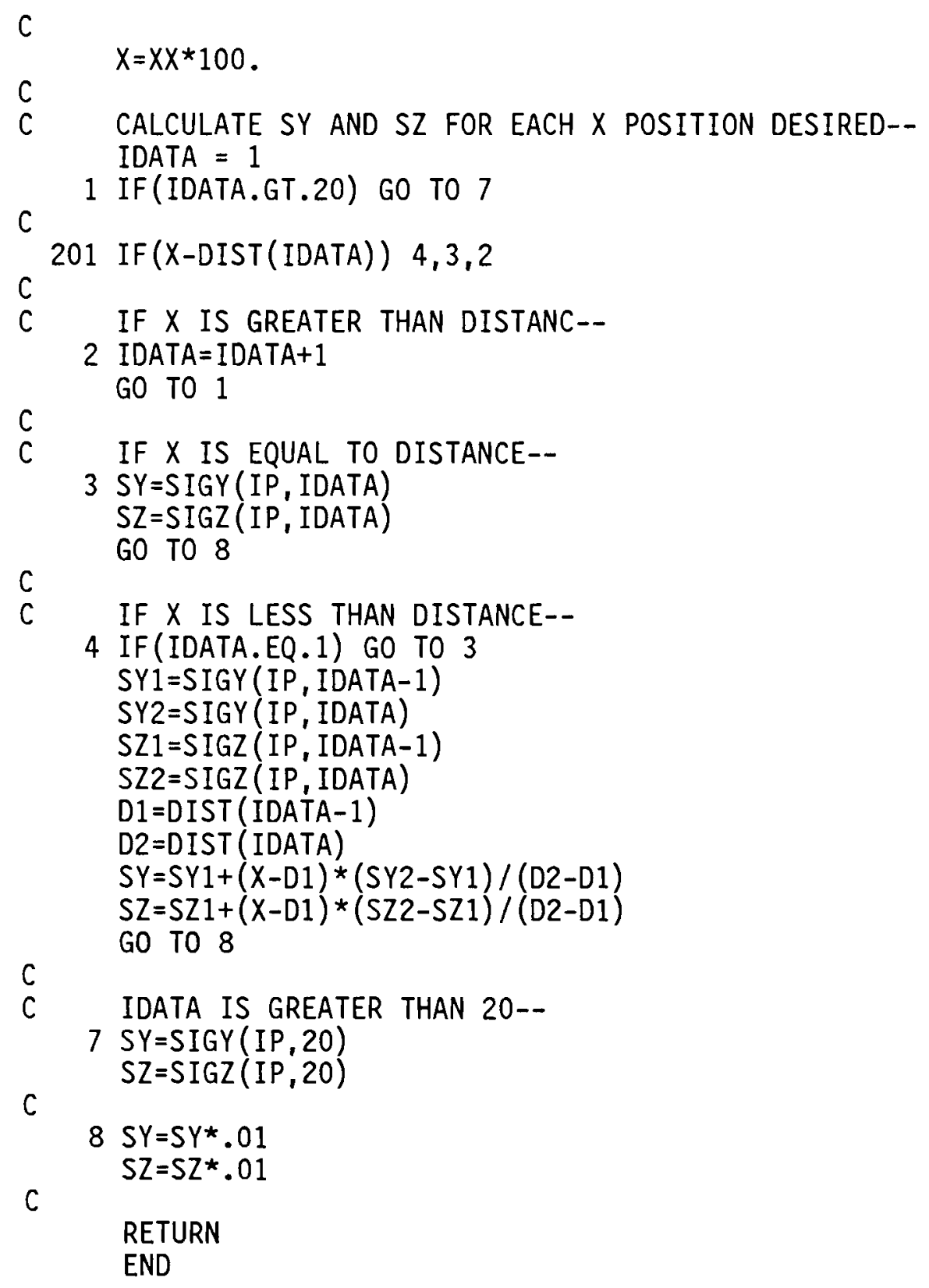

EIGURE D.1. DITTY Program Listing (continued) 
Module PMAC

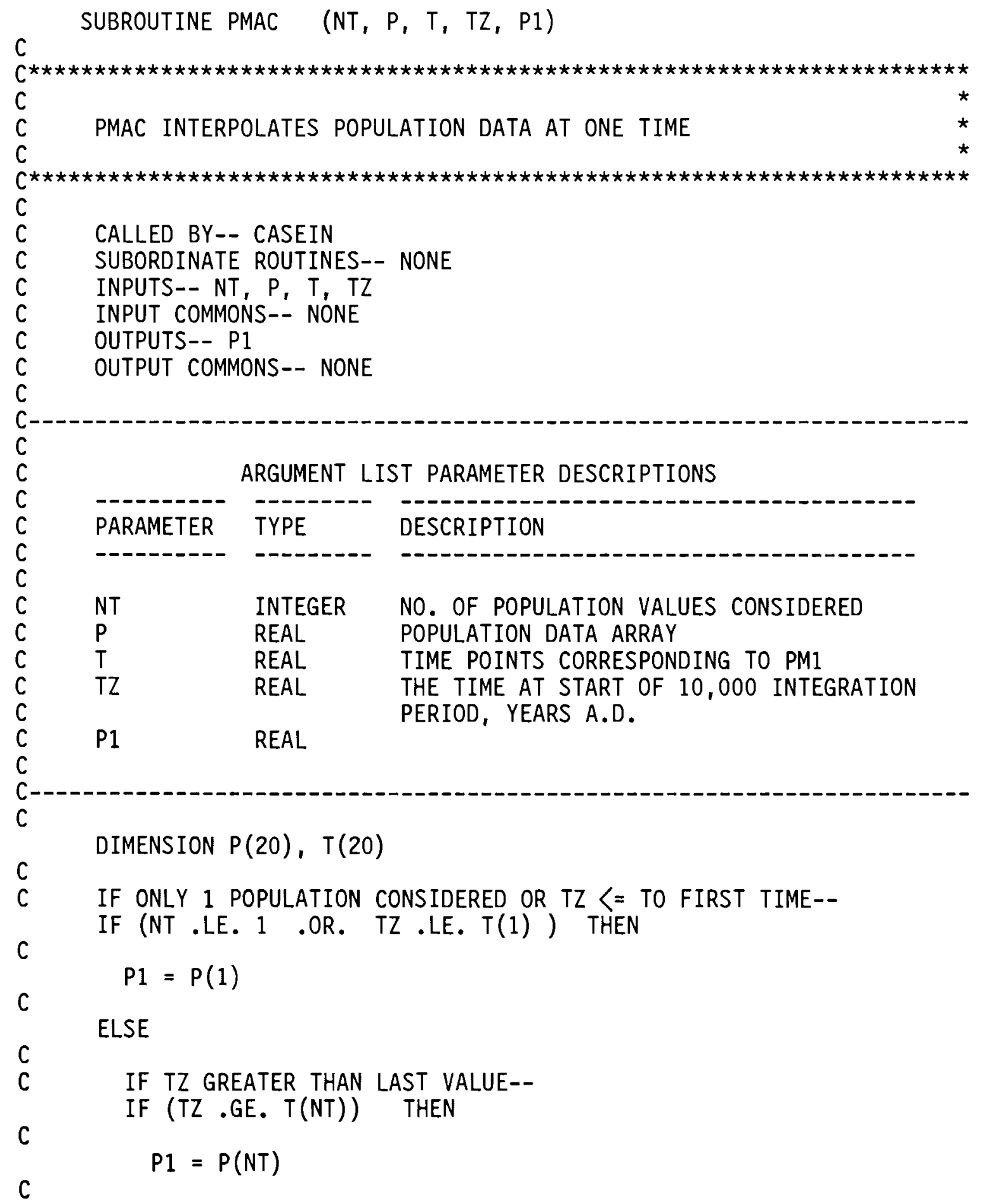

EIGURE D.1. DITTY Program Listing (continued) 


\section{Module PMAC}

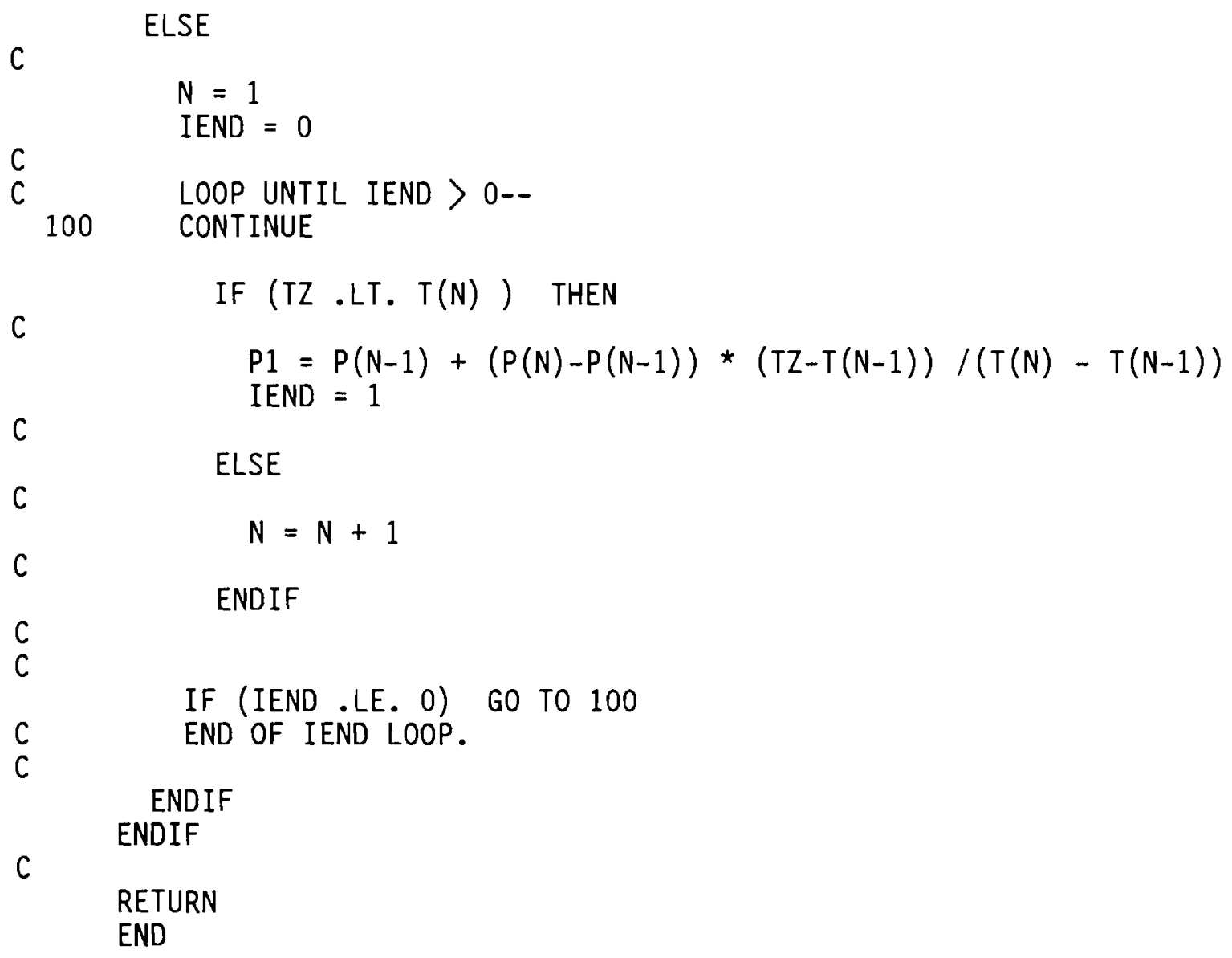

C

C ENDIF ENDIF

RETURN

END

EIGURE D.1. DITTY Program Listing (continued) 
Module PMEQ

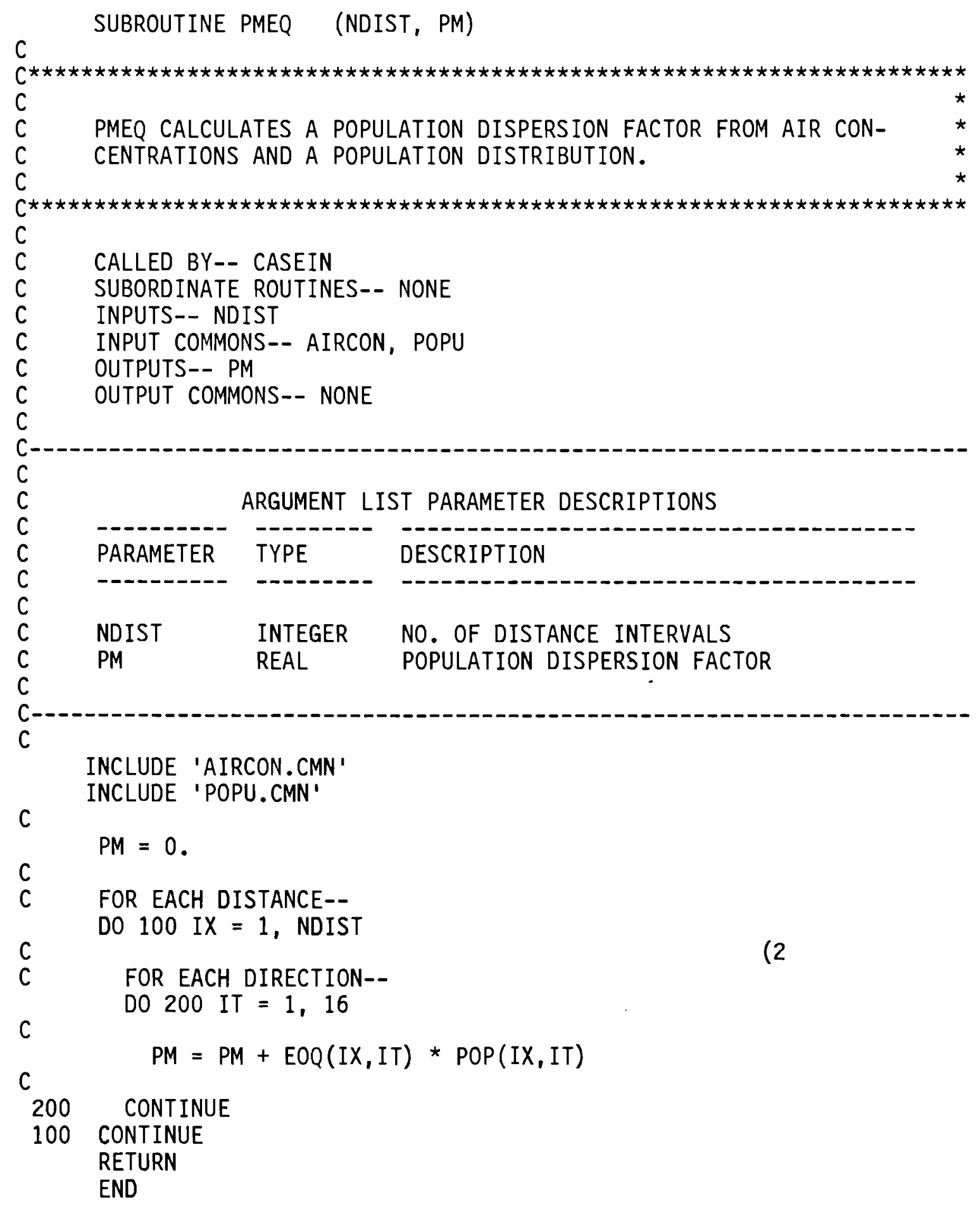

EIGURE 0.1. DITTY Program Listing (continued) 
Module PMINT

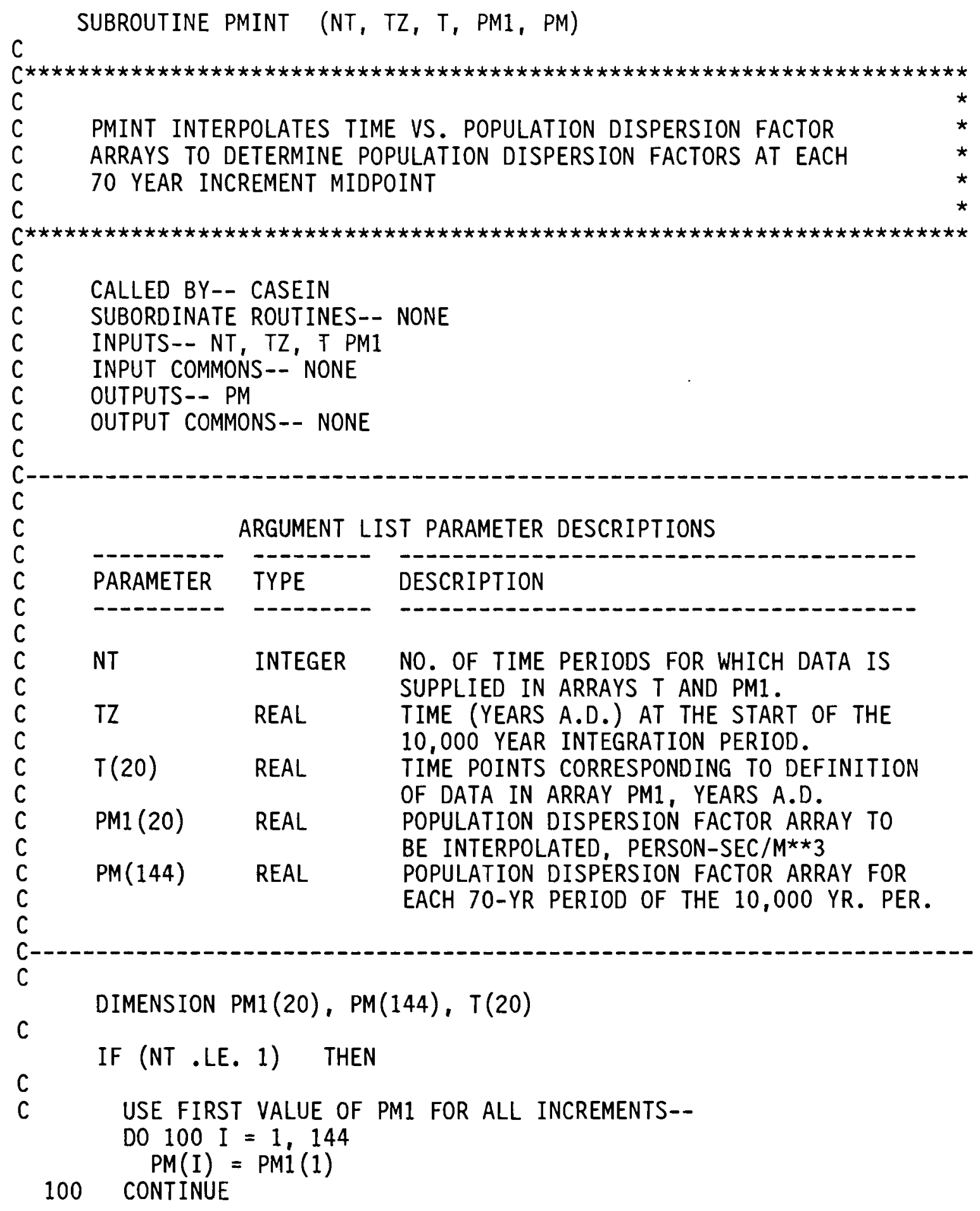

EIGURE 0.1. DITTY Program Listing (continued) 


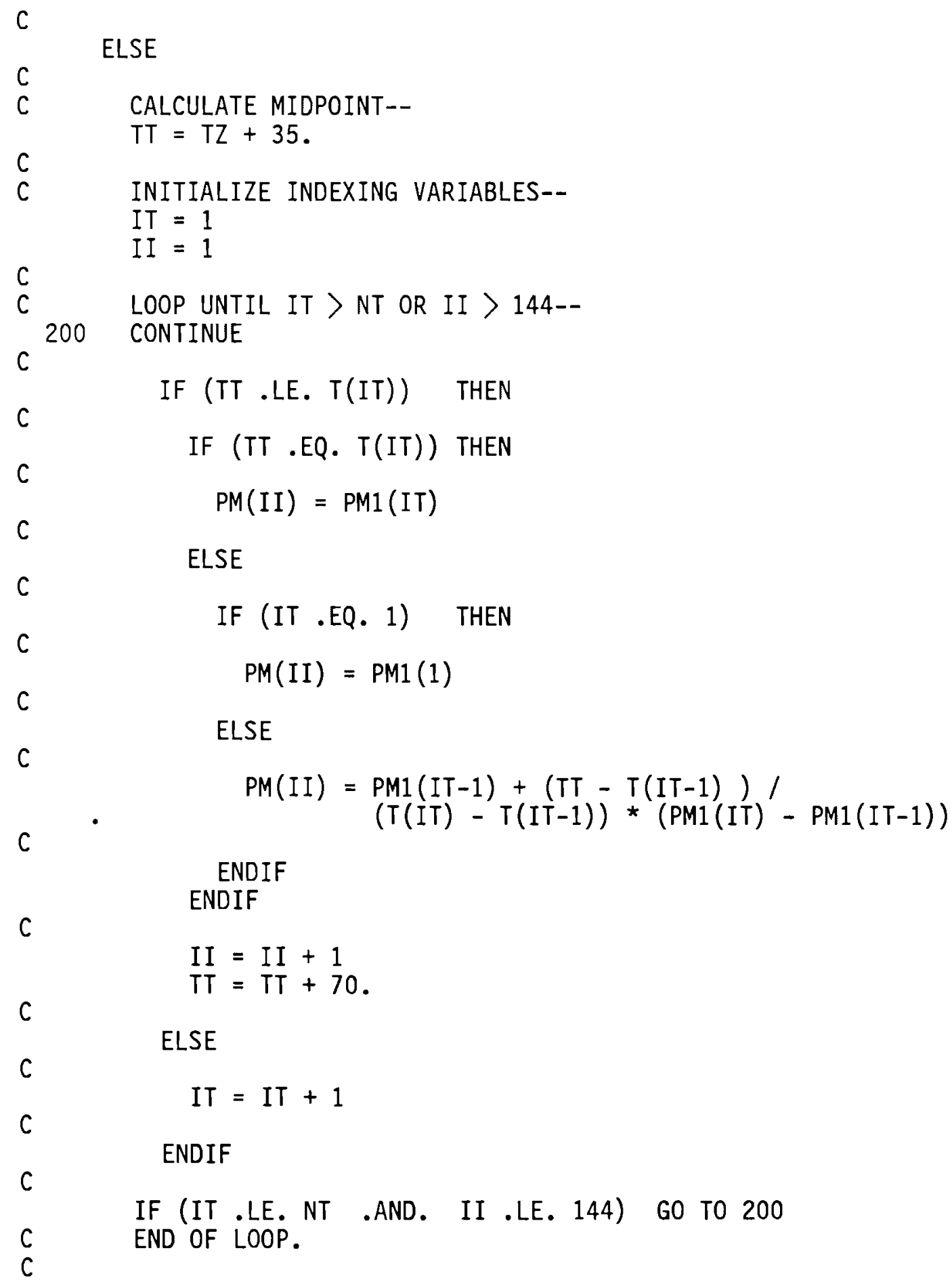




\section{Module PMINT}

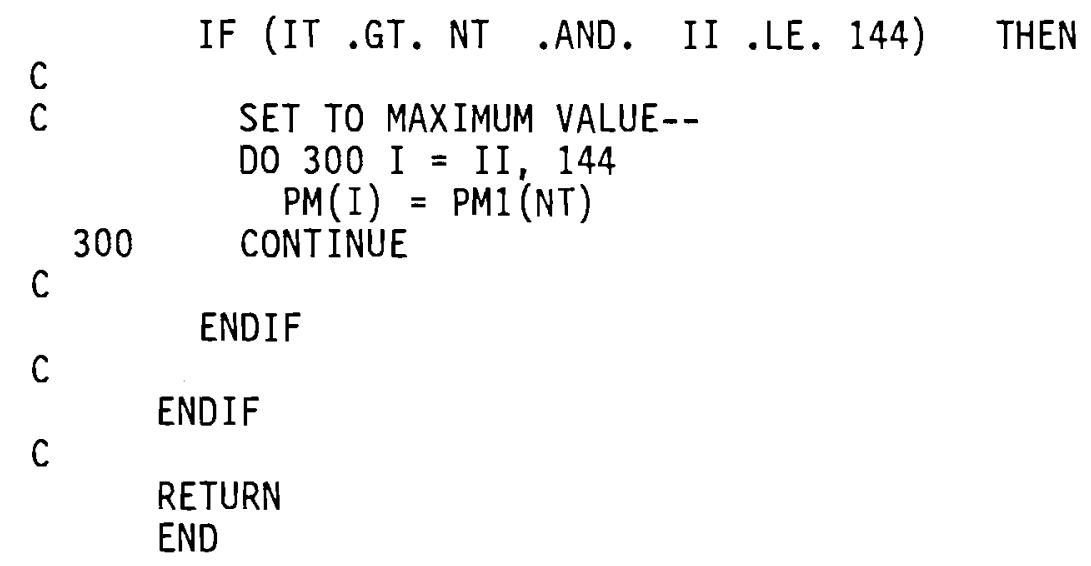

EIGURE D.1. DITTY Program Listing (continued)

D. 80 


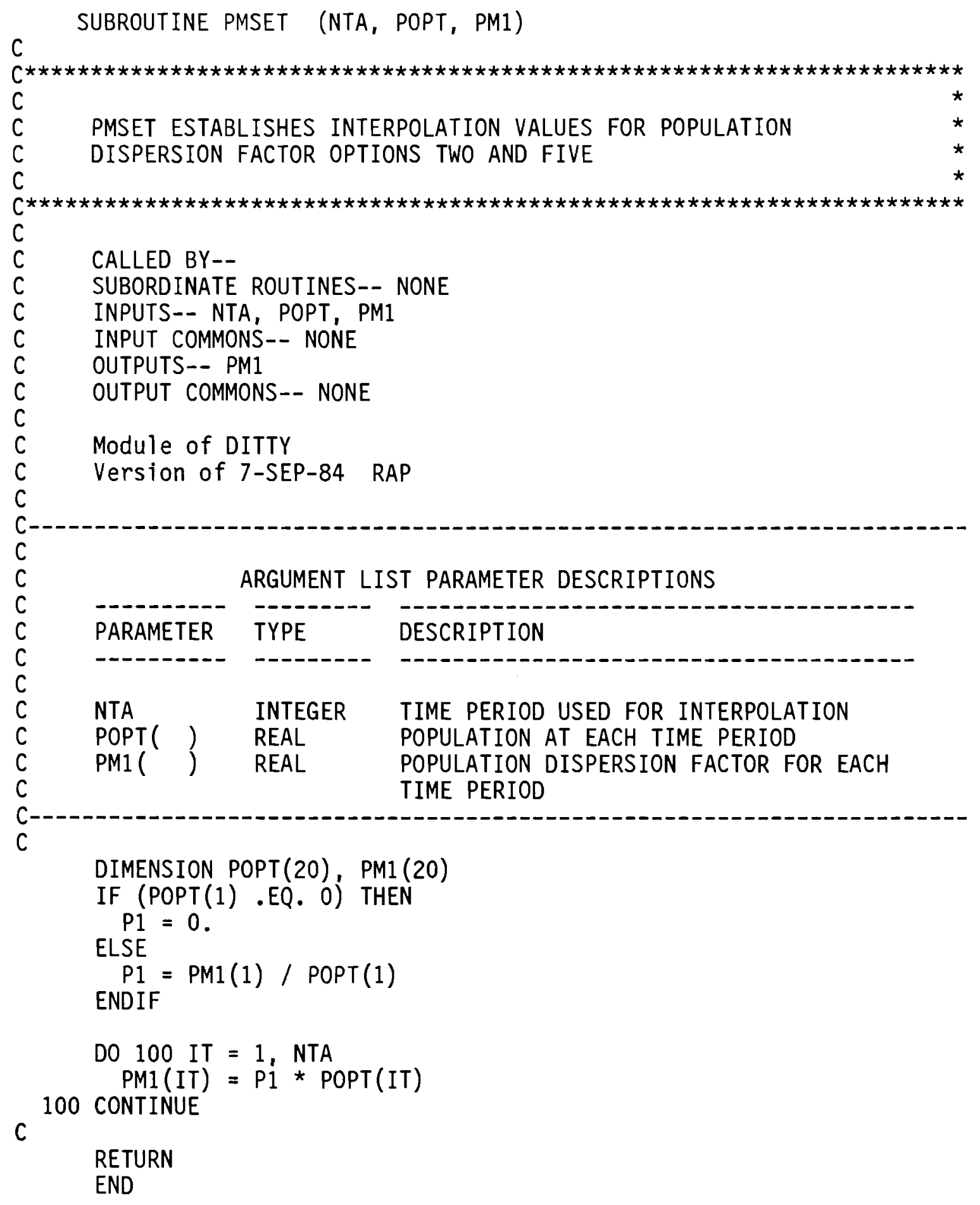

EIGURE D.1. DITTY Program Listing (continued) 
Module PRTGRF

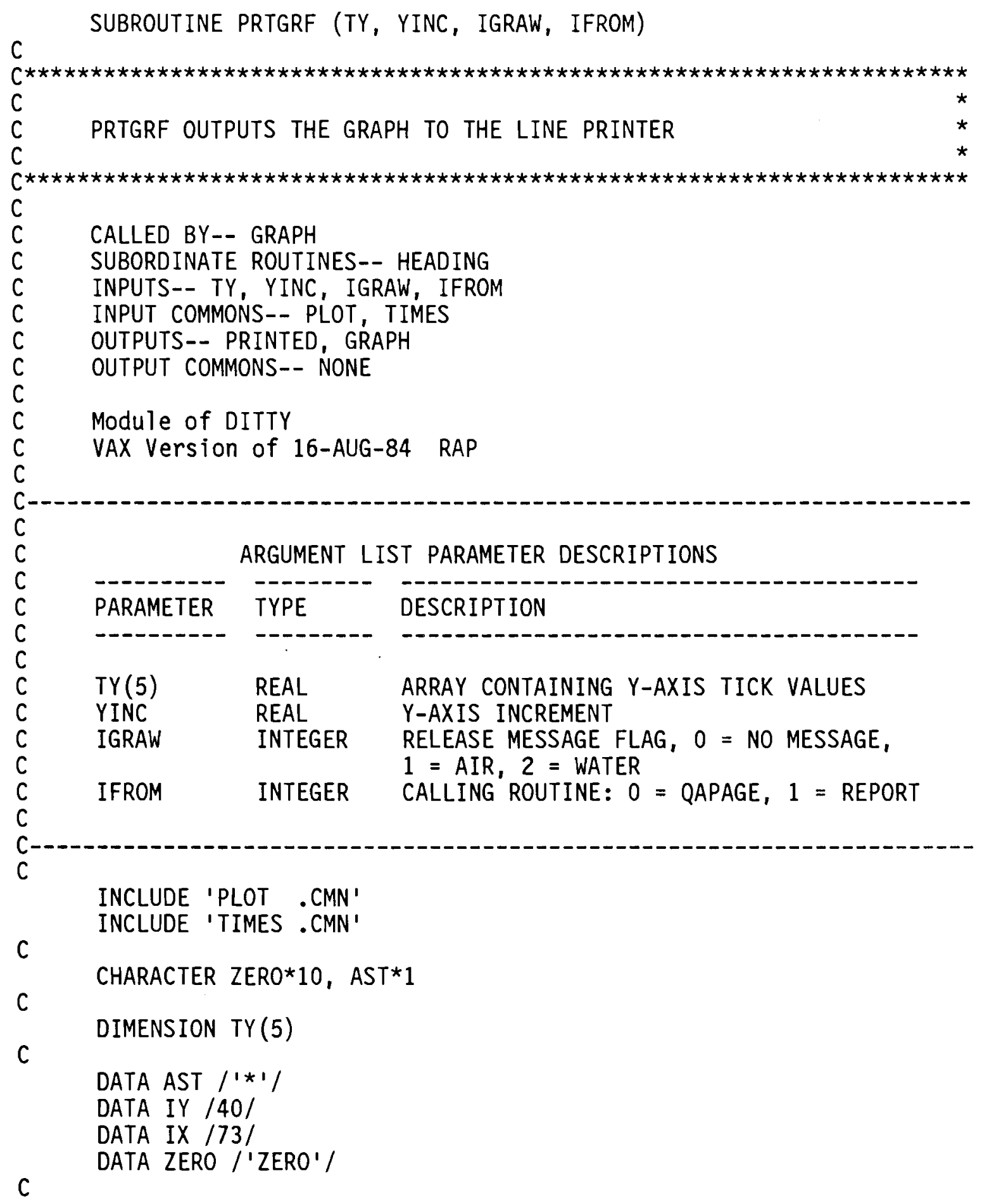

EIGURE D.1. DITTY Program Listing (continued) 


\section{Module PRTGRF}

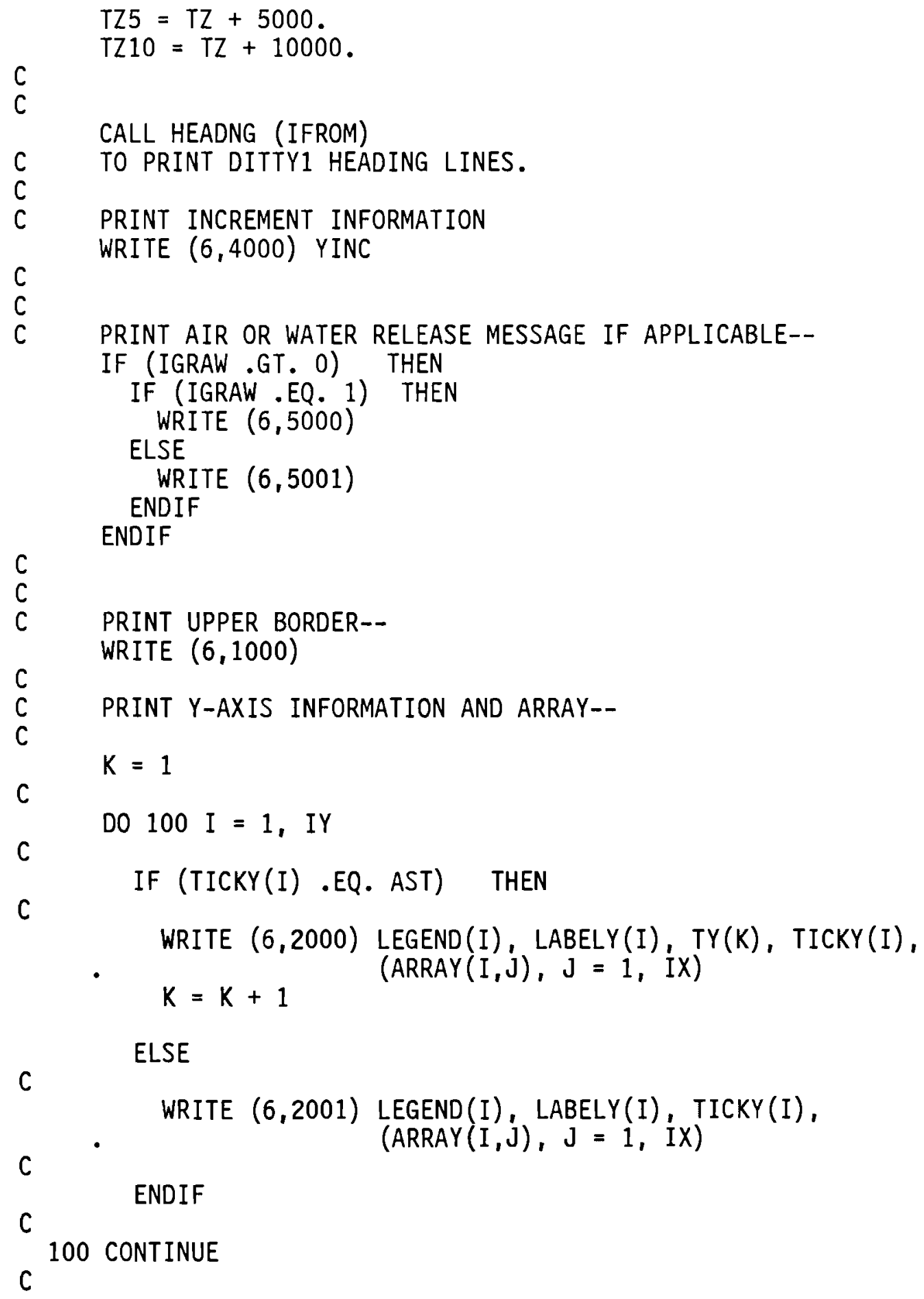

C

ENDIF

C

C

100 CONTINUE

EIGURE D.1. DITTY Program Listing (continued) 
Module PRTGRF

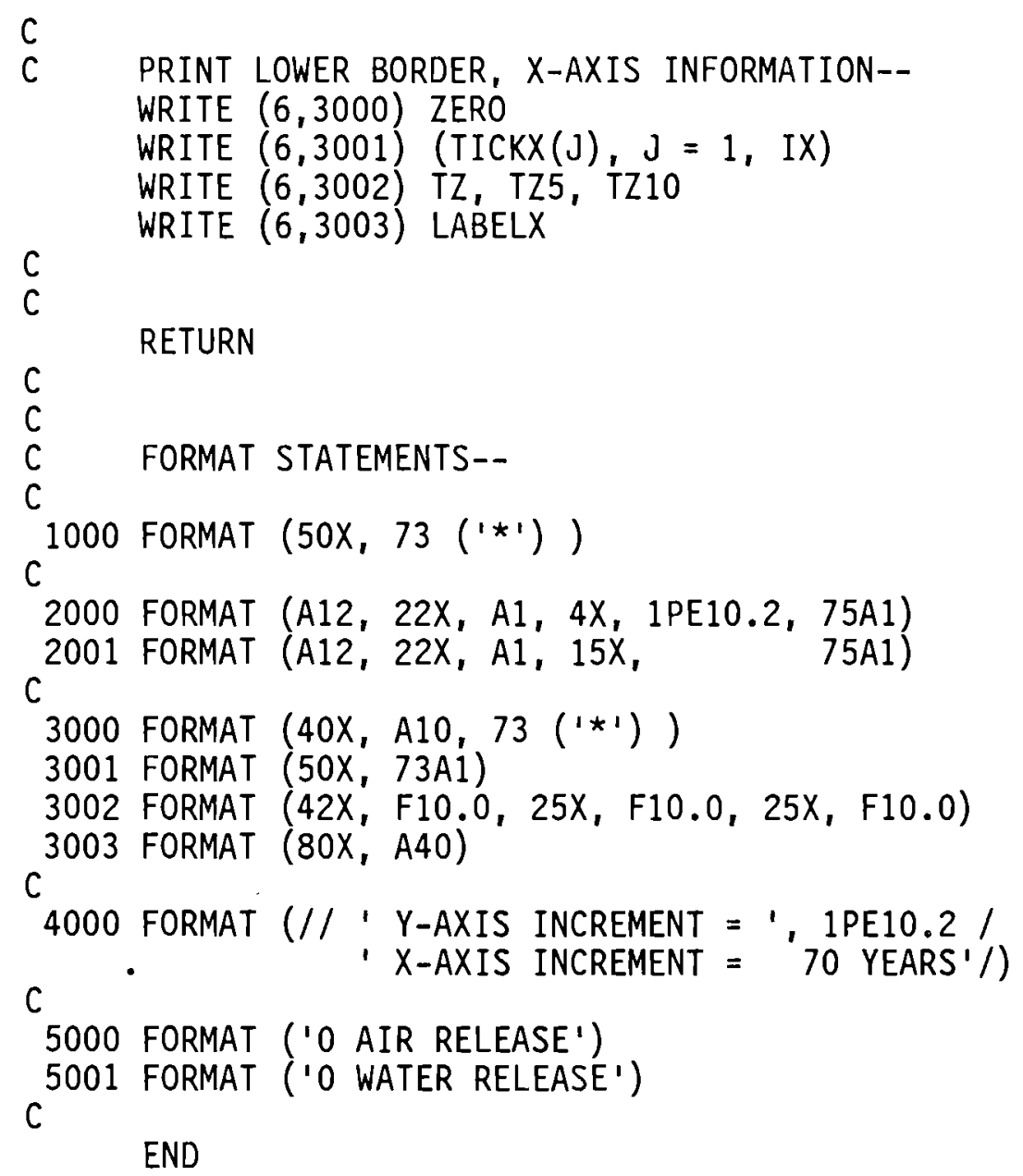

END

EIGURE D.1. DITTY Program Listing (continued) 


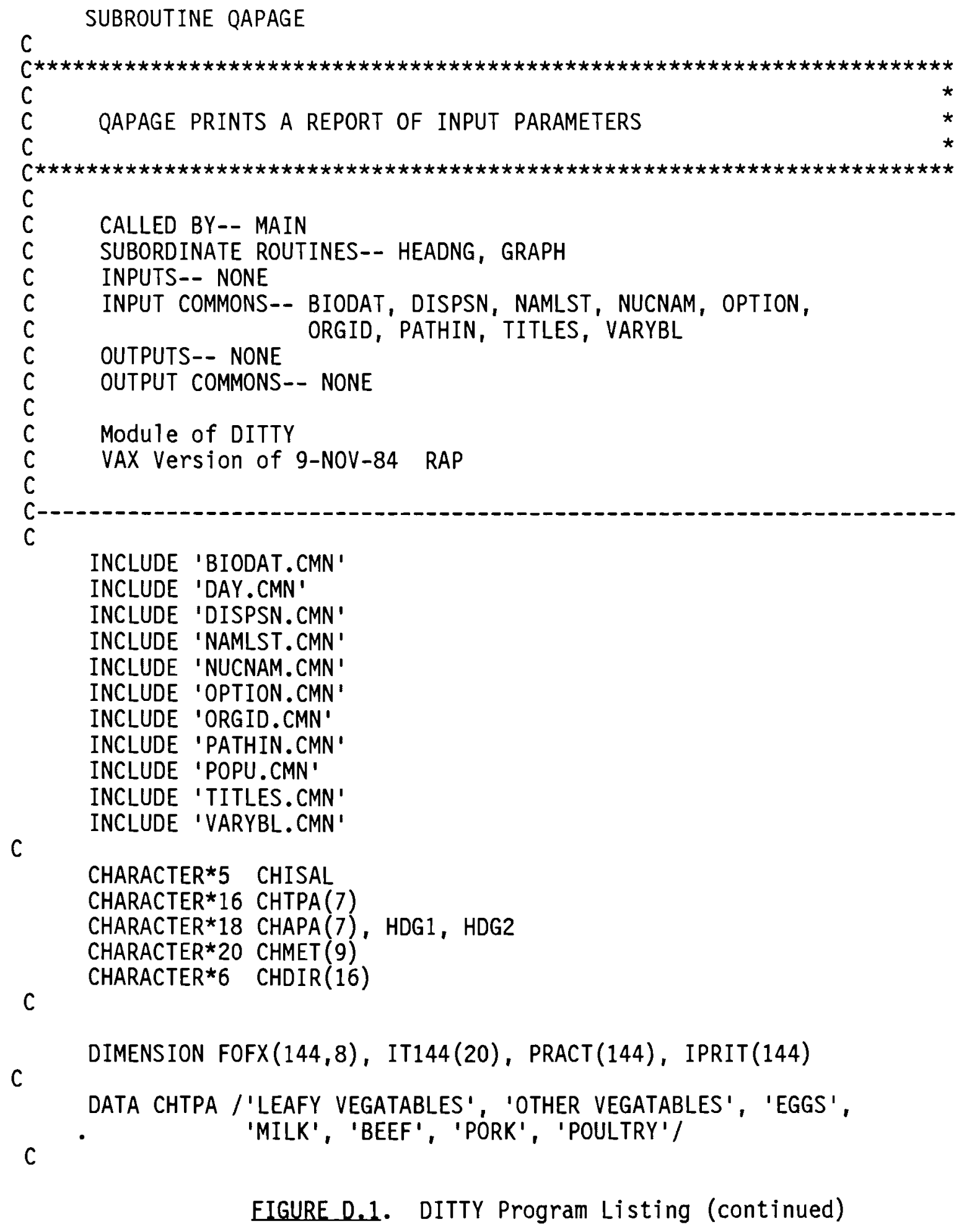

EIGURE D.1. DITTY Program Listing (continued) 


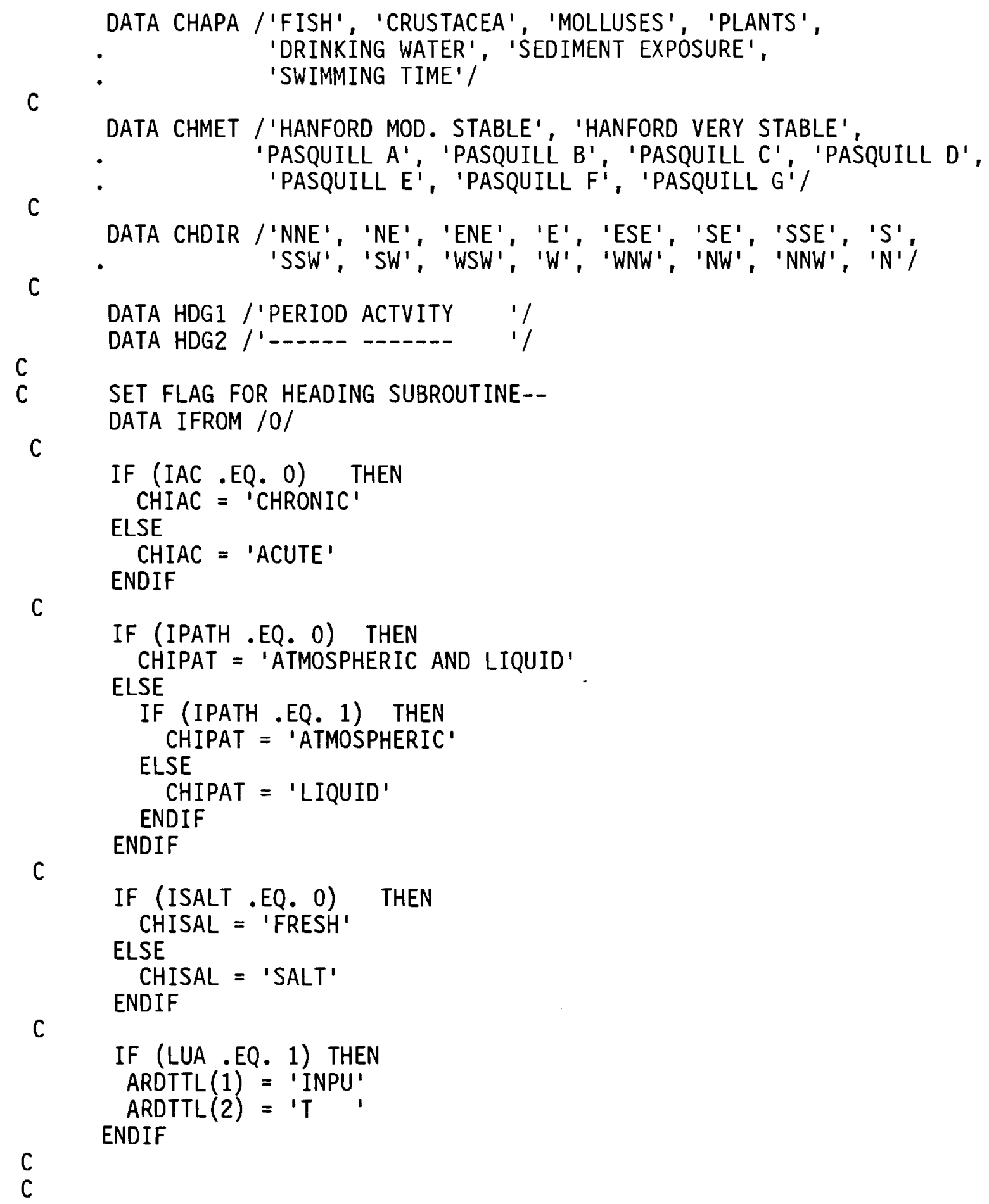

EIGURE D.1. DITTY Program Listing (continued) 


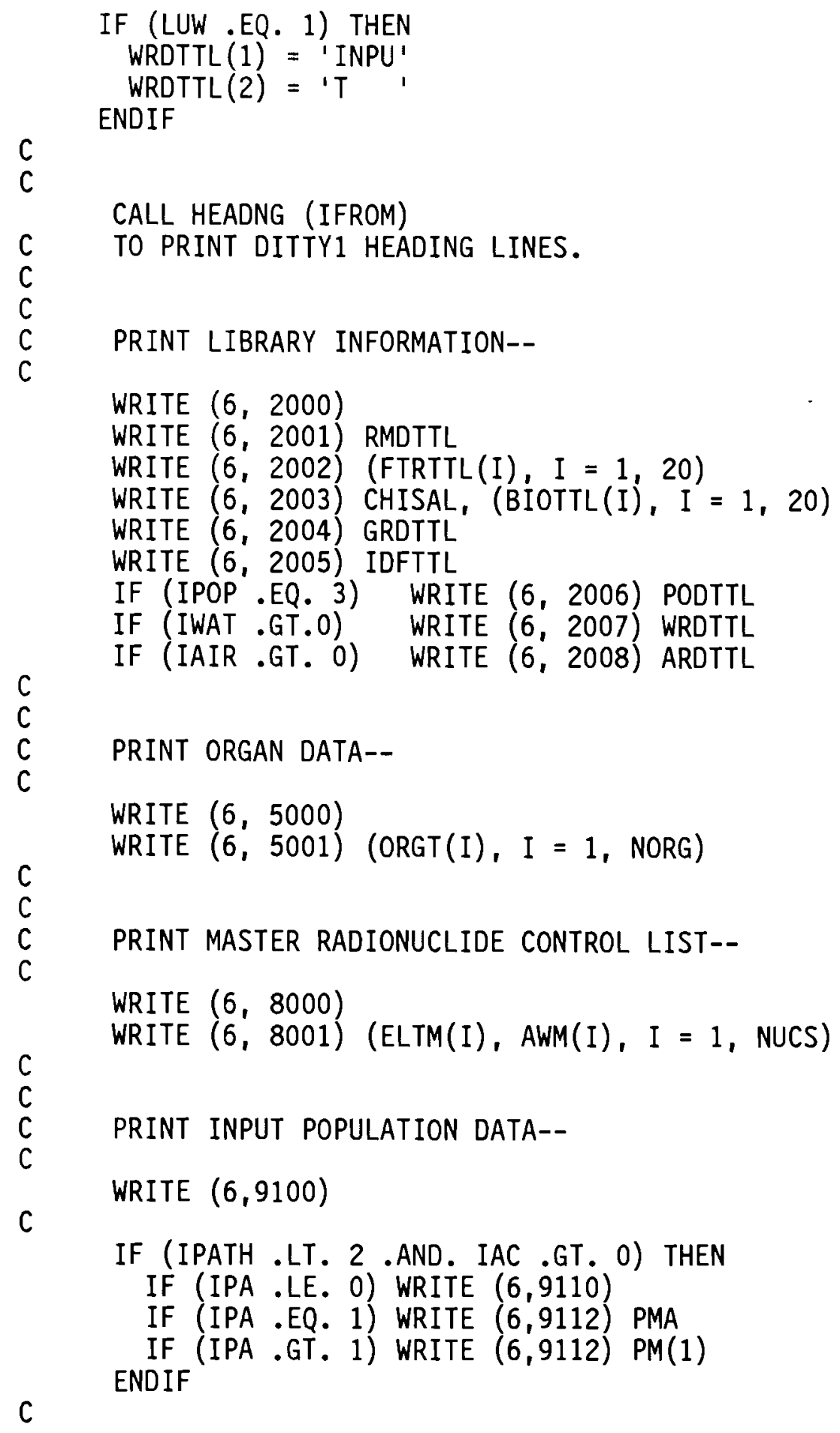

EIGURE D.1. DITTY Program Listing (continued) 
C

C

222

IF (IPATH .LT. 2) THEN

IF (IPOP .EQ. 0) WRITE $(6,9120)$

IF (IPOP .EQ. 1) WRITE $(6,9122)$

IF (IPOP .EQ. 2) THEN

WRITE $(6,9124)$ T(1), (DIST(I), I=1, NDIST)

WRITE $(6,9125)$

DO 222 IS $=1,16$

WRITE $(6,9126)$ CHDIR(IS), (POP(I, IS), I=1, NDIST) CONTINUE

WRITE $(6,9127)$

WRITE $(6,9128)(T(I), \operatorname{POPT}(I), I=1, N T A)$

C ENDIF

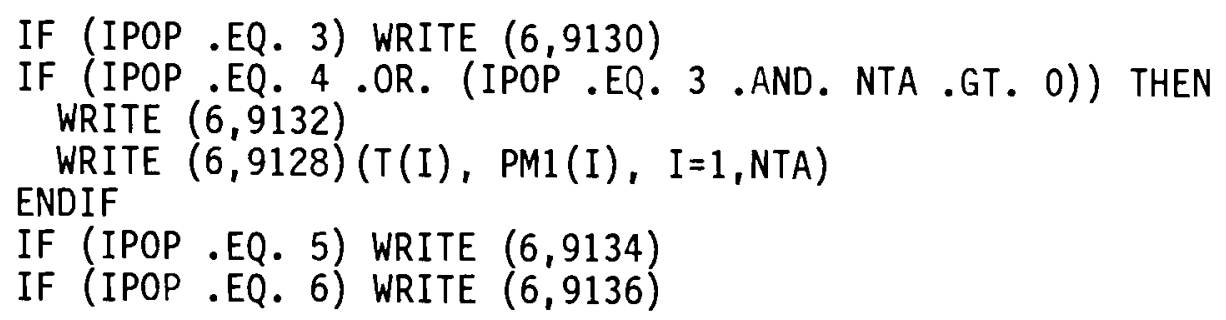

C

ENDIF

C

IF (IPATH .NE. 1 .AND. IAC .GT. 0) THEN

IF (IPL .LE. 0) WRITE $(6,9140)$

IF (IPL .EQ. 1) WRITE $(6,9142) \mathrm{PPL}$

IF (IPL .GT. 1) WRITE $(6,9142) \quad P L(1)$

C ENDIF

C

IF (IPATH .NE. 1) THEN

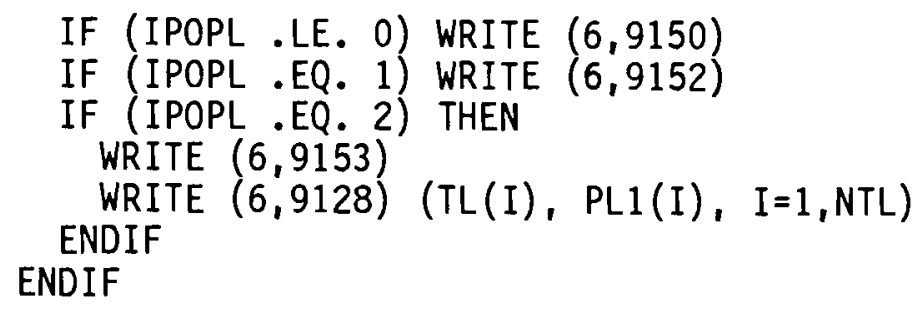

$c$
$C$
$C$

PRINT TERRESTRIAL AND AQUATIC PATHWAYS DATA--

WRITE $(6,3000)$

EIGURE D.1. DITTY Program Listing (continued) 


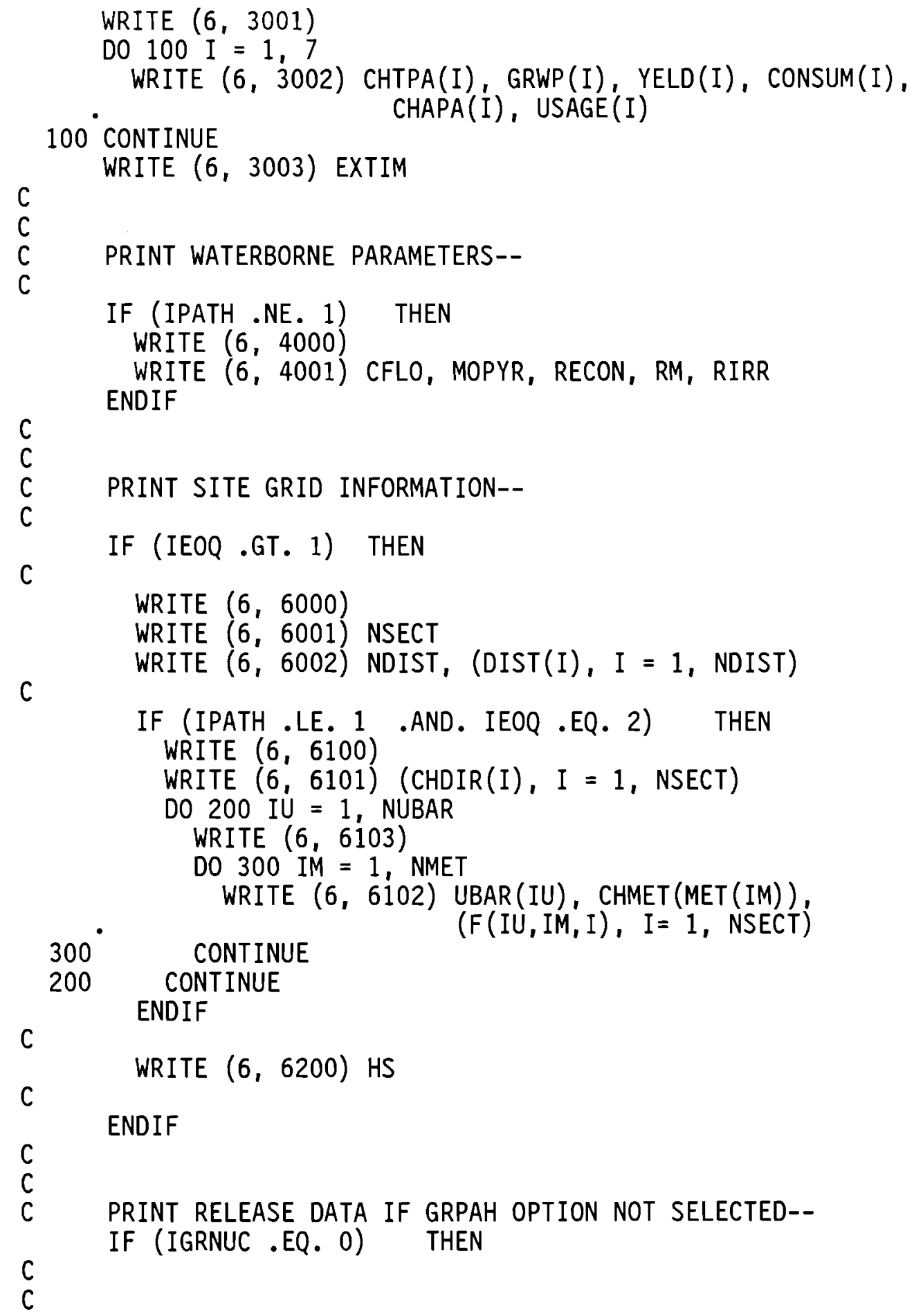

EIGURE D.1. DITTY Program Listing (continued) 


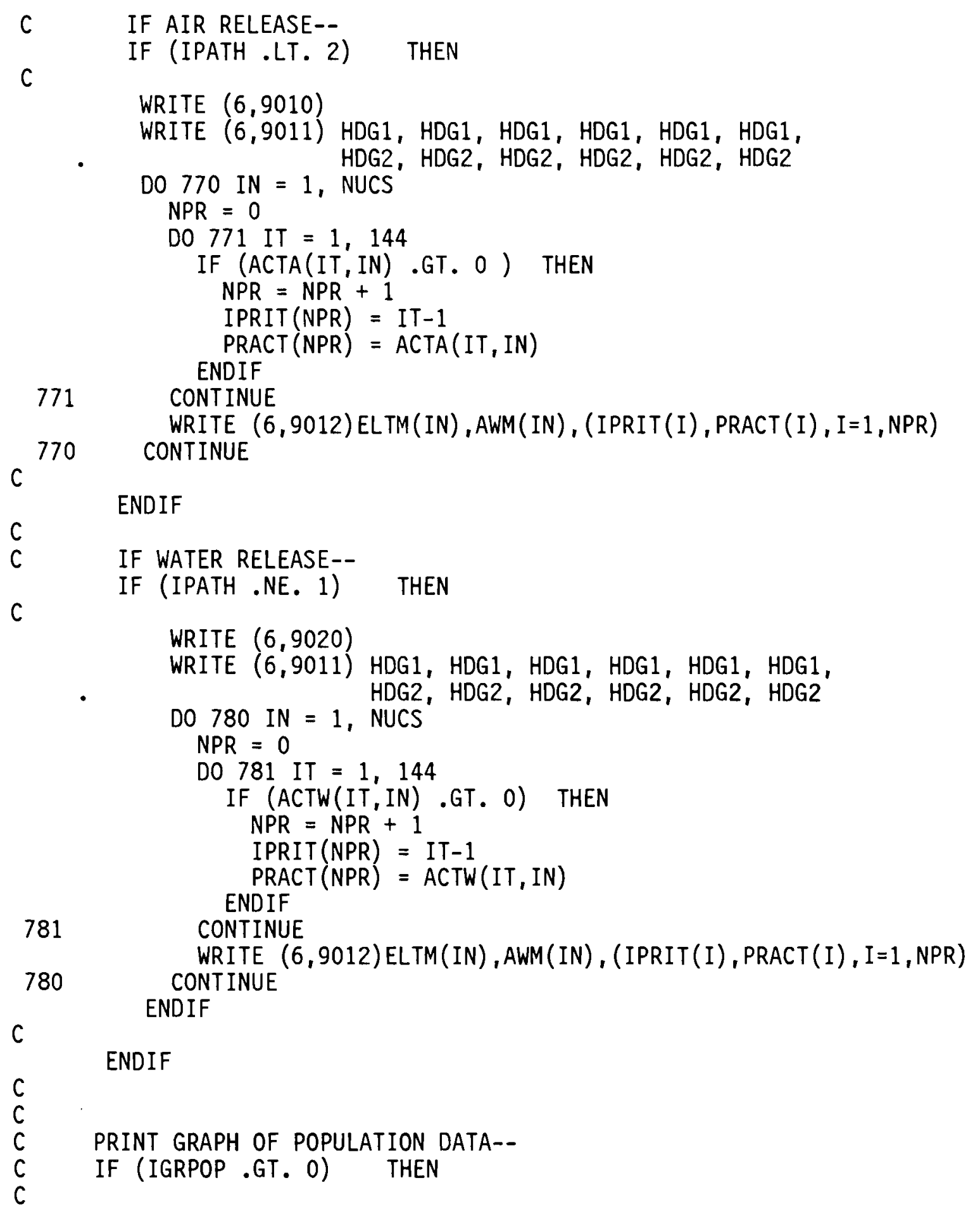

EIGURE D.1. DITTY Program Listing (continued) 


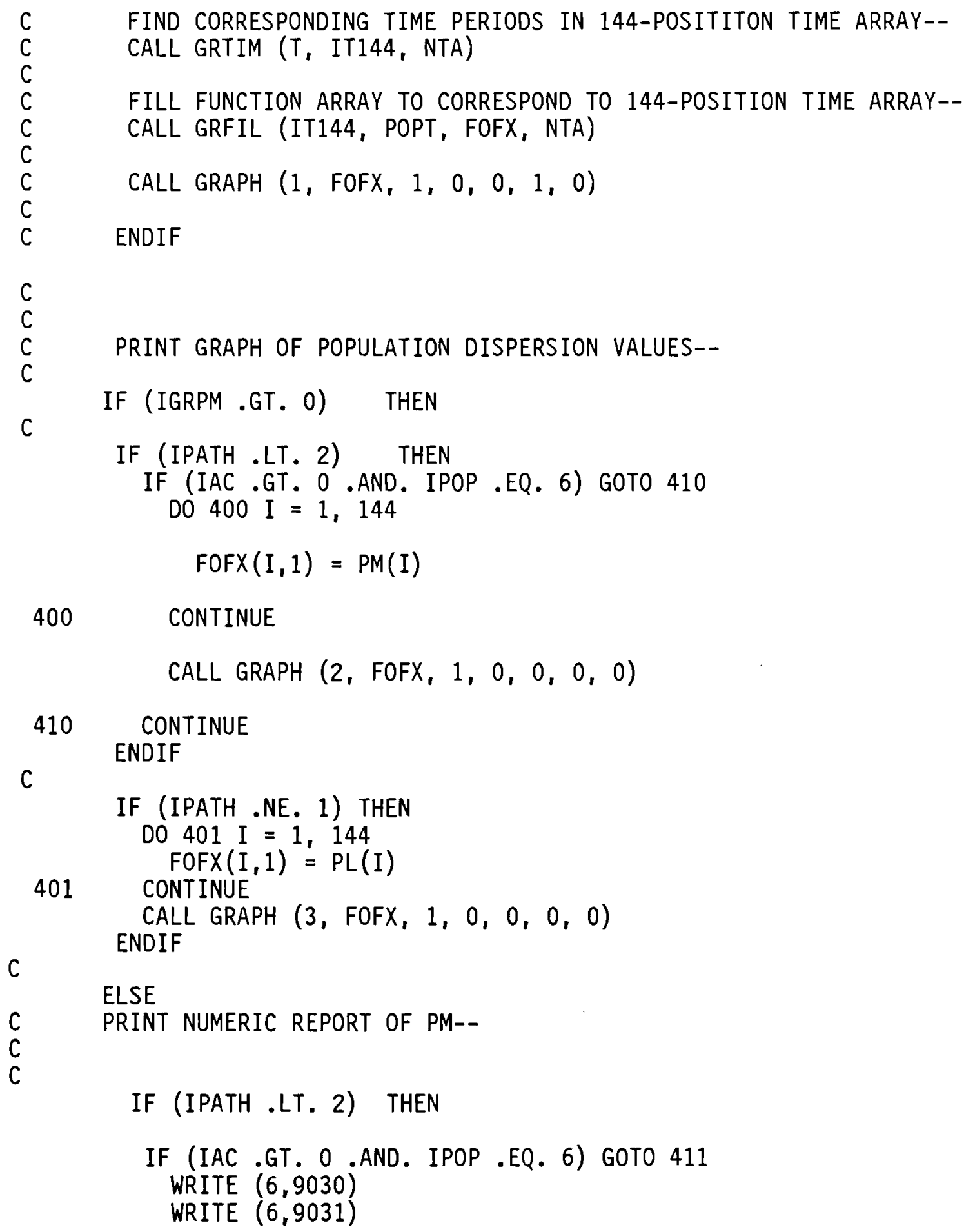

EIGURE 0.1. DITTY Program Listing (continued) 


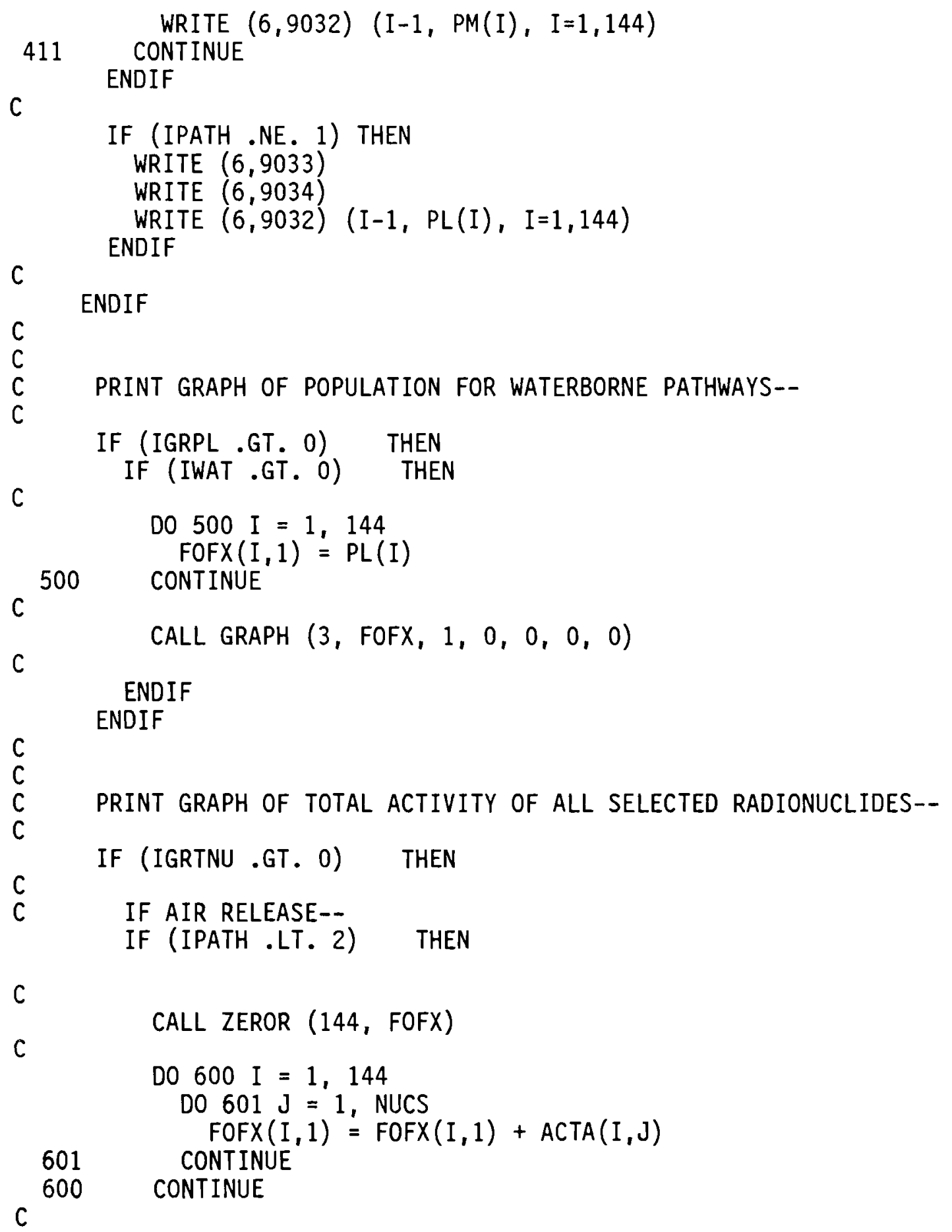

EIGURE 0.1. DITTY Program Listing (continued)

D. 92 
C

$c$
$C$
$C$

C

C

701

c

C

C

C

C

C

C

C

C

$c^{751}$

C

750

c

C

C

C

C

751

CALL GRAPH $(4$, FOFX, $1,0,0,0,1)$

ENDIF

IF WATER RELEASE--

IF (IPATH .NE. 1) THEN

CALL ZEROR (144, FOFX)

DO $700 \mathrm{I}=1,144$

DO $701 \mathrm{~J}=1$, NUCS

$\operatorname{FOFX}(I, 1)=\operatorname{FOFX}(I, 1)+\operatorname{ACTW}(I, J)$ CONTINUE

CONTINUE

CALL GRAPH $(4$, FOFX, $1,0,0,0,2)$

ENDIF

ENDIF

PRINT GRAPH OF ACTIVITY OF EACH RADIONUCLIDE--

IF (IGRNUC .GT. 0) THEN

IF AIR RELEASE--

IF (IPATH .LT. 2) THEN

DO 750 IN $=1$, NUCS

DO 751 IT $=1,144$

$\operatorname{FOFX}(I T, 1)=\operatorname{ACTA}(I T, I N)$ CONTINUE

CALL GRAPH $(5$, FOFX, 1, IN, $0,0,1)$

CONTINUE

ENDIF

FIGURE 0.1. DITTY Program Listing (continued)

D.93 


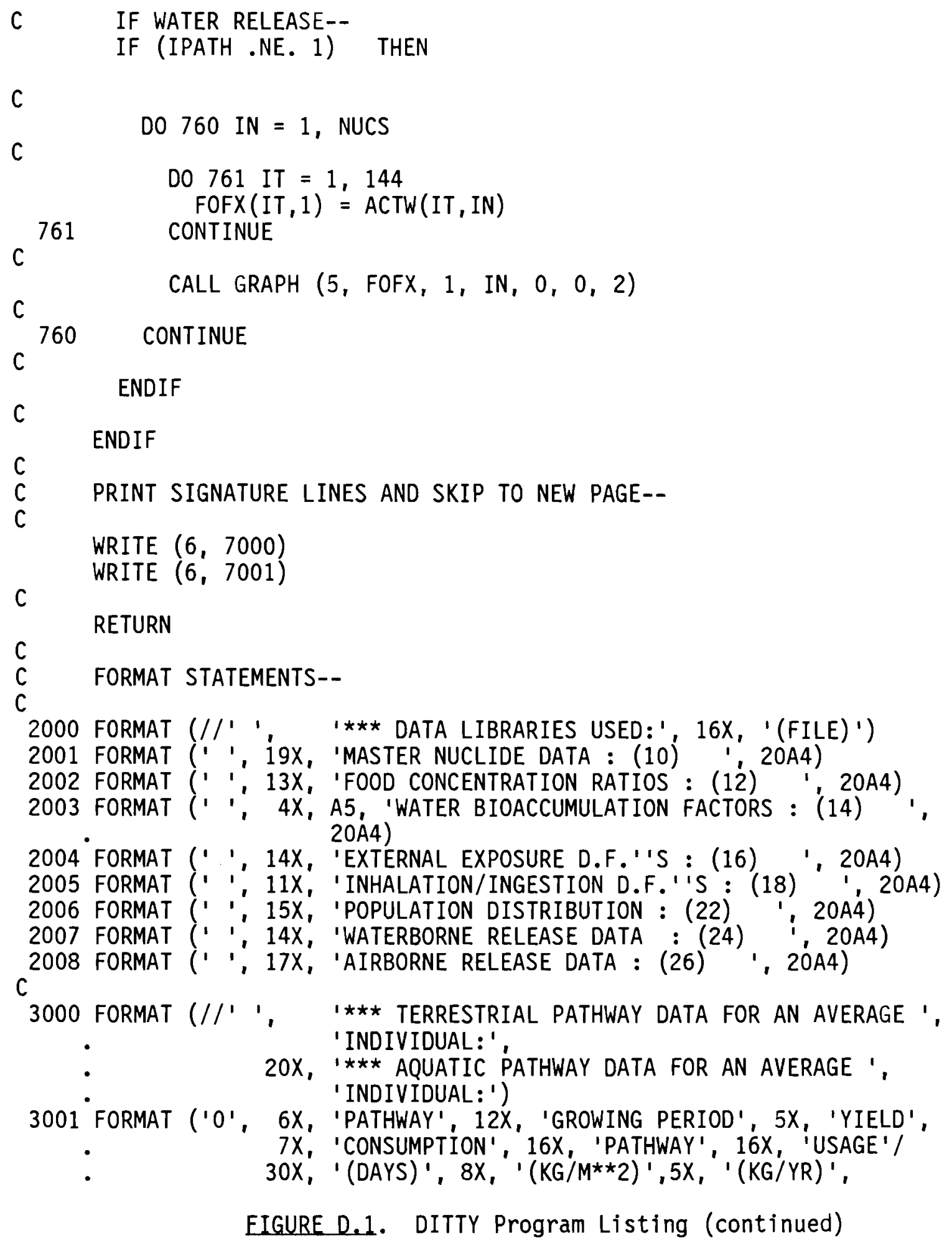

EIGURE D.1. DITTY Program Listing (continued) 


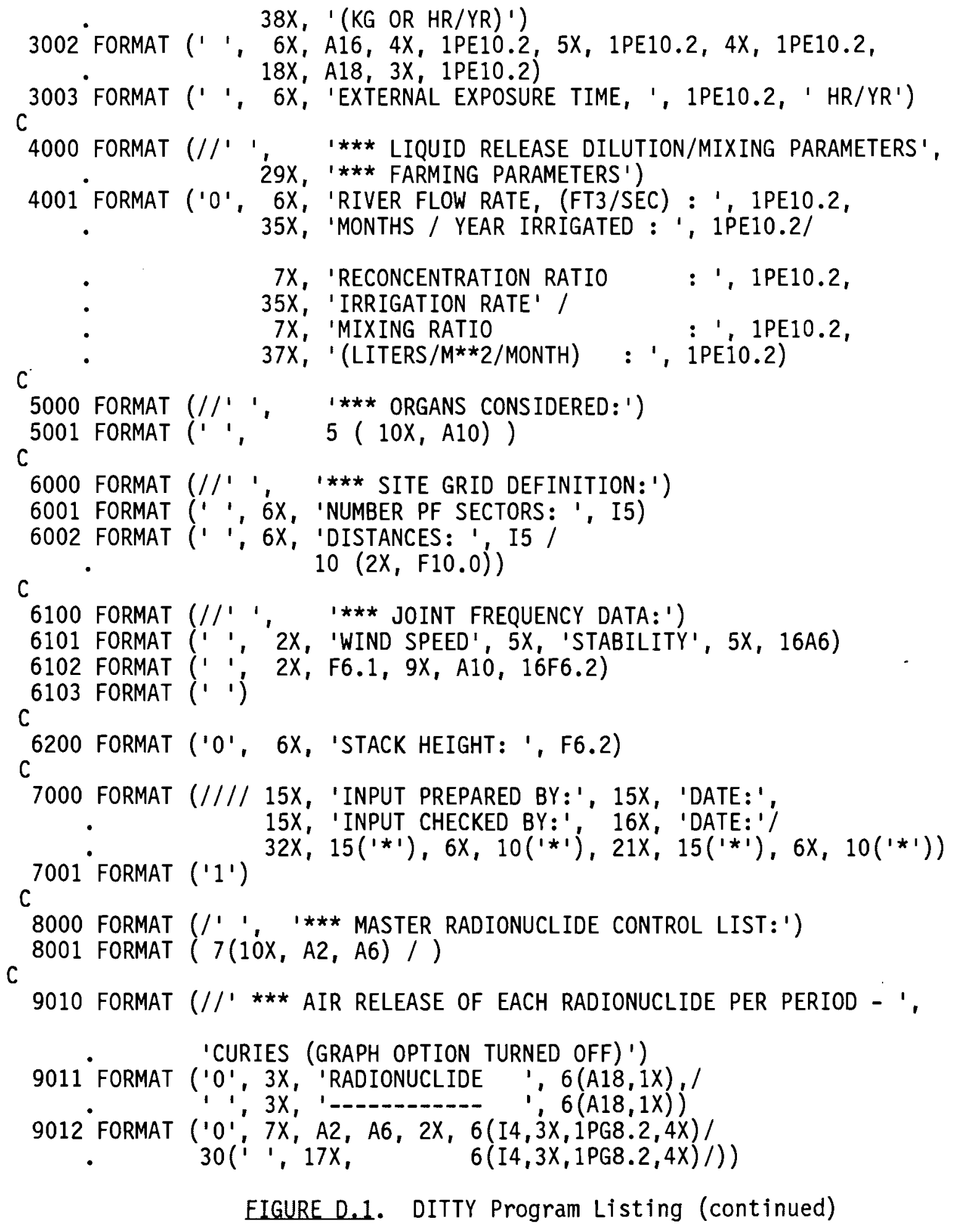

EIGURE D.1. DITTY Program Listing (continued) 


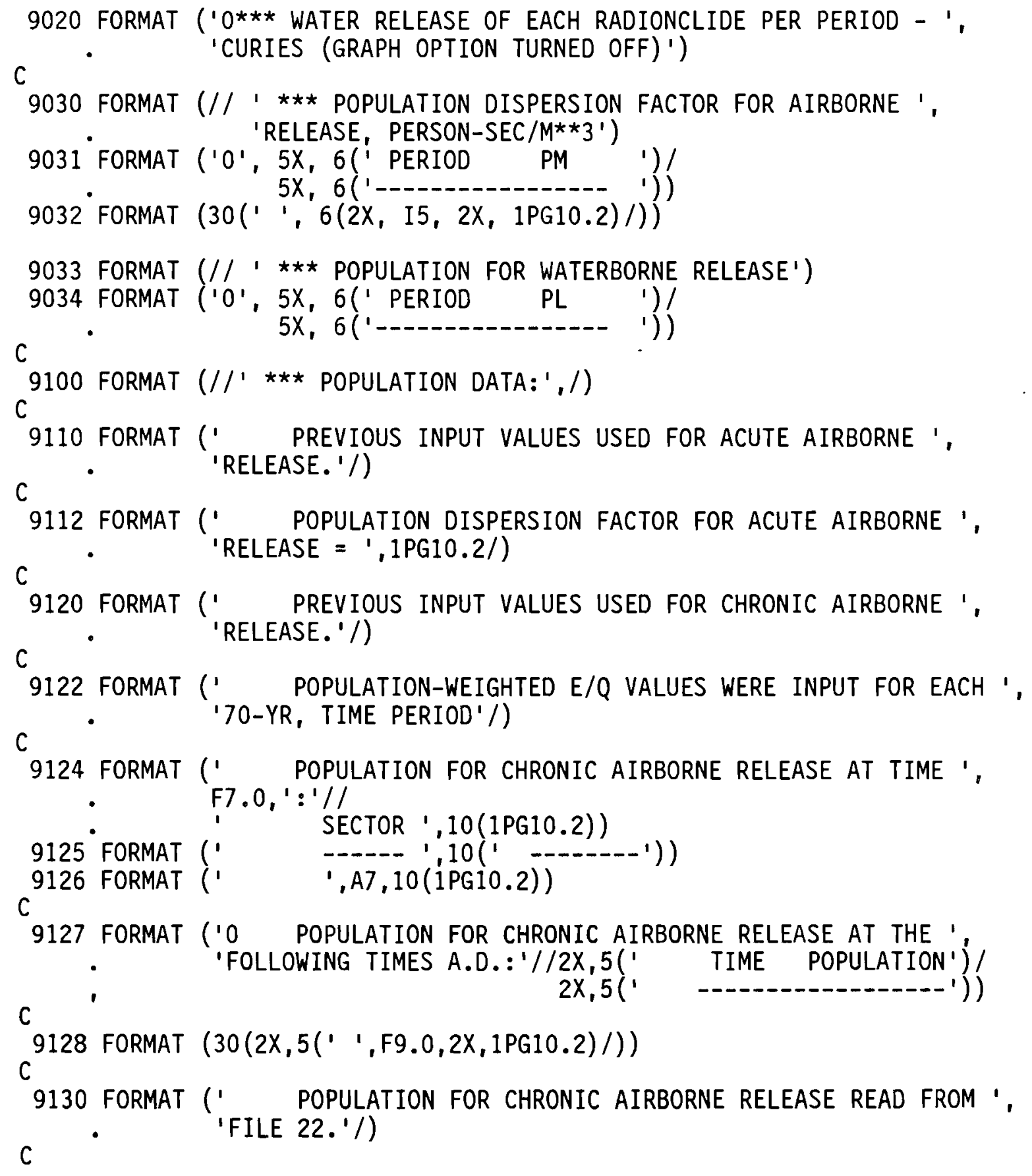

EIGURE D.1. DITTY Program Listing (continued) 


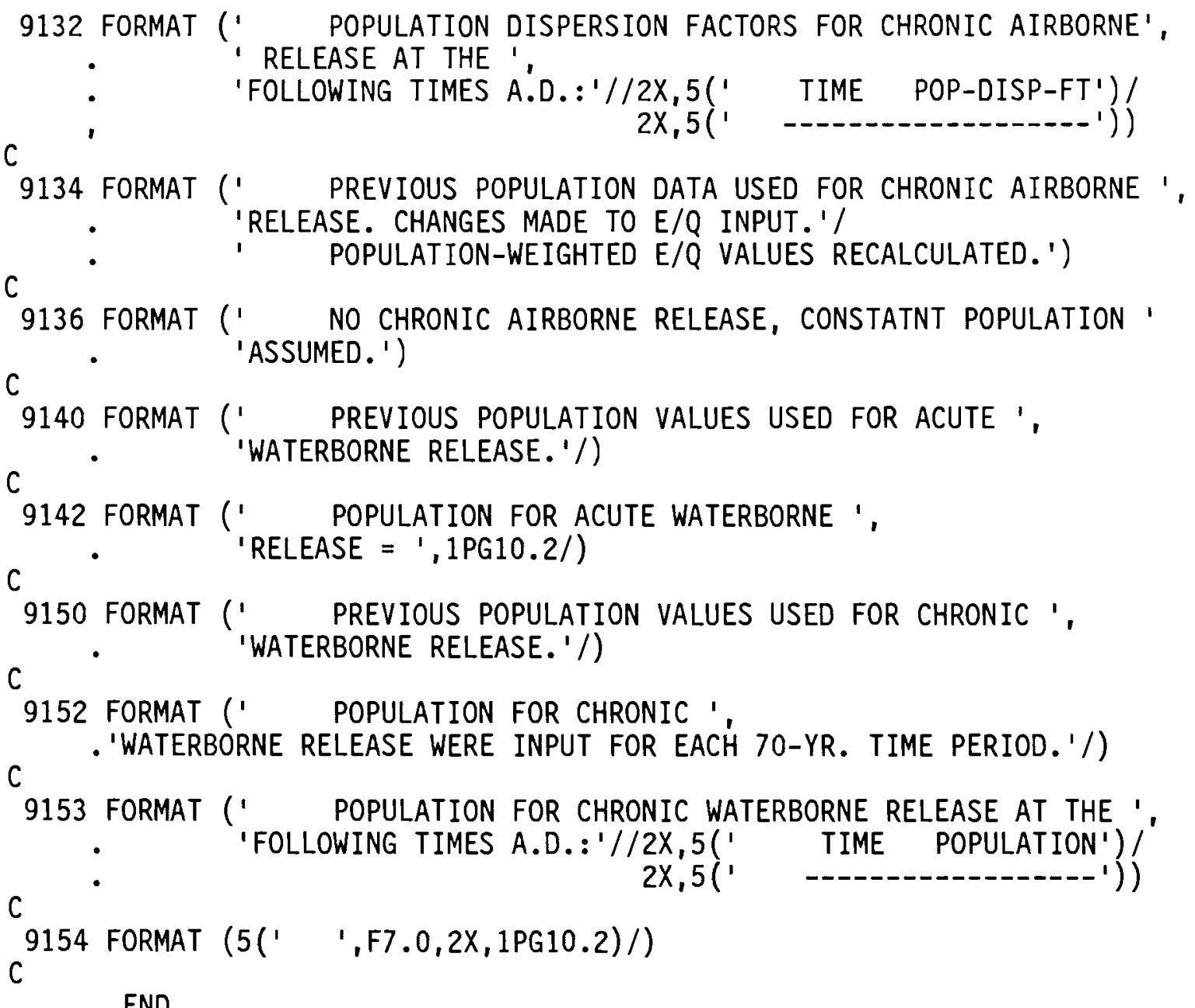

END

EIGURE D.1. DITTY Program Listing (continued) 


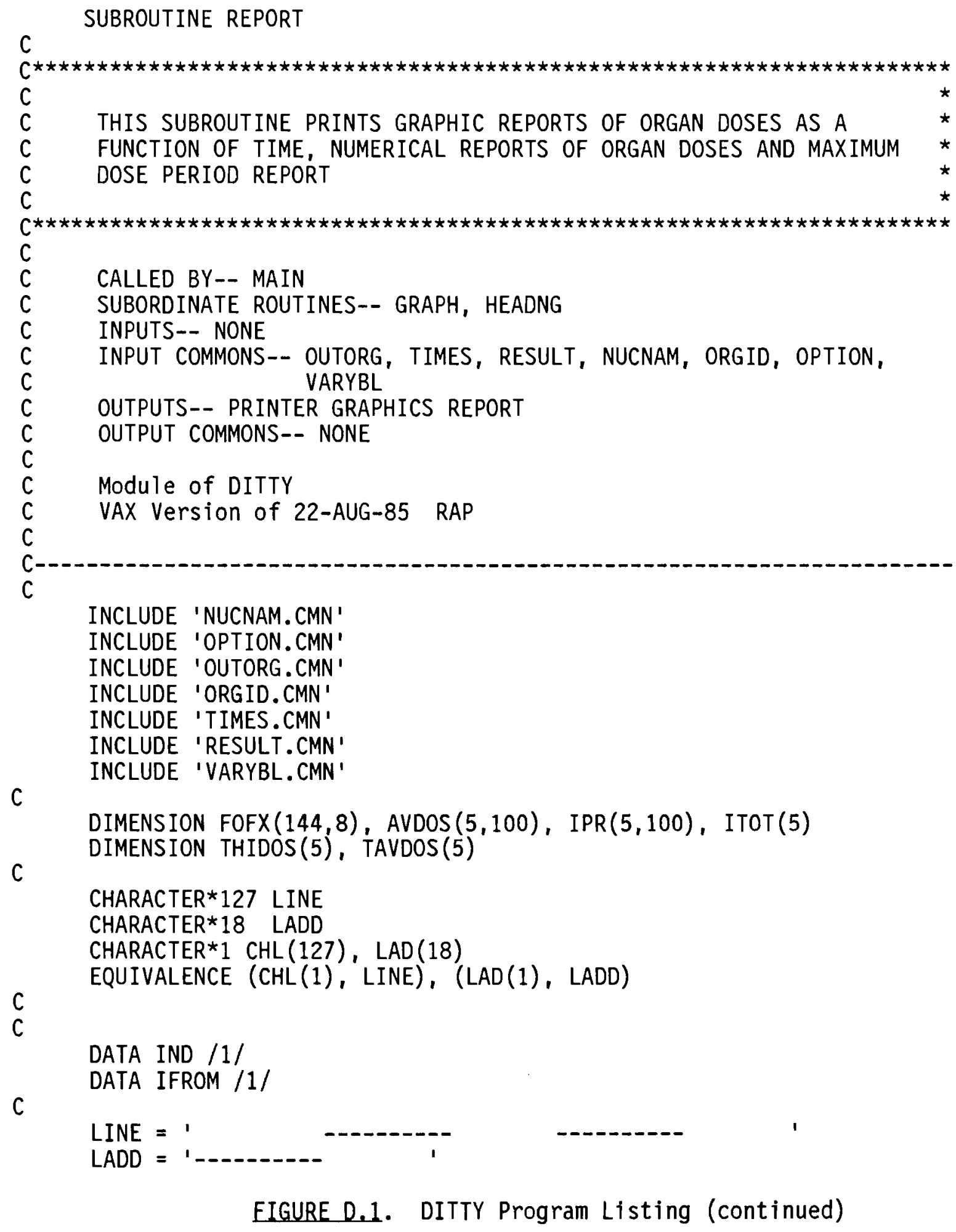

EIGURE D.1. DITTY Program Listing (continued) 
C

CALL ZEROR (500,AVDOS)

C

CALL ZEROI (500, IPR)

$$
\begin{aligned}
& \text { IF (ISPEC .GT. O) THEN } \\
& \text { LIMIT }=\text { NORG }+1 \\
& \text { ELSE } \\
& \text { LIMIT = NORG } \\
& \text { ENDIF } \\
& \text { ORGT }(\text { NORG }+1)=\text { 'PARAMETER' }
\end{aligned}
$$

C

C SET LENGTH OF UNDERLINE--

$$
\begin{aligned}
& \text { DO } 301 \text { IO }=1, \text { NORG } \\
& \text { I }=I 0 * 18+29 \\
& \text { I2 }=I+18 \\
& \text { III }=1 \\
& \text { DO } 303 \text { II }=\text { I, I2 } \\
& \text { IF (II .GT. 127) GO TO } 301
\end{aligned}
$$$$
\text { IF (III .GT. 18) GO TO } 301
$$

303

$$
\begin{aligned}
& \mathrm{CHL}(\mathrm{II})=\operatorname{LAD}(\text { III }) \\
& \mathrm{III}=\mathrm{III}+1
\end{aligned}
$$

C

301 CONTINUE

C PRINT GRAPH OF DOSE TO EACH SELECTED ORGAN--

C

$$
\begin{gathered}
\text { IF (IGRDOS .GT, 0) THEN } \\
\text { DO } 100 \text { IO }=1 \text {, NORG }
\end{gathered}
$$

C

200 CONTINUE

DO $200 I=1,144$

$$
\text { FOFX (I, IND) }=\operatorname{DTOTAL}(I 0, I)
$$

CALL GRAPH (7, FOFX, 1, I0, IFROM, 0, 0)

C TO PRINT GRAPH FOR THIS ORGAN.

C WRITE $(6,2004)$

100 CONTINUE ENDIF

$C$
$C$
$C$
$C$

PRINT NUMERIC REPORT OF DOSE TO EACH ORGAN FOR EACH TIME PERIOD--

$T T=T Z$

IPAGE $=50$

EIGURE D.1. DITTY Program Listing (continued) 


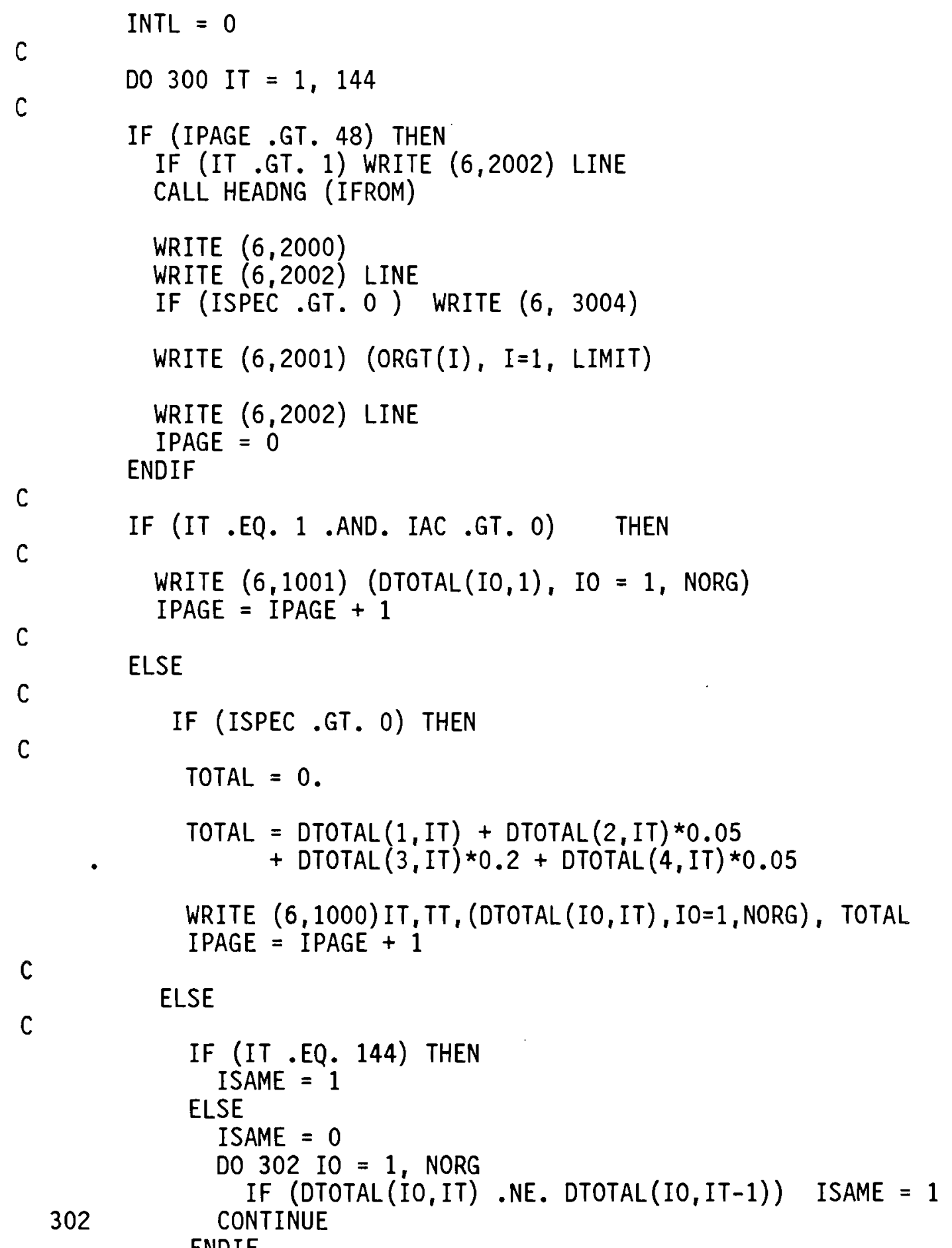
ENDIF

EIGURE D.1. DITTY Program Listing (continued) 
C

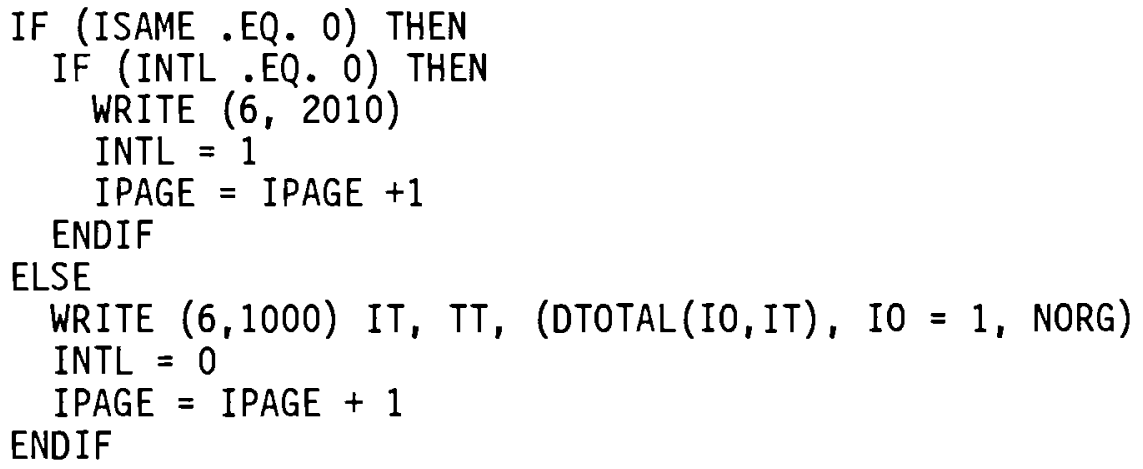

C

C

ENDIF

C

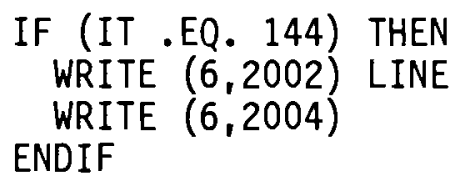

C$$
T T=T T+70 .
$$

C

300 CONTINUE

C

C

C

C PRINT REPORT OF MAXIMUM DOSE TIME PERIOD--

CALL HEADNG (IFROM)

WRITE $(6,3000)$

WRITE $(6,3001)$ MAXTIM

WRITE $(6,3010)$

WRITE $(6,3005)$ (CHL(II), II $=21,127)$

IF (ISPEC .GT. 0) WRITE $(6,3004)$

WRITE $(6,3002) \quad$ (ORGT(I), I $=1$, LIMIT)

C

WRITE $(6,3005) \quad(\mathrm{CHL}(\mathrm{II}), \mathrm{II}=21,127)$
DO 401 IO $=1$, NORG
$\operatorname{THIDOS}(\mathrm{IO})=0.0$
401 CONTINUE

C

EIGURE 0.1. DITTY Program Listing (continued) 


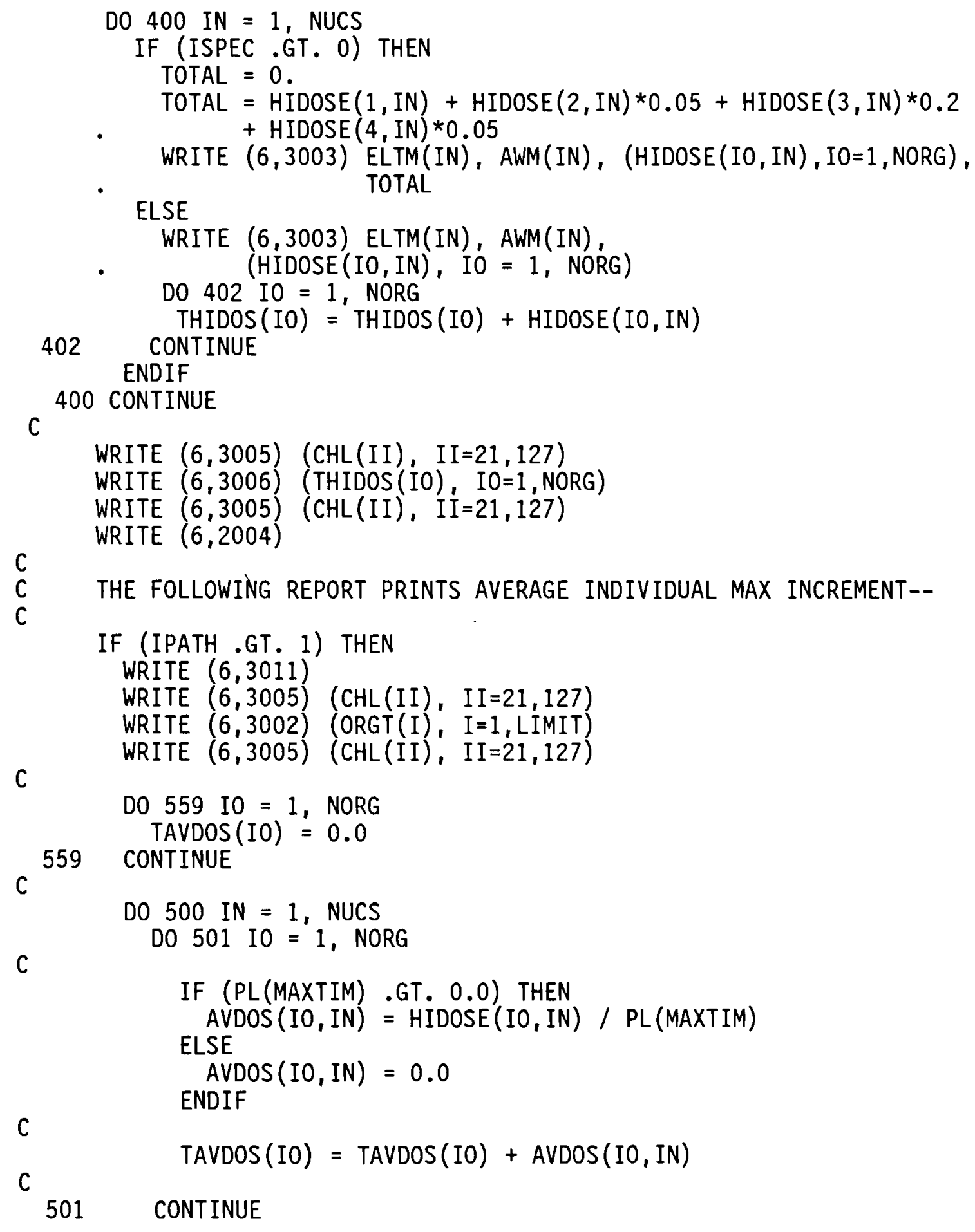

C

THE FOLLOWING REPORT PRINTS AVERAGE INDIVIDUAL MAX INCREMENT--

IF (IPATH .GT. 1) THEN WRITE $(6,3011)$

WRITE $(6,3005)$ (CHL (II), II $=21,127)$

WRITE $(6,3002) \quad$ (ORGT(I), I=1, LIMIT)

WRITE $(6,3005) \quad$ (CHL(II), II $=21,127)$

559 CONTINUE

DO 559 IO $=1$, NORG

$\operatorname{TAVDOS}(\mathrm{IO})=0.0$

C

DO 500 IN $=1$, NUCS

C

DO 501 IO $=1$, NORG
IF (PL (MAXTIM) .GT. 0.0) THEN $\operatorname{AVDOS}(I 0, I N)=\operatorname{HIDOSE}(I O, I N) / \mathrm{PL}($ MAXTIM)
$\operatorname{TAVDOS}(\mathrm{IO})=\operatorname{TAVDOS}(\mathrm{IO})+\operatorname{AVDOS}(\mathrm{IO}, \mathrm{IN})$
501 CONTINUE

C

C

EIGURE D.1. DITTY Program Listing (continued) 


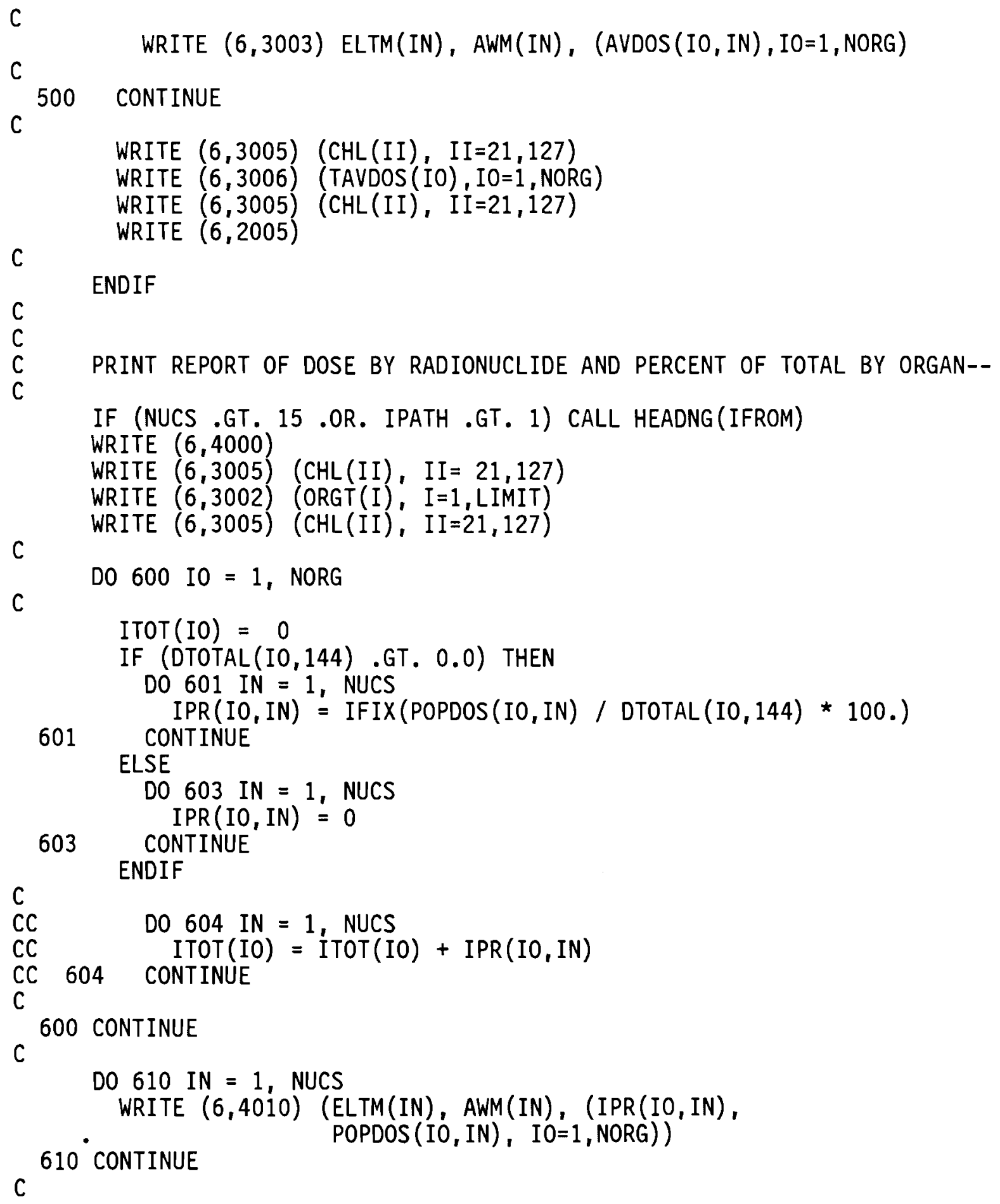

EIGURE 0.1. DITTY Program Listing (continued) 


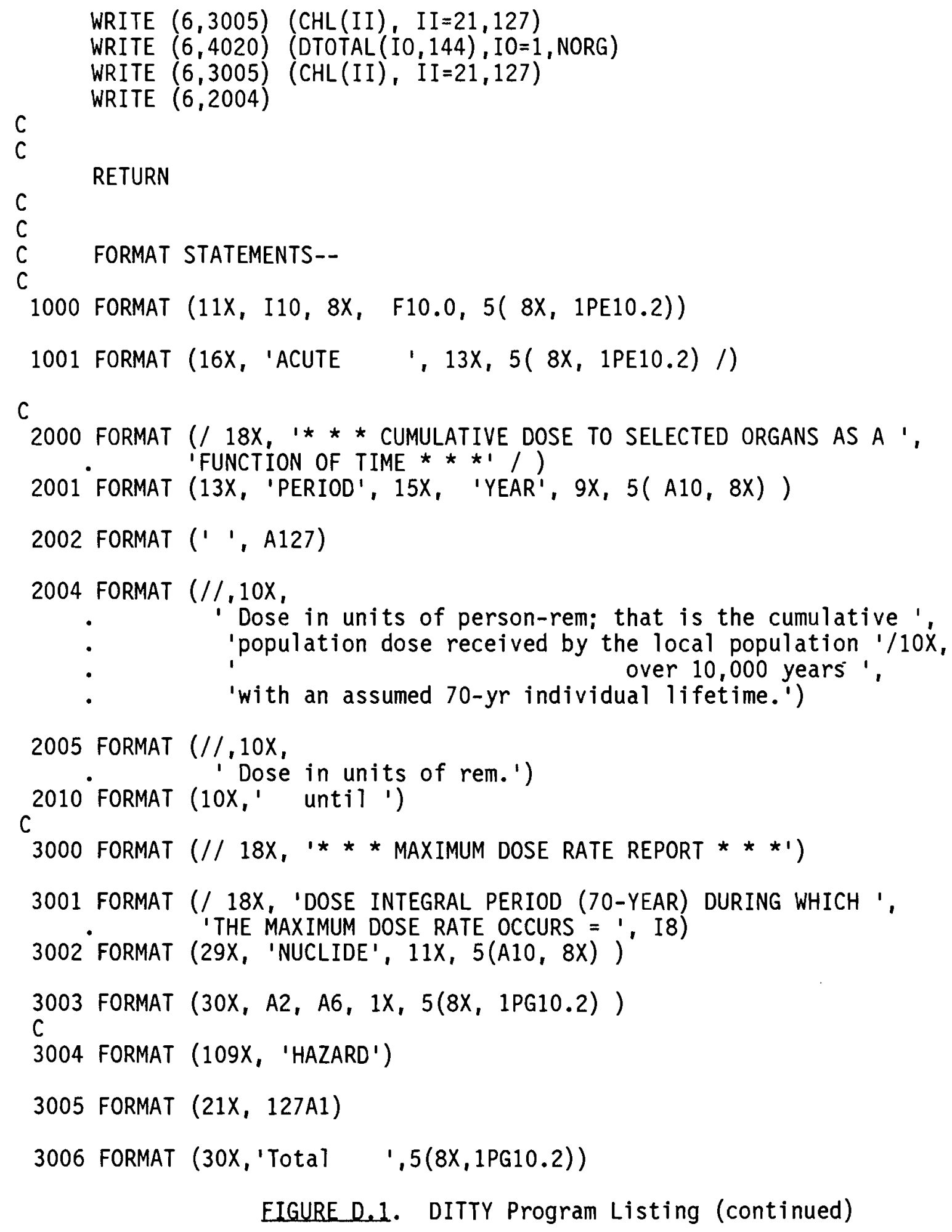


C 3010 FORMAT (///18X, $1 * \star \star$ MAXIMUM POPULATION DOSE INCREMENT TO ', ' TOTAL BODY BY ORGAN AND RADIONUCLIDE * * *1/)

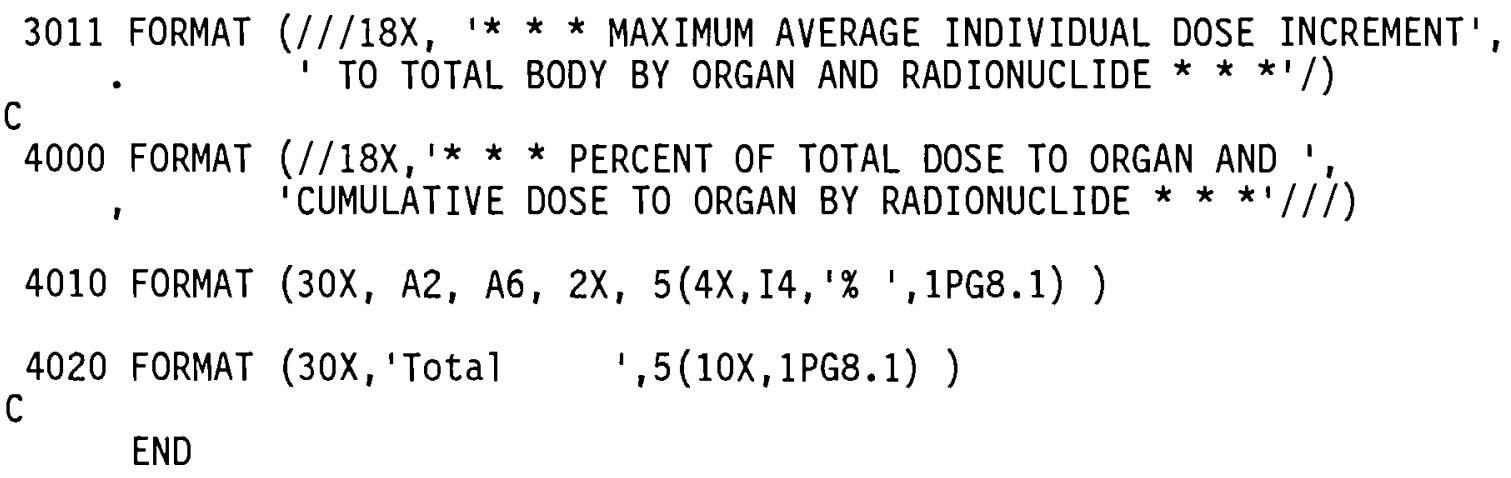

END 


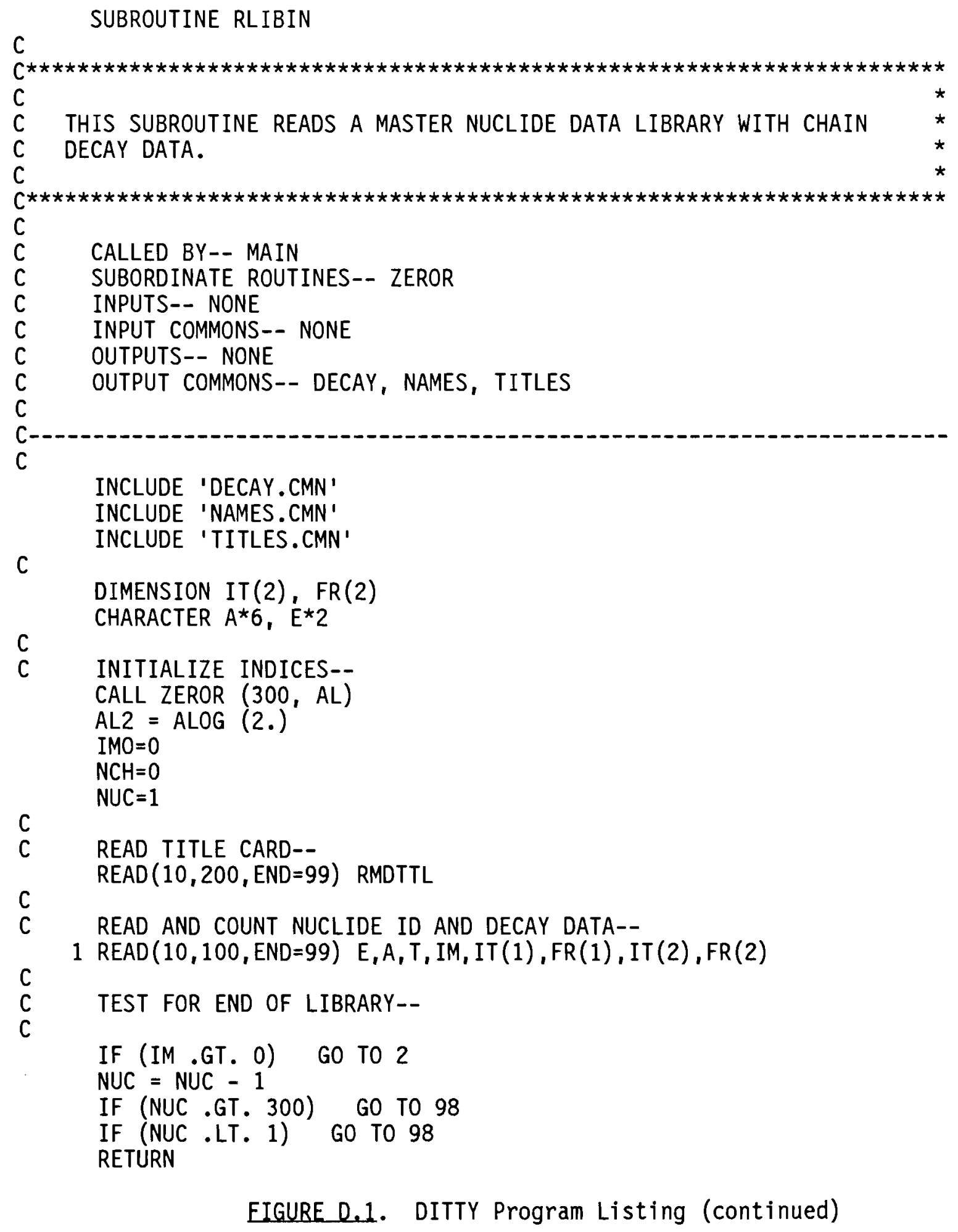

D. $10 f$ 


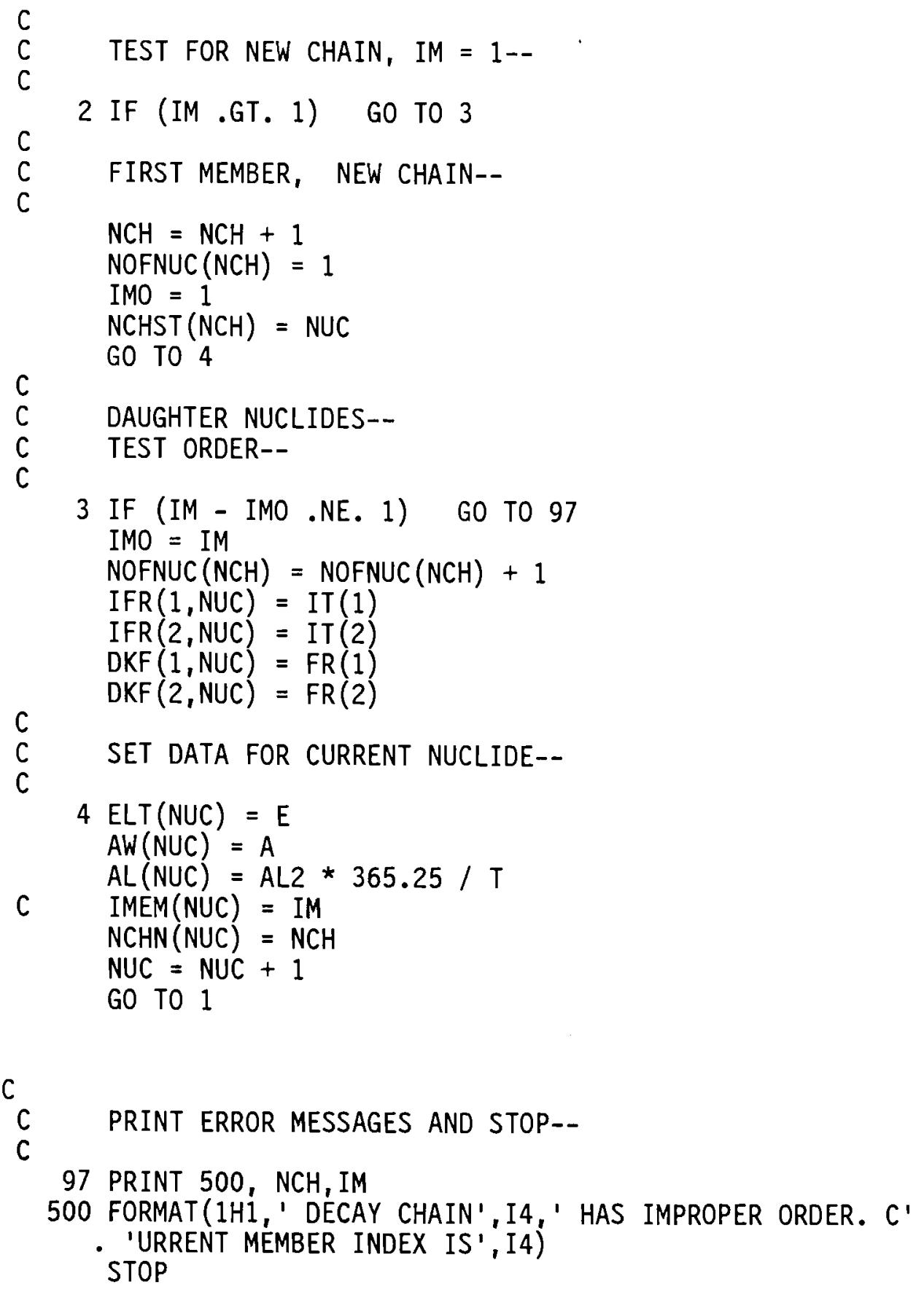

EIGURE 0.1. DITTY Program Listing (continued) 


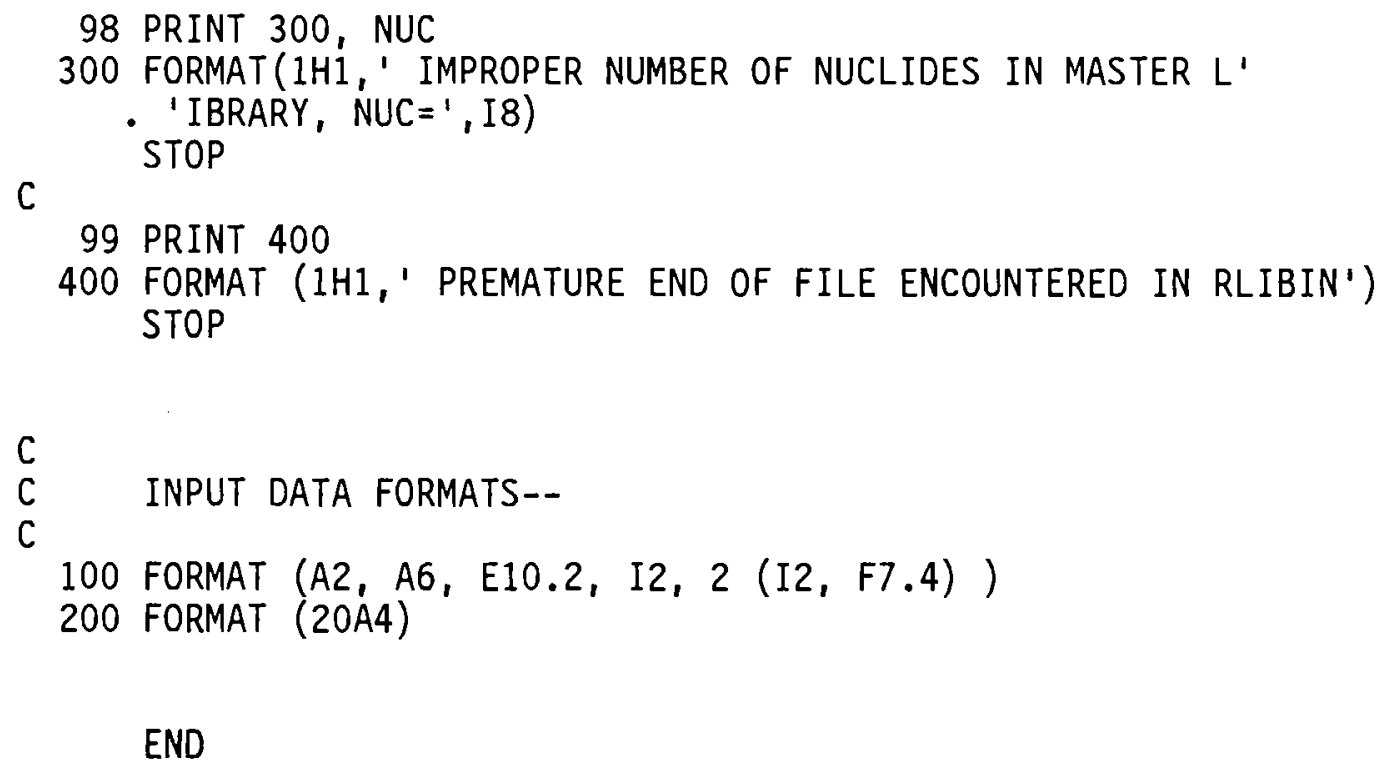

END 


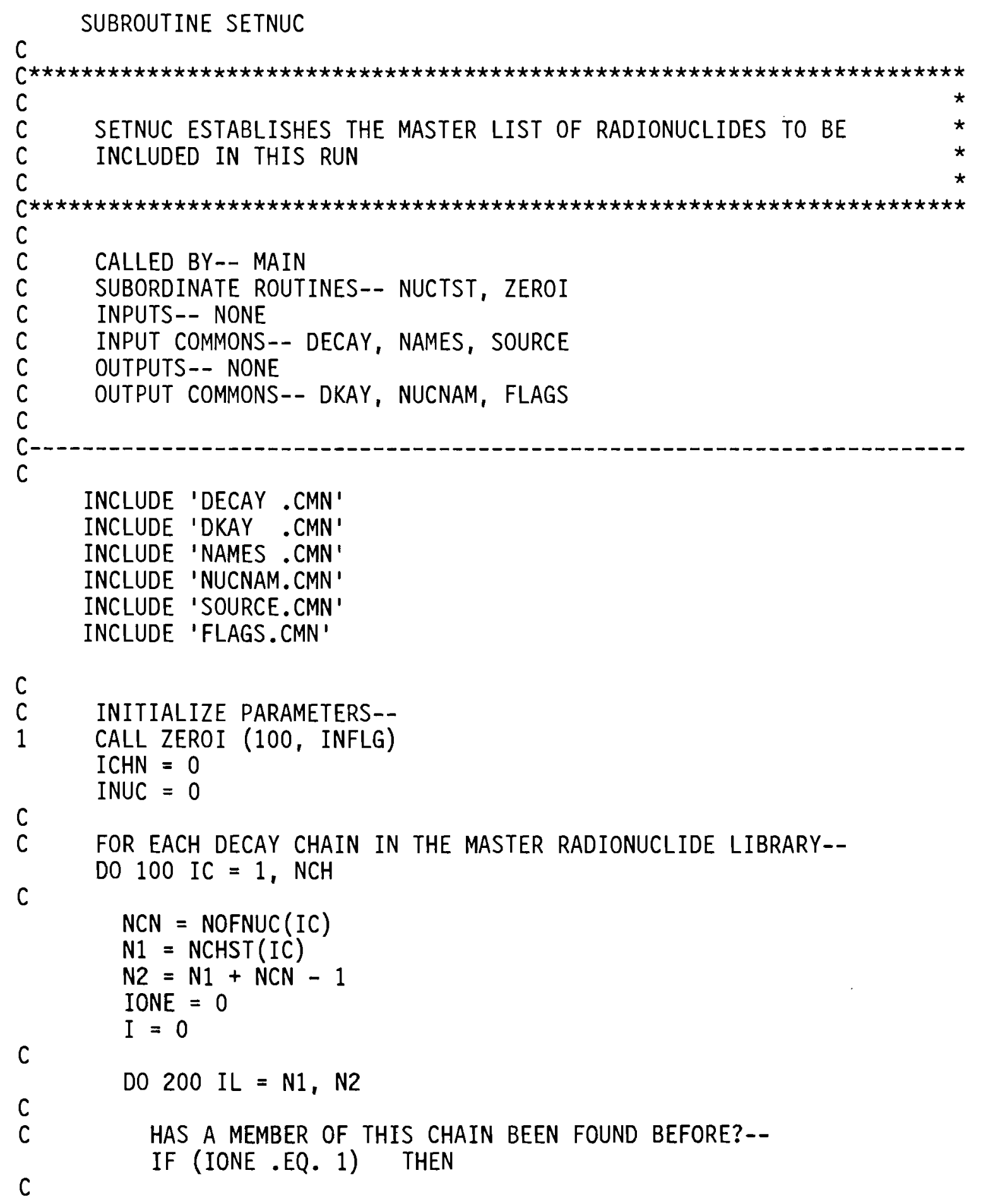

EIGURE D.1. DITTY Program Listing (continued) 


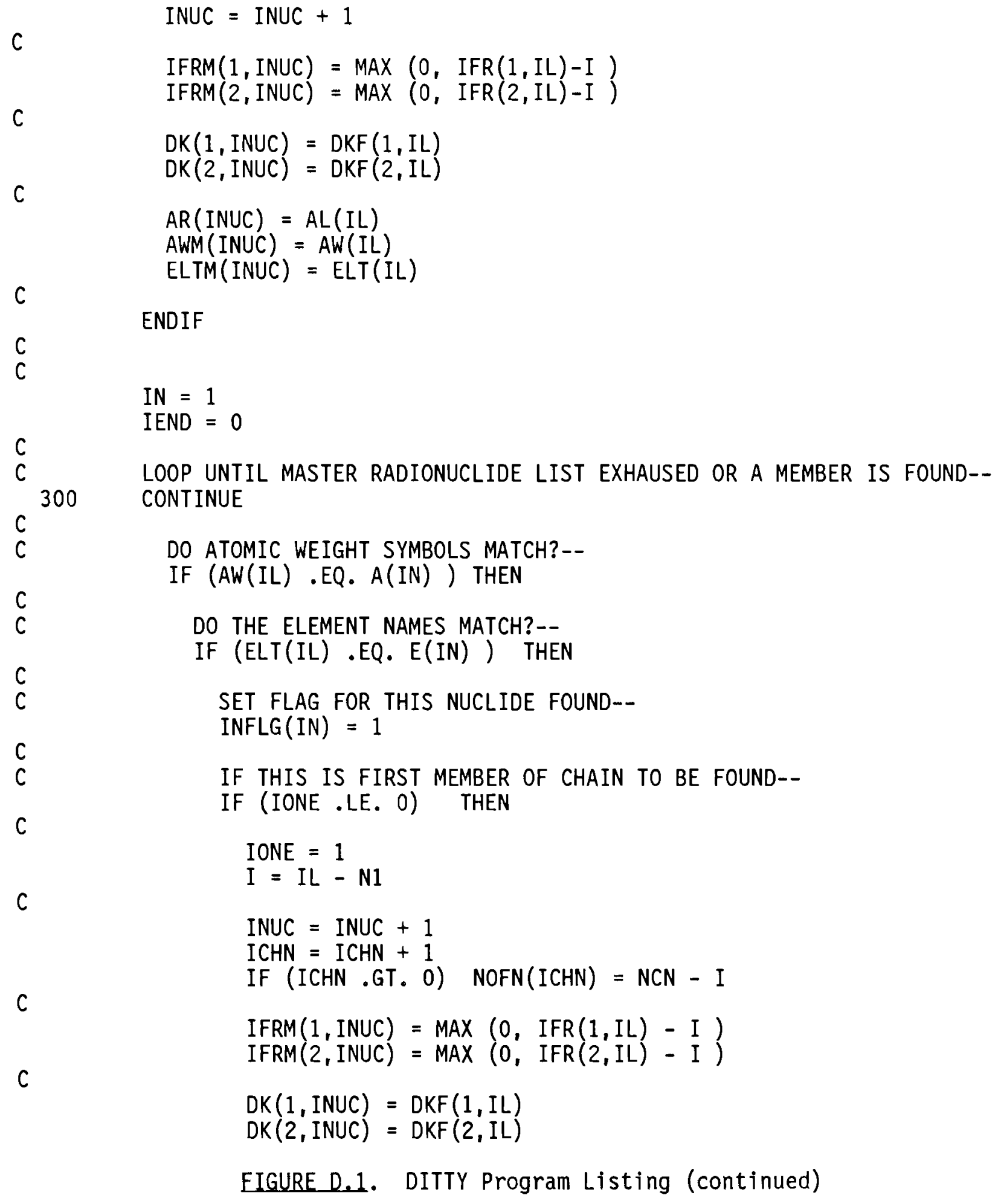




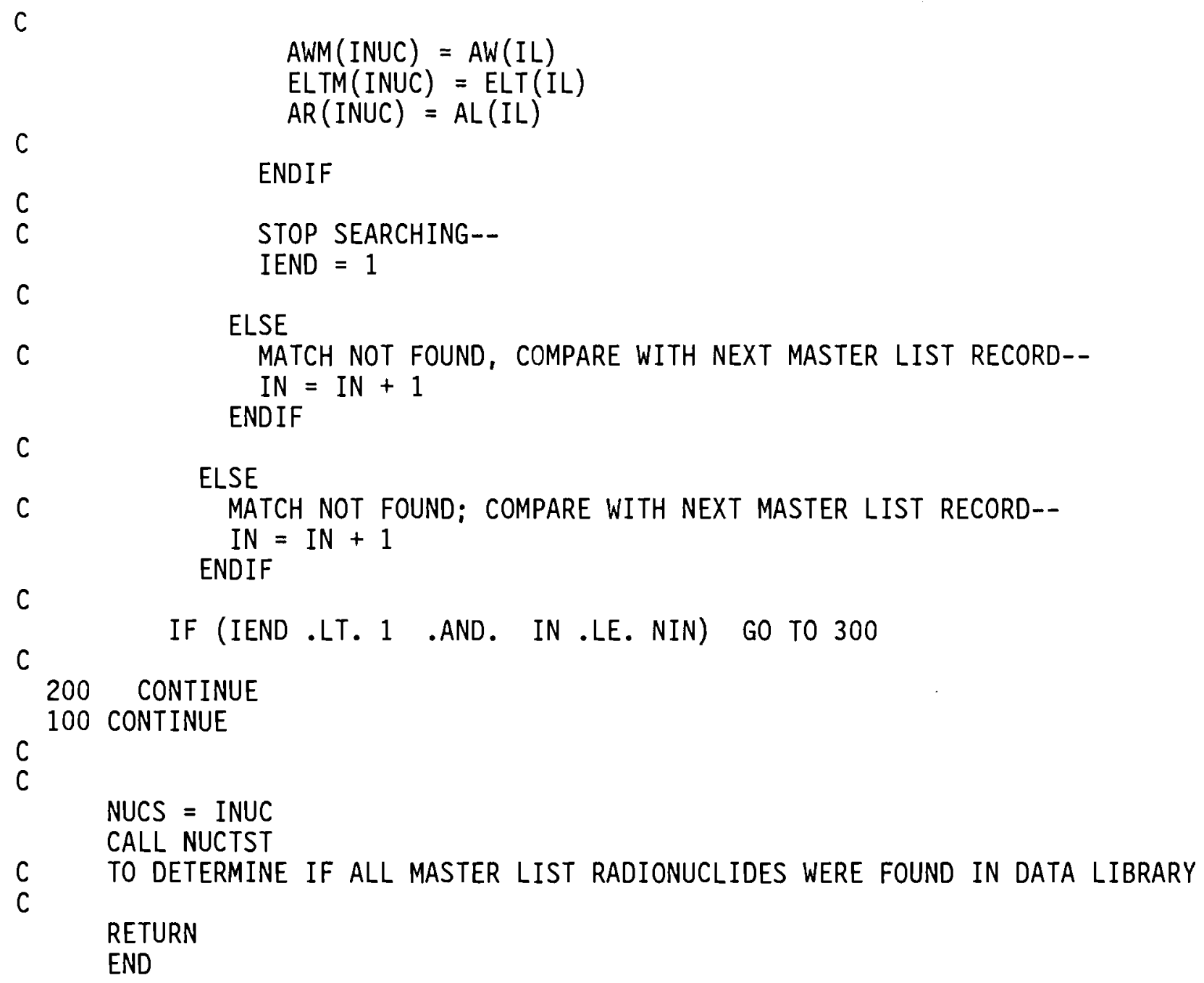

EIGURE D.1. DITTY Program Listing (continued) 


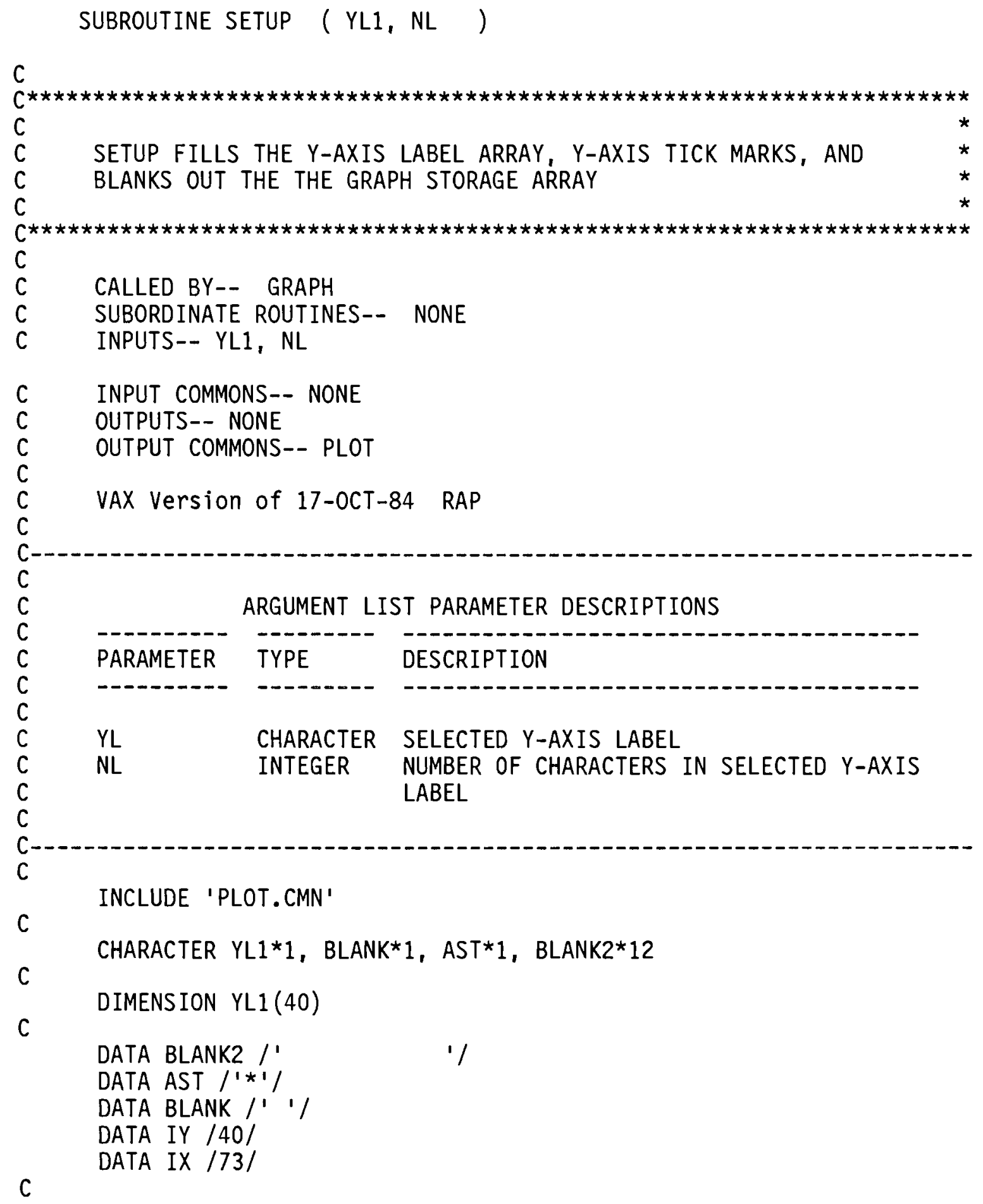

EIGURE D.1. DITTY Program Listing (continued)

D. 112 


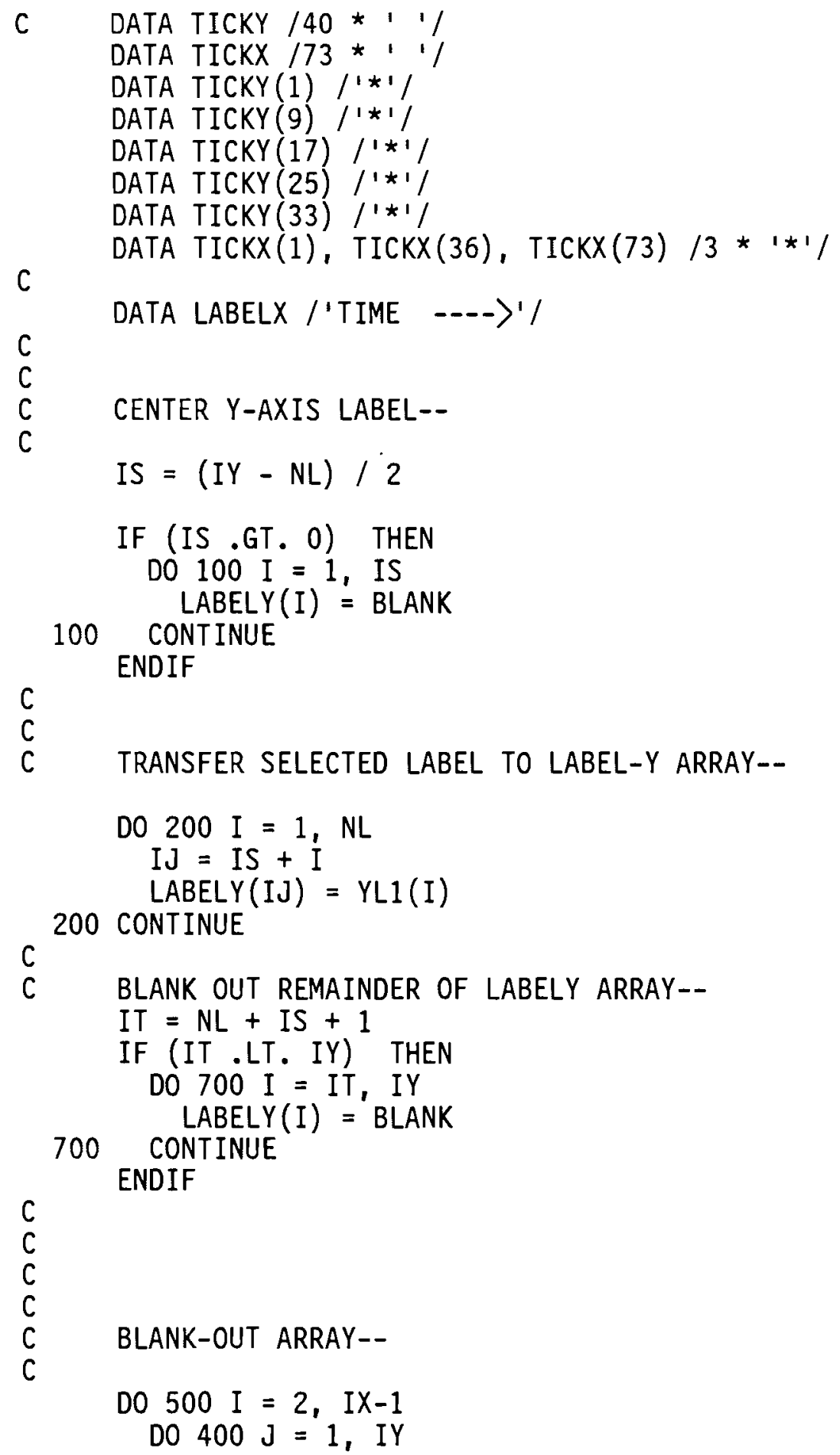

EIGURE D.1. DITTY Program Listing (continued) 


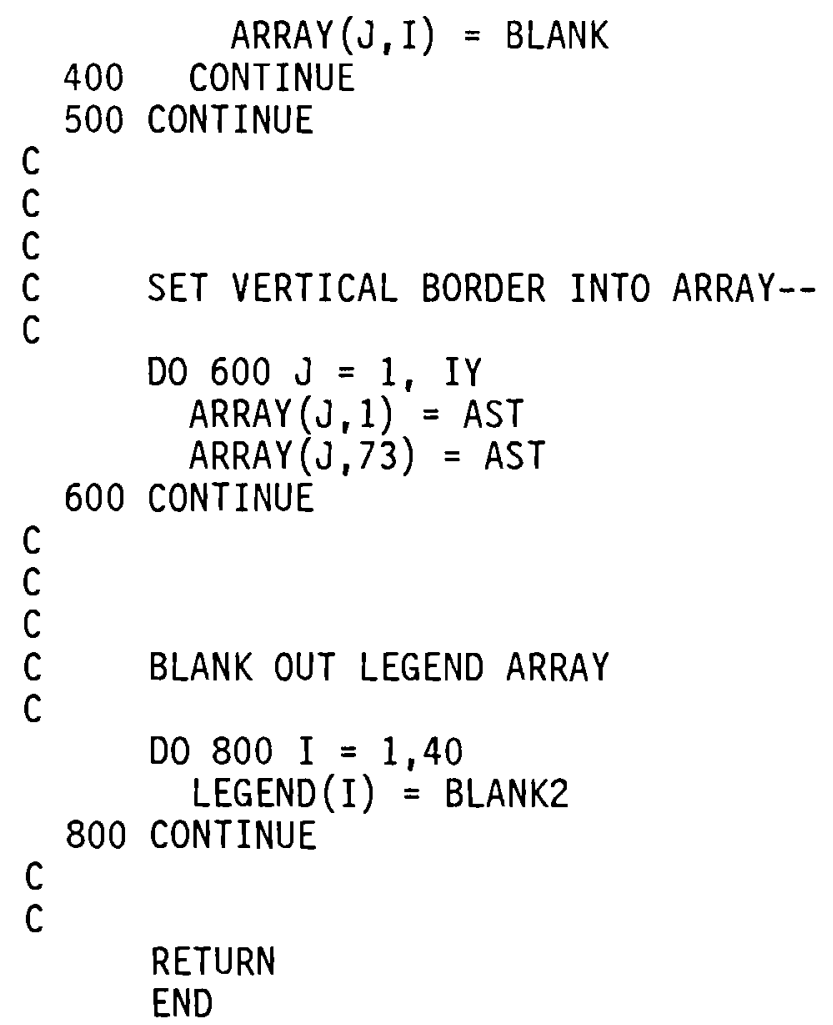

EIGURE D.1. DITTY Program Listing (continued) 


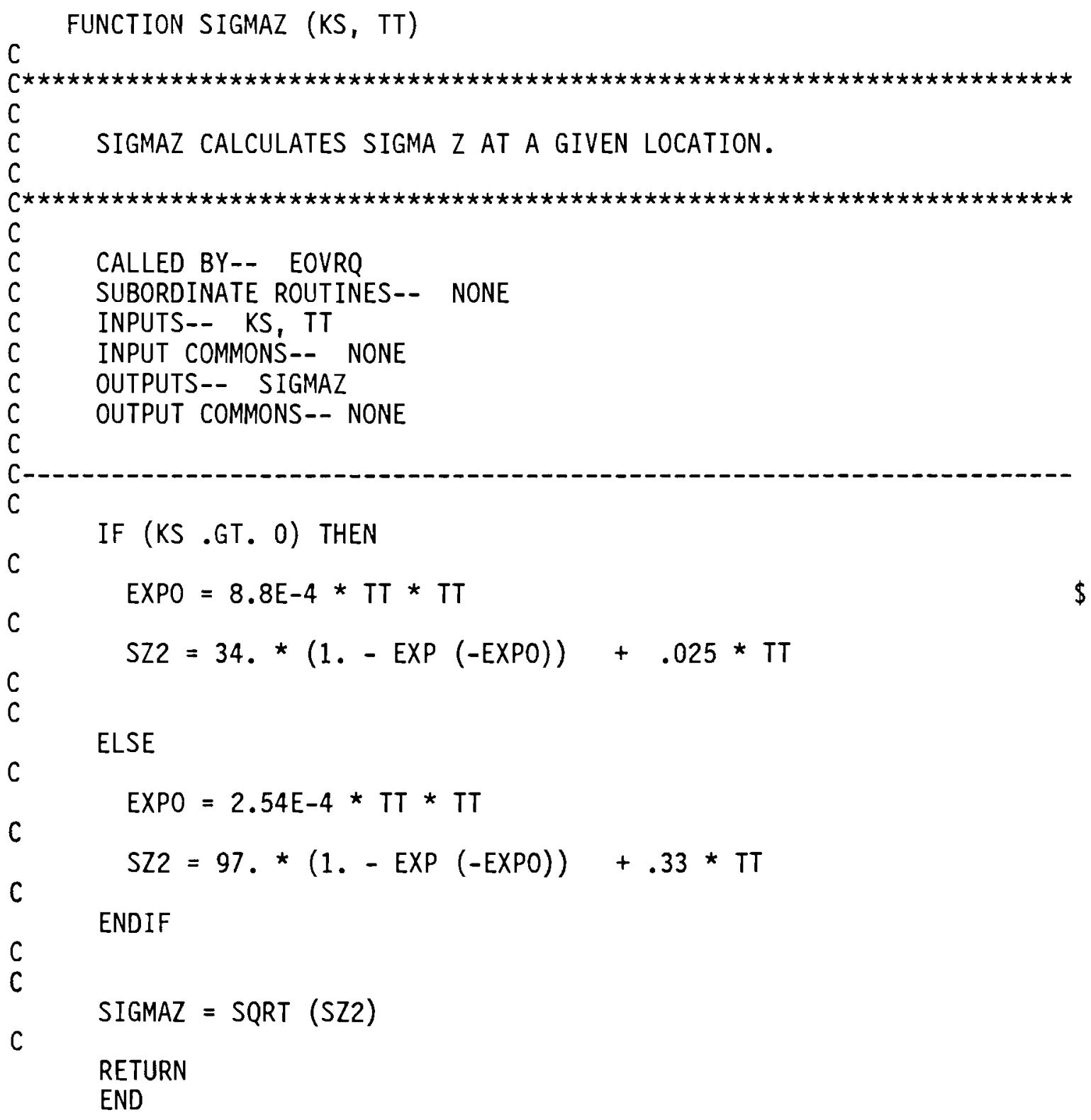

EIGURE D.1. DITTY Program Listing (continued) 
SUBROUTINE TRITUM (IST, IAW, WATCN, AIRCN, ANCONS, ANDRNK, CSOIL, C EDIBL, AQUA)

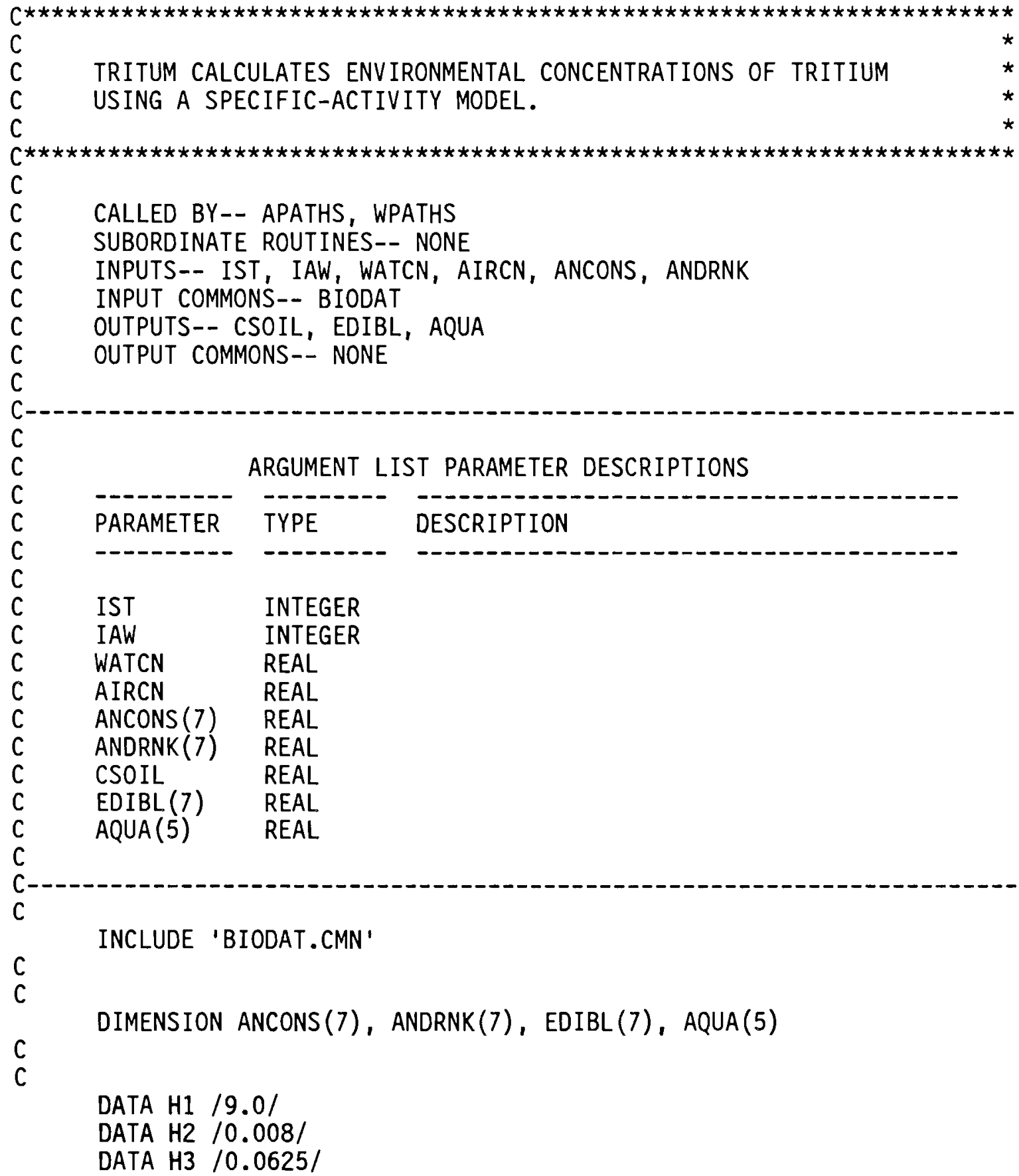

EIGURE D.1. DITTY Program Listing (continued) 


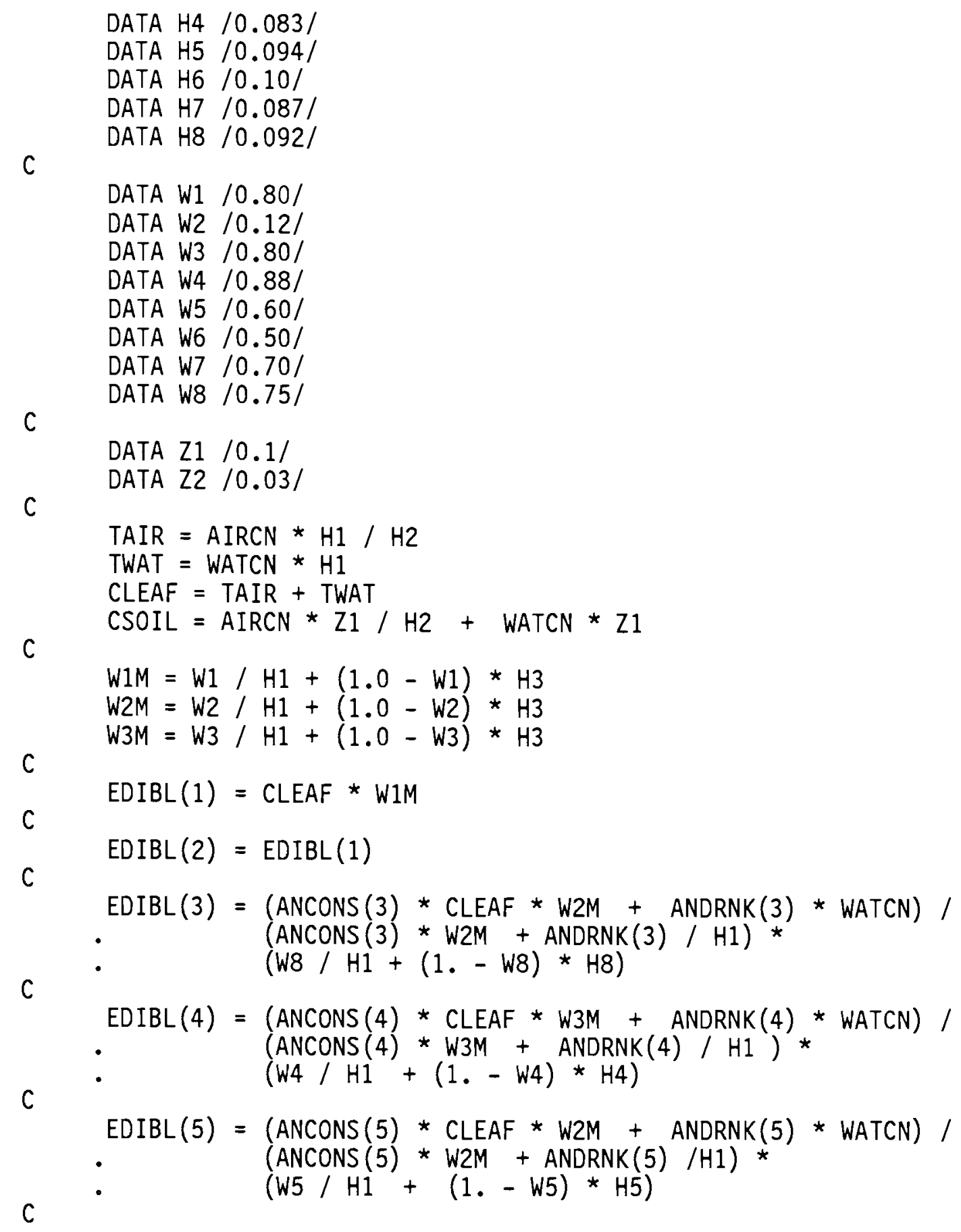

EIGURE D.1. DITTY Program Listing (continued) 


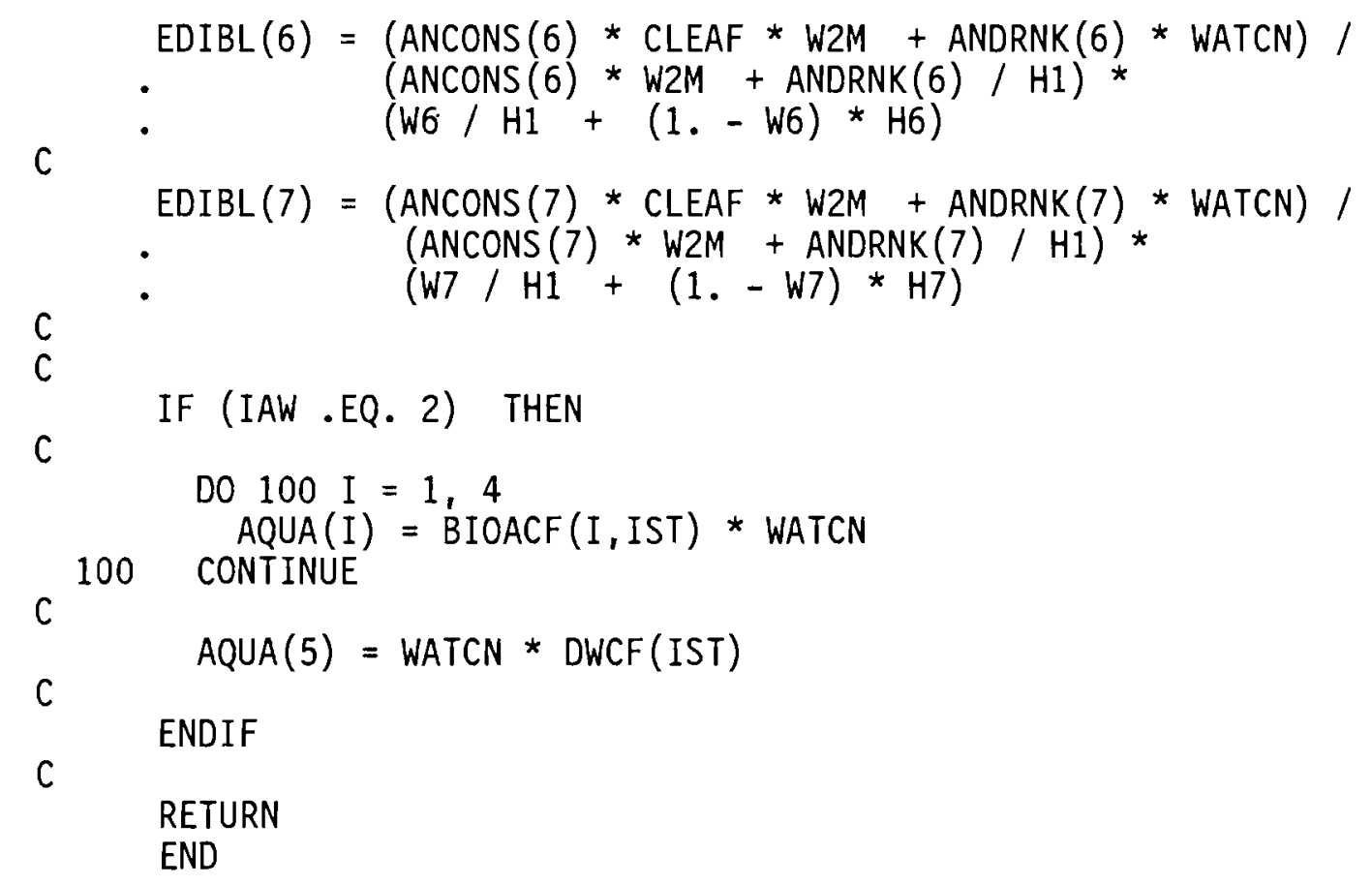

EIGURE D.1. DITTY Program Listing (continued)

D. 118 


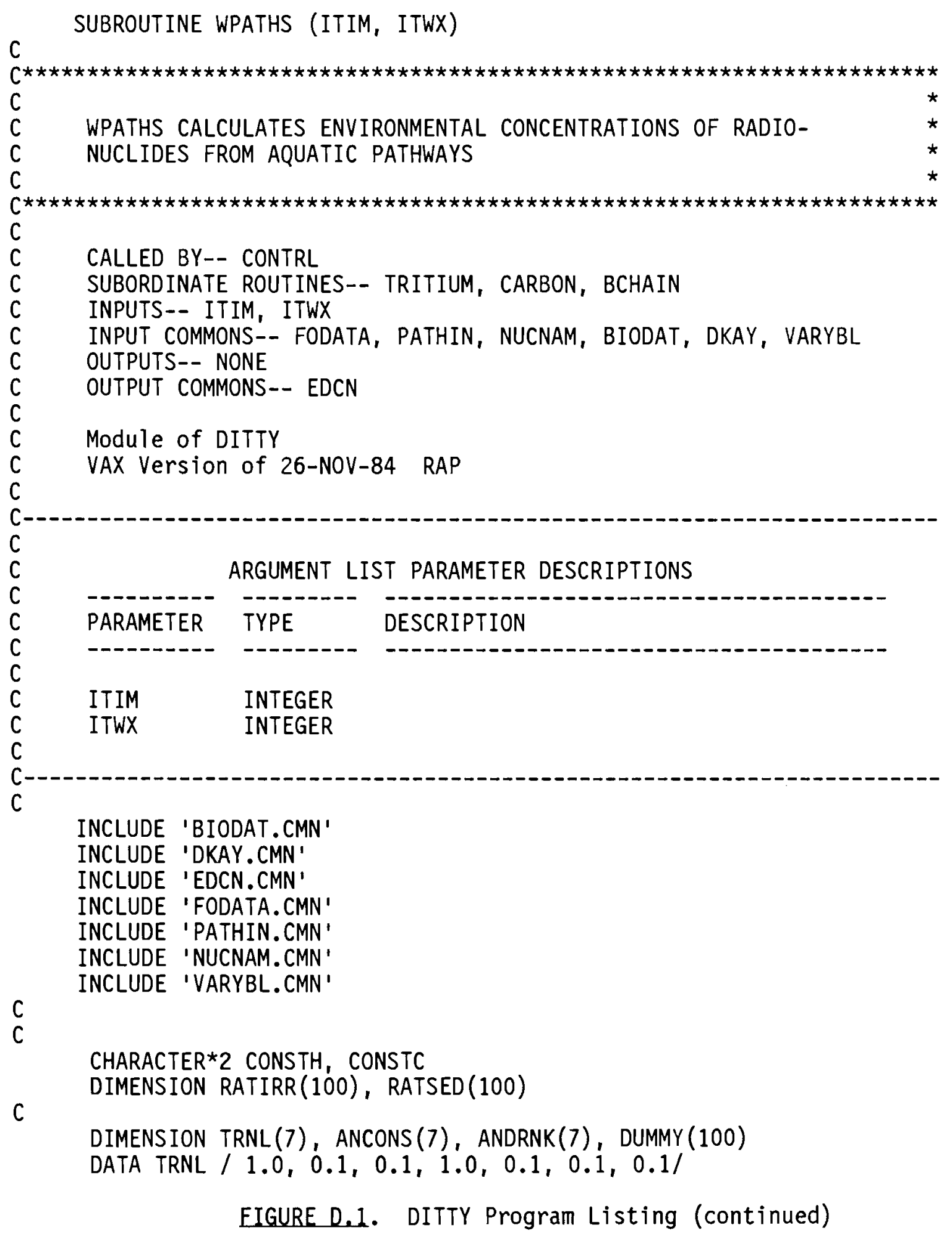

D. 119 
DATA ANCONS $/ 0 ., 0 ., 0.12,55 ., 68 ., 4.2,0.12 /$

C

DATA ANDRNK /0., $0 ., 0.3,60 ., 50 ., 10 ., 0.3 /$

DATA CONST1 /1.119E-9/

DATA CONST2 /224./

DATA CONST3 /25300./

DATA CONST5 /0.25/

C

DATA CONSTE /365.25/

C CONST4 $=0.69315 / 14 . * 365.25$

C

DATA CONST4 /18.0838/

DATA ONE /1./

DATA CONSTC /'C $' /$

C

DATA CONSTH / 'H '/

C

IF (RM .EQ. 0.0) RM $=1.0$

IF (RECON .EQ . 0.0) RECON $=1.0$

C

DO $101 \mathrm{I}=1$, NUCS

$\operatorname{DUMMY}(I)=A R(I)$

101 CONTINUE

JNUC $=0$

C

C

C FOR EACH DECAY CHAIN--

C

DO $100 \mathrm{ICH}=1$, ICHN

C

$$
\begin{aligned}
& \mathrm{J}=\mathrm{NOFN}(\mathrm{ICH}) \\
& \mathrm{IST}=\mathrm{JNUC}+1 \\
& \mathrm{JNUC}=\mathrm{JNUC}+\mathrm{J} \\
& \mathrm{K}=\mathrm{IST}+\mathrm{J}-1
\end{aligned}
$$

C

C FOR EACH NUCLIDE IN THE CHAIN-DO $200 \mathrm{I}=$ IST, $\mathrm{K}$

$$
\text { WATCON }(I)=\mathrm{PL}(\mathrm{ITIM}) \text { * RECON * RM *ACTW(ITIM, I) * CONST1 / }
$$

• CFLO / AR(I)

C

CONTINUE

C IF THIS ELEMENT IS ' $\mathrm{H}$ '--

IF (ELTM(IST) .EQ. CONSTH) THEN

C

CALL TRITUM (IST, 2, WATCON(IST), DUMMY1, ANCONS, ANDRNK,

EIGURE D.1. DITTY Program Listing (continued) 
Module WPATHS

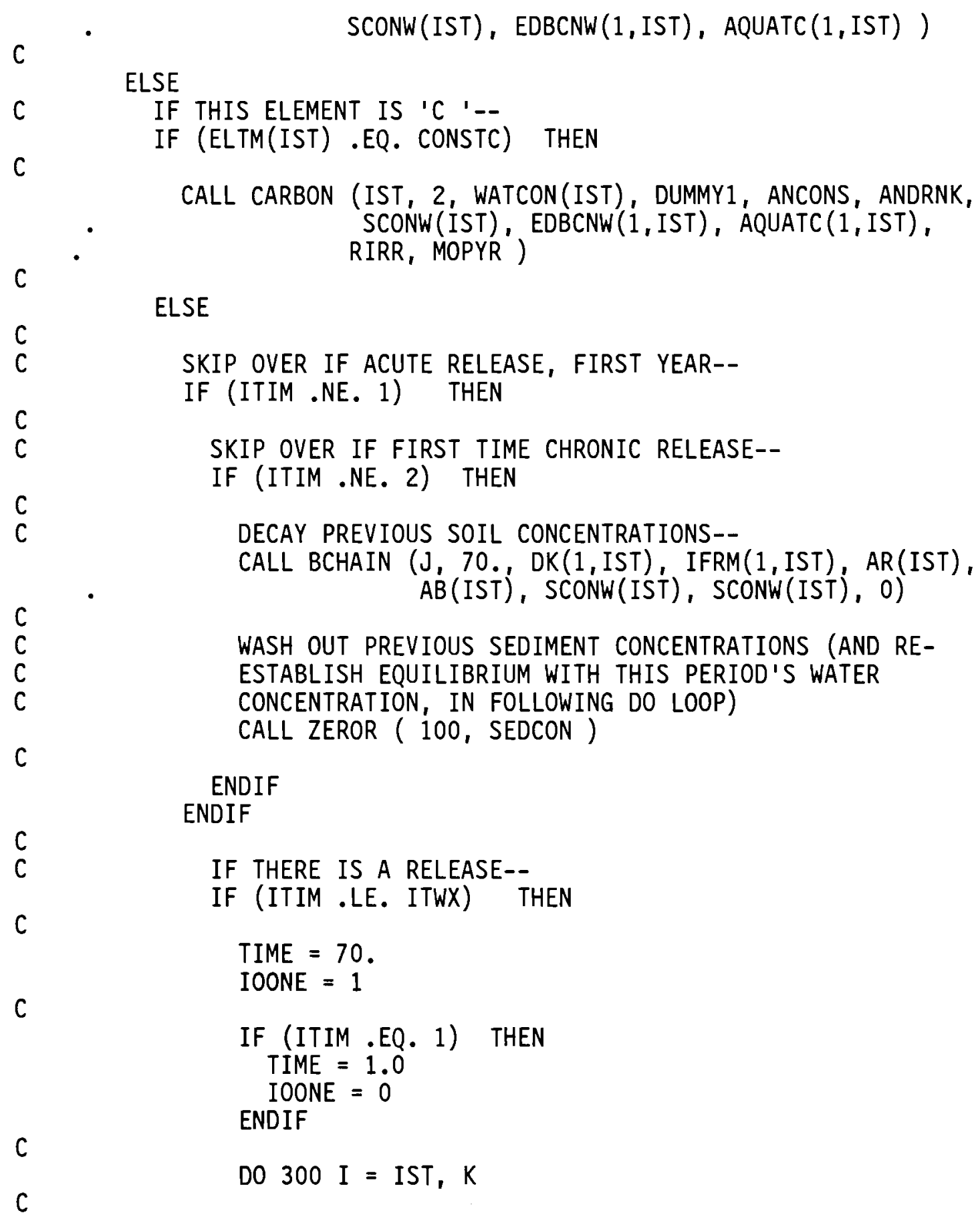

FIGURE D.1. DITTY Program Listing (continued) 
C

C

C

C

C

C

C

C

C

C

C

C

C

C

C

C

C

C

C

C

C

$\mathrm{C}$
IRRIGATION DEPOSITION RATE, WEIGHTED BY POPULATION AND DECAY CONSTANT, PERSON-CI-YR/KG-YR $\operatorname{RATIRR}(I)=W A T C O N(I)$ * RIRR $/$ CONST2 * MOPYR

SEDIMENT DEPOSITION RATE IN PERSON-CI-YR/M**2-YR RATSED $(I)=$ WATCON $(I) *$ CONST3

CONTINUE

CALL BCHAIN ( $J$, TIME, DK(1,IST), IFRM(1, IST), AR(IST), $A B(I S T), \operatorname{RATIRR}($ IST), RATIRR(IST), IOONE)

CALL BCHAIN (J, TIME, DK(1,IST), IFRM(1,IST), AR(IST), DUMMY (IST), RATSED(IST), RATSED(IST), 1)

The following code was added to correct population included in soil concentration--

$P L C=1.0$

IF (ITIM .GT. 1) THEN

IF (PL(ITIM) .GT. 0.0 .AND. PL(ITIM-1) .GT. 0.0) THEN

PLC $=$ PL (ITIM) $/$ PL (ITIM-1) ENDIF

ENDIF

SUM PREVIOUS AND CURRENT DEPOSITIONS--

DO $400 \mathrm{I}=\mathrm{IST}, \mathrm{K}$

$$
\begin{aligned}
& \operatorname{SCONW}(I)=\operatorname{SCONW}(I) * P L C+\operatorname{RATIRR}(I) \\
& \operatorname{SEDCON}(I)=\operatorname{SEDCON}(I)+\operatorname{RATSED}(I)
\end{aligned}
$$

CONTINUE

ENDIF

CALCULATE PATHWAY CONCENTRATIONS--

DO $500 \mathrm{I}=\mathrm{IST}, \mathrm{K}$

FIND ENVIRONMENTAL REMOVAL CONSTANT--

ENVLAM $=A R(I)+$ CONST4

LOOP ON TERRESTRIAL PATHWAYS--

DO 600 IP $=1,7$

EIGURE D.1. DITTY Program Listing (continued) 
C

C

IF (ITIM .EQ. 1) THEN

ACUTE LEAF CONCENTRATION--

RLFCON $=$ CONST5 * WATCON $(I) *$ RIRR * $12 . /$

ELSE YELD (IP)

C

CHRONIC LEAF CONCENTRATION--

RLFCON $=$ CONST5 $*($ WATCON $(I) *$ RIRR * 12. $+\operatorname{SCONW}(\mathrm{I})$ * DVEL (I) * .47)

* (ONE - EXP (-ENVLAM * GRWP(IP)/CONST6))

/ YELD(IP) / ENVLAM

C

ENDIF

C

C

$\operatorname{PLTCON}=\operatorname{RLFCON} * \operatorname{TRNL}(I P)+\operatorname{SCONW}(I) * \operatorname{CRATIO}(1, I)$

IF VEGATABLE PATHWAY--

IF (IP . LE. 2) THEN $\operatorname{EDBCNW}(I P, I)=\operatorname{PLTCON}$

ELSE

$\operatorname{EDBCNW}(I P, I)=(P L T C O N * \operatorname{ANCONS}(I P)+W A T C O N(I)$

ENDIF

* ANDRNK(IP)) * CRATIO(IP-1, I)

C

$600 \quad$ CONTINUE

C

C LOOP ON AQUATIC PATHWAYS--

DO 700 IWP $=1,4$ 700 CONTINUE

C

C DRINKING WATER--

$\operatorname{AQUATC}(5, I)=W A T C O N(I) * \operatorname{DWCF}(I)$

C

$500 \quad$ CONTINUE

ENDIF

ENDIF

100 CONTINUE

C

RETURN

END

EIGURE D.1. DITTY Program Listing (continued) 


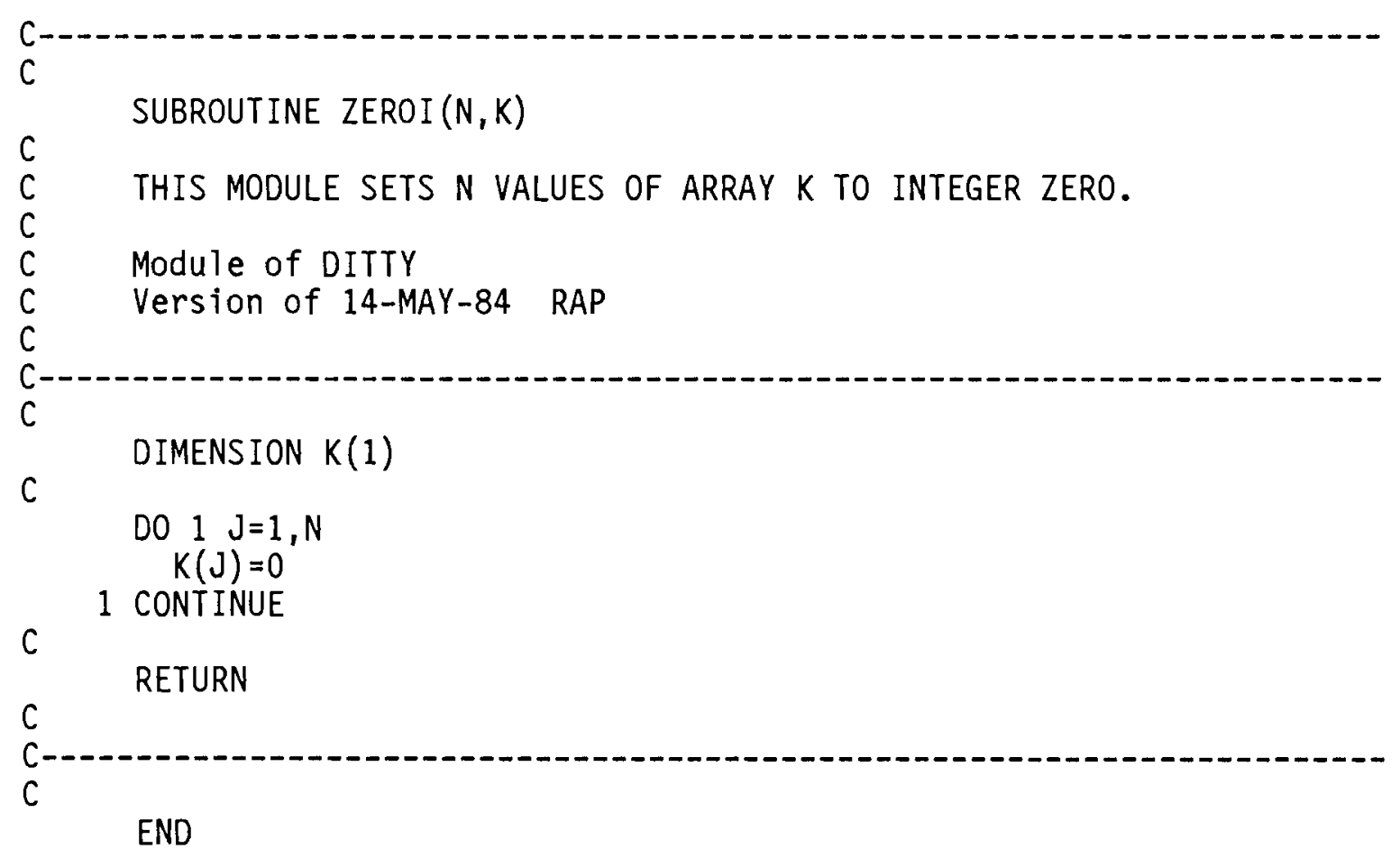

EIGURE 0.1. DITTY Program Listing (continued) 


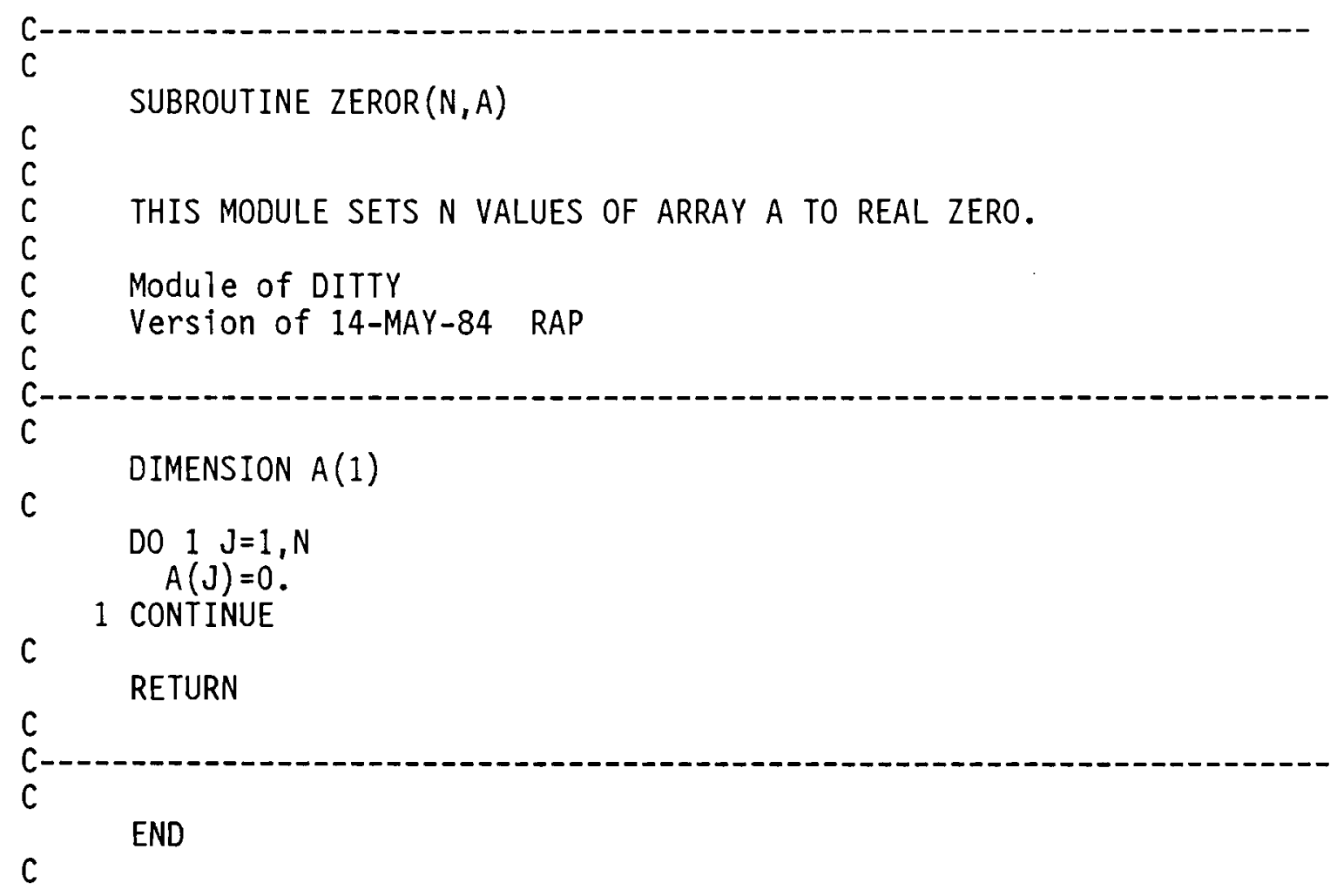

EIGURE D.1. DITTY Program Listing (continued)

D. 125 
COMMON BLOCK Modules

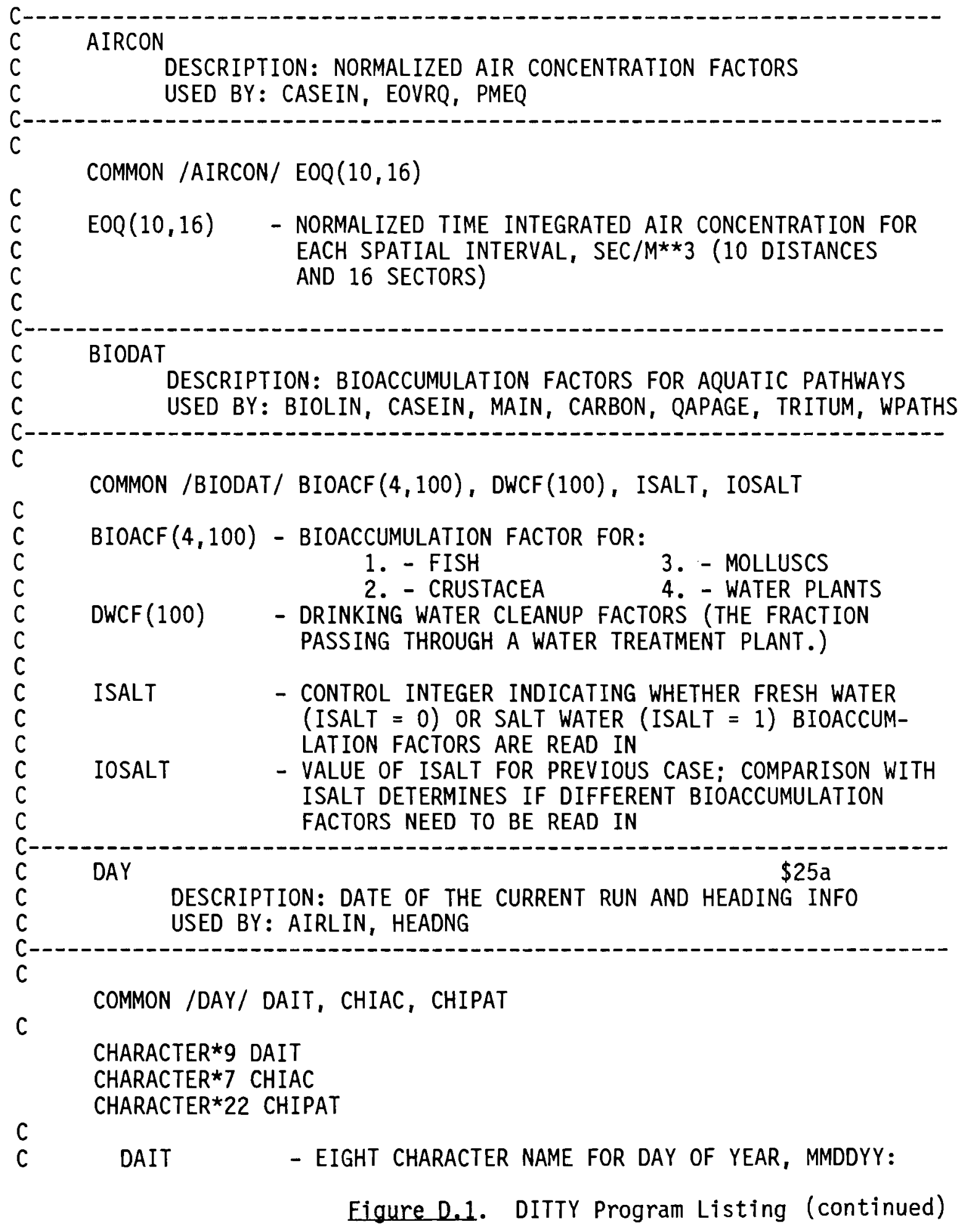

D. 126 
COMMON BLOCK Modules

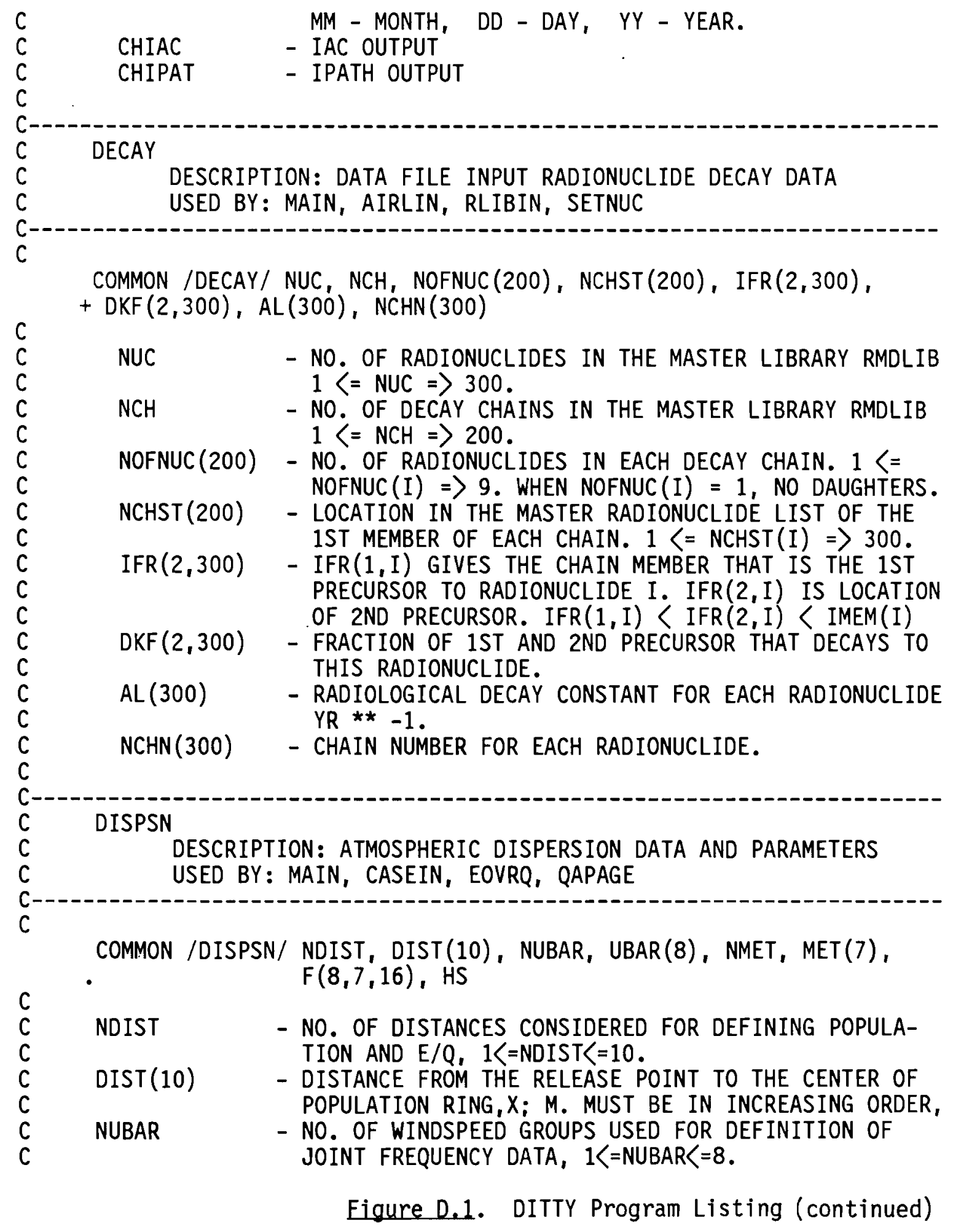


COMMON BLOCK Modules

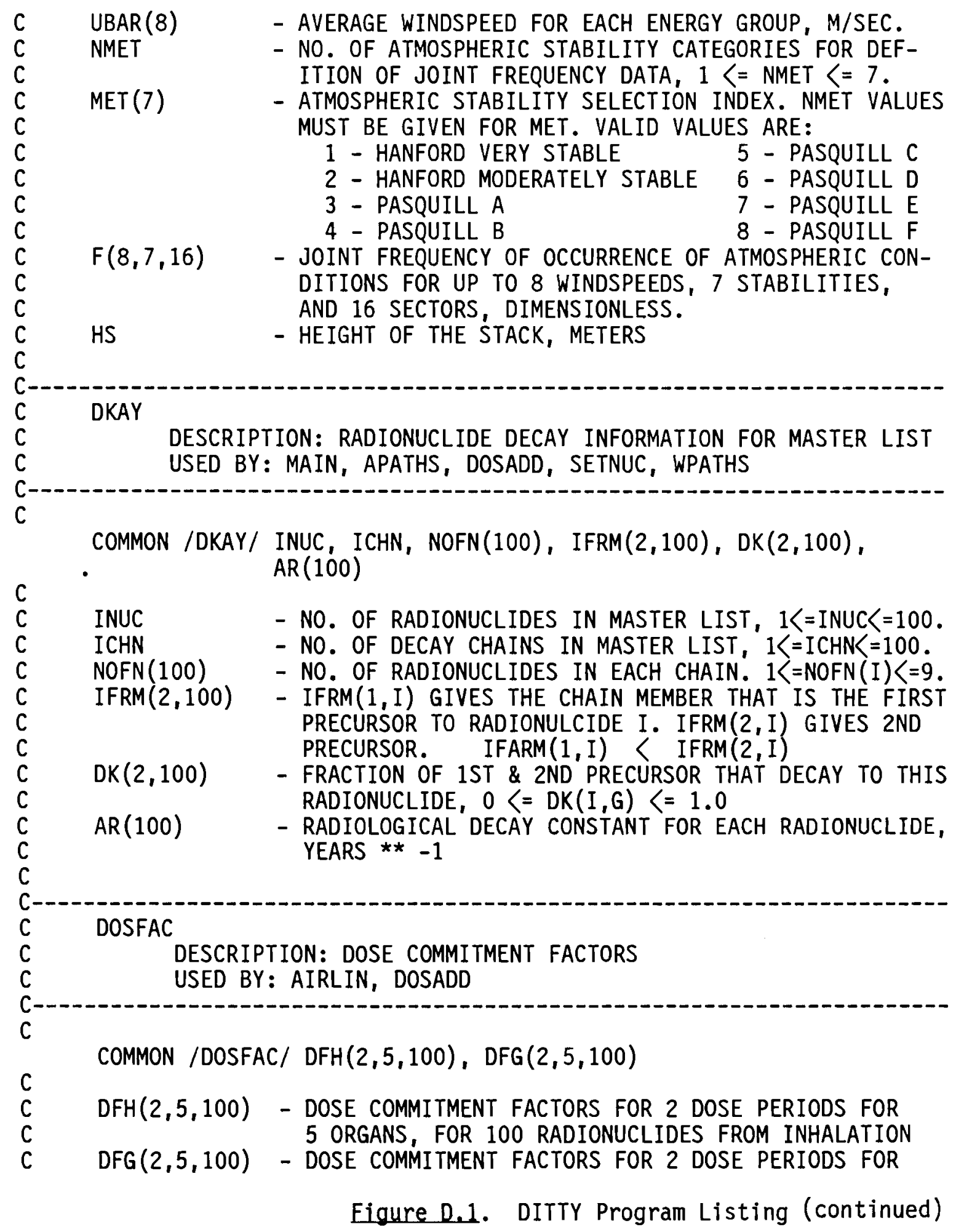


COMMON BLOCK Modules

$$
\begin{aligned}
& C \\
& C \\
& C \\
& C \\
& C \\
& C \\
& C \\
& C \\
& C \\
& C \\
& C
\end{aligned}
$$

5 ORGANS, FOR 100 RADIONUCLIDES FROM INGESTION

NOTE: BOTH OF THESE ARE BASED ON CONTINUOUS EXPOSURE AT A CONSTANT LEVEL FOR 70 YRS AND 1 YEAR.

C

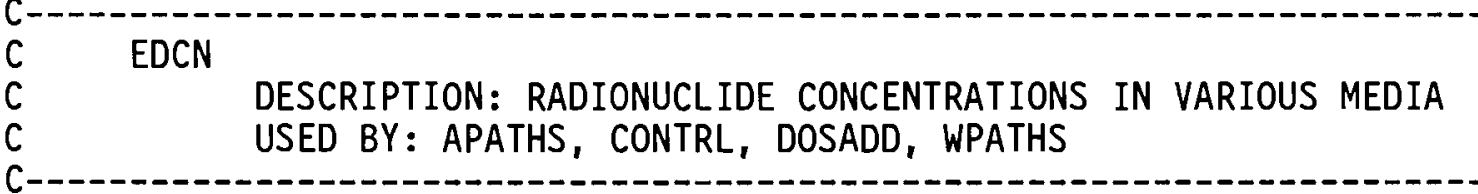

C

COMMON /EDCN/ WATCON(100), $\operatorname{SCONW}(100), \operatorname{SEDCON}(100), \operatorname{EDBCNW}(7,100)$, AQUATC $(5,100), \operatorname{AIRCON}(100), \operatorname{SLCON}(100)$, $\operatorname{EDBCON}(7,100)$

C

C

C

NOTE: ALL EDCN PARAMETERS ARE WEIGHTED WITH DECAY CONSTANT AND POPULATION

C WATCON(100) - WATER CONCENTRATIONS OF RADIONUCLIDES,

C CI/L-PERSON-YR

C SCONW(100) - FARM SOIL CONCENTRATIONS OF RADIONUCLIDES,

C PERSON-CI--YR/KG

C SEDCON(100) - RIVER SEDIMENT CONCENTRATIONS OF RADIONUCLIDES,

C PERSON-CI-YR/M**2

C $\operatorname{EDBCNW}(7,100)$ - CONCENTRATION OF RADIONUCLIDE IN THE EDIBLE

C

C

$\mathrm{C}$

C

C

C

C

C

C

C

C

C

$\mathrm{C}$

C

C PORTION OF THE TERRESTRIAL PLANTS AND ANIMALS, PERSON-CI-YR/KG FROM IRRIGATION DEPOSITION

AQUATC $(5,100)$ - CONCENTRATION OF RADIONUCLIDES IN THE EDIBLE PORTION OF AQUATIC PLANTS AND ANIMALS, PERSON-CI-YR/KG (OR PER LITER H(2)O

AIRCON(100) - ATMOSPHERIC CONCENTRATIONS OF RADIONUCLIDES FROM DISPERSION/DIFFUSION (NO RESUSPENSION), PERSON-CI - YR/M**3

SLCON(100) - CONCENTRATION IN FARM SOIL OF RADIONUCLIDES FROM ATMOSPHERIC DEPOSITION, PERSON-CI-YR/KG

$\operatorname{EDBCON}(7,100)$ - CONCENTRATION OF RADIONUCLIDES IN THE EDIBLE PORTION OF TERRESTRIAL ANIMALS AND PLANTS FROM ATMOSPHERIC DEPOSITION, PERSON-CI-YR/KG

\section{FLAGS}

DESCRIPTION: RADIONUCLIDE SELECTION CONTROL FLAGS USED BY: AIRLIN, NUCTST, SETNUC

C

COMMON /FLAGS/ INFLG(100)

Eigure D.1. DITTY Program Listing (continued) 


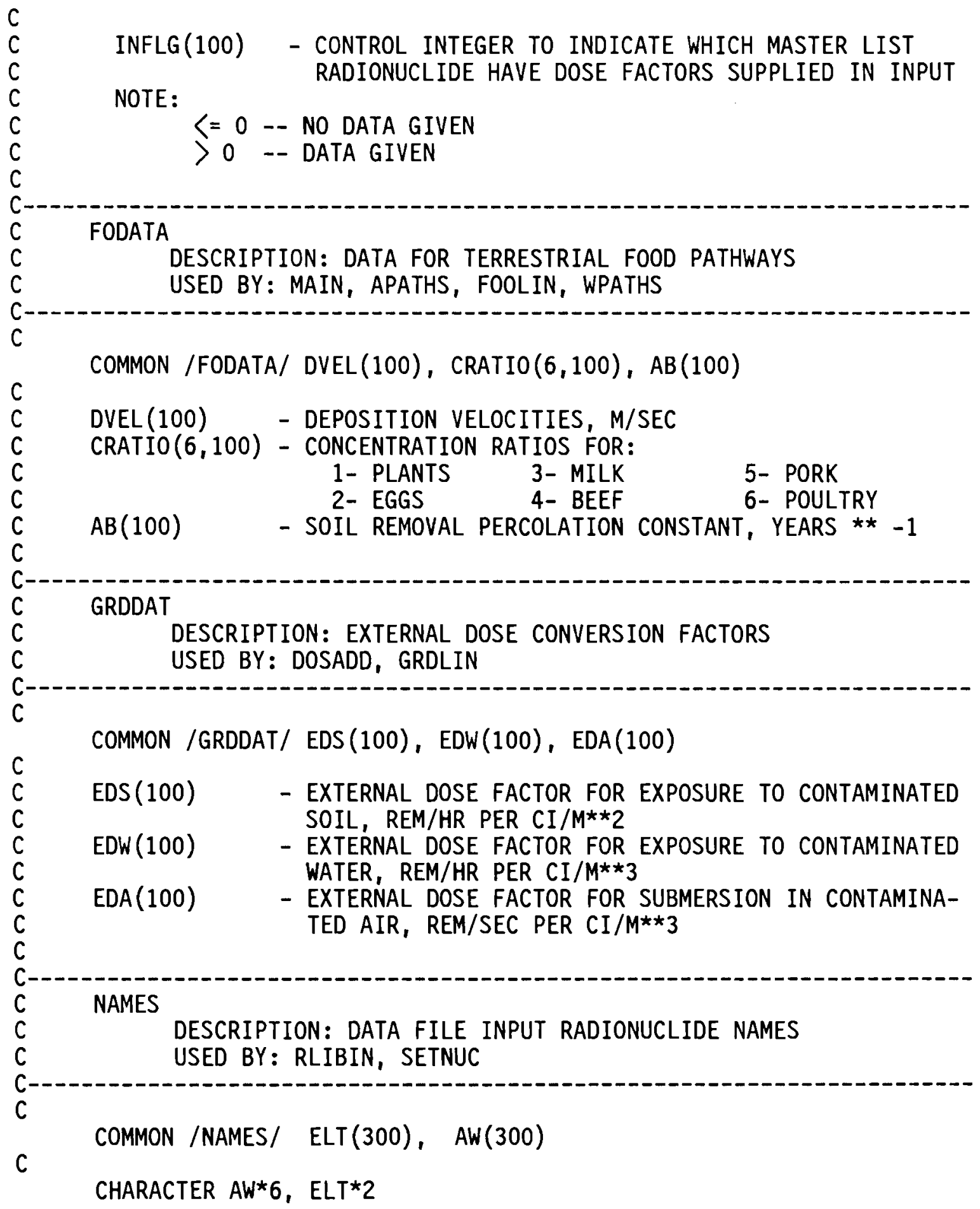

Eigure D.1. DITTY Program Listing (continued) 


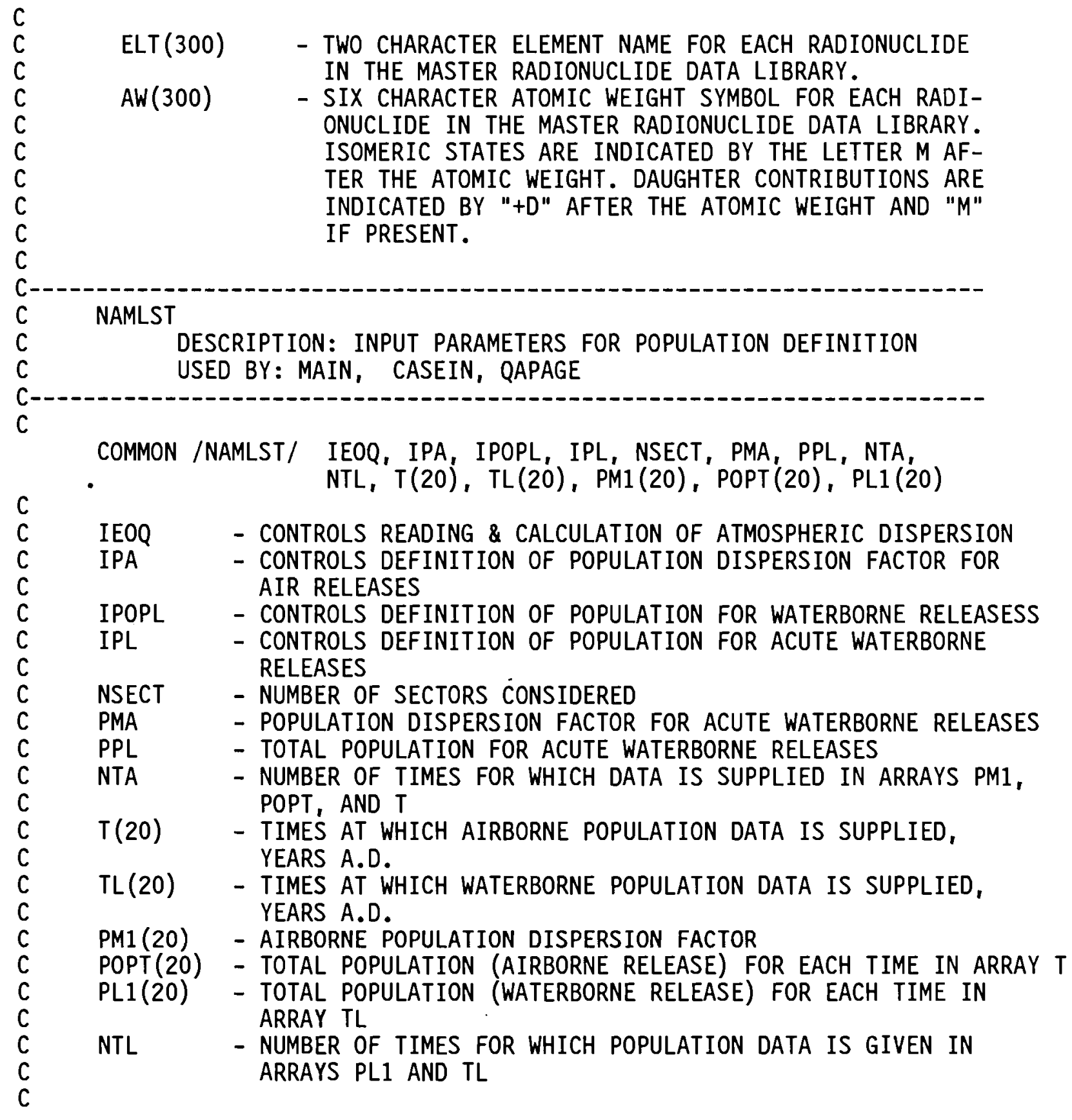

Figure D.1. DITTY Program Listing (continued) 
COMMON BLOCK Modules

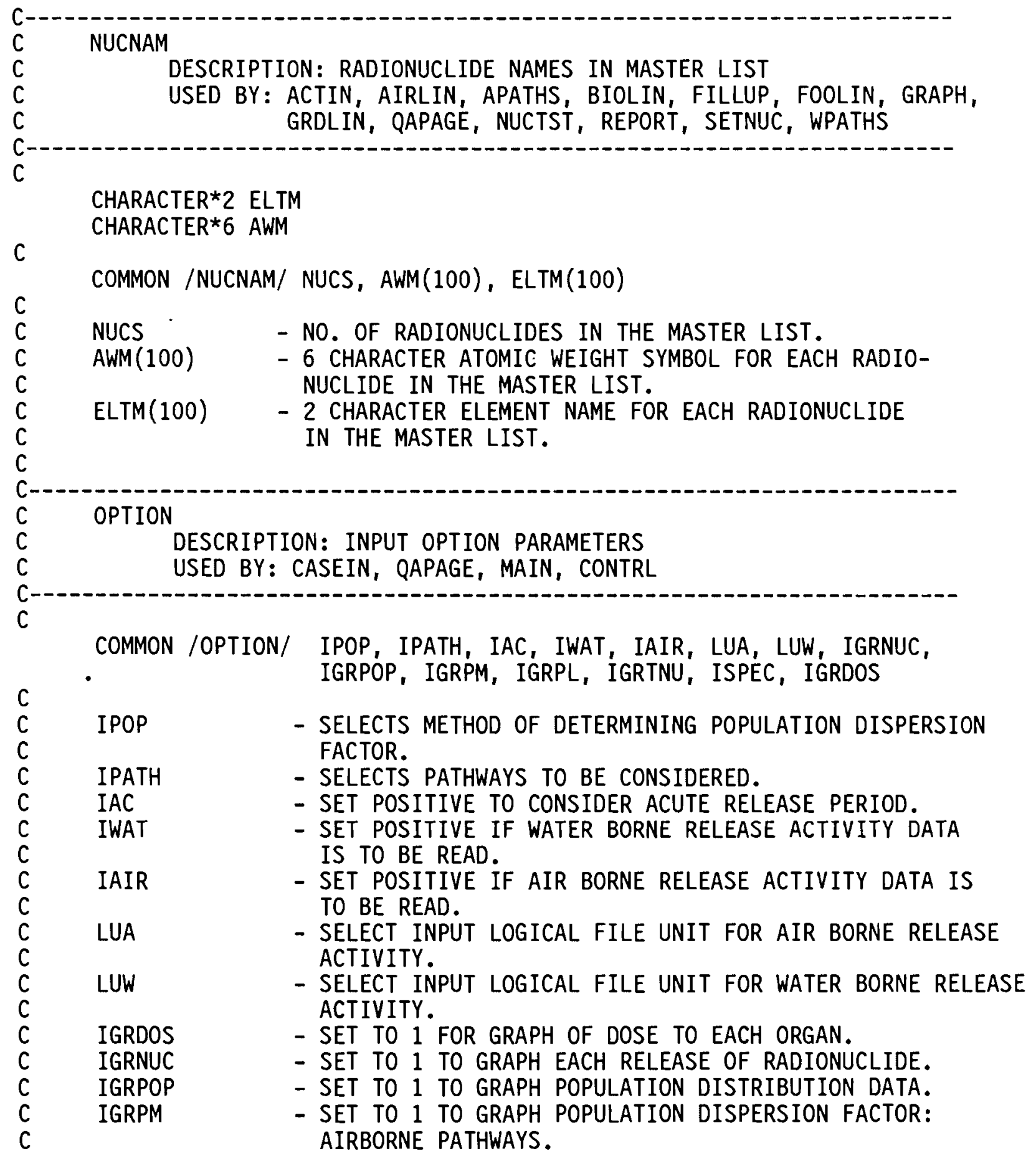

Figure D.1. DITTY Program Listing (continued) 


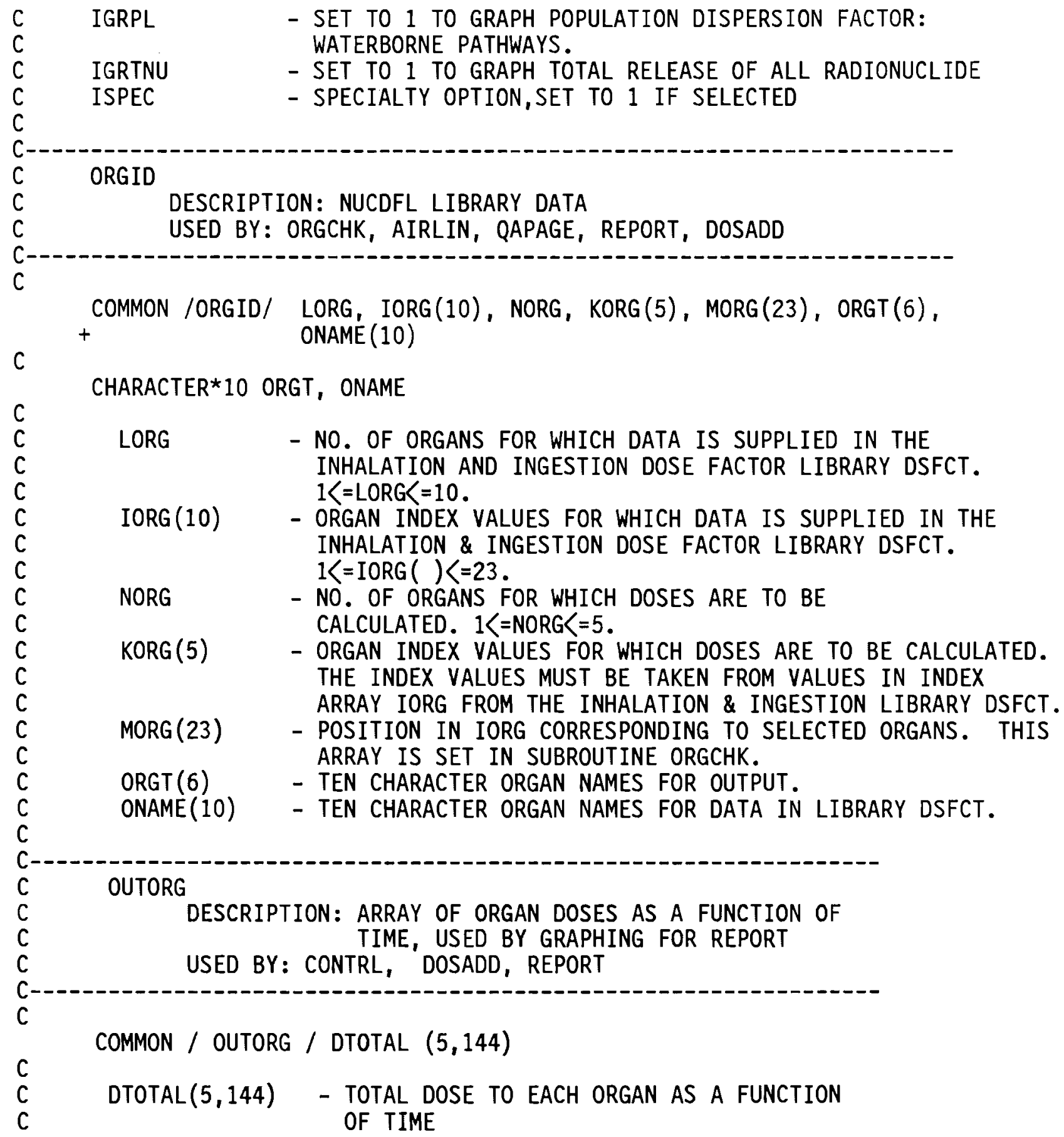

Eigure D.1. DITTY Program Listing (continued) 
COMMON BLOCK Modules
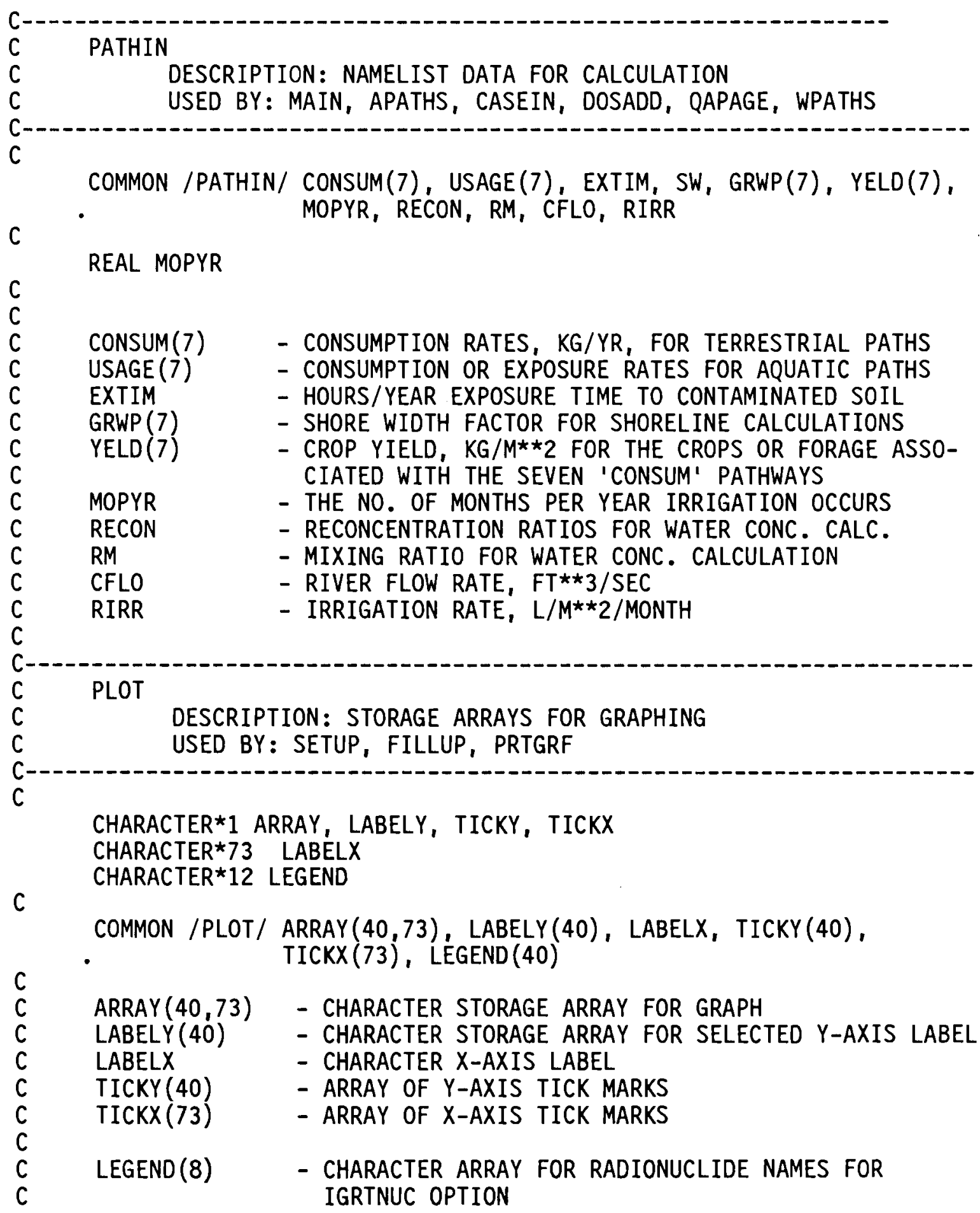

Eigure 0.1. DITTY Program Listing (continued) 
COMMON BLOCK Modules

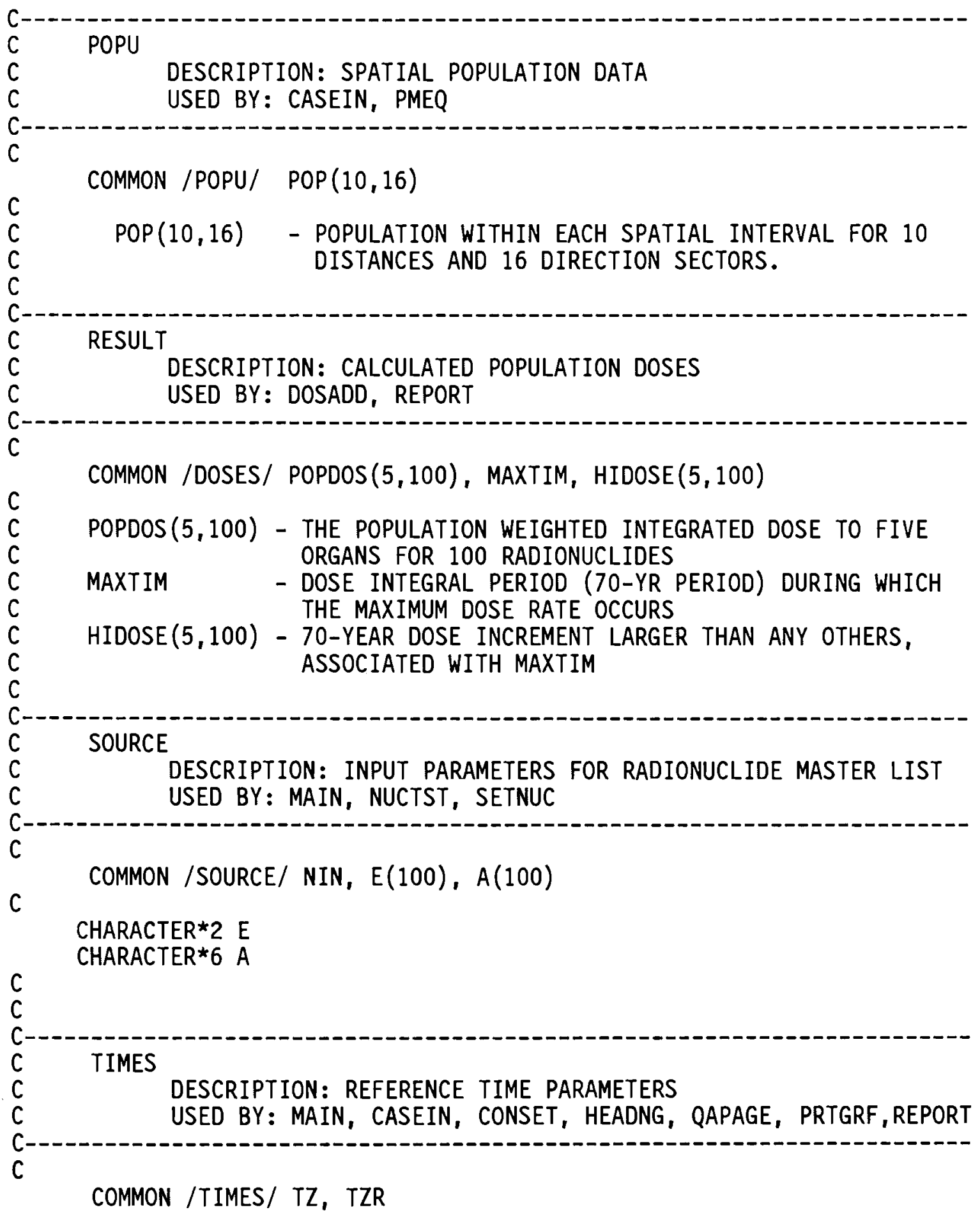

Eigure D.1. DITTY Program Listing (continued) 
COMMON BLOCK Modules

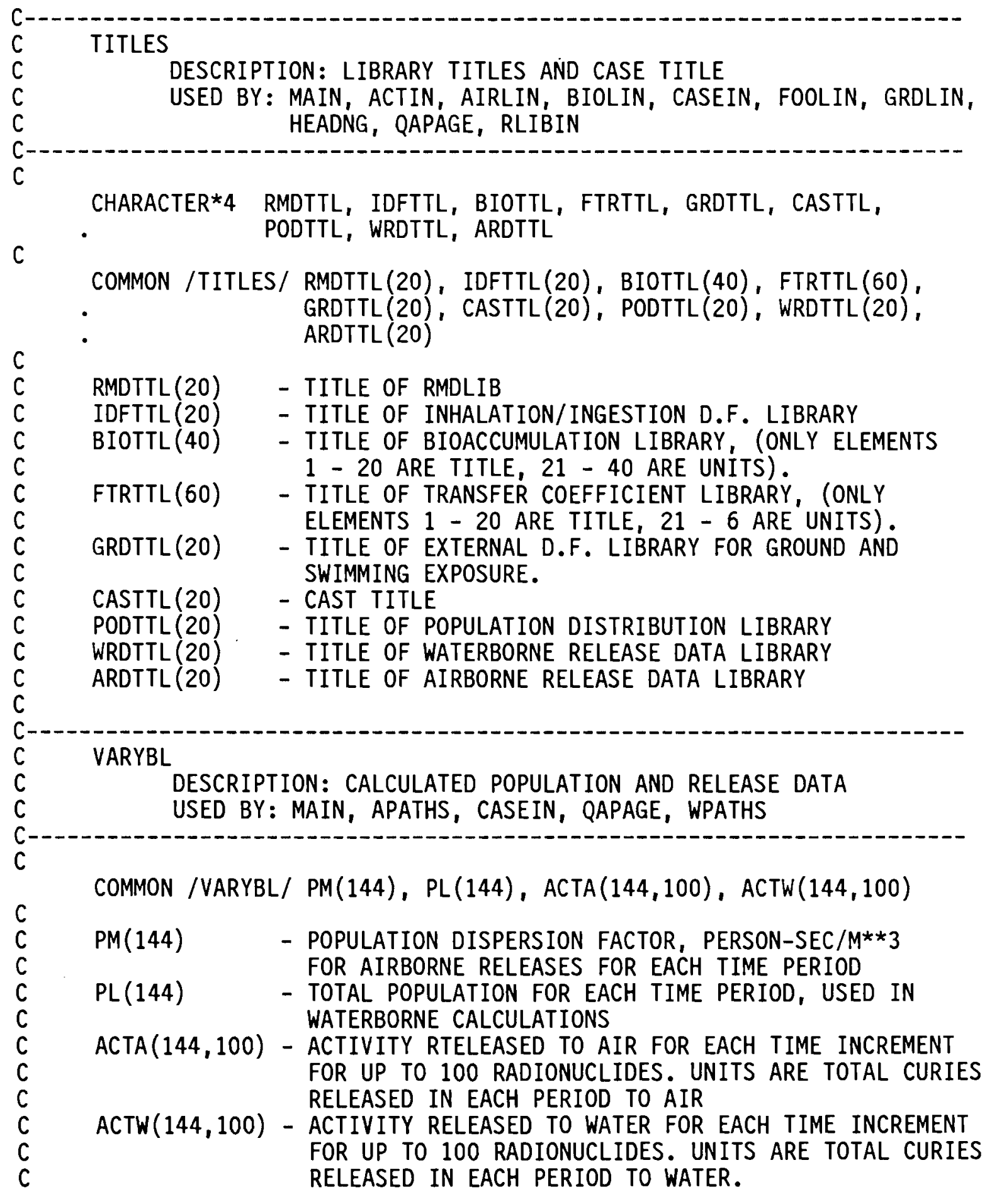

Eigure D.1. DITTY Program Listing (continued) 
RADIONUCLIDE MASTER DATA LIBRARY /W TRANSLOCATION CLASSES, 19-MAR-85 RAP

\begin{tabular}{|c|c|c|c|}
\hline H 3 & $4.51 E+3110$ & 0 & 11 \\
\hline BE10 & $5.84 E+8110$ & 0 & 12 \\
\hline C 14 & $2.091 E+610$ & 0 & 12 \\
\hline N 13 & $6.92 \mathrm{E}-310$ & 0 & 12 \\
\hline F 18 & $7.62 \mathrm{E}-210$ & 0 & 11 \\
\hline NA22 & $9.50 \mathrm{E}+210$ & 0 & 11 \\
\hline NA24 & $6.25 \mathrm{E}-1 \quad 10$ & 0 & 11 \\
\hline P 32 & $1.43 \mathrm{E}+110$ & 0 & 12 \\
\hline $\begin{array}{l}P \quad 33 \\
S \quad 35 \\
C L 36 \\
K \quad 40 \\
\text { AR39 }\end{array}$ & $\begin{array}{rrr}2.44 E+1 & 1 & 0 \\
8.72 E+1 & 1 & 0 \\
1.1 E+8 & 1 & 0 \\
4.67 E 11 & 1 & 0 \\
9.83 E+4 & 1 & 0\end{array}$ & $\begin{array}{l}0 \\
0 \\
0 \\
0 \\
0\end{array}$ & $\begin{array}{l}12 \\
12 \\
11 \\
11 \\
11\end{array}$ \\
\hline AR41 & $7.61 \mathrm{E}-210$ & 0 & 11 \\
\hline $\begin{array}{l}\text { CA41 } \\
\text { CA45 }\end{array}$ & $\begin{array}{lll}5.11 E+7 & 1 & 0 \\
2.77 E+1 & 1 & 0\end{array}$ & $\begin{array}{l}0 \\
0\end{array}$ & $\begin{array}{l}12 \\
12\end{array}$ \\
\hline SC46 & $8.38 \mathrm{E}+110$ & 0 & 13 \\
\hline CR51 & $2.77 E+110$ & 0 & 13 \\
\hline MN54 & $3.12 E+210$ & 0 & 13 \\
\hline MN56 & $1.07 \mathrm{E}-110$ & 0 & 13 \\
\hline FE55 & $9.86 \mathrm{E}+210$ & 0 & 13 \\
\hline FE59 & $4.46 \mathrm{E}+110$ & 0 & 13 \\
\hline $\operatorname{co57}$ & $2.71 E+210$ & 0 & 13 \\
\hline $\operatorname{co58}$ & $7.08 \mathrm{E}+110$ & 0 & 13 \\
\hline $\mathrm{CO60}$ & $1.92 \mathrm{E}+310$ & 0 & 13 \\
\hline NI59 & $2.74 E+7 \quad 10$ & 0 & \\
\hline
\end{tabular}

Figure D-2. RMDLIB Data File

D. 137 


\begin{tabular}{|c|c|c|c|}
\hline NI63 & $3.51 E+4110$ & 0 & 13 \\
\hline NI65 & $1.05 \mathrm{E}-110$ & 0 & 13 \\
\hline CU64 & $5.29 E-110$ & 0 & 13 \\
\hline ZN65 & $2.44 E+210$ & 0 & 13 \\
\hline $\begin{array}{l}\text { SE75 } \\
\text { AS76 }\end{array}$ & $\begin{array}{rrr}1.2 E+2 & 1 & 0 \\
1.10 E+0 & 1 & 0\end{array}$ & $\begin{array}{l}0 \\
0\end{array}$ & $\begin{array}{l}12 \\
12\end{array}$ \\
\hline SE79 & $2.37 E+7110$ & 0 & 12 \\
\hline BR82 & $1.47 E+010$ & 0 & 11 \\
\hline$B R 83+D$ & $9.96 \mathrm{E}-210$ & 0 & 11 \\
\hline $\begin{array}{l}\text { BR84 } \\
\text { SR85 }\end{array}$ & $\begin{array}{rrr}2.21 \mathrm{E}-2 & 1 & 0 \\
6.5 \mathrm{E}+1 & 1 & 0\end{array}$ & $\begin{array}{l}0 \\
0\end{array}$ & $\begin{array}{l}11 \\
13\end{array}$ \\
\hline KR90 & $3.74 \mathrm{E}-410$ & 0 & 11 \\
\hline KR91 & $1.13 E-410$ & 0 & 11 \\
\hline RB86 & $1.87 E+110$ & 0 & 11 \\
\hline$R B 89+D$ & $1.06 \mathrm{E}-210$ & 0 & 11 \\
\hline SR89+D & $5.06 \mathrm{E}+110$ & 0 & 13 \\
\hline$S R 90+D$ & $1.04 E+410$ & 0 & 13 \\
\hline SR91+D & $3.96 \mathrm{E}-110$ & 0 & 13 \\
\hline SR92+D & $1.13 \mathrm{E}-110$ & 0 & 13 \\
\hline Y $91 M+D$ & $3.45 \mathrm{E}-2110$ & 0 & 13 \\
\hline ZR93+D & $5.59 E+810$ & 0 & 13 \\
\hline ZR95+D & $6.40 E+1110$ & 0 & 13 \\
\hline ZR97+D & $7.04 \mathrm{E}-1110$ & 0 & 13 \\
\hline $\begin{array}{l}\text { M093 } \\
\text { NB94 }\end{array}$ & $\begin{array}{lll}3.65 E+4 & 1 & 0 \\
7.30 E+6 & 1 & 0\end{array}$ & $\begin{array}{l}0 \\
0\end{array}$ & $\begin{array}{l}13 \\
13\end{array}$ \\
\hline M099+D & $2.75 E+010$ & 0 & 13 \\
\hline
\end{tabular}

Figure D-2. RMDLIB Data File (continued) D. 138 


\begin{tabular}{|c|c|c|c|}
\hline TC101 & $9.86 \mathrm{E}-3110$ & 0 & 13 \\
\hline RU103+D & $3.94 \mathrm{E}+110$ & 0 & 13 \\
\hline RU105+D & $1.85 \mathrm{E}-110$ & 0 & 13 \\
\hline RU106+D & $3.68 \mathrm{E}+210$ & 0 & 13 \\
\hline PD107 & $2.37 E+910$ & 0 & 13 \\
\hline $\begin{array}{l}\text { CD109 } \\
\text { AG110M+D }\end{array}$ & $\begin{array}{rll}4.4 \mathrm{E}+2 & 1 & 0 \\
2.52 \mathrm{E}+2 & 1 & 0\end{array}$ & $\begin{array}{l}0 \\
0\end{array}$ & $\begin{array}{l}13 \\
13\end{array}$ \\
\hline $\begin{array}{l}\text { AG111 } \\
\text { IN111 }\end{array}$ & $\begin{array}{rrr}7.45 \mathrm{E}+0 & 1 & 0 \\
2.8 \mathrm{E}+0 & 1 & 0\end{array}$ & $\begin{array}{l}0 \\
0\end{array}$ & $\begin{array}{l}13 \\
13\end{array}$ \\
\hline CD113M & $4.97 \mathrm{E}+310$ & 0 & 13 \\
\hline SN117M & $1.40 \mathrm{E}+110$ & 0 & 13 \\
\hline SN119M & $2.50 \mathrm{E}+210$ & 0 & 13 \\
\hline SN121M & $2.78 E+410$ & 0 & 13 \\
\hline SN123 & $1.29 \mathrm{E}+210$ & 0 & 13 \\
\hline SN125+D & $9.64 E+010$ & 0 & 13 \\
\hline SN126+D & $3.65 E+710$ & 0 & 13 \\
\hline SB124 & $6.02 E+110$ & 0 & 13 \\
\hline $\begin{array}{l}\text { SB125+D } \\
\text { TE123M }\end{array}$ & $\begin{array}{lll}1.01 \mathrm{E}+3 & 1 & 0 \\
1.17 \mathrm{E}+2 & 1 & 0\end{array}$ & $\begin{array}{l}0 \\
0\end{array}$ & $\begin{array}{l}13 \\
13\end{array}$ \\
\hline TE127M+D & $1.09 \mathrm{E}+210$ & 0 & 13 \\
\hline TE129M+D & $3.36 \mathrm{E}+110$ & 0 & 13 \\
\hline$T E 131 M+D$ & $1.25 E+010$ & 0 & 13 \\
\hline TE131+D & $1.74 \mathrm{E}-210$ & 0 & 13 \\
\hline$T E 132+D$ & $3.26 \mathrm{E}+0110$ & 0 & 13 \\
\hline TE133M+D & $3.85 \mathrm{E}-210$ & 0 & 13 \\
\hline I $125+D$ & $5.97 \mathrm{E}+110$ & 0 & 12 \\
\hline
\end{tabular}

Figure D-2. RMDLIB Data File (continued) 


\begin{tabular}{|c|c|c|c|}
\hline I 130 & $5.15 \mathrm{E}-1110$ & 0 & 12 \\
\hline I $131+D$ & $8.04 \mathrm{E}+0110$ & 0 & 12 \\
\hline I $135+D$ & $2.75 \mathrm{E}-1110$ & 0 & 12 \\
\hline CS136 & $1.31 \mathrm{E}+110$ & 0 & 11 \\
\hline CS137+D & $1.10 E+410$ & 0 & 11 \\
\hline CS139+D & $6.53 \mathrm{E}-310$ & 0 & 11 \\
\hline BA140+D & $1.28 \mathrm{E}+110$ & 0 & 13 \\
\hline CE143+D & $1.38 \mathrm{E}+010$ & 0 & 23 \\
\hline CE144+D & $2.84 E+210$ & 0 & 23 \\
\hline PM148M+D & $4.13 E+110$ & 0 & 23 \\
\hline PM149 & $2.21 E+010$ & 0 & 23 \\
\hline SM153 & $1.95 \mathrm{E}+010$ & 0 & 23 \\
\hline EU152 & $4.97 E+3110$ & 0 & 23 \\
\hline EU153 & $1.94 \mathrm{E}+010$ & 0 & 23 \\
\hline EU154 & $3.14 E+310$ & 0 & 23 \\
\hline EU155 & $1.81 E+310$ & 0 & 23 \\
\hline EU156 & $1.52 \mathrm{E}+110$ & 0 & 23 \\
\hline GD153 & $2.42 E+2110$ & 0 & 23 \\
\hline TB160 & $7.23 \mathrm{E}+110$ & 0 & 23 \\
\hline H0166M & $4.38 \mathrm{E}+510$ & 0 & 23 \\
\hline W 181 & $1.40 \mathrm{E}+210$ & 0 & 23 \\
\hline $\begin{array}{l}\text { W } 185 \\
\text { OS185 } \\
\text { OS191 } \\
\text { IR192 } \\
\text { HG203 }\end{array}$ & $\begin{array}{rrr}7.51 \mathrm{E}+1 & 1 & 0 \\
9.40 \mathrm{E}+1 & 1 & 0 \\
1.5 \mathrm{E}+1 & 1 & 0 \\
7.3 \mathrm{E}+1 & 1 & 0 \\
4.66 \mathrm{E}+1 & 1 & 0\end{array}$ & $\begin{array}{l}0 \\
0 \\
0 \\
0 \\
0\end{array}$ & $\begin{array}{l}23 \\
23 \\
23 \\
23 \\
23\end{array}$ \\
\hline PB210+D & $8.14 E+310$ & 0 & 23 \\
\hline
\end{tabular}

Figure D-2. RMDLIB Data File (continued) 


\begin{tabular}{|c|c|c|c|}
\hline$B 1210+D$ & $5.01 \mathrm{E}+0110$ & 0 & 23 \\
\hline RN222+D & $3.82 \mathrm{E}+010$ & 0 & 11 \\
\hline RA223+D & $1.14 \mathrm{E}+110$ & 0 & 23 \\
\hline RA224+D & $3.66 \mathrm{E}+010$ & 0 & 23 \\
\hline RA225+D & $1.48 \mathrm{E}+110$ & 0 & 23 \\
\hline RA226+D & $5.84 E+510$ & 0 & 23 \\
\hline RA228+D & $2.10 E+310$ & 0 & 23 \\
\hline$A C 227+D$ & $7.95 E+310$ & 0 & 23 \\
\hline TH227+D & $1.87 E+110$ & 0 & 23 \\
\hline TH228+D & $6.99 \mathrm{E}+210$ & 0 & 23 \\
\hline TH230+D & $2.81 E+7110$ & 0 & 23 \\
\hline TH232+D & $5.13 \mathrm{E} 1210$ & 0 & 23 \\
\hline PA231+D & $1.19 \mathrm{E}+710$ & 0 & 23 \\
\hline$U 232+D$ & $2.62 E+410$ & 0 & 23 \\
\hline U $233+D$ & $5.79 \mathrm{E}+710$ & 0 & 23 \\
\hline U 234 & $8.91 E+7110$ & 0 & 23 \\
\hline$U 235+D$ & $2.59 E 1110$ & 0 & 23 \\
\hline U 236 & $8.55 E+910$ & 0 & 23 \\
\hline U $238+D$ & $1.65 \mathrm{E} 1210$ & 0 & 23 \\
\hline NP237+D & $7.82 E+8110$ & 0 & 23 \\
\hline PU236 & $1.04 \mathrm{E}+310$ & 0 & 23 \\
\hline PU237 & $4.56 \mathrm{E}+110$ & 0 & 23 \\
\hline PU241+D & $5.26 \mathrm{E}+310$ & 0 & 23 \\
\hline CM246 & $1.73 \mathrm{E}+610$ & 0 & 23 \\
\hline
\end{tabular}

Figure D-2. RMDLIB Data File (continued) 


\begin{tabular}{lllllll} 
CM247+D & $5.70 E+9$ & 1 & 0 & 0 & 23 \\
CM248 & $1.24 E+8$ & 1 & 0 & 0 & 23 \\
CF252 & $9.64 E+2$ & 1 & 0 & 0 & 23 \\
ZN69M & $5.73 E-1$ & 1 & 0 & & 0 & 13 \\
ZN69 & $3.96 E-2$ & 2 & 1 & 1.0 & 0 & 13 \\
BR83 & $9.96 E-2$ & 1 & 0 & 0 & 11 \\
KR83M & $7.62 E-2$ & 2 & 1 & 1.0 & 0 & 11 \\
BR85 & $1.99 E-3$ & 1 & 0 & 0 & 11 \\
KR85M & $1.87 E-1$ & 2 & 1 & 1.0 & 0 & 11 \\
KR85 & $3.92 E+3$ & 3 & 2 & 0.211 & 0 & 11 \\
KR87 & $5.30 E-2$ & 1 & 0 & 0 & 11 \\
RB87 & $1.72 E 13$ & 2 & 1 & 1.0 & 0 & 11 \\
KR88 & $1.18 E-1$ & 1 & 0 & 0 & 11 \\
RB88 & $1.24 E-2$ & 2 & 1 & 1.0 & 0 & 11 \\
KR89 & $2.20 E-3$ & 1 & 0 & 0 & 11 \\
RB89 & $1.06 E-2$ & 2 & 1 & 1.0 & 0 & 13 \\
SR89 & $5.06 E+1$ & 3 & 2 & 1.0 & 0 & 13 \\
Y 89M & $1.86 E-4$ & 4 & 3 & 0.0002 & 0 & 13 \\
SR90 & $1.04 E+4$ & 1 & 0 & & 0 & 13 \\
Y 90 & $2.67 E+0$ & 2 & 1 & 1.0 & 0 & 13 \\
SR91 & $3.96 E-1$ & 1 & 0 & 0 & 0 & 13 \\
Y 91M & $3.45 E-2$ & 2 & 1 & 0.58 & 0 & 13 \\
Y 91 & $5.85 E+1$ & 3 & 2 & 1.0 & 1 & 0.42 \\
SR92 & $1.13 E-1$ & 1 & 0 & 0 & 0 \\
Y 92 & $1.48 E-1$ & 2 & 1 & 1.0 & 0 & 0 \\
\hline
\end{tabular}

Figure D-2. RMDLIB Data File (continued) 


\begin{tabular}{|c|c|c|c|}
\hline Y 93 & $4.21 \mathrm{E}-110$ & 0 & 13 \\
\hline ZR93 & $5.59 \mathrm{E}+82211.0$ & 0 & 13 \\
\hline NB93M & $4.97 E+3320.25$ & 0 & 13 \\
\hline ZR95 & $6.40 E+110$ & 0 & 13 \\
\hline NB95M & $3.61 E+0210.007$ & 0 & 13 \\
\hline NB95 & $3.52 E+1321.0$ & 10.993 & 13 \\
\hline ZR97 & $7.04 \mathrm{E}-110$ & 0 & 13 \\
\hline NB97M & $6.94 \mathrm{E}-42210.946$ & & 13 \\
\hline NB97 & $5.01 \mathrm{E}-2321.0$ & 10.054 & 13 \\
\hline M099 & $2.75 E+0110$ & 0 & 13 \\
\hline TC99M & $2.51 E-1210.868$ & 0 & 13 \\
\hline TC99 & $7.78 E+7321.0$ & 10.132 & 13 \\
\hline RU103 & $3.94 E+110$ & 0 & 13 \\
\hline PD103 & $1.70 E+120$ & 0 & 13 \\
\hline RH103M & $3.90 \mathrm{E}-2 \quad 3 \quad 1.9974$ & 2.9997 & 13 \\
\hline RU105 & $1.85 \mathrm{E}-110$ & 0 & 13 \\
\hline RH105M & $5.21 \mathrm{E}-4210.28$ & 0 & 13 \\
\hline RH105 & $1.47 E+0321.0$ & 10.72 & 13 \\
\hline RU106 & $3.68 \mathrm{E}+210$ & 0 & 13 \\
\hline RH106 & $3.46 \mathrm{E}-4211.0$ & 0 & 13 \\
\hline PD109M & $5.43 \mathrm{E}-510$ & 0 & 13 \\
\hline PD109 & $5.61 \mathrm{E}-1211.0$ & 0 & 13 \\
\hline AG109M & $4.58 E-4321.0$ & 0 & 13 \\
\hline AG110M & $2.52 E+210$ & 0 & 13 \\
\hline
\end{tabular}

Figure D-2. RMDLIB Data File (continued) D. 143 


$\left.\begin{array}{lllllll}\text { AG110 } & 2.85 E-4 & 2 & 1 & 0.0113 & 0 & 13 \\ \text { IN114M } & 5.00 E+1 & 1 & 0 & 0 & 13 \\ \text { IN114 } & 8.33 E-4 & 2 & 1 & 1.0 & 0 & 13 \\ \text { CD115M } & 4.46 E+0 & 1 & 0 & 0 & 13 \\ \text { CD115 } & 2.23 E+0 & 2 & 0 & 0 & 13 \\ \text { IN115M } & 1.88 E-1 & 3 & 2 & 1.0 & 0 & 13 \\ \text { IN115 } & 2.19 E 17 & 4 & 3 & 0.963 & 1 & 1.0\end{array}\right]$.

Figure D-2. RMDLIB Data File (continued) D. 144 


\begin{tabular}{|c|c|c|c|}
\hline TE133M & $3.85 \mathrm{E}-210$ & 0 & 13 \\
\hline TE133 & $8.64 \mathrm{E}-32210.13$ & 0 & 13 \\
\hline I 133 & $8.67 \mathrm{E}-1321.0$ & 10.87 & 12 \\
\hline XE133M & $2.19 E+0 \quad 4 \quad 3 \quad 0.029$ & 0 & 11 \\
\hline XE133 & $5.24 \mathrm{E}+0541.0$ & 30.971 & 11 \\
\hline TE134 & $2.90 \mathrm{E}-210$ & 0 & 13 \\
\hline I 134 & $3.65 \mathrm{E}-2211.0$ & 0 & 12 \\
\hline CS134M & $1.21 \mathrm{E}-110$ & 0 & 11 \\
\hline $\operatorname{CS} 134$ & $7.53 \mathrm{E}+2211.0$ & 0 & 11 \\
\hline I 135 & $2.75 \mathrm{E}-1110$ & 0 & 12 \\
\hline XE135M & $1.09 \mathrm{E}-2210.166$ & 0 & 11 \\
\hline XE135 & $3.78 \mathrm{E}-1321.0$ & 10.834 & 11 \\
\hline $\operatorname{CS} 135$ & $8.40 E+8 \quad 431.0$ & 0 & 11 \\
\hline XE137 & $2.66 E-310$ & 0 & 11 \\
\hline CS137 & $1.10 E+4211.0$ & 0 & 11 \\
\hline BA137M & $1.77 \mathrm{E}-3 \quad 3220.946$ & 0 & 13 \\
\hline XE138 & $9.84 \mathrm{E}-310$ & 0 & 11 \\
\hline $\operatorname{cs} 138$ & $2.24 \mathrm{E}-2211.0$ & 0 & 11 \\
\hline XE139 & $4.98 \mathrm{E}-410$ & 0 & 11 \\
\hline $\operatorname{CS} 139$ & $6.53 \mathrm{E}-32211.0$ & 0 & 11 \\
\hline BA139 & $5.74 E-2321.0$ & 0 & 13 \\
\hline XE140 & $1.85 \mathrm{E}-410$ & 0 & 11 \\
\hline $\operatorname{cs} 140$ & $7.64 \mathrm{E}-4211.0$ & 0 & 11 \\
\hline BA140 & $1.28 \mathrm{E}+1321.0$ & 0 & 13 \\
\hline
\end{tabular}

Figure D-2. RMDLIB Data File (continued) D. 145 


\begin{tabular}{|c|c|c|c|}
\hline LA140 & $1.68 \mathrm{E}+0 \quad 4331.0$ & 0 & 23 \\
\hline BA141 & $1.27 \mathrm{E}-2 \quad 10$ & 0 & 13 \\
\hline LA141 & $1.64 \mathrm{E}-1211.0$ & 0 & 23 \\
\hline CE141 & $3.25 E+1321.0$ & 0 & 23 \\
\hline BA142 & $7.43 \mathrm{E}-3110$ & 0 & 13 \\
\hline LA142 & $6.44 \mathrm{E}-22211.0$ & 0 & 23 \\
\hline CE143 & $1.38 \mathrm{E}+0 \quad 10$ & 0 & 23 \\
\hline PR143 & $1.36 \mathrm{E}+12211.0$ & 0 & 23 \\
\hline CE144 & $2.84 E+2110$ & 0 & 23 \\
\hline PR144 & $1.20 \mathrm{E}-2 \quad 2 \quad 11.0$ & 0 & 23 \\
\hline ND144 & 8.77 E17 3221.0 & 0 & 23 \\
\hline ND147 & $1.11 E+1 \quad 10$ & 0 & 23 \\
\hline PM147 & $9.58 \mathrm{E}+2211.0$ & 0 & 23 \\
\hline SM147 & $3.91 E 133321.0$ & 0 & 23 \\
\hline PM148M & $4.13 E+110$ & 0 & 23 \\
\hline PM148 & $5.37 \mathrm{E}+0211.0$ & 0 & 23 \\
\hline PM151 & $1.18 \mathrm{E}+010$ & 0 & 23 \\
\hline SM151 & $3.29 E+42111.0$ & 0 & 23 \\
\hline W 187 & $9.95 \mathrm{E}-1110$ & 0 & 23 \\
\hline RE187 & $1.83 \mathrm{E} 132211.0$ & 0 & 23 \\
\hline TH230 & $2.81 E+7 \quad 10$ & 0 & 23 \\
\hline RA226 & $5.84 E+5211.0$ & 0 & 23 \\
\hline RN222 & $3.82 E+0321.0$ & & 11 \\
\hline PB210 & $8.14 E+3431.0$ & 0 & 23 \\
\hline BI210 & $5.01 E+0541.0$ & 0 & 23 \\
\hline
\end{tabular}

Figure D-2. RMDLIB Data File (continued) 


$\begin{array}{llllllll}\text { P0210 } & 1.38 \mathrm{E}+2 & 6 & 5 & 1.0 & 0 & 23 \\ \text { U 232 } & 2.62 \mathrm{E}+4 & 1 & 0 & & 0 & 23 \\ \text { TH232 } & 4.16 \mathrm{E} 13 & 2 & 0 & & 0 & 23 \\ \text { RA228 } & 2.10 \mathrm{E}+3 & 3 & 2 & 1.0 & 0 & 23 \\ \text { AC228 } & 2.55 \mathrm{E}-1 & 4 & 3 & 1.0 & 0 & 23 \\ \text { TH228 } & 6.99 \mathrm{E}+2 & 5 & 4 & 1.0 & 1 & 1.0 & 23 \\ \text { RA224 } & 3.66 \mathrm{E}+0 & 6 & 5 & 1.0 & 0 & 23 \\ \text { PB212 } & 4.43 \mathrm{E}-1 & 7 & 6 & 1.0 & 0 & 23 \\ \text { B1212 } & 4.20 \mathrm{E}-2 & 8 & 7 & 1.0 & 0 & 23 \\ \text { U 235 } & 2.59 \mathrm{E} 11 & 1 & 0 & & 0 & 23 \\ \text { TH231 } & 1.06 \mathrm{E}+0 & 2 & 1 & 1.0 & 0 & 23 \\ \text { PA231 } & 1.19 \mathrm{E}+7 & 3 & 2 & 1.0 & 0 & 23 \\ \text { AC227 } & 7.95 \mathrm{E}+3 & 4 & 3 & 1.0 & 0 & 23 \\ \text { TH227 } & 1.87 \mathrm{E}+1 & 5 & 4 & 0.9862 & 0 & 23 \\ \text { FR223 } & 1.51 \mathrm{E}-2 & 6 & 4 & 0.0138 & 0 & 23 \\ \text { RA223 } & 1.14 \mathrm{E}+1 & 7 & 5 & 1.0 & 6 & 1.0 & 23 \\ \text { U 237 } & 6.75 \mathrm{E}+0 & 1 & 0 & & 0 & 23 \\ \text { NP237 } & 7.82 \mathrm{E}+8 & 2 & 1 & 1.0 & 0 & 23 \\ \text { PA233 } & 2.70 \mathrm{E}+1 & 3 & 2 & 1.0 & 0 & 23 \\ \text { U 233 } & 5.79 \mathrm{E}+7 & 4 & 3 & 1.0 & 0 & 23 \\ \text { TH229 } & 2.68 \mathrm{E}+6 & 5 & 4 & 1.0 & 0 & 23 \\ \text { RA225 } & 1.48 \mathrm{E}+1 & 6 & 5 & 1.0 & 0 & 23 \\ \text { AC225 } & 1.00 \mathrm{E}+1 & 7 & 6 & 1.0 & 0 & 23 \\ \text { U 238 } & 1.65 \mathrm{E} 12 & 1 & 0 & 0.0 & 0 & 23 \\ & & & 0 & 0\end{array}$

Figure D-2. RMDLIB Data File (continued) D. 147 


\begin{tabular}{|c|c|c|c|}
\hline TH234 & $2.41 E+1211.0$ & 0 & 23 \\
\hline PA234M & $8.13 E-4321.0$ & 0 & 23 \\
\hline PA234 & $2.81 \mathrm{E}-143 \quad 30.0013$ & 0 & 23 \\
\hline AM242M & $5.55 E+410$ & 0 & 23 \\
\hline AM242 & $6.68 \mathrm{E}-1211.0$ & 0 & 23 \\
\hline CM242 & $1.63 E+2320.827$ & 0 & 23 \\
\hline PU242 & $1.41 E+8420.173$ & 0 & 23 \\
\hline NP238 & $2.18 \mathrm{E}+050$ & 0 & 23 \\
\hline PU238 & $3.21 E+4651.0$ & 31.0 & 23 \\
\hline CM244 & $6.61 E+310$ & 0 & 23 \\
\hline PU244 & $3.02 \mathrm{E} 1020$ & 0 & 23 \\
\hline U 240 & $5.88 \mathrm{E}-13220.999$ & 0 & 23 \\
\hline PU240 & $2.39 E+6 \quad 4 \quad 3 \quad 1.0$ & 11.0 & 23 \\
\hline CM247 & $5.70 E+910$ & 0 & 23 \\
\hline CM243 & $1.04 E+420$ & 0 & 23 \\
\hline PU243 & $2.06 \mathrm{E}-1311.0$ & 0 & 23 \\
\hline AM243 & $2.70 E+643 \quad 1.0$ & 20.0024 & 23 \\
\hline NP239 & $2.36 \mathrm{E}+0541.0$ & 0 & 23 \\
\hline PU239 & $8.91 \mathrm{E}+6651.0$ & 20.9976 & 23 \\
\hline CM245 & $3.10 E+6 \quad 10$ & 0 & 23 \\
\hline PU241 & $5.26 \mathrm{E}+3211.0$ & 0 & 23 \\
\hline AM241 & $1.58 E+5321.0$ & 0 & 23 \\
\hline
\end{tabular}

Figure D-2. RMDLIB Data File (continued) D. 148 


\begin{tabular}{|c|c|c|c|c|c|c|c|c|}
\hline $\begin{array}{l}* * * \\
\text { ELT }\end{array}$ & $\begin{array}{l}\text { FOOD TR } \\
\text { DEP. VEL. } \\
M / S E C\end{array}$ & $\begin{array}{l}\text { NSFER } \\
\text { PLANT } \\
--\end{array}$ & $\begin{array}{l}\text { COEFFICIENT } \\
\text { EGG } \\
D A Y / K G\end{array}$ & $\begin{array}{l}\text { LIBRARY } \\
\text { MILK } \\
\text { DAY/L }\end{array}$ & $\begin{array}{l}\text { RAP / } \\
\text { BEEF } \\
D A Y / K G\end{array}$ & $\begin{array}{c}9-24-85 \\
\text { PORK } \\
\text { DAY/KG }\end{array}$ & $\begin{array}{c}\text { (Tc Update } \\
\text { POULTRY } \\
\text { DAY/KG }\end{array}$ & $\star * \star$ \\
\hline $\mathrm{H}$ & 0.0 & 0.0 & 0.0 & 0.0 & 0.0 & 0.0 & 0.0 & $8.0 E-01$ \\
\hline $\mathrm{BE}$ & $1.0-03$ & $4.7-04$ & $2.0-02$ & $2.0-06$ & $8.0-04$ & $1.0-02$ & 4. 0-01 & 5. $0 \mathrm{E}-03$ \\
\hline & 0.0 & 0.0 & 0.0 & 0.0 & 0.0 & 0.0 & 0.0 & $8.0 \mathrm{E}-01$ \\
\hline $\mathbf{N}$ & $1.0-03$ & $7.5+00$ & $9.9-04$ & $1.1-02$ & $9.9-04$ & $9.9-04$ & $9.9-04$ & \\
\hline $\mathrm{F}$ & $1.0-02$ & $2.0-02$ & $9.9-04$ & $7.0-03$ & $2.0-02$ & $9.0-02$ & $9.9-04$ & \\
\hline NA & $1.0-03$ & $5.0-02$ & $2.0-01$ & $4.0-02$ & $5.0-02$ & $1.0-01$ & $1.0-02$ & \\
\hline$P$ & $1.0-03$ & $5.0+01$ & $1.0+01$ & $1.2-02$ & $5.0-02$ & 5.4-01 & $1.9-01$ & \\
\hline AR & 0.0 & 0.0 & 0.0 & 0.0 & 0.0 & 0.0 & 0.0 & \\
\hline$C A$ & $1.0-03$ & $4.0-02$ & $1.0+00$ & $8.0-03$ & $3.3-03$ & $3.3-03$ & $3.3-03$ & $1.7 \mathrm{E}-02$ \\
\hline SC & $1.0-03$ & $1.1-03$ & $9.9-04$ & $2.5-06$ & $6.0-03$ & $1.0-02$ & $4.0-03$ & \\
\hline CR & $1.0-03$ & $2.5-04$ & $9.9-04$ & $1.1-03$ & $9.9-04$ & $9.9-04$ & $9.9-04$ & \\
\hline MN & $1.0-03$ & $3.0-02$ & $1.0-01$ & $1.0-04$ & $5.0-03$ & $2.0-02$ & $1.1-01$ & \\
\hline $\mathrm{FE}$ & $1.0-03$ & $4.0-04$ & $1.0-01$ & $6.0-04$ & $2.0-02$ & $5.0-03$ & $1.0-03$ & \\
\hline $\mathrm{CO}$ & $1.0-03$ & $9.4-03$ & $1.0-01$ & $5.0-04$ & $1.0-03$ & $5.0-03$ & $1.0-03$ & 2. $3 \mathrm{E}-0$ \\
\hline NI & $1.0-03$ & $1.9-02$ & $1.0-01$ & $3.4-03$ & $1.0-03$ & $5.0-03$ & $1.0-03$ & $2.3 E-03$ \\
\hline $\mathrm{CU}$ & $1.0-03$ & $1.3-01$ & $2.0-01$ & $7.0-03$ & $1.0-02$ & $1.5-02$ & $2.0-03$ & \\
\hline$Z N$ & $1.0-03$ & $4.0-01$ & $4.0-03$ & $6.0-03$ & $5.0-02$ & $1.4-01$ & $2.0-03$ & \\
\hline AS & $1.0-03$ & $1.0-02$ & $9.9-04$ & $3.0-03$ & $1.47-3$ & $2.38-2$ & $8.33-1$ & \\
\hline SE & $1.0-03$ & $1.3+00$ & $2.1+00$ & $2.3-02$ & $1.0+00$ & $4.5-01$ & $3.7-01$ & $2.2 \mathrm{E}-02$ \\
\hline & $1.0-02$ & $7.6-01$ & $1.6+00$ & $2.5-02$ & $2.0-02$ & $9.0-02$ & $4.0-03$ & \\
\hline K & 0.0 & 0.0 & 0.0 & 0.0 & 0.0 & 0.0 & 0.0 & \\
\hline RE & $1.0-03$ & $1.3-01$ & $3.0+00$ & $1.0-02$ & $1.5-01$ & $2.0-01$ & $2.0+00$ & \\
\hline SF & $1.0-03$ & $2.0-01$ & $4.0-01$ & $1.5-03$ & $3.0-04$ & $7.3-03$ & $9.0-04$ & $4.5 E-03$ \\
\hline Y & $1.0-03$ & $2.5-03$ & $5.0-04$ & $5.0-06$ & $5.0-03$ & $5.0-03$ & $5.0-04$ & \\
\hline ZR & $1.0-03$ & $1.7-04$ & $1 \cdot 2-03$ & $2.5-06$ & $5.0-04$ & $1.0-03$ & $1.0-04$ & $1.1 \mathrm{E}-04$ \\
\hline NE & $1.0-03$ & $9.4-03$ & $1.2-03$ & $1 \cdot 2-03$ & $5.0-04$ & $1.0-03$ & $1.0-04$ & \\
\hline MO & $1.0-03$ & $1.3-01$ & $4.0-01$ & $4.0-03$ & $1.0-02$ & $2.0-02$ & $2.0-03$ & \\
\hline TC & 1.0 & 1.0 & $9.9-04$ & $1.2-02$ & $9.9-04$ & $9.9-04$ & $9.9-04$ & 8. \\
\hline $\mathrm{RL}$ & $1.0-03$ & $1.0-02$ & $4.0-03$ & $5.0-07$ & $1.0-03$ & $5.0-03$ & $3.0-04$ & 2.2 \\
\hline $\mathrm{RH}$ & $1.0-03$ & $1.3+01$ & $4.0-03$ & $5.0-03$ & $1.0-03$ & $5.0-03$ & $3.0-04$ & 2. \\
\hline$P L$ & 1.0 & $5.0+00$ & $4.0-03$ & $5.0-03$ & $1.0-03$ & $5.0-03$ & $3.0-04$ & $4.5 \mathrm{E}-03$ \\
\hline & & 1.5 & $9.9-04$ & -02 & & -04 & $9.9-04$ & \\
\hline Cl & & & -04 & -05 & 1.6 & $1.6-02$ & $1.6-02$ & 7 \\
\hline SI & & & -04 & 1. & & -04 & .04 & \\
\hline SE & & & 02 & & & 7.0 & $6.0-03$ & $7.0 \mathrm{E}-02$ \\
\hline & & & & & & 1. & -02 & \\
\hline I & 1.0 & & +00 & & 02 & -02 & $4.0-03$ & $7.0 E-02$ \\
\hline$X E$ & & & & & & & & \\
\hline CS & $1.0-03$ & & & -03 & -02 & 2.6-01 & $4.5+00$ & $1.1 \mathrm{E}-04$ \\
\hline BA & & & & & & -02 & $5.0-04$ & \\
\hline LA & & & -03 & -06 & -03 & -03 & $4.0-03$ & \\
\hline$C E$ & & & -03 & -05 & -03 & -03 & $6.0-04$ & $=-04$ \\
\hline PR & & & -03 & -06 & & -03 & -03 & \\
\hline ND & & & -04 & -06 & & -03 & $4.0-03$ & \\
\hline PM & 1.0 & & & & & 03 & $1.0-04$ & \\
\hline
\end{tabular}

Figure D-3. FTRANSLIB Data File 


\begin{tabular}{|c|c|c|c|c|c|c|c|}
\hline $\begin{array}{l}1.0-03 \\
1.0-03 \\
1.0-03 \\
1.0-03 \\
1.0-03 \\
1.0-03 \\
1.0-03 \\
1.0-03 \\
1.0-03 \\
1.0-03 \\
0.0 \\
1.0-03 \\
1.0-03 \\
1.0-03 \\
1.0-03 \\
1.0-03 \\
1.0-03 \\
1.0-03 \\
1.0-03 \\
1.0-03 \\
1.0-03\end{array}$ & $\begin{array}{l}2.5-03 \\
2.5-03 \\
2.6-03 \\
2.6-03 \\
1.8-02 \\
9.9-04 \\
3.8-01 \\
6.8-02 \\
1.5-01 \\
9.0-03 \\
0.0 \\
1.4-03 \\
2.5-03 \\
4.2-03 \\
2.5-03 \\
2.5-03 \\
2.5-03 \\
2.5-04 \\
2.5-04 \\
2.5-03 \\
2.5-03\end{array}$ & $\begin{array}{l}7.0-03 \\
7.0-03 \\
7.0-03 \\
7.0-03 \\
9.9-04 \\
9.9-04 \\
9.9-04 \\
9.9-04 \\
9.9-04 \\
9.9-04 \\
0.0 \\
2.0-05 \\
2.0-03 \\
2.0-03 \\
2 \cdot 0-03 \\
3.4-01 \\
2 \cdot 0-03 \\
2.0-03 \\
2.0-03 \\
2.0-03 \\
2.0-03\end{array}$ & $\begin{array}{l}2.5-06 \\
2.5-06 \\
2.5-06 \\
2.5-06 \\
2.5-04 \\
9.9-04 \\
1.9-02 \\
1.0-05 \\
2 \cdot 5-04 \\
1.2-04 \\
0.0 \\
2.0-04 \\
2.5-06 \\
2.5-06 \\
2 \cdot 5-06 \\
6.0-04 \\
2 \cdot 5-06 \\
2.5-08 \\
2.5-06 \\
2.5-06 \\
7.5-07\end{array}$ & $\begin{array}{l}5.0-03 \\
5.0-03 \\
5.0-03 \\
5.0-03 \\
9.9-04 \\
9.9-04 \\
1.0-01 \\
9.9-04 \\
9.9-04 \\
9.9-04 \\
0.0 \\
9.9-04 \\
5.0-03 \\
5.0-03 \\
5.0-03 \\
5.0-03 \\
5.0-03 \\
5.0-03 \\
5.0-03 \\
5.0-03 \\
5.0-03\end{array}$ & $\begin{array}{l}5.0-03 \\
5.0-03 \\
5.0-03 \\
5.0-03 \\
9.9-04 \\
9.9-04 \\
3.1+00 \\
9.9-04 \\
9.9-04 \\
9.9-04 \\
0.0 \\
9.9-04 \\
1.0-02 \\
1.0-02 \\
1.0-02 \\
6.0-04 \\
1.0-02 \\
1.0-02 \\
1.0-02 \\
1.0-02 \\
1.0-02\end{array}$ & $\begin{array}{l}4.0-03 \\
4.0-03 \\
4.0-03 \\
4.0-03 \\
9.9-04 \\
9.9-04 \\
1.1-02 \\
9.9-04 \\
9.9-04 \\
9.9-04 \\
0.0 \\
9.9-04 \\
4.0-03 \\
4 \cdot 0-03 \\
4 \cdot 0-03 \\
1.2-03 \\
4.0-03 \\
4.0-03 \\
4.0-03 \\
4.0-03 \\
4.0-03\end{array}$ & $\begin{array}{l} \\
2.3 \mathrm{E}-03 \\
2.3 \mathrm{E}-04 \\
4.6 \mathrm{E}-04 \\
9.0 \mathrm{E}-03 \\
2.2 \mathrm{E}-02 \\
2.3 \mathrm{E}-04 \\
2.3 \mathrm{E}-04 \\
2.3 \mathrm{E}-04\end{array}$ \\
\hline
\end{tabular}

Figure D-3. FTRANSLIB Data File (continued) D. 150 
BIOACCUMULATION FACTOR LIBRARY FOR FOOD, PABLM,MAXI BA NAPIER (28-NOV-83/RAP)

FISH CRUS. MOLL. ALGAE FISH CRUS. MOLL. ALGAE FACTORS

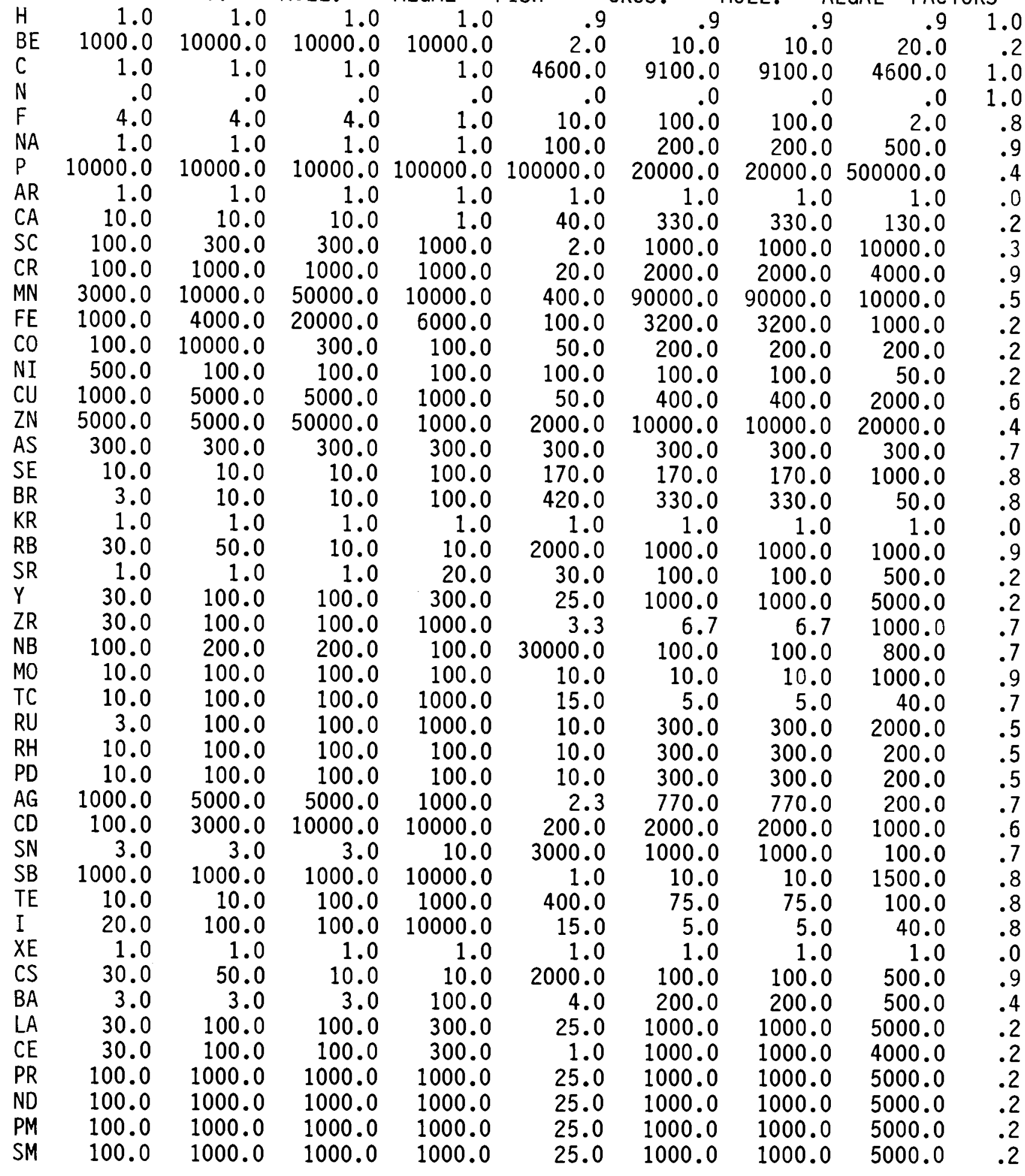

Figure D-4. BIOAC Data File 


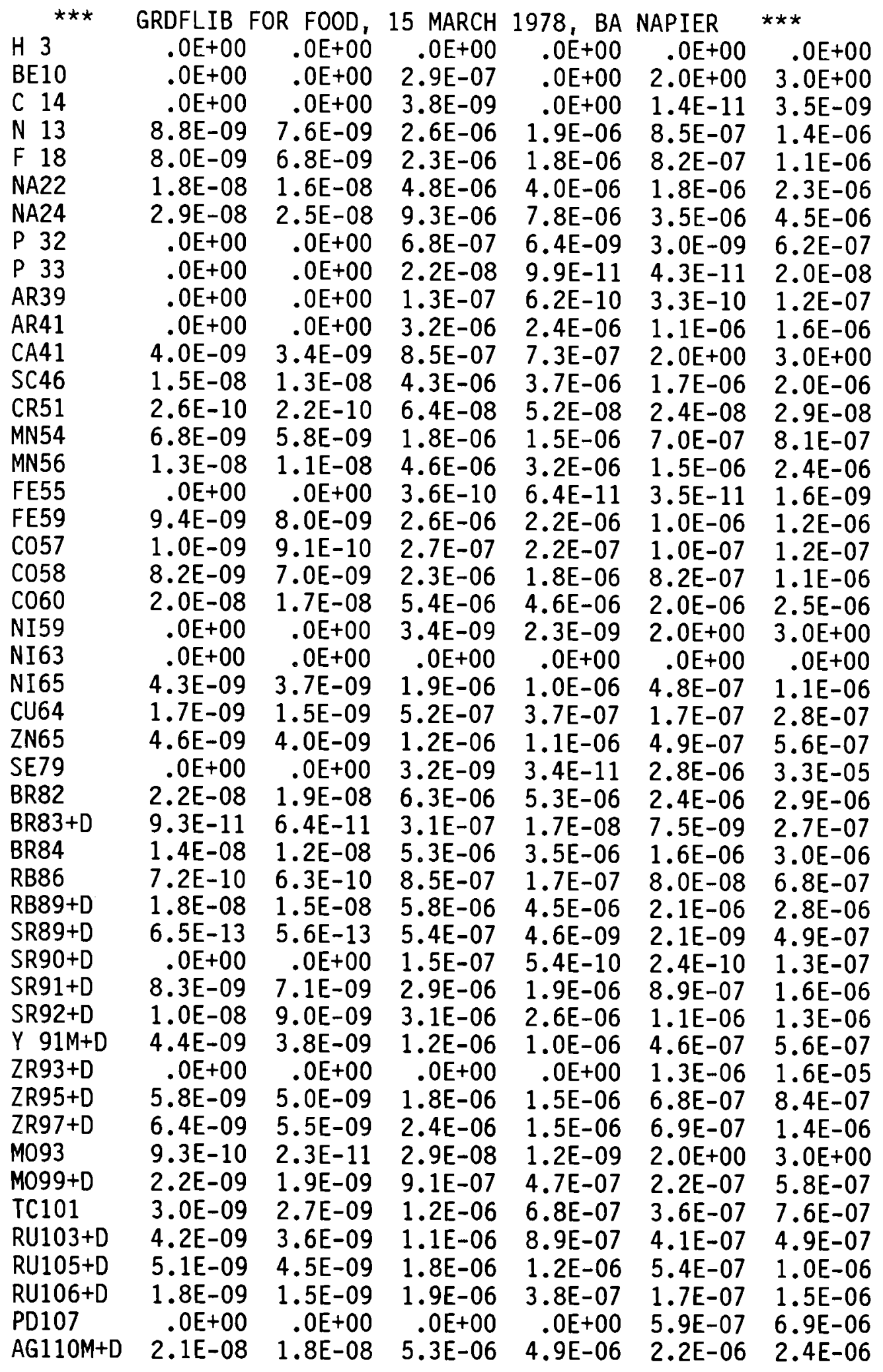

Figure D-5. GRDFLIB Data File 


\begin{tabular}{|c|c|c|c|c|c|c|}
\hline $\begin{array}{l}\text { AG111 } \\
\text { CD113M } \\
\text { SN123 } \\
\text { SN125+D } \\
\text { SN126+D } \\
\text { SB124 } \\
\text { SB125+D } \\
\text { TE127M+D } \\
\text { TE129M+D } \\
\text { TE131M+D } \\
\text { TE131+D } \\
\text { TE132+D } \\
\text { TE133M+D } \\
\text { I } 130 \\
\text { I } 131+D \\
\text { I } 135+D \\
\text { CS136 } \\
\text { CS137+D } \\
\text { CS139+D } \\
\text { BA140+D } \\
\text { CE143+D } \\
\text { CE144+D } \\
\text { PM148M+D } \\
\text { PM149 } \\
\text { SM153 } \\
\text { EU152 } \\
\text { EU154 } \\
\text { EU155 } \\
\text { EU156 } \\
\text { TB160 } \\
\text { HO166M } \\
N 181 \\
\text { N } 185 \\
\text { PB210+D } \\
3 I 210+D \\
\text { 2N222+D } \\
\text { RA223+D } \\
\text { RA224+D } \\
\text { 2A225+D } \\
\text { RA226+D } \\
\text { RA228+D } \\
\text { AC227+D } \\
\text { TH227+D } \\
\text { TH228+D } \\
\text { TH230+D } \\
\text { TH232+D } \\
\text { PA231+D } \\
\text { J 232+D }\end{array}$ & $\begin{array}{l}2.1 \mathrm{E}-10 \\
2.6 \mathrm{E}-12 \\
6.5 \mathrm{E}-08 \\
6.6 \mathrm{E}-10 \\
1.0 \mathrm{E}-08 \\
1.5 \mathrm{E}-08 \\
3.5 \mathrm{E}-09 \\
1.3 \mathrm{E}-12 \\
9.0 \mathrm{E}-10 \\
9.9 \mathrm{E}-09 \\
2.6 \mathrm{E}-06 \\
2.0 \mathrm{E}-09 \\
1.7 \mathrm{E}-08 \\
1.7 \mathrm{E}-08 \\
3.4 \mathrm{E}-09 \\
1.4 \mathrm{E}-08 \\
1.7 \mathrm{E}-08 \\
4.9 \mathrm{E}-09 \\
7.2 \mathrm{E}-09 \\
2.4 \mathrm{E}-09 \\
2.5 \mathrm{E}-09 \\
3.7 \mathrm{E}-10 \\
8.2 \mathrm{E}-08 \\
2.9 \mathrm{E}-11 \\
3.0 \mathrm{E}-10 \\
8.5 \mathrm{E}-09 \\
9.0 \mathrm{E}-09 \\
4.3 \mathrm{E}-10 \\
8.7 \mathrm{E}-09 \\
1.0 \mathrm{E}-08 \\
1.0 \mathrm{E}-08 \\
2.8 \mathrm{E}-12 \\
.0 \mathrm{E}+00 \\
1.7 \mathrm{E}-11 \\
.0 \mathrm{E}+00 \\
1.5 \mathrm{E}-08 \\
1.8 \mathrm{E}-09 \\
1.0 \mathrm{E}-08 \\
1.2 \mathrm{E}-10 \\
1.5 \mathrm{E}-08 \\
1.4 \mathrm{E}-08 \\
2.4 \mathrm{E}-09 \\
6.3 \mathrm{E}-10 \\
1.0 \mathrm{E}-08 \\
1.0 \mathrm{E}-10 \\
4.0 \mathrm{E}-09 \\
2.7 \mathrm{E}-09 \\
2.7 \mathrm{E}-11 \\
7.5 \mathrm{E}-11\end{array}$ & $\begin{array}{l}1.8 \mathrm{E}-10 \\
2.3 \mathrm{E}-12 \\
.0 \mathrm{E}+00 \\
5.7 \mathrm{E}-10 \\
9.0 \mathrm{E}-09 \\
1.3 \mathrm{E}-08 \\
3.1 \mathrm{E}-09 \\
1.1 \mathrm{E}-12 \\
7.7 \mathrm{E}-10 \\
8.4 \mathrm{E}-09 \\
2.2 \mathrm{E}-09 \\
1.7 \mathrm{E}-09 \\
1.5 \mathrm{E}-08 \\
1.4 \mathrm{E}-08 \\
2.8 \mathrm{E}-09 \\
1.2 \mathrm{E}-08 \\
1.5 \mathrm{E}-08 \\
4.2 \mathrm{E}-09 \\
6.3 \mathrm{E}-09 \\
2.1 \mathrm{E}-09 \\
2.2 \mathrm{E}-09 \\
3.2 \mathrm{E}-10 \\
1.4 \mathrm{E}-08 \\
2.5 \mathrm{E}-11 \\
2.7 \mathrm{E}-10 \\
7.4 \mathrm{E}-09 \\
7.8 \mathrm{E}-09 \\
3.8 \mathrm{E}-10 \\
7.6 \mathrm{E}-09 \\
8.6 \mathrm{E}-09 \\
8.9 \mathrm{E}-09 \\
2.1 \mathrm{E}-12 \\
.0 \mathrm{E}+00 \\
1.3 \mathrm{E}-11 \\
.0 \mathrm{E}+00 \\
1.3 \mathrm{E}-08 \\
1.5 \mathrm{E}-09 \\
8.9 \mathrm{E}-09 \\
8.4 \mathrm{E}-11 \\
1.3 \mathrm{E}-08 \\
1.2 \mathrm{E}-08 \\
2.0 \mathrm{E}-09 \\
5.1 \mathrm{E}-10 \\
8.9 \mathrm{E}-09 \\
7.8 \mathrm{E}-12 \\
3.0 \mathrm{E}-09 \\
2.2 \mathrm{E}-09 \\
2.6 \mathrm{E}-12\end{array}$ & $\begin{array}{l}3.8 \mathrm{E}-07 \\
1.4 \mathrm{E}-07 \\
5.0 \mathrm{E}-07 \\
1.1 \mathrm{E}-06 \\
6.0 \mathrm{E}-08 \\
4.5 \mathrm{E}-06 \\
9.5 \mathrm{E}-07 \\
1.8 \mathrm{E}-09 \\
7.4 \mathrm{E}-07 \\
2.7 \mathrm{E}-06 \\
1.6 \mathrm{E}-06 \\
4.8 \mathrm{E}-07 \\
5.0 \mathrm{E}-06 \\
4.8 \mathrm{E}-06 \\
9.3 \mathrm{E}-07 \\
4.0 \mathrm{E}-06 \\
4.8 \mathrm{E}-06 \\
1.4 \mathrm{E}-06 \\
3.2 \mathrm{E}-06 \\
7.6 \mathrm{E}-07 \\
1.0 \mathrm{E}-06 \\
1.4 \mathrm{E}-06 \\
4.5 \mathrm{E}-06 \\
3.5 \mathrm{E}-07 \\
2.5 \mathrm{E}-07 \\
2.1 \mathrm{E}-06 \\
2.7 \mathrm{E}-06 \\
1.1 \mathrm{E}-07 \\
2.8 \mathrm{E}-06 \\
2.8 \mathrm{E}-06 \\
2.8 \mathrm{E}-06 \\
6.8 \mathrm{E}-10 \\
7.9 \mathrm{E}-08 \\
3.6 \mathrm{E}-07 \\
3.5 \mathrm{E}-07 \\
5.0 \mathrm{E}-06 \\
1.3 \mathrm{E}-06 \\
3.5 \mathrm{E}-06 \\
6.3 \mathrm{E}-08 \\
5.0 \mathrm{E}-06 \\
4.8 \mathrm{E}-06 \\
6.3 \mathrm{E}-07 \\
1.6 \mathrm{E}-07 \\
3.5 \mathrm{E}-06 \\
4.4 \mathrm{E}-09 \\
4.8 \mathrm{E}-06 \\
7.0 \mathrm{E}-07 \\
1.1 \mathrm{E}-09 \\
2.9 \mathrm{E}-09\end{array}$ & $\begin{array}{l}4.8 \mathrm{E}-08 \\
5.9 \mathrm{E}-10 \\
.0 \mathrm{E}+00 \\
1.6 \mathrm{E}-07 \\
1.8 \mathrm{E}-08 \\
3.6 \mathrm{E}-06 \\
7.8 \mathrm{E}-07 \\
2.6 \mathrm{E}-10 \\
2.1 \mathrm{E}-07 \\
2.2 \mathrm{E}-06 \\
7.4 \mathrm{E}-07 \\
4.0 \mathrm{E}-07 \\
3.9 \mathrm{E}-06 \\
3.9 \mathrm{E}-06 \\
7.8 \mathrm{E}-07 \\
3.3 \mathrm{E}-06 \\
4.1 \mathrm{E}-06 \\
1.0 \mathrm{E}-06 \\
1.7 \mathrm{E}-06 \\
4.9 \mathrm{E}-07 \\
5.7 \mathrm{E}-07 \\
8.6 \mathrm{E}-08 \\
3.7 \mathrm{E}-06 \\
1.5 \mathrm{E}-08 \\
6.5 \mathrm{E}-08 \\
1.8 \mathrm{E}-06 \\
2.1 \mathrm{E}-06 \\
9.0 \mathrm{E}-08 \\
2.1 \mathrm{E}-06 \\
2.4 \mathrm{E}-06 \\
2.4 \mathrm{E}-06 \\
5.3 \mathrm{E}-10 \\
3.2 \mathrm{E}-10 \\
3.0 \mathrm{E}-09 \\
2.7 \mathrm{E}-09 \\
3.2 \mathrm{E}-06 \\
4.0 \mathrm{E}-07 \\
2.6 \mathrm{E}-06 \\
1.9 \mathrm{E}-08 \\
3.3 \mathrm{E}-06 \\
3.4 \mathrm{E}-06 \\
4.4 \mathrm{E}-07 \\
1.3 \mathrm{E}-07 \\
2.6 \mathrm{E}-06 \\
1.2 \mathrm{E}-09 \\
3.4 \mathrm{E}-06 \\
5.0 \mathrm{E}-07 \\
4.6 \mathrm{E}-10 \\
1.0 \mathrm{E}-09\end{array}$ & $\begin{array}{l}2.2 \mathrm{E}-08 \\
1.2 \mathrm{E}-05 \\
2.0 \mathrm{E}+00 \\
7.3 \mathrm{E}-08 \\
1.3 \mathrm{E}-05 \\
1.6 \mathrm{E}-06 \\
3.6 \mathrm{E}-07 \\
1.2 \mathrm{E}-10 \\
9.4 \mathrm{E}-08 \\
1.0 \mathrm{E}-06 \\
3.4 \mathrm{E}-07 \\
1.8 \mathrm{E}-07 \\
1.8 \mathrm{E}-06 \\
1.8 \mathrm{E}-06 \\
3.1 \mathrm{E}-07 \\
1.5 \mathrm{E}-06 \\
1.9 \mathrm{E}-06 \\
4.7 \mathrm{E}-07 \\
8.0 \mathrm{E}-07 \\
2.2 \mathrm{E}-07 \\
2.6 \mathrm{E}-07 \\
4.0 \mathrm{E}-08 \\
2.0 \mathrm{E}+00 \\
6.9 \mathrm{E}-09 \\
3.0 \mathrm{E}-08 \\
1.3 \mathrm{E}-05 \\
4.6 \mathrm{E}-05 \\
5.0 \mathrm{E}-06 \\
9.8 \mathrm{E}-07 \\
2.0 \mathrm{E}+00 \\
2.0 \mathrm{E}+00 \\
2.5 \mathrm{E}-10 \\
1.4 \mathrm{E}-10 \\
2.7 \mathrm{E}-09 \\
1.3 \mathrm{E}-09 \\
1.5 \mathrm{E}-06 \\
2.0 \mathrm{E}+00 \\
2.0 \mathrm{E}+00 \\
2.0 \mathrm{E}+00 \\
1.5 \mathrm{E}-06 \\
2.0 \mathrm{E}+00 \\
2.0 \mathrm{E}+00 \\
2.0 \mathrm{E}+00 \\
2.0 \mathrm{E}+00 \\
5.5 \mathrm{E}-10 \\
2.0 \mathrm{E}+00 \\
2.0 \mathrm{E}+00 \\
2.0 \mathrm{E}-10 \\
4.7 \mathrm{E}-10\end{array}$ & 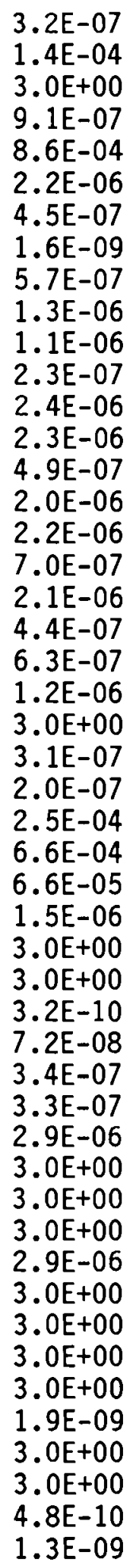 \\
\hline
\end{tabular}

Figure D-5. GRDFLIB Data File (continued) 


\begin{tabular}{|c|c|c|c|c|c|c|}
\hline $\begin{array}{l}\text { U } 234 \\
U \text { U } 235+D \\
\text { U } 236 \\
\text { U } 238+D \\
\text { NP237+D } \\
\text { PU241+D } \\
\text { CM246 } \\
\text { CM247+D } \\
\text { CM248 } \\
\text { CF252 } \\
\text { ZN69M } \\
\text { ZN69 } \\
\text { KR83M } \\
\text { BR85 } \\
\text { KR85M } \\
\text { KR85 } \\
\text { KR87 } \\
\text { RB87 } \\
\text { KR88 } \\
\text { RB88 } \\
\text { KR89 } \\
\text { SR90 } \\
\text { Y } 90 \\
\text { Y } 91 \\
\text { Y } 92 \\
\text { Y } 93 \\
\text { NB93M } \\
\text { NB95 } \\
\text { NB97 } \\
\text { TC99M } \\
\text { TC99 } \\
\text { RH105 } \\
\text { RU106 } \\
\text { PD109 } \\
\text { CD115M } \\
\text { TE125M } \\
\text { SN126 } \\
\text { SB126 } \\
\text { SB127 } \\
\text { TE127 } \\
\text { TE129 } \\
\text { I } 129 \\
\text { XE131M } \\
\text { I } 132 \\
\text { I } 133 \\
\text { XE133M } \\
\text { XE133 } \\
\text { TE134 } \\
\text { I } 134\end{array}$ & $\begin{array}{r}5.1 \mathrm{E}-10 \\
2.1 \mathrm{E}-09 \\
1.3 \mathrm{E}-10 \\
6.3 \mathrm{E}-10 \\
1.6 \mathrm{E}-09 \\
6.8 \mathrm{E}-12 \\
1.5 \mathrm{E}-11 \\
2.6 \mathrm{E}-09 \\
5.2 \mathrm{E}-09 \\
7.2 \mathrm{E}-08 \\
3.4 \mathrm{E}-09 \\
.0 \mathrm{E}+00 \\
4.2 \mathrm{E}-10 \\
.0 \mathrm{E}+00 \\
.0 \mathrm{E}+00 \\
.0 \mathrm{E}+00 \\
.0 \mathrm{E}+00 \\
.0 \mathrm{E}+00 \\
.0 \mathrm{E}+00 \\
4.0 \mathrm{E}-09 \\
.0 \mathrm{E}+00 \\
.0 \mathrm{E}+00 \\
2.6 \mathrm{E}-12 \\
2.7 \mathrm{E}-11 \\
1.9 \mathrm{E}-09 \\
7.8 \mathrm{E}-10 \\
1.0 \mathrm{E}-10 \\
6.0 \mathrm{E}-09 \\
5.4 \mathrm{E}-09 \\
1.1 \mathrm{E}-09 \\
.0 \mathrm{E}+00 \\
7.7 \mathrm{E}-10 \\
1.8 \mathrm{E}-09 \\
4.0 \mathrm{E}-11 \\
.0 \mathrm{E}+00 \\
4.8 \mathrm{E}-11 \\
1.0 \mathrm{E}-08 \\
1.0 \mathrm{E}-08 \\
6.6 \mathrm{E}-09 \\
1.1 \mathrm{E}-11 \\
8.4 \mathrm{E}-10 \\
7.5 \mathrm{E}-10 \\
.0 \mathrm{E}+00 \\
2.0 \mathrm{E}-08 \\
4.5 \mathrm{E}-09 \\
1.0 \mathrm{E}+00\end{array}$ & $\begin{array}{r}7.3 \mathrm{E}-12 \\
1.3 \mathrm{E}-09 \\
2.1 \mathrm{E}-13 \\
3.5 \mathrm{E}-10 \\
1.4 \mathrm{E}-09 \\
4.6 \mathrm{E}-12 \\
1.0 \mathrm{E}-12 \\
2.2 \mathrm{E}-09 \\
6.8 \mathrm{E}-09 \\
6.6 \mathrm{E}-08 \\
2.9 \mathrm{E}-09 \\
.0 \mathrm{E}+00 \\
1.3 \mathrm{E}-11 \\
.0 \mathrm{E}+00 \\
.0 \mathrm{E}+00 \\
.0 \mathrm{E}+00 \\
.0 \mathrm{E}+00 \\
.0 \mathrm{E}+00 \\
.0 \mathrm{E}+00 \\
3.5 \mathrm{E}-09 \\
.0 \mathrm{E}+00 \\
.0 \mathrm{E}+00 \\
2.2 \mathrm{E}-12 \\
2.4 \mathrm{E}-11 \\
1.6 \mathrm{E}-09 \\
5.7 \mathrm{E}-10 \\
8.2 \mathrm{E}-13 \\
5.1 \mathrm{E}-09 \\
4.6 \mathrm{E}-09 \\
9.6 \mathrm{E}-10 \\
.0 \mathrm{E}+00 \\
6.6 \mathrm{E}-10 \\
1.5 \mathrm{E}-09 \\
3.5 \mathrm{E}-11 \\
.0 \mathrm{E}+00 \\
3.5 \mathrm{E}-11 \\
9.0 \mathrm{E}-09 \\
8.9 \mathrm{E}-09 \\
5.7 \mathrm{E}-09 \\
1.0 \mathrm{E}-09 \\
7.1 \mathrm{E}-11 \\
4.5 \mathrm{E}-10 \\
.0 \mathrm{E}+00 \\
3.7 \mathrm{E}-08 \\
.0 \mathrm{E}-09\end{array}$ & $\begin{array}{l}1.2 \mathrm{E}-08 \\
3.8 \mathrm{E}-07 \\
3.1 \mathrm{E}-09 \\
9.3 \mathrm{E}-07 \\
4.5 \mathrm{E}-07 \\
9.5 \mathrm{E}-11 \\
3.3 \mathrm{E}-09 \\
7.5 \mathrm{E}-07 \\
4.7 \mathrm{E}-07 \\
1.7 \mathrm{E}-05 \\
1.2 \mathrm{E}-06 \\
2.8 \mathrm{E}-07 \\
9.4 \mathrm{E}-09 \\
1.1 \mathrm{E}-06 \\
5.1 \mathrm{E}-07 \\
1.8 \mathrm{E}-07 \\
4.6 \mathrm{E}-06 \\
2.5 \mathrm{E}-08 \\
7.7 \mathrm{E}-06 \\
3.6 \mathrm{E}-06 \\
6.8 \mathrm{E}-06 \\
1.5 \mathrm{E}-07 \\
9.6 \mathrm{E}-07 \\
5.7 \mathrm{E}-07 \\
2.0 \mathrm{E}-06 \\
1.4 \mathrm{E}-06 \\
3.0 \mathrm{E}-09 \\
1.6 \mathrm{E}-06 \\
1.9 \mathrm{E}-06 \\
2.7 \mathrm{E}-07 \\
2.6 \mathrm{E}-10 \\
3.0 \mathrm{E}-07 \\
1.9 \mathrm{E}-06 \\
3.4 \mathrm{E}-07 \\
.0 \mathrm{E}+00 \\
1.5 \mathrm{E}-08 \\
6.0 \mathrm{E}-08 \\
3.3 \mathrm{E}-06 \\
1.8 \mathrm{E}-06 \\
1.7 \mathrm{E}-07 \\
7.0 \mathrm{E}-07 \\
3.3 \mathrm{E}-08 \\
5.6 \mathrm{E}-08 \\
5.5 \mathrm{E}-06 \\
1.5 \mathrm{E}-06 \\
1.0 \mathrm{E}-07 \\
1.1 \mathrm{E}-07 \\
3.5 \mathrm{E}-07 \\
5.5 \mathrm{E}-06\end{array}$ & $\begin{array}{l}1.2 \mathrm{E}-09 \\
3.0 \mathrm{E}-07 \\
3.0 \mathrm{E}-12 \\
7.4 \mathrm{E}-08 \\
3.6 \mathrm{E}-07 \\
6.1 \mathrm{E}-11 \\
1.1 \mathrm{E}-10 \\
4.7 \mathrm{E}-07 \\
3.1 \mathrm{E}-07 \\
1.4 \mathrm{E}-05 \\
7.5 \mathrm{E}-07 \\
1.6 \mathrm{E}-09 \\
2.4 \mathrm{E}-11 \\
1.4 \mathrm{E}-08 \\
2.8 \mathrm{E}-07 \\
4.7 \mathrm{E}-09 \\
2.7 \mathrm{E}-06 \\
1.2 \mathrm{E}-10 \\
4.5 \mathrm{E}-06 \\
1.2 \mathrm{E}-06 \\
4.8 \mathrm{E}-06 \\
5.4 \mathrm{E}-10 \\
1.3 \mathrm{E}-08 \\
6.7 \mathrm{E}-09 \\
4.6 \mathrm{E}-07 \\
1.9 \mathrm{E}-07 \\
2.2 \mathrm{E}-11 \\
1.4 \mathrm{E}-06 \\
1.2 \mathrm{E}-06 \\
2.4 \mathrm{E}-07 \\
1.3 \mathrm{E}-10 \\
1.7 \mathrm{E}-07 \\
3.8 \mathrm{E}-07 \\
9.3 \mathrm{E}-09 \\
.0 \mathrm{E}+00 \\
3.7 \mathrm{E}-09 \\
1.8 \mathrm{E}-08 \\
2.4 \mathrm{E}-06 \\
1.5 \mathrm{E}-06 \\
2.8 \mathrm{E}-09 \\
1.9 \mathrm{E}-07 \\
1.7 \mathrm{E}-08 \\
6.2 \mathrm{E}-09 \\
4.4 \mathrm{E}-06 \\
9.6 \mathrm{E}-07 \\
6.0 \mathrm{E}-08 \\
5.7 \mathrm{E}-08 \\
2.5 \mathrm{E}-07 \\
4.2 \mathrm{E}-06\end{array}$ & $\begin{array}{l}1.4 \mathrm{E} \\
1.2 \mathrm{E} \\
3.4 \mathrm{E} \\
1.4 \mathrm{E} \\
2.8 \mathrm{E} \\
3.6 \mathrm{E} \\
2.0 \mathrm{E} \\
2.0 \mathrm{E} \\
.0 \mathrm{E} \\
3.4 \mathrm{E} \\
7.1 \mathrm{E} \\
.0 \mathrm{E} \\
6.7 \mathrm{E} \\
1.3 \mathrm{E} \\
2.2 \mathrm{E} \\
1.3 \mathrm{E} \\
2.0 \mathrm{E} \\
2.1 \mathrm{E} \\
5.6 \mathrm{E} \\
3.8 \mathrm{E} \\
2.4 \mathrm{E} \\
6.1 \mathrm{E} \\
3.1 \mathrm{E} \\
2.1 \mathrm{E} \\
8.7 \mathrm{E} \\
9.2 \mathrm{E} \\
6.4 \mathrm{E} \\
5.6 \mathrm{E} \\
1.1 \mathrm{E} \\
5.8 \mathrm{E} \\
7.8 \mathrm{E} \\
1.7 \mathrm{E} \\
4.3 \mathrm{E} \\
2.0 \mathrm{E} \\
1.7 \mathrm{E} \\
1.3 \mathrm{E} \\
5.0 \mathrm{E} \\
6.7 \mathrm{E} \\
1.2 \mathrm{E} \\
8.7 \mathrm{E} \\
2.7 \mathrm{E} \\
1.5 \mathrm{E} \\
2.2 \mathrm{E}\end{array}$ & $\begin{array}{l}5.3 \mathrm{E}-09 \\
1.9 \mathrm{E}-07 \\
1.3 \mathrm{E}-09 \\
8.1 \mathrm{E}-07 \\
2.1 \mathrm{E}-07 \\
4.2 \mathrm{E}-11 \\
4.0 \mathrm{E}-02 \\
3.0 \mathrm{E}+00 \\
3.0 \mathrm{E}+00 \\
.0 \mathrm{E}+00 \\
6.8 \mathrm{E}-07 \\
2.5 \mathrm{E}-07 \\
7.6 \mathrm{E}-10 \\
9.7 \mathrm{E}-07 \\
3.2 \mathrm{E}-07 \\
1.6 \mathrm{E}-07 \\
2.7 \mathrm{E}-06 \\
3.0 \mathrm{E}+00 \\
4.7 \mathrm{E}-06 \\
2.7 \mathrm{E}-06 \\
2.2 \mathrm{E}-06 \\
1.3 \mathrm{E}-07 \\
8.6 \mathrm{E}-07 \\
5.2 \mathrm{E}-07 \\
1.6 \mathrm{E}-06 \\
1.2 \mathrm{E}-06 \\
1.2 \mathrm{E}-09 \\
7.5 \mathrm{E}-07 \\
1.1 \mathrm{E}-06 \\
1.3 \mathrm{E}-07 \\
2.4 \mathrm{E}-08 \\
1.8 \mathrm{E}-07 \\
1.5 \mathrm{E}-06 \\
3.0 \mathrm{E}-07 \\
3.0 \mathrm{E}+00 \\
1.1 \mathrm{E}-08 \\
8.6 \mathrm{E}-04 \\
8.0 \mathrm{E}-05 \\
9.0 \mathrm{E}-07 \\
1.6 \mathrm{E}-07 \\
5.3 \mathrm{E}-07 \\
3.9 \mathrm{E}-08 \\
4.8 \mathrm{E}-08 \\
2.7 \mathrm{E}-06 \\
8.8 \mathrm{E}-07 \\
6.0 \mathrm{E}-08 \\
6.9 \mathrm{E}-08 \\
1.9 \mathrm{E}-07 \\
2.9 \mathrm{E}-06\end{array}$ \\
\hline
\end{tabular}

Figure D-5. GRDFLIB Data File (continued) 


\begin{tabular}{|c|c|c|c|c|c|c|}
\hline $\begin{array}{l}\text { CS134M } \\
\text { CS134 } \\
\text { XE135M } \\
\text { XE135 } \\
\text { CS135 } \\
\text { XE137 } \\
\text { CS137 } \\
\text { XE138 } \\
\text { CS138 } \\
\text { BA139 } \\
\text { LA140 } \\
\text { BA141 } \\
\text { LA141 } \\
\text { CE141 } \\
\text { BA142 } \\
\text { LA142 } \\
\text { PR143 } \\
\text { CE144 } \\
\text { PR144 } \\
\text { ND147 } \\
\text { PM147 } \\
\text { PM148 } \\
\text { PM151 } \\
\text { SM151 } \\
\text { W } 187 \\
\text { TH230 } \\
\text { RA226 } \\
\text { RN222 } \\
\text { PB210 } \\
\text { BI210 } \\
\text { P0210 } \\
\text { U 232 } \\
\text { TH232 } \\
\text { RA228 } \\
\text { TH228 } \\
\text { U 235 } \\
\text { PA231 } \\
\text { AC227 } \\
\text { U } 237 \\
\text { NP237 } \\
\text { PA233 } \\
\text { U } 233 \\
\text { TH229 } \\
\text { AC225 } \\
\text { U } 238 \\
\text { TH234 } \\
\text { AM242M } \\
\text { CM242 } \\
\text { PU242 }\end{array}$ & $\begin{array}{r}7.3 \mathrm{E}-10 \\
1.4 \mathrm{E}-08 \\
.0 \mathrm{E}+00 \\
.0 \mathrm{E}+00 \\
.0 \mathrm{E}+00 \\
.0 \mathrm{E}+00 \\
4.9 \mathrm{E}-09 \\
.0 \mathrm{E}+00 \\
2.4 \mathrm{E}-08 \\
2.7 \mathrm{E}-09 \\
1.7 \mathrm{E}-08 \\
4.9 \mathrm{E}-09 \\
2.8 \mathrm{E}-10 \\
6.2 \mathrm{E}-10 \\
9.0 \mathrm{E}-09 \\
1.8 \mathrm{E}-08 \\
.0 \mathrm{E}+00 \\
3.7 \mathrm{E}-10 \\
2.3 \mathrm{E}-10 \\
1.2 \mathrm{E}-09 \\
.0 \mathrm{E}+00 \\
5.3 \mathrm{E}-09 \\
2.3 \mathrm{E}-09 \\
2.1 \mathrm{E}-10 \\
3.6 \mathrm{E}-09 \\
1.0 \mathrm{E}-10 \\
1.5 \mathrm{E}-08 \\
1.5 \mathrm{E}-08 \\
1.7 \mathrm{E}-11 \\
.0 \mathrm{E}+00 \\
6.2 \mathrm{E}-14 \\
2.7 \mathrm{E}-11 \\
4.0 \mathrm{E}-09 \\
1.4 \mathrm{E}-08 \\
1.0 \mathrm{E}-08 \\
2.1 \mathrm{E}-09 \\
2.7 \mathrm{E}-09 \\
2.4 \mathrm{E}-09 \\
2.3 \mathrm{E}-09 \\
1.6 \mathrm{E}-09 \\
1.5 \mathrm{E}-09 \\
7.5 \mathrm{E}-11 \\
2.7 \mathrm{E}-09 \\
1.8 \mathrm{E}-09 \\
6.3 \mathrm{E}-10 \\
1.3 \mathrm{E}-10 \\
1.8 \mathrm{E}-10 \\
2.3 \mathrm{E}-11 \\
1.6 \mathrm{E}-11\end{array}$ & $\begin{array}{r}6.2 \mathrm{E}-10 \\
1.2 \mathrm{E}-08 \\
.0 \mathrm{E}+00 \\
.0 \mathrm{E}+00 \\
.0 \mathrm{E}+00 \\
.0 \mathrm{E}+00 \\
4.2 \mathrm{E}-09 \\
.0 \mathrm{E}+00 \\
2.1 \mathrm{E}-08 \\
2.4 \mathrm{E}-09 \\
1.5 \mathrm{E}-08 \\
4.3 \mathrm{E}-09 \\
2.5 \mathrm{E}-10 \\
5.5 \mathrm{E}-10 \\
7.9 \mathrm{E}-09 \\
1.5 \mathrm{E}-08 \\
.0 \mathrm{E}+00 \\
3.2 \mathrm{E}-10 \\
2.0 \mathrm{E}-10 \\
1.0 \mathrm{E}-09 \\
.0 \mathrm{E}+00 \\
4.6 \mathrm{E}-09 \\
2.2 \mathrm{E}-09 \\
4.8 \mathrm{E}-11 \\
3.1 \mathrm{E}-09 \\
7.8 \mathrm{E}-12 \\
1.3 \mathrm{E}-08 \\
1.3 \mathrm{E}-08 \\
1.3 \mathrm{E}-11 \\
.0 \mathrm{E}+00 \\
5.4 \mathrm{E}-14 \\
2.6 \mathrm{E}-12 \\
3.0 \mathrm{E}-09 \\
1.2 \mathrm{E}-08 \\
8.9 \mathrm{E}-09 \\
1.3 \mathrm{E}-09 \\
2.2 \mathrm{E}-09 \\
2.0 \mathrm{E}-09 \\
1.3 \mathrm{E}-09 \\
1.4 \mathrm{E}-09 \\
1.3 \mathrm{E}-09 \\
5.7 \mathrm{E}-12 \\
2.2 \mathrm{E}-09 \\
1.6 \mathrm{E}-09 \\
3.5 \mathrm{E}-10 \\
1.1 \mathrm{E}-10 \\
2.6 \mathrm{E}-11 \\
5.5 \mathrm{E}-12 \\
1.1 \mathrm{E}-12\end{array}$ & $\begin{array}{l}1.9 \mathrm{E}-07 \\
3.5 \mathrm{E}-06 \\
1.0 \mathrm{E}-06 \\
7.9 \mathrm{E}-07 \\
1.1 \mathrm{E}-08 \\
2.1 \mathrm{E}-06 \\
1.4 \mathrm{E}-06 \\
3.4 \mathrm{E}-06 \\
5.7 \mathrm{E}-06 \\
1.0 \mathrm{E}-06 \\
5.3 \mathrm{E}-06 \\
2.4 \mathrm{E}-06 \\
1.0 \mathrm{E}-06 \\
2.4 \mathrm{E}-07 \\
3.0 \mathrm{E}-06 \\
5.9 \mathrm{E}-06 \\
2.8 \mathrm{E}-07 \\
1.4 \mathrm{E}-06 \\
1.3 \mathrm{E}-06 \\
5.0 \mathrm{E}-07 \\
1.3 \mathrm{E}-08 \\
2.0 \mathrm{E}-06 \\
8.4 \mathrm{E}-07 \\
1.9 \mathrm{E}-09 \\
1.2 \mathrm{E}-06 \\
4.4 \mathrm{E}-09 \\
5.0 \mathrm{E}-06 \\
5.0 \mathrm{E}-06 \\
3.6 \mathrm{E}-07 \\
3.5 \mathrm{E}-07 \\
1.7 \mathrm{E}-11 \\
1.1 \mathrm{E}-09 \\
4.8 \mathrm{E}-06 \\
4.8 \mathrm{E}-06 \\
3.5 \mathrm{E}-06 \\
3.8 \mathrm{E}-07 \\
7.0 \mathrm{E}-07 \\
6.3 \mathrm{E}-07 \\
3.4 \mathrm{E}-07 \\
4.5 \mathrm{E}-07 \\
4.0 \mathrm{E}-07 \\
2.9 \mathrm{E}-09 \\
1.3 \mathrm{E}-06 \\
1.1 \mathrm{E}-06 \\
9.3 \mathrm{E}-07 \\
8.7 \mathrm{E}-07 \\
1.6 \mathrm{E}-07 \\
4.7 \mathrm{E}-09 \\
3.6 \mathrm{E}-09\end{array}$ & $\begin{array}{l}1.6 \mathrm{E}-07 \\
2.9 \mathrm{E}-06 \\
7.6 \mathrm{E}-07 \\
4.5 \mathrm{E}-07 \\
6.6 \mathrm{E}-11 \\
2.7 \mathrm{E}-07 \\
1.0 \mathrm{E}-06 \\
2.6 \mathrm{E}-06 \\
4.0 \mathrm{E}-06 \\
7.7 \mathrm{E}-08 \\
4.1 \mathrm{E}-06 \\
1.1 \mathrm{E}-06 \\
5.1 \mathrm{E}-08 \\
1.3 \mathrm{E}-07 \\
2.2 \mathrm{E}-06 \\
4.5 \mathrm{E}-06 \\
1.6 \mathrm{E}-09 \\
8.6 \mathrm{E}-08 \\
5.6 \mathrm{E}-08 \\
2.8 \mathrm{E}-07 \\
7.5 \mathrm{E}-11 \\
1.1 \mathrm{E}-06 \\
5.0 \mathrm{E}-07 \\
2.6 \mathrm{E}-10 \\
8.3 \mathrm{E}-07 \\
1.2 \mathrm{E}-09 \\
3.3 \mathrm{E}-06 \\
3.2 \mathrm{E}-06 \\
3.0 \mathrm{E}-09 \\
2.7 \mathrm{E}-09 \\
1.5 \mathrm{E}-11 \\
4.6 \mathrm{E}-10 \\
3.4 \mathrm{E}-06 \\
3.4 \mathrm{E}-06 \\
2.6 \mathrm{E}-06 \\
3.0 \mathrm{E}-07 \\
5.0 \mathrm{E}-07 \\
4.4 \mathrm{E}-07 \\
2.6 \mathrm{E}-07 \\
3.6 \mathrm{E}-07 \\
3.3 \mathrm{E}-07 \\
1.0 \mathrm{E}-09 \\
5.8 \mathrm{E}-07 \\
4.0 \mathrm{E}-07 \\
7.4 \mathrm{E}-08 \\
2.8 \mathrm{E}-08 \\
5.1 \mathrm{E}-09 \\
3.4 \mathrm{E}-10 \\
1.1 \mathrm{E}-10\end{array}$ & $\begin{array}{l}7.3 \mathrm{E}-08 \\
1.3 \mathrm{E}-06 \\
3.5 \mathrm{E}-07 \\
2.1 \mathrm{E}-07 \\
2.8 \mathrm{E}-11 \\
1.2 \mathrm{E}-07 \\
4.7 \mathrm{E}-07 \\
3.0 \mathrm{E}-06 \\
1.8 \mathrm{E}-06 \\
3.7 \mathrm{E}-08 \\
1.9 \mathrm{E}-06 \\
5.2 \mathrm{E}-07 \\
2.3 \mathrm{E}-09 \\
5.9 \mathrm{E}-08 \\
1.0 \mathrm{E}-06 \\
2.0 \mathrm{E}-06 \\
7.5 \mathrm{E}-10 \\
4.0 \mathrm{E}-08 \\
2.6 \mathrm{E}-08 \\
1.3 \mathrm{E}-07 \\
3.3 \mathrm{E}-11 \\
5.2 \mathrm{E}-07 \\
2.3 \mathrm{E}-07 \\
2.7 \mathrm{E}-06 \\
3.8 \mathrm{E}-07 \\
5.5 \mathrm{E}-10 \\
1.5 \mathrm{E}-06 \\
1.5 \mathrm{E}-06 \\
2.7 \mathrm{E}-09 \\
1.3 \mathrm{E}-09 \\
8.0 \mathrm{E}-12 \\
2.0 \mathrm{E}-10 \\
2.0 \mathrm{E}+00 \\
2.0 \mathrm{E}+00 \\
2.0 \mathrm{E}+00 \\
1.4 \mathrm{E}-07 \\
2.0 \mathrm{E}+00 \\
2.0 \mathrm{E}+00 \\
1.2 \mathrm{E}-07 \\
1.4 \mathrm{E}-07 \\
8.5 \mathrm{E}-06 \\
4.7 \mathrm{E}-10 \\
2.0 \mathrm{E}+00 \\
2.0 \mathrm{E}+00 \\
3.4 \mathrm{E}-08 \\
5.8 \mathrm{E}-05 \\
4.8 \mathrm{E}-05 \\
1.6 \mathrm{E}-10 \\
5.1 \mathrm{E}-11\end{array}$ & $\begin{array}{l}9.1 \mathrm{E}-08 \\
1.7 \mathrm{E}-06 \\
5.0 \mathrm{E}-07 \\
4.9 \mathrm{E}-07 \\
8.8 \mathrm{E}-09 \\
1.8 \mathrm{E}-06 \\
7.0 \mathrm{E}-07 \\
4.8 \mathrm{E}-06 \\
3.1 \mathrm{E}-06 \\
8.9 \mathrm{E}-07 \\
2.7 \mathrm{E}-06 \\
1.6 \mathrm{E}-06 \\
9.2 \mathrm{E}-07 \\
1.5 \mathrm{E}-07 \\
1.6 \mathrm{E}-06 \\
3.1 \mathrm{E}-06 \\
2.5 \mathrm{E}-07 \\
1.2 \mathrm{E}-06 \\
1.2 \mathrm{E}-06 \\
3.1 \mathrm{E}-07 \\
1.2 \mathrm{E}-08 \\
1.2 \mathrm{E}-06 \\
5.0 \mathrm{E}-07 \\
3.3 \mathrm{E}-05 \\
6.3 \mathrm{E}-07 \\
1.9 \mathrm{E}-09 \\
2.9 \mathrm{E}-06 \\
2.9 \mathrm{E}-06 \\
3.4 \mathrm{E}-07 \\
3.3 \mathrm{E}-07 \\
9.5 \mathrm{E}-12 \\
4.8 \mathrm{E}-10 \\
3.0 \mathrm{E}+00 \\
3.0 \mathrm{E}+00 \\
3.0 \mathrm{E}+00 \\
1.9 \mathrm{E}-07 \\
3.0 \mathrm{E}+00 \\
3.0 \mathrm{E}+00 \\
1.6 \mathrm{E}-07 \\
2.1 \mathrm{E}-07 \\
3.0 \mathrm{E}-05 \\
1.3 \mathrm{E}-09 \\
3.0 \mathrm{E}+00 \\
3.0 \mathrm{E}+00 \\
8.1 \mathrm{E}-07 \\
1.6 \mathrm{E}-04 \\
1.8 \mathrm{E}-02 \\
2.1 \mathrm{E}-09 \\
1.6 \mathrm{E}-09\end{array}$ \\
\hline
\end{tabular}

Figure D-5. GRDFLIB Data File (continued) 


$\begin{array}{lllllll}\text { NP238 } & 3.2 \mathrm{E}-09 & 2.8 \mathrm{E}-09 & 1.1 \mathrm{E}-06 & 7.7 \mathrm{E}-07 & 3.5 \mathrm{E}-07 & 5.7 \mathrm{E}-07 \\ \text { PU238 } & 1.8 \mathrm{E}-11 & 1.3 \mathrm{E}-12 & 4.0 \mathrm{E}-09 & 1.5 \mathrm{E}-10 & 6.8 \mathrm{E}-11 & 1.7 \mathrm{E}-09 \\ \text { CM244 } & 1.8 \mathrm{E}-11 & 2.9 \mathrm{E}-12 & 3.9 \mathrm{E}-09 & 2.6 \mathrm{E}-10 & 1.2 \mathrm{E}-10 & 1.7 \mathrm{E}-09 \\ \text { PU244 } & 9.6 \mathrm{E}-10 & 8.9 \mathrm{E}-10 & 1.5 \mathrm{E}-07 & 1.3 \mathrm{E}-07 & 2.0 \mathrm{E}+00 & 3.0 \mathrm{E}+00 \\ \text { PU240 } & 1.8 \mathrm{E}-11 & 1.3 \mathrm{E}-12 & 4.0 \mathrm{E}-09 & 1.4 \mathrm{E}-10 & 6.5 \mathrm{E}-11 & 1.7 \mathrm{E}-09 \\ \text { CM243 } & 1.4 \mathrm{E}-09 & 1.2 \mathrm{E}-09 & 2.9 \mathrm{E}-07 & 2.5 \mathrm{E}-07 & 1.2 \mathrm{E}-07 & 1.3 \mathrm{E}-07 \\ \text { AM243 } & 1.5 \mathrm{E}-09 & 1.3 \mathrm{E}-09 & 4.6 \mathrm{E}-07 & 3.1 \mathrm{E}-07 & 1.4 \mathrm{E}-07 & 2.5 \mathrm{E}-07 \\ \text { NP239 } & 1.1 \mathrm{E}-09 & 9.5 \mathrm{E}-10 & 3.7 \mathrm{E}-07 & 2.4 \mathrm{E}-07 & 1.1 \mathrm{E}-07 & 2.1 \mathrm{E}-07 \\ \text { PU239 } & 7.7 \mathrm{E}-12 & 7.9 \mathrm{E}-13 & 1.7 \mathrm{E}-09 & 1.2 \mathrm{E}-10 & 5.6 \mathrm{E}-11 & 7.6 \mathrm{E}-10 \\ \text { CM245 } & 1.2 \mathrm{E}-09 & 9.5 \mathrm{E}-10 & 1.3 \mathrm{E}-07 & 9.6 \mathrm{E}-08 & 3.6 \mathrm{E}-05 & 4.3 \mathrm{E}-02 \\ \text { AM241 } & 2.6 \mathrm{E}-10 & 1.8 \mathrm{E}-10 & 6.1 \mathrm{E}-08 & 3.9 \mathrm{E}-08 & 1.8 \mathrm{E}-08 & 2.7 \mathrm{E}-08\end{array}$

Figure D-5. GRDFLIB Data File (continued) D. 156 


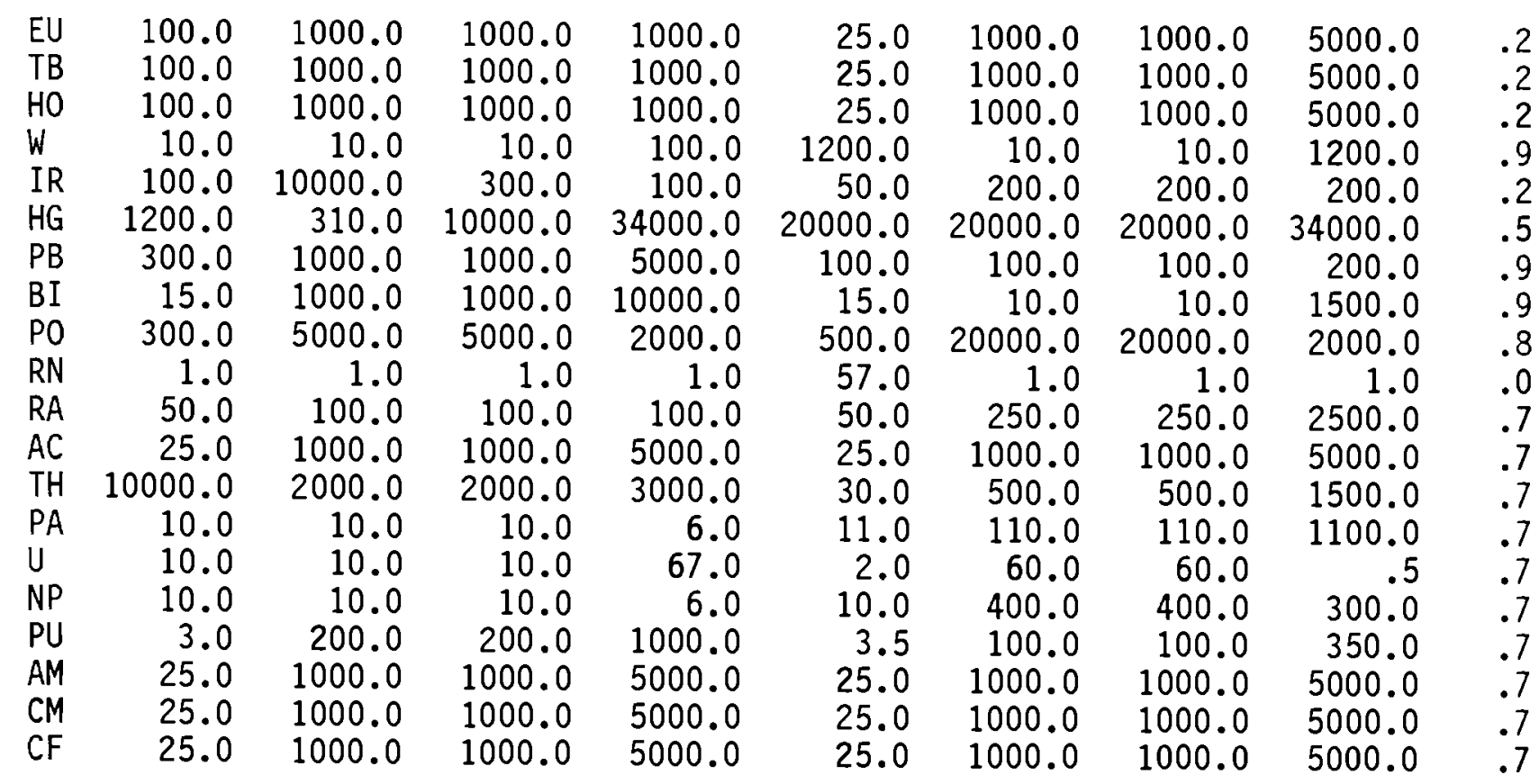

Figure D-6. DSFCT Data File D. 157 
$\begin{array}{lllllll}5 & 1 & 6 & 8 & 16 & 23\end{array}$

INTERNAL DOSE CONVERSION FACTOR LIBRARY FOR DITTY1 REV. 1-20-81 (BAN/DLS/RAP)

TOTAL BODYBONE LUNG THYROID GI-LLI

$\begin{array}{llllll}\mathrm{H}^{3} & 4 & & & & \\ 1 & & 1.7 \mathrm{E}-02 & 1.7 \mathrm{E}-02 & 6.1 \mathrm{E}-01 & 6.1 \mathrm{E}+01 \\ 8 & & 1.7 \mathrm{E}-02 & 1.7 \mathrm{E}-02 & 6.1 \mathrm{E}+01 & 6.1 \mathrm{E}+01 \\ 16 & & 1.7 \mathrm{E}-02 & 1.7 \mathrm{E}-02 & 6.1 \mathrm{E}+01 & 6.1 \mathrm{E}+01 \\ 23 & & 0.0 & 0.0 & 6.1 \mathrm{E}+01 & 6.1 \mathrm{E}+01 \\ \mathrm{C} 14 & 5 & & & & \\ 1 & & 7.9 \mathrm{E}-02 & 7.9 \mathrm{E}-02 & 5.7 \mathrm{E}+02 & 5.7 \mathrm{E}+02 \\ 6 & & 3.9 \mathrm{E}-01 & 3.9 \mathrm{E}-01 & 2.8 \mathrm{E}+03 & 2.8 \mathrm{E}+03 \\ 8 & & 7.9 \mathrm{E}-02 & 7.9 \mathrm{E}-02 & 5.7 \mathrm{E}+02 & 5.7 \mathrm{E}+02 \\ 16 & & 7.9 \mathrm{E}-02 & 7.9 \mathrm{E}-02 & 5.7 \mathrm{E}+02 & 5.7 \mathrm{E}+02 \\ 23 & & 6.5 \mathrm{E}-02 & 6.5 \mathrm{E}-02 & 5.7 \mathrm{E}+02 & 5.7 \mathrm{E}+02 \\ \mathrm{C} 060 & 3 & & & & \\ 1 & & 1.8 & 6.8 \mathrm{E}-01 & 4.7 \mathrm{E}+03 & 4.7 \mathrm{E}+03 \\ 8 & & 6.0 \mathrm{E}+02 & 6.7 \mathrm{E}+02 & 0.0 & 0.0 \\ 23 & & 1.5 & 5.5 & 0.0 & 0.0 \\ \mathrm{NI} 59 & 4 & & & & \\ 1 & & 6.2 \mathrm{E}-01 & 6.0 \mathrm{E}-01 & 1.6 \mathrm{E}+03 & 1.6 \mathrm{E}+03 \\ 6 & & 3.7 & 3.6 & 9.8 \mathrm{E}+03 & 9.3 \mathrm{E}+03 \\ 8 & & 9.2 & 8.9 & 0.0 & 0.0 \\ 23 & & 2.6 \mathrm{E}-02 & 2.6 \mathrm{E}-02 & 0.0 & 0.0\end{array}$

$\begin{array}{llllll}\text { NI63 } & 4 & & & & \\ 1 & & 1.7 & 1.6 & 4.4 \mathrm{E}+03 & 4.2 \mathrm{E}+03 \\ 6 & & 5.0 \mathrm{E}+01 & 4.7 \mathrm{E}+01 & 1.3 \mathrm{E}+05 & 1.2 \mathrm{E}+05 \\ 8 & & 2.5 \mathrm{E}+01 & 2.4 \mathrm{E}+01 & 0.0 & 0.0 \\ 23 & & 7.1 \mathrm{E}-02 & 7.1 \mathrm{E}-02 & 0.0 & 0.0\end{array}$

$\begin{array}{clllll}\text { SE79 } & 3 & & & & \\ 1 & & 6.6 \mathrm{E}-02 & 6.6 \mathrm{E}-02 & 4.4 \mathrm{E}+02 & 4.4 \mathrm{E}+02 \\ 8 & & 5.1 & 5.1 & 0.0 & 0.0 \\ 23 & & 2.0 \mathrm{E}-02 & 2.0 \mathrm{E}-02 & 0.0 & 0.0\end{array}$

PD107 3

$\begin{array}{llllll}1 & & 5.2 \mathrm{E}-03 & 5.2 \mathrm{E}-03 & 9.4 & 9.4 \\ 8 & & 1.1 \mathrm{E}+01 & 1.0 \mathrm{E}+01 & 0.0 & 0.0 \\ 23 & & 3.4 \mathrm{E}-02 & 3.4 \mathrm{E}-02 & 0.0 & 0.0 \\ \text { RA224+D } & 4 & & & & \\ 1 & & 4.4 \mathrm{E}+01 & 4.4 \mathrm{E}+01 & 3.2 \mathrm{E}+05 & 3.2 \mathrm{E}+05 \\ 6 & & 2.2 \mathrm{E}+02 & 2.2 \mathrm{E}+02 & 1.7 \mathrm{E}+06 & 1.7 \mathrm{E}+06 \\ 8 & & 4.9 \mathrm{E}+03 & 4.9 \mathrm{E}+03 & 0.0 & 0.0 \\ 23 & & 3.0 \mathrm{E}+01 & 3.0 \mathrm{E}+01 & 0.0 & 0.0 \\ \mathrm{U} 234 & 4 & & & & \\ 1 & & 1.4 \mathrm{E}+02 & 1.4 \mathrm{E}+02 & 5.2 \mathrm{E}+04 & 5.1 \mathrm{E}+04 \\ 6 & & 2.3 \mathrm{E}+03 & 2.3 \mathrm{E}+03 & 8.4 \mathrm{E}+05 & 8.2 \mathrm{E}+05 \\ 8 & & 1.0 \mathrm{E}+05 & 1.0 \mathrm{E}+05 & 0.0 & 0.0 \\ 23 & & 7.6 & 7.6 & 6.8 \mathrm{E}+04 & 6.8 \mathrm{E}+04 \\ \mathrm{U} 236 & 4 & & & & \\ 1 & & 1.4 \mathrm{E}+02 & 1.4 \mathrm{E}+02 & 5.0 \mathrm{E}+04 & 4.9 \mathrm{E}+04\end{array}$

Figure D-6. DSFCT Data File (continued) 


\begin{tabular}{|c|c|c|c|c|c|}
\hline $\begin{array}{l}6 \\
8 \\
23 \\
U 238+0\end{array}$ & 4 & $\begin{array}{l}2.2 E+03 \\
9.8 E+04 \\
7.1\end{array}$ & $\begin{array}{l}2.2 \mathrm{E}+03 \\
9.6 \mathrm{E}+04 \\
7.1\end{array}$ & $\begin{array}{l}8.0 \mathrm{E}+05 \\
0.0 \\
0.0\end{array}$ & $\begin{array}{l}7.9 E+05 \\
0.0 \\
0.0\end{array}$ \\
\hline $\begin{array}{c}1 \\
6 \\
8 \\
23 \\
\text { SR9O }\end{array}$ & 4 & $\begin{array}{l}1.3 \mathrm{E}+02 \\
2.1 \mathrm{E}+03 \\
9.0 \mathrm{E}+04 \\
6.8\end{array}$ & $\begin{array}{l}1.3 \mathrm{E}+02 \\
2.1 \mathrm{E}+03 \\
8.8 \mathrm{E}+04 \\
6.8\end{array}$ & $\begin{array}{l}4.5 \mathrm{E}+04 \\
7.7 \mathrm{E}+05 \\
0.0 \\
6.1 \mathrm{E}+04\end{array}$ & $\begin{array}{l}4.5 E+04 \\
7.5 E+05 \\
0.0 \\
6.1 E+04\end{array}$ \\
\hline $\begin{array}{c}1 \\
6 \\
8 \\
23 \\
Y \quad 90\end{array}$ & 4 & $\begin{array}{l}4.0 E+02 \\
5.9 E+03 \\
1.5 E+03 \\
2.6\end{array}$ & $\begin{array}{l}3.3 \mathrm{E}+02 \\
5.0 \mathrm{E}+03 \\
1.4 \mathrm{E}+03 \\
2.6\end{array}$ & $\begin{array}{l}1.0 \mathrm{E}+06 \\
3.9 \mathrm{E}+06 \\
0.0 \\
7.8 \mathrm{E}+04\end{array}$ & $\begin{array}{l}8.7 E+05 \\
3.3 E+06 \\
0.0 \\
7.7 E+04\end{array}$ \\
\hline $\begin{array}{c}1 \\
6 \\
8 \\
23 \\
\text { ZR93 }\end{array}$ & 4 & $\begin{array}{l}2.4 \mathrm{E}-01 \\
9.1 \\
6.7 \\
3.8\end{array}$ & $\begin{array}{l}2.4 \mathrm{E}-01 \\
9.1 \\
6.7 \\
3.8\end{array}$ & $\begin{array}{l}2.6 \mathrm{E}-01 \\
9.6 \\
0.0 \\
1.1 \mathrm{E}+05\end{array}$ & $\begin{array}{l}2.6 \mathrm{E}-01 \\
9.6 \\
0.0 \\
1.1 \mathrm{E}+05\end{array}$ \\
\hline $\begin{array}{c}1 \\
6 \\
8 \\
23 \\
\text { NB93M }\end{array}$ & 4 & $\begin{array}{l}1.1 \\
4.4 \mathrm{E}+01 \\
2.9 \mathrm{E}+01 \\
9.2 \mathrm{E}-02\end{array}$ & $\begin{array}{l}1.1 \\
4.1 \mathrm{E}+01 \\
2.8 \mathrm{E}+01 \\
9.2 \mathrm{E}-02\end{array}$ & $\begin{array}{l}1.1 \\
4.2 \mathrm{E}+01 \\
0.0 \\
0.0\end{array}$ & $\begin{array}{l}1.1 \\
4.0 \mathrm{E}+01 \\
0.0 \\
0.0\end{array}$ \\
\hline $\begin{array}{c}1 \\
6 \\
8 \\
23 \\
\text { ZR95 }\end{array}$ & 4 & $\begin{array}{l}2.2 \\
2.7 \mathrm{E}+01 \\
4.1 \mathrm{E}+01 \\
1.4 \mathrm{E}-01\end{array}$ & $\begin{array}{l}2.1 \\
2.6 \mathrm{E}+01 \\
4.0 \mathrm{E}+01 \\
1.4 \mathrm{E}-01\end{array}$ & $\begin{array}{l}2.1 \\
2.6 \mathrm{E}+01 \\
0.0 \\
0.0\end{array}$ & $\begin{array}{l}2.0 \\
2.5 \mathrm{E}+01 \\
0.0 \\
0.0\end{array}$ \\
\hline $\begin{array}{c}1 \\
6 \\
8 \\
23 \\
\text { NB95 }\end{array}$ &. & $\begin{array}{l}6.7 \\
3.1 \mathrm{E}+01 \\
7.7 \mathrm{E}+01 \\
1.1\end{array}$ & $\begin{array}{l}6.7 \\
3.1 \mathrm{E}+01 \\
7.6 \mathrm{E}+01 \\
1.1\end{array}$ & $\begin{array}{l}6.5 \\
3.0 \mathrm{E}+01 \\
0.0 \\
0.0\end{array}$ & $\begin{array}{l}6.4 \\
3.0 \mathrm{E}+01 \\
0.0 \\
0.0\end{array}$ \\
\hline $\begin{array}{c}1 \\
6 \\
8 \\
23 \\
\text { TC } 99\end{array}$ & 4 & $\begin{array}{l}1.9 \\
6.4 \\
2.1 \mathrm{E}+01 \\
7.9 \mathrm{E}-01\end{array}$ & $\begin{array}{l}1.9 \\
6.4 \\
2.1 \mathrm{E}+01 \\
7.9 \mathrm{E}-01\end{array}$ & $\begin{array}{l}1.9 \\
6.2 \\
0.0 \\
0.0\end{array}$ & $\begin{array}{l}1.9 \\
6.2 \\
0.0 \\
0.0\end{array}$ \\
\hline $\begin{array}{c}1 \\
6 \\
8 \\
23 \\
\text { RU106 }\end{array}$ & & $\begin{array}{l}1.2 \mathrm{E}-02 \\
3.0 \mathrm{E}-02 \\
1.1 \mathrm{E}+02 \\
2.3 \mathrm{E}-01\end{array}$ & $\begin{array}{l}1.2 \mathrm{E}-02 \\
3.0 \mathrm{E}-02 \\
1.1 \mathrm{E}+02 \\
2.3 \mathrm{E}-01\end{array}$ & $\begin{array}{l}5.0 \mathrm{E}+01 \\
1.3 \mathrm{E}+02 \\
1.6 \mathrm{E}+01 \\
6.8 \mathrm{E}+03\end{array}$ & $\begin{array}{l}5.0 \mathrm{E}+01 \\
1.3 \mathrm{E}+02 \\
1.6 \mathrm{E}+01 \\
6.8 \mathrm{E}+03\end{array}$ \\
\hline $\begin{array}{c}1 \\
6 \\
8 \\
23 \\
5 N 126\end{array}$ & & $\begin{array}{l}1.2 \\
9.6 \\
7.1 \mathrm{E}+02 \\
6.7\end{array}$ & $\begin{array}{l}1.2 \\
9.6 \\
7.0 \mathrm{E}+02 \\
6.7\end{array}$ & $\begin{array}{l}3.5 \mathrm{E}+02 \\
2.6 \mathrm{E}+03 \\
0.0 \\
2.0 \mathrm{E}+05\end{array}$ & $\begin{array}{l}3.5 \mathrm{E}+02 \\
2.8 \mathrm{E}+03 \\
0.0 \\
2.0 \mathrm{E}+05\end{array}$ \\
\hline
\end{tabular}

Figure D-6. DSFCT Data File (continued) D. 159 


\begin{tabular}{|c|c|c|c|c|c|}
\hline $\begin{array}{l}1 \\
6 \\
8 \\
16 \\
23 \\
\text { SB126 }\end{array}$ & 5 & $\begin{array}{l}5.1 \\
1.3 \mathrm{E}+02 \\
1.3 \mathrm{E}+03 \\
1.0 \\
9.2 \mathrm{E}-01\end{array}$ & $\begin{array}{l}5.1 \\
1.3 \mathrm{E}+02 \\
1.3 \mathrm{E}+03 \\
1.0 \\
9.2 \mathrm{E}-01\end{array}$ & $\begin{array}{l}2.4 \mathrm{E}+03 \\
8.5 \mathrm{E}+04 \\
0.0 \\
5.0 \mathrm{E}+02 \\
0.0\end{array}$ & $\begin{array}{l}2.4 E+03 \\
8.4 E+04 \\
0.0 \\
5.0 E+02 \\
0.0\end{array}$ \\
\hline $\begin{array}{l}1 \\
6 \\
8 \\
16 \\
23 \\
\text { I } 129\end{array}$ & 5 & $\begin{array}{l}3.9 \mathrm{E}-02 \\
9.2 \mathrm{E}-02 \\
1.3 \\
1.9 \mathrm{E}-03 \\
1.3\end{array}$ & $\begin{array}{l}3.9 \mathrm{E}-02 \\
9.2 \mathrm{E}-02 \\
1.3 \\
1.9 \mathrm{E}-03 \\
1.3\end{array}$ & $\begin{array}{l}1.7 \mathrm{E}+01 \\
4.0 \mathrm{E}+01 \\
0.0 \\
8.0 \mathrm{E}-01 \\
0.0\end{array}$ & $\begin{array}{l}1.7 \mathrm{E}+01 \\
4.0 \mathrm{E}+01 \\
0.0 \\
8.0 \mathrm{E}-01 \\
0.0\end{array}$ \\
\hline $\begin{array}{l}1 \\
6 \\
8 \\
16 \\
23 \\
\text { CS135 }\end{array}$ & 4 & $\begin{array}{l}1.3 \\
4.5 \mathrm{E}-01 \\
9.9 \\
1.0 \mathrm{E}+03 \\
1.7 \mathrm{E}-02\end{array}$ & $\begin{array}{l}1.3 \\
4.5 \mathrm{E}-01 \\
9.9 \\
9.9 \mathrm{E}+02 \\
1.7 \mathrm{E}-02\end{array}$ & $\begin{array}{l}9.2 \mathrm{E}+03 \\
3.3 \mathrm{E}+03 \\
0.0 \\
7.2 \mathrm{E}+06 \\
5.0 \mathrm{E}+02\end{array}$ & $\begin{array}{l}9.1 \mathrm{E}+03 \\
3.3 \mathrm{E}+03 \\
0.0 \\
7.2 \mathrm{E}+06 \\
5.0 \mathrm{E}+02\end{array}$ \\
\hline $\begin{array}{c}1 \\
6 \\
8 \\
23 \\
\text { CS } 137\end{array}$ & 4 & $\begin{array}{l}1.1 \\
2.7 \\
4.1 \mathrm{E}-01 \\
1.6 \mathrm{E}-02\end{array}$ & $\begin{array}{l}1.1 \\
2.7 \\
4.1 \mathrm{E}-01 \\
1.6 \mathrm{E}-02\end{array}$ & $\begin{array}{l}8.0 \mathrm{E}+03 \\
2.0 \mathrm{E}+04 \\
2.1 \mathrm{E}+03 \\
0.0\end{array}$ & $\begin{array}{l}8.0 E+03 \\
2.0 E+04 \\
2.0 E+03 \\
0.0\end{array}$ \\
\hline $\begin{array}{c}1 \\
6 \\
8 \\
23 \\
\text { SM151 }\end{array}$ & 4 & $\begin{array}{l}9.9 \\
1.1 \mathrm{E}+01 \\
2.6 \\
8.0 \mathrm{E}-02\end{array}$ & $\begin{array}{l}9.8 \\
1.1 \mathrm{E}+01 \\
2.5 \\
8.0 \mathrm{E}-02\end{array}$ & $\begin{array}{l}7.1 E+04 \\
8.0 E+04 \\
1.3 E+04 \\
2.3 E+03\end{array}$ & $\begin{array}{l}7.1 E+04 \\
8.0 E+04 \\
1.3 E+04 \\
2.3 E+03\end{array}$ \\
\hline $\begin{array}{c}1 \\
6 \\
8 \\
23 \\
\text { TH } 230\end{array}$ & 4 & $\begin{array}{l}7.6 \mathrm{E}-01 \\
1.8 \mathrm{E}+01 \\
4.9 \mathrm{E}+01 \\
6.5 \mathrm{E}-01\end{array}$ & $\begin{array}{l}\text { 7.3E-01 } \\
1.7 \mathrm{E}+01 \\
4.8 \mathrm{E}+01 \\
6.5 \mathrm{E}-01\end{array}$ & $\begin{array}{l}2.9 \\
6.9 \mathrm{E}+01 \\
0.0 \\
0.0\end{array}$ & $\begin{array}{l}2.8 \\
6.3 \mathrm{E}+01 \\
0.0 \\
0.0\end{array}$ \\
\hline $\begin{array}{c}1 \\
6 \\
8 \\
23 \\
\text { RA226 }\end{array}$ & 4 & $\begin{array}{l}2.0 \mathrm{E}+04 \\
6.6 \mathrm{E}+05 \\
1.0 \mathrm{E}+05 \\
7.5\end{array}$ & $\begin{array}{l}1.1 \mathrm{E}+04 \\
3.6 \mathrm{E}+05 \\
9.8 \mathrm{E}+04 \\
7.5\end{array}$ & $\begin{array}{l}7.7 \mathrm{E}+04 \\
2.5 \mathrm{E}+06 \\
0.0 \\
0.0\end{array}$ & $\begin{array}{l}4.1 E+04 \\
1.4 E+06 \\
0.0 \\
0.0\end{array}$ \\
\hline $\begin{array}{c}1 \\
6 \\
8 \\
23 \\
\text { PB210 }\end{array}$ & 4 & $\begin{array}{l}5.0 \mathrm{E}+04 \\
7.4 \mathrm{E}+04 \\
2.3 \mathrm{E}+05 \\
4.1 \mathrm{E}+01\end{array}$ & $\begin{array}{l}3.3 E+04 \\
4.4 E+04 \\
2.2 E+05 \\
4.1 E+01\end{array}$ & $\begin{array}{l}2.5 \mathrm{E}+08 \\
3.7 \mathrm{E}+09 \\
0.0 \\
0.0\end{array}$ & $\begin{array}{l}1.7 \mathrm{E}+08 \\
2.2 \mathrm{E}+08 \\
0.0 \\
0.0\end{array}$ \\
\hline $\begin{array}{c}1 \\
6 \\
8 \\
23 \\
\text { BI210 }\end{array}$ & 4 & $\begin{array}{l}2.4 \mathrm{E}+02 \\
7.6 \mathrm{E}+03 \\
8.5 \mathrm{E}+04 \\
6.7\end{array}$ & $\begin{array}{l}2.2 E+02 \\
6.6 E+03 \\
8.3 E+04 \\
6.7\end{array}$ & $\begin{array}{l}5.4 \mathrm{E}+05 \\
1.5 \mathrm{E}+07 \\
0.0 \\
0.0\end{array}$ & $\begin{array}{l}5.1 \mathrm{E}+05 \\
1.3 \mathrm{E}+07 \\
0.0 \\
0.0\end{array}$ \\
\hline 1 & & $4.6 \mathrm{E}-01$ & $4.6 \mathrm{E}-01$ & $2.6 E+02$ & $2.6 \mathrm{E}+02$ \\
\hline
\end{tabular}

Figure D-6. DSFCT Data File (continued) 


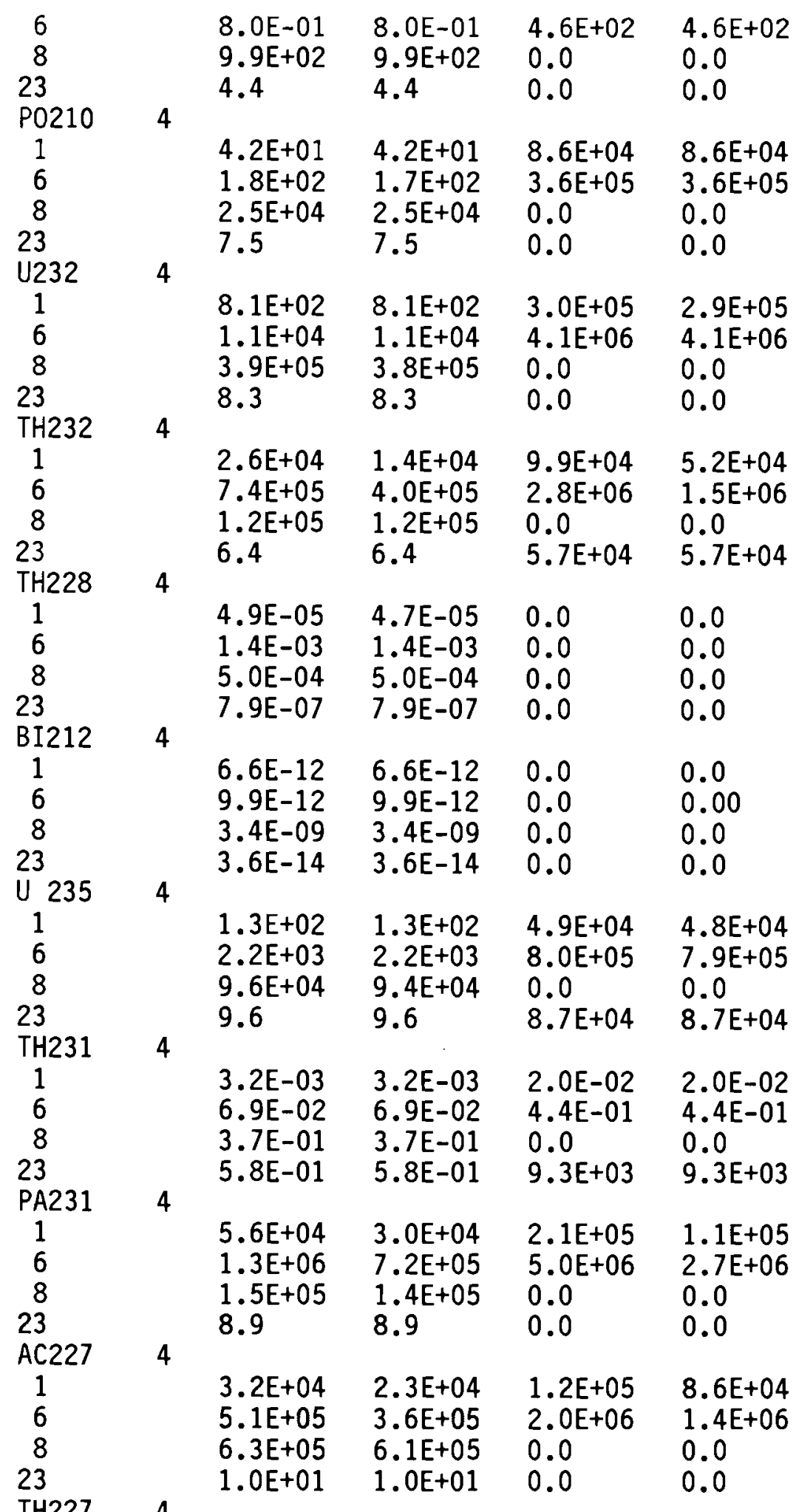

Figure D-6. DSFCT Data File (continued) 


\begin{tabular}{|c|c|c|c|c|c|}
\hline $\begin{array}{c}1 \\
6 \\
8 \\
23 \\
\text { NP237 }\end{array}$ & 4 & $\begin{array}{l}3.1 \mathrm{E}-05 \\
1.1 \mathrm{E}-03 \\
5.1 \mathrm{E}-03 \\
2.4 \mathrm{E}-05\end{array}$ & $\begin{array}{l}3.1 \mathrm{E}-05 \\
1.1 \mathrm{E}-03 \\
5.1 \mathrm{E}-03 \\
2.4 \mathrm{E}-05\end{array}$ & $\begin{array}{l}0.0 \\
0.0 \\
0.0 \\
0.0\end{array}$ & $\begin{array}{l}0.0 \\
0.0 \\
0.0 \\
0.0\end{array}$ \\
\hline $\begin{array}{c}1 \\
6 \\
8 \\
23 \\
\text { PA233 }\end{array}$ & 4 & $\begin{array}{l}1.9 \mathrm{E}+04 \\
4.4 \mathrm{E}+05 \\
1.0 \mathrm{E}+05 \\
9.9\end{array}$ & $\begin{array}{l}1.0 \mathrm{E}+04 \\
2.4 \mathrm{E}+05 \\
1.0 \mathrm{E}+05 \\
9.9\end{array}$ & $\begin{array}{l}7.3 \mathrm{E}+04 \\
1.7 \mathrm{E}+06 \\
0.0 \\
0.0\end{array}$ & $\begin{array}{l}4.0 \mathrm{E}+04 \\
9.0 \mathrm{E}+05 \\
0.0 \\
0.0\end{array}$ \\
\hline $\begin{array}{c}1 \\
6 \\
8 \\
23 \\
\text { U } 233\end{array}$ & 4 & $\begin{array}{l}5.3 \mathrm{E}-08 \\
3.1 \mathrm{E}-07 \\
2.4 \mathrm{E}-06 \\
5.4 \mathrm{E}-07\end{array}$ & $\begin{array}{l}5.3 \mathrm{E}-08 \\
3.0 \mathrm{E}-07 \\
2.4 \mathrm{E}-06 \\
5.4 \mathrm{E}-07\end{array}$ & $\begin{array}{l}0.0 \\
0.0 \\
0.0 \\
0.0\end{array}$ & $\begin{array}{l}0.0 \\
0.0 \\
0.0 \\
0.0\end{array}$ \\
\hline $\begin{array}{c}1 \\
6 \\
8 \\
23 \\
\text { TH2229 }\end{array}$ & 4 & $\begin{array}{l}1.5 \mathrm{E}+02 \\
2.4 \mathrm{E}+03 \\
1.0 \mathrm{E}+05 \\
7.7\end{array}$ & $\begin{array}{l}1.5 \mathrm{E}+02 \\
2.4 \mathrm{E}+03 \\
1.0 \mathrm{E}+05 \\
7.7\end{array}$ & $\begin{array}{l}5.3 E+04 \\
8.7 E+05 \\
0.0 \\
0.0\end{array}$ & $\begin{array}{l}5.3 E+04 \\
8.6 E+05 \\
0.0 \\
0.0\end{array}$ \\
\hline $\begin{array}{c}1 \\
6 \\
8 \\
23 \\
\text { RA225 }\end{array}$ & 4 & $\begin{array}{l}1.4 \mathrm{E}+05 \\
2.9 \mathrm{E}+06 \\
5.7 \mathrm{E}+05 \\
6.4 \mathrm{E}+01\end{array}$ & $\begin{array}{l}7.4 \mathrm{E}+04 \\
1.5 \mathrm{E}+06 \\
5.5 \mathrm{E}+05 \\
6.4 \mathrm{E}+01\end{array}$ & $\begin{array}{l}5.3 \mathrm{E}+05 \\
1.1 \mathrm{E}+07 \\
0.0 \\
0.0\end{array}$ & $\begin{array}{l}2.8 \mathrm{E}+05 \\
5.7 \mathrm{E}+06 \\
0.0 \\
0.0\end{array}$ \\
\hline $\begin{array}{c}1 \\
6 \\
8 \\
23 \\
\text { AM242M }\end{array}$ & 4 & $\begin{array}{l}1.1 \mathrm{E}-04 \\
5.5 \mathrm{E}-04 \\
6.9 \mathrm{E}-03 \\
1.7 \mathrm{E}-05\end{array}$ & $\begin{array}{l}1.1 \mathrm{E}-04 \\
5.4 \mathrm{E}-04 \\
6.9 \mathrm{E}-03 \\
1.7 \mathrm{E}-05\end{array}$ & $\begin{array}{l}0.0 \\
0.0 \\
0.0 \\
0.0\end{array}$ & $\begin{array}{l}0.0 \\
0.0 \\
0.0 \\
0.0\end{array}$ \\
\hline $\begin{array}{c}1 \\
6 \\
8 \\
23 \\
\text { AM242 }\end{array}$ & 4 & $\begin{array}{l}1.8 \mathrm{E}+04 \\
4.6 \mathrm{E}+05 \\
8.3 \mathrm{E}+04 \\
1.2 \mathrm{E}+01\end{array}$ & $\begin{array}{l}1.1 \mathrm{E}+04 \\
2.6 \mathrm{E}+05 \\
8.1 \mathrm{E}+04 \\
1.2 \mathrm{E}+01\end{array}$ & $\begin{array}{l}6.6 \mathrm{E}+04 \\
1.7 \mathrm{E}+06 \\
0.0 \\
0.0\end{array}$ & $\begin{array}{l}4.0 E+04 \\
9.9 E+05 \\
0.0 \\
0.0\end{array}$ \\
\hline $\begin{array}{c}1 \\
6 \\
8 \\
23 \\
\text { CM242 }\end{array}$ & 4 & $\begin{array}{l}8.9 \mathrm{E}+06 \\
2.0 \mathrm{E}-04 \\
6.1 \mathrm{E}-04 \\
1.0 \mathrm{E}-05\end{array}$ & $\begin{array}{l}8.9 \mathrm{E}-06 \\
2.0 \mathrm{E}-04 \\
6.1 \mathrm{E}-04 \\
1.0 \mathrm{E}-05\end{array}$ & $\begin{array}{l}0.0 \\
0.0 \\
0.0 \\
0.0\end{array}$ & $\begin{array}{l}0.0 \\
0.0 \\
0.0 \\
0.0\end{array}$ \\
\hline $\begin{array}{c}1 \\
6 \\
8 \\
23 \\
\text { PU242 }\end{array}$ & 4 & $\begin{array}{l}3.2 \mathrm{E}+02 \\
7.3 \mathrm{E}+03 \\
3.3 \mathrm{E}+04 \\
9.4\end{array}$ & $\begin{array}{l}3.2 \mathrm{E}+02 \\
7.2 \mathrm{E}+03 \\
3.3 \mathrm{E}+04 \\
9.4\end{array}$ & $\begin{array}{l}1.4 \mathrm{E}+03 \\
3.1 \mathrm{E}+04 \\
0.0 \\
0.0\end{array}$ & $\begin{array}{l}1.4 \mathrm{E}+03 \\
3.1 \mathrm{E}+04 \\
0.0 \\
0.0\end{array}$ \\
\hline $\begin{array}{r}1 \\
6 \\
8 \\
23\end{array}$ & & $\begin{array}{l}2.2 E+04 \\
4.4 E+05 \\
1.1 E+05 \\
8.1\end{array}$ & $\begin{array}{l}1.2 \mathrm{E}+04 \\
2.4 \mathrm{E}+05 \\
1.0 \mathrm{E}+05 \\
8.1\end{array}$ & $\begin{array}{l}2.5 \mathrm{E}+04 \\
5.0 \mathrm{E}+05 \\
0.0 \\
7.3 \mathrm{E}+04\end{array}$ & $\begin{array}{l}1.3 E+04 \\
2.7 E+05 \\
0.0 \\
7.3 E+04\end{array}$ \\
\hline
\end{tabular}

Figure D-6. DSFCT Data File (continued) 


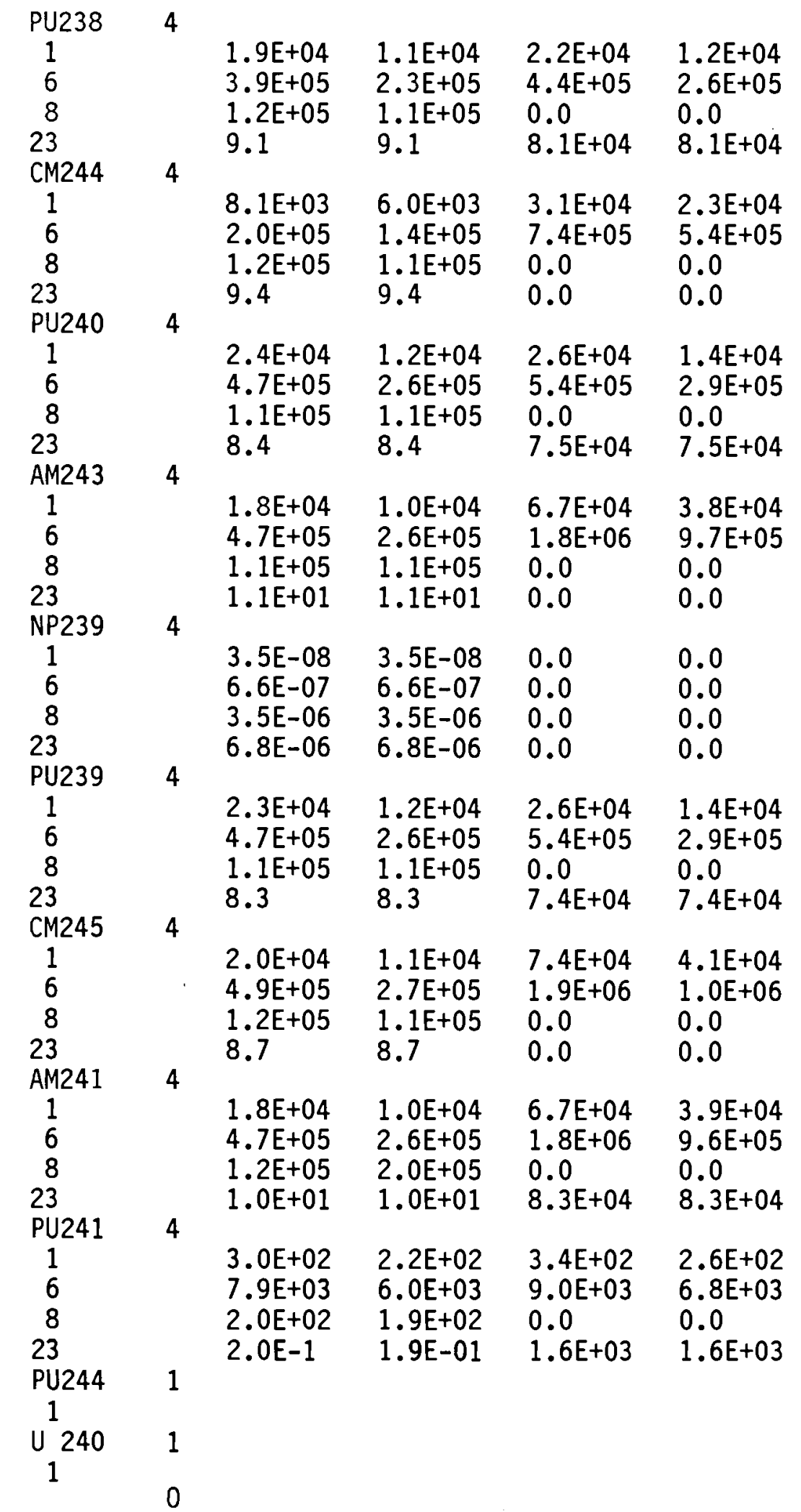

Figure D-6. DSFCT Data File (continued) D. 163 
:

.

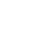


APPENDIX E

INPUT PREPARATION 
Use of the computer program DITTY requires proper assignment of several data files (described in Appendix $C$ ) and careful preparation of an input record file. This appendix describes preparation of the input record file. This file has been designed to allow efficient use of the computer program with minimum effort by the user in preparing input records. Each execution of DITTY can have an unlimited number of cases. An execution file for DITTY contains the following classes of records:

1) Host computer system commands to connect library files to the appropriate logical unit devices. (See Appendix C for details.)

2) Host computer system commands to connect user data files of population and release data to appropriate logical unit devices if this option is selected. (See Appendix C for details.)

3) Host computer system command to initiate execution of the DITTY program.

4) A master radionuclide control list defining any radionuclides to be considered in this set. Radionuclides considered in any of the cases is based on the interrelationship of several parameters:

- time of release in relation to time period considered;

- type of release (acute or chronic) and whether that type of release is considered in a particular problem of a set;

- release pathway (airborne or waterborne) and whether that pathway is considered in a particular problem of the set;

- input options of release data; whether release data is read for this case or whether release data is in effect from a previous problem.

The radionuclide control 1 ist is entered as record types 2 and 3 .

5) A list of organs of interest for this case. Doses to each of the selected organs will be calculated for all problems in this set. The list of organs is entered in the format of record types 4 and 5 . 
6) A group of records for each problem in the set consisting of the following types of records:

- title for this case (Note: the title for the first case of a set is positioned before the master radionuclide list and the organ selection.);

- a NAMELIST parameter set;

- air concentration factors (record type 6), optional;

- joint frequency data (record type 7), optional;

- population distribution data (record types 8 and 9), optional;

- activity airborne release data (record types 10, 11, and 12), optional;

- activity waterborne release data (record types 10, 11, and 12), optional.

The order of the records is determined by control integers as indicated in the input record logic diagram of Figure E.1. This diagram should be referred to when preparing input records for DITTY. Each record type is discussed below.

The first record for each run is a type 1 title card for the first case as described in Table E.1.

TABLE E.1. Record Type 1, Case Titles

$\frac{\text { Variable }}{\text { CASTTL(20) }} \quad \frac{\text { Columns }}{1-80} \quad \frac{\text { Format }}{20 A 4} \quad \begin{aligned} & \text { Description } \\ & \begin{array}{l}\text { Descriptive title for the current run to } \\ \text { be printed on output report headings }\end{array}\end{aligned}$

At the beginning of each run names of all radionuclides to be considered are read. These names are used to select needed data from library files. The number of names is read (Record type 2) followed by the names of the 


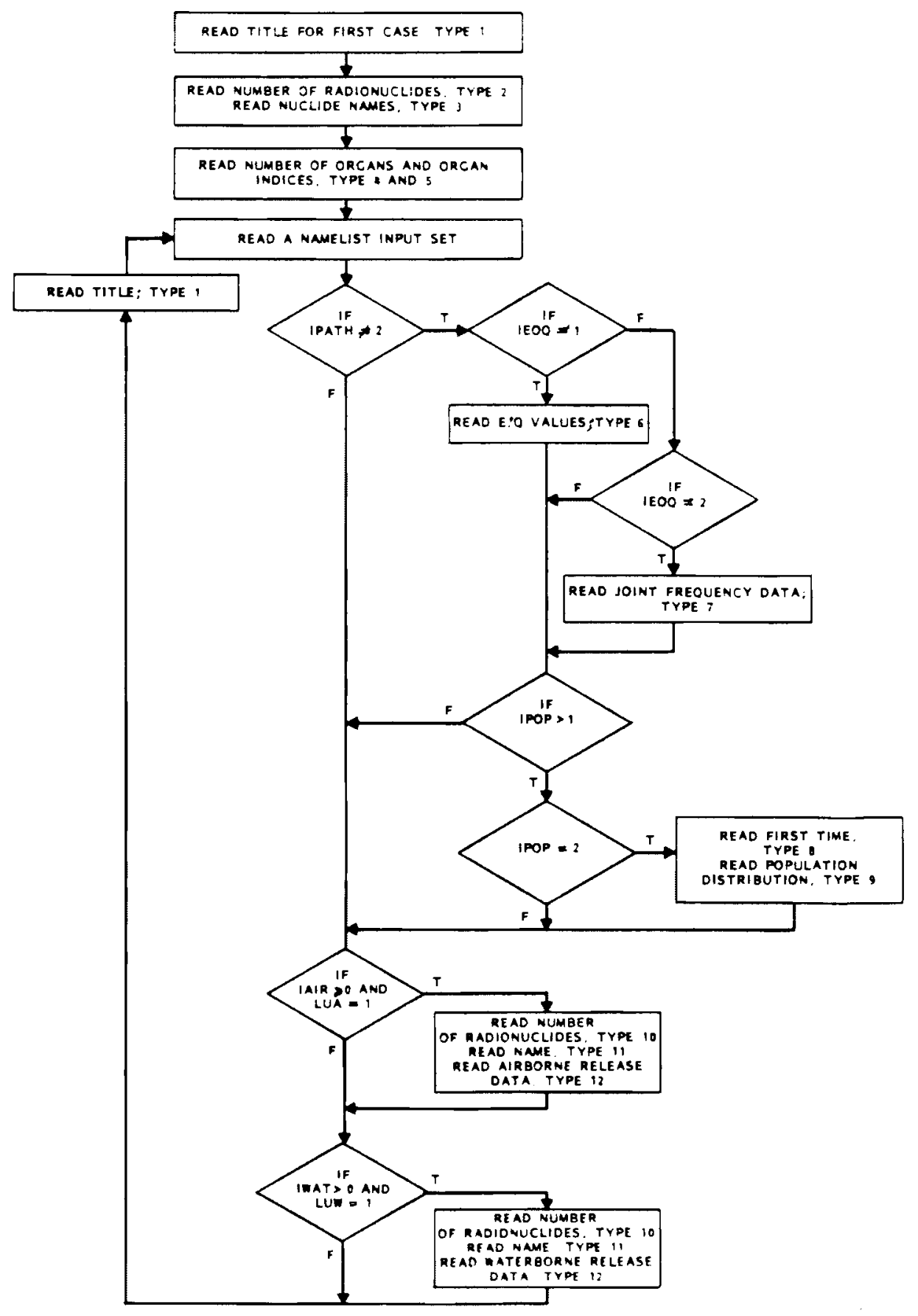

FIGURE E.1. DITTY Input Record Logic Diagram

E.3 
radionuclides (Record type 3 ). The data record formats are described in Table E.2. The maximum number of radionuclides allowed is 100 (25 for IBM-PC version). This number includes any unsolicited daughters which will automatically be added to the master list by the program. Addition of daughters is determined by decay chain information in the File 10 radionuclide data library (see Appendix C).

\section{TABLE E.2. Record Types 2 and 3, Master Radionuclide Names}

\begin{tabular}{|c|c|c|c|}
\hline Parameter & Columns & Format & Description \\
\hline $\begin{array}{l}\text { Record Type } 2 \\
\text { NIN }\end{array}$ & $1-5$ & I5 & $\begin{array}{l}\text { Number of radionuclide names to be read, } \\
1 \leq N I N \leq 100 . \quad(1 \leq N I N \leq 25 \text { for } I B M-P C)\end{array}$ \\
\hline $\begin{array}{l}\text { Record Type } 3 \\
E(i) \\
A(i)\end{array}$ & $\begin{array}{l}1-2 \\
3-8\end{array}$ & $\begin{array}{l}\text { A2 } \\
A 6\end{array}$ & $\begin{array}{l}\text { Element symbol for a radionuclide. } \\
\text { Atomic weight symbol for the radionuclide }\end{array}$ \\
\hline
\end{tabular}

The spelling of the radionuclide name symbols must correspond to the spelling given in the file 10 radionuclide data library.

After reading the radionuclide names the organs to be considered in this run are specified on record types 4 and 5 . The number of organs and organ selection indices are given as described in Table E.3. A list of available organs and index values is given in Table E.4.

TABLE E.3. Record Types 4 and 5, Selected Organs

\begin{tabular}{|c|c|c|c|}
\hline Parameter & Columns & Format & Description \\
\hline $\begin{array}{l}\text { Record Type } 4 \\
\text { NORG }\end{array}$ & $1-5$ & I5 & $\begin{array}{l}\text { Number of organs to be considered during } \\
\text { this run, } 1 \leq N O R G \leq 5 \text {. }\end{array}$ \\
\hline $\begin{array}{l}\text { Record Type } 5 \\
\text { KORG(i) }\end{array}$ & $\begin{array}{l}1-3 \\
4-6 \\
\dot{13} \\
\dot{13}-15\end{array}$ & 513 & $\begin{array}{l}\text { Organ index values for each organ to be } \\
\text { considered. Values of KORG are to be } \\
\text { selected from Table E. } 4 \text { and should cor- } \\
\text { respond to data available in the internal } \\
\text { dose conversion factor data file. }\end{array}$ \\
\hline
\end{tabular}


TABLE E.4. Suggested Organ Index List

$\begin{array}{lc}\text { Organ of Reference } & \text { Index Value } \\ \text { Total body } & 1 \\ \text { Adrenals } & 9 \\ \text { Bone } & 6 \\ \text { Brain } & 16 \\ \text { Fat } & 7 \\ \text { GI Tract } & \\ \quad \text { Stomach } & 20 \\ \text { Small intestine } & 21 \\ \text { Upper large intestine } & 22 \\ \quad \text { Lower large intestine } & 23 \\ \text { Heart } & 18 \\ \text { Kidneys } & 3 \\ \text { Liver } & 4 \\ \text { Lungs } & 8 \\ \text { Muscle } & 14 \\ \text { Ovaries } & 11 \\ \text { Pancreas } & 17 \\ \text { Prostate } & 15 \\ \text { Skin } & 12 \\ \text { Spleen } & 5 \\ \text { Testes } & 10 \\ \text { Thyroid } & 16\end{array}$

The data records described above are read at the beginning of each run. The remaining records are read for each case as determined by input parameters. Control parameters and selected model parameters are read next in a NAMELIST INPUT record set. The first record of this set must begin with \$INPUT in columns 2-7 and the last record must end with \$END in any column except column 1. Each parameter is supplied by setting it equal to the desired value. For example, to set the parameter IPATH to 2, enter IPATH $=2$ starting after column 8 on the first record. Array values are specified by 
including the array subscript. For example, to set position 2 of array LORG to 6 enter $\operatorname{LORG}(2)=6$. Each entry must be separated by a comma. The NAMELIST INPUT parameters recognized by "DITTY" are described in Table E.5 by the following categories:

- general control integers

- time references

- site grid description

- atmospheric disperson

- population description

- waterborne pathways

- terrestrial pathways (for airborne and waterborne releases)

- graphical output selection options.

Input requirements for the IBM-PC version of DITTY are essentially identical to those described for mainframe computers. The major difference is that all variables dimensioned to 100 for the mainframe version are only dimensional to 25 for the IBM-PC version. All other logic remains the same.

\section{TABLE E.5. NAMELJST INPUT Parameters}

\section{A. General Control Integers}

IAC

To consider an acute release period at the beginning of the first $70-y r$ period set IAC $>0$. Default is IAC $=0$.

IAIR

This parameter is set positive if airborne release activity data are to be read. Default is IAIR $=0$.

IPATH This parameter selects pathways to be considered as follows:

IPATH < 0; airborne and waterborne

IPATH $\equiv 1$; airborne on $7 y$

IPATH $\geq 2$; waterborne only 
TABLE E.5. (contd)

A. Genera 1 Control Integers (contd)

No defaut value is specified for IPATH.

IWAT This parameter is set positive if waterborne release activity data are to be read. Default is IWAT $=0$.

LUA This parameter selects the input logical file unit for reading of airborne release activity data as follows:

LUA $=1$; use input unit 5

LUA $\neq 1$; use data file unit 26

Default is LUA $=1$.

LUW This parameter selects the input logical file unit for reading of waterborne release activity data as follows:

LUW $=1$; use card input unit 5

LUW $\neq 1$; use Tibrary file unit 24

Default is LUW $=1$.

ISALT This parameter determines if fresh or saltwater factors are considered in bioaccumulation factors as follows:

ISALT $=0$; freshwater

ISALT $=1$; sal twater

Default is ISALT $=0$

B. Time Reference Parameters

TZ The beginning of the ten-thousand year dose period is given by this parameter in years A.D. Default is $T Z=2000$.

TZR

The beginning of the release history data is given by this parameter in years A.D. TZR is used for both airborne and waterborne release data. Default is $T Z R=2000$. For acute exposure case TZR must be equal to $T Z$.

C. Site Grid Description Parameters

DIST(10) These values represent the distance from the release point to the midpoint of each distance interval, meters. Default values are not specified for DIST. 
TABLE E.5. (contd)

C. Site Grid Description Parameters (contd)

NDIST This integer gives the number of distance intervals to be considered, $1 \leq$ NDIST $\leq 10$. Default is NDIST $=\emptyset$.

NSECT This integer gives the number of sectors to be considered in the calculation of population dispersion factors (PM) and in the atmospheric dispersion calculation. $1 \leq N S E C T \leq 16$. Default is $\mathrm{NSECT}=16$.

D. Atmospheric Dispersion Parameters

IECQ

This integer is used to control reading and calculation of atmospheric dispersion data as follows:

IEOQ $\leq 0$; use previous data

IEOQ $=1$; read normalized air concentrations from cards (Type 5)

IEOQ $=2$; read joint frequency data from cards (Type 6) and calculate normalized air concentration

IEOQ $=3$; use previous data to calculate normalized air concentration

IEOQ > 3; use previous data.

Default is $I E O Q=0$.

HS This parameter gives the effective release height for airborne release. HS is used when normalized air concentrations are to be calculated (IEOQ $=2$ or 3$)$. Default is HS $=0$.

NMET This integer gives the number of atmospheric stability categories to be considered in definition of the joint frequency data, Card Type $6.1 \leq$ NMET $\leq 7$. NMET is used when IEOQ $=2$ or 3 . Default is NMET $=\varnothing$.

NUBAR This integer gives the number of windspeed groups used in definition of the joint frequency data, Card Type $6.1 \leq$ NUBAR $\leq 8$. NUBAR is used when IEOQ $=2$ or 3 . Default is NUBAR $=\emptyset$. 


\section{TABLE E.5. (contd)}

MET(7) This integer array selects the atmospheric dispersion category for each of the NMET stability categories. Values for NMET( $i)$ are as follows:

$\operatorname{MET}(i)=1$ for Hanford moderately stable

$\operatorname{MET}(i)=2$ for Hanford very stable

$\operatorname{MET}(i)=3$ for Pasquill $A$

$\operatorname{MET}(i)=4$ for Pasquill $B$

$\operatorname{MET}(i)=5$ for Pasquill $C$

$\operatorname{MET}(i)=6$ for Pasquill D

$\operatorname{MET}(i)=7$ for Pasquill E

$\operatorname{MET}(i)=8$ for Pasquill $\mathrm{F}$

$\operatorname{MET}(i)=9$ for Pasquil1 G

Default values are $\operatorname{MET}(i)=0$.

$\operatorname{UBAR}(8) \quad$ This array gives the average windspeed for each of the NUBAR windspeed groups, $\mathrm{m} / \mathrm{sec}$. Default values are zero.

E. Population Description Parameters

Population Parameters for Chronic Airborne Releases

Population dispersion factors are required for each 70-yr time increment of the 10,000 year integration period (143 increments). Six options are provided for generation of the population dispersion factors for chronic airborne releases.

METHOD ONE

The first method allows the user to supply all values through input $(I P O P=1)$.

METHOD TWO

The second method (IPOP $=2$ ) uses an initial population distribution to generate the population dispersion factor for the first time increment. Then the increase in total population is supplied as a function of time and the program increases the population dispersion factor in proportion to the population increase. The user supplies the initial distribution in the input stream. 


\section{TABLE E.5. (contd)}

\section{METHOD THREE}

The third method (IPOP $=3$ ) uses population distributions at specified times read from data file unit 22. Population dispersion values are calculated for each specified time. These values are interpolated to determine the population dispersion values for each $70-\mathrm{yr}$ increment.

METHOD FOUR

The fourth method (IPOP $=4$ ) allows specification of population dispersion values at specified times. This data is interpolated to determine values for each $70-y$ r increment.

\section{METHOD FIVE}

The fifth method (IPOP $=5$ ) uses the previous population distribution data but uses new E/Q data to generate the first time value for PM (air) or PL (water).

The second, third, and fifth methods use atmospheric dispersion data (E/Q values) as calculated in subroutine EOVRO or supplied on input.

\section{METHOD SIX}

The sixth method (IPOP $=6$ ) indicates that there is no chronic release. Use of this method ensures that population is specified properly for a case with an acute release only. dispersion factors for airborne releases as follows:

IPOP $\leq 0$; use previous value. No additional population input required.

IPOP = 1 ; supply a11 144 values for array PM in NAMELIST INPUT.

IPOP $=2$; read population data for the first time, $T(1)$, and calculate PM. Then generate PM for other times from population (PM1) and time ( $T$ ) data by ratio with initial total population. Supply record types 8 and 9 plus NAMELIST INPUT prameters NTA, T, and PM1. 
TABLE E.5. (contd)

IPOP $=3$; read population data for each time from file 22 and calculate PM for each time. Both time, T, and population, POP, will be read from file 22. Plus $<0 Q$.

IPOP $=4$; supply population dispersion factors in array PMI at times $T$ and interpolate this data to generate PM values for each 70-yr increment. Supply values for NAMELIST INPUT parameters NTA, T, and PM1.

IPOP $=5$; use previous population distribution data but recalculate the first time value for $P M$ using new $E / Q$ data. This method is similar to method 2 except no population data is read. No additional population input required.

IPOP = 6; There will be no chronic release during this case (IPA must be used).

IPOP > 6; not allowed.

Default is $I P O P=4$.

NTA This integer gives the number of times for which airborne population history data are supplied in arrays PMI and T. $1 \leq N T A \leq 20$. Default is 1 .

$\mathrm{PM}(144) \quad$ Population dispersion factor, person-sec $/ \mathrm{m}^{3}$ for airborne releases for each $70-y r$ period. This is an effective population-weighted $E / Q$.

PM1(20) This array gives population dispersion factor data for airborne releases corresponding to times in array $T$. This data is used when IPATH $<1$ and IPA $>1$ or when IPOP $=2,4$ or 5 . When IPOP $=$ 2 , the data represents total population at each time. When IPOP $=4$, the data represents population dispersion factors. When IPOP $=5$, previous data are used (the form is not important). When IPA $>1$, the data represents population dispersion factors unless IPOP $=2$ in which case total population values are given. Default values are not specified for PM1.

POPT(20) This array gives total population for airborne releases at each time given in array T. POPT is used for IPATH $\leq 1$ and IPOP $=2$ or 5. Default is all POPT values set to zero.

$T(20) \quad T h i s$ array gives times at which population data is supplied for airborne releases. Times are in years A.D. $T$ is used when IPATH $\leq 1$ and IPOP $=2,4$, or 5 or IPA $>1$. 
TABLE E.5. (contd)

POPULATION PARAMETERS FOR ACUTE AIRBORNE RELEASES

IPA

This control integer indicates the method (see text for discussion of methods) for specification of the population dispersion factor for the acute release period for airborne releases.

IPA $\leq 0$; use previous values

IPA $\equiv 1$; use the value given for PMA

$I P A=2$; calculate the value for time $T Z$ from calculated time history data; population data for chronic airborne release must be entered if this option is selected

Default is $I P A=1$.

PMA This parameter is the population disperion factor for the acute airborne release period used when IAC $>0$ and IPA $=1$. Default value is $P M A=0$.

POPULATION PARAMETERS FOR CHRONIC WATERBORNE RELEASES

IPOPL This control integer selects the method for determining populations for waterborne release as follows:

IPOPL < 0 ; use previous PL values. No additional population input required.

IPOPL $=1$; supply a11 144 values for array PL in NAMELIST INPUT.

IPOPL $=2$; supply total population value data in arrays PLI and $\mathrm{TL}$ and generate $\mathrm{PL}$ values by interpolation. Provide values for NAMELIST INPUT parameters NTL, TL, and PL1.

IPOPL > 2; not allowed.

Default is $I P O P L=2$.

NTL This integer gives the number of times for which waterborne population history data are supplied in arrays PLI and TL. $1 \leq N T L \leq 20$. Default is 1 .

PL(144) This array gives total population for waterborne pathways for the acute period, PL(1) and each 70-yr period (143). Default is all values set to zero.

PL1(20) This array gives total population for waterborne pathways corresponding to times in array $\mathrm{TL}$. This data is used when IPL $>1$ or when IPOPL $=2$. Default is all PLI values set to zero. 
TABLE E.5. (contd)

$T L(20) \quad$ This array gives time at which population data is supplied for waterborne releases. Times are in years A.D. TL is used when IPATH $\neq 1$ and either IPL $>1$ or IPOPL $=2$. Default values for TL are zero.

POPULATION PARAMETERS FOR ACUTE WATERBORNE RELEASES

IPL

This control integer indicates the method for specification of population data for the acute release period for waterborne releases.

IPL $\leq 0$; use previous values. No additional population required. IPL $\equiv 1$; use the value given for PPL

IPL > 1; calculate the value for time TZ from given population time history data. Population data for chronic waterborne release must be entered if this option is set $>1$.

Default is $I P L=1$.

PPL This parameter is the total population for the acute waterborne release period used when $I A C>0$ and $I P L=1$. Default value is $P P L=0$.

\section{F. Waterborne Pathway Parameters}

CFLO

This parameter is used in the calculation of the dilution of liquid releases. It is the flow rate, in cubic feet per second (cfs) of the water into which the radionuclides are released. A default value is not specified for CFLO.

RECON This parameter is also used in the calculation of liquid dilution. It is used in particular cases where the inlet to a contamination facility is downstream of the outlet where reconcentration may occur. Default is 1.0 .

RM

This parameter is used in the calculation of liquid dilution where the receptor is near the release point. It relates the amount of the river flow actually mixed with the released radionuclides. $0 \leq \mathrm{RM} \leq 1$. Default is 1.0 .

USAGE(7) This array contains input values of the consumption or exposure rates for the waterborne pathway parameters for individuals:

1. fish consumption, $\mathrm{kg} / \mathrm{yr}$

2. crustacea consumption, $\mathrm{kg} / \mathrm{yr}$

3. mollusc consumption, $\mathrm{kg} / \mathrm{yr}$

4. water plant consumption, $\mathrm{kg} / \mathrm{yr}$

5. drinking water consumption, L/yr

6. exposure to contaminated sediments, $\mathrm{hr} / \mathrm{yr}$

7. swimming in contaminated water, $\mathrm{hr} / \mathrm{yr}$. 
G. Terrestrial Pathway Parameters

CONSUM(7) This array contains values of consumption rates, $\mathrm{kg} / \mathrm{hr}$ for the terrestrial pathways for individuals:

1. leafy vegetables

2. other vegetables

3. eggs

4. milk

5. beef

6. pork

7. poultry.

EXTIM This parameter relates the average time, $\mathrm{hr} / \mathrm{hr}$, that an individual spends exposed to surface soils contaminated by either atmospheric or irrigation deposition.

GRWP(7) The growing period (time of foliage above ground) for the 7 crops enumerated under the variable CONSUM. For the animal products, GRWP is the time above ground for feed or forage.

MOPYR This value is the months per year that irrigation is used on crops.

RIRR This parameter is the irrigation rate of the crops under CONSUM. Units are $\mathrm{L} / \mathrm{m}^{2} /$ month. For the animal products, this is the irrigation rate of the animal forage crops.

YELD(7) This array contains the crop or forage yield, $\mathrm{kg} / \mathrm{m}^{2}$, for the 7 pathways under CONSUM.

H. Graphical Output Control Parameters

Some QA input data and results from DITTY1 calculations are presented as graphical functions of the data versus time. Various parameters may be plotted as described below.

IGRPOP If set, this parameter allows plotting of the total population affected by airborne releases against time if nonzero. If IGRPOP is equal to zero, an abbreviated numeric report of population data is printed. Default is IGRPOP $=0$.

IGRPM This parameter allows plotting of the population weighted $\bar{x} / 0$ (PM) versus time if initialized. Default is IGRPM $=0$.

IGRPL This parameter allows plotting of the total population affected by aquatic pathways if nonzero. Default is IGRPL $=0$.

IGRTNU This parameter allows plotting of the total radionuclide release rate, in curies per 70-yr period versus time, if nonzero. Default is IGRTNU $=0$. 
When the population control integer IPOP is equal to 2 , one set of population distribution data is read. This data set uses record of type 8 and 9 as described in Table E.8. One record of type 8 is read followed by NSECT records of type 9 . Each type 9 record contains data for one sector and each distance interval.

When airborne release data are to be included in the input stream (IAIR > and ILUA $=1$ ), the data are supplied on records of type 10, 11 and 12 . One set of records is read for each radionuclide. Reading is terminated by placing a zero value for parameter NT of record type 11 . These records are described in Table E.9.

\section{TABLE E.8. Record Types 8 and 9, Population Distribution}

\section{Parameter \\ Record Type 8}

$T(1)$

Record Type 9

$\operatorname{POP}(10, i)$

Columns Format

$1-10 \quad E 10.2$

Description

Time at which the population distribution data is defined, years A.D.

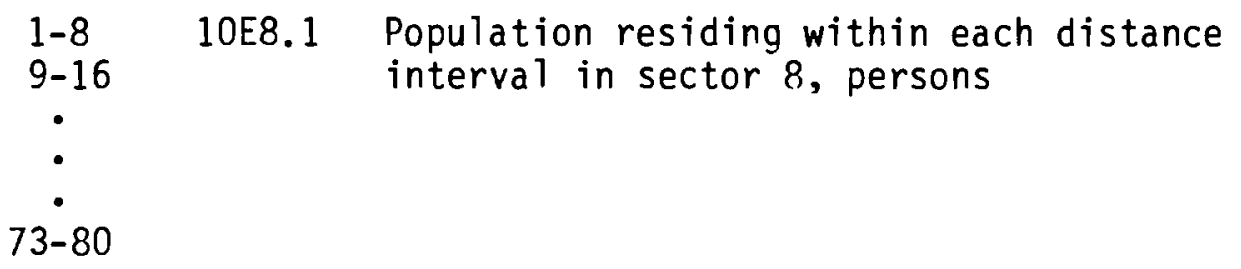

When waterborne releases are to be included in the input stream (IWAT $>0$ and $L U W=1$ ), the data are read using record types 10,11 and 12 as for the airborne release set.

Calculations are performed after input of necessary data. If additional cases are to be considered, the same card types are used based on new values given for the control parameters in the new NAMELIST set. Each succeeding case starts with input of a title card and a NAMELIST INPUT set. 


\section{TABLE E.5. (contd)}

IGRNUC This parameter allows plotting of the release rates of individual nuclides, curies per $70-y r$ period, versus time if nonzero. If IGRNUC is equal to zero a numeric report of release activity is printed for each radionuclide. Default is IGRNUC $=0$.

IGRDOS This parameter allows plotting of the dose to each organ versus time in the output if nonzero. Default: IGRDOS $=\varnothing$.

The NAMELIST parameter IEOQ controls input of atmospheric dispersion data. When $I E O Q=1$, normalized air concentration data (E/Q) are read on records of type 6 as described in Table E.6. The number of records of this type to be read is equal to the number of sectors (NSECT from NAMELIST). Each record contains data for one sector.

TABLE E.6. Record Type 6, Air Concentrations

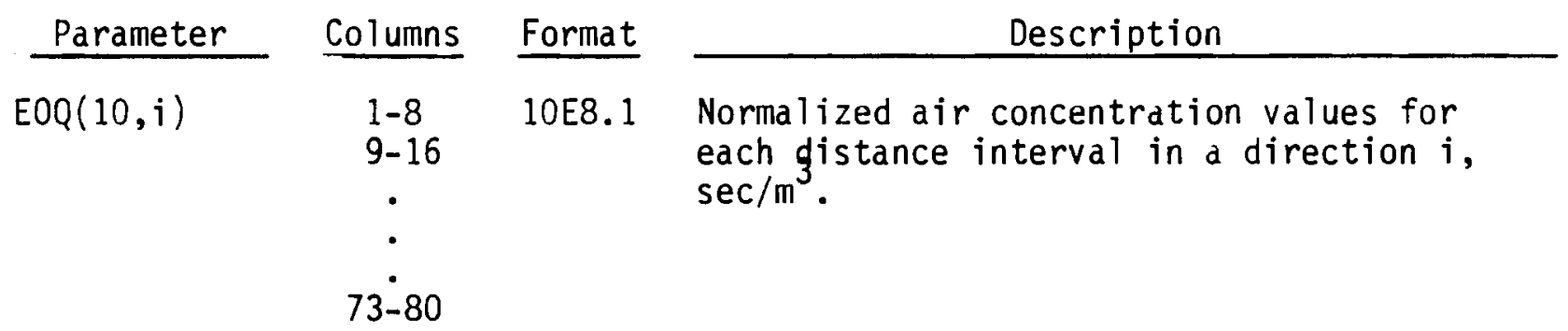

When IEOQ $=2$, the normalized air concentration values are to be calculated from annual average meteorological data of joint frequency of occurrence of windspeed, atmospheric stability and wind direction. This data is read from records of type 7 as described in Table E.7. Each record contains data for one windspeed group, one stability and all (NSECT) sectors. The total number of records of this type is given by the product of NUBAR and NMET.

TABLE E.7. Record Type 7, Joint Frequency Data

\begin{tabular}{|c|c|c|c|}
\hline Parameter & Columns & Format & Description \\
\hline$F(i, j, 16)$ & $\begin{array}{c}1-5 \\
6-10 \\
\vdots \\
76-80\end{array}$ & $16 \mathrm{~F} 5.2$ & $\begin{array}{l}\text { Joint frequency meteorological data for } \\
\text { windspeed group } i \text {, atmospheric stability } \\
\text { group } j \text { and up to } 16 \text { sectors. Values are } \\
\text { supplied as percent of time for persistence } \\
\text { of each condition. }\end{array}$ \\
\hline
\end{tabular}


TABLE E.9. Record Types 10, 11 and 12, Radionuclides Release Data

\begin{tabular}{|c|c|c|c|}
\hline Parameter & Columns & Format & Description \\
\hline Record Type 10 & $\begin{array}{l}(\text { NNAT) } \\
1-5\end{array}$ & I5 & $\begin{array}{l}\text { Number of radionuclides activity release } \\
\text { data are supplied for. }\end{array}$ \\
\hline$\underset{\mathrm{E}}{\text { Record Type } 11}$ & $1-2$ & A2 & $\begin{array}{l}\text { Element symbol for the current radio- } \\
\text { nuclide. }\end{array}$ \\
\hline A & $3-8$ & A6 & $\begin{array}{l}\text { Atomic weight symbol for the current radio- } \\
\text { nuclide. }\end{array}$ \\
\hline & $9-10$ & $2 x$ & Blank \\
\hline NT & $11-15$ & I5 & $\begin{array}{l}\text { Number of times for which release rates } \\
\text { will be supplied, NT } \leq 300 \text {. When NT } \leq 0 \text {, } \\
\text { reading of activity release data is teer- } \\
\text { minated. NT determines the number of } \\
\text { records of type } 12 \text { to be read. }\end{array}$ \\
\hline $\begin{array}{l}\text { Record Type } 12 \\
\text { TA(i) }\end{array}$ & $1-10$ & E10.2 & $\begin{array}{l}\text { Time at which the current release rate is } \\
\text { defined; years since start of release } \\
\text { based on parameter TZR. }\end{array}$ \\
\hline$c(i)$ & $11-20$ & E10.2 & $\begin{array}{l}\text { Release rate, } \mathrm{Ci} / \mathrm{yr} \text {, for the current radio- } \\
\text { nuclide at time } \mathrm{TA}(\boldsymbol{i}) \text {. }\end{array}$ \\
\hline
\end{tabular}




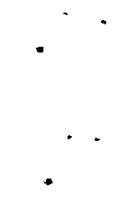

- 
APPENDIX $F$

SAMPLE PROBLEM 


\section{APPENDIX $F$}

SAMPLE PROBLEM

\section{DITTY SAMPLE PROBLEMS}

Sample problems for DITTY are provided to:

1) familiarize the user with DITTY input preparation,

2) give examples of DITTY input and output,

3) create a basis for hand calculations and checking of the computer code logic, and

4) establish a reference for verification of future versions and modifications of DITTY.

Seven sample problems (i.e., cases) are included to give adequate coverage of the wide range of input options available to the user. The seven sample problems are organized into three sets of inputs. Each set is an execution file containing system control records, a master radionuclide list, indices of selected organs and input parameters for one or more sample problems. The organization of the execution file was presented in Appendix $E$. Sample Set 1 contains the first sarnple problem, Sample Set 2 contains Sample Problems Two, Three, and Four, and Sample Set 3 contains Sample Problems Five, Six, and Seven. Table F.l summarizes input parameter usage in the sample problems.

Set One

The Sample Set 1 input file is shown in Figure F.1. Only one radionuclide $\left({ }^{241} A m\right.$ ), one organ (total body), and one problem or case are considered in this set. All input for this set is contained in the execution file; no auxiliary files are used.

Set Two

Figure F.2 is the Sample Set 2 execution file. Sample Set 2 considers airborne release pathways. Radionuclide release data for ${ }^{241_{A m} \text { and }}{ }^{238} \mathrm{Pu}$ is read for Sample Problem Two and used in Sample Problems Two and Three. (Note: the acute release of ${ }^{241} \mathrm{Am}$ is not considered in Sample Problem Two.) New 
TABLE F.1. Sample Problem Input Parameter Values

\begin{tabular}{|c|c|c|c|c|c|c|c|}
\hline \multirow[b]{2}{*}{ Input Parameter } & \multirow{2}{*}{$\begin{array}{l}\text { Sample } \\
\text { Set 1 } \\
\text { One }\end{array}$} & \multicolumn{3}{|c|}{ Sample Set 2} & \multicolumn{3}{|c|}{ Sample Set 3} \\
\hline & & Two & Three & Four & Five & Six & Seven \\
\hline IPATH & 1 & 1 & 1 & 1 & 2 & 2 & 0 \\
\hline IAC & 1 & 0 & 1 & 0 & 0 & 1 & 0 \\
\hline IAIR & 1 & 1 & 0 & 1 & - & - & 1 \\
\hline LUA & 1 & 1 & - & 0 & - & - & 1 \\
\hline IWAT & - & - & - & - & 1 & 0 & - \\
\hline LUW & - & - & - & - & 0 & - & - \\
\hline IPA & 1 & - & 1 & - & - & - & - \\
\hline IPOP & 6 & 4 & 0 & 2 & - & - & 2 \\
\hline IPL & - & - & - & - & - & 2 & - \\
\hline IPOPL & - & - & - & - & 2 & 0 & - \\
\hline IEOQ & - & - & - & 2 & - & - & 2 \\
\hline NORG & 1 & 2 & 2 & 2 & 5 & 5 & 5 \\
\hline $\operatorname{KORG}(n)$ & 1 & 1,6 & 1,6 & 1,6 & $\begin{array}{l}1,6,8, \\
16,23\end{array}$ & $\begin{array}{l}1,6,8, \\
16,23\end{array}$ & $\begin{array}{l}1,6,8, \\
16,23\end{array}$ \\
\hline Organs considered & T. Body & $\begin{array}{l}\text { T. Body } \\
\text { Bone }\end{array}$ & $\begin{array}{l}\text { T. Body } \\
\text { Bone }\end{array}$ & $\begin{array}{l}\text { T. Body } \\
\text { Bone }\end{array}$ & $\begin{array}{l}\text { T. Body } \\
\text { Bone } \\
\text { Lung } \\
\text { Thyroid } \\
\text { LLI }\end{array}$ & $\begin{array}{l}\text { T. Body } \\
\text { Bone } \\
\text { Lung } \\
\text { Thyroid } \\
\text { LLI }\end{array}$ & $\begin{array}{l}\text { T. Body } \\
\text { Bone } \\
\text { Lung } \\
\text { Thyroid } \\
\text { LLI }\end{array}$ \\
\hline $\begin{array}{l}\text { Radionuclides } \\
\text { released to air }\end{array}$ & ${ }^{241} \mathrm{Am}$ & ${ }^{238} \mathrm{Pu}$ & $\begin{array}{l}{ }^{241} \mathrm{Am} \\
238_{\mathrm{Pu}}\end{array}$ & ${ }^{90} \mathrm{Sr}$ & & & ${ }^{90} \mathrm{Sr}$ \\
\hline $\begin{array}{l}\text { Radionuclides } \\
\text { released to water }\end{array}$ & & & & & $\begin{array}{l}{ }^{90} \mathrm{Sr} \\
{ }^{129} \mathrm{I}\end{array}$ & $\begin{array}{l}{ }^{90} \mathrm{Sr} \\
{ }^{129} \mathrm{I} \\
{ }^{14} \mathrm{C}\end{array}$ & $\begin{array}{l}{ }^{90} \mathrm{Sr} \\
{ }^{129} \mathrm{I}\end{array}$ \\
\hline
\end{tabular}




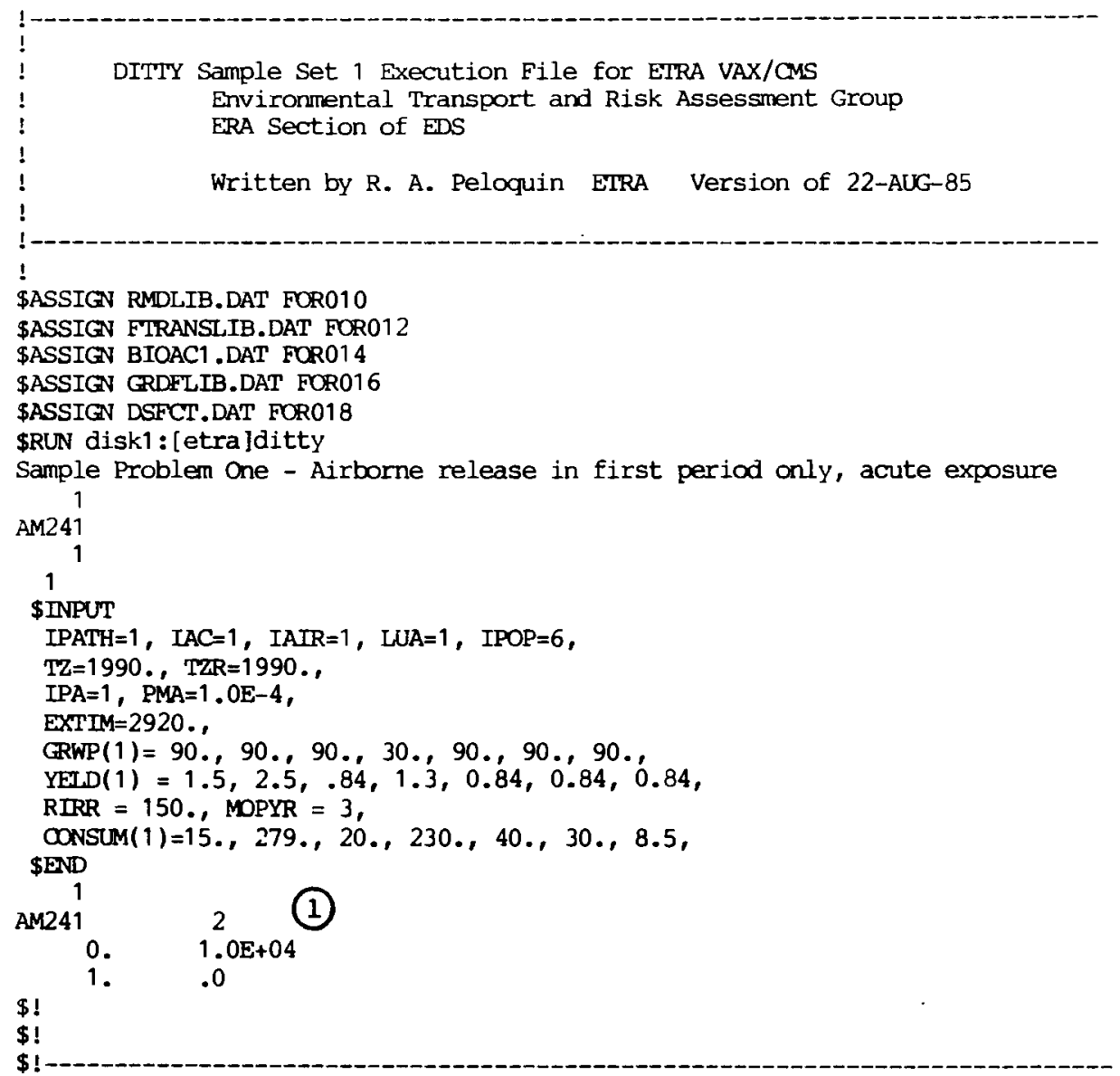

FIGURE F.1. Sample Set 1 Input 


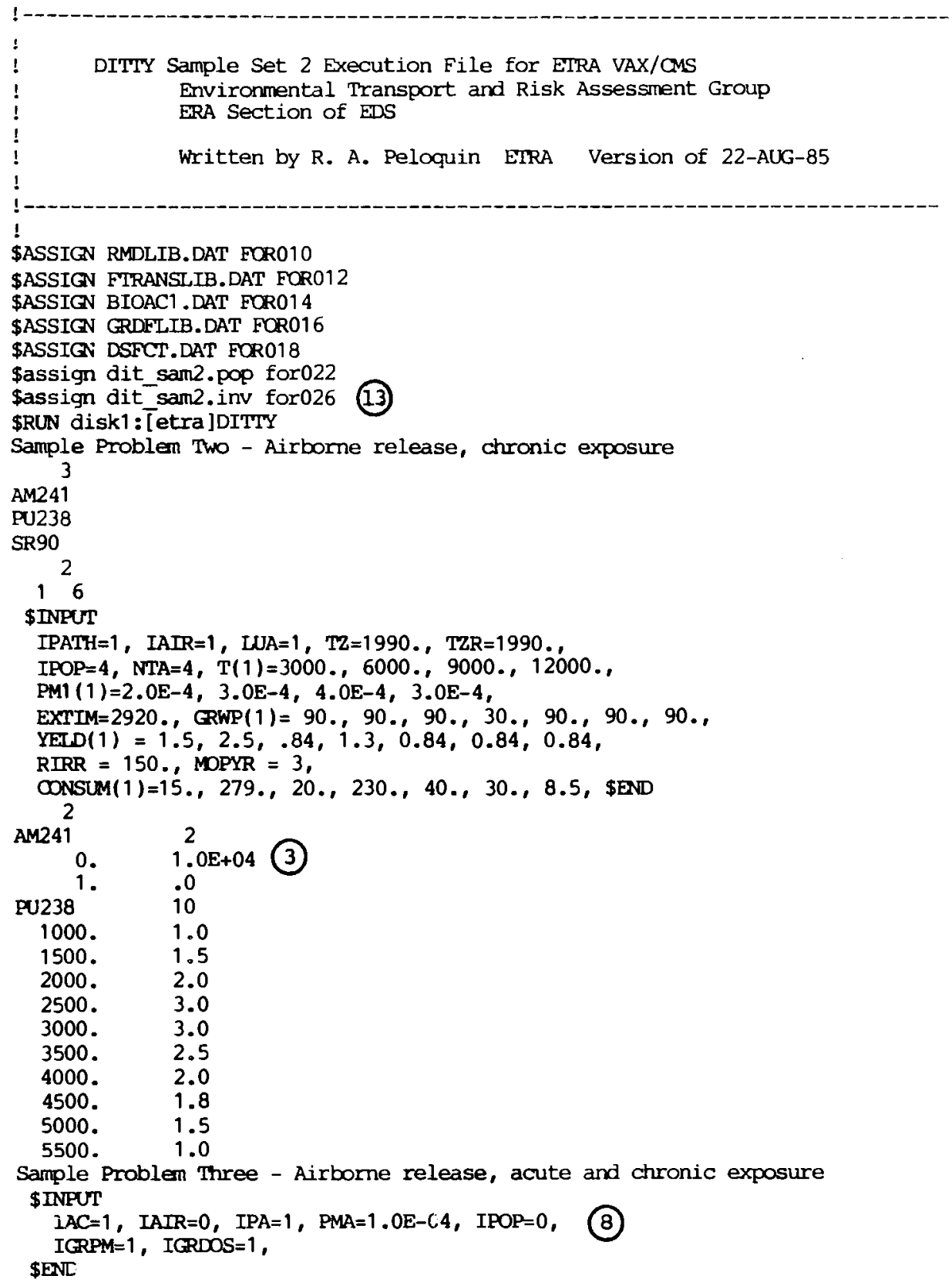

FIGURE F.2. Sample Set 2 Input 


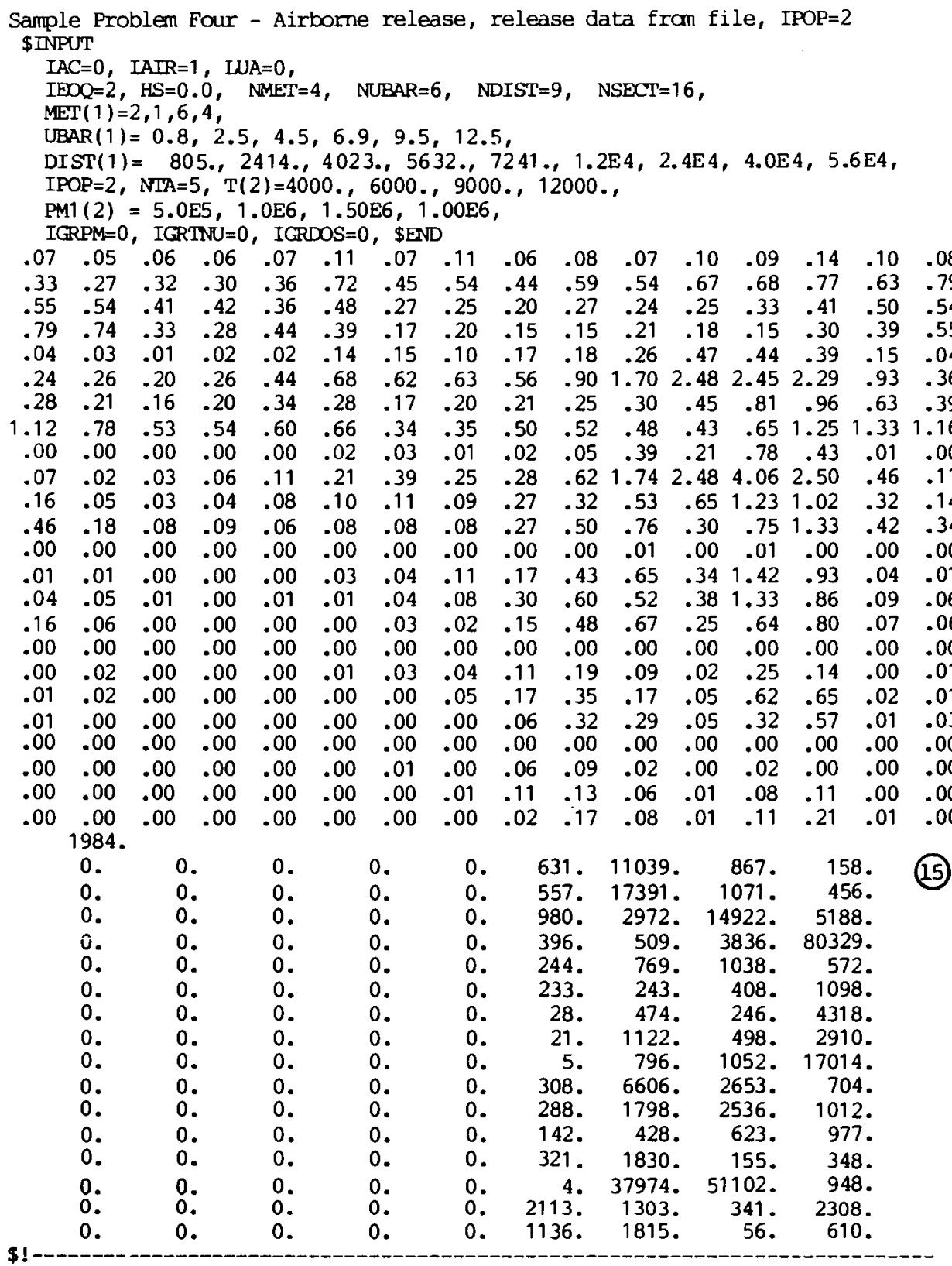

FIGURE F.2. (contd) 
radionuclide release data is read for Sample Problem Four. Release data is read both from the execution file and from an auxiliary file. Doses are calculated for total body and bone in each case. Sample Problem Three is a combination of Sample Problems One and Two. The dose totals from Sample Problems One and Two should equal the doses in Sample Problem Three.

Set Three

The Sample Set 3 execution file is shown in Figure F.3. Both waterborne and airborne pathways are considered in this set. Waterborne release data is read from an auxiliary file in Sample Problem Five and used for Sample Problems Five, Six, and Seven. (Note: the acute release of ${ }^{14} \mathrm{C}$ is only considered $[I A C=1]$ in Sample Problem Six.) Waterborne release data is read both from the execution file $\left({ }^{90} \mathrm{Sr}\right.$ and $\left.{ }^{129} \mathrm{I}\right)$ and from an auxiliary file $\left({ }^{14} \mathrm{C}\right)$. Airborne release data $\left({ }^{238} \mathrm{Pu}\right)$ is read from the execution file. Additional ${ }^{238} \mathrm{Pu}$ airborne release data is read for Sample Problem Seven from the execution file. Doses to total body, bone, lung, thyroid, and the lower large intestine of the GI-tract are calculated in this set. Sample Problem Seven is a composite of Sample Problems Four and Five. The dose totals from Sample Problenss Four and Five should equal the dose received in Sainple Problem Seven.

Computer System commands have been included with each sample set as an aid to user. These system commands are for the VAX-11/780 computer. The user is responsible for appropriate syntax and file assignments on the host computer.

The input and output listings of the sample problems have been annotated with circled numbers to clarify the following discussion. These annotations are referred to as "item \#n" in the text. An index of all annotations is given in Table F.2. 


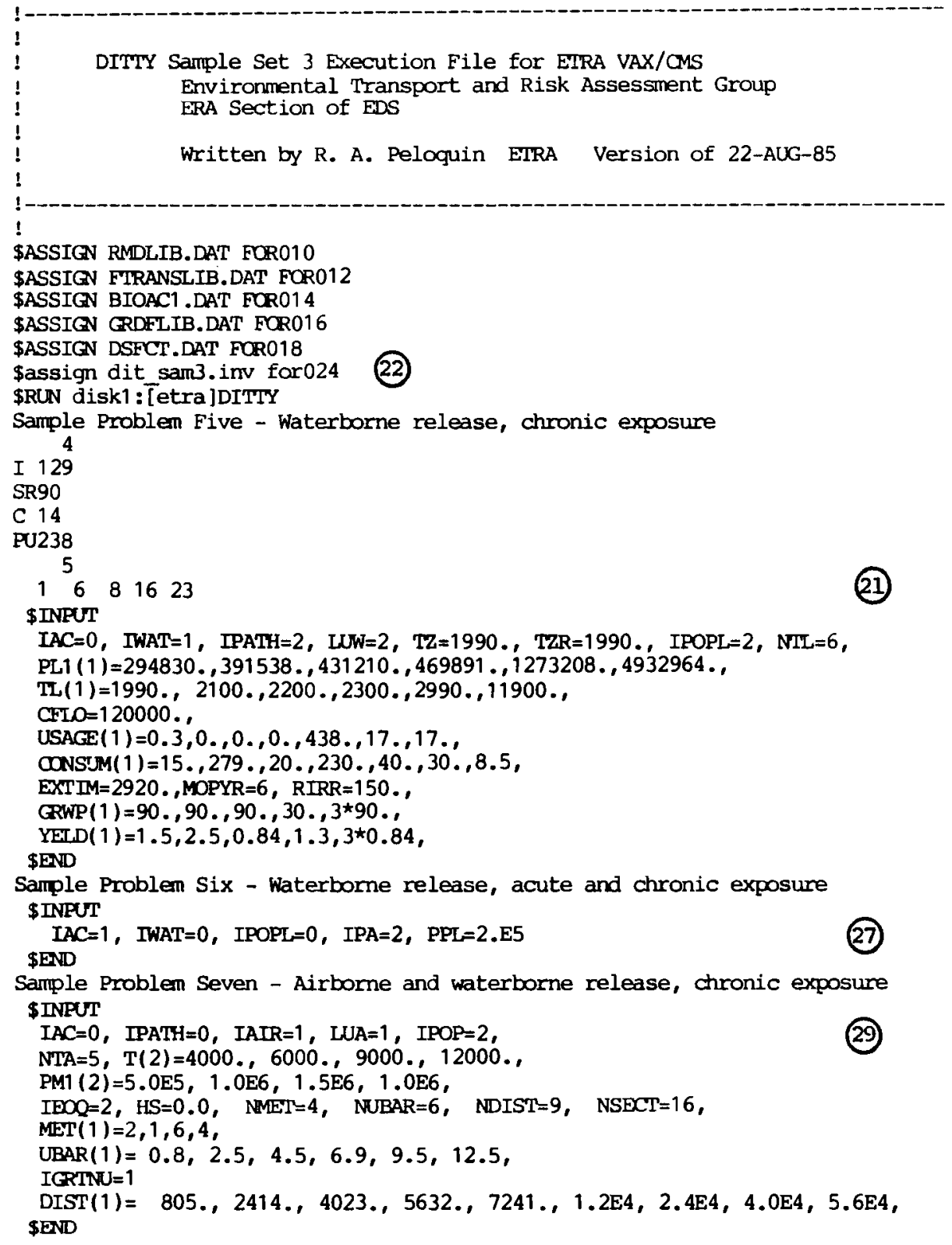

\section{FIGURE F.3. Sample Set 3 Input}




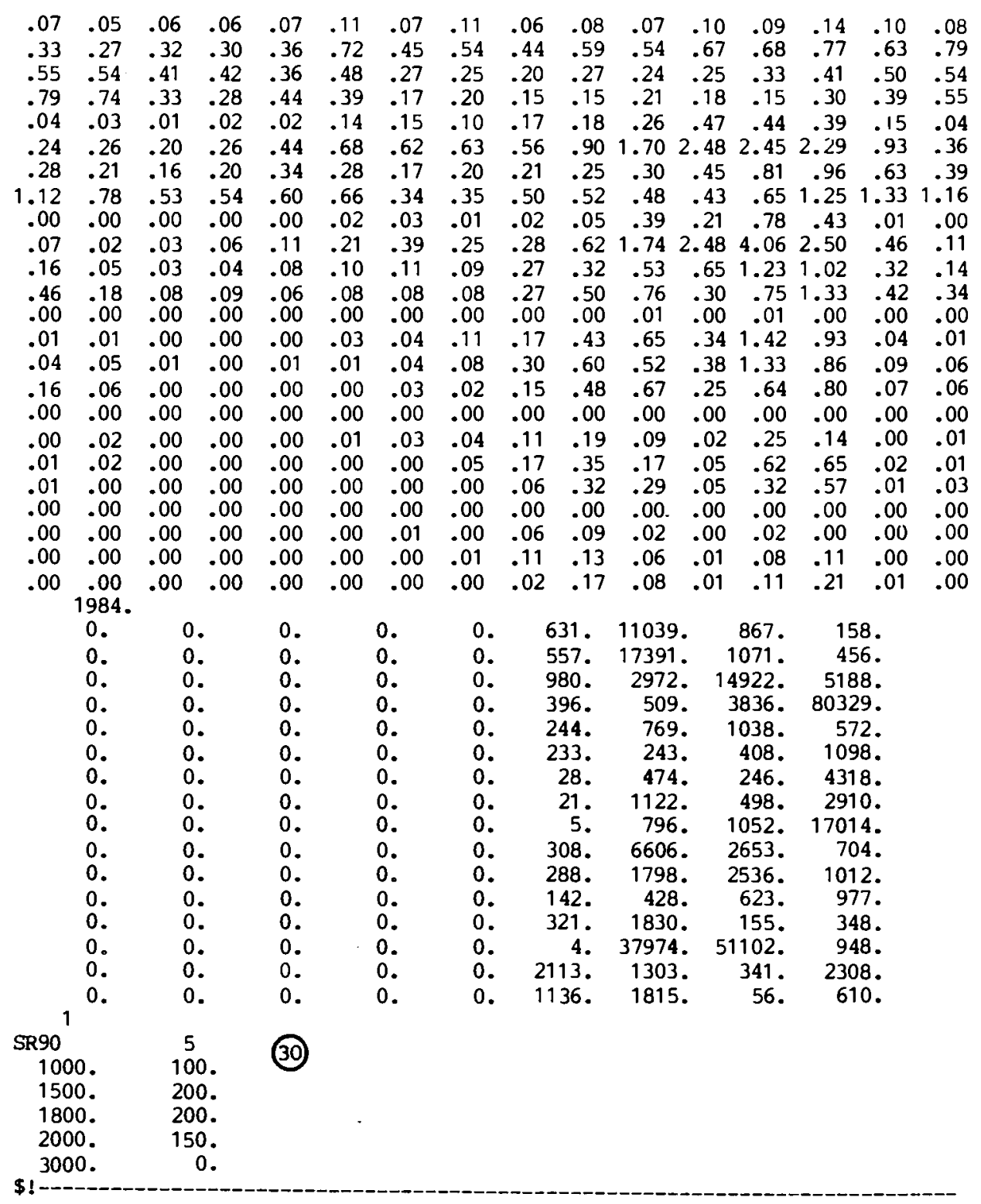

FIGURE F.3. (contd) 
TABLE F.2. Sample Problems Annotation Index

\begin{tabular}{|c|c|c|}
\hline $\begin{array}{c}\text { Itern } \\
\text { Number } \\
\end{array}$ & $\begin{array}{l}\text { Figure } \\
\text { Number } \\
\end{array}$ & Description \\
\hline 1 & F.1 & Specification of an acute release, Sample Problem One \\
\hline 2 & $\mathrm{~F} .4$ & Resulting cumulative dose, Sample Problem One \\
\hline 3 & F. 2 & Specification of an acute release, Sample Problem Two \\
\hline 4 & F. 5 & Airborne population dispersion factors as input \\
\hline 5 & F.5 & $\begin{array}{l}\text { Airborne population dispersion factors interpolated } \\
\text { for each } 70 \text {-year time period }\end{array}$ \\
\hline 6 & F. 5 & $\begin{array}{l}\text { Radionuclide release interpolated for each } 70 \text {-year } \\
\text { time period }\end{array}$ \\
\hline 7 & F. 5 & Resulting cumulative dose, Sample Problem Two \\
\hline 8 & F.2 & $\begin{array}{l}\text { Use of NAMELSIT to change parameter values for subse- } \\
\text { quent cases in a set }\end{array}$ \\
\hline 9 & F.6 & Population dispersion graphic report \\
\hline 10 & F. 6 & $\begin{array}{l}\text { Resulting cumulative dose to total body graphic report, } \\
\text { Sample Problem Three }\end{array}$ \\
\hline 11 & F. 6 & Maximum dose rate report, Sample Problem Three \\
\hline 12 & F. 6 & $\begin{array}{l}\text { Percent of total dose to organ by radionuclide, Sample } \\
\text { Problem Three }\end{array}$ \\
\hline 13 & F.2 & Assignment of airborne release auxiliary file (lun 26) \\
\hline 14 & F. 2 & Input of joint frequency data \\
\hline 15 & $F .2$ & Input of initial population distribution \\
\hline 16 & F.8 & Report of initial population distribution \\
\hline 17 & F.8 & Report of input population dispersion factors \\
\hline 18 & F.8 & $\begin{array}{l}\text { Report of population dispersion factors calculated for } \\
\text { the } 14470 \text {-year time periods }\end{array}$ \\
\hline 19 & F.8 & Joint frequency data report \\
\hline 20 & $\mathrm{~F} .8$ & Resulting cumulative dose, Sample Problem Four \\
\hline 21 & $F .3$ & Sample Problem Five input \\
\hline 22 & $\mathrm{~F} .3$ & Assignment of waterborne release auxiliary file (lun 24) \\
\hline 23 & F.9 & Specification of an acute release, Sample Problem Five \\
\hline 24 & $F .10$ & Resulting cumulative dose, Sample Problem Five \\
\hline 25 & F. 10 & Maximum dose rate report, Sample Problem Five \\
\hline 26 & $\mathrm{~F} .10$ & Percent of total dose report, Sample Problem Five \\
\hline 27 & F.3 & Sample Problem Six input \\
\hline
\end{tabular}


TABLE F.2 (contd)

Item Figure

Number Number

28

29

30

31
F.11

F.3

F.3

F.12
Description

Resulting cumulative dose, Sample Problem Six

Sample Problem Seven input

Release data input, Sample Problem Six

Resulting cumulative dose, Sample Problem Seven 
The first sample problem attempts to acquaint the user with DITTY execution on an elementary level. It is suggested that this problem be executed before proceeding to the remaining sample problems.

The user specifies a case title (Record type 1), the master radionuclide list (Record types 2 and 3), selected organs (Record types 4 and 5), NAMELIST INPUT parameters (see Table E.5), and the radionuclide release data (Record types 10, 11, and 12) for a single case as shown in Figure F.1.

Sample Problem One simulates acute exposure (IAC=1) to an airborne release (IPATH=1) of ${ }^{241}$ Am in the calendar year of 1990 (TZ). Release data is entered for this case (IAIR=1) in the execution file ( $L U A=1)$. A value is provided $(I P A=1)$ for the population dispersion factor $\left(P M A=1.0 \times 10^{-4}\right)$. Constant population is assumed (IPOP=6) for this acute release. Generic values are used for terrestrial pathway parameters (EXTIM, GRWP, YELD, RIRR, MOPYR, and CONSUM).

The user should note the method used to specify an acute release. The acute release data history begins in year 1990 (TZR). For an acute release, this date must be the same year as the beginning of the 10,000 year integration period (TZ). The acute release of 10,000 curies of ${ }^{241} \mathrm{Am}$ is entered as a time off-set from the start of the reledse data history of 0 (item \#1 in Figure F.1). When specifying an acute release, a release of 0.0 curies must be entered at year 1 of the release history data to turn off the acute exposure.

In this sample set only dose to total body is calculated. A cumulative population dose of 18,000 person-rem is received by the local population over 10,000 years as shown in Figure F.4 (item \#2). 
QA PAGE FOR DITTY (VAX VERSION 1.0) RUN ON 27-JAN-86

INIEGRATED POPULATION DOSE CALCULATED FOR ACUTE ATMOSPHERIC

RETEASE FROM TIME 1990. A.D. ONWARD FOR 10,000 YEARS

CASE TITIE: Sample Problem One - Airborne release in first period only, acute exposure

*** DATA LIBRARIES USED: (ETLE)

MASTER NUCLIDE DATA : (10)

FOOD CONCTNIRATION RATIOS : (12)

FRESHWATER BIOAOCUMUIATION FACTORS : $(14)$

EXIERNAL EXPOSURE D.F.'S : (16)

INHALATION/INGESTION D.F.' 'S : $(18)$

IRECRNE RETFASE DATA : $(26)$

RADIONUCLIDE MASTER DATA LIBRARY / $w$ TRANSLOCATION CLASSES, 19-MAR-85 RAP

ACOMU TRANSFER OOEFFICIENT LIBRARY RAP / 9-24-85 (9R (28-NOV-83/RAP)

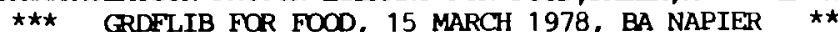

INTERNAL DOSE CONVERSION FACTOR LIBRARY FOR DITTY1 REV. 1-20-81 (BAN/DLS/RAP) TNPUT

\section{*** ORGANS CONSIDERED:}

TOTAL BOOY

$\star \star \star$ MASTER RADIONUCLIDE CONIROL LIST:

AM241

$\star \star \star$ POPULATION DATA:

POPULATICA DISPERSION FACTOR FOR ACUTE AIRBCRNE REILASE $=1.00 E-04$

NO GIRONIC AIRBORNE REIEASE, OONSTATNT POPULATION ASSUMED.

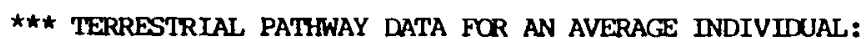

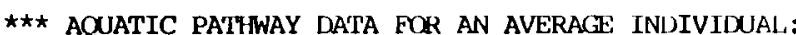

\begin{tabular}{|c|c|c|c|}
\hline PATHWAY & $\begin{array}{l}\text { GROWING PERIOD } \\
\text { (DAYS) }\end{array}$ & $\begin{array}{l}\text { YIETD } \\
\left(K G / M^{\star \star} 2\right)\end{array}$ & $\underset{(\mathrm{KG} / \mathrm{YR})}{\operatorname{CONSUMPTION}}$ \\
\hline LEAFY VEGATABLES & $9.00 \mathrm{E}+01$ & $1.50 \mathrm{E}+00$ & $1.50 \mathrm{E}+01$ \\
\hline OTHER VEGATABLES & $9.00 \mathrm{E}+01$ & $2.50 \mathrm{E}+00$ & $2.79 E+02$ \\
\hline EGGS & $9.00 E+01$ & $8.40 \mathrm{E}-01$ & $2.00 \mathrm{E}+01$ \\
\hline MILK & $3.00 \mathrm{E}+01$ & $1.30 \mathrm{E}+00$ & $2.30 \mathrm{E}+02$ \\
\hline BEEF & $9.00 \mathrm{E}+01$ & 8. $40 \mathrm{E}-01$ & $4.00 \mathrm{E}+01$ \\
\hline PORK & $9.00 \mathrm{E}+01$ & $8.40 \mathrm{E}-01$ & $3.00 \mathrm{E}+01$ \\
\hline POULTRY & $9.00 \mathrm{E}+01$ & $8.40 \mathrm{E}-01$ & $8.50 \mathrm{E}+00$ \\
\hline
\end{tabular}

\begin{tabular}{|c|c|}
\hline PATHWAY & $\begin{array}{c}\text { USAGE } \\
\text { (KG } \mathrm{OR} \text { HR/YR) }\end{array}$ \\
\hline FISH & $0.00 \mathrm{E}+00$ \\
\hline CRUSTACEA & $0.00 E+00$ \\
\hline MOLLUSES & $0.00 \mathrm{E}+00$ \\
\hline PLANIS & $0.00 E+00$ \\
\hline DRINKING WATER & $0.00 \mathrm{E}+00$ \\
\hline SEDIMENT EXXOSURE & $0.00 \mathrm{E}+00$ \\
\hline SWIMMING TIME & $0.00 \mathrm{E}+00$ \\
\hline
\end{tabular}

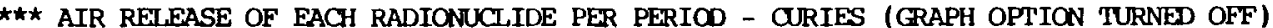

$\begin{array}{lllllll}\text { RADIONUCLIDE } & \text { PERIOD ACTVITY } & \text { PERIOD ACTVITY } & \text { PERIOD ACTVITY } & \text { PERIOD ACTVITY } & \text { PERIOD ACTVITY } & \text { PERIOD ACTVITY }\end{array}$

AM241 $\quad 0 \quad 1.00 \mathrm{E}+04$

INPUT PREPARED BY: 4 tof

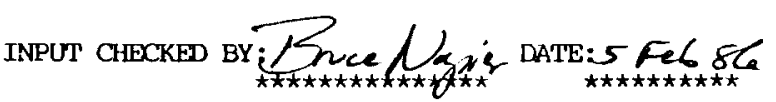

FIGURE F.4. Sample Problem One Output 
REPORT FOR DITTY (VAX VERSION 1.0) RUN ON 27-JAN-86

DNTEGRATED POPULATION DOSE CALOILATED FOR ACUTE ATMOSPHERIC

RETEASE FROM TDE 1990. A.D. ONWARD FOR 10,000 YEARS
CASE TITLE: Sample Problem One - Airborne release in first period only, acute exposure

* * * oumlative dose to seifcited organs as a function OF TIME * * *

\begin{tabular}{|c|c|c|}
\hline PERIOD & YEAR & TOTAL BOOY \\
\hline ACUTE & & $1.84 \mathrm{E}+04$ \\
\hline 144 & 11930. & $1.84 \mathrm{E}+04$ \\
\hline
\end{tabular}

Dose in units of person-rem; that is the cumulative population dose received by the local population over 10,000 years with an assumed 70-yr individual lifetime.

\section{FIGURE F.4. (contd)}


(blank)

F. 14 
Sample Problem Two is the first of three problems in Sample Set 2. The DITTY execution file for Sample Set 2 is shown in Figure F.2.

Sample Problem Two simulates chronic exposure to an airborne release (IPATH=1) of ${ }^{238} \mathrm{Pu}$. The 10,000 year integration period begins in calendar year 1990 (TZ). Population dispersion values (PMI) are estimated at four (NTA=4) times (T) during the 10,000 year period. Generic values are used for terrestrial pathway parameters (EXTIM, GRWP, YELD, RIRR, MOPYR, and CONSUM).

Radionuclide release data is read (IAIR=1) from the execution file (LUA-=1). The starting time of the release history is year 1990 A.D. (TZR). A varying quantity of 1.0 to 3.0 curies of ${ }^{238} \mathrm{Pu}$ (see \#3 in Figure F.2) is released to the atmosphere during calendar years $2990(1000+1990)$ through $7490(5500+1990)$. Note that ${ }^{241}$ Am acute release data is also entered at this time. ${ }^{241} \mathrm{Am}$ is not considered in Sample Problem Two because an acute release (IAC) is not specified. The ${ }^{241}$ Am release is considered in Sample Problem Three.

Figure F.5 is partial output from Sample Problem Two. In addition to a report of input parameters, tables of population dispersion, as entered (item \#4) and as interpolated for each 70-year time period (item \#5), are included. Radionuclide releases as interpolated for each 70-year time period are listed (item \#6). The cumulative dose report (item \#7) shows doses of 27,000 personrem to total body and $5.7 \times 10^{5}$ person-rem to bone at the end of the 10,000 -year integration period. 
QA PAGE FOR DITTY (VAX VERSION 1.0) RUN ON 27-JAN-86

INTECRATED POPULATION DOSE CAICUIATED FOR CHRONIC ATMOSPHERIC REI.EASE FROM TIME 1990 . A.D. ONWARD FOR 10,000 YEARS
CASE TITIE: Sample Problen Two - Airborne release, chronic exposure

$\star \star \star$ DATA LIBRARIES USED:
MASTER NUCLIDE DATA : (10)

FOOD OONCENIRATION RATIOS : (12)

FRESHWATER BIOACCUMULATION FACTORS : (14)

EXIERNAL EXPOSURE D.F.'S : (16)

INHAIATION/INGESTIION D.F.' $S$ : $(18)$

AIRBORNE RETEASE DATA : (26)

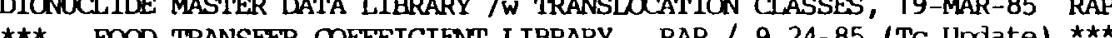
IIOACCUMULATION FACTOR LIBRARY FOR FOOD, PABIM, MAXI BA NAPIER (28-NOV-83/RAP) $\star \star \star \quad$ GRFLIB FOR FOOD, 15 MARCH 1978, BA NAPIER $\star \star \star$

INTERNAL DOSE CONVERSION FACTOR LIARARY FOR DITTY1 REV. 1-20-81 (BAN/DLS/RAP) INPUI

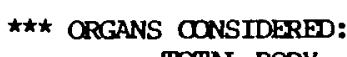

BONE

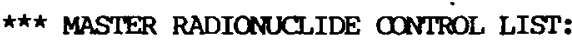

SR90

Y 90

PU238

AM241

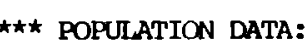

POPULATION DISPERSION FACTORS FOR CHRONIC AIREORNE RELEASE AT THE FOLLOWING TIMES A.D.:

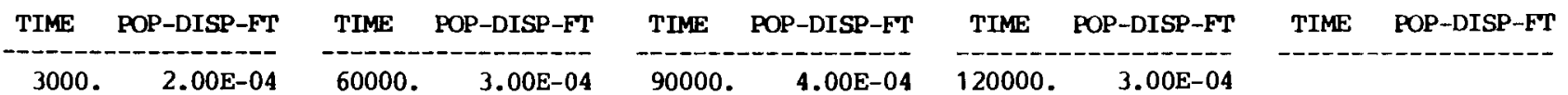

\section{$\star \star \star$ TERRESTRIAL PATHWAY DATA FOR AN AVERAGE INDIVIDUAL:}

\begin{tabular}{|c|c|c|c|}
\hline PATHWAY & $\begin{array}{l}\text { GROWING PERIOD } \\
\text { (DAYS) }\end{array}$ & $\begin{array}{l}\text { YIEIID } \\
\left(\mathrm{KG} / M^{\star *} 2\right)\end{array}$ & $\begin{array}{l}\text { ONSG/YRTION } \\
\text { (KG/YR }\end{array}$ \\
\hline LEAFY VEGATABILES & $9.00 \mathrm{E}+01$ & $1.50 E+00$ & $1.50 \mathrm{E}+01$ \\
\hline OTHER VEGATABLES & $9.00 \mathrm{E}+01$ & $2.50 \mathrm{E}+00$ & $2.79 \mathrm{E}+02$ \\
\hline EOGS & $9.00 \mathrm{E}+01$ & $8.40 \mathrm{E}-01$ & $2.00 \mathrm{E}+01$ \\
\hline MILK & $3.00 E+01$ & $1.30 \mathrm{E}+00$ & $2.30 \mathrm{E}+02$ \\
\hline BEEFF & $9.00 \mathrm{E}+01$ & 8. 40E-01 & $4.00 E+01$ \\
\hline PORK & $9.00 \mathrm{E}+01$ & 8. 40E -01 & $3.00 \mathrm{E}+01$ \\
\hline POULTRY & $9.00 \mathrm{E}+01$ & $8.40 \mathrm{E}-01$ & $8.50 \mathrm{E}+00$ \\
\hline
\end{tabular}

$\star \star \star$ AQUATIC PATHWAY DATA FOR AN AVERAGE INDIVIDUAL:

$\begin{array}{lc}\text { PATHWAY } & \text { USAGE } \\ & \text { (KG OR HR/YR) } \\ \text { FISH } & 0.00 \mathrm{E}+00 \\ \text { CRUSTACEA } & 0.00 \mathrm{E}+00 \\ \text { MOLLUSES } & 0.00 \mathrm{E}+00 \\ \text { PLANIS } & 0.00 \mathrm{E}+00 \\ \text { DRINKING WATER } & 0.00 \mathrm{E}+00 \\ \text { SEDIMENT EXPOSURE } & 0.00 \mathrm{E}+00 \\ \text { SWIMMING TIME } & 0.00 \mathrm{E}+00\end{array}$

FIGURE F.5. Sample Problem Two Output 


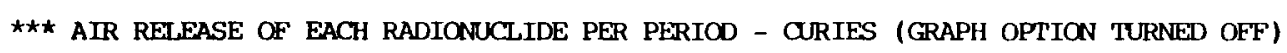

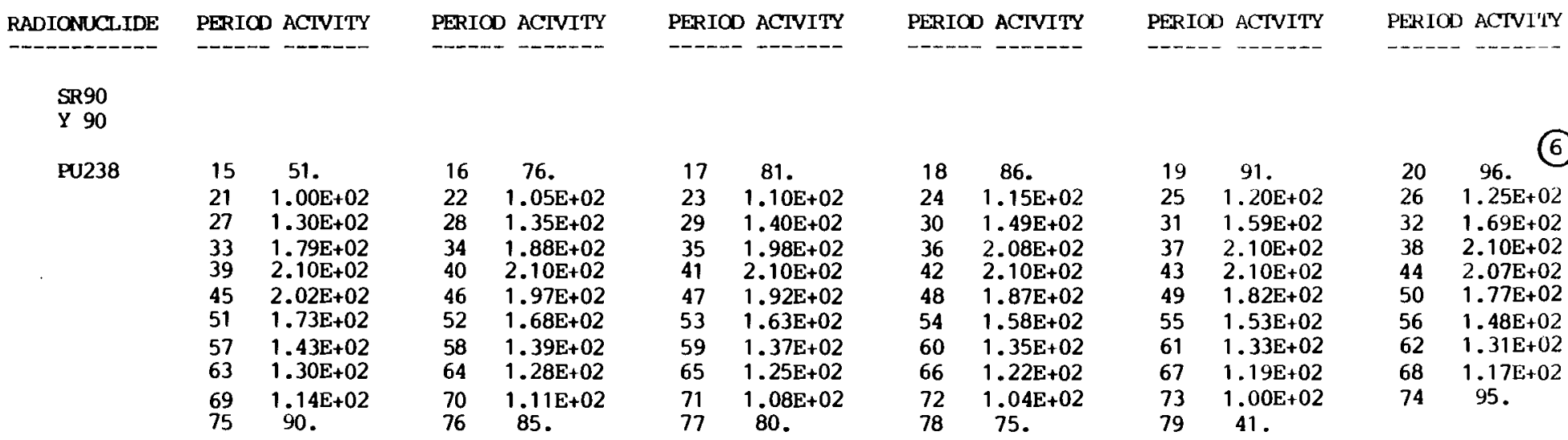

AM241

$0 \quad 1.00 \mathrm{E}+04$

$\star \star \star$ POPULATION DISPERSION FACTOR FOR AIRBORNE REILASE, PERSON-SEC/M**3

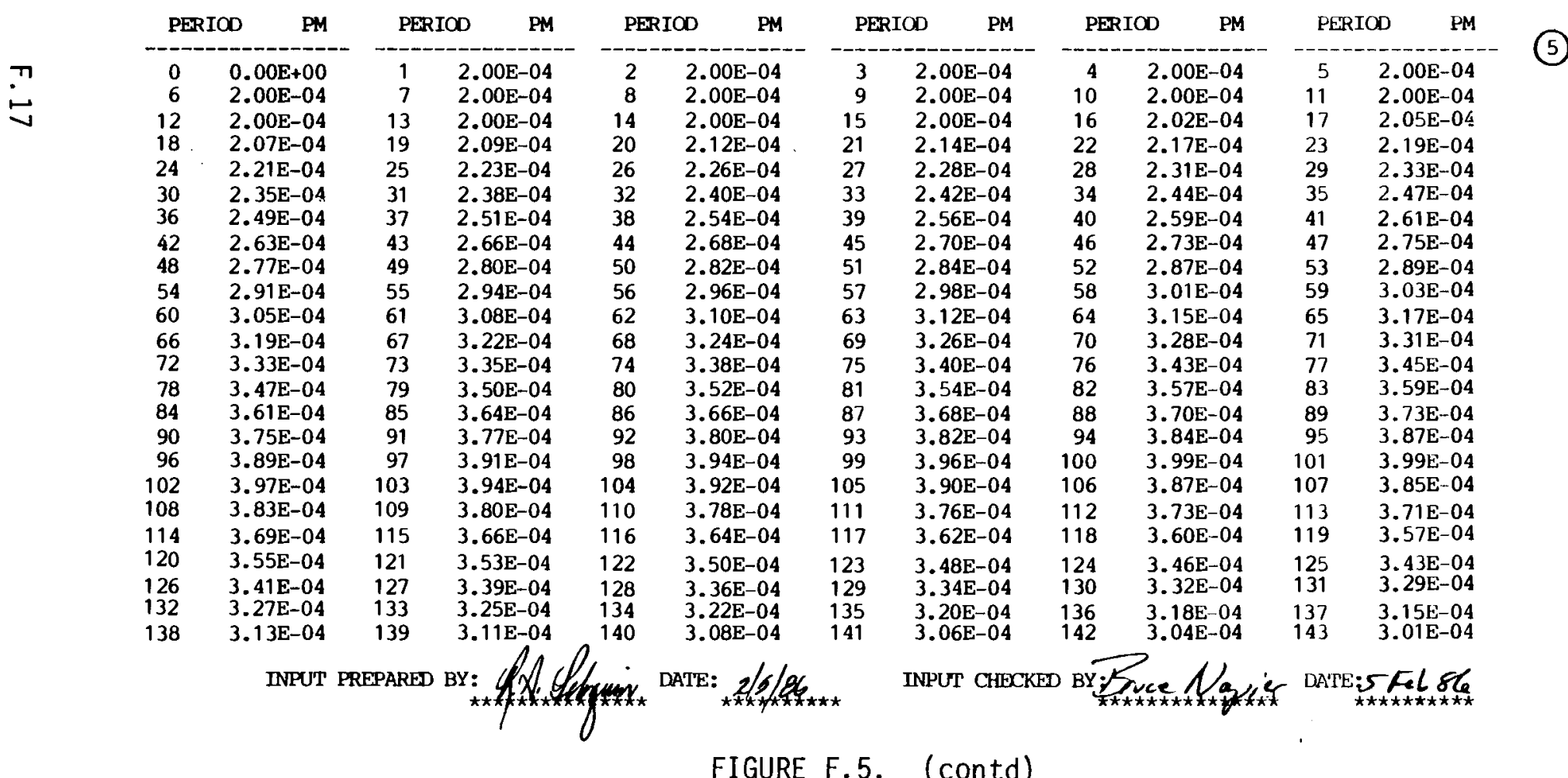

FIGURE F.5. (contd) 
REPORT FOR DITIY (VAX VERSION 1.0) RUN ON 27-JAN-86

INTEGRATED POPULATION DOSE CALCULATED FOR CHRONIC ATMOSPHERIC

REIEASE FROM TIME 1990. A.D. ONWARD FOR 10,000 YEARS

CASE TITLE: Sample Problem Two - Airborne release, chronic exposure

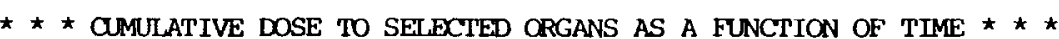

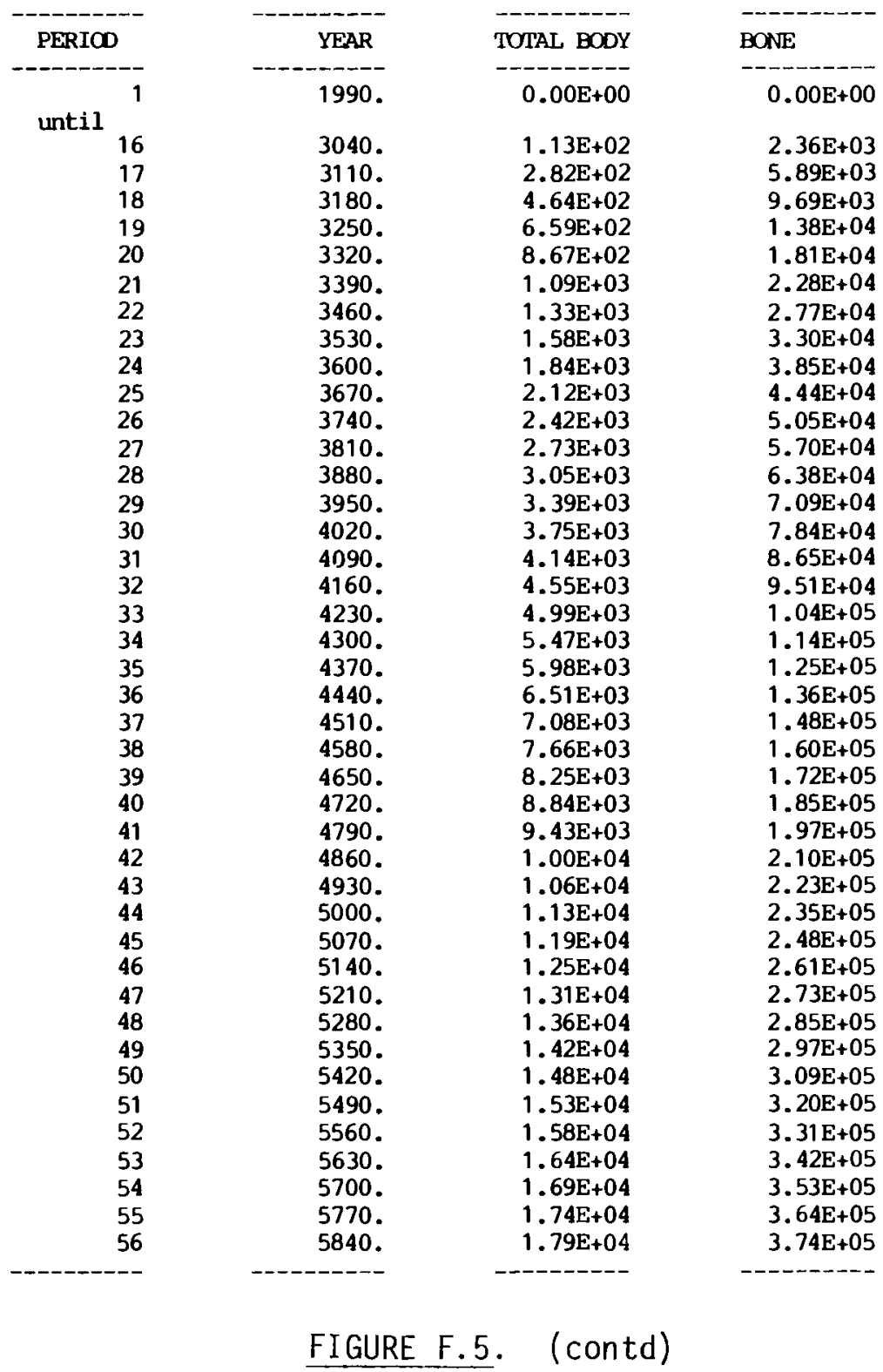


REPORT FOR DITTY (VAX VERSION 1.0) RLN ON 27-JAN-86

INTEGRATED POPULATION DOSE CALCUIATED FOR CHRONIC ATMOSPFERIC

RET.EASE FROM TIME 1990. A.D. ONWARD FOR 10,000 YEARS

CASE TITIE: Sample Problem Two - Airborne release, chronic exposure

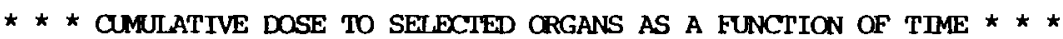

\begin{tabular}{|c|c|c|c|}
\hline PERIOD & YEAR & TOTAL BODY & BONE \\
\hline 57 & 5910. & $1.84 E+04$ & $3.84 \mathrm{E}+05$ \\
\hline 58 & 5980. & $1.88 \mathrm{E}+04$ & $3.94 \mathrm{E}+05$ \\
\hline 59 & 6050 . & $1.93 \mathrm{E}+04$ & $4.04 \mathrm{E}+05$ \\
\hline 60 & 6120 . & $1.98 \mathrm{E}+04$ & $4.13 E+05$ \\
\hline 61 & 6190. & $2.02 E+04$ & $4.23 E+05$ \\
\hline 62 & 6260. & $2.07 \mathrm{E}+04$ & $4.32 \mathrm{E}+05$ \\
\hline 63 & 6330. & $2.11 \mathrm{E}+04$ & $4.41 \mathrm{E}+05$ \\
\hline 64 & 6400 & $2.16 \mathrm{E}+04$ & $4.51 \mathrm{E}+05$ \\
\hline 65 & 6470 . & $2.20 \mathrm{E}+04$ & $4.60 \mathrm{E}+05$ \\
\hline 66 & 6540 . & $2.24 E+04$ & $4.69 E+05$ \\
\hline 67 & 6610. & $2.29 E+04$ & $4.78 \mathrm{E}+05$ \\
\hline 68 & 6680 . & $2.33 E+04$ & $4.87 E+05$ \\
\hline 69 & 6750 . & $2.37 \mathrm{E}+04$ & $4.95 \mathrm{E}+05$ \\
\hline 70 & 6820 . & $2.41 E+04$ & $5.04 \mathrm{E}+05$ \\
\hline 71 & 6890. & $2.45 E+04$ & $5.12 \mathrm{E}+05$ \\
\hline 72 & 6960. & $2.49 E+04$ & $5.21 E+05$ \\
\hline 73 & 7030 & $2.53 E+04$ & $5.29 \mathrm{E}+05$ \\
\hline 74 & 7100. & $2.56 \mathrm{E}+04$ & $5.36 \mathrm{E}+05$ \\
\hline 75 & 7170 . & $2.60 E+04$ & $5.44 \mathrm{E}+05$ \\
\hline 76 & 7240 . & $2.63 E+04$ & $5.51 \mathrm{E}+05$ \\
\hline 77 & 7310. & $2.67 \mathrm{E}+04$ & $5.57 \mathrm{E}+05$ \\
\hline 78 & 7380 . & $2.70 E+04$ & $5.64 \mathrm{E}+05$ \\
\hline 79 & 7450 . & $2.72 E+04$ & $5.70 \mathrm{E}+05$ \\
\hline 80 & 7520 . & $2.74 \mathrm{E}+04$ & $5.73 E+05$ \\
\hline \multicolumn{4}{|l|}{ until } \\
\hline 144 & 12000. & $2.74 E+04$ & $5.73 \mathrm{E}+05$ \\
\hline
\end{tabular}

(ㄱ)

Dose in units of person-rem; that is the cumulative population dose received by the local population over 10,000 years with an assumed $70-y r$ individual lifetime.

FIGURE F.5. (contd) 
-

. 


\section{SAMPLE PROBLEM THREE}

Sample Problem Three is a composite of the acute and chronic exposure scenarios defined in Sample Problems One and Two. Input parameters from Sample Problem Two remain in effect except for changes to NAMELIST parameters (item \#8 in Figure F.2). The parameter IAC is set to 1 to activate the dose calculation for acute exposure. Release data for the previous sample problem is used $(A I R=0)$. Previous population data for chronic exposure is used $(I P O P=0)$. A population dispersion factor for the acute exposure period is added (IPA=1, PMA=1.0E-04). Graphic reports of population dispersion (IGRPM) and cumulative dose (IGRDOS) are requested.

Figure F.6 shows partial output from Sample Problem Three. A graph of the population dispersion factors as interpolated for each 70-year time period is included in the report (item \#9). The graphic report of the cumulative dose to total body is shown (item \#10). Item \#11 indicates the maximum population dose rate report. The dose integral period during which the maximum dose rate for total body occurred during time period 1. Time period 1 is actually not a 70-year time period but the 1-year acute exposure time period. Included is a report of dose received during the stated time period by radionuclide and organ. A final report (see \#12) identifies the percentage of total dose and cumulative dose by radionuclide and organ over the entire 10,000-year integration period.

A cumulative dose of 46,000 person-rem to total body is reported. This result equals the sum of dose to total body from Sample Problem One (acute exposure) and Sample Problem Two (chronic exposure). Total body doses of 18,000 and 27,000 person-rem are calculated in Sample Problem One and Two, respectively, for a total dose of 46,000 person-rem. Fifty-nine percent of the dose to total body was a result of exposure to ${ }^{238} \mathrm{Pu}$ while $40 \%$ of the total dose to total body was a result of exposure to ${ }^{241} \mathrm{Am}$. A cumulative dose to bone of $1.1 \times 10^{6}$ is reported in Sample Problem Three, $54 \%$ of the dose resulting from exposure to ${ }^{238} \mathrm{Pu}$ and $45 \%$ of the dose resulting from ${ }^{241} \mathrm{Am}$. 
QA PAGE FOR DITTY (VAX VERSION 1.0) RUN ON 27-JAN-86

INTECRATED POPULATION DOSE CALCULATED FOR ACUTE ATMOSPHERIC

RELEASE FROM TIME 1990. A.D. ONWARD FOR 10,000 YEARS

CASE TITLE: Sample Problem Three - Airborne release, acute and chronic exposure

*** DATA LIBRARIES USED:

MASTER NUCLIDE DATA (FILE)

OOD CONCENIRATION RATIOS : (12)

RADIONUCLIDE MASTER DATA LIBRARY /W TRANSLOCATION CLASSES, 19-MAR-85 RAP

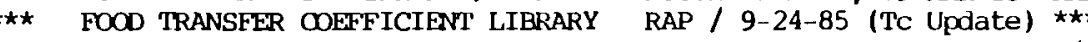
FRESHNATER BIOCCWMTATION RATIOS: $(12)$

EXIERNAL EXPOSURE D.F.' $S:(16)$

BIOACCUMULATION FACTOR LIBRARY FOR FOOD, PABLM, MAXI BA NAPIER (28-NOV-83/RAP)
$\star \star \star$
GRDFLIB FOR FOOD, 15 MARCH 1978, BA NAPIER

INHALATION/TNGESTION D.F.'S : (18)

INTERNAL DOSE OONVERSION FACTOR LIBRARY FOR DITIY1 REV. 1-20-81 (BAN/DLS/RAP)

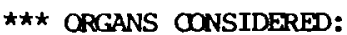

TOTAL BODY

BONE

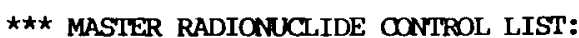
SR90
Y 90
PU238
AM241

* $\star *$ POPULATION DATA:

POPULATION DISPERSION FACTOR FOR ACUIE AIRBORNE REIEASE $=1.00 \mathrm{E}-04$

PREVIOUS INPUT VAUUES USED FOR CHRONIC AIRBORNE RETEASE.

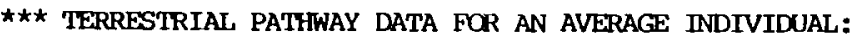

*** AQUATIC PATHWAY DATA FOR AN AVERAGE INDIVIDUAL:

\begin{tabular}{|c|c|c|c|}
\hline PATHWAY & $\begin{array}{l}\text { GROWING PERIOD } \\
\text { (DAYS) }\end{array}$ & $\begin{array}{l}\text { YIEID } \\
\left(\mathrm{KG} / \mathrm{M}^{\star \star \star} 2\right)\end{array}$ & $\begin{array}{l}\text { CONSUMPTIO } \\
(\mathrm{KG} / \mathrm{YR})\end{array}$ \\
\hline LEAFY VEGATARIES & $9.00 \mathrm{E}+01$ & $1.50 \mathrm{E}+00$ & $1.50 \mathrm{E}+01$ \\
\hline OTHER VEGATABLES & $9.00 E+01$ & $2.50 \mathrm{E}+00$ & $2.79 \mathrm{E}+02$ \\
\hline BOGS & $9.00 \mathrm{E}+01$ & $8.40 \mathrm{E}-01$ & $2.00 \mathrm{E}+01$ \\
\hline MILK & $3.00 \mathrm{E}+01$ & $1.30 \mathrm{E}+00$ & $2.30 \mathrm{E}+02$ \\
\hline BEFF & $9.00 \mathrm{E}+01$ & $8.40 \mathrm{E}-01$ & $4.00 \mathrm{E}+01$ \\
\hline PORK & $9.00 E+01$ & $8.40 \mathrm{E}-01$ & $3.00 \mathrm{E}+01$ \\
\hline POULTRY & $9.00 \mathrm{E}+01$ & $8.40 \mathrm{E}-01$ & $8.50 \mathrm{E}+00$ \\
\hline
\end{tabular}

\begin{tabular}{lr} 
PATHWAY & $\begin{array}{c}\text { USAGE } \\
\text { (KG OR HR/YR) } \\
\text { FISH }\end{array}$ \\
CRUSTACEA & $0.00 \mathrm{E}+00$ \\
MOLLUSES & $0.00 \mathrm{E}+00$ \\
PLANIS & $0.00 \mathrm{E}+00$ \\
DRINKING WATER & $0.00 \mathrm{E}+00$ \\
SEDIMENT EXPOSURE & $0.00 \mathrm{E}+00$ \\
SWIMMING TIME & $0.00 \mathrm{E}+00$ \\
\hline
\end{tabular}

*** AIR RELEASE OF EACH RADIONUCLIDE PER PERIOD - ORIES (GRAPH OPTION TURNED OFF)

\begin{tabular}{|c|c|c|c|c|c|c|c|c|c|c|c|c|}
\hline RADIONUCLIDE & PERIO & D ACTVITY & PERIO & D ACTVITY & PERIO & D ACTVITY & PERIO & D ACTVITY & PERIO & D ACTVITY & PERIO & D ACIVITY \\
\hline $\begin{array}{l}\text { SR90 } \\
\text { Y } 90\end{array}$ & & & & & & & & & & & & \\
\hline PU238 & 15 & 51 & 16 & 76 & 17 & 81. & 18 & 86. & 19 & 91. & 20 & 96. \\
\hline & 21 & $1.00 \mathrm{E}+02$ & 22 & $1.05 E+02$ & 23 & $1.10 \mathrm{E}+02$ & 24 & $1.15 \mathrm{E}+02$ & 25 & $1.20 \mathrm{E}+02$ & 26 & $1.25 E+02$ \\
\hline & 27 & $1.30 \mathrm{E}+02$ & 28 & $1.35 \mathrm{E}+02$ & 29 & $1.40 \mathrm{E}+02$ & 30 & $1.49 \mathrm{E}+02$ & 31 & $1.59 \mathrm{E}+02$ & 32 & $1.69 \mathrm{E}+02$ \\
\hline & 33 & $1.79 \mathrm{E}+02$ & 34 & $1.88 \mathrm{E}+02$ & 35 & $1.98 \mathrm{E}+02$ & 36 & $2.08 \mathrm{E}+02$ & 37 & $2.10 \mathrm{E}+02$ & 38 & $2.10 \mathrm{E}+02$ \\
\hline & 39 & $2.10 \mathrm{E}+02$ & 40 & $2.10 \mathrm{E}+02$ & 41 & $2.10 \mathrm{E}+02$ & 42 & $2.10 \mathrm{E}+02$ & 43 & $2.10 \mathrm{E}+02$ & 44 & $2.07 \mathrm{E}+02$ \\
\hline & 45 & $2.02 \mathrm{E}+02$ & 46 & $1.97 \mathrm{E}+02$ & 47 & $1.92 \mathrm{E}+02$ & 48 & $1.87 \mathrm{E}+02$ & 49 & $1.82 E+02$ & 50 & $1.77 \mathrm{E}+02$ \\
\hline & 51 & $1.73 \mathrm{E}+02$ & 52 & $1.68 \mathrm{E}+02$ & 53 & $1.63 \mathrm{E}+02$ & 54 & $1.58 \mathrm{E}+02$ & 55 & $1.53 E+02$ & 56 & $1.48 \mathrm{E}+02$ \\
\hline & 57 & $1.43 \mathrm{E}+02$ & 58 & $1.39 \mathrm{E}+02$ & 59 & $1.37 \mathrm{E}+02$ & 60 & 1. $35 \mathrm{E}+02$ & 61 & $1.33 \mathrm{E}+02$ & 62 & $1.31 \mathrm{E}+02$ \\
\hline & 63 & 1. $30 \mathrm{E}+02$ & 64 & $1.28 \mathrm{E}+02$ & 65 & $1.25 \mathrm{E}+02$ & 66 & $1.22 \mathrm{E}+02$ & 67 & $1.19 \mathrm{E}+02$ & 68 & $1.17 \mathrm{E}+02$ \\
\hline & 69 & $1.14 \mathrm{E}+02$ & 70 & $1.11 \mathrm{E}+02$ & 71 & $1.08 \mathrm{E}+02$ & 72 & $1.04 \mathrm{E}+02$ & 73 & $1.00 \mathrm{E}+02$ & 74 & 95. \\
\hline & 75 & 90 & 76 & 85. & 77 & 80 & 78 & 75. & 79 & 41 & & \\
\hline
\end{tabular}

FIGURE F.6. Sample Problem Three Output 
QA PAGE FOR DITIY (VAX VERSION 1.0) RUN ON 27-JAN-86

INTECRATED POPULATION DOSE CALOULATED FOR ACUTE ATMOSPHERIC

REJEASE FROM TIME 1990. A.D. ONWARD FOR 10,000 YEARS

CASE TITLE: Sample Problen Three - Airborne release, acute and chronic exposure

Y-AXIS INCREMENT $=9.98 \mathrm{E}-06$

$X$-AXIS INCREMENT $=70$ YEARS

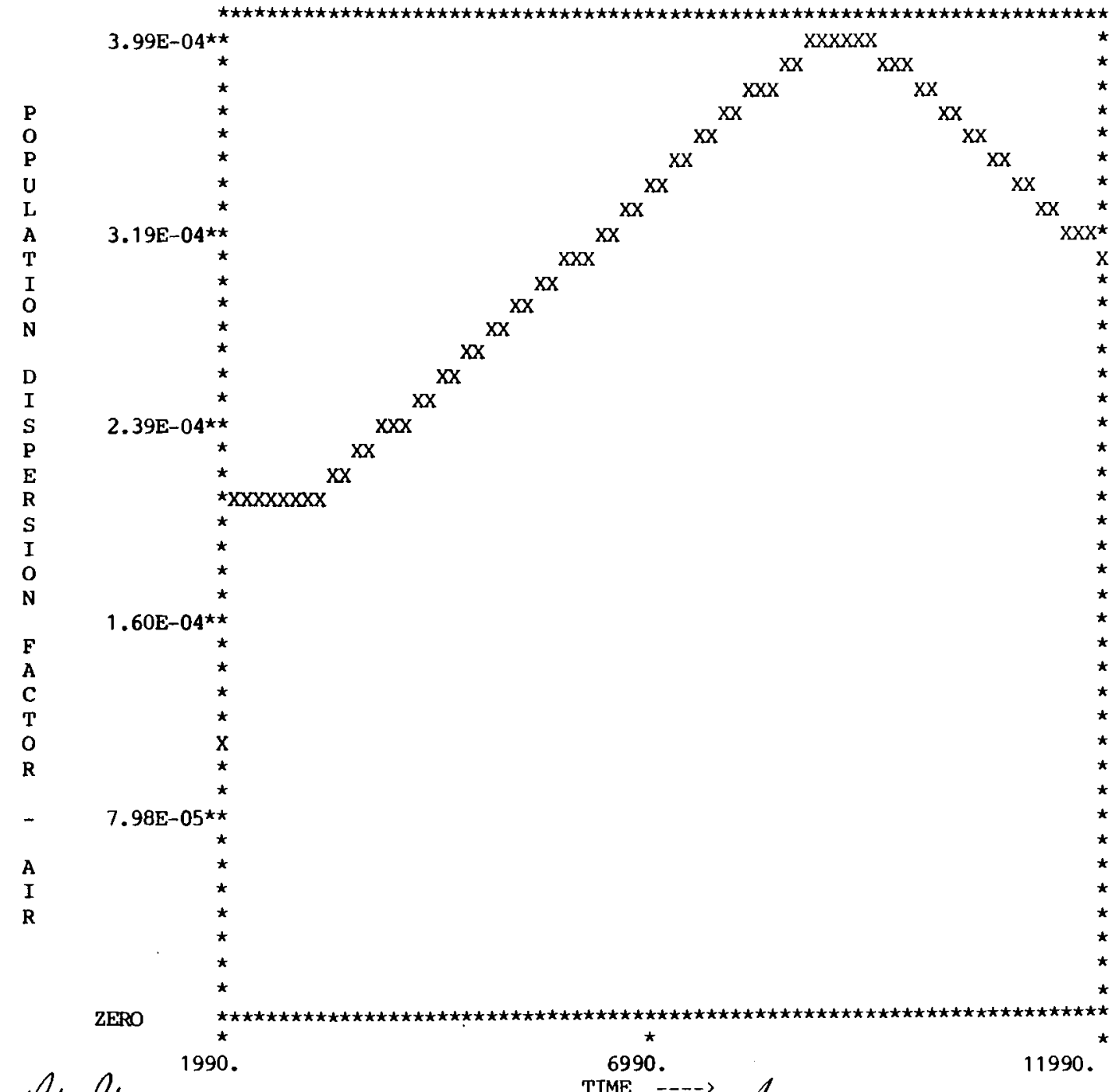

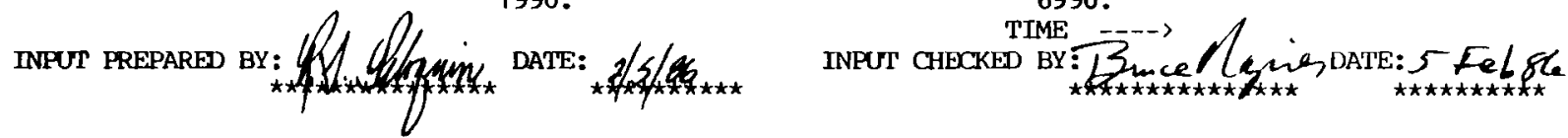

FIGURE F.6. (contd) 
REPORT FOR DITTY (VAX VERSION 1.0) RUN ON 27-JAN-86

INTEGRATED POPUI ATION DOSE CAIOILATED FOR ACITE ATMOSPHERIC

RELEASE FROM TIME 1990. A.D. ONWARD FOR 10,000 YEARS

CASE TITLE: Sample Problem Three - Airborne release, acute and chronic exposure

Y-AXIS INCREMENT $=1,14 \mathrm{E}+03$

$\mathrm{X}$-AXIS INCREMENT $=70$ YEARS

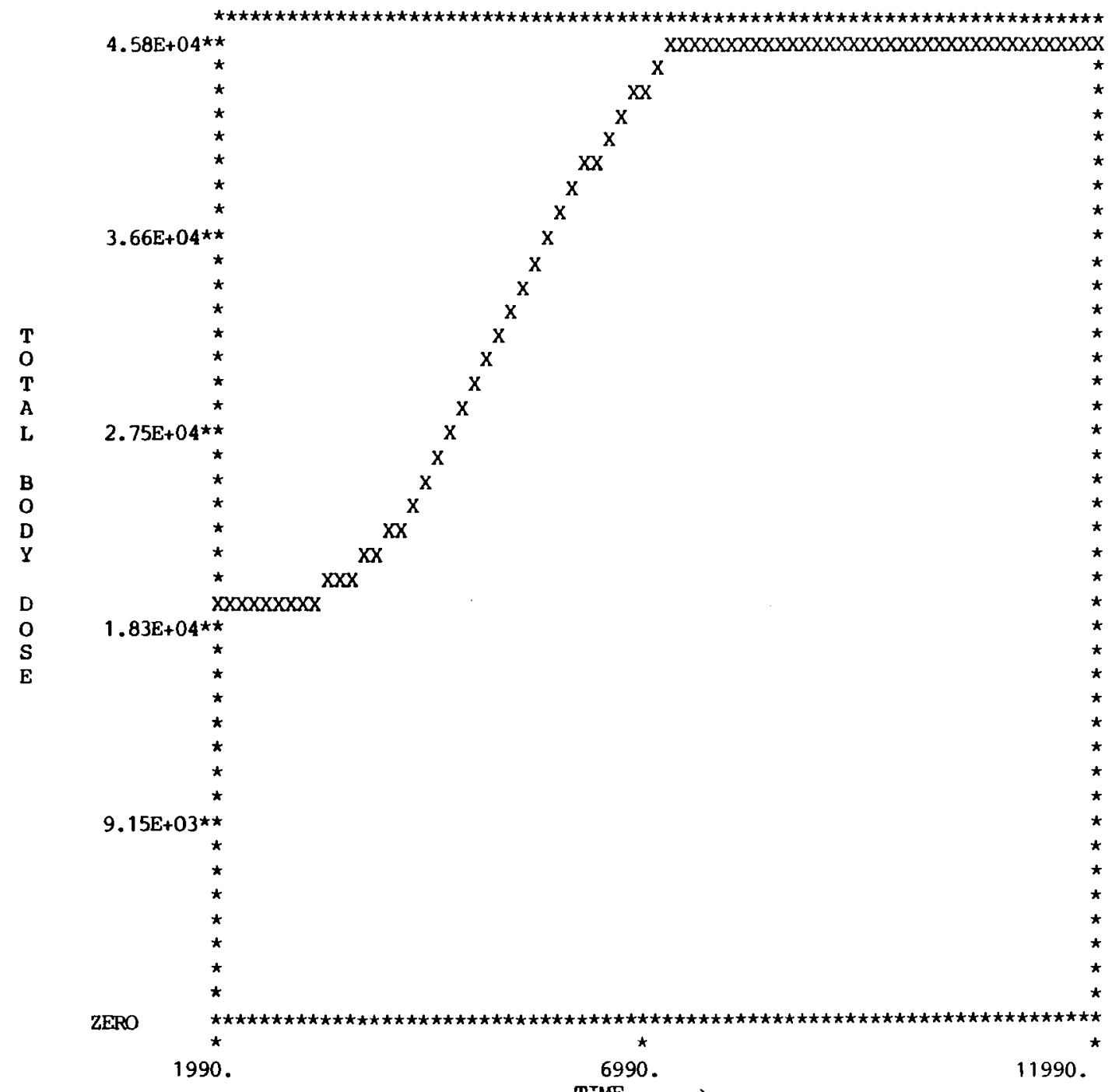

Dose in units of person-rem; that is the cumulative population dose received by the local population over 10,000 years with an assumed 70 -yr individual lifetime.

\section{FIGURE F.6. (contd)}


REPORT FOR DITTY (VAX VERSION 1.0) RUN ON 27-JAN-B6

INTEGRATED POPULATION DOSE CALOULATED FOR AOUTE ATMOSPHERIC

REIEASE FROM TIME 1990. A.D. ONWARD FOR 10,000 YEARS

CASE TITLE: Sample Problem Three - Airborne release, acute and chronic exposure

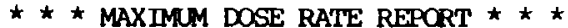

DOSE INTEGRAL PERIOD (70-YEAR) DURING WHICH THE MAXIMUM DOSE RATE OCOURS $=$

* * * MAXIMMM POPULATION DOSE INCREMENT TO TOTAL BODY BY ORGAN AND RADIONUCLIDE * * *

\begin{tabular}{|c|c|c|}
\hline NUCLIDE & TOTAL BODY & BONE \\
\hline $\begin{array}{l}\text { SR90 } \\
\text { Y } 90\end{array}$ & $\begin{array}{l}0.00 \mathrm{E}+00 \\
0.00 \mathrm{E}+00\end{array}$ & $\begin{array}{l}0.00 \mathrm{E}+00 \\
0.00 \mathrm{E}+00\end{array}$ \\
\hline $\begin{array}{l}\text { PU238 } \\
\text { AM241 }\end{array}$ & $\begin{array}{l}0.00 \mathrm{E}+00 \\
1.84 \mathrm{E}+04\end{array}$ & $\begin{array}{l}0.00 \mathrm{E}+00 \\
4.80 \mathrm{E}+05\end{array}$ \\
\hline Total & $1.84 \mathrm{E}+04$ & $4.80 E+05$ \\
\hline
\end{tabular}

Dose in units of person-rem; that is the cumulative population dose received by the local population over 10,000 years with an assumed 70 -yr individual lifetime.

$\star \star \star$ PERCENT OF TOTAL DOSE TO ORGAN AND CUMLLATIVE DOSE TO ORGAN BY RADIONUClidE * * *

\begin{tabular}{|c|c|c|c|c|}
\hline \multirow{2}{*}{$\begin{array}{l}\text { NUCLIDE } \\
\text { SR90 } \\
\text { Y 90 } \\
\text { PU238 } \\
\text { AM241 }\end{array}$} & \multicolumn{2}{|c|}{ TOTAL BODY } & \multicolumn{2}{|c|}{ BONE } \\
\hline & $\begin{array}{r}08 \\
08 \\
598 \\
408\end{array}$ & $\begin{array}{l}0.0 \mathrm{E}+00 \\
0.0 \mathrm{E}+00 \\
2.7 \mathrm{E}+04 \\
1.8 \mathrm{E}+04\end{array}$ & $\begin{array}{r}08 \\
08 \\
548 \\
458\end{array}$ & $\begin{array}{l}0.0 \mathrm{E}+00 \\
0.0 \mathrm{E}+00 \\
5.7 \mathrm{E}+05 \\
4.8 \mathrm{E}+05\end{array}$ \\
\hline Total & & $4.6 \mathrm{E}+04$ & & 1. $1 \mathrm{E}+06$ \\
\hline
\end{tabular}

Dose in units of person-rem; that is the cumulative population dose received by the local population over 10,000 years with an assumed 70-yr individual lifetime.

\section{FIGURE F.6. (contd)}


.

. 
The fourth sample problem demonstrates some alternative input options for airborne releases. Normalized air concentrations are calculated from input meteorological data (IEQ=2). Population dispersion factors are calculated from input populdtion data (IPOP=2).

Sample Problem Four considers on airborne releâse of ${ }^{90} \mathrm{Sr}$. The acute exposure pathway is deactivated $(I A C=0)$. Terrestrial pathway parameter values from the previous cases remain in effect. Average annual meteorological data entered through NAMELIST INPUT consists of site grid description parameters (NDIST, DIST, NSECT) and atinospheric dispersion parameters (HS, NMET, MET, NUBAR, UBAR). Population data entered through NAMELIST INPUT consists of a set (NTA) of population dispersion factors (PMI) at specified times ( $T$ ). Release data will be input (IAIR=1) from an auxiliary file (LUA=0). Graphical report options are deactivated. The airborne release file is assigned to logical unit device 26 (item \#13 in Figure F.2). Figure F.7 shows the file containing release data for Sample Problem Four. Joint frequency data (Record type 6) follows the NAMELIST INPUT record set (item \#14 in Figure F.8). Finally, the initial population distribution is included in the format of Record types 8 and 9 (item \#15 in Figure F.2).

Reports of population and atmospheric dispersion input are included in the QA PAGE report for DITTY as shown in Figure F.8. Reports of the initial population distribution (item \#16) and population dispersion factors as input (item \#17) are followed by a report of the calculated population dispersion factors that is used for each 70-year time period ( $i$ tem \#18). I tem \#19 points to the joint frequency data report.

A cumulative dose of $1.7 \times 10^{6}$ and $1.5 \times 10^{7}$ person-rem for total body and bone, respectively, is reported for Sample Problem Four (item \#20 in Figure F.8).

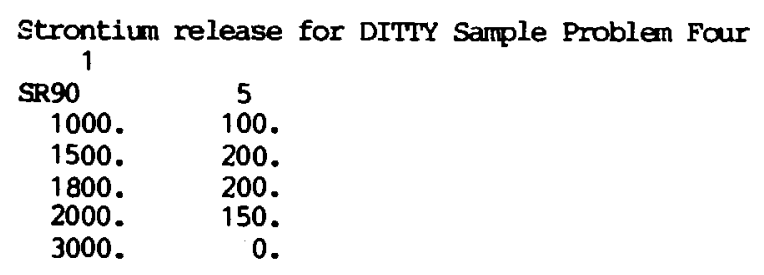

FIGURE F.7. Inventory File for Sample Set 2 
QA PAGE FOR DITTS $($ VAX VERSION 1.0 ) RUN ON 4 -FEB-86

REILASE FROM TIME 1990. A.D. ONWARD FOR 10,000 YEARS

CASE TITIE: Sample Problem Four - Airborne release, release data from file, IPOP=2

$\star \star \star$ DATA LIBRARIES USED: (FILE)

MASTER NUCLIDE DATA : $(10)$

FOOO OONCENIRATION RATIOS : (12)

FRESHWATER BIOACCUMULATION FACIORS : $(14)$

EXTERNAL EXPOSURE D.F.'S : (16)

INHALATION

AIRBORNE REIEASE DATA : $(26)$

RADIONUCLIDE MASTER DATA LIBRARY /W TRANSLOCATION CIASSES, 19-MAR-85 RAP

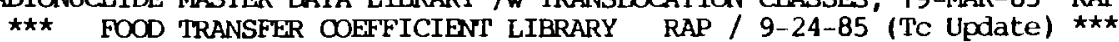
BIOACOUMULATION FACIOR LIBRARY FOR FOOD, PABLM, MAXI BA NAPIER (28-NOV-83/RAP)

INTERNAL DOSE OONVERSION FACTOR LIBRARY FOR DITTY1 REV. 1-20-81 (BAN/DIS/RAP) Strontium release for DITTY Sample Problem Four

$\star \star \star$ ORGANS CONSIDERED:

TOTAL BODY

BONE

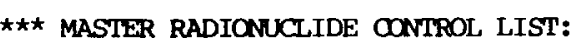

SR90

$\Psi 90$

PU238

AM241

$\star \star \star$ POPULATION DATA:

POPULATION FOR GHRONIC AIRBORNE RELEASE AT TIME 1984.:

\begin{tabular}{l} 
SECTOR \\
\hline NNE \\
NE \\
ENE \\
E \\
ESE \\
SE \\
SSE \\
S \\
SSW \\
SW \\
WSW \\
W \\
WNW \\
NW \\
NNW
\end{tabular}

\begin{tabular}{lllllll}
$8.05 \mathrm{E}+02$ & $2.41 \mathrm{E}+03$ & $4.02 \mathrm{E}+03$ & $5.63 \mathrm{E}+03$ & $7.24 \mathrm{E}+03$ & $1.20 \mathrm{E}+04$ & 2.4 \\
\hdashline $0.00 \mathrm{E}+00$ & $-0.00 \mathrm{E}+00$ & $0.00 \mathrm{E}+00$ & $0.00 \mathrm{E}+00$ & $0.00 \mathrm{E}+00$ & $6.31 \mathrm{E}+02$ & 1.1 \\
$0.00 \mathrm{E}+00$ & $0.00 \mathrm{E}+00$ & $0.00 \mathrm{E}+00$ & $0.00 \mathrm{E}+00$ & $0.00 \mathrm{E}+00$ & $5.57 \mathrm{E}+02$ & 1.7 \\
$0.00 \mathrm{E}+00$ & $0.00 \mathrm{E}+00$ & $0.00 \mathrm{E}+00$ & $0.00 \mathrm{E}+00$ & $0.00 \mathrm{E}+00$ & $9.80 \mathrm{E}+02$ & 2.9 \\
$0.00 \mathrm{E}+00$ & $0.00 \mathrm{E}+00$ & $0.00 \mathrm{E}+00$ & $0.00 \mathrm{E}+00$ & $0.00 \mathrm{E}+00$ & $3.96 \mathrm{E}+02$ & 5.0 \\
$0.00 \mathrm{E}+00$ & $0.00 \mathrm{E}+00$ & $0.00 \mathrm{E}+00$ & $0.00 \mathrm{E}+00$ & $0.00 \mathrm{E}+00$ & $2.44 \mathrm{E}+02$ & 7.6 \\
$0.00 \mathrm{E}+00$ & $0.00 \mathrm{E}+00$ & $0.00 \mathrm{E}+00$ & $0.00 \mathrm{E}+00$ & $0.00 \mathrm{E}+00$ & $2.33 \mathrm{E}+02$ & 2.4
\end{tabular}

$0.00 \mathrm{E}+00 \quad 0.00 \mathrm{E}+00 \quad 0.00 \mathrm{E}+00 \quad 0.00 \mathrm{E}+00 \quad 0.00 \mathrm{E}+00$

$\begin{array}{lllll}0.00 \mathrm{E}+00 & 0.00 \mathrm{E}+00 & 0.00 \mathrm{E}+00 & 0.00 \mathrm{E}+00 & 0.00 \mathrm{E}+00\end{array}$

$\begin{array}{lllll}0.00 \mathrm{E}+00 & 0.00 \mathrm{E}+00 & 0.00 \mathrm{E}+00 & 0.00 \mathrm{E}+00 & 0.00 \mathrm{E}+00\end{array}$

$\begin{array}{lllll}0.00 \mathrm{E}+00 & 0.00 \mathrm{E}+00 & 0.00 \mathrm{E}+00 & 0.00 \mathrm{E}+00 & 0.00 \mathrm{E}+00\end{array}$

28 .

\section{0}

$3.08 \mathrm{E}+02$

$\begin{array}{llllll}0.00 \mathrm{E}+00 & 0.00 \mathrm{E}+00 & 0.00 \mathrm{E}+00 & 0.00 \mathrm{E}+00 & 0.00 \mathrm{E}+00 & 1.42 \mathrm{E}+02\end{array}$

$1.28 \mathrm{E}+02 \quad 6.23 \mathrm{E}+02 \quad 9.77 \mathrm{E}+02$

$\begin{array}{lllllllll}0.00 \mathrm{E}+00 & 0.00 \mathrm{E}+00 & 0.00 \mathrm{E}+00 & 0.00 \mathrm{E}+00 & 0.00 \mathrm{E}+00 & 3.21 \mathrm{E}+02 & 1.83 \mathrm{E}+03 & 1.55 \mathrm{E}+02 & 3.48 \mathrm{E}+02\end{array}$

$\begin{array}{lllllllll}0.00 \mathrm{E}+00 & 0.00 \mathrm{E}+00 & 0.00 \mathrm{E}+00 & 0.00 \mathrm{E}+00 & 0.00 \mathrm{E}+00 & 4.0 & 3.80 \mathrm{E}+04 & 5.11 \mathrm{E}+04 & 9.48 \mathrm{E}+02\end{array}$

$\begin{array}{llllllllll}\mathrm{NNW} & 0.00 \mathrm{E}+00 & 0.00 \mathrm{E}+00 & 0.00 \mathrm{E}+00 & 0.00 \mathrm{E}+00 & 0.00 \mathrm{E}+00 & 2.11 \mathrm{E}+03 & 1.30 \mathrm{E}+03 & 3.41 \mathrm{E}+02 & 2.31 \mathrm{E}+03\end{array}$

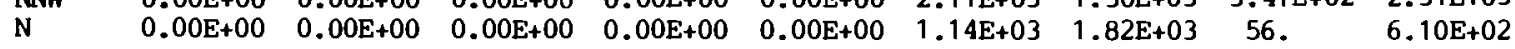

POPULATION FOR CHRONIC AIRBORNE RELEASE AT THE FOLLOWING TIMES A.D.:

\begin{tabular}{|c|c|c|c|c|c|c|c|c|c|}
\hline TIME & POPULATION & TIME & POPULAT'ION & TIME & POPULATION & TIME & FOPUIATION & TIME & POPULATION \\
\hline 1984. & $2.95 E+05$ & 40000 . & $5.00 E+05$ & 60000 . & $1.00 \mathrm{E}+06$ & 90000 . & $1.50 \mathrm{E}+06$ & 120000 . & $1.00 \mathrm{E}+06$ \\
\hline
\end{tabular}

FIGURE F.8. Sample Problem Four Output 


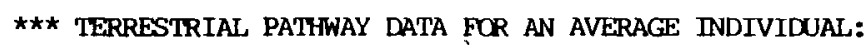

\begin{tabular}{|c|c|c|c|}
\hline PATHWAY & $\begin{array}{c}\text { GROWING PERIOD } \\
\text { (DAYS) }\end{array}$ & $\begin{array}{l}\text { YIETD } \\
\left(K G / M^{\star \star 2}\right)\end{array}$ & $\begin{array}{c}\text { OONSUMPTION } \\
\text { (KG/YR) }\end{array}$ \\
\hline LEAFY VEGATABLES & $9.00 \mathrm{E}+01$ & $1.50 \mathrm{E}+00$ & $1.50 \mathrm{E}+01$ \\
\hline OTHER VEGATABLES & $9.00 \mathrm{E}+01$ & $2.50 \mathrm{E}+00$ & $2.79 E+02$ \\
\hline FGGS & $9.00 \mathrm{E}+01$ & $8.40 \mathrm{E}-01$ & $2.00 \mathrm{E}+01$ \\
\hline MILK & $3.00 \mathrm{E}+01$ & $1.30 E+00$ & $2.30 E+02$ \\
\hline BEEF & $9.00 \mathrm{E}+01$ & $8.40 \mathrm{E}-01$ & $4.00 \mathrm{E}+01$ \\
\hline PORK & $9.00 \mathrm{E}+01$ & $8.40 \mathrm{E}-01$ & $3.00 \mathrm{E}+01$ \\
\hline POULTRY & $9.00 \mathrm{E}+01$ & $8.40 \mathrm{E}-01$ & $8.50 E+00$ \\
\hline
\end{tabular}

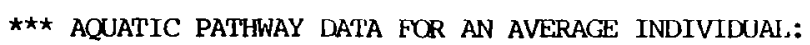

\begin{tabular}{|c|c|}
\hline PATHINAY & USAGE \\
\hline FISH & $\begin{array}{c}\text { (KG } \mathrm{OR} \mathrm{HR} / \mathrm{YR}) \\
0.00 \mathrm{E}+00\end{array}$ \\
\hline $\begin{array}{l}\text { QRUSTACFA } \\
\text { MOLUUSES }\end{array}$ & $\begin{array}{l}0.00 \mathrm{E}+00 \\
0.00 \mathrm{E}+00\end{array}$ \\
\hline PLANTS & $0.00 \mathrm{E}+00$ \\
\hline DRINKING WATER & $0.00 E+00$ \\
\hline SEDIMENT EXPOSURE & $0.00 \mathrm{E}+00$ \\
\hline SWIMMING TIME & $0.00 \mathrm{E}+00$ \\
\hline
\end{tabular}

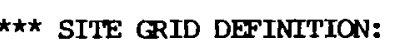

NUMBER PF SFCTORS: 16

$\begin{array}{lrlllll}\text { 805. } & 2414 . & 9 & & & & \end{array}$

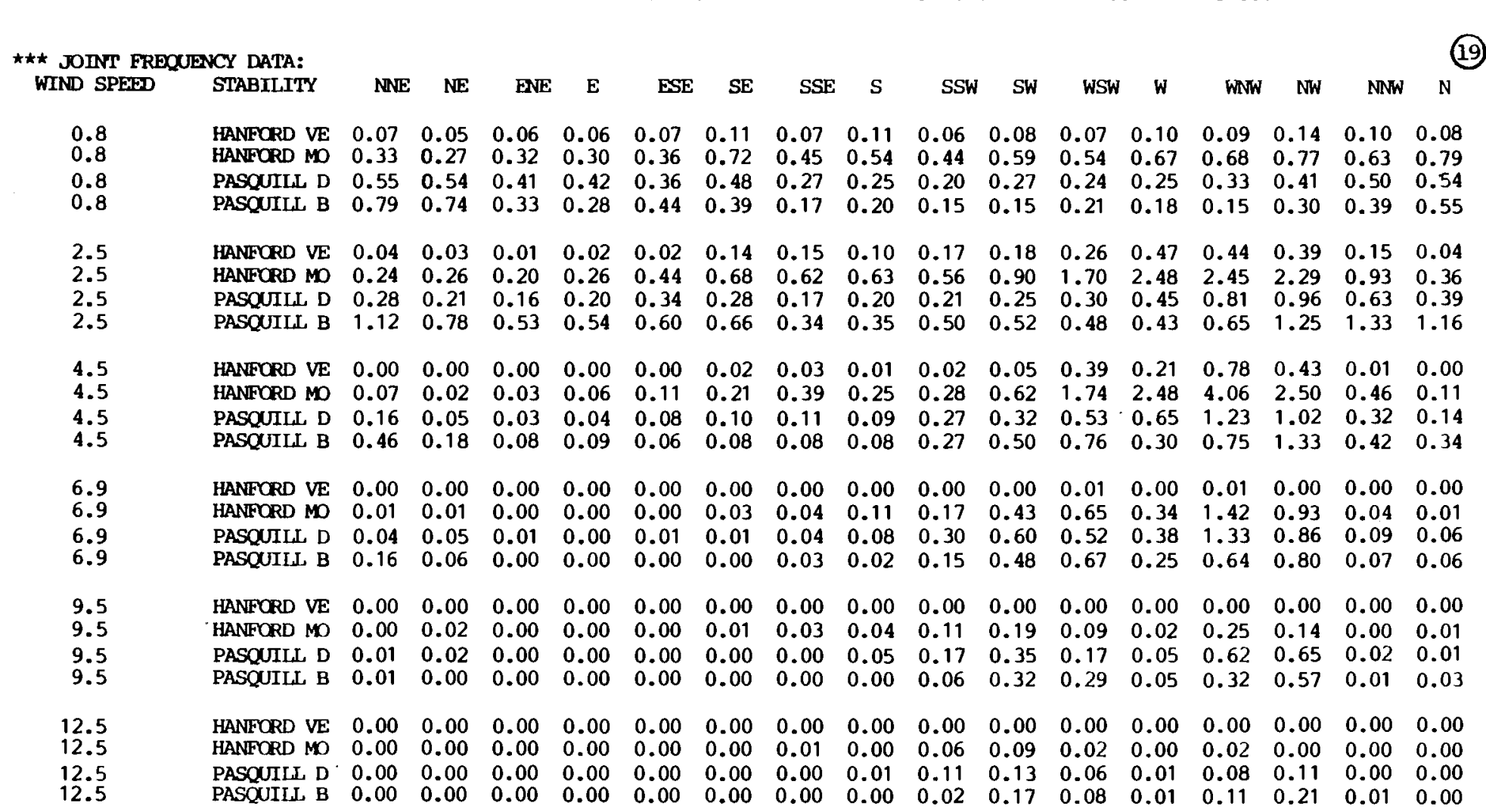

STACK HETGHT: $\quad 0.00$

FIGURE F.8. (contd) 
*** AIR RELEASE OF EACH RADIONUCLIDE PER PERIOD CURIES (GRAPH OPTION TURNED OFF) RADTONUCLIDE PERIOD ACTVITY

PERIOD ACIVITY

PERIOD ACTVITY

PERIOD ACIVITY

PERIOD ACTVITY

PERIOD ACTVITY

SR90

$\begin{array}{ll}15 & 5.25 \mathrm{E}+03 \\ 21 & 1.31 \mathrm{E}+04 \\ 27 & 1.30 \mathrm{E}+04 \\ 33 & 7.61 \mathrm{E}+03 \\ 39 & 3.20 \mathrm{E}+03\end{array}$

$\begin{array}{ll}16 & 8.19 \mathrm{E}+03 \\ 22 & 1.39 \mathrm{E}+04 \\ 28 & 1.18 \mathrm{E}+04 \\ 34 & 6.88 \mathrm{E}+03 \\ 40 & 2.47 \mathrm{E}+03\end{array}$

$\begin{array}{ll}17 & 9.17 \mathrm{E}+03 \\ 23 & 1.40 \mathrm{E}+04 \\ 29 & 1.06 \mathrm{E}+04 \\ 35 & 6.14 \mathrm{E}+03 \\ 41 & 1.73 \mathrm{E}+03\end{array}$

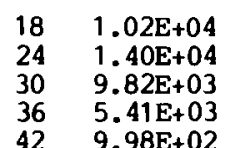
$\begin{array}{ll}19 & 1.11 \mathrm{E}+04 \\ 25 & 1.40 \mathrm{E}+04\end{array}$ $9.08 \mathrm{E}+03$
$4.67 \mathrm{E}+03$
$43 \quad 2.70 \mathrm{E}+02$

$20 \quad 1.21 \mathrm{E}+04$

$34 \quad 6.88 \mathrm{E}+03$

$\begin{array}{ll}35 & 6.14 \mathrm{E}+03 \\ 41 & 1.73 \mathrm{E}+03\end{array}$

$42 \quad 9.98 \mathrm{E}+02$

Y 90

PU238

AM241

$\star \star \star$ POPULATION DISPERSION FACTOR FOR AIRBORNE REILASE, PERSON-SEC/M $\star \star 3$

\begin{tabular}{rrrr}
\multicolumn{1}{r}{ PERIOD } & PM & \multicolumn{2}{c}{ PERIOD } \\
\hline 0 & $1.00 \mathrm{E}-04$ & 1 & $5.96 \mathrm{E}-03$ \\
6 & $6.67 \mathrm{E}-03$ & 7 & $6.81 \mathrm{E}-03$ \\
12 & $7.52 \mathrm{E}-03$ & 13 & $7.67 \mathrm{E}-03$ \\
18 & $8.38 \mathrm{E}-03$ & 19 & $8.52 \mathrm{E}-03$ \\
24 & $9.23 \mathrm{E}-03$ & 25 & $9.37 \mathrm{E}-03$ \\
30 & $1.02 \mathrm{E}-02$ & 31 & $1.06 \mathrm{E}-02$ \\
36 & $1.23 \mathrm{E}-02$ & 37 & $1.27 \mathrm{E}-02$ \\
42 & $1.44 \mathrm{E}-02$ & 43 & $1.48 \mathrm{E}-02$ \\
48 & $1.65 \mathrm{E}-02$ & 49 & $1.69 \mathrm{E}-02$ \\
54 & $1.86 \mathrm{E}-02$ & 55 & $1.90 \mathrm{E}-02$ \\
60 & $2.05 \mathrm{E}-02$ & 61 & $2.07 \mathrm{E}-02$ \\
66 & $2.18 \mathrm{E}-02$ & 67 & $2.21 \mathrm{E}-02$ \\
72 & $2.32 \mathrm{E}-02$ & 73 & $2.35 \mathrm{E}-02$ \\
78 & $2.46 \mathrm{E}-02$ & 79 & $2.49 \mathrm{E}-02$ \\
84 & $2.60 \mathrm{E}-02$ & 85 & $2.63 \mathrm{E}-02$ \\
90 & $2.74 \mathrm{E}-02$ & 91 & $2.77 \mathrm{E}-02$ \\
96 & $2.88 \mathrm{E}-02$ & 97 & $2.91 \mathrm{E}-02$ \\
102 & $2.96 \mathrm{E}-02$ & 103 & $2.94 \mathrm{E}-02$ \\
108 & $2.82 \mathrm{E}-02$ & 109 & $2.80 \mathrm{E}-02$ \\
114 & $2.68 \mathrm{E}-02$ & 115 & $2.66 \mathrm{E}-02$ \\
120 & $2.54 \mathrm{E}-02$ & 121 & $2.52 \mathrm{E}-02$ \\
126 & $2.40 \mathrm{E}-02$ & 127 & $2.38 \mathrm{E}-02$ \\
132 & $2.26 \mathrm{E}-02$ & 133 & $2.24 \mathrm{E}-02$ \\
138 & $2.12 \mathrm{E}-02$ & 139 & $2.10 \mathrm{E}-02$
\end{tabular}

\begin{tabular}{rr}
\multicolumn{1}{r}{ PERIOD } & PM \\
-2 & $6.10 \mathrm{E}-03$ \\
8 & $6.96 \mathrm{E}-03$ \\
14 & $7.81 \mathrm{E}-03$ \\
20 & $8.66 \mathrm{E}-03$ \\
26 & $9.51 \mathrm{E}-03$ \\
32 & $1.09 \mathrm{E}-02$ \\
38 & $1.30 \mathrm{E}-02$ \\
44 & $1.51 \mathrm{E}-02$ \\
50 & $1.72 \mathrm{E}-02$ \\
56 & $1.93 \mathrm{E}-02$ \\
62 & $2.09 \mathrm{E}-02$ \\
68 & $2.23 \mathrm{E}-02$ \\
74 & $2.37 \mathrm{E}-02$ \\
80 & $2.51 \mathrm{E}-02$ \\
86 & $2.65 \mathrm{E}-02$ \\
92 & $2.79 \mathrm{E}-02$ \\
98 & $2.93 \mathrm{E}-02$ \\
104 & $2.91 \mathrm{E}-02$ \\
110 & $2.77 \mathrm{E}-02$ \\
116 & $2.63 \mathrm{E}-02$ \\
122 & $2.49 \mathrm{E}-02$ \\
128 & $2.35 \mathrm{E}-02$ \\
134 & $2.21 \mathrm{E}-02$ \\
140 & $2.08 \mathrm{E}-02$
\end{tabular}

\begin{tabular}{rr}
\multicolumn{1}{r}{ PERIOD } \\
-3 & PM \\
\hline 9 & $7.25 \mathrm{E}-03$ \\
15 & $7.95 \mathrm{E}-03$ \\
21 & $8.80 \mathrm{E}-03$ \\
27 & $9.65 \mathrm{E}-03$ \\
33 & $1.13 \mathrm{E}-02$ \\
39 & $1.34 \mathrm{E}-02$ \\
45 & $1.55 \mathrm{E}-02$ \\
51 & $1.76 \mathrm{E}-02$ \\
57 & $1.97 \mathrm{E}-02$ \\
63 & $2.11 \mathrm{E}-02$ \\
69 & $2.25 \mathrm{E}-02$ \\
75 & $2.39 \mathrm{E}-02$ \\
81 & $2.53 \mathrm{E}-02$ \\
87 & $2.67 \mathrm{E}-02$ \\
93 & $2.81 \mathrm{E}-02$ \\
99 & $2.95 \mathrm{E}-02$ \\
105 & $2.89 \mathrm{E}-02$ \\
111 & $2.75 \mathrm{E}-02$ \\
117 & $2.61 \mathrm{E}-02$ \\
123 & $2.47 \mathrm{E}-02$ \\
129 & $2.33 \mathrm{E}-02$ \\
135 & $2.19 \mathrm{E}-02$ \\
141 & $2.05 \mathrm{E}-02$
\end{tabular}

\begin{tabular}{rr} 
PERIOD & PM \\
\hline 4 & $6.39 \mathrm{E}-03$ \\
10 & $7.24 \mathrm{E}-03$ \\
16 & $8.09 \mathrm{E}-03$ \\
22 & $8.94 \mathrm{E}-03$ \\
28 & $9.80 \mathrm{E}-03$ \\
34 & $1.16 \mathrm{E}-02$ \\
40 & $1.37 \mathrm{E}-02$ \\
46 & $1.58 \mathrm{E}-02$ \\
52 & $1.79 \mathrm{E}-02$ \\
58 & $2.00 \mathrm{E}-02$ \\
64 & $2.14 \mathrm{E}-02$ \\
70 & $2.28 \mathrm{E}-02$ \\
76 & $2.42 \mathrm{E}-02$ \\
82 & $2.56 \mathrm{E}-02$ \\
88 & $2.70 \mathrm{E}-02$ \\
94 & $2.84 \mathrm{E}-02$ \\
100 & $2.98 \mathrm{E}-02$ \\
106 & $2.87 \mathrm{E}-02$ \\
112 & $2.73 \mathrm{E}-02$ \\
118 & $2.59 \mathrm{E}-02$ \\
124 & $2.45 \mathrm{E}-02$ \\
130 & $2.31 \mathrm{E}-02$ \\
136 & $2.17 \mathrm{E}-02$ \\
142 & $2.03 \mathrm{E}-02$
\end{tabular}

PERIOD

PM

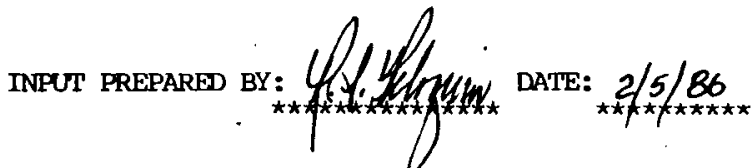

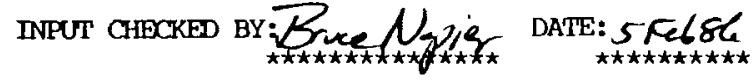

FIGURE F.8. (contd) 
REPORT FOR DITTY (VAX VERSION 1.0) RIN ON 4-FEB-86

INTERRATED POPULATION DOSE CALCULATED FOR CHRONIC ATMOSPHERIC

RETLASE FROM TIME 1990. A.D. ONWARD FOR 10,000 YEARS

CASE TITIE: Sample Problem Four - Airborne release, release data from fille, IPOP $=2$

* * * Cumllative dose to seiffcted ORGans as a function OF TIME * * *

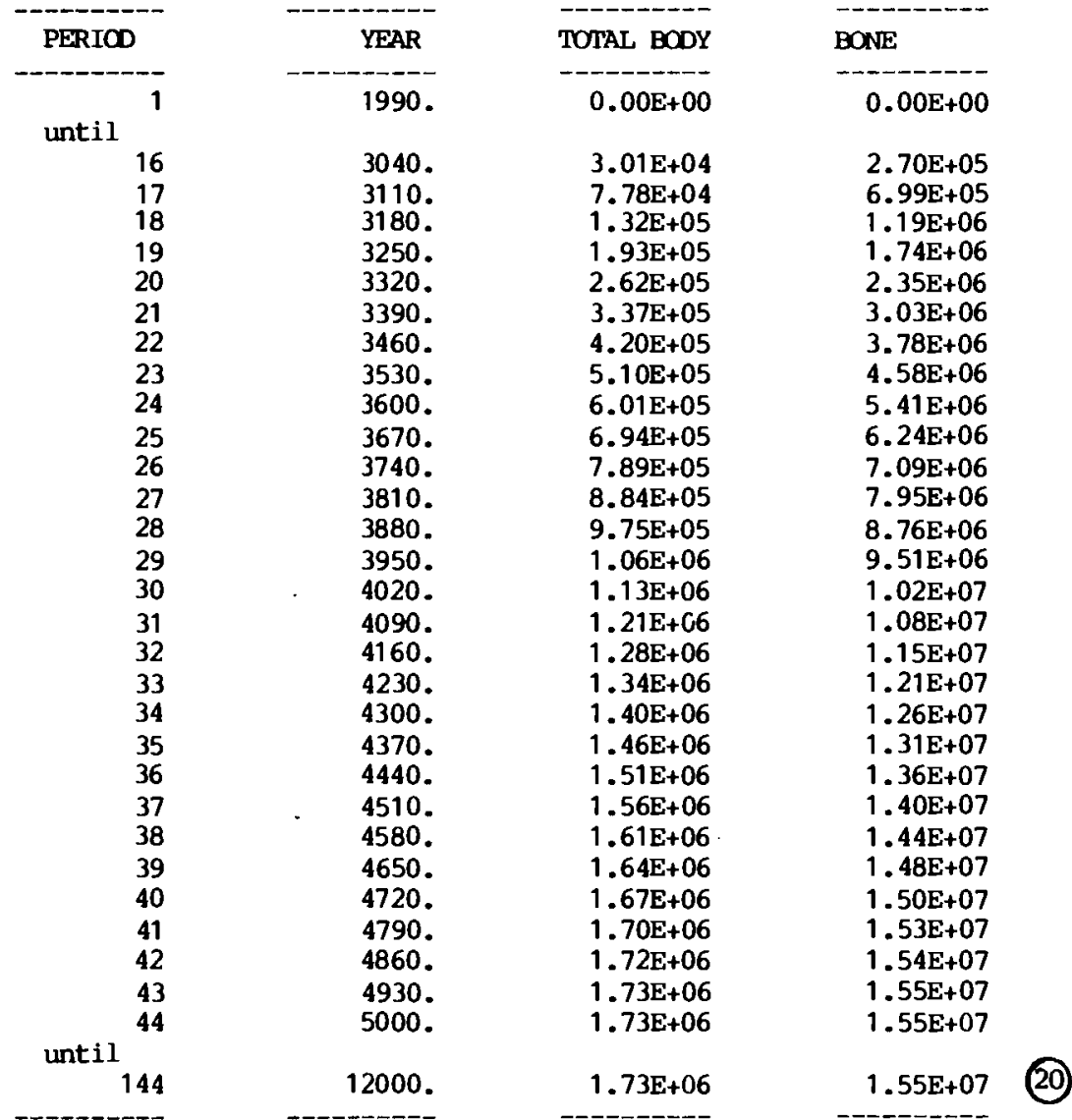

Dase in units of person-rem; that is the cumulative population dose received by the local population over 10,000 years with an assumed 70 -yr individual lifetine.

FIGURE F.8. (contd) 


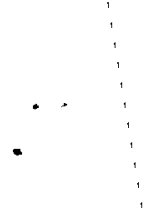




\section{SAMPLE PROBLEM FIVE}

Sample Problem Five is the first of three problems in Sample Set 3. Chronic exposure to a water release of ${ }^{90} \mathrm{Sr}$ and ${ }^{129} \mathrm{I}$ is simulated during this scenario. Input for Sample Problem Five is shown in Figure F.3 (item \#21).

NAMELIST INPUT parameters for this sample problem specify that release data is entered (IWAT $=1$ ) from an auxiliary file ( $L U W=0)$. Total population (PL1) for six $(N T L=6)$ times (TL) during the 10,000-year integration period are specified. Generic terrestrial and waterborne pathway parameter values are used (USAGE, CONSUM, EXTIM, GRWP, MOPYR, RIRR, YELD).

The waterborne release file for Sample Problem Five is shown in Figure F.9. This file must be assigned to lun 24 (item \#22 in Figure F.3). Release data is included for ${ }^{14} \mathrm{C},{ }^{90} \mathrm{Sr}$, and ${ }^{129} \mathrm{I}$. The ${ }^{14} \mathrm{C}$ release will not be considered in this sample problem because it is specified as an acute release (item \#23 in Figure F.9) and the acute exposure pathway (IAC=0) is not selected (item \#21 in Figure F.3). The ${ }^{14} \mathrm{C}$ release will be considered in a following sample problem.

Cumulative doses estimates in units of person-rem for Sample Problem Five are $1.2 \times 10^{4}$ total body, $3.8 \times 10^{4}$ to bone, $7.5 \times 10^{2}$ to 1 ung, $1.2 \times 10^{6}$ to thyroid, and $1.7 \times 10^{3}$ to the lower large intestine of the GI tract (item \#24 in Figure F.10). The maximum dose rate increment (to total body) occurs during dose integral period nine (item \#25 in Figure F.10). The maximum dose rate report for waterborne pathways includes maximum dose increments for both population dose and maximum individual dose. Eighty-one percent of the dose to total body and $96 \%$ of the dose to borie is due to ${ }^{90} \mathrm{Sr}$ (item \#26 in Figure F.10). Ninety-nine percent of the dose to lung and thyroid is due to ${ }^{129} \mathrm{I} .{ }^{90} \mathrm{Sr}$ and ${ }^{129} \mathrm{I}$ are each responsible for half of the dose to the lower large intestine of the GI tract. 
Waterborne release data for sample set $\# 3$
C 14
0 .
2 $.75 E+6$
1.
I 129
9000 .
10000.
10001 .
SR90
0 .
3
1.0
1.0
21
0 .
$5.1852 \mathrm{E}+023.5094 \mathrm{E}-22$
$5.2199 \mathrm{E}+022.1156 \mathrm{E}-01$
$5.2546 \mathrm{E}+026.9540 \mathrm{E}-01$
$5.2893 \mathrm{E}+027.1749$
$5.3240 \mathrm{E}+025.1563$
$5.3587 \mathrm{E}+024.4288$
$5.3934 \mathrm{E}+021.0549 \mathrm{E}-03$
$5.4281 \mathrm{E}+027.9938$
$5.4628 \mathrm{E}+026.6183$
$5.4975 \mathrm{E}+026.0509$
$5.5322 \mathrm{E}+024.5113$
$5.5669 \mathrm{E}+022.5153$
$5.6016 \mathrm{E}+021.3844$
$5.6363 \mathrm{E}+027.7096 \mathrm{E}-01$
$5.6710 \mathrm{E}+024.2537 \mathrm{E}-01$
$5.7057 \mathrm{E}+021.9468 \mathrm{E}-01$
$5.7404 \mathrm{E}+021.0359 \mathrm{E}-01$
$5.7751 \mathrm{~S}+024.3661 \mathrm{E}-02$
$5.8 \mathrm{C} 98 \mathrm{E}+021.9646 \mathrm{E}-02$
$5.84 \ll 5 \mathrm{E}+021.0873 \mathrm{E}-03$
$5.8792 \mathrm{E}+024.1130 \mathrm{E}-25$

FIGURE F.9. Inventory File for Sample Set 3 
QA PAGE FOR DITTY (VAX VERSION 1.0) RUN ON 27-JAN-86

INIBGRATED POPULATION DOSE CAICULATED FOR CHRONIC LIQUID

REIEASE FROM TIME 1990. A.D. ONWARD FOR 10,000 YEARS

CASE TITLE: Sample Problem Five - Waterborne release, chronic exposure

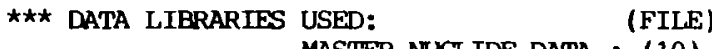

MASTER NUCLIDE DATA : $(10)$

FOOD CONCFNIRATION RATIOS : (12)

FRESHWATER BIOACOUMULATION FACTORS : (14) EXTERNAL EXPOSURE D.F.'S : (16)

INHALATION/ INGESTTON D.F.'S : (18)

RADIONUCLIDE MASTER DATA LIBRARY /W TRANSLOCATION CIASSES, 19-MAR-85 RAP

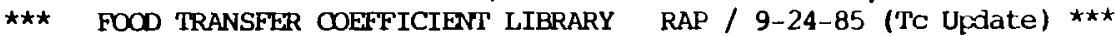

BIOACCUMULATION FACTOR LIBRARY FOR FOOD, PABLM, MAXI BA NAPIER (28-NOV-83/RAP)

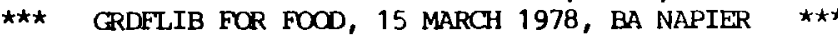
WATBRNE REIEASE DATA : (24) Waterborne release data for sample set \#3

$\star \star \star$ ORGANS CONSIDERED:

TOTAL BODY

BONE

LUNG

THYROID

GI-LLI

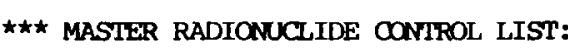
C 14
$\mathrm{SR} 90$
Y 90
I 129
PU238

$\star \star \star$ POPULATION DATA:

POPULATION FOR GRONIC WATERBORNE RETEASE AT THE FOLLOWING TDMES A.D.:

\begin{tabular}{|c|c|c|c|c|c|c|c|c|c|}
\hline TIME & POFULATION & TIME & POPULATION & TIME & POPULATION & TIME & POPULATION & TIME & POPULATION \\
\hline $\begin{array}{r}1990 . \\
19000 .\end{array}$ & $\begin{array}{l}2.95 \\
4.93\end{array}$ & & $3.92 \mathrm{E}+05$ & 22000 . & $4.31 E+05$ & 23000 . & 4. $70 \mathrm{E}+05$ & 29900. & \\
\hline
\end{tabular}

$\star \star \star$ TERRESTRIAL, PATHWAY DATA FOR AN AVERAGE INDIVIDUAL:
PATHWAY

LEAFY VEGATABLES

DOGS

MILK

BEFF

PORK

POULIRY

GROWING PERIOD

(DAYS)
$9.00 \mathrm{E}+01$

$9.00 \mathrm{E}+01$

$9.00 \mathrm{E}+01$

$3.00 \mathrm{E}+01$

$9.00 \mathrm{E}+01$

$9.00 \mathrm{E}+01$

EXTERNAL EXPOSURE TIME,
OTHER VECATABLES

\section{YIETD}

( $K G / M \star \star 2)$

1. $50 \mathrm{E}+00$

2. $50 \mathrm{E}+00$

8. $40 \mathrm{E}-01$

$1.30 \mathrm{E}+00$

$8.40 \mathrm{E}-01$

8. 40E-01

8. 40E-01

8. 40

CONSUMPTION
(KG/YR)
$1.50 \mathrm{E}+01$
$2.79 \mathrm{E}+02$
$2.00 \mathrm{E}+01$
$2.30 \mathrm{E}+02$
$4.00 \mathrm{E}+01$
$3.00 \mathrm{E}+01$
$8.50 \mathrm{E}+00$

$\star \star \star$ AQUATIC PATHWAY DATA FOR AN AVERAGE INDIVIDUAL:

$\begin{array}{lc}\text { PATHWAY } & \begin{array}{c}\text { USAGE } \\ \text { (KG OR HR/YR) } \\ \text { FISH }\end{array} \\ \text { CRUSTACEA } & 0.00 \mathrm{E}-01 \\ \text { MOLLUSES } & 0.00 \mathrm{E}+00 \\ \text { PLANIS } & 0.00 \mathrm{E}+00 \\ \text { DRINKING WATER } & 0.00 \mathrm{E}+00 \\ \text { SEDIMENT EXPOSURE } & 4.38 \mathrm{E}+02 \\ \text { SWIMMING TIME } & 1.70 \mathrm{E}+01 \\ & 1.70 \mathrm{E}+01\end{array}$

$\star \star \star$ FARMTNG PARAMETERS

MONTHS / YEAR IRRIGATED : $6.00 \mathrm{E}+00$

(LITERS/M ${ }^{\star \star 2} 2 /$ MONTH) $: \quad: 1.50 \mathrm{E}+02$ IRRIGATION RATE

$\begin{array}{lll}\text { RIVER FLOW RATE, (FT3/SEC) } & 1.20 \mathrm{E}+05 \\ \text { REOONCENIRATION RATIO } & \vdots & 1.00 \mathrm{E}+00 \\ \text { MIXING RATIO } & : 1.00 \mathrm{E}+00\end{array}$
FIGURE F.10. Sample Problein Five Output 


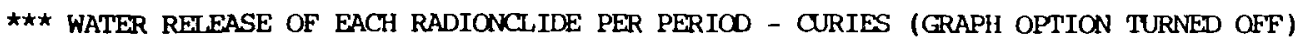

\begin{tabular}{|c|c|c|c|c|c|c|c|c|c|c|c|c|}
\hline RADIONUCLIDE & PERIOD & D ACTVITY & PERIOD & AC:VITY & PERIOD & ACIVITY & PERIOD & ACTVITY & PERIOD & ACTVITY & PERIOD & ACTV \\
\hline C 14 & 0 & $7.50 \mathrm{E}+05$ & & & & & & & & & & \\
\hline SR90 & 8 & $1.60 \mathrm{E}+02$ & 9 & 8.0 & & & & & & & & \\
\hline Y 90 & & & & & & & & & & & & \\
\hline I 129 & $\begin{array}{l}129 \\
135 \\
141\end{array}$ & $\begin{array}{l}30 . \\
70 . \\
70 .\end{array}$ & $\begin{array}{l}130 \\
136 \\
142\end{array}$ & $\begin{array}{l}70 . \\
70 . \\
70 .\end{array}$ & $\begin{array}{l}131 \\
137 \\
143\end{array}$ & $\begin{array}{l}70 . \\
70 . \\
61 .\end{array}$ & $\begin{array}{l}132 \\
138\end{array}$ & $\begin{array}{l}70 . \\
70 .\end{array}$ & $\begin{array}{l}133 \\
139\end{array}$ & $\begin{array}{l}70 . \\
70 .\end{array}$ & $\begin{array}{l}134 \\
140\end{array}$ & $\begin{array}{l}70 . \\
70 .\end{array}$ \\
\hline
\end{tabular}

$\star \star \star$ POPUIATION FOR WATERBORNE REIEASE

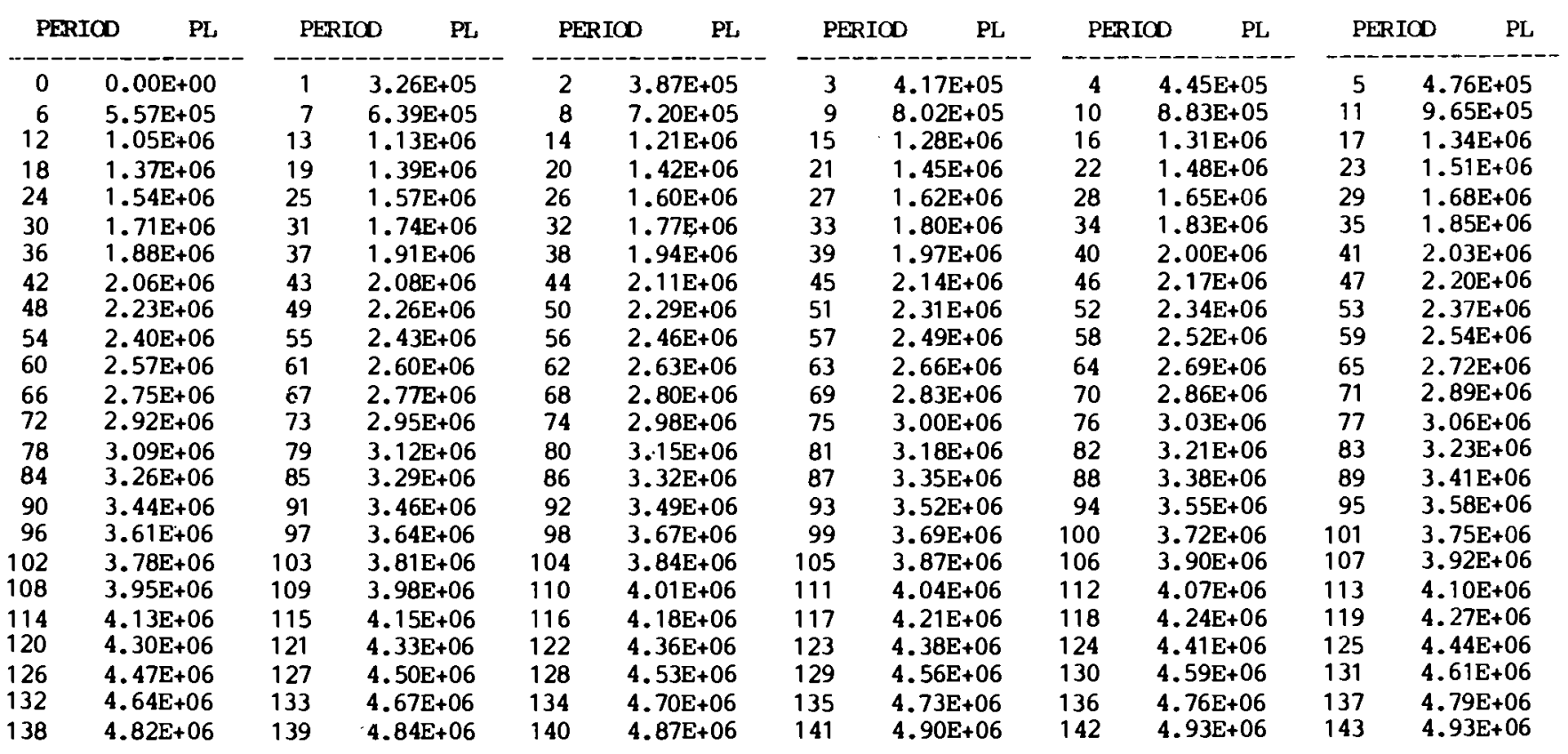

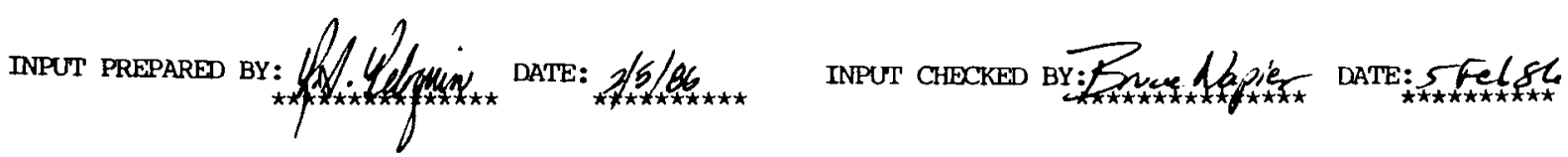

FIGURE F.10. (contd) 
REPORT FOR DITTY (VAX VERSION 1.0) RUN ON 27-JAN-86

INTEGRATED POPULATION DOSE CALCUIAATED FOR CHRONIC LIQUID

RETEASE FROM TTME 1990. A.D. ONWARD FOR 10,000 YEARS

CASE TITLE: Sample Problem Five - Waterborne release, chronic exposure

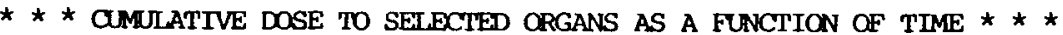

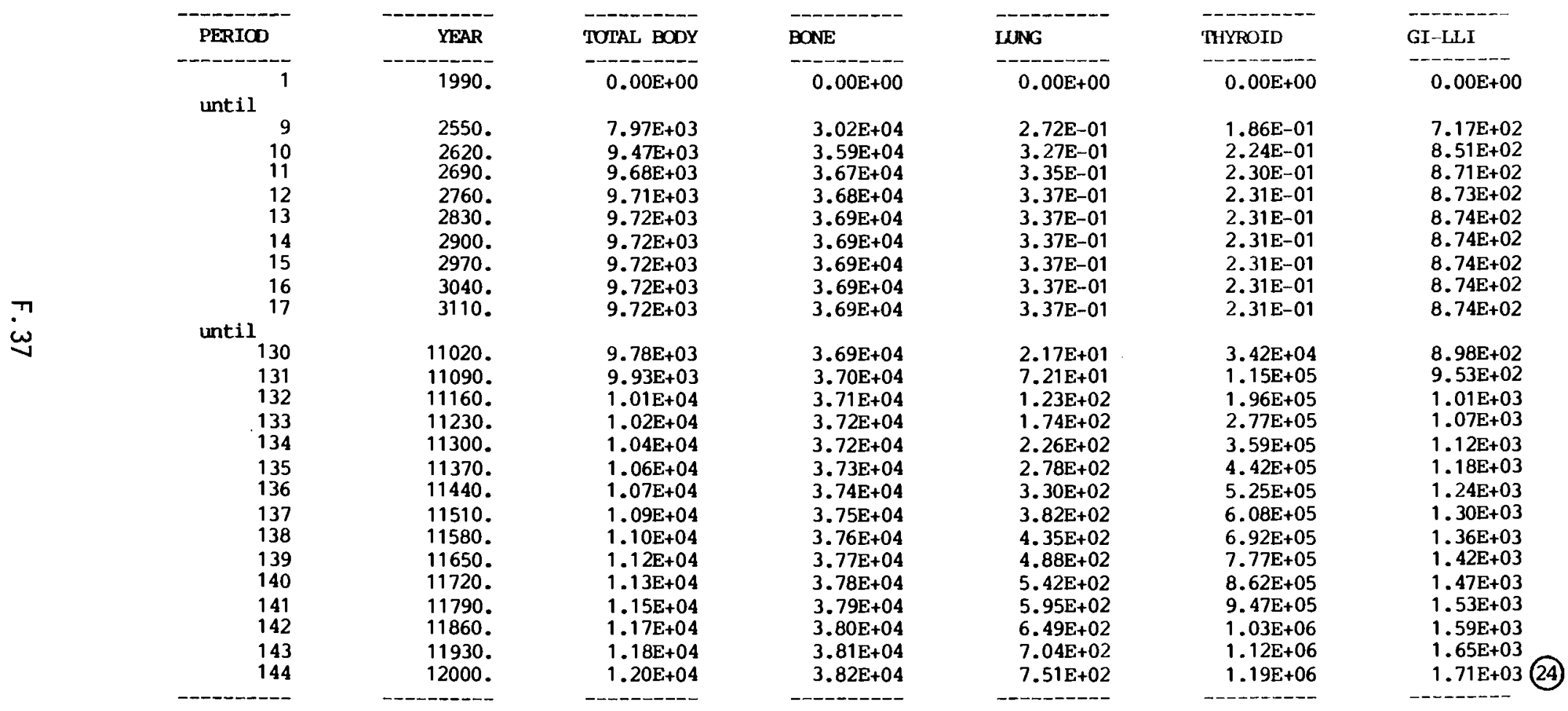

Dose in units of person-rem; that is the cumulative population dose received by the local population over 10,000 years with an assumed $70-y \mathrm{r}$ individual lifetime.

FIGURE F.10. (contd) 
REPORT FOR DITTY (VAX VERSION 1.0) RUN ON 27-JAN-86

INTEGRATED POPULATION DOSE CALCULATED FOR CHRONIC LIQUID

RETEASE FROM TIME 1990 . A.D. ONWARD FOR 10,000 YEARS

CASE TITLE: Sample Problem Five - Waterborne release, chronic exposure

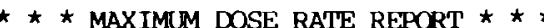

DOSE INTEGRAL PERIOD (70-YEAR) DURING WHICH THE MAXIMUM DOSE RATE OCCURS $=$

9

* * * MAXIMUM POPULATION DOSE INCREMENT TO TOTAL BODY BY ORGAN AND RADIONUCLIDE * * *

\begin{tabular}{|c|c|c|c|c|}
\hline NUCAIDE & TOTAL BODY & BONE & LUNG & THYROID \\
\hline C 14 & $0.00 \mathrm{E}+00$ & $0.00 \mathrm{E}+00$ & $0.00 \mathrm{E}+00$ & $0.00 \mathrm{E}+00$ \\
\hline SR90 & $7.97 \mathrm{E}+03$ & $3.02 E+04$ & $8.51 E-02$ & $9.84 \mathrm{E}-06$ \\
\hline Y 90 & 0.19 & 0.19 & 0.19 & 0.19 \\
\hline I 129 & $0.00 \mathrm{E}+00$ & $0.00 E+00$ & $0.00 \mathrm{E}+00$ & $0.00 \mathrm{E}+00$ \\
\hline PU238 & $0.00 \mathrm{E}+00$ & $0.00 \mathrm{E}+00$ & $0.00 \mathrm{E}+00$ & $0.00 E+00$ \\
\hline Total & $7.97 \mathrm{E}+03$ & $3.02 \mathrm{E}+04$ & 0.27 & 0.19 \\
\hline
\end{tabular}

$$
\begin{aligned}
& \text { GI-ILI } \\
& -0.00 \mathrm{E}+00 \\
& 7.05 \mathrm{E}+02 \\
& 11 . \\
& 0.00 \mathrm{E}+00 \\
& 0.00 \mathrm{E}+00 \\
& -7.17 \mathrm{E}+02
\end{aligned}
$$

Dose in units of person-rem; that is the cumulative population dose received by the local population over 10,000 years with an assumed 70-yr individual lifetime.

\section{* * * MAXIMUM AVERAGE INDIVIDUAL DOSE INCREMENT}

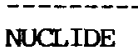

$\pi_{i}$

\begin{tabular}{l} 
C 14 \\
SR90 \\
Y 90 \\
I 129 \\
PU238 \\
\hdashline Total
\end{tabular}

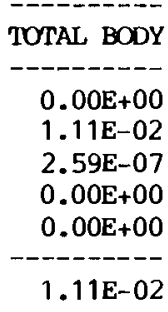

$1.11 \mathrm{E}-02$

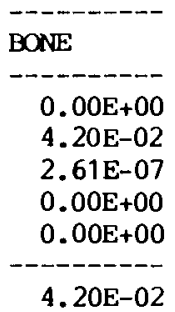

4. $20 \mathrm{E}-02$

Dose in units of rem.

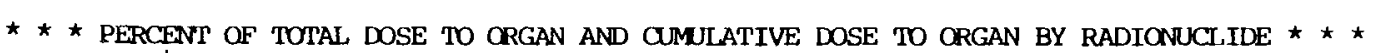

NUCLIDE
SR 14
Y 90
I 129
PU238
Total

$$
\begin{array}{rl}
\text { TOTAL BODY } \\
\hdashline 08 & 0.0 \mathrm{E}+00 \\
818 & 9.7 \mathrm{E}+03 \\
08 & 0.2 \\
188 & 2.3 \mathrm{E}+03 \\
0 ₹ & 0.0 \mathrm{E}+00 \\
\hdashline & 1.2 \mathrm{E}+04
\end{array}
$$

\begin{tabular}{rl} 
BONE \\
\hdashline 08 & $0.0 \mathrm{E}+00$ \\
968 & $3.7 \mathrm{E}+04$ \\
08 & 0.2 \\
38 & $1.3 \mathrm{E}+03$ \\
08 & $0.0 \mathrm{E}+00$ \\
\hdashline $3.8 \mathrm{E}+04$
\end{tabular}

\begin{tabular}{rl}
\hline LUNG \\
\hline 08 & $0.0 \mathrm{E}+00$ \\
08 & 0.1 \\
08 & 0.2 \\
998 & $7.5 \mathrm{E}+02$ \\
08 & $0.0 \mathrm{E}+00$ \\
\hline $7.5 \mathrm{E}+02$
\end{tabular}

\section{THYROID}

$08 \quad 0.0 \mathrm{E}+00$

$080.0 \mathrm{E}+00$

080.2

998 1.2E+06

$\begin{array}{rr}998 & 1.2 \mathrm{E}+06 \\ 08 & 0.0 \mathrm{E}+00\end{array}$

$1.2 \mathrm{E}+06$

Dose in units of person-rem; that is the cumulative population dose received by the local population over 10,000 years with an assumed $70-y r$ individual lifetine.

FIGURE F.10. (contd) 
Sample Problem Six is similar to Sample Problem Five with the addition of an acute release of ${ }^{14} \mathrm{C}$. Input for this problem is shown in Figure F.3 (item \#27).

Previous release data is used (IWAT=0) and the acute exposure pathway activated $(I A C=1)$ in Sample Problem Six. It should be noted that the ${ }^{14} \mathrm{C}$ acute release data was input with Sample Problem Five but not used because the acute exposure pathway was not turned on. Previous population data is used for chronic exposure (IPOPL=0). Population data for acute exposure is entered in the NAMELIST INPUT set (IPA, PPL).

A cumulative dose to total body of $1.5 \times 10^{4}$ person-rem is reported in Sample Problem Six (item \#28 in Figure F.11). Twenty percent of this dose is due to exposure to ${ }^{14} \mathrm{C}, 64 \%$ is due to ${ }^{90} \mathrm{Sr}$, and $15 \%$ is due to ${ }^{129} \mathrm{I}$. Cumulative dose estimates in units of person-rem to bone, lung, thyroid and the lower large intestine of the GI tract are $5.3 \times 10^{4}, 3.8 \times 10^{3}, 1.2 \times 10^{6}$, and $4.7 \times 10^{3}$, respectively. 
QA PAGE FOR DITTY (VAX VERSION 1.0) RUN ON 27-JAN-86

INTEGRATED POPULATION DOSE CALOULATED FOR ACUTE LIOUID

REIEASE FROM TIME 1990. A.D. ONWARD FOR 10,000 YEARS

CASE TITLE: Sample Problem Six - Waterborne release, acute and chronic exposure

$\star \star \star$ DATA LIBRARIES USED:
MASTER NUCLIDE DATA : (10)

FOOD CONCEMIRATION RATIOS : (12)

FRESHWATER BIOACCUMULATION FACTORS : (14)

RADIONUCLIDE MASTER DATA LIBRARY /w TRANSLOCATION CIASSES, 19-MAR-85 RAP

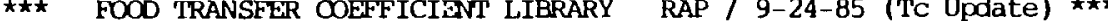

EXTERNAL EXPOSURE D.F.'S : (16)

BIOACCUMULATION FACIOR LIBRARY FOR FOOD, PABLM, MAXI BA NAPIER (28-NOV-83/RAP)

$\star \star \star$ GROFLIB FOR FOOD, 15 MARCH 1978, BA NAPIER $\star \star \star$

INHALATION/ INGESTION D.F.'S : (18)

INTERNAL, DOSE CONVERSION FACTOR LIBRARY FOR DITTY1 REV. 1-20-81 (BAN/DLS/RAP)

$\star \star \star$ ORGANS CONSIDERED:

TOTAL BODY

BONE

LUNG

THYROID

GI-LLI

$\star \star \star$ MASTER RADIONUCLIDE CONTROL LIST:
C 14
SR90
Y 90
I 129
PU238

$\star \star \star$ POPUI ATION DATA:

POPULATION FOR ACUTE WATERBORNE REIEASE $=2.00 E+05$

PREVIOUS POPULATION VALUES USED FOR CHRONIC WATERBORNE RETEASE.

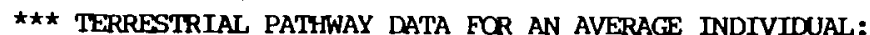

$\begin{array}{lccc}\text { PATHWAY } & \begin{array}{c}\text { GROWING PERIOD } \\ \text { (DAYS) }\end{array} & \begin{array}{c}\text { YIEED } \\ (\mathrm{KG} / \mathrm{M} \star \star 2)\end{array} & \begin{array}{c}\text { CONSUMPTION } \\ (\mathrm{KG} / \mathrm{YR})\end{array} \\ \text { LEAFY VEGATABI.ES } & 9.00 \mathrm{E}+01 & 1.50 \mathrm{E}+00 & 1.50 \mathrm{E}+01 \\ \text { OTHER VEGATARIES } & 9.00 \mathrm{E}+01 & 2.50 \mathrm{E}+00 & 2.79 \mathrm{E}+02 \\ \text { EOGS } & 9.00 \mathrm{E}+01 & 8.40 \mathrm{E}-01 & 2.00 \mathrm{E}+01 \\ \text { MILK } & 3.00 \mathrm{E}+01 & 1.30 \mathrm{E}+00 & 2.30 \mathrm{E}+02 \\ \text { BEEF } & 9.00 \mathrm{E}+01 & 8.40 \mathrm{E}-01 & 4.00 \mathrm{E}+01 \\ \text { PORK } & 9.00 \mathrm{E}+01 & 8.40 \mathrm{E}-01 & 3.00 \mathrm{E}+01 \\ \text { POULTRY } & 9.00 \mathrm{E}+01 & 8.40 \mathrm{E}-01 & 8.50 \mathrm{E}+00 \\ \text { EXIERNAL EXPOSURE TIME } & 2.92 \mathrm{E}+03 & \end{array}$

$\star \star \star$ LIOUID REI.EASE DILUTION/MIXING PARAMETERS

RIVER FLOW RATE, (FT3/SEC) $: 11.20 \mathrm{E}+05$
RECONCENTRATION RATIO
MIXING RATIO

$\star \star \star$ AQUATIC PATHINAY DATA FOR AN AVERAGE INDIVIDUAL:

$\begin{array}{lc}\text { PATHWAY } & \begin{array}{c}\text { USAGE } \\ \text { (KG OR HR/YR) } \\ \text { FISH }\end{array} \\ \text { CRUSTACEA } & 0.00 \mathrm{E}-01 \\ \text { MOLLUSES } & 0.00 \mathrm{E}+00 \\ \text { PLANIS } & 0.00 \mathrm{E}+00 \\ \text { DRINKING WATER } & 4.38 \mathrm{E}+02 \\ \text { SEDIMENT EXPOSURE } & 1.70 \mathrm{E}+01 \\ \text { SWIMMING TTME } & 1.70 \mathrm{E}+01\end{array}$

$\star \star \star$ FARMING PARAMETERS MONTHS / YEAR IRRIGATED : $6.00 \mathrm{E}+00$
IRRIGATION RATE

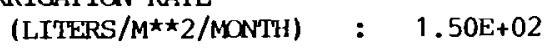

FIGURE F.11. Sample Problem Six Output 


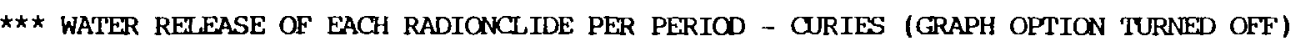

RADIONUCLIDE PERIOD ACTVITY PERIOD ACTVITY PERIOD ACTVITY PERIOD ACTVITY PERIOD ACTVITY PERIOD ACTVITY

\begin{tabular}{|c|c|c|c|c|c|c|c|c|c|c|c|}
\hline C 14 & 0 & $7.50 \mathrm{E}+05$ & & & & & & & & & \\
\hline SR90 & 8 & $1.60 \mathrm{E}+02$ & 9 & 8.0 & & & & & & & \\
\hline Y 90 & & & & & & & & & & & \\
\hline I 129 & $\begin{array}{l}129 \\
135 \\
141\end{array}$ & $\begin{array}{l}30 . \\
70 . \\
70 .\end{array}$ & $\begin{array}{l}130 \\
136 \\
142\end{array}$ & $\begin{array}{l}70 . \\
70 . \\
70 .\end{array}$ & $\begin{array}{l}131 \\
137 \\
143\end{array}$ & $\begin{array}{l}70 . \\
70 . \\
61 .\end{array}$ & $\begin{array}{l}132 \\
138\end{array}$ & $\begin{array}{l}70 . \\
70 .\end{array}$ & $\begin{array}{l}133 \\
139\end{array}$ & $\begin{array}{l}70 . \\
70 .\end{array}$ & $\begin{array}{l}134 \\
140\end{array}$ \\
\hline
\end{tabular}

PU238

$\star \star \star$ POPULATION FOR WATERBORNE RETEASE

\begin{tabular}{|c|c|c|c|c|c|c|c|c|c|c|c|}
\hline PERIO & PL & & PL & & PL & & PL & & PL & & PL \\
\hline 0 & $2.00 \mathrm{E}+05$ & 1 & $3.26 \mathrm{E}+05$ & 2 & $3.87 \mathrm{E}+05$ & 3 & $4.17 \mathrm{E}+05$ & 4 & $4.45 \mathrm{E}+05$ & 5 & $4.76 E+05$ \\
\hline 6 & $5.57 \mathrm{E}+05$ & 7 & $6.39 \mathrm{E}+05$ & 8 & $7.20 \mathrm{E}+05$ & 9 & $8.02 E+05$ & 10 & $8.83 \mathrm{E}+05$ & 11 & $9.65 E+05$ \\
\hline 12 & $1.05 E+06$ & 13 & $1.13 E+06$ & 14 & $1.21 E+06$ & 15 & $1.28 \mathrm{E}+06$ & 16 & $1.31 \mathrm{E}+06$ & 17 & $1.34 \mathrm{E}+06$ \\
\hline 18 & 1. $37 \mathrm{E}+06$ & 19 & $1.39 E+06$ & 20 & $1.42 \mathrm{E}+06$ & 21 & $1.45 \mathrm{E}+06$ & 22 & $1.48 \mathrm{E}+06$ & 23 & $1.51 \mathrm{E}+06$ \\
\hline 24 & $1.54 \mathrm{E}+06$ & 25 & $1.57 \mathrm{E}+06$ & 26 & $1.60 \mathrm{E}+06$ & 27 & $1.62 \mathrm{E}+06$ & 28 & $1.65 E+06$ & 29 & $1.68 E+06$ \\
\hline 30 & $1.71 \mathrm{E}+06$ & 31 & $1.74 \mathrm{E}+06$ & 32 & $1.77 E+06$ & 33 & $1.80 \mathrm{E}+06$ & 34 & $1.83 \mathrm{E}+06$ & 35 & $1.85 E+06$ \\
\hline 36 & $1.88 \mathrm{E}+06$ & 37 & $1.91 \mathrm{E}+06$ & 38 & $1.94 \mathrm{E}+06$ & 39 & $1.97 \mathrm{E}+06$ & 40 & $2.00 \mathrm{E}+06$ & 41 & $2.03 E+06$ \\
\hline 42 & $2.06 \mathrm{E}+06$ & 43 & $2.08 \mathrm{E}+06$ & 44 & $2.11 E+06$ & 45 & $2.14 \mathrm{E}+06$ & 46 & $2.17 \mathrm{E}+06$ & 47 & $2.20 \mathrm{E}+06$ \\
\hline 48 & $2.23 \mathrm{E}+06$ & 49 & $2.26 \mathrm{E}+06$ & 50 & $2.29 \mathrm{E}+06$ & 51 & $2.31 \mathrm{E}+06$ & 52 & $2.34 \mathrm{E}+06$ & 53 & $2.37 \mathrm{E}+06$ \\
\hline 54 & $2.40 \mathrm{E}+06$ & 55 & $2.43 E+06$ & 56 & $2.46 \mathrm{E}+06$ & 57 & $2.49 \mathrm{E}+06$ & 58 & $2.52 \mathrm{E}+06$ & 59 & $2.54 \mathrm{E}+06$ \\
\hline 60 & $2.57 \mathrm{E}+06$ & 61 & $2.60 \mathrm{E}+06$ & 62 & $2.63 E+06$ & 63 & $2.66 E+06$ & 64 & $2.69 \mathrm{E}+06$ & 65 & $2.72 \mathrm{E}+06$ \\
\hline 66 & $2.75 \mathrm{E}+06$ & 67 & $2.77 \mathrm{E}+06$ & 68 & $2.80 \mathrm{E}+06$ & 69 & $2.83 \mathrm{E}+06$ & 70 & $2.86 \mathrm{E}+06$ & 71 & $2.89 E+06$ \\
\hline 72 & $2.92 \mathrm{E}+06$ & 73 & $2.95 E+06$ & 74 & $2.98 E+06$ & 75 & $3.00 \mathrm{E}+06$ & 76 & $3.03 E+06$ & 77 & $3.06 \mathrm{E}+06$ \\
\hline 78 & $3.09 E+06$ & 79 & $3.12 \mathrm{E}+06$ & 80 & $3.15 E+06$ & 81 & $3.18 \mathrm{E}+06$ & 82 & $3.21 \mathrm{E}+06$ & 83 & $3.23 \mathrm{E}+06$ \\
\hline 84 & $3.26 \mathrm{E}+06$ & 85 & $3.29 \mathrm{E}+06$ & 86 & $3.32 \mathrm{E}+06$ & 87 & $3.35 \mathrm{E}+06$ & 88 & $3.38 \mathrm{E}+06$ & 89 & $3.41 E+06$ \\
\hline 90 & $3.44 \mathrm{E}+06$ & 91 & $3.46 \mathrm{E}+06$ & 92 & $3.49 \mathrm{E}+06$ & 93 & $3.52 \mathrm{E}+06$ & 94 & $3.55 E+06$ & 95 & $3.58 \mathrm{E}+06$ \\
\hline 96 & $3.61 \mathrm{E}+06$ & 97 & $3.64 \mathrm{E}+06$ & 98 & $3.67 E+06$ & 99 & $3.69 E+06$ & 100 & $3.72 \mathrm{E}+06$ & 101 & $3.75 E+06$ \\
\hline 102 & $3.78 \mathrm{E}+06$ & 103 & $3.81 E+06$ & 104 & $3.84 E+06$ & 105 & $3.87 E+06$ & 106 & $3.90 \mathrm{E}+06$ & 107 & $3.92 \mathrm{E}+06$ \\
\hline 108 & $3.95 \mathrm{E}+06$ & 109 & $3.98 \mathrm{E}+06$ & 110 & $4.01 E+06$ & 111 & $4.04 \mathrm{E}+06$ & 112 & $4.07 \mathrm{E}+06$ & 113 & $4.10 E+06$ \\
\hline 114 & $4.13 E+06$ & 115 & $4.15 E+06$ & 116 & $4.18 \mathrm{E}+06$ & 117 & $4.21 E+06$ & 118 & $4.24 \mathrm{E}+06$ & 119 & $4.27 \mathrm{E}+06$ \\
\hline 120 & $4.30 \mathrm{E}+06$ & 121 & $4.33 E+06$ & 122 & $4.36 \mathrm{E}+06$ & 123 & $4.38 E+06$ & 124 & $4.41 E+06$ & 125 & $4.44 E+06$ \\
\hline 126 & $4.47 \mathrm{E}+06$ & 127 & $4.50 \mathrm{E}: 06$ & 128 & $4.53 E+06$ & 129 & $4.56 \mathrm{E}+06$ & 130 & $4.59 E+06$ & 131 & $4.61 E+06$ \\
\hline 132 & $4.64 \mathrm{E}+06$ & 133 & $4.67 \mathrm{E}+06$ & 134 & $4.70 \mathrm{E}+06$ & 135 & $4.73 \mathrm{E}+06$ & 136 & $4.76 \mathrm{E}+06$ & 137 & $4.79 \mathrm{E}+06$ \\
\hline 138 & $4.82 \mathrm{E}+06$ & 139 & $4.84 \mathrm{E}+06$ & 140 & $4.87 E+06$ & 141 & $4.90 \mathrm{E}+06$ & 142 & $4.93 \mathrm{E}+06$ & 143 & $4.93 \mathrm{E}+06$ \\
\hline
\end{tabular}

INPUT PREPARED BY: FIGURE F.11. (contd) 
REPORT FOR DITTY (VAX VERSION 1.0) RUN ON 27-JAN-86

INTEGRATED POPULATION DOSE CALOULATED FOR AOUTE LIQUTD

REIEASE FROM TIME 1990. A.D. ONWARD FOR 10,000 YEARS

CASE TITLE: Sample Problem Six - Waterborne release, acute and chronic exposure

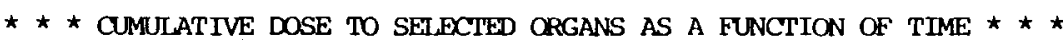

\begin{tabular}{rr}
\multicolumn{1}{c}{ PERIOD } & YEAR \\
ACIIE & \\
until & \\
9 & 2480. \\
10 & 2550. \\
11 & 2620. \\
12 & 2690. \\
13 & 2760. \\
14 & 2830. \\
15 & 2900. \\
16 & 2970. \\
17 & 3040. \\
until & \\
130 & 10950. \\
131 & 11020. \\
132 & 11090. \\
133 & 11160. \\
134 & 11230. \\
135 & 11300. \\
136 & 11370. \\
137 & 11440. \\
138 & 11510. \\
139 & 11580. \\
140 & 11650. \\
141 & 11720. \\
142 & 11790. \\
143 & 11860. \\
144 & 11930. \\
---- & $--1 .-1$
\end{tabular}

\begin{tabular}{l} 
TOTAL BODY \\
\hdashline $3.02 \mathrm{E}+03$ \\
$1.10 \mathrm{E}+04$ \\
$1.25 \mathrm{E}+04$ \\
$1.27 \mathrm{E}+04$ \\
$1.27 \mathrm{E}+04$ \\
$1.27 \mathrm{E}+04$ \\
$1.27 \mathrm{E}+04$ \\
$1.27 \mathrm{E}+04$ \\
$1.27 \mathrm{E}+04$ \\
$1.27 \mathrm{E}+04$ \\
$1.28 \mathrm{E}+04$ \\
$1.30 \mathrm{E}+04$ \\
$1.31 \mathrm{E}+04$ \\
$1.33 \mathrm{E}+04$ \\
$1.34 \mathrm{E}+04$ \\
$1.36 \mathrm{E}+04$ \\
$1.37 \mathrm{E}+04$ \\
$1.39 \mathrm{E}+04$ \\
$1.40 \mathrm{E}+04$ \\
$1.42 \mathrm{E}+04$ \\
$1.44 \mathrm{E}+04$ \\
$1.45 \mathrm{E}+04$ \\
$1.47 \mathrm{E}+04$ \\
$1.49 \mathrm{E}+04$ \\
$1.50 \mathrm{E}+04$ \\
\hline
\end{tabular}

\begin{tabular}{l} 
BONE \\
\hline $1.48 \mathrm{E}+04$ \\
$4.51 \mathrm{E}+04$ \\
$5.08 \mathrm{E}+04$ \\
$5.16 \mathrm{E}+04$ \\
$5.17 \mathrm{E}+04$ \\
$5.17 \mathrm{E}+04$ \\
$5.17 \mathrm{E}+04$ \\
$5.17 \mathrm{E}+04$ \\
$5.17 \mathrm{E}+04$ \\
$5.17 \mathrm{E}+04$ \\
\\
$5.17 \mathrm{E}+04$ \\
$5.18 \mathrm{E}+04$ \\
$5.19 \mathrm{E}+04$ \\
$5.20 \mathrm{E}+04$ \\
$5.21 \mathrm{E}+04$ \\
$5.22 \mathrm{E}+04$ \\
$5.23 \mathrm{E}+04$ \\
$5.24 \mathrm{E}+04$ \\
$5.25 \mathrm{E}+04$ \\
$5.25 \mathrm{E}+04$ \\
$5.26 \mathrm{E}+04$ \\
$5.27 \mathrm{E}+04$ \\
$5.28 \mathrm{E}+04$ \\
$5.29 \mathrm{E}+04$ \\
$5.30 \mathrm{E}+04$ \\
\end{tabular}

\begin{tabular}{l} 
LUNG \\
\hline $3.02 \mathrm{E}+03$ \\
$3.02 \mathrm{E}+03$ \\
$3.02 \mathrm{E}+03$ \\
$3.02 \mathrm{E}+03$ \\
$3.02 \mathrm{E}+03$ \\
$3.02 \mathrm{E}+03$ \\
$3.02 \mathrm{E}+03$ \\
$3.02 \mathrm{E}+03$ \\
$3.02 \mathrm{E}+03$ \\
$3.02 \mathrm{E}+03$ \\
\\
$3.04 \mathrm{E}+03$ \\
$3.09 \mathrm{E}+03$ \\
$3.15 \mathrm{E}+03$ \\
$3.20 \mathrm{E}+03$ \\
$3.25 \mathrm{E}+03$ \\
$3.30 \mathrm{E}+03$ \\
$3.35 \mathrm{E}+03$ \\
$3.40 \mathrm{E}+03$ \\
$3.46 \mathrm{E}+03$ \\
$3.51 \mathrm{E}+03$ \\
$3.56 \mathrm{E}+03$ \\
$3.62 \mathrm{E}+03$ \\
$3.67 \mathrm{E}+03$ \\
$3.73 \mathrm{E}+03$ \\
$3.77 \mathrm{E}+03$ \\
\hline
\end{tabular}

\begin{tabular}{l}
\hline $.02 \mathrm{E}+03$ \\
THYOID \\
$3.02 \mathrm{E}+03$ \\
$3.02 \mathrm{E}+03$ \\
$3.02 \mathrm{E}+03$ \\
$3.02 \mathrm{E}+03$ \\
$3.02 \mathrm{E}+03$ \\
$3.02 \mathrm{E}+03$ \\
$3.02 \mathrm{E}+03$ \\
$3.02 \mathrm{E}+03$ \\
$3.02 \mathrm{E}+03$ \\
\\
$3.73 \mathrm{E}+04$ \\
$1.18 \mathrm{E}+05$ \\
$1.99 \mathrm{E}+05$ \\
$2.80 \mathrm{E}+05$ \\
$3.62 \mathrm{E}+05$ \\
$4.45 \mathrm{E}+05$ \\
$5.28 \mathrm{E}+05$ \\
$6.11 \mathrm{E}+05$ \\
$6.95 \mathrm{E}+05$ \\
$7.80 \mathrm{E}+05$ \\
$8.65 \mathrm{E}+05$ \\
$9.50 \mathrm{E}+05$ \\
$1.04 \mathrm{E}+06$ \\
$1.12 \mathrm{E}+06$ \\
$1.20 \mathrm{E}+06$ \\
-
\end{tabular}

GI-LLI

Dose in units of person-rem; that is the cumulative population dose received by the local population over 10,000 years with an assumed 70-yr individual lifetime.

FIGURE F.11. (contd) 
REPORT FOR DITTY (VAX VERSION 1.0) RUN ON 27-JAN-86

INTEGRATED POPULATION DOSE CALCULATED FOR ACUTE LIQUID

RETEASE FROM TIME 1990. A.D. ONWARD FOR 10,000 YEARS

CASE TITLE: Sample Problem Six - Waterborme release, acute and chronic exposure

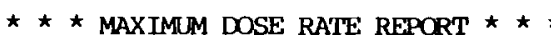

DOSE INTEGRAL PERIOD (70-YEAR) DURING WHICH THE MAXIMUM DOSE RATE OOOURS $=$

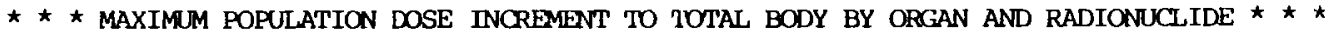

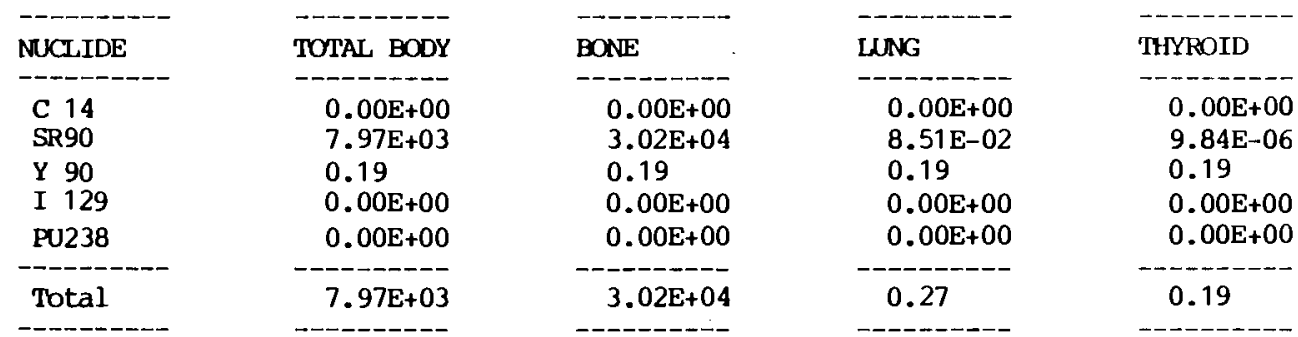

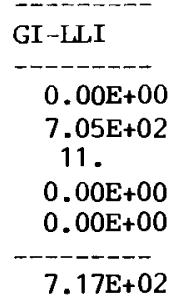

Dose in units of person-rem; that is the cumulative population dose received by the local population over 10,000 years with an assumed 70-yr individual lifetime.

* * * MAXIMUM AVERAGE INDIVIDUAL DOSE INCREMENT TO TOTAL BODY BY ORGAN AND RADIONUClidE * * *

\begin{tabular}{l} 
NUCLIDE \\
- C 14 \\
SR90 \\
Y 90 \\
I 129 \\
PU238 \\
\hdashline Total \\
\hline
\end{tabular}

TOTAL BODY
$0.00 \mathrm{E}+00$
$1.11 \mathrm{E}-02$
$2.59 \mathrm{E}-07$
$0.00 \mathrm{E}+00$
$0.00 \mathrm{E}+00$
$-1.11 \mathrm{E}-02$

BONE
$-0.00 \mathrm{E}+00$
$4.20 \mathrm{E}-02$
$2.61 \mathrm{E}-07$
$0.00 \mathrm{E}+00$
$0.00 \mathrm{E}+00$
$-4.20 \mathrm{E}-02$

\section{LUNG}

-

$0.00 \mathrm{E}+00$

$1.18 \mathrm{E}-07$

$2.59 \mathrm{E}-07$
$0.00 \mathrm{E}+00$

$0.00 \mathrm{E}+00$

3.77E-07

4. 20E-02

\begin{tabular}{l} 
THYROID \\
$0.00 \mathrm{E}+00$ \\
$1.37 \mathrm{E}-11$ \\
$2.59 \mathrm{E}-07$ \\
$0.00 \mathrm{E}+00$ \\
$0.00 \mathrm{E}+00$ \\
\hdashline $2.59 \mathrm{E}-07$
\end{tabular}

GI-LI

$0.00 \mathrm{E}+00$

$9.79 \mathrm{E}-04$

$1.55 \mathrm{E}-05$

$0.00 \mathrm{E}+00$

$0.00 \mathrm{E}+00$

9.95E-04

Dose in units of rem.

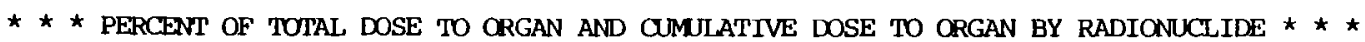

NUCLIDE
- C 14
SR90
Y 90
I 129
PU238
Total

\begin{tabular}{|c|c|c|c|}
\hline \multicolumn{2}{|c|}{ TOTAL, BODY } & \multicolumn{2}{|c|}{ BONE } \\
\hline 208 & $3.0 \mathrm{E}+03$ & 28 응 & $1.5 E+04$ \\
\hline $\begin{array}{r}648 \\
08\end{array}$ & $\begin{array}{l}9.7 \mathrm{E}+03 \\
0.2\end{array}$ & $\begin{array}{r}698 \\
08\end{array}$ & $\begin{array}{l}3.7 \mathrm{E}+04 \\
0.2\end{array}$ \\
\hline $\begin{array}{r}158 \\
08\end{array}$ & $\begin{array}{l}2.3 \mathrm{E}+03 \\
0.0 \mathrm{E}+00\end{array}$ & $\begin{array}{l}28 \\
0 z\end{array}$ & $\begin{array}{l}1.3 \mathrm{E}+03 \\
0.0 \mathrm{E}+00\end{array}$ \\
\hline & 1.5E+04 & & $5.3 E+04$ \\
\hline
\end{tabular}

\begin{tabular}{rl}
\hline LUNG \\
\hdashline $80 \%$ & $3.0 \mathrm{E}+03$ \\
08 & 0.1 \\
08 & 0.2 \\
198 & $7.5 \mathrm{E}+02$ \\
08 & $0.0 \mathrm{E}+00$ \\
\hdashline & $3.8 \mathrm{E}+03$ \\
\hline
\end{tabular}

THYROI

$\begin{array}{ll}08 & 3.0 \mathrm{E}+03 \\ 08 & 1.0 \mathrm{E}-05\end{array}$

0 웅 0.2

$99 \mathrm{z} \quad 1.2 \mathrm{E}+06$

0 8 $0.0 \mathrm{E}+00$

$1.2 \mathrm{E}+06$

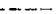

Dose in units of person-rem; that is the cumulative population dose received by the local population over 10,000 years with an assumed $70-\mathrm{yr}$ individual lifetime.

FIGURE F.11. (contd) 



\section{SAMPLE PROBLEM SEVEN}

The final sample problem combines the chronic exposure scenarios in Sample Problens Four (airborne pathways) and Five (waterborne pathways). Dose totals for Sample Problem Seven should equal the sum of doses from Sample Problems Four and Five. Input for this sample problem is shown in Figure F.3 (item \#29).

The acute exposure pathway is deactivated (IAC=0). Meteorological and airborne population data is input in the same format as for Sample Problem Four. ${ }^{238} \mathrm{Pu}$ airborne release data (itern $\# 30$ in Figure F.3) are read from the execution file (IAIR=1, LUA=1). Graphical reports of the total radionuclide release over time is requested (IGRTNU=1). This report for the airborne release is shown in Figure F.12 (item \#31). A similar report is generated for the waterborne releases.

Total cumulative doses of $1.7 \times 10^{6}$ person-rem to total body and $1.6 \times 10^{7}$ person-rem to bone are reported for Sample Problem Seven (item \#32 in Figure F.12). 


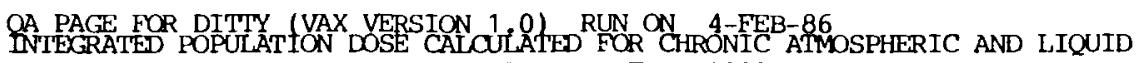

REIEASE FROM TIME 1990. A.D. ONWARD FOR 10,000 YEARS

CASE TITLE: Sample Problem Seven - Airbome and waterborne release, chronic exposure

$\star \star \star$ DATA LIBRARIES USED:

(FILE)

MASTER NUCLIDE DATA : $(10)$

FOOD OONCENIRATION RATIOS : (12)

FRESHWATER BIOACCUMULATION FACTORS : $(14)$

EXTERINAL EXPOSURE D.F.'S : $(16)$

INHALATION/INGESTION D.F.'S

AIRBORNE RELLEASE DATA : $(26)$

RADIONUCLIDE MASTER DATA LIBRARY / $w$ TRANSLOCATION CIASSES, 19-MAR-85 RAP

$\star \star \star$ FOOD TRANSFER OOEFFICIENT LIBRARY RAP / 9-24-85 (TC Update) $\star \star \star ~$ BIOACCUMULATION FACTOR LIBRARY FOR FOOD, PABLM, MAXI BA NAPIER (28-NOV-83/RAP) $\star \star \star$ GRDFLIB FOR FOOD, 15 MARCH 1978, BA NAPIER $\star \star \star ~$

INTPERNAL DOSE CONVERSION FACTOR LIBRARY FOR DITTY1 REV. 1-20-81 (BAN/DLS/RAP) INPUT

$\star \star \star$ ORGANS CONSIDERED:

TOTAL BODY

BONE

LUNG

THYROID

GI-LLI

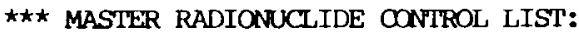

C 14

SR90

Y 90

I 129

PU238

$\star \star \star$ POPULATION DATA:

POPULATION FOR GHRONIC AIRBORNE RELEASE AT TIME 1984.:

\begin{tabular}{|c|c|c|c|c|c|c|c|c|c|}
\hline SECTOR & $8.05 E+02$ & $2.41 E+03$ & $4.02 \mathrm{E}+03$ & $5.63 E+03$ & $7.24 \mathrm{E}+03$ & 1. $20 \mathrm{E}+04$ & $2.40 \mathrm{E}+04$ & $4.00 \mathrm{E}+04$ & $5.60 \mathrm{E}+04$ \\
\hline $\begin{array}{l}\text { NNE } \\
N E E\end{array}$ & & & & $0.00 \mathrm{E}$ & $0.00 \mathrm{E}+00$ & 6.31 & $1.10 \mathrm{E}+04$ & +02 & \\
\hline ENE & & +00 & +00 & $\begin{array}{r}+00 \\
+00\end{array}$ & $\begin{array}{l}+00 \\
+00\end{array}$ & $\begin{array}{l}5.571 \\
9.801\end{array}$ & $\begin{array}{l}1.74 \mathrm{E}+04 \\
2.97 \mathrm{E}+03\end{array}$ & $\begin{array}{l}1.07 \mathrm{E}+03 \\
1.49 \mathrm{E}+04\end{array}$ & \\
\hline$E$ & & & & & & 02 & $5.09 E+02$ & & \\
\hline ESE & & $E+00$ & $0.00 \mathrm{E}+00$ & $0.00 \mathrm{E}+00$ & $0.00 E+00$ & $2.44 \mathrm{E}+02$ & $7.69 \mathrm{E}+02$ & & \\
\hline $\mathrm{SE}$ & & & 0.0 & & $0.00 \mathrm{E}+00$ & $2.33 E+02$ & $2.43 E+02$ & +02 & \\
\hline SSE & & & & & & .28 & & & \\
\hline $\mathrm{s}$ & +00 & & & & & 21. & $1.12 \mathrm{E}$ & .02 & \\
\hline SSW & 00 & & 0.0 & & $0.00 \mathrm{E}+00$ & 5.0 & $7.96 \mathrm{E}+02$ & 03 & \\
\hline SW & & & & & & $3.08 E+02$ & & & \\
\hline WSW & & & & & & & & & \\
\hline w & & & +00 & 0.0 & $0.00 \mathrm{E}+00$ & $1.42 \mathrm{E}+02$ & $4.28 E+02$ & $6.23 E+02$ & 9.77 \\
\hline WNW & $00 \mathrm{E}+00$ & +00 & $0.00 \mathrm{E}+00$ & $0.00 E+00$ & $0.00 \mathrm{E}+00$ & $3.21 \mathrm{E}+02$ & $1.83 \mathrm{E}+03$ & $1.55 \mathrm{E}+02$ & \\
\hline NW & & & & & $0.00 \mathrm{E}+00$ & 4.0 & $3.80 \mathrm{E}+04$ & $5.11 E+04$ & \\
\hline$N N W$ & & & & & & & & & \\
\hline & $E+00$ & $0.00 \mathrm{E}+00$ & $0.00 E+00$ & $0.00 \mathrm{E}+00$ & & & & & $6,10 \mathrm{E}+$ \\
\hline
\end{tabular}

POPULATION FOR CHRONIC AIRBORNE RETEASE AT THE FOLLOWING TIMES A.D.:

\begin{tabular}{|c|c|c|c|c|c|c|c|c|c|}
\hline TIME & POPULATION & TIME & POPULATION & TIME & POPULATION & TIME & POPULATION & TIME & POPULATION \\
\hline 1984. & $2.95 \mathrm{E}+05$ & 40000 . & $5.00 E+05$ & 60000 . & $1.00 E+06$ & 90000 & $1.50 \mathrm{E}+06$ & 120000 & $1.00 \mathrm{E}+06$ \\
\hline
\end{tabular}

PREVIOUS POPULATION VALUES USED FOR CHRONIC WATERBORNE RELEASE.

FIGURE F.12. Sample Problen Seven Output 
$\star \star \star$ TERRESTRIAL PATHWAY DATA FOR AN AVERAGE INDIVIDUAL: PATHWAY

$$
\text { GROWING PERIOD }
$$

$$
\text { (DAYS) }
$$

LEAFY VEGATABLES OTHER VEGATABLFS

EOGS

MILK

BEEF 9.00E+01 $9.00 \mathrm{E}+01$ $9.00 \mathrm{E}+01$ 3.00E+01 $9.00 \mathrm{E}+01$ $9.00 \mathrm{E}+01$ $9.00 \mathrm{E}+01$

YIETD $(\mathrm{KG} / \mathrm{M} \star 2)$ $1.50 \mathrm{E}+00$ $2.50 \mathrm{E}+00$ 8. $40 \mathrm{E}-01$ 1. $30 \mathrm{E}+00$ $8.40 \mathrm{E}-01$ $8.40 \mathrm{E}-01$ EXIERNAL EXPOSURE TTME, 2.92E+03 HR/YR

$\star \star \star$ LIQUID REIEASE DILUTION/MIXING PARAMETERS RIVER FLOW RATE, (FT3/SEC) : $1.20 \mathrm{E}+05$ REOONCENIRATION RATIO
MIXING RATIO
CONSUMPTION (KG/YR)

$1.50 \mathrm{E}+01$ $2.79 \mathrm{E}+02$ $2.00 \mathrm{E}+01$ $2.30 \mathrm{E}+02$ 4.00E+01 $3.00 \mathrm{E}+01$ $8.50 \mathrm{E}+00$

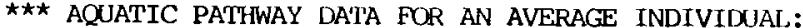
PATHWAY

$$
\text { USAGE }
$$

\section{FISH}

\section{CRUSTACEA}

MOLUSES

DRINKING WATER

POSURE

SWIMMING TIME

(KG OR HR/YR)

$3.00 \mathrm{E}-01$

$0.00 \mathrm{E}+00$

$0.00 \mathrm{E}+00$

$0.00 \mathrm{E}+00$

4.38E+02

$1.70 \mathrm{E}+01$
$1.70 \mathrm{E}+01$

$\star \star \star$ FARMING PARAMETERS

MONITS / YEAR IRRIGATED : $6.00 \mathrm{E}+00$ IRRIGATION RATE

(LITERS/M $\star \star 2 / M O N T H): 1.50 \mathrm{E}+02$

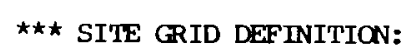

NUMBER PF SECTORS: 16

DISTANCES:

16

$4023 . \quad 5632$.

7241.

12000

24000 .

40000 .

56000

is

JOINT FREOUENCY DATA:

WIND SPEED

NNE NE $\quad$ NEE

ESE SE SSE S

SSW SW WSW W

WNW NW NNW N

0.8
0.8

0.8

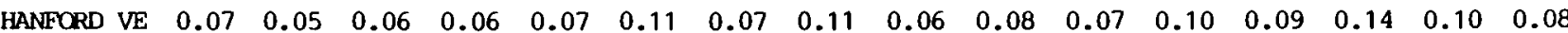
$\begin{array}{llllllllllllllllll}\text { HANFORD MO } & 0.33 & 0.27 & 0.32 & 0.30 & 0.36 & 0.72 & 0.45 & 0.54 & 0.44 & 0.59 & 0.54 & 0.67 & 0.68 & 0.77 & 0.63 & 0.79\end{array}$

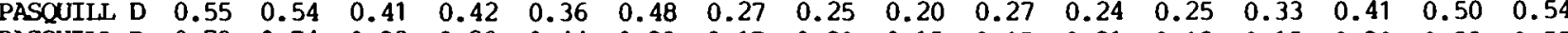

2.5

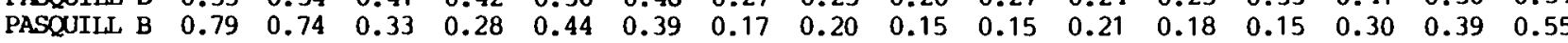

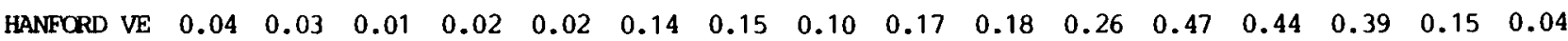
$\begin{array}{llllllllllllllllll}\text { HANFORD MO } & 0.24 & 0.26 & 0.20 & 0.26 & 0.44 & 0.68 & 0.62 & 0.63 & 0.56 & 0.90 & 1.70 & 2.48 & 2.45 & 2.29 & 0.93 & 0.36\end{array}$ $\begin{array}{lllllllllllllllll}\text { PASOUIJU, D } & 0.28 & 0.21 & 0.16 & 0.20 & 0.34 & 0.28 & 0.17 & 0.20 & 0.21 & 0.25 & 0.30 & 0.45 & 0.81 & 0.96 & 0.63 & 0.39\end{array}$

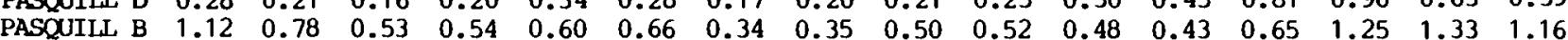

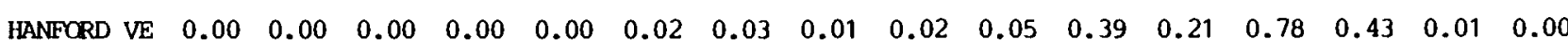

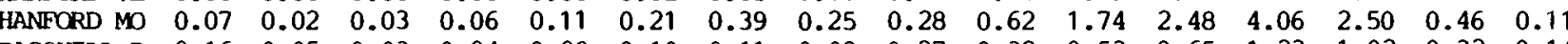

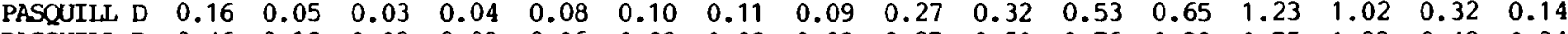

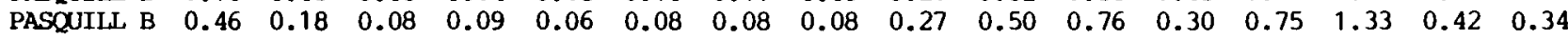

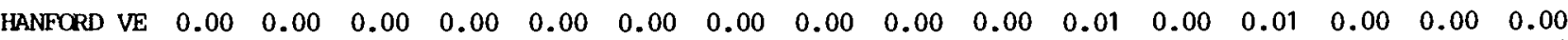

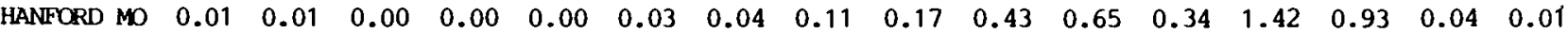
$\begin{array}{lllllllllllllllll}\text { PASQUILL D } & 0.04 & 0.05 & 0.01 & 0.00 & 0.01 & 0.01 & 0.04 & 0.08 & 0.30 & 0.60 & 0.52 & 0.38 & 1.33 & 0.86 & 0.09 & 0.06\end{array}$ $\begin{array}{lllllllllllllllll}\text { PASQUILL B } & 0.16 & 0.06 & 0.00 & 0.00 & 0.00 & 0.00 & 0.03 & 0.02 & 0.15 & 0.48 & 0.67 & 0.25 & 0.64 & 0.80 & 0.07 & 0.06\end{array}$

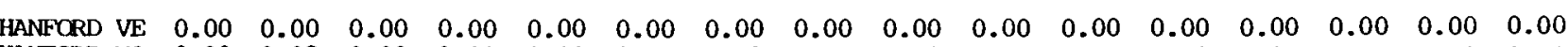
$\begin{array}{lllllllllllllllll}\text { HANFORD MO } & 0.00 & 0.02 & 0.00 & 0.00 & 0.00 & 0.01 & 0.03 & 0.04 & 0.11 & 0.19 & 0.09 & 0.02 & 0.25 & 0.14 & 0.00 & 0.01\end{array}$

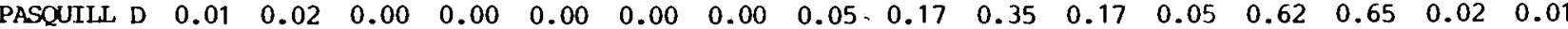

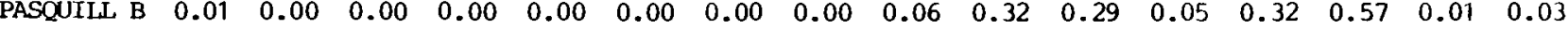

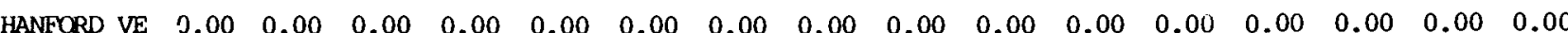

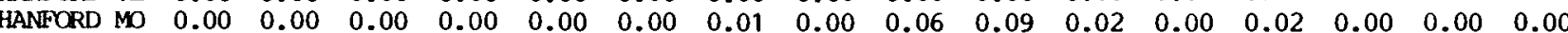

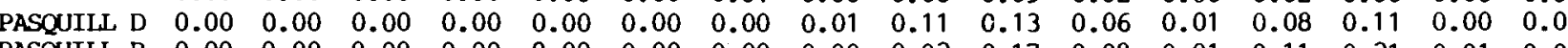


$\star \star \star$ POPULATION DISPERSION FACTOR FOR AIRBORNE RETEASE, PERSON-SEC/M $\star \star 3$

PERIOD PM PERIOD PM PERIOD PM PERIOD

\begin{tabular}{rrrrrrrr}
\multicolumn{1}{r}{ PERIOD } & PM & \multicolumn{1}{c}{ PERIOD } & PM & \multicolumn{1}{c}{ PERIOD } & PM & \multicolumn{1}{c}{ PERIOD } & PM \\
-0 & $0.00 \mathrm{E}+00$ & 1 & $5.96 \mathrm{E}-03$ & 2 & $6.10 \mathrm{E}-03$ & 3 & $6.25 \mathrm{E}-03$ \\
6 & $6.67 \mathrm{E}-03$ & 7 & $6.81 \mathrm{E}-03$ & 8 & $6.96 \mathrm{E}-03$ & 9 & $7.10 \mathrm{E}-03$ \\
12 & $7.52 \mathrm{E}-03$ & 13 & $7.67 \mathrm{E}-03$ & 14 & $7.81 \mathrm{E}-03$ & 15 & $7.95 \mathrm{E}-03$ \\
18 & $8.38 \mathrm{E}-03$ & 19 & $8.52 \mathrm{E}-03$ & 20 & $8.66 \mathrm{E}-03$ & 21 & $8.80 \mathrm{E}-03$ \\
24 & $9.23 \mathrm{E}-03$ & 25 & $9.37 \mathrm{E}-03$ & 26 & $9.51 \mathrm{E}-03$ & 27 & $9.65 \mathrm{E}-03$ \\
30 & $1.02 \mathrm{E}-02$ & 31 & $1.06 \mathrm{E}-02$ & 32 & $1.09 \mathrm{E}-02$ & 33 & $1.13 \mathrm{E}-02$ \\
36 & $1.23 \mathrm{E}-02$ & 37 & $1.27 \mathrm{E}-02$ & 38 & $1.30 \mathrm{E}-02$ & 39 & $1.34 \mathrm{E}-02$ \\
42 & $1.44 \mathrm{E}-02$ & 43 & $1.48 \mathrm{E}-02$ & 44 & $1.51 \mathrm{E}-02$ & 45 & $1.55 \mathrm{E}-02$ \\
48 & $1.65 \mathrm{E}-02$ & 49 & $1.69 \mathrm{E}-02$ & 50 & $1.72 \mathrm{E}-02$ & 51 & $1.76 \mathrm{E}-02$ \\
54 & $1.86 \mathrm{E}-02$ & 55 & $1.90 \mathrm{E}-02$ & 56 & $1.93 \mathrm{E}-02$ & 57 & $1.97 \mathrm{E}-02$ \\
60 & $2.05 \mathrm{E}-02$ & 61 & $2.07 \mathrm{E}-02$ & 62 & $2.09 \mathrm{E}-02$ & 63 & $2.11 \mathrm{E}-02$ \\
66 & $2.18 \mathrm{E}-02$ & 67 & $2.21 \mathrm{E}-02$ & 68 & $2.23 \mathrm{E}-02$ & 69 & $2.25 \mathrm{E}-02$ \\
72 & $2.32 \mathrm{E}-02$ & 73 & $2.35 \mathrm{E}-02$ & 74 & $2.37 \mathrm{E}-02$ & 75 & $2.39 \mathrm{E}-02$ \\
78 & $2.46 \mathrm{E}-02$ & 79 & $2.49 \mathrm{E}-02$ & 80 & $2.51 \mathrm{E}-02$ & 81 & $2.53 \mathrm{E}-02$ \\
84 & $2.60 \mathrm{E}-02$ & 85 & $2.63 \mathrm{E}-02$ & 86 & $2.65 \mathrm{E}-02$ & 87 & $2.67 \mathrm{E}-02$ \\
90 & $2.74 \mathrm{E}-02$ & 91 & $2.77 \mathrm{E}-02$ & 92 & $2.79 \mathrm{E}-02$ & 93 & $2.81 \mathrm{E}-02$ \\
96 & $2.88 \mathrm{E}-02$ & 97 & $2.91 \mathrm{E}-02$ & 98 & $2.93 \mathrm{E}-02$ & 99 & $2.95 \mathrm{E}-02$ \\
102 & $2.96 \mathrm{E}-02$ & 103 & $2.94 \mathrm{E}-02$ & 104 & $2.91 \mathrm{E}-02$ & 105 & $2.89 \mathrm{E}-02$ \\
108 & $2.82 \mathrm{E}-02$ & 109 & $2.80 \mathrm{E}-02$ & 110 & $2.77 \mathrm{E}-02$ & 111 & $2.75 \mathrm{E}-02$ \\
114 & $2.68 \mathrm{E}-02$ & 115 & $2.66 \mathrm{E}-02$ & 116 & $2.63 \mathrm{E}-02$ & 117 & $2.61 \mathrm{E}-02$ \\
120 & $2.54 \mathrm{E}-02$ & 121 & $2.52 \mathrm{E}-02$ & 122 & $2.49 \mathrm{E}-02$ & 123 & $2.47 \mathrm{E}-02$ \\
126 & $2.40 \mathrm{E}-02$ & 127 & $2.38 \mathrm{E}-02$ & 128 & $2.35 \mathrm{E}-02$ & 129 & $2.33 \mathrm{E}-02$ \\
132 & $2.26 \mathrm{E}-02$ & 133 & $2.24 \mathrm{E}-02$ & 134 & $2.21 \mathrm{E}-02$ & 135 & $2.19 \mathrm{E}-02$ \\
138 & $2.12 \mathrm{E}-02$ & 139 & $2.10 \mathrm{E}-02$ & 140 & $2.08 \mathrm{E}-02$ & 141 & $2.05 \mathrm{E}-02$
\end{tabular}

\begin{tabular}{llcl} 
PERIOD PM PERIOD PM & \\
\hline 4 & $6.39 \mathrm{E}-03$ & 5 & $6.53 \mathrm{E}-03$
\end{tabular}

$\begin{array}{rrrr}4 & 6.39 \mathrm{E}-03 & 5 & 6.53 \mathrm{E}-03 \\ 10 & 7.24 \mathrm{E}-03 & 11 & 7.38 \mathrm{E}-03\end{array}$

$\begin{array}{llll}16 & 8.09 \mathrm{E}-03 & 17 & 8.23 \mathrm{E}-03\end{array}$

$\begin{array}{llll}22 & 8.94 \mathrm{E}-03 & 23 & 9.09 \mathrm{E}-03 \\ 28 & 9.80 \mathrm{E}-03 & 29 & 9.94 \mathrm{E}-03\end{array}$

$34 \quad 1.16 \mathrm{E}-02 \quad 35 \quad 1.20 \mathrm{E}-02$

$40 \quad 1.37 \mathrm{E}-02 \quad 41 \quad 1.41 \mathrm{E}-02$

$46 \quad 1.58 \mathrm{E}-02 \quad 47 \quad 1.62 \mathrm{E}-02$

$52 \quad 1.79 \mathrm{E}-02 \quad 53 \quad 1.83 \mathrm{E}-02$

$\begin{array}{llll}52 & 1.79 \mathrm{E}-02 & 53 & 1.83 \mathrm{E}-02 \\ 58 & 2.00 \mathrm{E}-02 & 59 & 2.02 \mathrm{E}-02\end{array}$

$\begin{array}{llll}64 & 2.14 \mathrm{E}-02 & 65 & 2.16 \mathrm{E}-02\end{array}$

$\begin{array}{llll}70 & 2.28 \mathrm{E}-02 & 71 & 2.30 \mathrm{E}-02\end{array}$

$\begin{array}{llll}76 & 2.42 \mathrm{E}-02 & 77 & 2.44 \mathrm{E}-02\end{array}$

$2.56 \mathrm{E}-02 \quad 83 \quad 2.58 \mathrm{E}-02$

$2.70 \mathrm{E}-02 \quad 89 \quad 2.72 \mathrm{E}-02$

$2.84 \mathrm{E}-02 \quad 95 \quad 2.86 \mathrm{E}-02$

$2.98 \mathrm{E}-02 \quad 101 \quad 2.98 \mathrm{E}-02$

$2.87 \mathrm{E}-02 \quad 107 \quad 2.84 \mathrm{E}-02$

$2.73 \mathrm{E}-02 \quad 113 \quad 2.70 \mathrm{E}-02$

$2.59 \mathrm{E}-02 \quad 119 \quad 2.56 \mathrm{E}-02$

2.45E-02 $125 \quad 2.42 \mathrm{E}-02$

$2.31 \mathrm{E}-02 \quad 131 \quad 2.28 \mathrm{E}-02$

$\begin{array}{lll}2.17 \mathrm{E}-02 & 137 & 2.14 \mathrm{E}-02 \\ 2.03 \mathrm{E}-02 & 143 & 2.01 \mathrm{E}-02\end{array}$

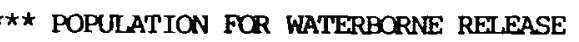

\begin{tabular}{rr} 
PERIOD & PL \\
\hline 0 & $1.99 \mathrm{E}-02$ \\
6 & $5.57 \mathrm{E}+05$ \\
12 & $1.05 \mathrm{E}+06$ \\
18 & $1.37 \mathrm{E}+06$ \\
24 & $1.54 \mathrm{E}+06$ \\
30 & $1.71 \mathrm{E}+06$ \\
36 & $1.88 \mathrm{E}+06$ \\
42 & $2.06 \mathrm{E}+06$ \\
48 & $2.23 \mathrm{E}+06$ \\
54 & $2.40 \mathrm{E}+06$ \\
60 & $2.57 \mathrm{E}+06$ \\
66 & $2.75 \mathrm{E}+06$ \\
72 & $2.92 \mathrm{E}+06$ \\
78 & $3.09 \mathrm{E}+06$ \\
84 & $3.26 \mathrm{E}+06$ \\
90 & $3.44 \mathrm{E}+06$ \\
96 & $3.61 \mathrm{E}+06$ \\
102 & $3.78 \mathrm{E}+06$ \\
108 & $3.95 \mathrm{E}+06$ \\
114 & $4.13 \mathrm{E}+06$ \\
120 & $4.30 \mathrm{E}+06$ \\
126 & $4.47 \mathrm{E}+06$ \\
132 & $4.64 \mathrm{E}+06$ \\
138 & $4.82 \mathrm{E}+06$
\end{tabular}

\begin{tabular}{rrrr}
\multicolumn{1}{r}{ PERIOD } & \multicolumn{2}{c}{ PERIOD } \\
\hdashline 1 & $3.26 \mathrm{E}+05$ & 2 & $3.87 \mathrm{E}+05$ \\
7 & $6.39 \mathrm{E}+05$ & 8 & $7.20 \mathrm{E}+05$ \\
13 & $1.13 \mathrm{E}+06$ & 14 & $1.21 \mathrm{E}+06$ \\
19 & $1.39 \mathrm{E}+06$ & 20 & $1.42 \mathrm{E}+06$ \\
25 & $1.57 \mathrm{E}+06$ & 26 & $1.60 \mathrm{E}+06$ \\
31 & $1.74 \mathrm{E}+06$ & 32 & $1.77 \mathrm{E}+06$ \\
37 & $1.91 \mathrm{E}+06$ & 38 & $1.94 \mathrm{E}+06$ \\
43 & $2.08 \mathrm{E}+06$ & 44 & $2.11 \mathrm{E}+06$ \\
49 & $2.26 \mathrm{E}+06$ & 50 & $2.29 \mathrm{E}+06$ \\
55 & $2.43 \mathrm{E}+06$ & 56 & $2.46 \mathrm{E}+06$ \\
61 & $2.60 \mathrm{E}+06$ & 62 & $2.63 \mathrm{E}+06$ \\
67 & $2.77 \mathrm{E}+06$ & 68 & $2.80 \mathrm{E}+06$ \\
73 & $2.95 \mathrm{E}+06$ & 74 & $2.98 \mathrm{E}+06$ \\
79 & $3.12 \mathrm{E}+06$ & 80 & $3.15 \mathrm{E}+06$ \\
85 & $3.29 \mathrm{E}+06$ & 86 & $3.32 \mathrm{E}+06$ \\
91 & $3.46 \mathrm{E}+06$ & 92 & $3.49 \mathrm{E}+06$ \\
97 & $3.64 \mathrm{E}+06$ & 98 & $3.67 \mathrm{E}+06$ \\
103 & $3.81 \mathrm{E}+06$ & 104 & $3.84 \mathrm{E}+06$ \\
109 & $3.98 \mathrm{E}+06$ & 110 & $4.01 \mathrm{E}+06$ \\
115 & $4.15 \mathrm{E}+06$ & 116 & $4.18 \mathrm{E}+06$ \\
121 & $4.33 \mathrm{E}+06$ & 122 & $4.36 \mathrm{E}+06$ \\
127 & $4.50 \mathrm{E}+06$ & 128 & $4.53 \mathrm{E}+06$ \\
133 & $4.67 \mathrm{E}+06$ & 134 & $4.70 \mathrm{E}+06$ \\
139 & $4.84 \mathrm{E}+06$ & 140 & $4.87 \mathrm{E}+06$
\end{tabular}

\begin{tabular}{rc}
\multicolumn{2}{c}{ PERIOD PL } \\
\hline 3 & $4.17 \mathrm{E}+05$ \\
9 & $8.02 \mathrm{E}+05$ \\
15 & $1.28 \mathrm{E}+06$ \\
21 & $1.45 \mathrm{E}+06$ \\
27 & $1.62 \mathrm{E}+06$ \\
33 & $1.80 \mathrm{E}+06$ \\
39 & $1.97 \mathrm{E}+06$
\end{tabular}

$2.14 \mathrm{E}+06$

2. $31 \mathrm{E}+06$

$2.49 \mathrm{E}+06$

$2.83 \mathrm{E}+06$

$3.00 \mathrm{E}+06$

$3.18 \mathrm{E}+06$

3. $35 \mathrm{E}+06$

$3.52 \mathrm{E}+06$

$3.69 \mathrm{E}+06$

$3.87 \mathrm{E}+06$

$4.04 \mathrm{E}+06$

4. $21 \mathrm{E}+06$

4. $38 \mathrm{E}+06$

4. $56 \mathrm{E}+06$

$4.73 \mathrm{E}+06$

4. $90 \mathrm{E}+06$

\begin{tabular}{|c|c|c|c|}
\hline & PL & & PL \\
\hline 4 & $4.45 E+05$ & 5 & 4. $76 \mathrm{E}+05$ \\
\hline 10 & $8.83 E+05$ & 11 & $9.65 E+05$ \\
\hline 16 & $1.31 \mathrm{E}+06$ & 17 & 1. $34 \mathrm{E}+06$ \\
\hline 22 & $1.48 \mathrm{E}+06$ & 23 & $1.51 \mathrm{E}+06$ \\
\hline 28 & $1.65 \mathrm{E}+06$ & 29 & $1.68 \mathrm{E}+06$ \\
\hline 34 & $1.83 \mathrm{E}+06$ & 35 & $1.85 E+06$ \\
\hline 40 & $2.00 \mathrm{E}+06$ & 41 & $2.03 \mathrm{E}+06$ \\
\hline 46 & $2.17 \mathrm{E}+06$ & 47 & $2.20 \mathrm{E}+06$ \\
\hline 52 & $2.34 \mathrm{E}+06$ & 53 & $2.37 \mathrm{E}+06$ \\
\hline 58 & $2.52 \mathrm{E}+06$ & 59 & $2.54 \mathrm{E}+06$ \\
\hline 64 & $2.69 \mathrm{E}+06$ & 65 & $2.72 \mathrm{E}+06$ \\
\hline 70 & $2.86 \mathrm{E}+06$ & 71 & $2.89 \mathrm{E}+06$ \\
\hline 76 & $3.03 E+06$ & 77 & $3.06 \mathrm{E}+06$ \\
\hline 82 & $3.21 \mathrm{E}+06$ & 83 & 3. $23 \mathrm{E}+06$ \\
\hline 88 & 3. $38 \mathrm{E}+06$ & 89 & $3.41 \mathrm{E}+06$ \\
\hline 94 & $3.55 \mathrm{E}+06$ & 95 & $3.58 \mathrm{E}+06$ \\
\hline 100 & $3.72 \mathrm{E}+06$ & 101 & $3.75 \mathrm{E}+06$ \\
\hline 106 & $3.90 \mathrm{E}+06$ & 107 & $3.92 \mathrm{E}+06$ \\
\hline 112 & $4.07 \mathrm{E}+06$ & 113 & $4.10 \mathrm{E}+06$ \\
\hline 118 & $4.24 \mathrm{E}+06$ & 119 & $4.27 \mathrm{E}+06$ \\
\hline 124 & $4.41 E+06$ & 125 & $4.44 \mathrm{E}+06$ \\
\hline 130 & $4.59 \mathrm{E}+06$ & 131 & $4.61 \mathrm{E}+06$ \\
\hline 136 & 4. $76 \mathrm{E}+06$ & 137 & $4.79 \mathrm{E}+06$ \\
\hline 142 & $4.93 \mathrm{E}+06$ & 143 & $4.93 \mathrm{E}+06$ \\
\hline
\end{tabular}

FIGURE F.12. (contd) 


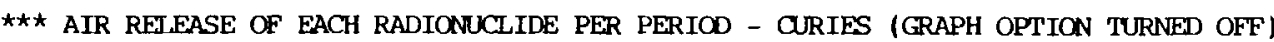

PERIOD ACTVITY

PERIOD ACTVITY

PERIOD ACTVITY

PERIOD ACTVITY

PERIOD ACTVITY

PERIOD ACTVITY

C 14

SR90

$\begin{array}{ll}15 & 5.25 E+03 \\ 21 & 1.31 E+04 \\ 27 & 1.30 E+04 \\ 33 & 7.61 E+03 \\ 39 & 3.20 E+03\end{array}$

$\begin{array}{ll}16 & 8.19 E+03 \\ 22 & 1.39 E+04 \\ 28 & 1.18 E+04 \\ 34 & 6.88 E+03 \\ 40 & 2.47 E+03\end{array}$
$17 \quad 9.17 \mathrm{E}+03$
$23 \quad 1.40 \mathrm{E}+04$

$18+1.02+04$

- - -..- -.--.--.

Y 90

I 129

PU238

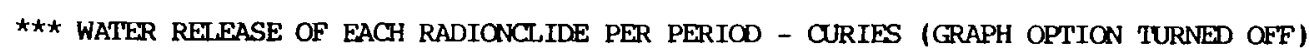

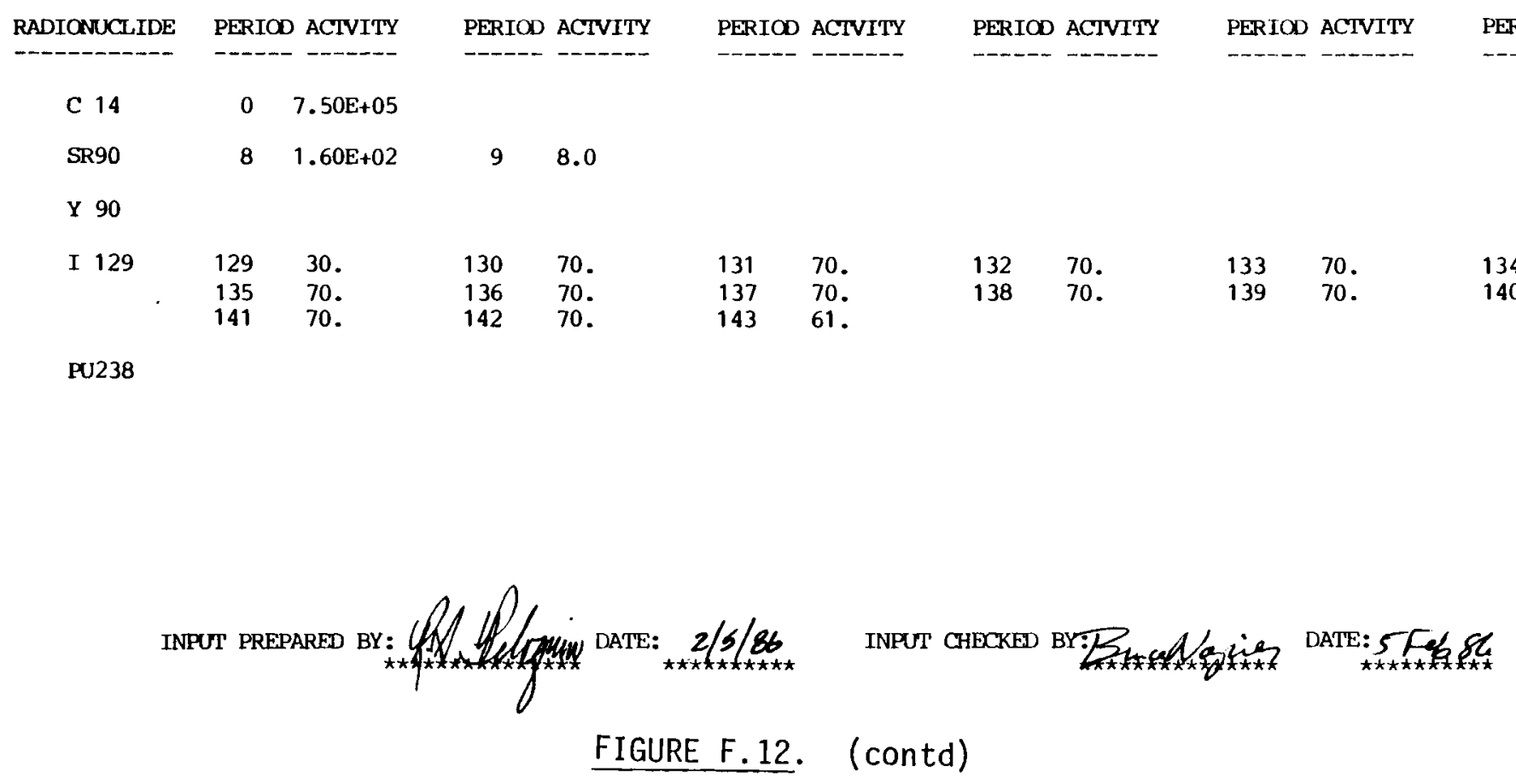

PERIOD ACIVITY

3470

4070 
REPORT FOR DITIY (VAX VERSION 1.0) RUN ON 4-FEB-86

INTEXPATED POPULATION DOSE CALCULATED FOR CHRONIC ATMOSPHERIC AND EIQUID

RETEASE FROM TIME 1990. A.D. ONWARD FOR 10,000 YEARS

CASE TITIE: Sample Problem Seven - Airborne and waterborne release, chronic exposure

* * * MAXIMUM DOSE RATE REPORT * * *

DOSE INTFGRAL, PERIOD (70-YEAR) DURING WHICH THE MAXIMUM DOSE RATE OCOURS =

27

* * * MaXimum POPUlation DOSE INCREMENT TO TOTAL BODY BY ORGAN AND RADIONUCLIDE * * *

\begin{tabular}{l} 
NUCLIDE \\
\hdashline C 14 \\
SR90 \\
Y 90 \\
I 129 \\
PU238 \\
\hdashline Total \\
\hline
\end{tabular}

$\begin{array}{r}------ \\ \text { TOTAL BODY } \\ -0.00 \mathrm{E}+00 \\ 9.56 \mathrm{E}+04 \\ 2.98 \mathrm{E}-14 \\ 0.00 \mathrm{E}+00 \\ 0.00 \mathrm{E}+00 \\ \hline 9.56 \mathrm{E}+04 \\ \hline\end{array}$

\begin{tabular}{l}
\hline BONE \\
$-0.00 \mathrm{E}+00$ \\
$8.59 \mathrm{E}+05$ \\
$3.00 \mathrm{E}-14$ \\
$0.00 \mathrm{E}+00$ \\
$0.00 \mathrm{E}+00$ \\
\hline $8.59 \mathrm{E}+05$ \\
\hline
\end{tabular}

LUNG
$-0.00 \mathrm{E}+00$
$1.85 \mathrm{E}+05$
$2.99 \mathrm{E}-14$
$0.00 \mathrm{E}+00$
$0.00 \mathrm{E}+00$
$-1.85 \mathrm{E}+05$
-

\begin{tabular}{l}
------- \\
THYROID \\
\hdashline $0.00 \mathrm{E}+00$ \\
$8.83 \mathrm{E}-03$ \\
$2.98 \mathrm{E}-14$ \\
$0.00 \mathrm{E}+00$ \\
$0.00 \mathrm{E}+00$ \\
$-8.83 \mathrm{E}-03$ \\
\hline
\end{tabular}

GI-LLI

$0.00 \mathrm{E}+00$

$4.93 \mathrm{E}+03$

$1.79 \mathrm{E}-12$

$0.00 \mathrm{E}+00$

$0.00 \mathrm{E}+00$

$4.93 \mathrm{E}+03$

Dose in units of person-rem; that is the cumulative population dose received by the local population over 10,000 years with an assumed 70-yr individual lifetime.

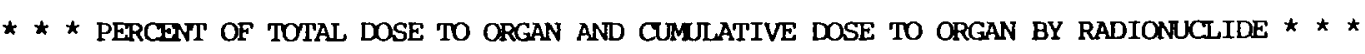

\begin{tabular}{l} 
NUCLIDE \\
\hline C 14 \\
SR90 \\
Y 90 \\
I 129 \\
PU238 \\
- Total
\end{tabular}

\begin{tabular}{rl}
\hline TOTAL BODY \\
\hdashline 08 & $0.0 \mathrm{E}+00$ \\
998 & $1.7 \mathrm{E}+06$ \\
08 & 0.2 \\
08 & $2.3 \mathrm{E}+03$ \\
08 & $0.0 \mathrm{E}+00$ \\
\hline & $1.7 \mathrm{E}+06$
\end{tabular}

\begin{tabular}{rl}
\hline \multicolumn{1}{c}{ BONE } \\
\hdashline 08 & $0.0 \mathrm{E}+00$ \\
998 & $1.6 \mathrm{E}+07$ \\
08 & 0.2 \\
08 & $1.3 \mathrm{E}+03$ \\
08 & $0.0 \mathrm{E}+00$ \\
- & $1.6 \mathrm{E}+07$ \\
\hline
\end{tabular}

\begin{tabular}{rl}
\hline LUNG \\
\hdashline 08 & $0.0 \mathrm{E}+00$ \\
998 & $3.4 \mathrm{E}+06$ \\
08 & 0.2 \\
08 & $7.5 \mathrm{E}+02$ \\
08 & $0.0 \mathrm{E}+00$ \\
- & $3.4 \mathrm{E}+06$ \\
\hline
\end{tabular}

THYROID

$08 \quad 0.0 \mathrm{E}+00$

080.2

$\begin{array}{ll}08 & 0.2 \\ 0 \mathrm{z} & 0.2\end{array}$

$9981.2 \mathrm{E}+06$

$08 \quad 0.0 \mathrm{E}+00$

$1.2 \mathrm{E}+06$

$1.2 \mathrm{E}+06$

GI-LLI

$08 \quad 0.0 E+00$

$998 \quad 9.0 \mathrm{E}+04$

$08 \quad 1.4 \mathrm{E}+01$

0 을 $8.3 \mathrm{E}+02$

$080.0 \mathrm{E}+00$

$9.1 \mathrm{E}+04$

Dose in units of person-rem; that is the cumulative population dose received by the local population over 10,000 years with an assumed 70-yr individual lifetime.

FIGURE F.12. (contd) 
APPENDIX G

DIAGNOSTIC MESSAGES 
The computer program DITTY contains several read error tests and internal tests on input data. For each error condition detected a diagnostic message is printed prior to termination of execution. The messages printed by DITTY are listed in alphabetized order in Table G.1. Also provided is the name of the module the message is printed from, the severity of the error ( $F$ for fatal or I for informative), and a brief description of the cause of the error.

\section{TABLE G.1. DITTY Diagnostic Messages}

\begin{tabular}{|c|c|c|}
\hline Module & Severity & Message/Cause \\
\hline AIRLIN & $F$ & $\begin{array}{l}\text { "Bad library organ index value, IGRG (I0): _- } \\
\text { The organ selection index array IORG has a value out of } \\
\text { range, } 1<\text { IORG (I0) } 23 \text {. The values are read from the } \\
\text { internal dose conversion factor data file (logical unit } \\
\text { 18). }\end{array}$ \\
\hline ORGCHK & $F$ & $\begin{array}{l}\text { "Bad value for KORG }(I)=-" \\
\text { A value in the master organ index array is out of range, } \\
1 \leq K O R G \leq 23 \text {. }\end{array}$ \\
\hline RLIBIN & $\mathrm{F}$ & $\begin{array}{l}\text { "Decay chain has improper order. Current member } \\
\text { index is } \\
\text { Chain decay data in master radionuclide data file } \\
\text { (logical unit) is out of order. Check the values of the } \\
\text { chain member indices for increasing order within chains. }\end{array}$ \\
\hline CASEIN & $F$ & $\begin{array}{l}\text { "E/Q read error encountered in CASEIN" } \\
\text { An error occurred when reading of chi/Q values was } \\
\text { attempted from the input stream (logical unit } 5 \text { ), record } \\
\text { type } 6 \text {. }\end{array}$ \\
\hline EXMO & $\mathrm{F}$ & $\begin{array}{l}\text { "Error in function EXMO, positive arg = - } \\
\text { A positive value was passed to function EXMO through the } \\
\text { first argument position, ARG. This parameter must be } \\
\text { less than or equal to zero. This message is an } \\
\text { indication of serious problems in basic radionuclide } \\
\text { data arrays. }\end{array}$ \\
\hline
\end{tabular}

G.1 
TABLE G.1. (contd)

\begin{tabular}{ll} 
Module Severity & \multicolumn{1}{c}{ Message/Cause } \\
CASEIN & "Error reading population in file 22. encountered in \\
& CASEIN" \\
An error occurred while reading population data was \\
being read from the library population file (logical \\
unit 22). \\
RLIBIN
\end{tabular}

G.2 
TABLE G.1. (contd)

\begin{tabular}{|c|c|c|}
\hline Module & Severity & Message/Cause \\
\hline EOVRO & $\mathrm{F}$ & $\begin{array}{l}\text { "NUBAR is out of range; _- } \\
\text { The value of the NAMELIST parameter NUBAR is out of } \\
\text { range, } 1 \leq \text { NUBAR } \leq 8 \text {. }\end{array}$ \\
\hline NUCTST & $F$ & $\begin{array}{l}\text { "Nuclide } \_ \text {not found } \\
\text { The named radionuclide read from input (logical unit 5) } \\
\text { did not match any of the master radionuclides also } \\
\text { supplied on the input file. }\end{array}$ \\
\hline ORGCHK & $\mathrm{F}$ & $\begin{array}{l}\text { "Number of errors in } \mathrm{ORGCHK}=" \\
\text { Errors were detected in the master organ input data } \\
\text { (logical unit } 5 \text { ). This message is always preceeded by } \\
\text { other messages. }\end{array}$ \\
\hline AIRLIN & $F$ & $\begin{array}{l}\text { "Number of library organs incorrect, LORG: } \\
\text { The value of LORG read from the internal organ dose } \\
\text { conversion factor data file (logical unit 18) was out of } \\
\text { range, } 1 \leq \text { LORG } \leq 10 \text {. }\end{array}$ \\
\hline CASEIN & $\mathrm{F}$ & $\begin{array}{l}\text { "Population for airborne release error in input file." } \\
\text { An error occurred with the attempted read of population } \\
\text { data, record type } 9 \text {, from the input stream (logical } \\
\text { unit 5). }\end{array}$ \\
\hline CASEIN & $\mathrm{F}$ & $\begin{array}{l}\text { "Population title airborne release error in file } 22 . " \\
\text { An error occurred when either an attempt was made to } \\
\text { open the file assigned to logic unit } 22 \text { or when an } \\
\text { attempt was made to read the title (first line) of the } \\
\text { file. }\end{array}$ \\
\hline ACT IN & $\mathrm{F}$ & $\begin{array}{l}\text { "Premature end-of-file encountered in ACTIN" } \\
\text { An attempt was made to read beyond the end of data on the } \\
\text { release rate input file (logical unit } 5,24 \text { or } 26 \\
\text { depending on control integers IP and IAW). }\end{array}$ \\
\hline AIRLIN & $\mathrm{F}$ & $\begin{array}{l}\text { "Premature end-of-file encountered in IARLIN" } \\
\text { An attempt was made to read beyond the end of data on } \\
\text { the internal dose conversion factor data file (logical } \\
\text { unit 18). }\end{array}$ \\
\hline
\end{tabular}


TABLE G.1. (contd)

\begin{tabular}{|c|c|c|}
\hline Module & Severity & Message/Cause \\
\hline BIOLIN & $\mathrm{F}$ & $\begin{array}{l}\text { "Premature end-of-file encountered in BIOLIN" } \\
\text { An attempt was made to read beyond the end of data on } \\
\text { the bioaccumulation factor data file (logical unit 14). }\end{array}$ \\
\hline CASEIN & $F$ & $\begin{array}{l}\text { "Premature end-of-file encountered in CASEIN" } \\
\text { An attempt was made to read beyond the end of data on } \\
\text { the input file (logical unit 5). }\end{array}$ \\
\hline FOOLIN & $\mathrm{F}$ & $\begin{array}{l}\text { "Premature end-of-file encountered in FOOLIN" } \\
\text { An attempt was made to read beyond the end of data on } \\
\text { the food transfer coefficient data library (logical } \\
\text { unit 12). }\end{array}$ \\
\hline GRDL IN & $F$ & $\begin{array}{l}\text { "Premature end-of-file encountered in GRDLIN" } \\
\text { An attempt was made to read beyond the end of data on } \\
\text { the external dose conversion factor data file (logical } \\
\text { unit 16). }\end{array}$ \\
\hline MAIN & $\mathrm{F}$ & $\begin{array}{l}\text { "Premature end-of-file encountered in MAIN" } \\
\text { An input file (logical unit } 5 \text { ) read attempt was made } \\
\text { beyond the end of data in the file. }\end{array}$ \\
\hline RLIBIN & $\mathrm{F}$ & $\begin{array}{l}\text { "Premature end-of-file encountered in RLIBIN" } \\
\text { An attempt was made to read beyond the end of data on } \\
\text { the master radionuclide data file (logical unit 10). }\end{array}$ \\
\hline ACTIN & $\mathrm{F}$ & $\begin{array}{l}\text { "Read error encountered in ACTIN" } \\
\text { A read attempt resulted in an error condition on the } \\
\text { release data file (logical unit } 5,24 \text {, or } 26 \text { depending } \\
\text { on control integers IP and IAW). }\end{array}$ \\
\hline AIRL IN & $F$ & $\begin{array}{l}\text { "Read error encountered in AIRLIN" } \\
\text { A read attempt resulted in an error condition on the } \\
\text { internal dose conversion factor data file (logical unit } \\
\text { 18). }\end{array}$ \\
\hline
\end{tabular}


TABLE G.1. (contd)

\begin{tabular}{ll} 
Module Severity & \multicolumn{1}{c}{ Message/Cause } \\
\hline BIOLIN & "Read error encountered in BIOLIN" \\
FOOLIN & $F \quad \begin{array}{l}\text { A read attempt resulted in an error condition on the } \\
\text { bioaccumulation factor data file (logical unit 14). }\end{array}$ \\
"Read error encountered in FOOLIN" \\
A read attempt resulted in an error condition on the \\
food transfer coefficient data library (logical unit \\
12).
\end{tabular}




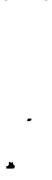




\section{APPENDIX $\mathrm{H}$}

VAX IBM PC CODE VARIATIONS 
APPENDIX H

VAX IBM PC CODE VARIATIONS

A few minor differences exist between the mainframe and IBM-PC versions of DITTY. These are:

1. An emulator for the FORTRAN statement NAMELIST was written for user input instructions compatibility between the VAX and IBM PC versions of DITTY. The emulator consists of the following components:

- Common Block NMCHR - contains arrays for storing variable names

- Common Block NMLST - contains flags and indices of NAMELIST parameters; also contains general purpose variables for storing NAMELIST parameter values

- Subroutine DECOD - reads NAMELIST input from the user's input file, decodes the variable names, and stores input values into general purpose parameters

- Subroutine NAMLS - interface between the calling program and the subroutine DECOD. NAMLS sets up the crossreference between NAMELIST parameters in the calling program and the general purpose variables stored in common blocks NMCHR and NMLST that are used by DECOD.

In the calling program, the NAMELIST statement and the READ of the NAMELIST input set are removed. A call to the subroutine NAMLS replaces these statements. Two parameters are passed to NAMLS: LUNI (the logical unit number to which the input file is assigned) and NAM (the character name of the NAMELIST set to be read).

2. The total number of radionuclides considered in any one case was reduced in the IBM-PC version to 25. This resulted in a $75 \%$ decrease in storage requirements for a number of large arrays, permitting DITTY to fit onto machines having as little as $256 \mathrm{~K}$ of available memory.

3. The functions ASUM and SUMPRD were incorporated directly into the decay processor routine BCHAIN. The coding of BCHAIN was simply increased with the actual coding of the two functions. 
COMMON BLOCK Modules

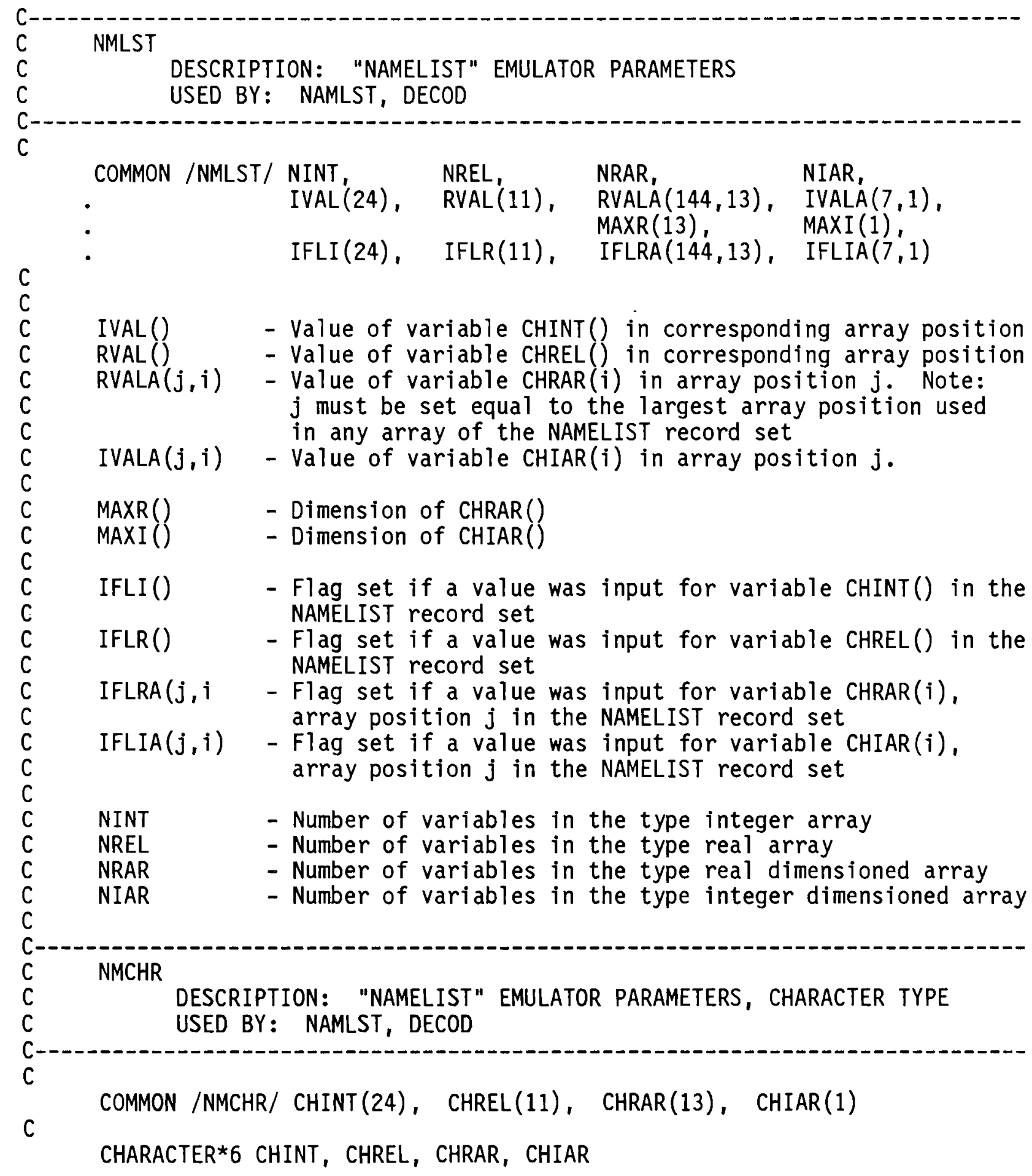

EIGURE H.1. IBM PC Code Additions 
COMMON BLOCK Modules

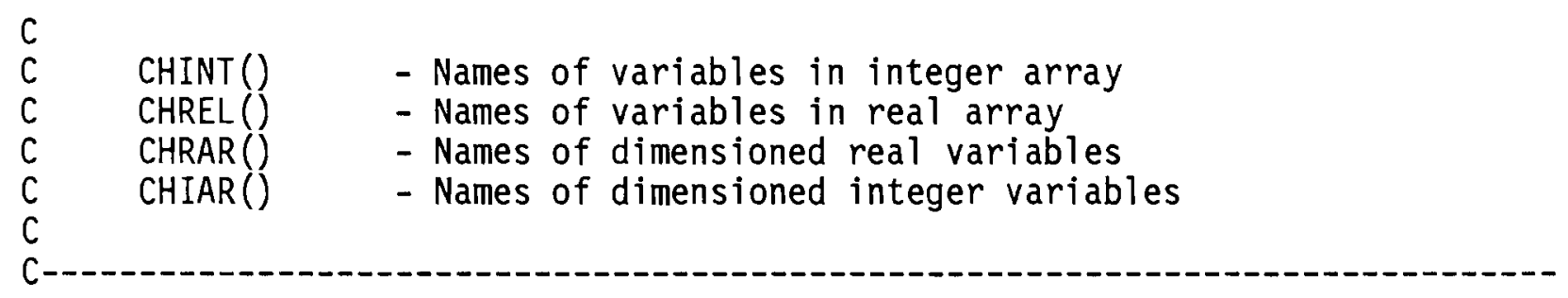

EIGURE H.1. IBM PC Code Additions (continued)

H. 3 
Module NAMLS

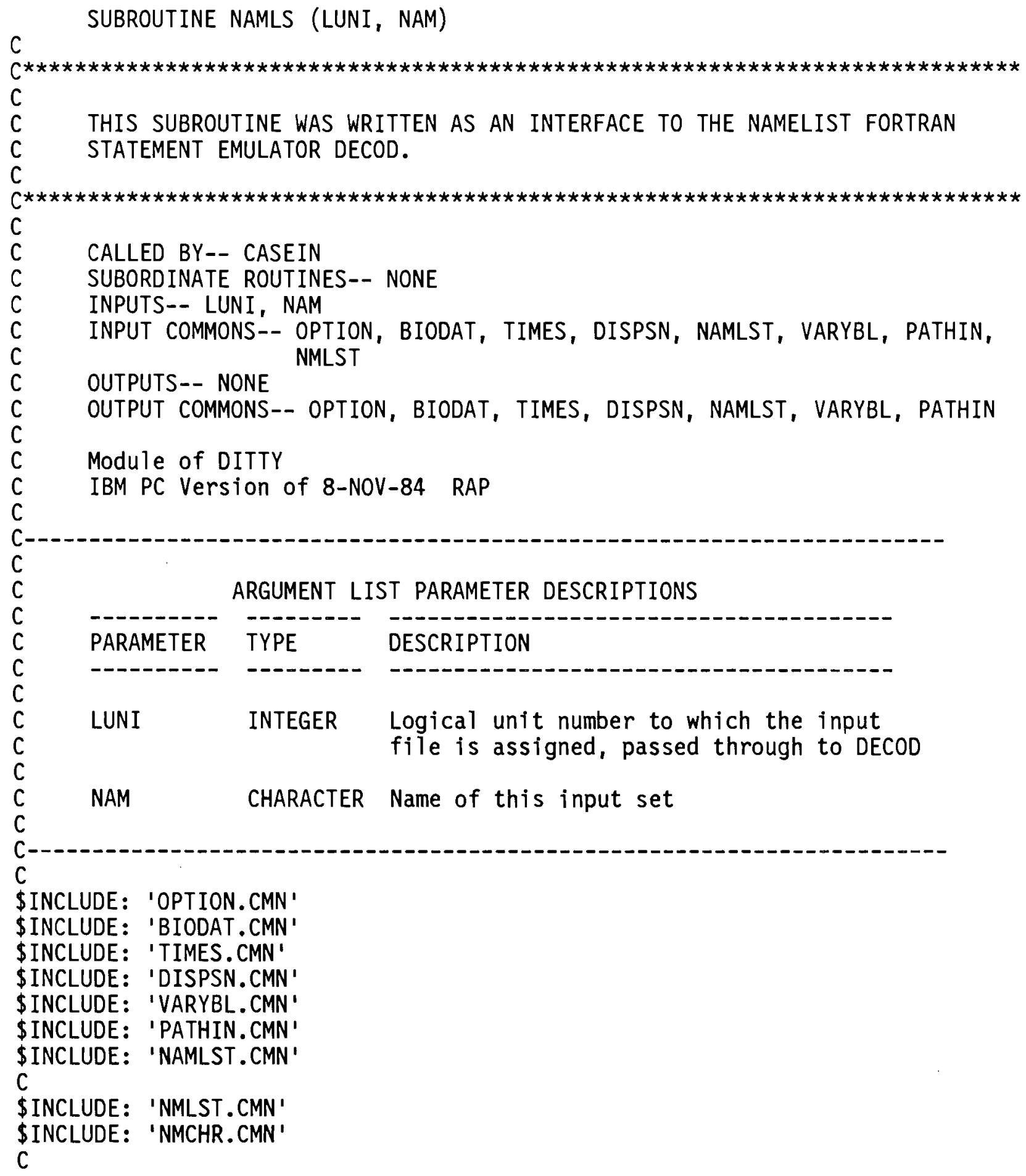

EIGURE H.1. IBM PC Code Additions (continued)

H. 4 


\section{Module NAMLS}

CHARACTER NAM* 6

C

C

C

C Set number of variables for integer, real, real array, \& integer array-C

NINT $=24$

NREL $=11$

NRAR $=13$

C

NIAR $=1$

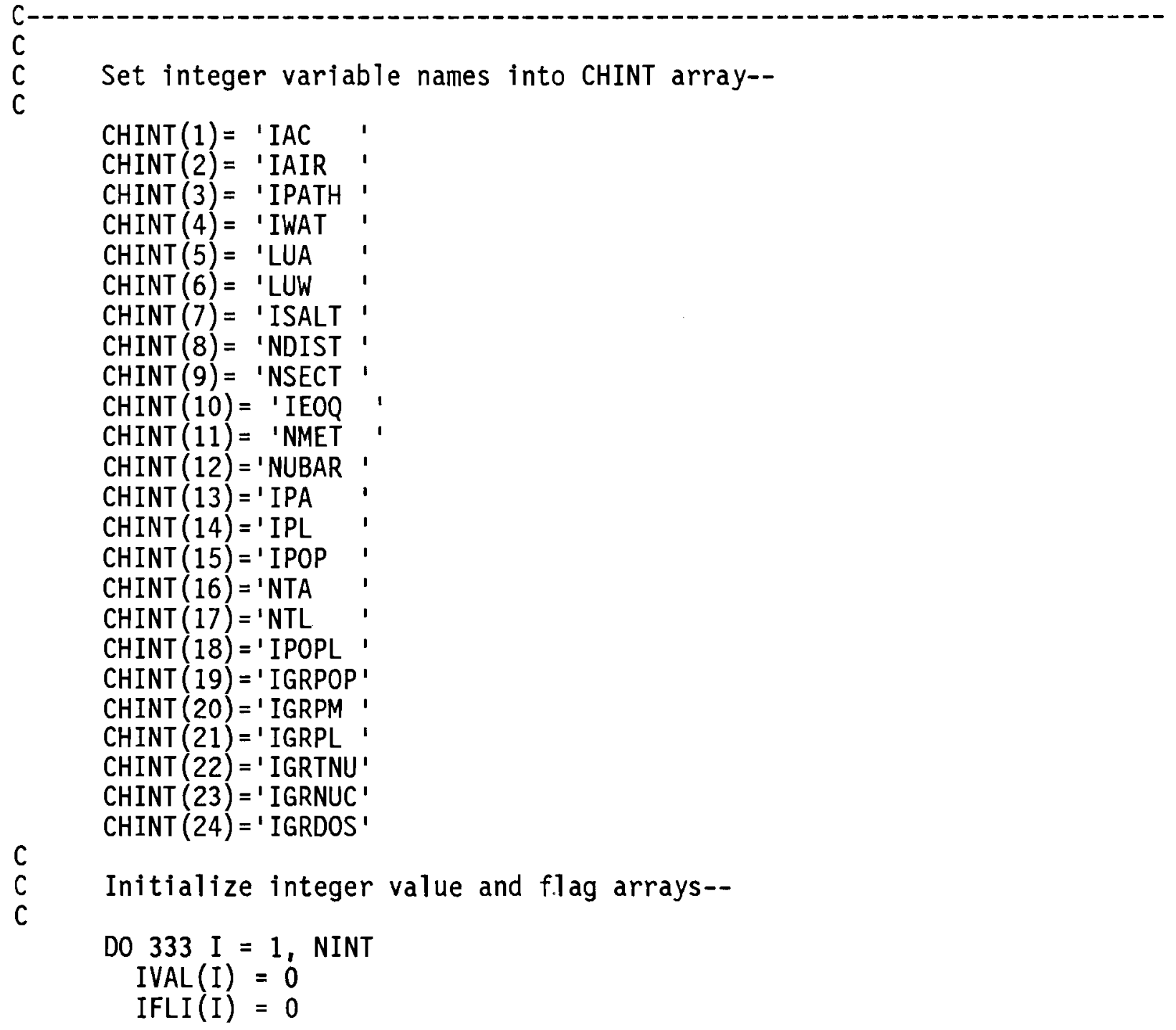

EIGURE H.1. IBM PC Code Additions (continued) 
Module NAMLS

333 CONTINUE

C

C Set real variable names into CHREL array--

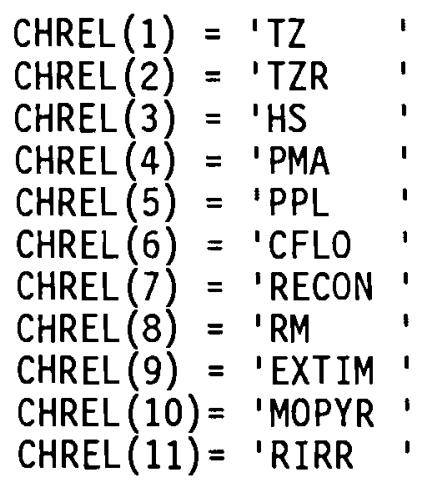

C

C Initialize real value and flag arrays--

C

DO $335 \mathrm{I}=1$, NREL

$\operatorname{RVAL}(I)=0.0$

$\operatorname{IFLR}(\mathrm{I})=0$

335 CONTINUE

C

C

C Set real array variable names into CHRAR array--

C

\begin{tabular}{|c|c|}
\hline $\begin{array}{l}\operatorname{CHRAR}(1) \\
\operatorname{CHRAR}(2) \\
\operatorname{CHRAR}(3) \\
\operatorname{CHRAR}(4) \\
\text { CHRAR (5) } \\
\text { CHRAR (6) } \\
\text { CHRAR (7) } \\
\text { CHRAR (8) } \\
\text { CHRAR (9) } \\
\text { CHRAR (10) } \\
\text { CHRAR (11) } \\
\text { CHRAR (12) } \\
\text { CHRAR (13) }\end{array}$ & $\begin{array}{l}=\text { 'DIST } \\
=\text { 'UBAR } \\
=\text { 'PL } \\
=\text { 'PL1 } \\
=\text { 'PM1 } \\
=\text { 'PM } \\
=\text { 'POPT } \\
=\text { 'USAGE } \\
=\text { 'CONSUM } \\
=\text { 'GRWP } \\
=\text { 'YELD } \\
=\text { 'T } \\
=\text { 'TL }\end{array}$ \\
\hline
\end{tabular}

C

C Set number of elements in each real array--

EIGURE H.1. IBM PC Code Additions (continued)

H. 6 
Module NAMLS

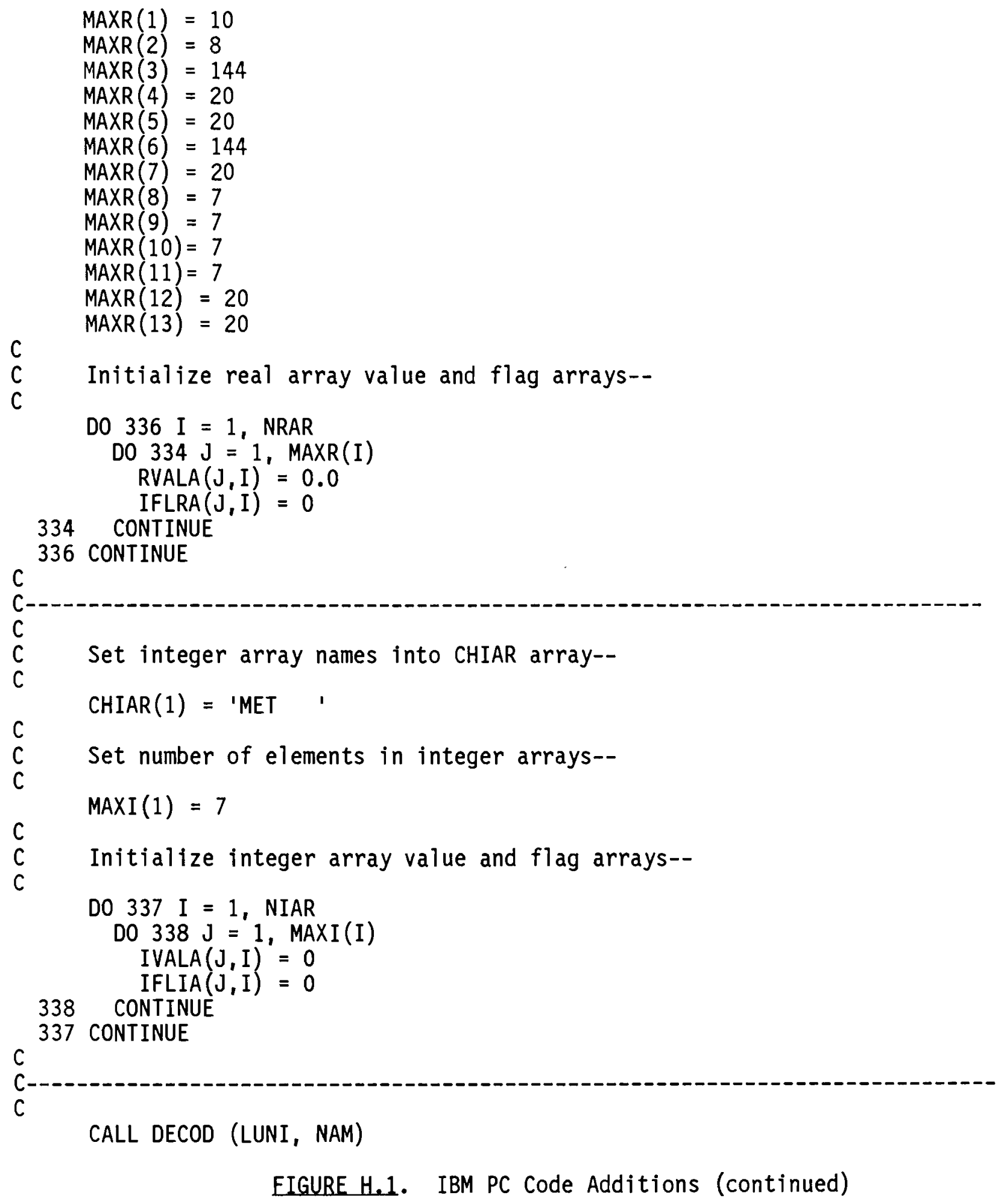

H. 7 
Module NAMLS

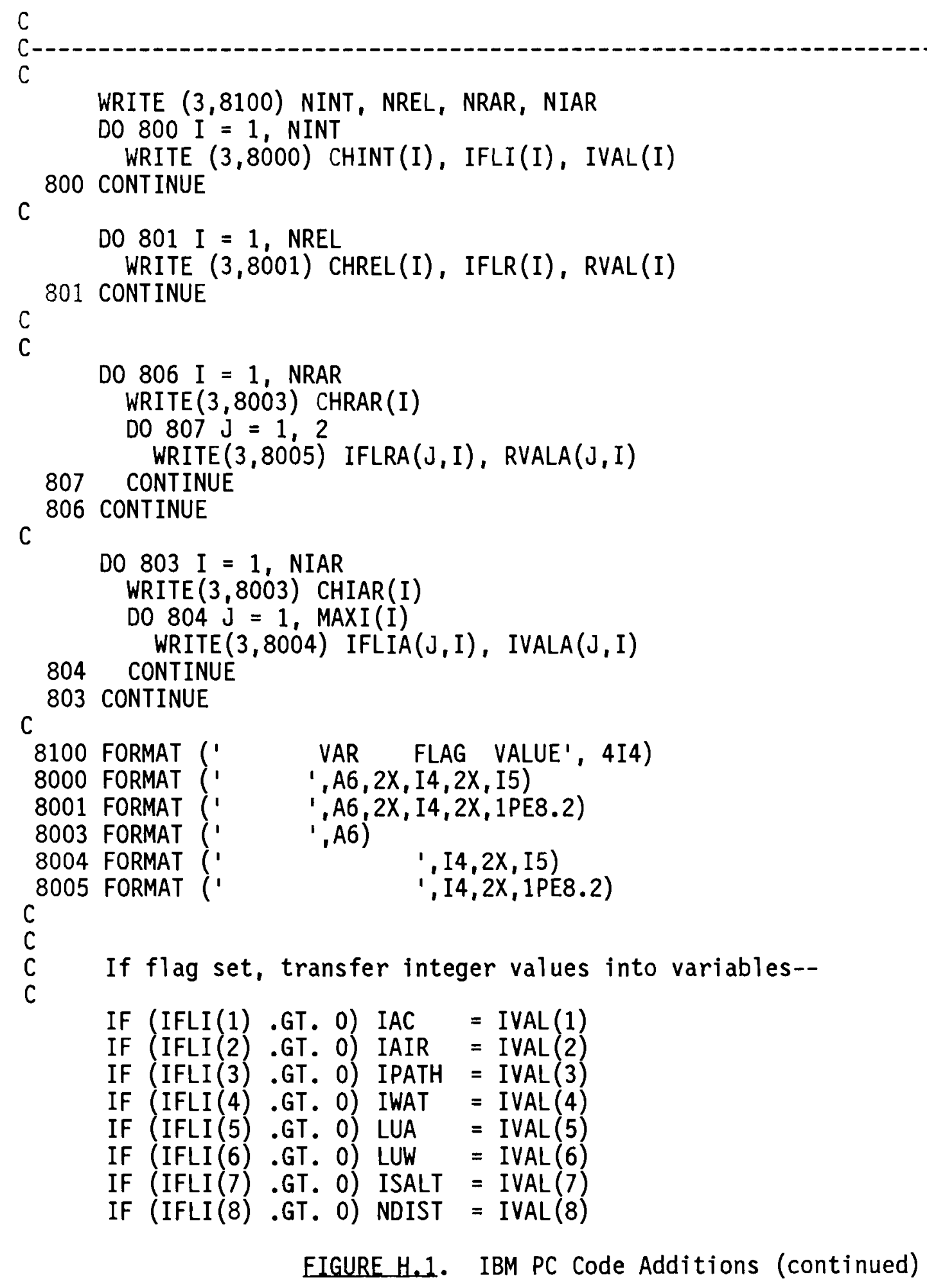

EIGURE H.1. IBM PC Code Additions (continued) 
Module NAMLS

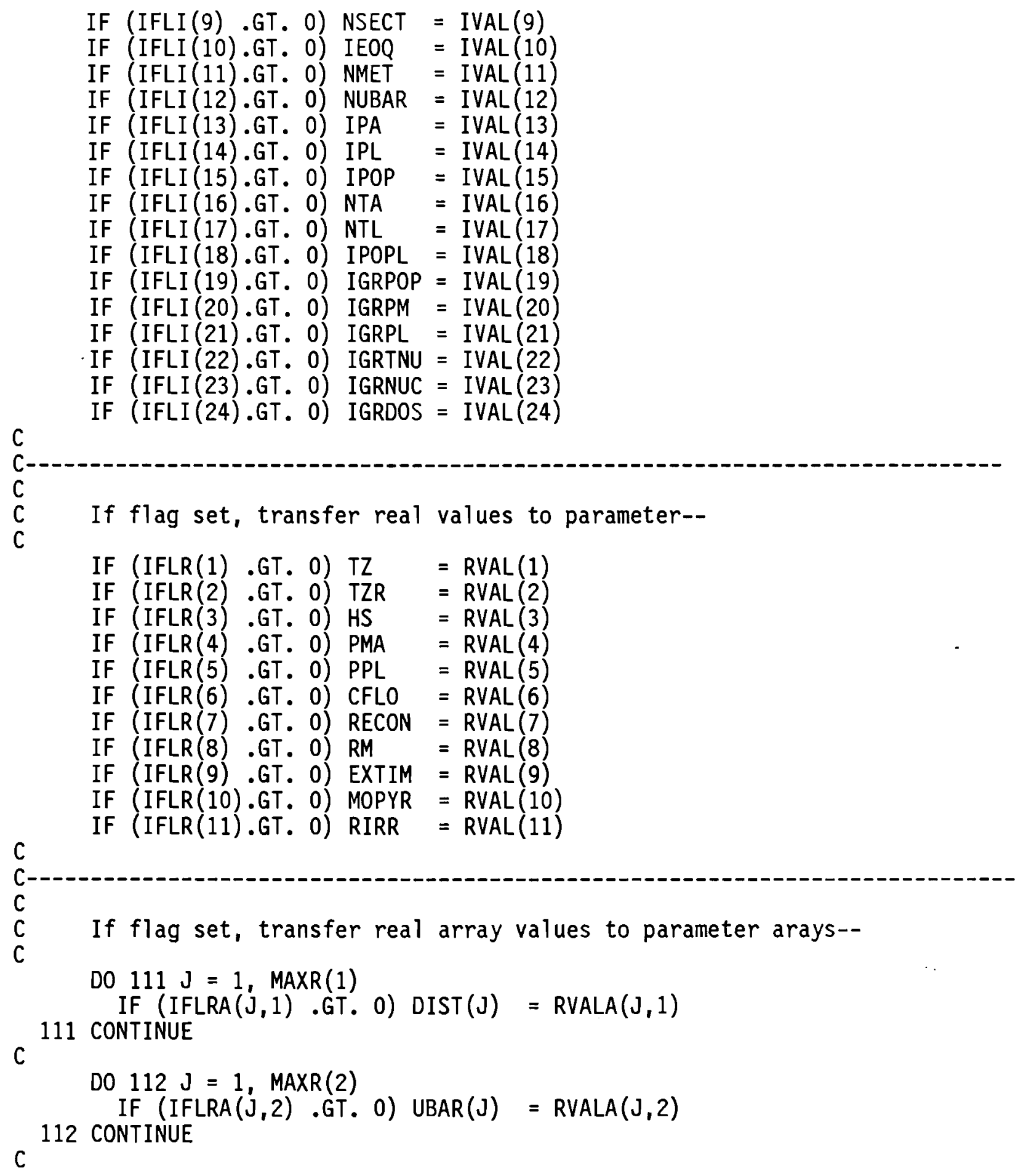

EIGURE H.1. IBM PC Code Additions (continued) 
Module NAMLS

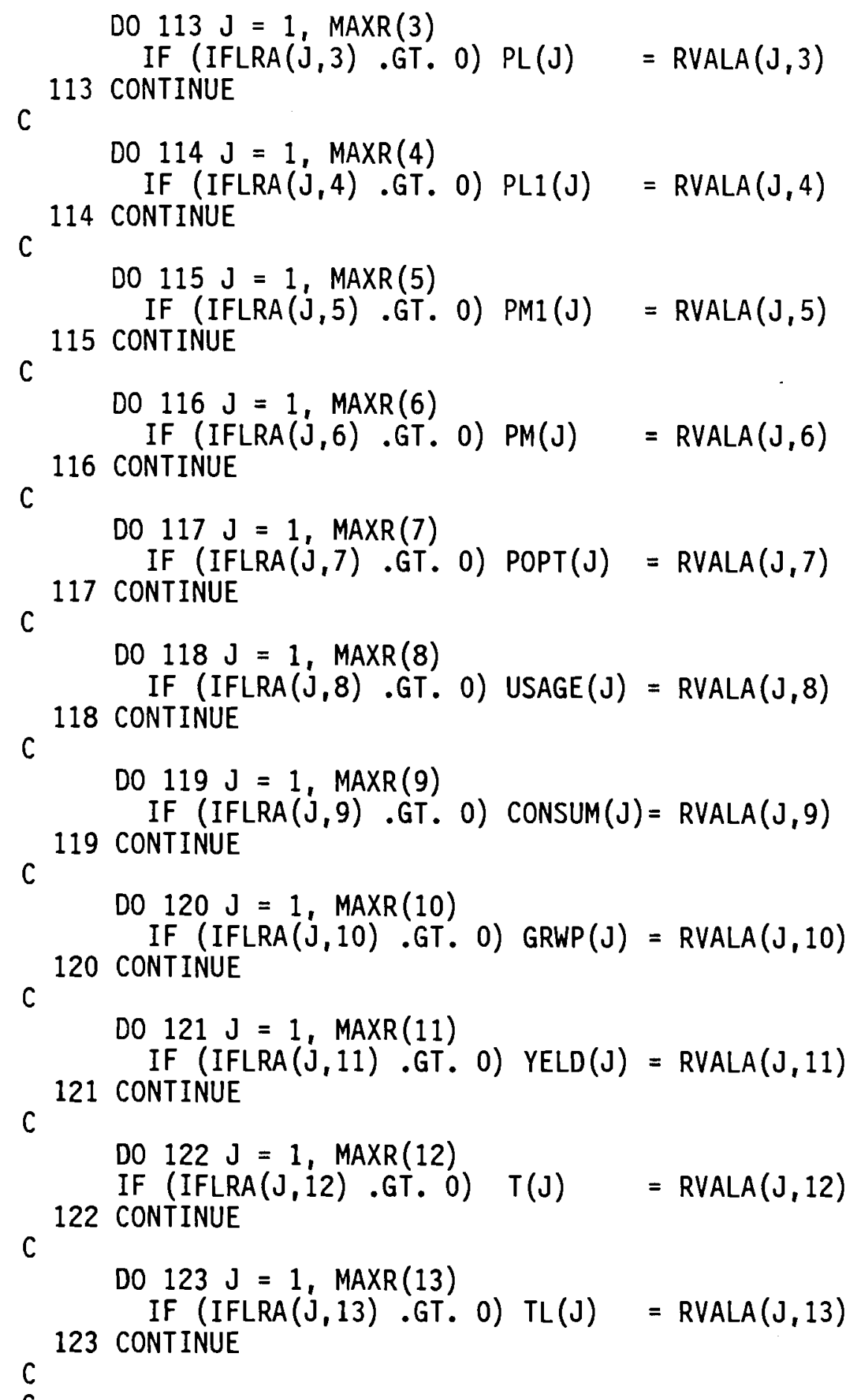

EIGURE H.1. IBM PC Code Additions (continued) 


\section{Module NAMLS}

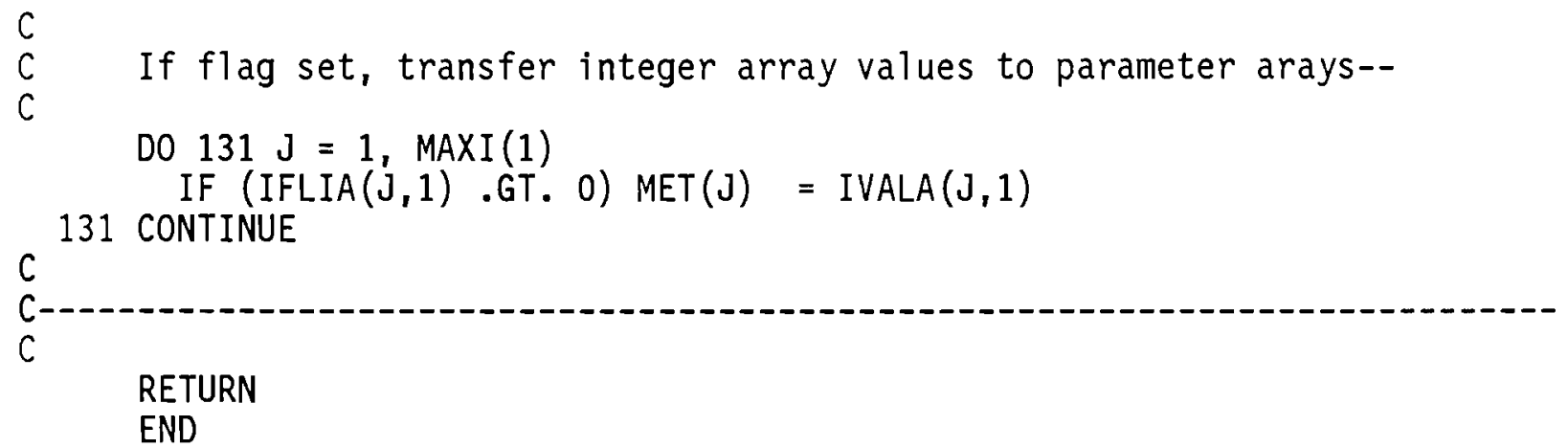

EIGURE H.1. IBM PC Code Additions (continued) 
Module DECOD

SUBROUTINE DECOD (LUNI, NAM)

$C$

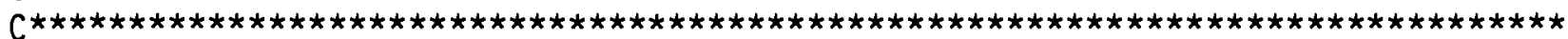

$C$

C

THIS SUBROUTINE WAS WRITTEN TO EMULATE THE NAMELIST FORTRAN STATE-

MENT ON THE IBM PC WITH MICROSOFT FORTRAN TO MAXIMIZE CODE

C COMPATIBILITY.

C

C

C CALLED BY-- CASEIN

C SUBORDINATE ROUTINES-- NONE

C INPUTS-- LUNI, NAM

C INPUT COMMONS-- NONE

C OUTPUTS-- NONE

C OUTPUT COMMONS-- NMLST

C

C Module of DITTY

C IBM PC Version of 11-NOV-84 RAP

C

C

C

C

C

C

C

C

C

C

C

C

C

c

c

C

C

C

C

ARGUMENT LIST PARAMETER DESCRIPTIONS

$\begin{array}{lll}\text { PARAMETER } & \text { TYPE } & \text { DESCRIPTION } \\ \text { LUNI } & \text { INTEGER } & \begin{array}{l}\text { Logical unit number to which the input } \\ \text { file is assigned }\end{array}\end{array}$

NAM CHARACTER Name of this input set

INTERNAL VARIABLE PARAMETER DESCRIPTIONS

PARAMETER TYPE DESCRIPTION

CHNUM CHARACTER Character representation of allowable numeric input

EIGURE H.1. IBM PC Code Additions (continued) 
Module DECOD

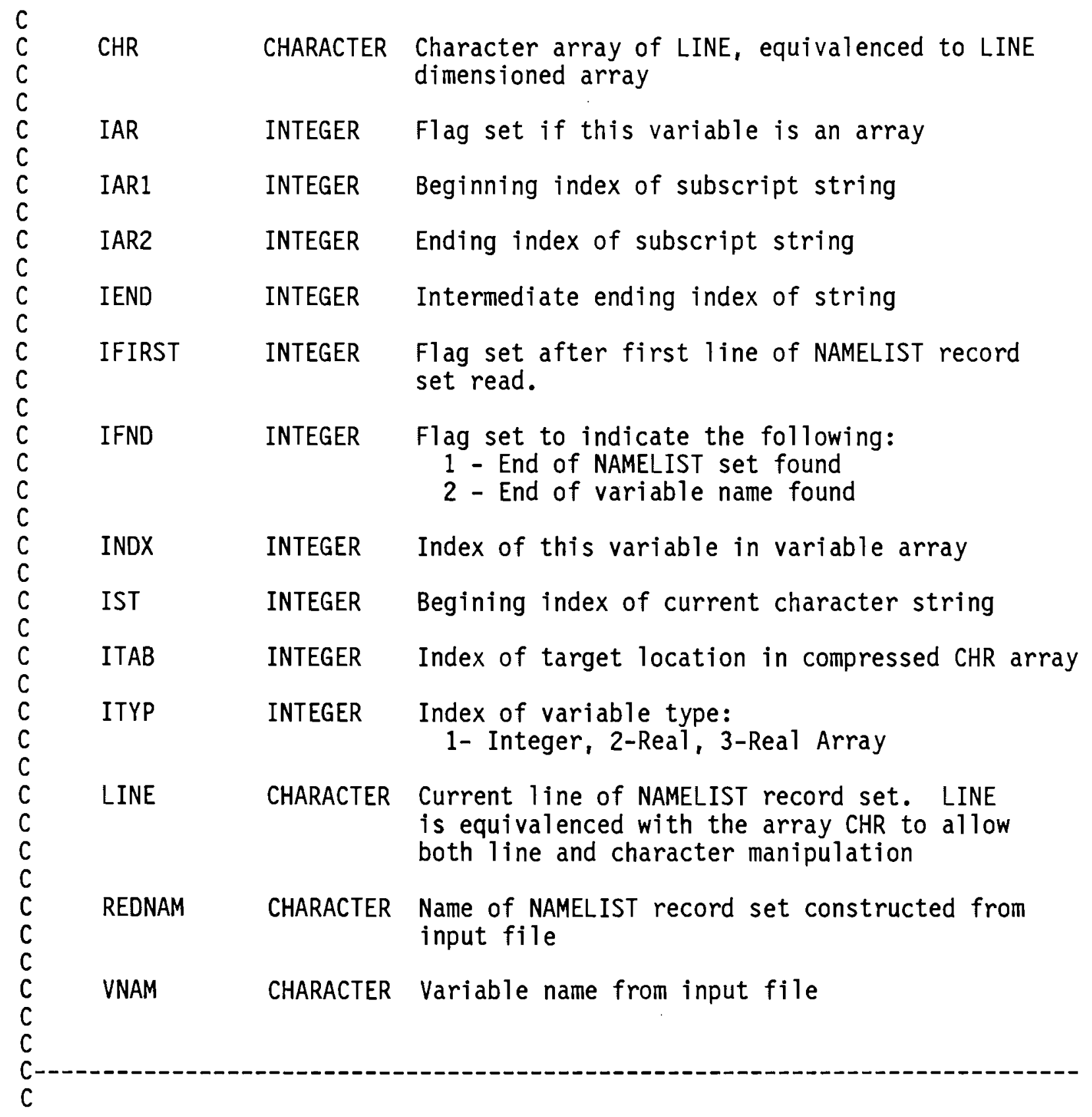

EIGURE H.1. IBM PC Code Additions (continued) 
Module DECOD

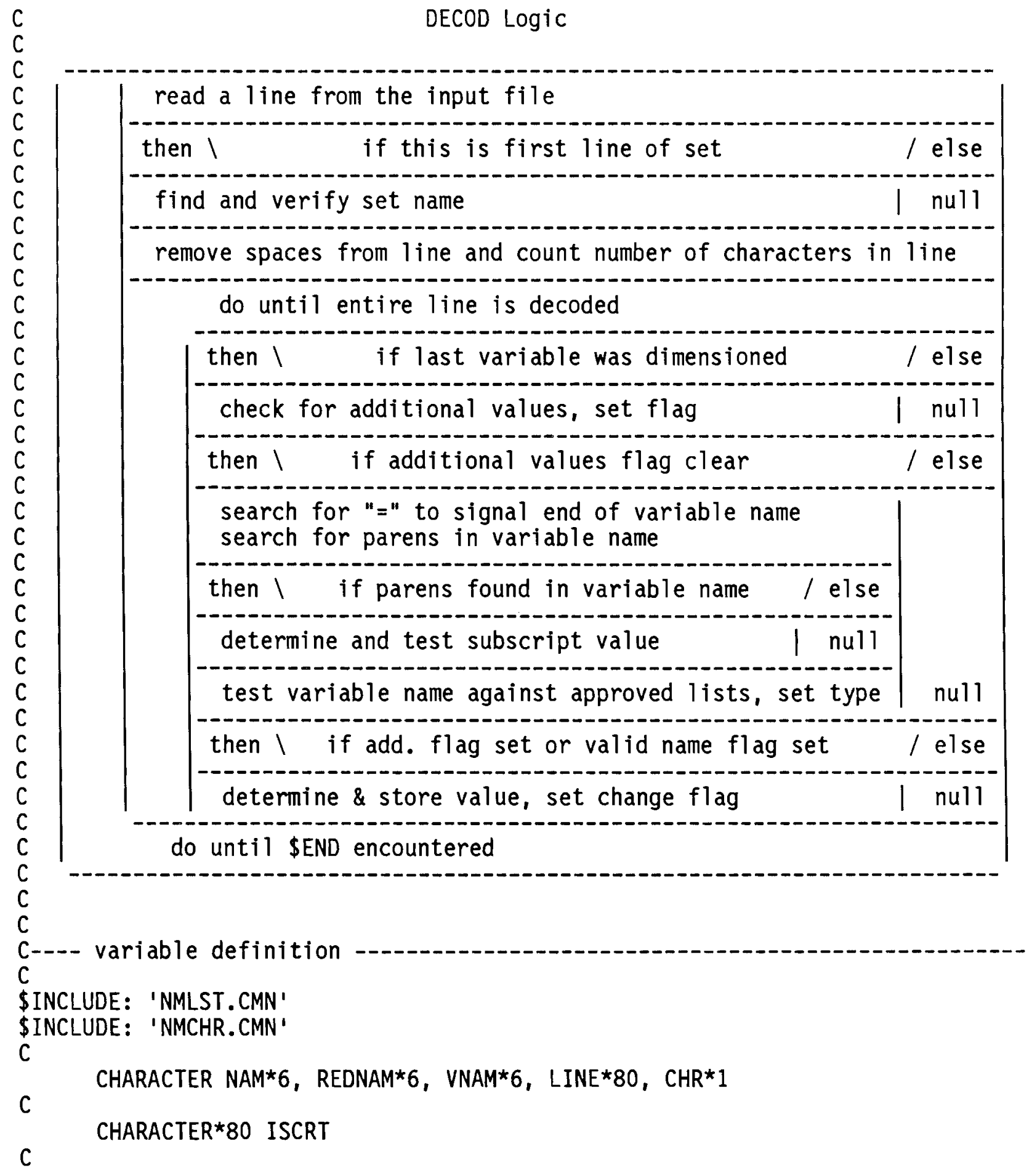

EIGURE H.1. IBM PC Code Additions (continued) 
CHARACTER*1 DOLLAR, EQUAL, SPACE， COMMA， LPRN, RPRN, ASTRIK DIMENSION CHR(80)

C EQUIVALENCE (LINE, CHR(1))

DIMENSION CHNUM (12)

CHARACTER $* 1$ CHNUM

c

DATA CHNUM /'1', '2', '3', '4', '5', '6', '7', '8', '9', '0', 'E', '.'/

DATA DOLLAR, EQUAL, SPACE, COMMA, LPRN, RPRN, ASTRIK /'\$', '=',

C

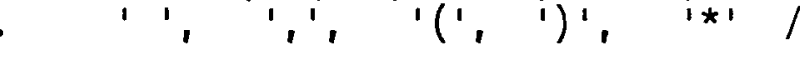
IFIRST $=0$
IFND $=0$
$I A D D=0$
ITYP $=0$
ISUB $=0$

C

C\#\#\# read a line from input file and set beginning location index \#\#\#\#\#\#\#\#\#

C

C 100 CONTINUE

c

READ (LUNI, 1000) LINE

C Set beginning character index--

c IST $=1$

C

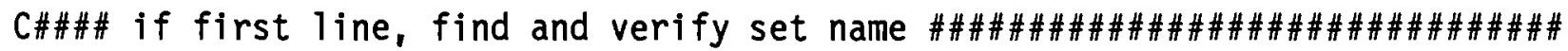
C

c IF (IFIRST .LT. 1) THEN

C Search for dollar sign-DO 122 I = IST, 80

122 CONTINUE

IF (CHR(I) .EQ. DOLLAR) GOTO 123

C

C Dollar sign not found, error condition-GOTO 901

C

123 CONTINUE

C

$$
\text { IST }=I+1
$$

Search for space to signal end of name--

D0 $126 \mathrm{I}=$ IST, IST+7

IF (CHR(I) .EQ. SPACE) GOTO 127

EIGURE H.1. IBM PC Code Additions (continued) 
Module DECOD

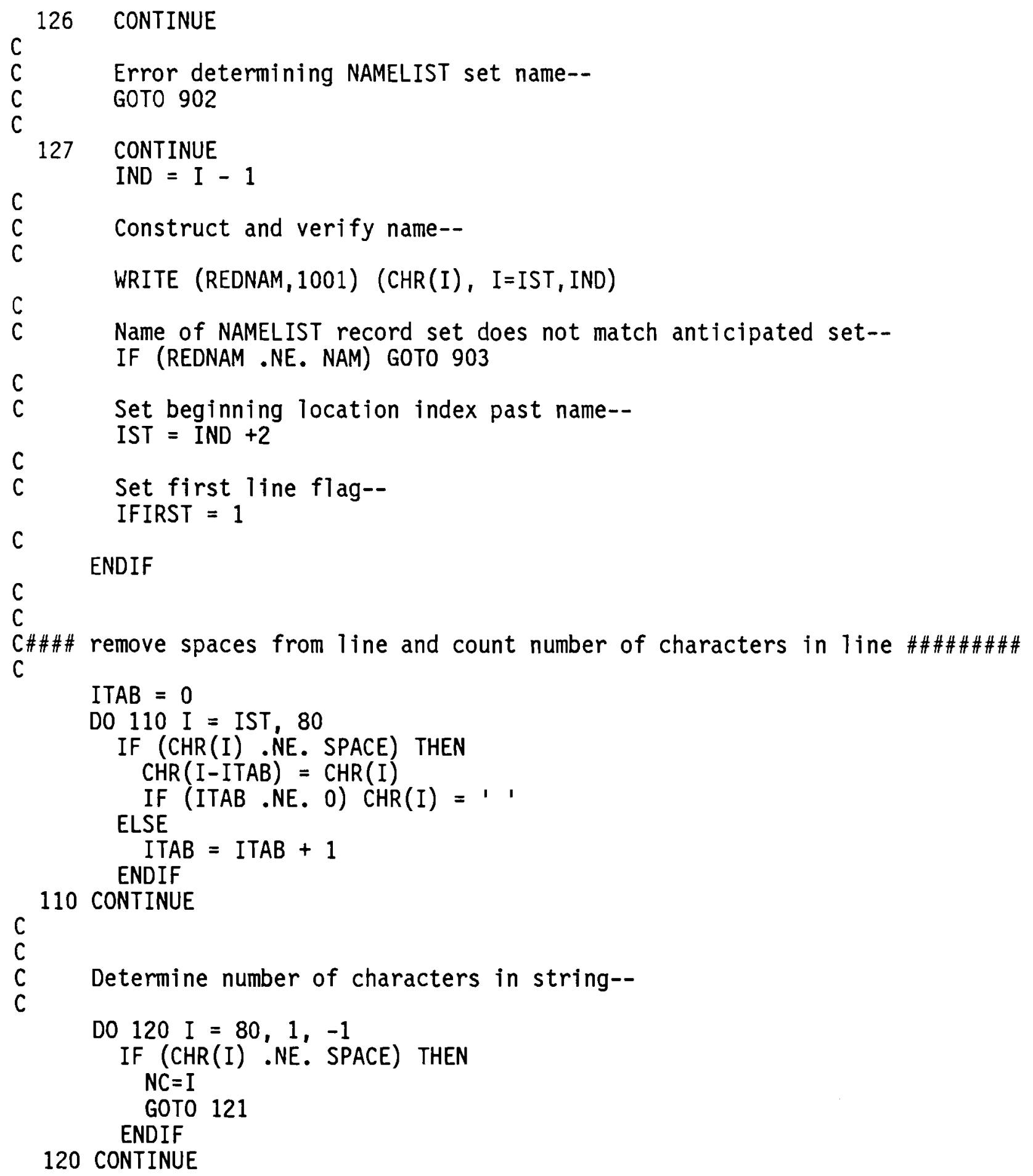

EIGURE H.1. IBM PC Code Additions (continued) 
Module DECOD

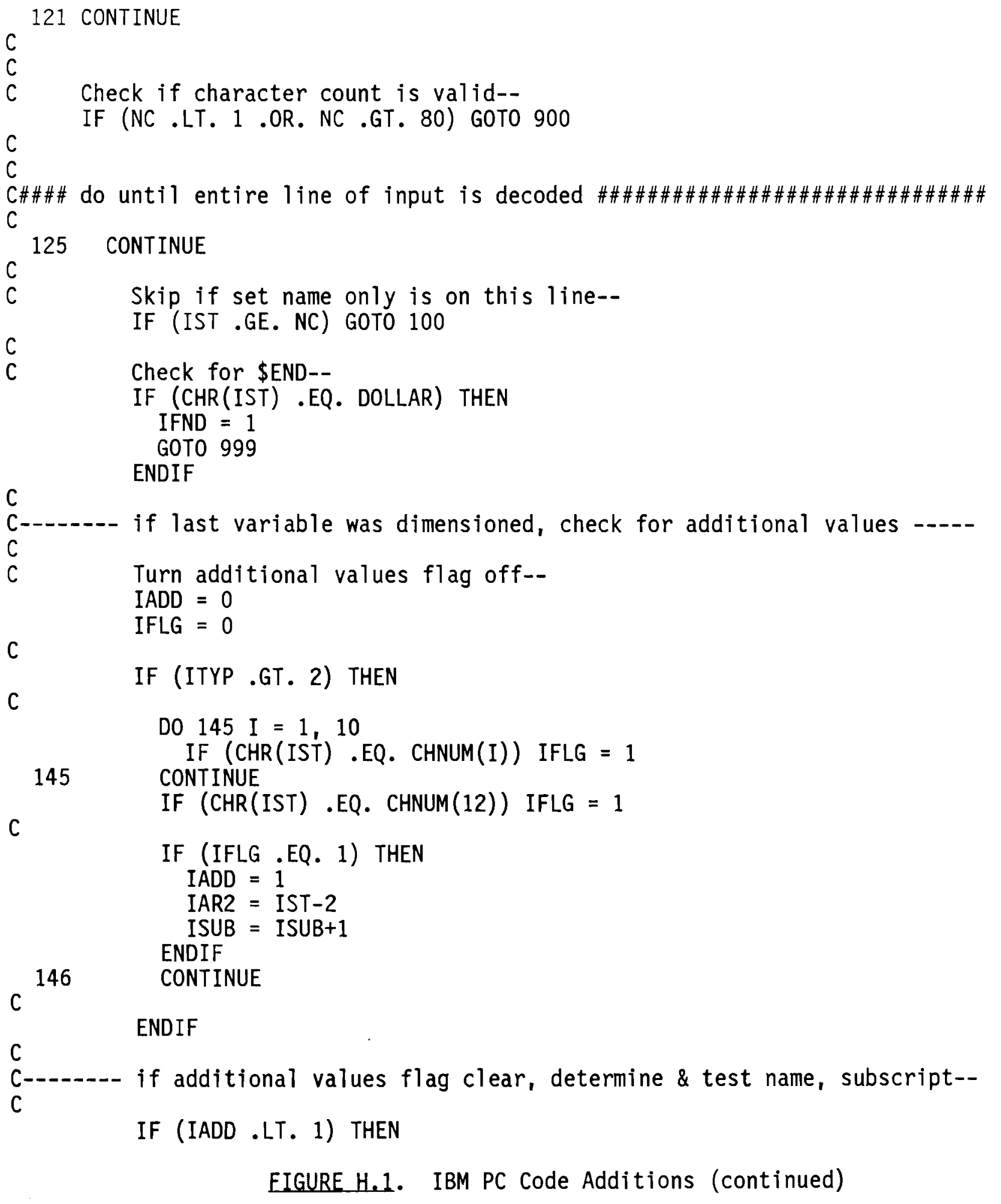

H. 17 


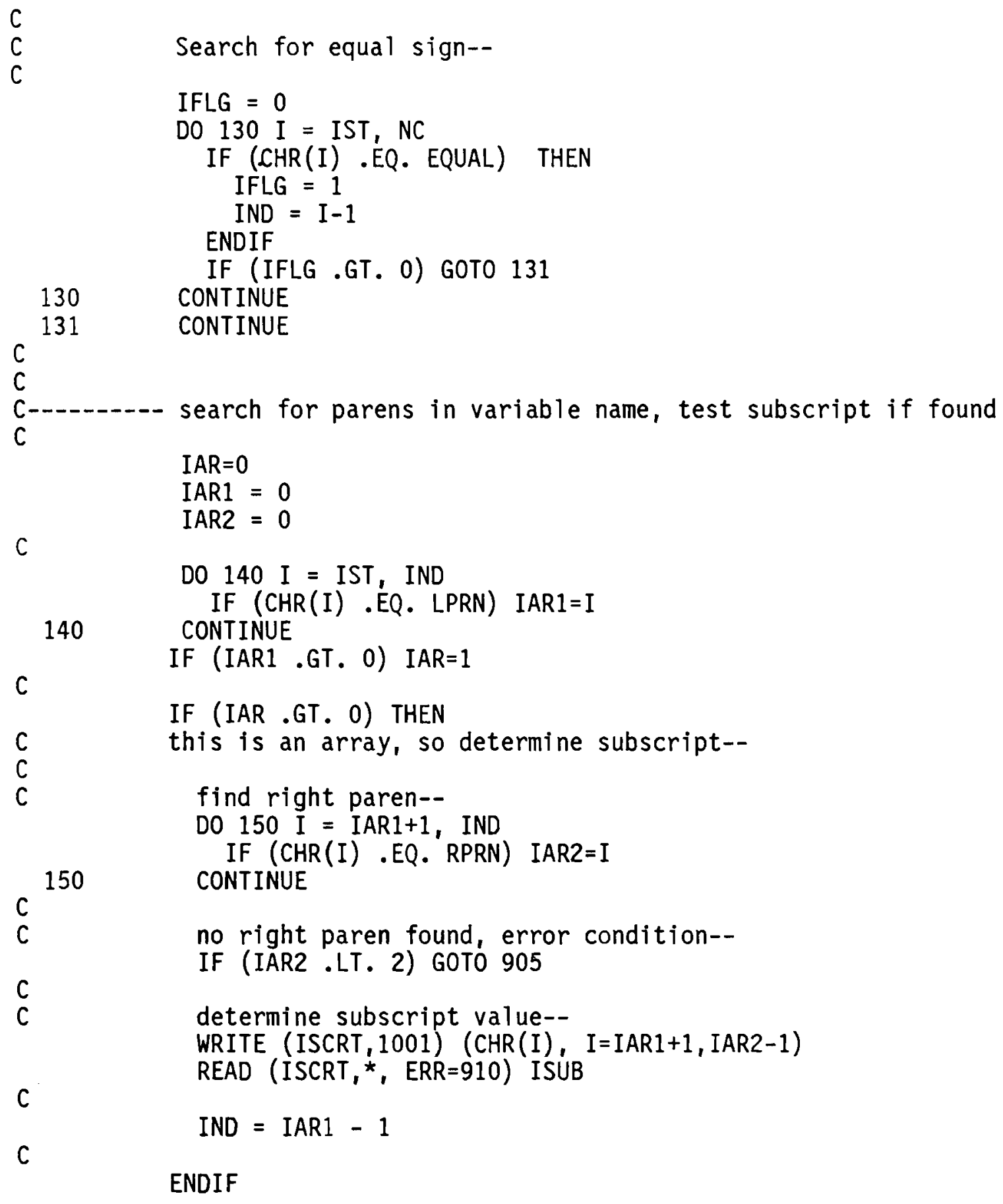

EIGURE H.1. IBM PC Code Additions (continued) 
ModuTe DECOD

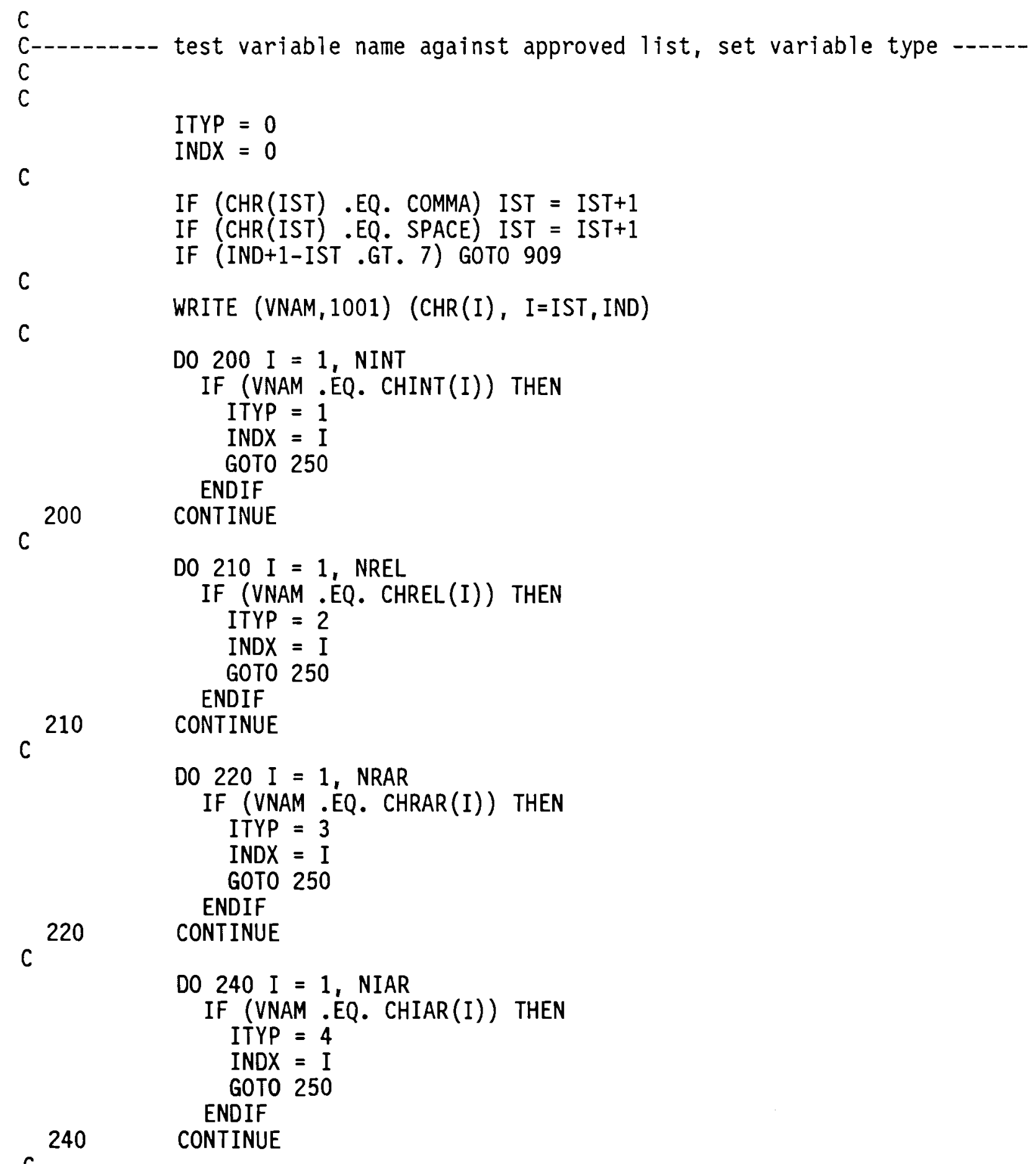

C

C WRITE (VNAM, 1001) (CHR(I), I=IST, IND)

C DO 200 I $=1$, NINT

EIGURE H.1. IBM PC Code Additions (continued) 


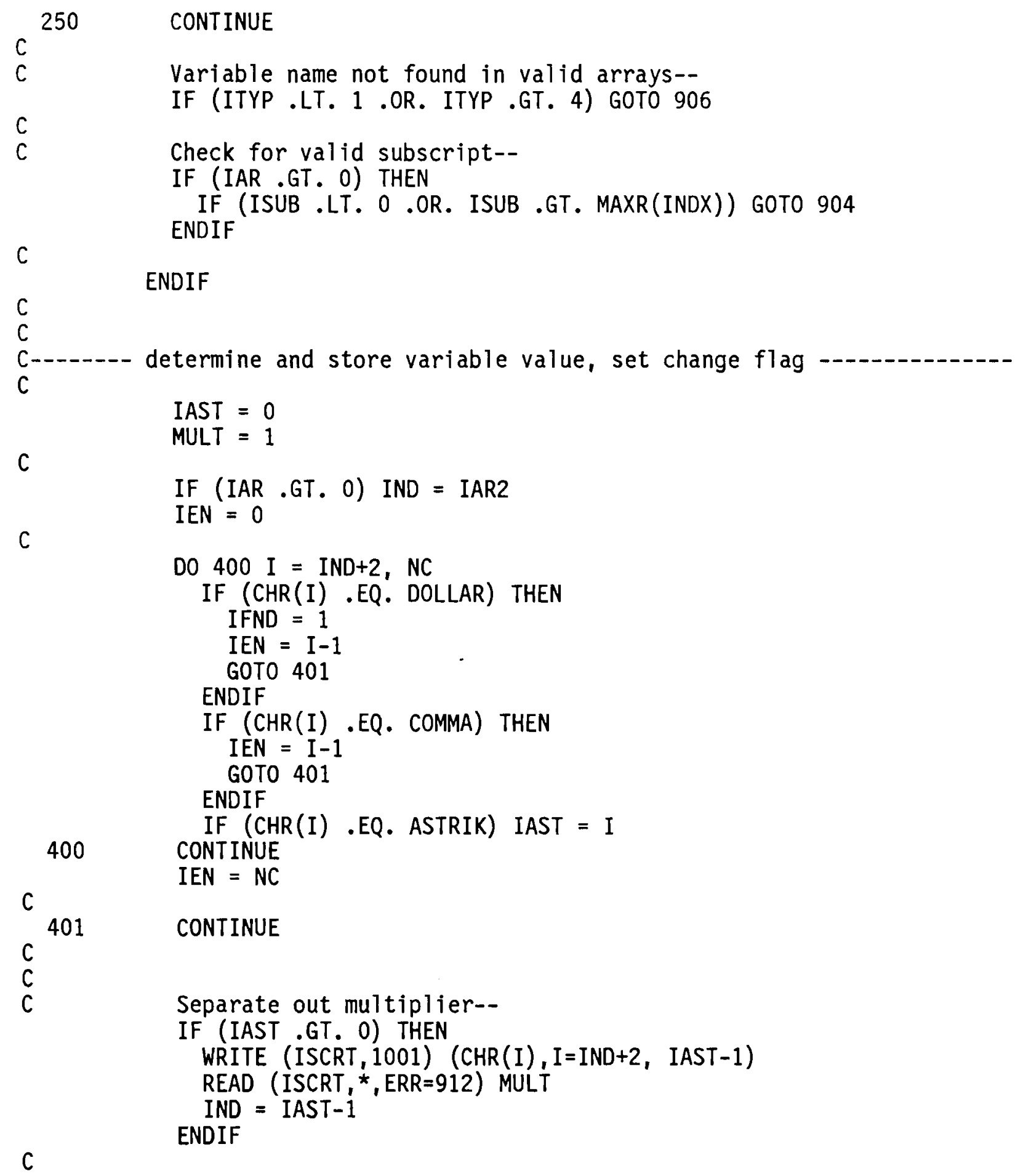

FIGURE H.1. IBM PC Code Additions (continued) 


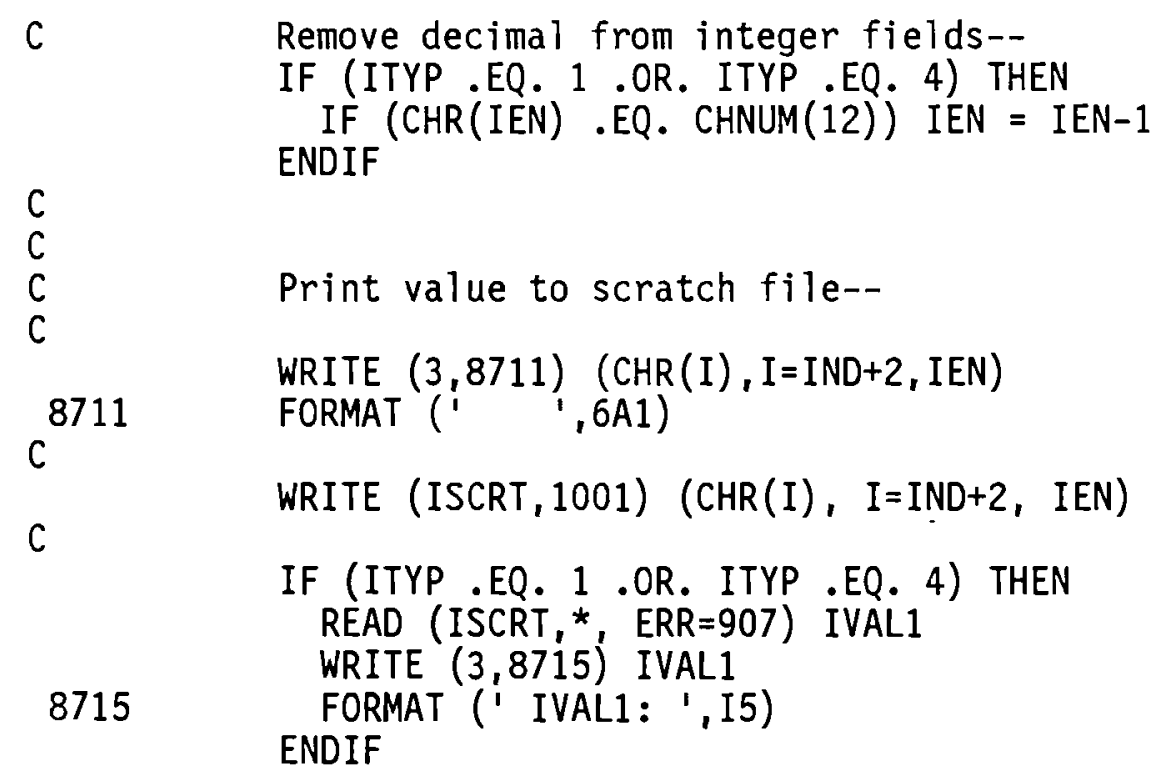

C

IF (ITYP .EQ. 2 .OR. ITYP .EQ. 3) THEN

READ (ISCRT, *, ERR $=908$ ) RVAL1

8712 FORMAT ('RVAL1: ', 1PE10.3)

ENDIF

C

C

C

C

C

Store value in proper array--

IF (ITYP .EQ. 1) THEN

$\operatorname{IVAL}($ INDX) $=$ IVAL1

$\operatorname{IFLI}(\operatorname{INDX})=1$

C

ENDIF

IF (ITYP .EQ. 2) THEN

RVAL (INDX) $=$ RVAL1

$\operatorname{IFLR}(\operatorname{INDX})=1$

ENDIF

C

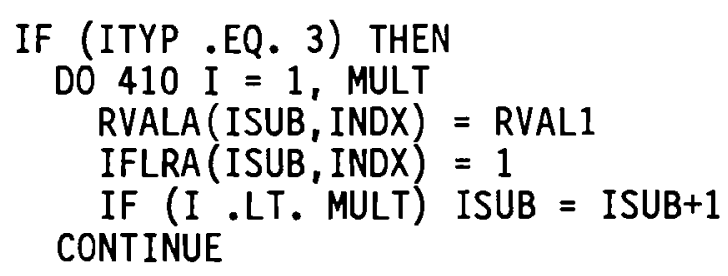

EIGURE H.1. IBM PC Code Additions (continued) 
ModuTe DECOD

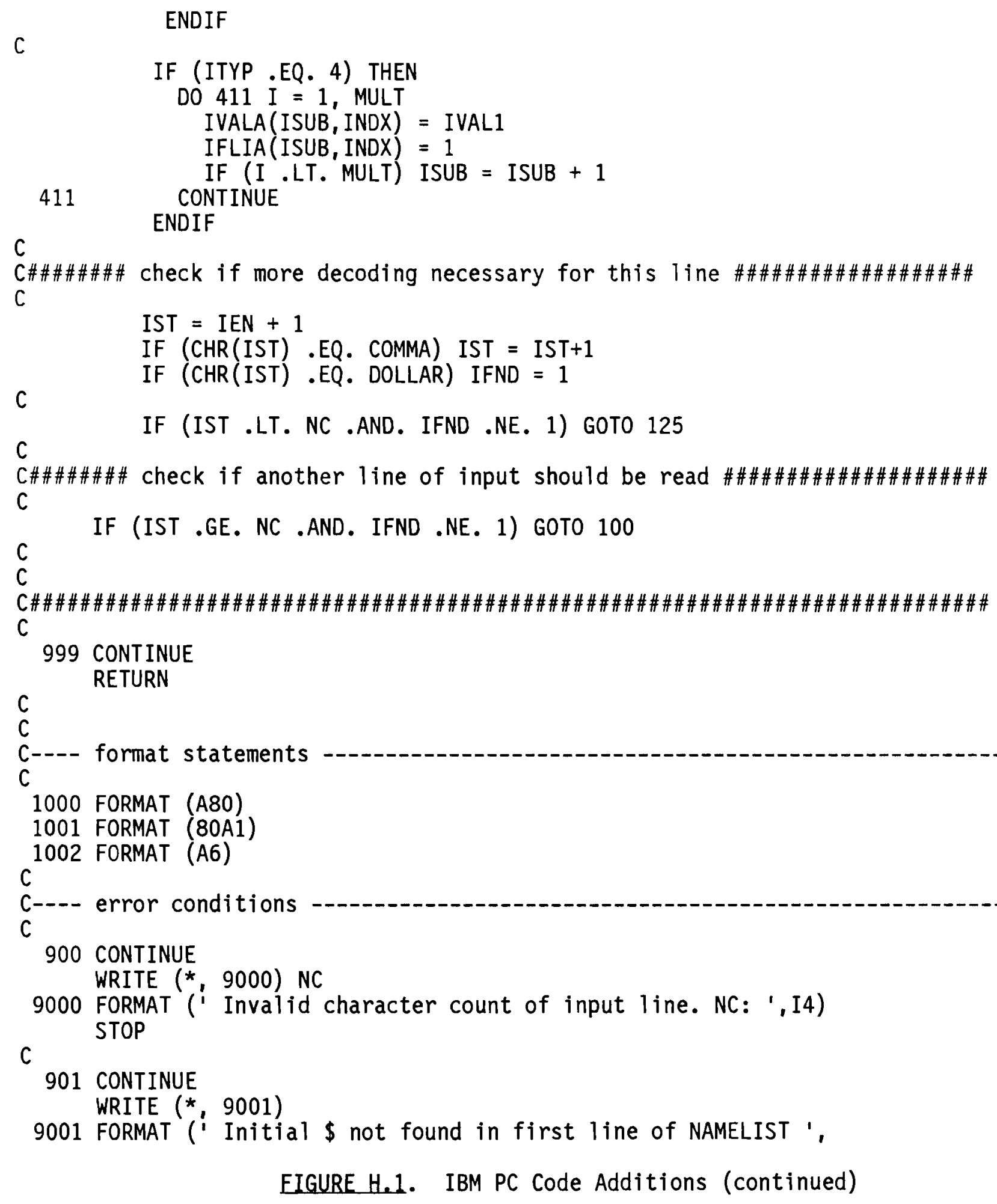


Module DECOD

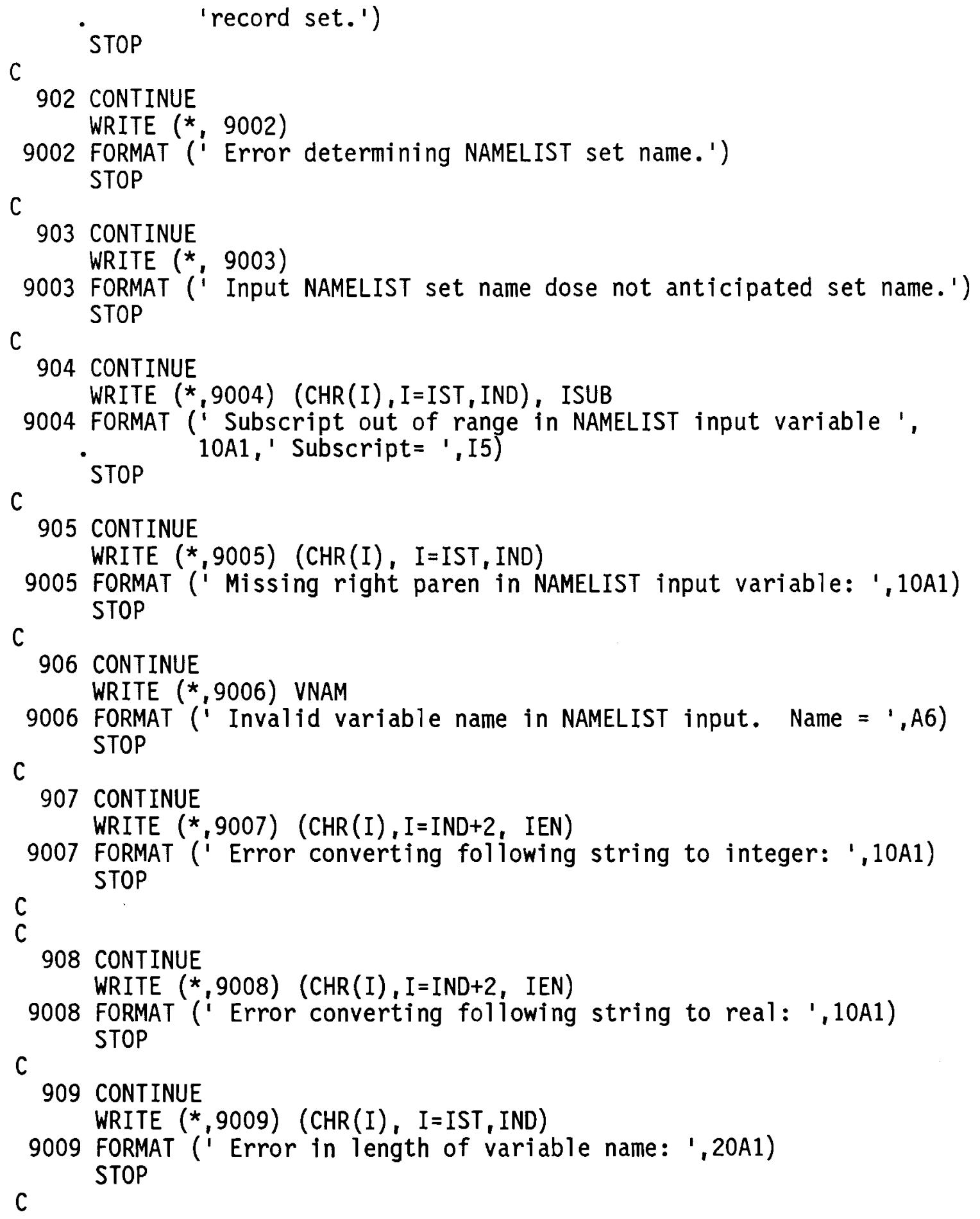

EIGURE H.1. IBM PC Code Additions (continued) 


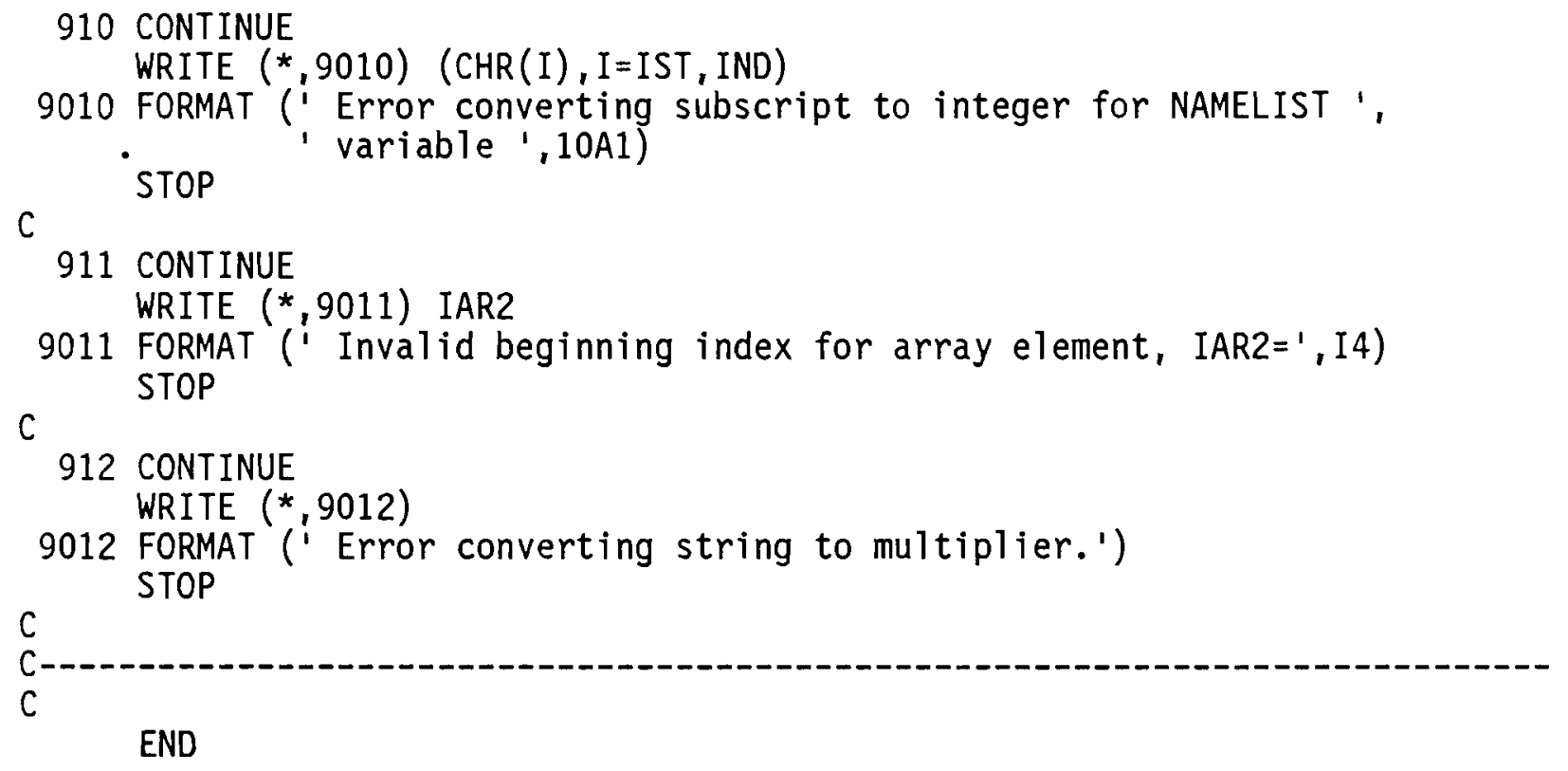

EIGURE H.1. IBM PC Code Additions (continued) 
No. of

Copies

OFFSITE

2 DOE Technical Information Center

ONS ITE

3 DOE Richland Operations Office

R. A. Holten

E. A. Bracken

J. J. White

51 Pacific Northwest Laboratory

V. L. Brouns

J. B. Burnham (10)

D. W. Dragnich

C. E. Elderkin

J. M. Hales

P. C. Hays

W. E. Kennedy, Jr.

W. W. Laity

B. A. Napier (20)

I. C. Nelson

R. A. Peloquin

R. F. Schreckhise

J. G. Stephan

J. A. Stottlemyre

D. L. Strenge

R. E. Wildung

Publishing Coordination (2)

Technical Information (5) 
- 